\title{
Punish, seduce and persuade
}

\author{
Citation for published version (APA):
}

Leeuw, H. B. M. (2017). Punish, seduce and persuade: an empirical assessment of anti-piracy interventions. [Doctoral Thesis, Maastricht University]. Eleven International publishing. https://doi.org/10.26481/dis.20170615hl

Document status and date:

Published: 01/01/2017

DOI:

10.26481/dis.20170615hl

Document Version:

Publisher's PDF, also known as Version of record

\section{Please check the document version of this publication:}

- A submitted manuscript is the version of the article upon submission and before peer-review. There can be important differences between the submitted version and the official published version of record.

People interested in the research are advised to contact the author for the final version of the publication, or visit the DOI to the publisher's website.

- The final author version and the galley proof are versions of the publication after peer review.

- The final published version features the final layout of the paper including the volume, issue and page numbers.

Link to publication

\footnotetext{
General rights rights.

- You may freely distribute the URL identifying the publication in the public portal. please follow below link for the End User Agreement:

www.umlib.nl/taverne-license

Take down policy

If you believe that this document breaches copyright please contact us at:

repository@maastrichtuniversity.nl

providing details and we will investigate your claim.
}

Copyright and moral rights for the publications made accessible in the public portal are retained by the authors and/or other copyright owners and it is a condition of accessing publications that users recognise and abide by the legal requirements associated with these

- Users may download and print one copy of any publication from the public portal for the purpose of private study or research.

- You may not further distribute the material or use it for any profit-making activity or commercial gain

If the publication is distributed under the terms of Article $25 \mathrm{fa}$ of the Dutch Copyright Act, indicated by the "Taverne" license above, 
Punish, Seduce or Persuade 
The commercial edition of this book is published by Eleven International Publishing.

ISBN 978-94-6236-741-8

ISBN 978-94-6274-674-9 (E-book)

(C) 2017 H.B.M. Leeuw | Eleven International Publishing

Published, sold and distributed by Eleven International Publishing

P.O. Box 85576

2508 CG The Hague

The Netherlands

Tel.: +31703307033

Fax: +31 703307030

e-mail: sales@elevenpub.nl

www.elevenpub.com

Sold and distributed in USA and Canada

International Specialized Book Services

920 NE 58th Avenue, Suite 300

Portland, OR 97213-3786, USA

Tel: 1-800-944-6190 (toll-free)

Fax: +1-503-280-8832

orders@isbs.com

www.isbs.com

Eleven International Publishing is an imprint of Boom uitgevers Den Haag.

This publication is protected by international copyright law.

All rights reserved. No part of this publication may be reproduced, stored in a retrieval system, or transmitted in any form or by any means, electronic,

mechanical, photocopying, recording or otherwise, without the prior permission of the publisher.

Printed in The Netherlands 


\section{Punish, Seduce or Persuade}

An Empirical Assessment of Anti-piracy Interventions

\section{DISSERTATION}

to obtain the degree of Doctor at Maastricht University, on the authority of the Rector Magnificus, prof.dr. Rianne M. Letschert, in accordance with the decision of the Board of Deans, to be defended in public on Thursday 15 June 2017, at 14.00 hours

by

Hendrikus Bastiaan Maria Leeuw 
Supervisor:

Prof. dr. mr. J.M. Nelen

\title{
Co-supervisor
}

Dr. M.R. Vanderhallen

\author{
Assessment Committee \\ Prof. dr. mr. A.W.J. Kamperman Sanders (Chair) \\ Prof. dr. M.G. Faure \\ Prof. dr. M. Jelicic \\ Prof. dr. L. Pauwels (Universiteit Gent) \\ Prof. dr. W. Ph. Stol (Open Universiteit)
}




\section{Acknowledgements}

In 2009, I was enrolled in a master's degree in Criminology at the University of Sydney. Part of the experience was living in the International House, which is a dormitory for international students enrolled at this university. With over 200 students living in this dormitory, it was and remains a place to meet students from all over the world and exchange ideas. In addition to ideas, what also was exchanged was a plethora of music, movies, video games and other (more unsavoury) types of digital content, without having to pay a single penny. All of this was facilitated by an in-house high-speed P2P-network, to which all resident students were connected. Needless to say, most students, including myself, happily made use of the possibilities of this network. Yet as my studies in the field of criminology progressed, I started to wonder why people obtained content in this manner, especially since it is often illegal. In my earlier studies in the field of (criminal) law, I had already taken an interest not just in the law in the books but also in the law in action. It was apparent that there were many efforts taken to curb the number of individuals that obtain music, movies and video games through illegal means. Yet many individuals engaged in this behaviour nonetheless. Where all these efforts in vain? Could these measures be improved? These and other questions challenged me during the last phase of my study and have interested me ever since.

This led to the development of a PhD-proposal, a proposal that was the basis of this book. In September 2010, I set out on my journey to better understand digital piracy and the measures taken to curb this behaviour. I had begun my academic career full of enthusiasm and optimism. This end-product hopefully reflects this enthusiasm. At the same time, the process writing a $\mathrm{PhD}$ is not without challenges. Out of curiosity and stubbornness, I decided to apply new research methods that I was not very experienced with. This required a lot of trial and error, and has perhaps made the journey more difficult than might have been necessary. But it also meant that I had the opportunity to learn many new skills and techniques.

Looking back, the journey was never truly lonesome, though it might have felt as such at times. In that regard, I am indebted to a number of people. First and foremost my supervisors, Hans Nelen and Miet Vanderhallen. I have known Hans since my first experiences with the field of criminology. Even though my research interests are somewhat different from his own, Hans has always been supportive and enthusiastic about my $\mathrm{PhD}$ (even when I myself doubted my own progress), and always took the time to critically examine my work and guide me on my 
journey. When Miet joined our illustrious duo sometime later she offered additional important insights, feedback and suggestions, in particularly in relation to the more methodological aspects of the project. Without her support, I am not sure the dissertation would have been finished at all. The final product has improved immensely thanks to them. I cannot thank them enough, both as a young researcher and as a person. I will forever take to heart one of Hans' acronyms: 'KISS' ('Keep It Simple, Stupid').

Other colleagues have also aided me in completing the $\mathrm{PhD}$ in some form or shape. These include, but are not limited to, Jacques Claessen, Roland Moerland, Johannes Keiler, Liesbeth Vink, Dorris de Vocht, Christina Peristidotolu David Roef, Anke Moerland, Licette Poll, Anna Beckers, Jaap Hage, Andre Klip, René de Groot, Sascha Hardt, Jos Hamers, Taru Spronken, Tanja van der Meer, and Carol Ní Ghiollarnáth. I would like to thank each and every one of you for the support have you given me throughout the years. In addition, I would also like to thank all other colleagues at the Faculty of Law for their continued assistance and advice.

I must extend my gratitude to individuals outside the faculty as well. Though they are scattered across the Netherlands and beyond, they too have aided me in the $\mathrm{PhD}$-process. These include, but are not limited to, Frank Willemsen, Paula Duff, Jan-Jaap Kuipers, Hester van der Kaaij, Jasper Beyers, Joris Beckers, Sabrine den Os, Jatinder Mann, Bill Snyzek, David Buckley, Jasper Leeuw, Marijke Frederikse, Math von Berg, Gustav Petersson, Mary Curtis, Anne Peters \& Bao Vo and Trees \& Leon Beurskens.

Of particular note are both my parents, Frans Leeuw and Rosanne Monod de Froideville, who have nurtured my interest in the world at large, as well as my academic interests. In addition they also gave emotional and mental support whenever the situation called for it. I believe they never doubted my ability to complete a $\mathrm{PhD}$, and I want to thank them both for all their efforts, worries and guidance they have given met that have let me down the academic path. I am forever grateful for their support.

But I owe the largest debt of gratitude to my love, sparring-partner, and fellow geek Maaike Peters. The start of my PhD nearly coincided with the start of our relationship. As the $\mathrm{PhD}$ progressed, our relationship matured and deepened, and you were and are a continuous source of support. I am certain that I would not have made it to the finish-line without you. You experienced every up and down that was part of this PhD-research, which sometimes was something of an emotional rollercoaster-ride. I am certain that you are almost as glad as I am that 
my $\mathrm{PhD}$ is, finally, done (perhaps even more so). That chapter is now concluded, yet the book on our relationship is far from ended. I like to think that our prologue is now concluded and that our plot is only just starting to thicken. I look forward towards a bright future in which we, together, face new challenges and opportunities together. But most importantly, one where we can continue to support, love and cherish each other. Thank you.

The Hague/Maastricht, 17-03-2017 



\section{Table of contents}

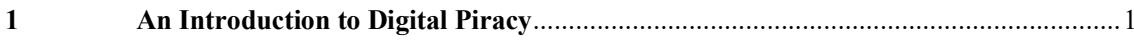

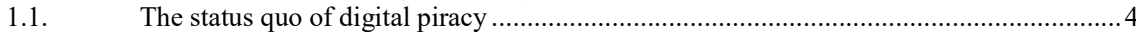

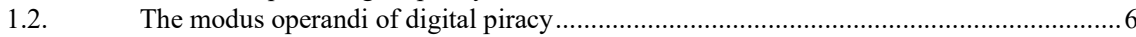

1.3. Delineating the concept of digital piracy .................................................................

1.4. The relationship between digital piracy and copyright law ......................................... 11

1.5. The discrepancy between copyright law and digital behaviour ............................... 13

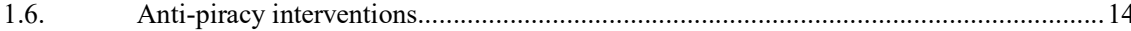

1.7. Objectives of the research and research question ................................................. 16

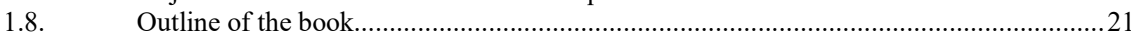

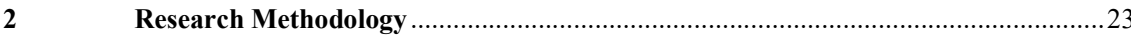

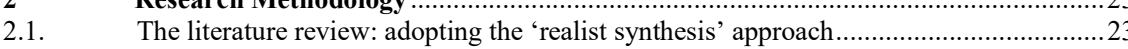

2.2. The first empirical study: the stated preference method .............................................. 30

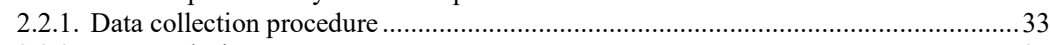

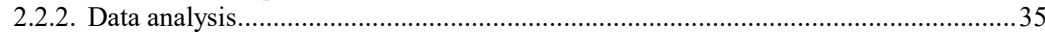

2.3. The second empirical study: Big Data and online search behaviour............................ 38

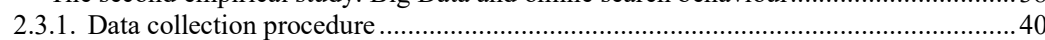

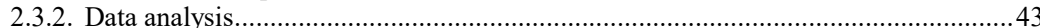

2.3.3. Attributing the changes to the anti-piracy intervention ....................................... 44

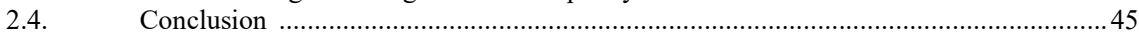

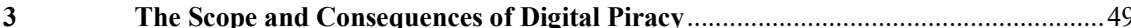

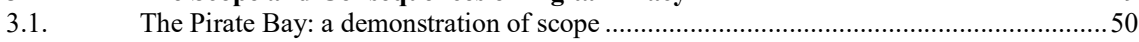

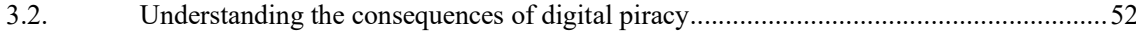

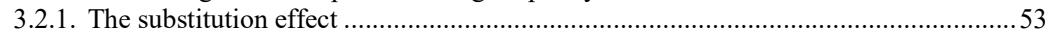

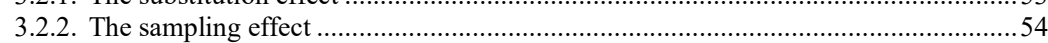

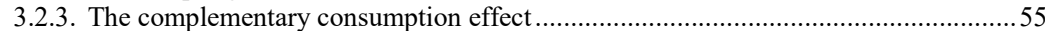

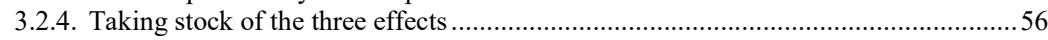

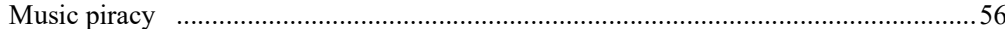

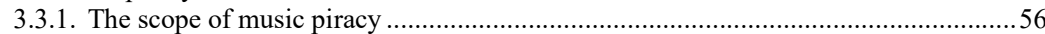

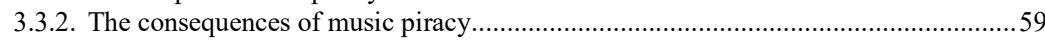

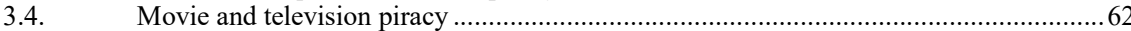

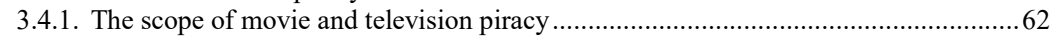

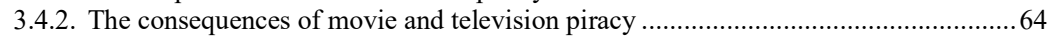

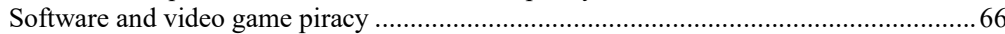

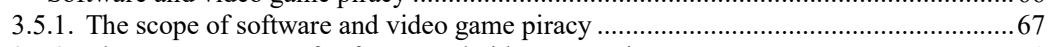

3.5.2. The consequences of software and video game piracy.......................................... 71

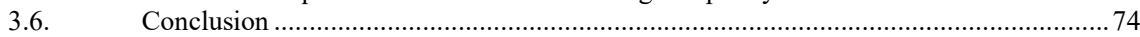

4 How can the Behaviour of Digital Pirates be Explained? A Synthesis through the

Lens of the Situational Action Theory ................................................................... 77

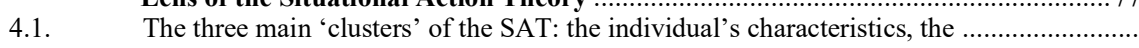

environmental features and the process of choice ..................................................... 78

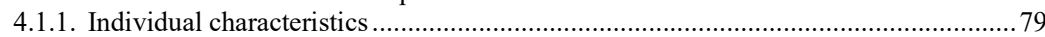

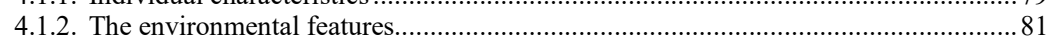

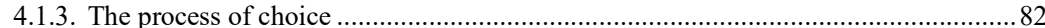

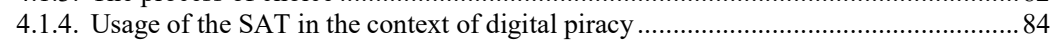

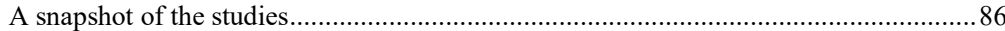

The propensity of the individual: which characteristics seem to matter?.........................8 87

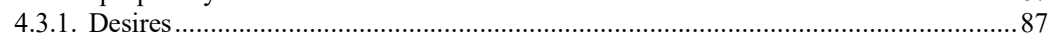

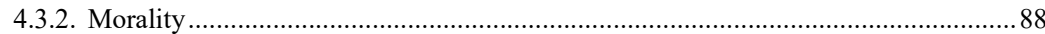

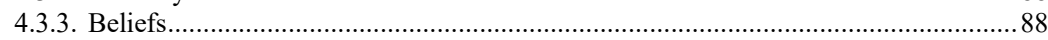


4.3.4. Gender....

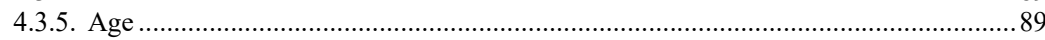

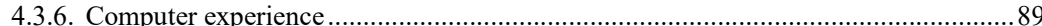

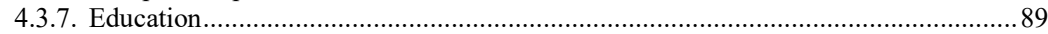

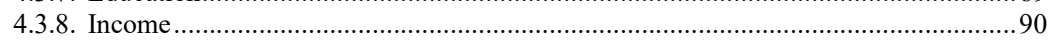

The environmental features: which features seem to matter? ........................................ 90

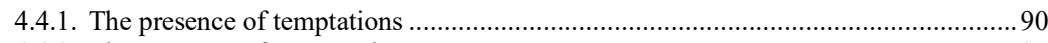

4.4.2. The presence of provocations ............................................................................. 91

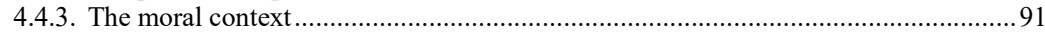

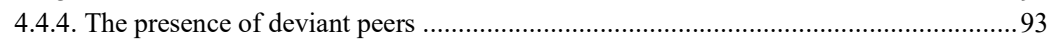

The process of choice: which components seem to matter? .........................................93

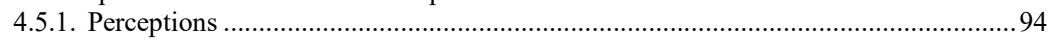

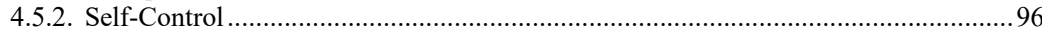

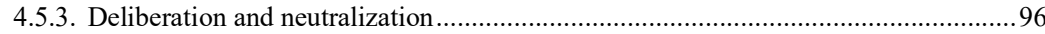

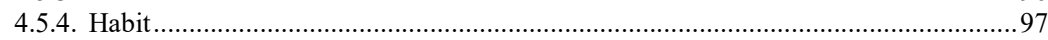

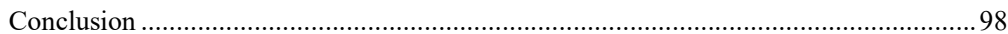

$5 \quad$ How to Discourage Digital Pirates: Focusing on Anti-Piracy Interventions and

Their Mechanisms ...................................................................................... 103

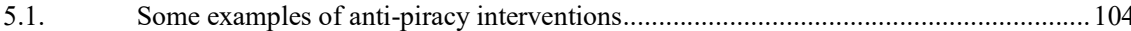

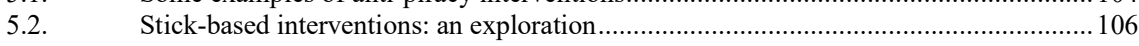

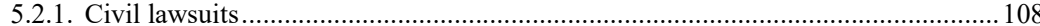

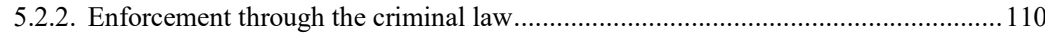

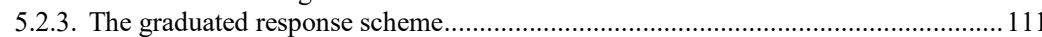

5.2.4. Designed to frustrate: deterrence through technical restrictions............................ 114

5.2.5. Do stick-based interventions reach the appropriate target population? ................... 117

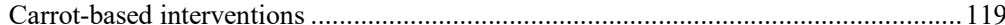

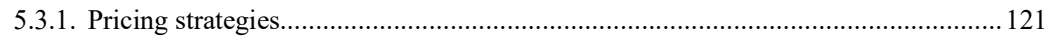

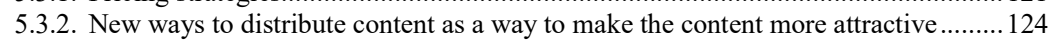

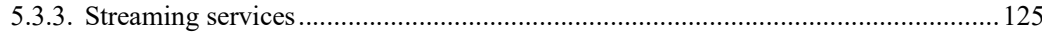

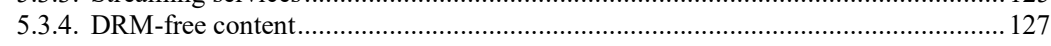

5.3.5. Do carrot-based interventions reach the appropriate target population?................... 127

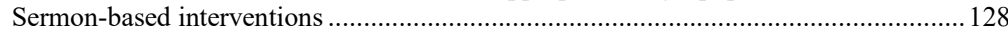

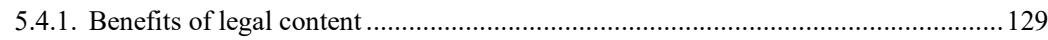

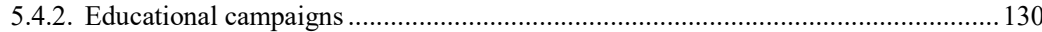

5.4.3. Fear appeals and harm attribution ............................................................... 131

5.4.4. Do sermon-based interventions reach the appropriate target population? ................ 134

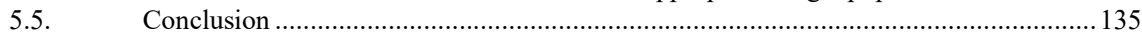

6 An Assessment of Anti-Piracy Interventions: Requirements for the Three

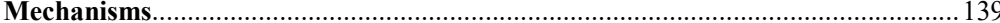

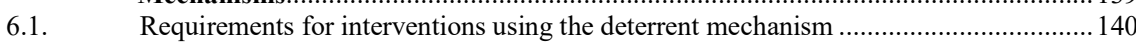

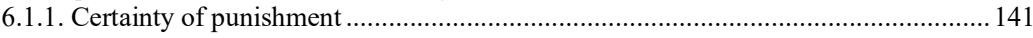

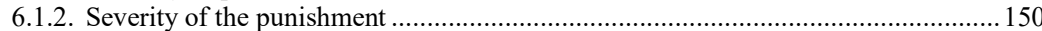

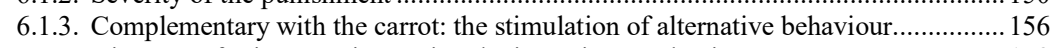

Requirements for interventions using the incentive-mechanism.............................. 158

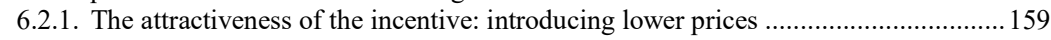

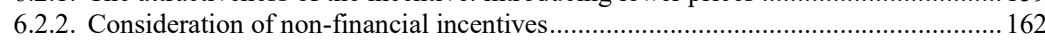

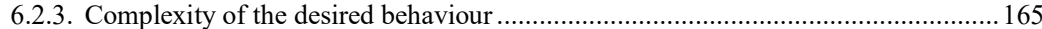

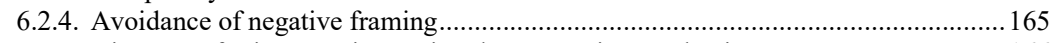

Requirements for interventions using the persuasive mechanism............................. 166

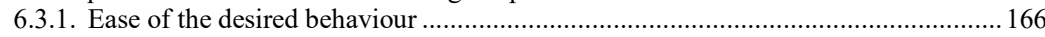

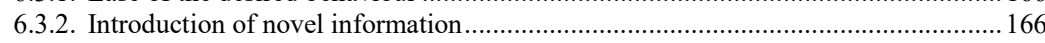

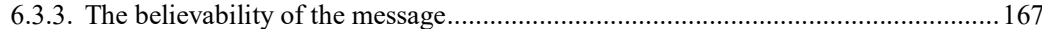

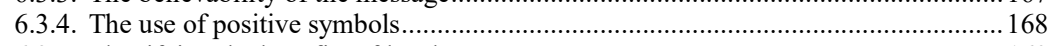

6.3.5. Identifying the benefits of legal content................................................................. 169

6.3.6. Aligning the desired behaviour with those of the target population ....................... 170

6.3.7. Meaningful fear appeals and harm attributions .................................................. 173

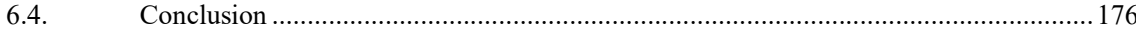


7.1. Past content consumption and digital piracy .................................................... 180

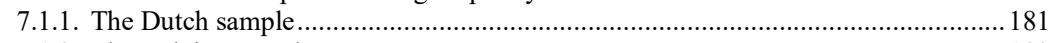

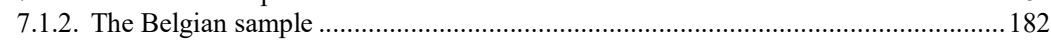

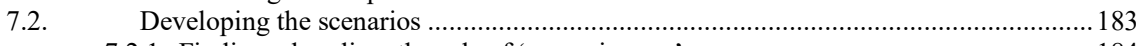

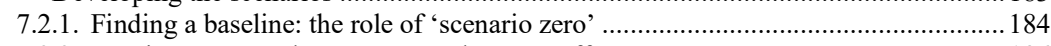

7.2.2. Requirements used to generate a deterrent effect................................................ 186

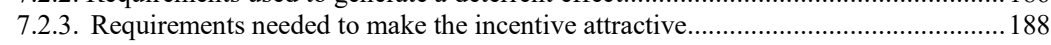

7.2.4. Requirements in order to persuade the target population ....................................... 189

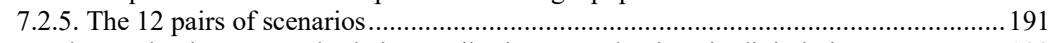

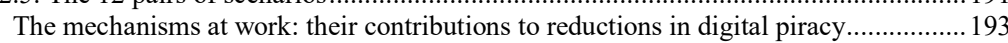

7.3.1. Most convincing mechanism and strength of conviction (Dutch sample) .............. 193

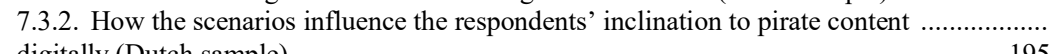

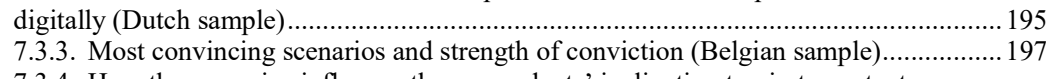

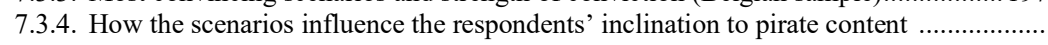

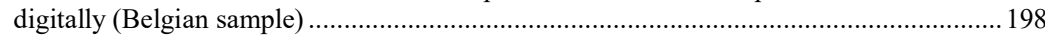

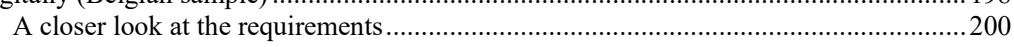

7.4.1. Responses to the requirements in the Dutch sample .............................................200

7.4.2. Responses to the requirements in the Belgian sample........................................203

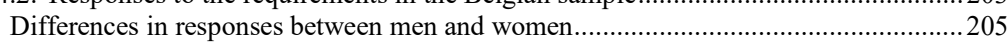

Methodological limitations and their consequences for the findings ...........................207

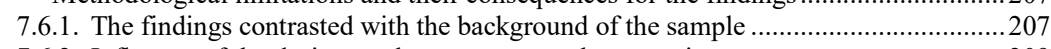

7.6.2. Influence of the design on the responses to the scenarios .........................................209

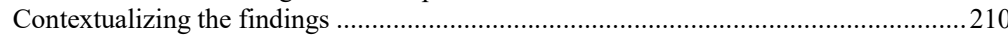

7.7.1. The preference for the deterrent scenarios and the relevance of formal deterrence... 210

7.7.2. The relevance of the severity of the punishment................................................... 211

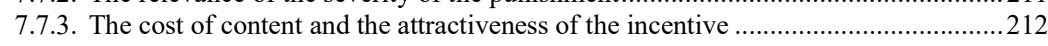

7.7.4. The relevance of the role of viruses ................................................................... 212

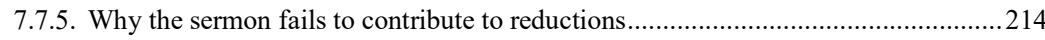

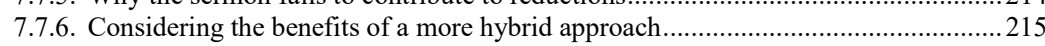

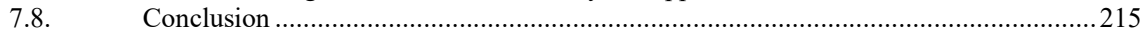

8 Changes in Online Search Behaviour after the Implementation of an Anti-Piracy

Intervention: the Copyright Alert System as a Case Study .................................... 217

8.1 The CAS and its assumed influence on digital piracy ...........................................2 219

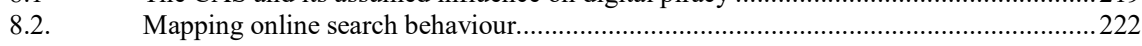

8.3. Observed changes in online search behaviour .................................................... 225

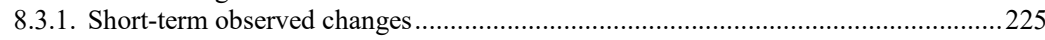

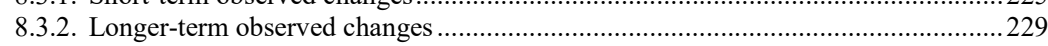

Observing the counterfactual: what if the CAS had not been implemented? .................233

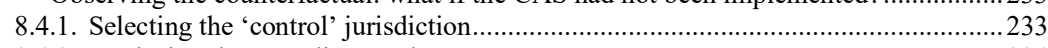

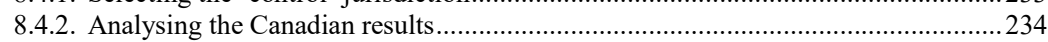

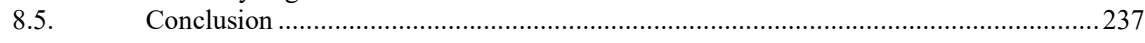

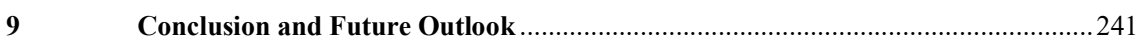

9.1 A closer look at the most important findings............................................................2 243

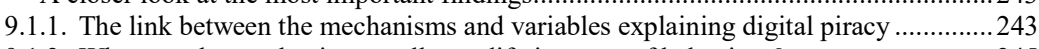

9.1.2. What can the mechanisms really modify in terms of behaviour? .................................245

9.1.3. Changing perceptions .................................................................................... 247

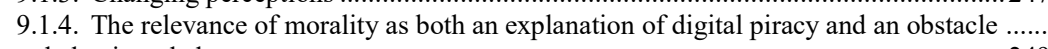

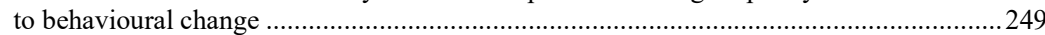

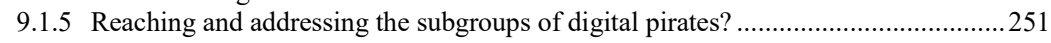

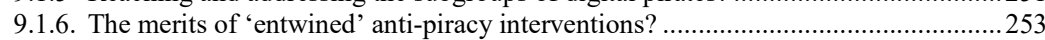

9.1.7. The limits of anti-piracy intervention? A balance between input and output ...........254

9.2 A look towards the future: six scenarios to consider ..........................................256 
9.2.1. The introduction and wide-spread availability of 3D-printers.

9.2.2. Changing the demographics of digital piracy: geriatric pirates of the Caribbean? ...259

9.2.3. An abundance of legal content: risk of competition and cannibalization ..................261

9.2.4. Streaming becomes the dominant form of content consumption............................263

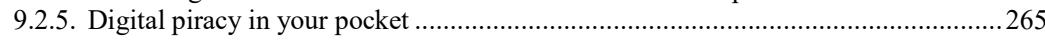

9.2.6. New and innovative ways to study digital piracy..............................................266

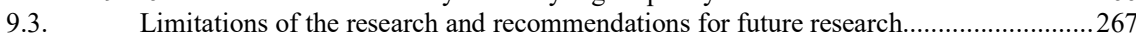

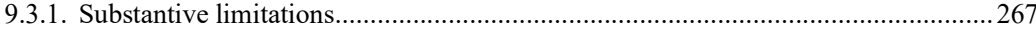

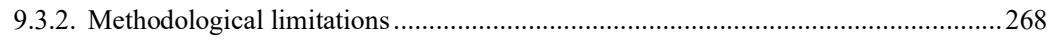

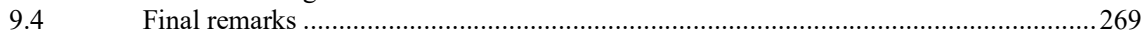

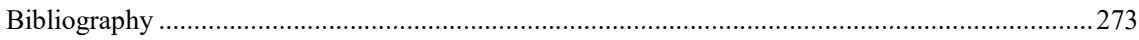

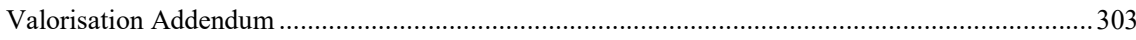

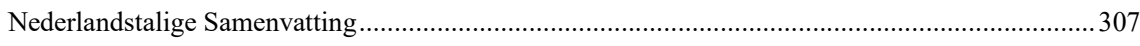

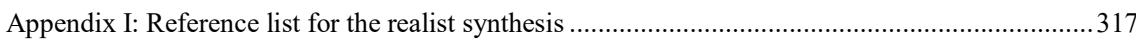

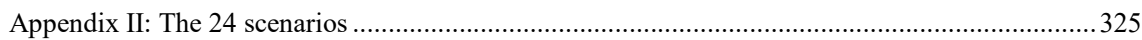

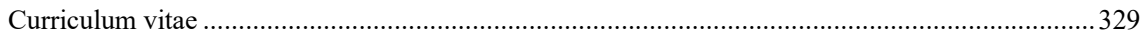




\section{List of Text Boxes}

Text Box 1.1: Summary of the research question and sub-questions.................................................19

Text Box 2.1: Overview of sub-questions and associated methods ......................................................46

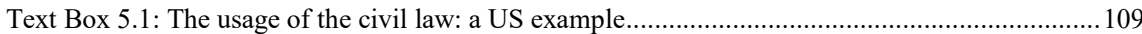

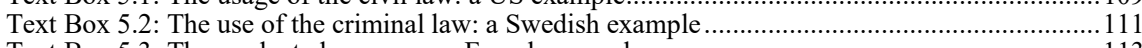

Text Box 5.3: The graduated response: a French example ............................................................. 113

Text Box 6.1: Empirical assessment of technical anti-piracy interventions........................................ 156

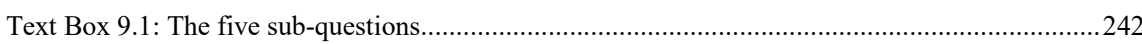

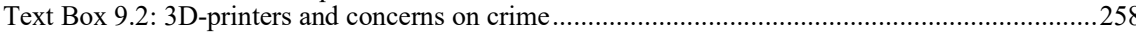

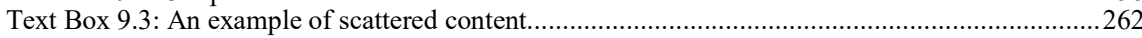

\section{List of Figures}

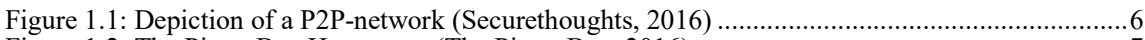

Figure 1.2: The Pirate Bay Homepage (The Pirate Bay, 2016) …………........................................

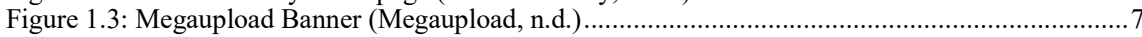

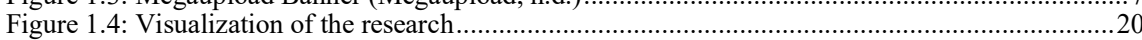

Figure 2.1: Example of a root query and related queries ..............................................................4

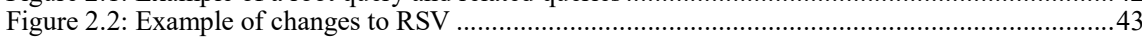

Figure 3.1: Number of downloading individual users (leechers) on The Pirate Bay,

per content type

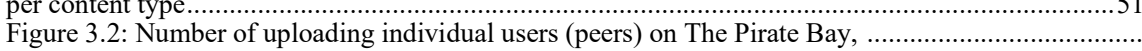

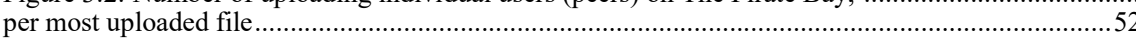

Figure 3.3: Software Piracy Rates (\%) per Region (2008-2013)

(BSA, 2014; BSA \& IDC, 2008, 2010, 2011, 2012)

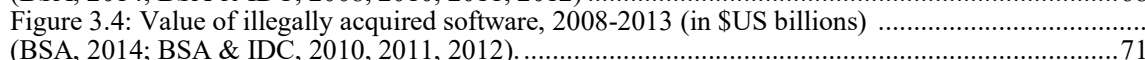

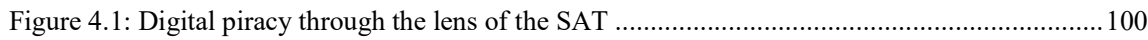

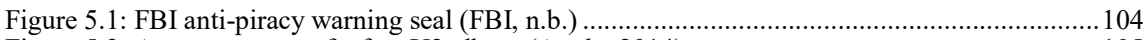

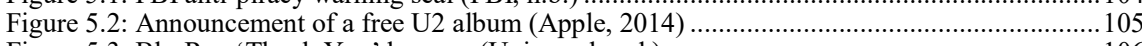

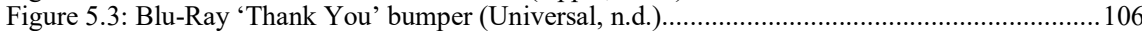

Figure 5.4: Young users and the CAS (Center for Copyright Information, n.d.)................................ 118

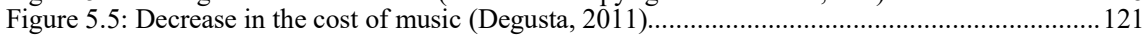

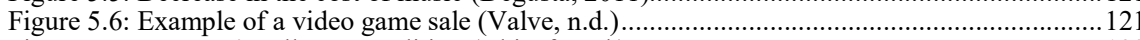

Figure 5.7: Far Cry 4 Collector's Edition (Ubisoft, n.d.)..............................................................122

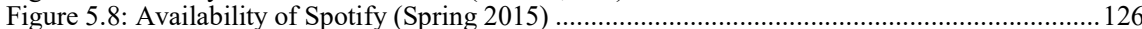

Figure 5.9: Spotify's younger target population (Spotify, n.d.-b) …………………..................... 128

Figure 5.10: Example of identifying the benefits of legal content (FICCI, n.d.) ………………..........130

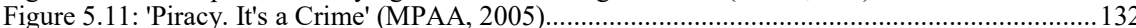

Figure 5.12: 'Don't Copy that Floppy' (Software Publishers Association, 1992) .................................133

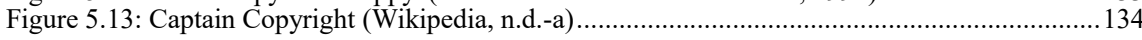

Figure 6.1: UCSF Campaign (Cenite, Wang, Peiwen, \& Chan, 2009) ...............................................151

Figure 6.2: Stimulation of alternative behaviour by the CAS (Sinclair \& Green, 2016)........................ 158

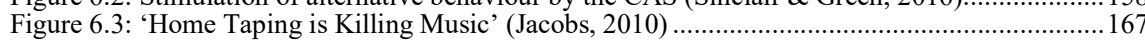

Figure 7.1: Depiction of 'scenario zero' (Dutch sample) ...............................................................184

Figure 7.2: The eight stick-based scenarios............................................................................... 186

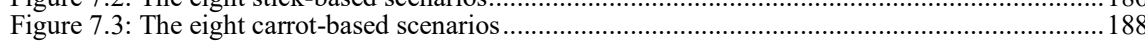

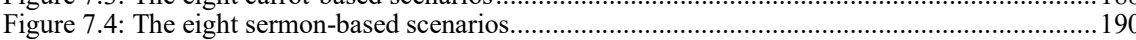

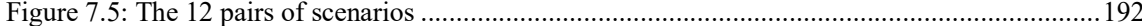

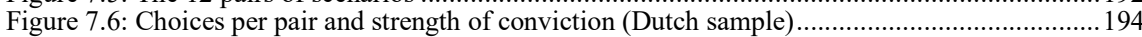

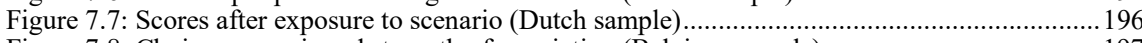

Figure 7.8: Choices per pair and strength of conviction (Belgium sample) …………………….........197

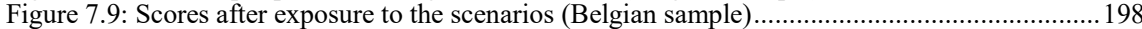

Figure 7.10: Changes in reported scores based on stick-related requirements (Dutch sample)............201 
Figure 7.11: Changes in scores based on carrot-related requirements (Dutch sample)....................201

Figure 7.12: Changes in scores based on sermon-related requirements (Dutch sample).................202

Figure 7.13: Changes in scores based on stick-related requirements (Belgian sample) .........................203

Figure 7.14: Changes in scores based on carrot-related requirements (Belgian sample) ..................204

Figure 7.15: Changes in scores based on sermon-related requirements (Belgian sample)................205

Figure 7.16: Gender differences and the requirements ..........................................................206

Figure 8.1: Example of a mitigation measure (Farivar, 2013) .....................................................222

Figure 8.2: Short-term changes to the RSV of all search queries ................225

Figure 8.3: Short-term changes to the queries 'P2P-Piracy' (RSV of Feb-March 2013) ..................226

Figure 8.4: Short-term changes to the queries 'Legal Content' (RSV of Feb-March 2013) ................227

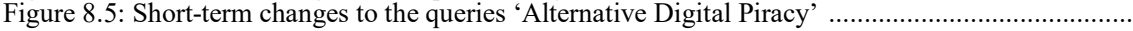

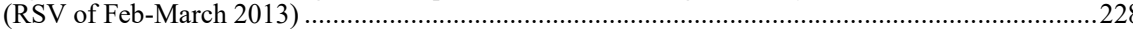

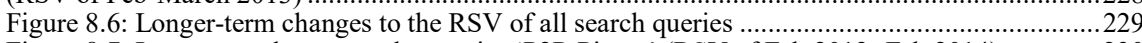

Figure 8.7: Long-term changes to the queries 'P2P-Piracy' (RSV of Feb 2012- Feb 2014) ................230

Figure 8.8: Long-term changes to the queries 'Legal Content' (RSV of Feb 2012- Feb 2014) .........231

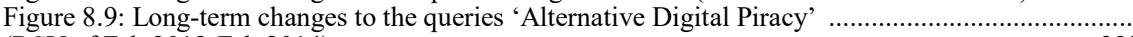

(RSV of Feb 2012-Feb 2014) ........................................................................................2.232

Figure 8.10: Comparison of the RSV of 'P2P Piracy' queries between the USA and Canada...........235

Figure 8.11: Comparison of the RSV of 'Legal Content' quer ques between the USA and Canada ............

Figure 8.12: Comparison of the RSV of 'Alternative Piracy' queries between the USA and Canada ......

Figure 9.1: Example of measures taken against video game pirates (Greenheart Games, 2013) .......253

\section{List of Tables}

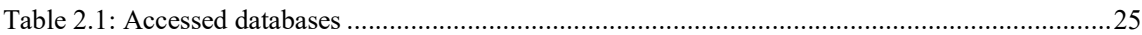

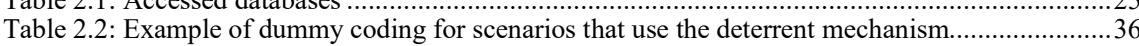

Table 2.3: Socio-demographic overview (Dutch sample)................................................................3

Table 2.4: Socio-demographic overview (Belgian sample) ..........................................................37

Table 3.1: Scope of music piracy according to industry reports ....................................................57

Table 3.2: Academic studies examining the scope of music piracy.................................................5

Table 3.3: Consequences of music piracy ...................................................................................59

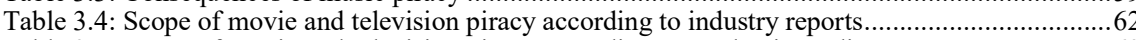

Table 3.5: Scope of movie and television piracy according to academic studies..................................63

Table 3.6: Consequences of movie and television piracy ..................65

Table 3.7: Top 5 game downloads 2011-2012 (Coolpctips, 2012; TorrentFreak, 2011c)..................69

Table 3.8: Scope of software and video game piracy according to academic studies ...............................69

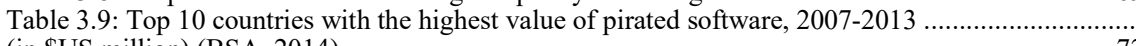

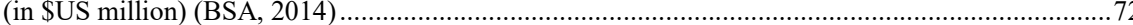

Table 3.10: Consequences of software and video game piracy according to the academic studies......73

Table 6.1: Studies on the certainty of being caught or punished

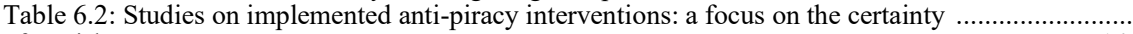

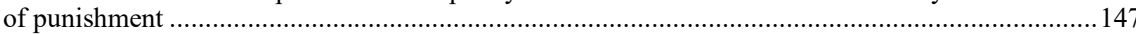

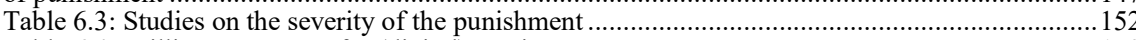

Table 6.4: Willingness to pay for (digital) music ......................................................................159

Table 6.5: Studies on the introduction of pricing strategies .................................................... 160

Table 6.6: Studies on the various non-financial incentives....................................................... 162

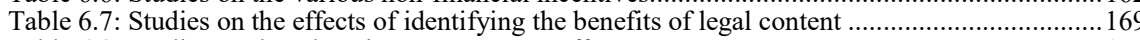

Table 6.8: Studies on the education or awareness efforts

Table 6.9: Studies on the attribution of harm ........................................................................... 175

Table 7.1: Content consumption, past and future digital piracy (Dutch sample) $\mathrm{N}=69$................... 181

Table 7.2: Content consumption, past and future digital piracy (Belgian sample) $\mathrm{N}=110 \ldots \ldots \ldots \ldots \ldots . .182$

Table 7.3: Example of a pair of scenarios (translated from Dutch) ............................................... 192 


\section{An Introduction to Digital Piracy}

The digital age has introduced mankind to many technological innovations. Thanks to developments such as the computer, networked systems, the Internet, social media and the quantified self (Swan, 2013), a large part of human behaviour has, or will, migrate to the digital environment. The emergence of such technologies have profoundly changed modern society (Castells, 2014). The Internet is the clearest example of these innovations. In 2016, over three billion individuals had access to the Internet, an increase of no less than $832 \%$ from 2000 (Internet World Stats, 2016). Thanks to its versatility and usability, the Internet is considered to be the most important innovation in recent years (Lievrouw, 2012; Loader \& Dutton, 2012).

As is often the case with innovations, the Internet comes with a dark side. Unwanted, deviant or criminal acts have also migrated to the digital environment. Online child pornography, hacking, cyberbullying and copyright infringements exist thanks to the Internet and related technologies. When concerns about these and other acts are raised, the focus is often on those labelled as 'cybercrimes'. When computer networks are used to commit acts that violate the criminal law, these acts are identified as cybercrimes. Traditional crimes such as fraud, child pornography and extortion have become digital, as computer networks can now be used to commit them. New forms of crime have also emerged. These are crimes where the computer, the network or information stored on the systems itself is the target of the crime, rather than just the means or a tool used to commit a crime. Hacking and Distributed Denial of Service-attacks (DDOS) are examples of these newer forms of crime (Van der Hulst \& Neve, 2008).

Similar to cybercrimes, traditional forms of deviance - i.e. behaviour that is socially disapproved or that violates the acceptable standards of conduct - have migrated to the digital environment (Heckert \& Heckert, 2002). Behaviours such as bullying have obtained clear digital properties, earning the moniker 'cyberbullying' (Kowalski, Morgan, Drake-Lavelle, \& Allison, 2016). 'Revenge pornography', ${ }^{1}$ an example of virtual sexual conduct, is likewise an example of deviant behaviour that is digital (Citron \& Franks, 2014). Finally, the act of downloading copyrighted content without permission or without having legally

\footnotetext{
${ }^{1}$ This is also known as 'non-consensual pornography'. This involves the distribution of sexually graphic images of individuals without their consent. This includes images originally obtained without consent (e.g., hidden recordings or recordings of sexual assaults) as well as images originally obtained with consent, usually within the context of a private or confidential relationship (e.g., images consensually given to an intimate partner who later distributes them without consent, popularly referred to as 'revenge porn'). Because the term 'revenge porn' is used so frequently as shorthand for all forms of non-consensual pornography, we will use it interchangeably with non-consensual porn (Citron \& Franks, 2014).
} 


\section{$\underline{\text { Punish, Seduce or Persuade }}$}

purchased it is an act of digital copyright infringement. The digital nature of this behaviour has earned it the moniker 'digital piracy'. Given the fact that these acts now take place in the digital environment, these forms of deviance have earned the moniker 'cyber-deviances', referring to the propensity of some Internet users to act in a nonconformist, unethical or socially disapproved manner while online (Selwyn, 2008). Acts of cyber-deviance do not necessarily violate the criminal law. Instead, cyber-deviance can be in conflict with the social norms of society as well as other types of law (administrative or civil).

Governments and private parties have taken and are taking actions to counteract cyber-deviances, as they can have consequences for society as a whole. Yet, it is often unclear whether or not such actions are successful in reducing the prevalence of various types of cyber-deviance and minimizing their consequences for society. Behaviours such as cyberbullying, forms of virtual sexual conduct (Reyns, Henson, \& Fishers, 2014) and digital piracy (Maratea and Kavanagh (2012) all have consequences for society. This can be illustrated by focusing on digital piracy, where reported losses represent billions of US dollars of revenue for the creative industries (Kariithi, 2011). Cyber-deviance is a topic that requires more academic attention, but a focus on one specific type of deviance is necessary, as it is otherwise impossible to examine the issue in depth. Digital piracy is a type of cyber-deviance that serves this purpose. Given the many efforts in place intended to reduce its prevalence, it is necessary to examine whether such efforts are indeed capable of fulfilling this objective in the context of digital piracy.

It was already stated that digital piracy involves the act of downloading copyrighted content without permission from the content owner or without having purchased it legally. Put differently, digital piracy is an act which involves the downloading of pirated content from an illegal source. Downloading refers to the act of receiving data to a local system (such as a PC) from a remote system, for instance a website or server. Downloading pirated content from an illegal source means that the individual has not purchased this content legally. An act of digital piracy is facilitated through specific websites and software; the 'illegal source'. Websites such as 'The Pirate Bay' are examples of these facilitators.

Although the underlying act of copyright infringement is a type of deviance that has been part of society since the $15^{\text {th }}$ century (Adrian, 2009; Varian, 2005), the mid-1990s saw the digitalization and subsequent expansion of this behaviour and has seriously worried the creative industry ever since. The creative industry is concerned that it suffers losses to their sales and revenues, as individuals who infringe on copyright (e.g., those who download pirated content) would no longer be willing to purchase this content legally, since they have already acquired it for 
free. The creative industries and governments around the globe have attempted to reduce the frequency and (assumed) consequences of digital piracy via various anti-piracy interventions. Despite these interventions, digital piracy remains common in Western societies. In the Netherlands, $27 \%$ of the population engages in this type of deviance (Poort \& Weda, 2015). It is estimated that $89 \%$ of Peerto-Peer (P2P) traffic through a BitTorrent service is used to pirate content (Layton \& Watters, 2010). In Australia, almost half of the examined respondents had pirated either software or video games (Larsson, Wnukowska-Mtonga, Svensson, $\&$ de Kaminski, 2014).

Although such behaviour clearly infringes upon the rights of artists, developers and publishers (e.g., the creative industry), many individuals who engage in this activity fail to see it as a moral or deviant issue (Siponen, Vance, \& Willison, 2012). The belief that digital piracy is a 'non-issue' or even acceptable aids in explaining why this behaviour is so common and persistent, as individuals who think that digital piracy is acceptable are more likely to act in this manner. Irrespective of this belief, creative industries and governments clearly consider digital piracy to be deviant behaviour. In addition, it is often claimed that digital piracy has caused (or at least contributed to) the reductions in sales and revenues that the creative industries have experienced in the past decades (Liebowitz, 2016). This has led to call for measures capable of dealing with the issue of digital piracy. Thus, most countries have taken measures to inhibit or limit it, with criminalization of this behaviour being one of the available options. An intersection between criminal and copyright law is thus present when studying digital piracy (Bitton, 2012). In addition, acts of digital piracy also violate a social norm: the protection of content and remuneration for the creator when the content is used, which are encapsulated in various copyright laws.

The concerns of the creative industry about the potential consequences of digital piracy, as well as its deviant status and infringing nature, have led to the development of a variety of anti-piracy interventions that are used to reduce digital piracy. These are meant to influence the behaviour of the individuals (or digital pirates). It is thought that modifying the context or setting in which digital piracy takes place can result in a change in behaviour and reduce the likelihood of digital piracy. Examples of anti-piracy interventions currently used include: 1) the sanctioning of digital piracy through criminal law or through civil law suits; 2) the stimulation of desired behaviour by making legal content (which refers to content that the users can legally purchase) more attractive; and 3) awareness campaigns informing the public on the immorality of or harm caused by digital piracy. One assumption underlying some of these interventions is that, through the threat of punishment, individuals can be deterred from pirating content digitally. A second assumption is that, by offering some form of incentive or 


\section{$\underline{\text { Punish, Seduce or Persuade }}$}

reward when using the content in a legal manner, it becomes more attractive to consume the content legally. Finally, awareness campaigns assume that, by making individuals aware of the immorality or potential consequences of their behaviour (for themselves, the artist or the creative industry), they can be persuaded to stop pirating content digitally. Most of the anti-piracy interventions follow one (or more) of these assumptions.

However, it is often unclear what the effects of most of these interventions are and whether these assumptions are valid. Cyber-deviance, and the responses to this issue, are relatively understudied topics in the fields of criminology and evaluation studies (Leeuw \& Leeuw, 2012). Digital piracy is no exception. Determining whether anti-piracy interventions (can) succeed in reducing digital piracy poses a challenge since it requires the researcher to understand the link between digital human behaviour (digital piracy) and the interventions themselves. This means that, without insights into why individuals pirate content digitally, it is nearly impossible to assess whether the interventions can truly change this behaviour. The focus of this research is therefore on explaining digital piracy, the link between this behaviour and the anti-piracy interventions and whether and how these interventions can contribute to reductions in digital piracy.

\subsection{The status quo of digital piracy}

The emergence of the Internet marked the moment when copyright infringements became more abundant and earned the label of being 'digital'. Digital piracy materialized fully in 1999, when the file-sharing program Napster was launched. It was primarily used (by university students) to share music files (known as MP3 $\mathrm{s}^{2}$ ), which were often ripped from CD's (Bridy, 2009). Over time, as Internet and computer capabilities increased, movies, video games, software, and pornography were being shared over the Internet. Although Napster was shut down in $2001,{ }^{3}$ many other systems, websites and platforms emerged since then. These included other P2P-networks, FTP-servers, BitTorrent-clients, and cyberlockers. Pandora's Box had been opened. It has never been easier for individuals to search for, find and obtain pirated content.

Even prior to the introduction of the Internet, governments, policy makers, the creative industry, and content owners were concerned about copyright infringements. In the 1970s, Bill Gates already warned that the rampant copying of software would inhibit the developers from designing and producing new and better software. In 1976 he wrote an open letter to computer hobbyists, expressing his concerns on software piracy (Gates, 1976). Simultaneously, legislators around

${ }^{2}$ A common audio format that is meant for consumer playback.

${ }^{3}$ Although Napster relaunched in 2004 as a pay-per-download service (Roettgers, 2016) 


\section{An Introduction to Digital Piracy}

the globe were attempting to tackle various types of piracy, such as record piracy, which refers to the unauthorized duplication of the sounds on copyrighted records, tapes, cassettes, compact disks, or any other form of sound storage (Thom, 1988). Each subsequent technological innovation enabled individuals to engage in new forms of copyright infringement. The 1990s and 2000s brought a rapid succession of such innovations. In addition to the Internet, the MP3- and MP4-file formats, portable music players, CD-ROMs and CD-ROM drives, the MPEG-4 computer file compression format, DVDs, Blu-Ray, P2P-networks, streaming technologies, and e-books have been developed in the past years (Wall \& Yar, 2011). All these technological advancements enabled the digital piracy of music, video games and software, as well as movies and television series.

Thanks to these and many other (technological) developments, digital piracy is simple to do. Nowadays nearly anybody can pirate content digitally, as any substantial technological knowledge is no longer needed (Yar, 2007). The reduction or outright removal of quality degradation, which plagued earlier variants of copyright infringement, has also increased the commonality of this behaviour. In recent years, the quality of the digital content has been maintained, regardless of how often it is downloaded, copied or shared. Since digital content uses standardised formats (such as MP3 or MP4 in the context of music piracy or MPEG-4 in the case of movies) individuals can easily share their files with others. Thanks to the increased storage capacities of hard-drives, an individual can store massive quantity of pirated content on his or her computer. ${ }^{4,5}$ Finally, and perhaps, most importantly, access to computers and the Internet has increased in the past decades (Yar, 2007). 73.5\% and 87.9\% of the populations of Europe and NorthAmerica have access to the Internet (Internet World Stats, 2016), making digital piracy possible for many individuals. Collectively, all of these developments have contributed to the emergence and persistence of digital piracy.

Clearly, digital piracy is a widespread phenomenon. It has expanded beyond music, movies, software, and video games. E-books are now also pirated. This has raised concerns that the amount of pirated e-books will increase and cause losses to the legal e-book market (Blankfield \& Stevenson, 2012) or possibly even the traditional paper-market, similar to their counterparts in the music and movie industries. The development of the 3D-printer has likewise raised concerns. Will individuals be able to download and print a wide-range of copyrighted products thanks to the emergence and availability of the 3D-printer? This seems likely. Although the practical applications of such devices are currently still relatively

\footnotetext{
${ }^{4}$ From this point onwards, 'he' will be used in this research.

${ }^{5}$ For instance, the laptop used to write this chapter has storage of 2 Terabytes. Depending on the quality of the movie (and its size), this laptop could store between 200 and around 2600 movies.
} 


\section{$\underline{\text { Punish, Seduce or Persuade }}$}

limited, the printing of certain objects, such as Lego blocks or toy figurines (such as Transformer action figurines) is already possible (Mallough, 2013). This has worried the toy industry for some time now (Desai \& Magliocca, 2014). More alarming is the fact that the first functional guns have already been printed, raising issues both about copyrights and security. Such developments only scratch the surface of what could be possible with this technology in a few years or in the coming decades. 'Napster-like' scenarios are possible, meaning that many individuals could be engaging in these activities once the technology is cheap and accessible. Governments and content owners will likely deem it necessary to continue to combat these and other forms of digital piracy through various interventions (Neagle, 2013). Understanding whether these interventions can contribute to reductions in digital piracy is therefore not only currently relevant but will be necessary in order to develop and adjust future policy on copyrights and the enforcement thereof.

\subsection{The modus operandi of digital piracy}

In order to better understand the issue of digital piracy, it helps to be clear on how individuals pirate content digitally. Many current and past methods are based on P2P-architecture (also known as 'file sharing'). This architecture is defined as:

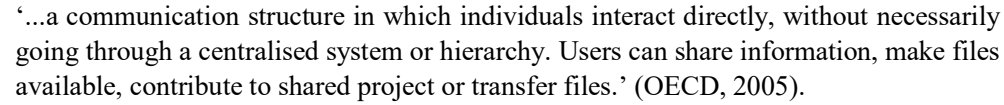

'...a communication structure in which individuals interact directly, without necessarily going through a centralised system or hierarchy. Users can share information, make files available, contribute to shared project or transfer files.' (OECD, 2005).

Through P2P-networks, computers are connected and linked together, with the goal of exchanging files or data. The files themselves can be legal but this exchange can be used to share pirated content with users on the network (OECD, 2009). With a sufficiently large number of users in this network, any P2P-user can easily find and quickly download Figure 0.1: Depiction of a P2P-network (Securethoughts, 2016)

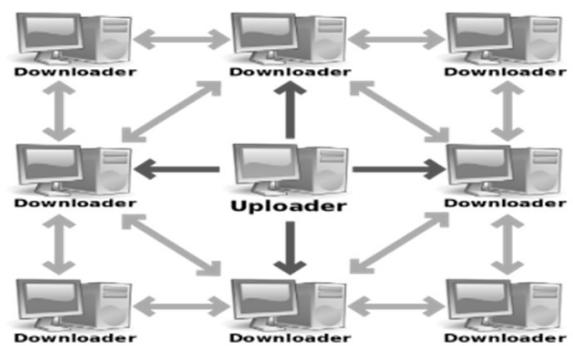
the content that he desires, as the combined capabilities of networked computers provide unprecedented access to digital resources. Most P2P-networks are decentralised, meaning that such networks rely on individual users to upload and distribute the content to other users. These networks encourage the users to be both consumers (downloaders, or leechers) and suppliers (uploaders, or seeders) of the digital content. Having more uploaders increases the efficiency of the network, as users can download (parts of) the content from multiple uploaders, 


\section{An Introduction to Digital Piracy}

accelerating the overall process. Frequent uploaders are often rewarded with better social standing in the piracy community (OECD, 2009). These networks can be used to distribute essentially all types of digital content, including pirated music, movies and software. Examples of P2P-networks are Gnutella, eDonkey and, currently one of the most prominent networks, BitTorrent (and other types of Figure 0.2: The Pirate Bay Homepage (The torrents) services. Websites such as the Pirate Bay, 2016)

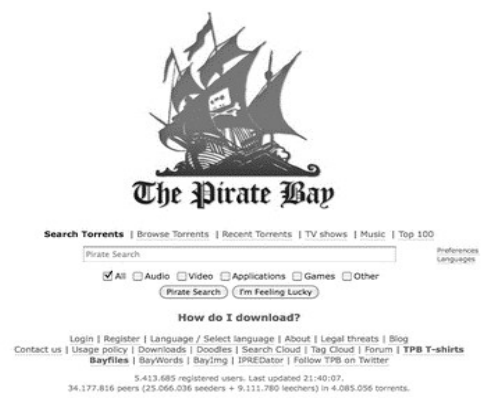
Pirate Bay provide for links to this content (without uploading or hosting the content itself), allowing users to search, download and share all types of content, legal or otherwise.

There are other methods through which pirated content can be distributed digitally (OECD, 2009). One such method are the 'Warez-sites'. 6 Through these websites, a broad spectrum of pirated digital content is distributed. Organised groups, often called 'release groups', specialize in delivering new digital content to selected websites or servers (such as FTP-sites) where users can access large quantities of illegally copied content. As opposed to the P2P-networks, this content is not as easily accessible as users often have to be a member of specific forums, websites or services. Sometimes, users have to purchase this membership status, but these costs are often much lower than the price of the legal content.

Highly popular are the 'one-click hosting services'. These sites, also known as 'file-' or 'cyberlockers', allow Internet users to download and upload content easily and free of charge from their hard drive onto the one-click host's server and vice versa. Most of these services present a hyperlink in order to download the digital content. Many Internet forums exist in order to share such links. Aside from legal content, a vast number of files that are hosted on these services contain pirated Figure 0.3: Megaupload Banner (Megaupload, n.d.)

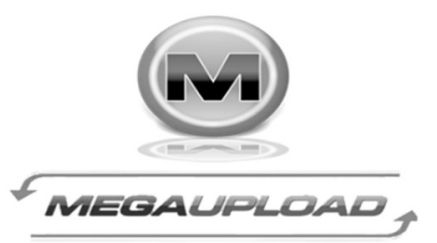
content (Drath, 2012). A well-known example of such a hosting service was the website Megaupload.com, which was shut down in 2012 due to copyright infringements. It has a successor in the form of Mega.co.nz.

\footnotetext{
${ }^{6}$ Warez-sites are generally unauthorized releases by organized groups, as opposed to file sharing between friends or large groups of people. The word warez is a leetspeak plural form of ware, short for computer software.
} 


\section{$\underline{\text { Punish, Seduce or Persuade }}$}

A more recent addition to the aforementioned methods is the usage of streaming services in order to watch pirated content online. Video and music can be streamed from a server in order to enjoy the content, without having to download the content onto one's computer (Padmanabhan, Wang, Chou, \& Sripanidkulchai, 2002). Although a large number of legal streaming services exist (such as Spotify, Netflix and Deezer), streaming can also include pirated content. Websites offering streaming services attract a large amount of traffic, which will only increase in the near future. In fact, illegal streaming may become the preferred way to experience digital content such as music and movies (Eggerton, 2011). The most recent development is the piracy of applications meant for mobile devices (e.g., smart phones and tablets) (Choi, Au, \& Liu, 2014), demonstrating that digital piracy is an issue that is undergoing continuous development (makeuseof, 2015).

\subsection{Delineating the concept of digital piracy}

Precisely the fact that digital piracy is easy, common and often not considered to be deviant by those who pirate makes it an interesting topic to examine scientifically. The labelling of the act of obtaining content through an illegal source as an act of 'piracy' calls upon the imagination of many. On the one hand, the term 'pirate' seems to evoke an image of a carefree individual, beyond the reach of the law who takes what he needs from the wealthy (akin to a modern-day Robin Hood (Shoham, Ruvio, \& Davidow, 2008)). Here, digital piracy is seen as being adventurous and exciting. The digital pirates themselves believe to exist in a moral twilight zone. Their own depiction of digital piracy is opposite to how the creative industries and content owners perceive and present the digital pirate (High, 2015), which is more negative. According to the latter, digital pirates steal and pillage and are outlaws. The creed 'take what you can, give nothing back' seems to be the manner in which digital pirates are perceived by some. But digital pirates themselves are not likely to see their own behaviour in this manner. Clearly, digital piracy has two different connotations; one more positive than the other. Some degree of dissonance between these two positions has thus been observed (Rendas, 2015). Regardless of how digital piracy is perceived, it nonetheless refers to a broad range of behaviour, as was seen in $§ 1.2$. (supra p. 6). This range is also reflected in the definitions used to further delineate digital piracy in this research. There is no definitive agreement on how digital piracy should be defined in the academic literature. Scholars have presented various definitions, ranging from rather generic to more specific definitions. For example, Taylor, Ishida, and Wallace (2009, p. 246) present a rather brief, and at the same time broad, definition.

\footnotetext{
'...digital piracy (DP), defined herein as the consumption of illegal copies of digital
} services.’ 


\section{An Introduction to Digital Piracy}

This definition fails to specify how a digital pirate should acquire the pirated content. The digital aspect is derived from the characteristics of the services themselves, rather than the method through which these services are obtained, but the illegal nature of the copying is made clear. Still, what is to be understood with 'services'? The meaning of 'consumption' also remains vague. Is one pirated copy sufficient or is there a minimum amount needed before one can argue that an act falls within the reach of this definition of digital piracy? These are questions that are left unanswered by these scholars.

Others present a more detailed definition. Higgins, Fell, and Wilson (2006, pp. 34) define digital piracy as follows:

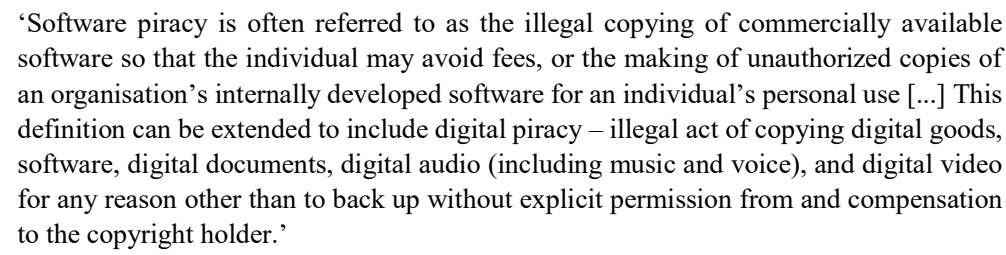

This definition clarifies what kinds of digital content can fall under the phenomenon. In their study, Higgins et al. (2006) suggest that digital content can be defined in a broad sense, including software, music, movies, and possibly more. This means that the definition enjoys more clarity in this regard than the previous one. There are also some behavioural elements referred to in this definition, as motives are identified. This somewhat limits the applicability of this definition, as there can be other reasons than these to pirate content digitally.

Other definitions of digital piracy are even broader and make a distinction between digital piracy and software piracy, as Al-Rafee and Rouibah (2010, p. 283) illustrate:

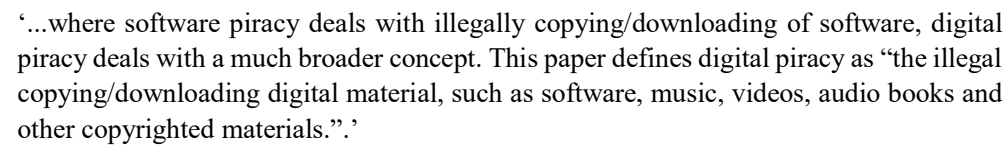

Software piracy is, in this definition, seen as a sub-variant of digital piracy. Other scholars prefer to use a definition that is more delineated by depicting clearly what does not count as digital piracy. Gopal, Sanders, Bhattacharjee, Agrawal, and Wagner (2004, p. 90), for example, state:

'Digital piracy is the illegal act of copying digital goods [...] for any reason other than backup without the explicit permission from and compensation to the copyright holder.' 


\section{$\underline{\text { Punish, Seduce or Persuade }}$}

This definition states that copying digital content for the purpose of creating a backup is not an act of digital piracy, assuming that the copyright holder has given explicit permission to do so and that compensation is provided. Such behaviour would be legal (Gopal et al, 2004). However, if this backup is subsequently distributed, it clearly becomes an act of digital piracy. It is unclear what 'explicit permission' means, however. How explicit does this permission have to be? How should the individual obtain this permission? Incorporating notions of 'permission' thus does not necessarily add to the clarity of a digital piracy definition.

The above-described definitions have similar elements and are sometimes complementary. These definitions therefore have been used to develop an overall definition used in this research:

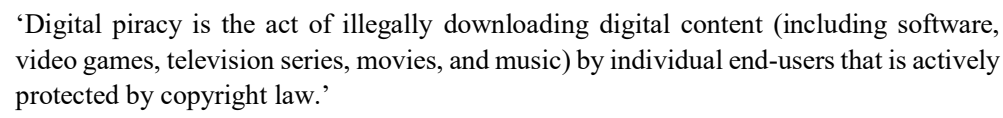

The first important characteristic of this definition is its focus on individual endusers, making this definition quite specific compared to most of the definitions discussed earlier. Only Higgins et al. (2006) refer directly to the individual. This focus is not unimportant as different subgroups of digital pirates exist, each with different reasons for pirating content. In addition to the end-users, there are those that pirate content for direct financial gain, meaning that they attempt to sell the pirated content to others. Another subgroup is made up of individuals who make the content available in the first place and mostly upload content, essentially supplying the pirated content. Finally, the definition excludes any instance of digital piracy where organized crime groups are directly involved in the act of digital piracy (Janssens, Vandaele, \& vander Beken, 2009). A focus on a specific subgroup allows for a more detailed examination of why individuals, belonging to this subgroup, pirate content digitally and how they might react to anti-piracy interventions. It also allows for more focus on the interventions that target this subgroup specifically, as opposed to those that also target the 'suppliers'. This means that this research does not focus on the uploaders of pirated content, which is underlined given the focus on downloading. This further delineates the topic of this research. While this research focuses on a specific type of digital pirate, it does incorporate a wide range of digital content. This means that music, movies, television series, software, or video games are all types of content that are examined in this research. Therefore, insights that originate from software piracy are as useful as those on music piracy. The reason for this broad approach is that it has been demonstrated that individuals who pirate content digitally will often 


\section{An Introduction to Digital Piracy}

pirate multiple types of content (Huygen et al., 2009), making it very likely that the reasons for doing so are similar.

The definition does exclude content that is no longer actively protected by copyrights. Without such protection, copying content no longer leads to a copyright infringement, regardless of its source, placing it outside the scope of the definition used. Various types of content lack such protection. These include content that has entered the public domain, ${ }^{7}$ free-, share-, and abandonware. ${ }^{8} \mathrm{As}$ the concept of illegality is part of this definition, instances where back-ups of digital content are made with the permission of the copyright holder are excluded, as the content was legally purchased in the first place. The digital nature of the definition also excludes analogue piracy, such as copying a physical CD for one's own use. These types of piracy are therefore not instances of 'digital piracy'. Although this research only deals with piracy which relies on the Internet, computer transfers, or sharing over LAN-networks, this does not mean that there is no overlap between digital and analogue types of piracy. An example would be an individual who rips the content of a physical $\mathrm{CD}$ and uploads this to a cyberlocker. Other individuals can download the content and distribute the content further, further infringing the copyright. This latter part would fall within the scope of digital piracy, as a clear digital component is present (the downloading of the content by others). When the digital component is completely lacking and only physical 'hard media' is used, the infringement is not considered to be an instance of 'digital piracy' and is not included in this research.

\subsection{The relationship between digital piracy and copyright law}

The definition above requires content to be copyrighted in order for an act of downloading to be labelled as digital piracy. Copyrights are an important feature of legal content and the creative industries. They give a monopoly to the creators of content, for their own and society's benefit. In this way, they serve to protect the rights of those who developed or created content, yet they also allow consumers to access and use the content in a legal manner (Drassinower, 2009). A balance needs to be found between the monopoly of the creator and the access of the consumer (Landes \& Posner, 1989). Too much protection leads to severe restrictions for the users, as they are limited in the way in which they can use and enjoy the content. Too little protection can result in a decrease of innovation and hamper the creation of content, as, without this protection, users are free to copy and share the content without compensating the creator (Alexander, 2007),

\footnotetext{
${ }^{7}$ Often the result of the expiration of the copyright.

${ }^{8}$ Copyrights expire after a certain period of time. Following this expiration, the content can be said to be in the public domain and is available to all.
} 


\section{$\underline{\text { Punish, Seduce or Persuade }}$}

removing the incentive to create new content. Therefore, the protection of property, ideas or creative content provides incentives for creators to create new content. This applies to music, movies, software, and other content alike. Without such protection, anyone can appropriate the content. There could be no innovation, as investors only see their content being distributed for free, meaning that they obtain no returns on their investment (Anderson Jr, 2008). For instance, movie studios might no longer be willing to invest in new and innovative movies. An incentive to innovate would therefore be hampered. This is an essential reason for having copyrights. Copyright owners and creative industries need incentives and, arguably, acts of digital piracy can remove this incentive.

Copyrights do more than just create a balance between the rights of creators and the rights of consumers. Four rationales further underline the need for copyrights: the justice, cultural, personality, and economic rationales (Grosheide, 1986). The first two are the most relevant in understanding the manner through which digital piracy affects the underlying principles of copyright law. The 'justice' rationale states that the creator is entitled to 'equitable' remuneration for each and every use of his work as a matter of fairness (Helberger \& Hugenholtz, 2007; Van Lingen, 2002). This rationale follows the line of reasoning that without the creator in the first place there would be no product or content and nobody would be able to use it. It is therefore only fair that the creator has a right to benefit from his work and protect it against infringement (Spoor, Verkade, \& Visser, 2005). The second relevant rationale, the 'cultural' rationale, states that copyright acts as an incentive to create and disseminate works that advance knowledge and contribute to our cultural expression (Van Lingen, 2002). The remaining two rationales are less relevant in the context of digital piracy and referred to in passing. ${ }^{9}$ Protecting copyrights, ensuring compensation and providing incentives are essential features of most Western copyright regimes due to these rationales. Digital piracy undermines these rationales and the copyright law itself. A pirated digital copy results in a lack of direct remuneration for the creator and removes the incentives the creative industry has for creating new content. In addition, the creator loses some control of his creation. Regardless of which other consequences digital piracy may have, the fact that such actions undermine copyright laws provides a clear justification for why governments and the creative industries are actively

\footnotetext{
${ }^{9}$ The 'personality' rationale refers to the notion that the produced content is the materialization of the personality of its creator. This creates a bond between the content and the creator, which justifies the creation of copyright law to offer protection to him. This approach is linked to ideas stemming from the field of natural law (Senftleben, 2004). The economic rationale departs from the notion that there are costs involved in the creation of content and, if 'free rider' behaviour occurs, these costs cannot be recovered. Copyrights are put in place to give legal rights to content creators and limit this risk of the free riding and allow for creators to recover their costs as they have the right to reproduce, distribute and sell the content (Elkin-Koren, 1997).
} 


\section{An Introduction to Digital Piracy}

attempting to reduce this behaviour. Clearly, some degree of protection and enforcement of copyrighted content is warranted.

There is one far-reaching solution to the problem of digital piracy. This solution would entail the relaxation or removal of copyrights from (digital) content altogether. Without a copyright to infringe, the act of downloading does not obtain its illegal characteristic, as it is no longer an instance of copyright infringement. As some criminologists might argue, without such laws, the deviant behaviour would seize to exist (Sutherland, 2006). This does not really change the underlying behaviour, but, from a strictly legalistic point of view, the issue of digital piracy would be solved. However, such a radical solution would forgo the fact that copyrights are needed in modern society, as was previously established. Simply removing copyrights is therefore not a realistic solution to the issue of digital piracy. Instead, potential solutions will likely come in the form of antipiracy interventions.

\subsection{The discrepancy between copyright law and digital behaviour}

The act of digital piracy (as defined in this research) thus inherently results in a violation of copyright law and its underlying rationales, clearly making digital piracy an example of cyber-deviance. Many laws and treaties on copyright state that it is the exclusive right of the author to make the work public or reproduce it. ${ }^{10}$ This exclusivity, which is an essential concept in copyright law, is infringed upon, which in turn infringes on the underlying (social) norms. Given the fact that digital piracy runs counter to these norms, applying the label 'cyber-deviance' to this behaviour is fitting.

As already discussed (§1.1. (supra p. 4)), not all will perceive digital piracy in this manner. As Stewart, Bing, and Davison (2009, p. 210) argue: 'deviance is in the eye of the beholder'. Different segments of society will vary in what they deem to be deviant behaviour or even criminal behaviour. This means that some individuals, organizations or governments understand digital piracy to be deviant while others do not, which further complicates the discussion. Thus, there exist competing moral frameworks (Edwards, Klein, Lee, Moss, \& Philip, 2015b). Clearly, the copyright holders, creative industry and most governments do see digital piracy as deviant. In contrast, those individuals who pirate content digitally often see this differently. The issue of digital piracy is thus not necessarily a 'black

\footnotetext{
${ }^{10}$ See, for example, article 1 of the Dutch Copyright Act of 1912, article 6 of the World Intellectual Property Organization Copyright Treaty of 1996, article 16 of the Agreement on Trade Related Aspects of Intellectual Property Rights (TRIPS) of 1996, article 16 of the UK Copyright, Designs and Patents Act 1988 and $\S 106$, Title 17 of the United States Code.
} 


\section{$\underline{\text { Punish, Seduce or Persuade }}$}

and white' issue but rather one of various shades of grey. Cluley (2013) states that, while digital piracy can be seen as being illegal (given the fact that it involves a violation of copyright law) it is not as straightforward as to state that it is also immoral. This discrepancy between the law and the perception thereof provides a breeding ground for digital piracy. Most digital pirates are aware of the illegality of their own behaviour. Yet, they pirate content nonetheless, as many individuals do not perceive that their behaviour is wrong or immoral (Cluley, 2013). And since changing behaviour becomes more difficult if it is not seen as being problematic, anti-piracy interventions inherently face an uphill battle.

\subsection{Anti-piracy interventions}

While there is still some debate on whether or not digital piracy indeed causes reductions in sales and revenues (Kariithi, 2011), it is quite clear that governments and the creative industry have developed and implemented a large number of antipiracy interventions, which try to enforce copyright in one way or another. In fact, new interventions are continuously being developed, such as the Copyright Alert System, which was implemented in the United States of America (USA) in 2013. This suggests that, at the very least, governments and the creative industries consider digital piracy an illegal act. Regardless of whether digital piracy is indeed causes reductions in sales and revenues, anti-piracy interventions are 'here to stay', which makes them an interesting object of scientific investigation. This raises the question as to whether these anti-piracy interventions indeed contribute to a reduction in digital piracy.

Some examples of different anti-piracy interventions can be given in order to provide some additional context to the research question and sub-questions that will be discussed in the next section. Three general 'flavours' of anti-piracy interventions are identified in this research, which can be categorized into the 'Sticks, Carrot and Sermon'-division as proposed by Vedung (1998).

One flavour is to prohibit, sanction or otherwise deter instances of digital piracy. This is accomplished by using a variety of legal instruments such as civil suits, criminal fines, settlements, and even imprisonment in certain extreme cases. The most recent addition to these prohibitive interventions are the so-called 'graduated response schemes', which are monitoring and notification schemes. Subscribers to Internet Service Providers (ISPs), whose acts of digital piracy are detected, start receiving warnings from the ISPs. Through these warnings, the subscriber is informed about the illegality of his behaviour and directed to venues where the content can be obtained legally. If the subscriber continues to pirate content digitally, he will be warned again. The warnings will become sterner and are 


\section{An Introduction to Digital Piracy}

followed by mitigation measures, such as bandwidth throttling, disconnection from the Internet and fines. Technological measures that attempt to make the act of digital piracy more difficult also belong to this flavour. Such measures focus on the more practical aspects of digital piracy. For example, Dutch ISP's blocked the website 'The Pirate Bay' from the beginning of 2012 to the beginning of 2014 (Poort et al., 2014). This was meant to make the pirated content more difficult to access, forcing the digital pirate to expend more time and resources to find the pirated content, hopefully making the act of digital piracy less attractive. Simultaneously, certain types of digital content, such as video games, possess technological characteristics that make it inherently more difficult for individuals to pirate this content successfully.

The second flavour is to make the legal content more attractive. This means that the price of legal content is reduced in order to better compete with the free, yet illegal, pirated copy. Such a pricing strategy can motivate individuals not to pirate this content, but rather to purchase it legally. Other examples of other ways to 'lure' or 'tempt' individuals away from digital piracy are the introduction of legal downloading and streaming services that are meant to compete with the pirate venues. The inclusion of features that the pirated copy lacks is likewise meant to make the legal copy more attractive. Free updates are one example of these features.

A third and final approach is to persuade users that digital piracy is immoral or wrong. Using public awareness campaigns to inform potential pirates about the potential consequences of their digital piracy behaviour has been used extensively in the past. Rather than tempting or punishing the pirates, these approaches try to persuade (would-be) digital pirates that such behaviour is undesired, immoral or even criminal. Other measures belonging to this approach identify the risks associated with digital piracy (such as infecting one's computer through a pirated copy) or the benefits of the legal content, with the aim of making the individual reconsider the costs and benefits of digital piracy. In turn, this could persuade the individual not to pirate content digitally.

In addition to being costly to develop, implement and maintain, some of these interventions are controversial. For instance, the graduated response scheme has garnered criticism from various scholars, as it is a measure that encroaches on users' privacy and freedom of speech (Bridy, 2012; Giblin, 2014; Ranaivoson \& Lorrain, 2012). If such interventions are unable to contribute to reductions in digital piracy, governments and the creative industries alike might need to reconsider the implementation of such measures. At the same time, insights on which anti-piracy interventions work and, more importantly, why they work, can 


\section{$\underline{\text { Punish, Seduce or Persuade }}$}

allow governments and the creative industries to select the more suitable type of intervention or to fine-tune the existing ones.

The creative industry often claims that these interventions have resulted in better management of digital piracy and are necessary to protect their content. But it is not clear whether this is truly the case as (digital) piracy has remained a rather constant factor over the past three decades, despite the presence of many antipiracy interventions. Once again, this raises the important question whether the various interventions can actually contribute to a reduction in digital piracy. This research focuses on this matter in depth and from a neutral vantage point, with no relation to either side of the debate. Beyond a small grant from the Horowitz Foundation for Social Policy ${ }^{11}$ (used to conduct one of the two empirical studies used in this research), no external funding was received. The Foundation has had no influence on the content or direction of this research. No other third parties were involved in the research, in order to guarantee an independent research project.

To examine the interventions in detail, it is important to understand that each intervention uses a different approach in order to contribute to this reduction, as was previously discussed. In fact, each intervention uses a specific mechanism. These mechanisms influence the behaviour of digital pirates and are meant to trigger behavioural change. Understanding the various anti-piracy interventions and the ways in which they 'operate' and can influence behaviour means that these mechanisms must be studied in depth.

\subsection{Objectives of the research and research question}

The previous discussion leads directly to the two main goals of this research, which are:

1. to determine which mechanisms, as the (behavioural) 'building blocks' of anti-piracy interventions, are activated when organizations and stakeholders implement these interventions; and

2. to assess whether these mechanisms enable interventions to contribute to reductions in digital piracy.

By examining each mechanism, it is determined which ones are capable of contributing to reductions in digital piracy and in which particular setting. This examination also allows for an estimation of the size of the contributions. The focus on mechanisms therefore serves as a recurring theme throughout this research. The main goals are translated into the following research question:

${ }^{11}$ See http://www.horowitz-foundation.org/, last accessed on 17-01-2017. 
'Which mechanisms, used in the designs of various anti-piracy interventions, contribute to reductions in digital piracy and to what extent?'

To substantiate this research question and to provide the building blocks needed to answer it, a number of sub-questions are posed. The focal point of these subquestions is the link between digital piracy as behaviour and the mechanisms used in the anti-piracy interventions. This means that it needs to be clear what makes an individual more prone or inclined to pirate content digitally in order to be able to assess the functioning of each mechanism properly.

In order to examine this link, it first needs to be clear why individuals decide to pirate content digitally. To that end, the first sub-question asks how can the behaviour of digital pirates be explained? To answer it, insights are obtained that depict the relevant behavioural variables that make digital piracy more likely in a given context. Such insights are useful as they enable an assessment as to whether or not the anti-piracy interventions influence the variables that cause digital piracy. For instance, if evidence suggests that the high price of legal content increases the likelihood of digital piracy, the price-mechanism that is a building block in some of the interventions becomes more relevant. The variables that are found in the literature will be structured through the lens of the Situational Action Theory (SAT). Simply put, this theory proposes that deviant behaviour is the consequence of the interaction between the propensity of an individual to act in a deviant manner, the conduciveness of the environment towards deviance and the individual's decision-making process (or process of choice) (Wikström, 2006). The individual's propensity and the environmental features determine whether an individual is motivated to pirate content digitally, while the process of choice influences whether this motivation is translated into intention. In turn, this intention can lead to behaviour: the act of digital piracy. This approach results in three distinct clusters consisting of variables that motivate an individual to pirate content digitally. By placing the explanatory variables in one of these three clusters, the interaction between the individual and his environment can be analysed, allowing for a more integrative approach in answering the first subquestion.

With the first part of the link between digital piracy and the anti-piracy interventions established, the next step is to start to focus on these interventions and their associated mechanisms. However, before it can be examined which mechanisms are used in the design of the various interventions, it is necessary to provide an overview of the types of anti-piracy interventions currently found. This results in the second sub-question which asks which interventions, both from governmental and other (public and private) organisations, are currently applied in the context of digital piracy? The overview also allows for a global assessment 


\section{$\underline{\text { Punish, Seduce or Persuade }}$}

as to how these various interventions attempt to reduce digital piracy. This subquestion forms the bridge between why people pirate content digitally and whether anti-piracy interventions are capable of contributing to a reduction. The antipiracy interventions found are categorized based on the mechanism used. As stated in §1.6. (supra p. 14), interventions either attempt to deter, tempt or persuade pirates to act differently ('Sticks, Carrots or Sermons'). This division is followed in the categorization of the various anti-piracy interventions (Vedung, 1998).

Each intervention uses a specific mechanism. The proper functioning of each mechanism is dependent on a number of requirements that must be met. Interventions are examined in more detail in order to identify which mechanisms are used and, importantly, what the associated requirements of the mechanisms are. The third sub-question therefore asks: which (behavioural) mechanisms are applied in the design of the various anti-piracy interventions and what are the requirements for their proper functioning? The link between digital piracy as behaviour and the mechanism is present, as certain mechanisms will target specific reasons or motivations as to why individuals pirate content digitally. Determining whether or not each mechanism identified meets the requirements is important in understanding whether these mechanisms are capable of contributing to reductions in digital piracy.

To examine whether the interventions are indeed capable of contributing to reductions in digital piracy, the fourth sub-question asks: to what extent do the underlying mechanisms contribute to reductions in digital piracy. The answer to this question feeds back into the behavioural aspects of digital piracy. It is determined if and when these mechanisms can contribute to any reductions. The term contribution refers to changes in the intention or inclinations of individuals to pirate content digitally. Although intention or inclinations do not equate actual behaviour, they are an important predictor of such behaviour (Ajzen, 1991). Changes to intention or inclinations can thus be indicators of changes to actual behaviour. To answer this sub-question, the linkage between the mechanisms and digital piracy becomes the most concrete as these mechanisms can directly influence this behaviour. Each mechanism is evaluated on its own merits but also the manner in which it is applied in practice. In this manner, observations on the expected extent of the contributions to the reductions (if any) can be made. These observations are insightful with regard to how the design and implementation of anti-piracy interventions can be streamlined or improved and which interventions seem most likely to be able to contribute to reductions in digital piracy. 


\section{An Introduction to Digital Piracy}

The fifth and final sub-question tries to map how the online search behaviour of digital pirates has changed after the implementation of a specific anti-piracy intervention. It goes one step further than what the fourth sub-question allows, since the answer to it focuses on how the various mechanisms and their associated requirements are processed by respondents. In contrast, the fifth sub-question examines which changes occurred in real-life after the implementation of an antipiracy intervention. Thus, it asks which changes can be observed in the online search behaviour of digital pirates after the implementation of a specific antipiracy intervention? These changes can be indicative of the contribution (if any) that this specific intervention has had on reductions in digital piracy. The answer to the fifth sub-question presents an in-depth examination of the possible outcomes of one specific intervention, whereas the fourth sub-question looks at a wider range of interventions and mechanisms.

Text Box 1.1 summarizes the research question and associated sub-questions.

Text Box 0.1: Summary of the research question and sub-questions

\section{Research question}

Which mechanisms, used in the designs of various anti-piracy interventions, contribute to reductions in digital piracy and to what extent?

\section{Sub-Questions}

1. How can the behaviour of digital pirates be explained?

2. Which interventions, both from governmental and other (public and private) organisations, are currently applied in the context of digital piracy?

3. Which (behavioural) mechanisms are applied in the design of the various anti-piracy interventions and what are the requirements for their proper functioning?

4. To what extent do the underlying mechanisms contribute to reductions in digital piracy?

5. Which changes can be observed in the online search behaviour of digital pirates after the implementation of a specific anti-piracy intervention?

The sub-questions are visualized in Figure 1.4. This figure provides an overview of the various steps that have been taken in order to answer the sub-questions, and, in turn, the research question. The visualization thus does not present a model that will be tested empirically in this research, nor does the visualization stem from a theoretical perspective or vantage point. The SAT is referenced since this theory structures the various explanations of digital piracy. Testing the SAT is not the aim of this research. 
Figure 0.4: Visualization of the research

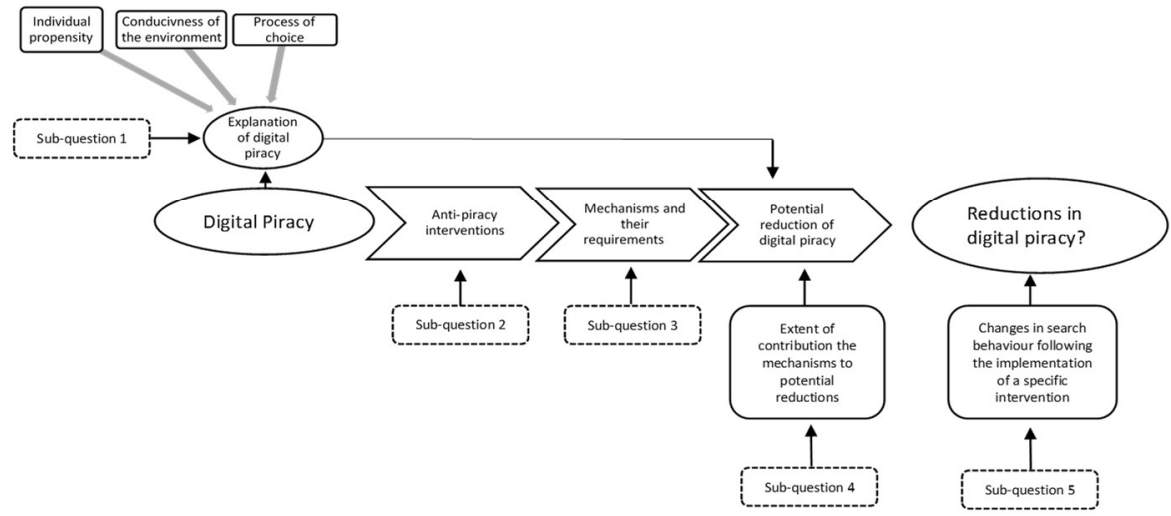

This figure illustrates that the various sub-questions focus on different aspects of digital piracy and anti-piracy interventions. The buildings blocks of the research are positioned in relation to each other. It also reveals how these steps follow each other and how they all contribute to answering the main research question. The arrows that stem from each sub-question show which building block of the research are guided by which specific sub-question. The figure (further) clarifies the logically arranged order of the sub-questions. For instance, it is necessary to know firstly which anti-piracy interventions can be discovered (sub-question 2) before the mechanisms used in the design of the intervention can be identified (sub-question 3). The figure shows that thee sub-questions are divided into two groups. The first focuses on explaining digital piracy (sub-question 1). The latter focuses on the analysis of the anti-piracy interventions and their mechanisms, and whether these can contribute to reductions in digital piracy (sub-questions 2, 3, 4 and 5). Nevertheless, the figure clarifies that sub-questions can converge to a certain extent. After all, explaining digital piracy will also be informative towards the question whether or not anti-piracy interventions reduce digital piracy.

The first three sub-questions are of a descriptive nature. The fourth sub-question, in contrast, focuses on evaluating the identified mechanisms in anti-piracy interventions and their influence on respondents' inclination to pirate content digitally. Finally, the fifth sub-question explores whether reductions in digital piracy-related behaviour (online search behaviour) are observed after the implementation of a specific anti-piracy intervention.

The focus on the mechanisms is novel in the (research) world on digital piracy. Most research that has examined anti-piracy interventions so far has done so by focusing on the interventions in a more general manner. Research has rarely examined the selected mechanisms in detail. This research examines the 'inner 


\section{An Introduction to Digital Piracy}

workings' of the main anti-piracy interventions and therefore uses a different approach compared to other research on digital piracy.

\subsection{Outline of the book}

This book consists of three parts. Following a methodological account in Chapter 2, the first part focuses on the phenomenon of digital piracy. In Chapter 3, the scope and potential consequences of digital piracy on society are examined. It is often assumed that digital piracy is not only common but also reduces the creative industry's sales and revenues. Copyright owners in particular subscribe to this point of view. This is an assumption that needs to be examined in detail and perhaps even challenged. Insights into the potential consequences of digital piracy are useful in better understanding the phenomenon of digital piracy. This also presents insights into why the creative industry in particular has been proactive in designing and implementing anti-piracy interventions.

The second part focuses on the first sub-question and presents insights into how digital piracy can be explained. A wide range of empirical studies is examined in Chapter 4 in order to identify the variables that influence digital piracy. Not only do these insights aid in explaining why individuals pirate content digitally but they can also be used to better understand the relevance of the various mechanisms that are used in the design of anti-piracy interventions.

In the third part of this book, the anti-piracy interventions take the centre stage. An overview of the types of interventions is presented in Chapter 5. There, the interventions are not only described but also categorized, in order to answer the second sub-question. In addition, the manner in which these interventions hope to accomplish their goals is also depicted, providing tools to analyse their underlying mechanisms. Chapters 6 and 7 focus specifically on these mechanisms. Chapter 6 is mostly theory-based. Here, the mechanisms are examined by focusing on whether or not they are used in a manner that is conducive to contributing to reductions in digital piracy. In Chapter 7 , the underlying mechanisms are examined again and tested through newly collected empirical data. These insights allow for more conclusive statements on the extent of the contribution of mechanisms used in the various anti-piracy interventions. When taken together, Chapters 6 and 7 answer the third and fourth sub-questions. Chapter 8 provides an answer to the fifth sub-question. In this chapter, the effects of one specific implemented anti-piracy intervention are examined by analysing the changes in behaviour both prior to and after its implementation. The answer to this question can also be used to better understand the 'extent' of the contributions made by the various anti-piracy interventions. 
The book concludes with an answer to the research question, which is presented in Chapter 9. That chapter also presents an outlook towards the future, indicating in what manner the obtained insights can be beneficial for understanding current and future challenges in the field digital piracy and copyright infringements. 


\section{Research Methodology}

The research question: 'Which mechanisms, used in the designs of various antipiracy interventions, contribute to reductions in digital piracy and to what extent?' incorporates five sub-questions which required a combination of different methods in order to answer them.

Collectively, the five sub-questions were answered by using insights derived from the academic literature and by carrying out two empirical studies. One of these empirical studies uses primary data (stated preference study), while the other uses secondary data (Big Data study). The literature review predominantly served to synthesise and analyse existing studies on digital piracy. The literature provided insights into the various explanations of digital piracy, the types of various antipiracy interventions and their underlying mechanisms, as well as insights into the results that these interventions have yielded. The stated preference study and the Big Data study are the two empirical studies that were carried out to understand with more precision which mechanisms are more likely to be capable of a contribution to a reduction in digital piracy and the extent thereof. This chapter serves to explain these three methodological elements in more detail.

\subsection{The literature review: adopting the 'realist synthesis' approach}

In this research, the literature study primarily served as a tool to convey what knowledge and (theoretical) ideas have previously been established on the nature, extent and causes of digital piracy, as well as on the interventions and the underlying mechanisms that have been developed to counteract this behaviour. This knowledge is conveyed for two specific reasons. Firstly, it allowed for the exploration of digital piracy in a more general sense (which was reported on in Chapter 1) and the exploration of the potential consequences of digital piracy (which will be reported on in Chapter 3). In order complete this exploration, literature was sought in a structured manner. Secondly, the literature was used in a more in-depth manner, which provided information used to answer (parts of) the various sub-questions posed in Chapter 1 . To do so, literature was sought in a structured manner as well, but it was also examined through the principles provided by a specific type of literature review: the realist synthesis. It is insightful to expand upon the type of literature review used to answer (parts of) the various sub-questions.

Traditionally, three types of literature reviews are identified: the narrative, metaanalytical and systematic reviews (Rhoades, 2011). Of these three, the systematic 


\section{$\underline{\text { Punish, Seduce or Persuade }}$}

review normally offers an approach that is attuned to quantitative data and allows for a very structured review of the literature. ${ }^{12}$ In the context of digital piracy however, the systematic review did not fulfil the goal that the literature review, as used in this research, served. This was due to the strictness of the methodology of the systematic review. Most systematic reviews are primarily interested in the robustness of the research design or methodology used in each reviewed study. Studies are selected by means of eligibility criteria, which can include a minimum level of methodological quality, the manner in which the sample was selected or the statistical analysis used (Farrington \& Petrosino, 2001; Shlonsky, Noonan, Littell, \& Montgomery, 2011; The Steering Group of the Campbell Collaboration, 2015). The design and methodology used in most studies that examined digital piracy from an empirical perspective would simply not meet the eligibility criteria of a systematic review, as one important criterion is the minimum level of methodological quality (Pawson, Greenhalgh, Harvey, \& Walshe, 2004). Quasiexperiments or even randomized experiments (which both score high on the Maryland Scientific Methods Scale ${ }^{13}$ ) often represent the minimum level of methodological quality required by the systematic review. Studies that fail to reach this minimum level are excluded from further analysis. Potentially valuable insights from the literature are thus cast aside. A consequence of these strict eligibility criterion was that only a few studies could be used in this research, which would have limited the richness of the literature review. In the context of studies on digital piracy, most studies used a cross-sectional design, which would be a ground for their exclusion if the systematic review-approach is followed. This is why this approach is less suitable for this specific research. Furthermore, insights from studies that were descriptive or exploratory could still be insightful in explaining why individuals pirate digital content, even if they did not necessarily meet the high standards set by the systematic review.

Instead, the 'realist synthesis' approach was selected as a way to review and process the literature (Pawson \& Tilley, 1997). The realist synthesis examines the relevance of the findings of the studies first, followed by the methodological quality of the study. In addition, the realist synthesis does not follow a specific protocol. The realist synthesis requires a series of judgements on the relevance and robustness (or rigour) of the study or data (Wong, Greenhalgh, Westhorp, Buckingham, \& Pawson, 2013). As a result, the methodological quality of the

\footnotetext{
${ }^{12}$ Further benefits of the systematic review include clear inclusion and exclusion criteria, an explicit search strategy, systematic coding and analysis of included studies, and, when possible, a meta-analysis (The Campbell Collaboration, n.d.). Special attention is paid to the methodological quality of the study.

${ }^{13}$ The Maryland Scientific Methods Scale (MSMS) is a scale to measure the internal validity of the used research designs. Designs can be scored on this scale, with higher scores reflecting better statistical control of external variables on the observed outcome and will establish causal order (Farrington, Gottfredson, Sherman, \& Welsh, 2002).
} 


\section{$\underline{\text { Research Methodology }}$}

study did not serve as an absolute inclusion or exclusion criterion, in contrast with the systematic review. The understanding is that even studies with lower quality research designs and methodologies can still be used in answering the research question and sub-questions, as they still offer insights that are relevant (Pawson, 2002; Pawson, 2013). This led to a wider and richer body of literature to work with, which was necessary in order to answer the research question and subquestions. The realist synthesis uses keyword searches, search engines and databases to search for potentially relevant literature. It also allowed for the incorporation of so-called 'grey' literature into the synthesis (Pawson et al., 2004).

The literature search was performed in a broad manner, to avoid overlooking potentially relevant or insightful studies. This led to the usage of general keywords: 'digital piracy', 'illegal downloading', 'copyright infringement' and combinations thereof. ${ }^{14}$ These keywords and combinations were inputted into 29 data bases in three rounds; the initial one (covering the literature up to the beginning of 2011) and two follow-ups. The synthesis was last updated in 2016, the $15^{\text {th }}$ of September of that year being the end-date of the review.

Table 2.1: Accessed databases

\begin{tabular}{|c|c|c|}
\hline Annual Reviews & Emerald & PubMed \\
\hline $\begin{array}{l}\text { Arts \& Humanities Citation } \\
\text { Index }\end{array}$ & ERIC & Sage \\
\hline EBSCO & IFLP & SCI \\
\hline Cambridge Journals & LWW & ScienceDirect \\
\hline CINHAHL & Medline & SocINDEX \\
\hline UM Catalogue & OECD & Springerlink \\
\hline DOAJ & Oxford Journals & Social Sciences Citation Index \\
\hline Econlit & PiCarta & Web of Science \\
\hline JSTOR & $\begin{array}{l}\text { Psychology and Behavioural } \\
\text { Sciences }\end{array}$ & Wiley Online \\
\hline EMBASE & PsychINFO & \\
\hline
\end{tabular}

Not all of the found studies were relevant, requiring some eligibility criteria in order to narrow down the scope of the studies. These criteria focused the relevance of the studies, in line with the realist synthesis-approach (Pawson et al., 2004) $)^{15}$

- the study did not cover the topic of digital piracy, illegal downloading or copyright infringement at all. While such terms were present in the article, they had no bearing on the topic as defined in this research;

\footnotetext{
${ }^{14}$ And the Dutch translations of these keywords.

${ }^{15}$ The fact that the selection of the studies was not dependent solely on the rigour of the studies is mirrored in other studies, where criteria also tend to focus on the relevance of the study (Leeman et al., 2010; Rycroft-Malone et al., 2012; Wilis et al., 2016).
} 
- the study was in a language other than English or Dutch;

- $\quad$ the study was published prior to 1995. Given the fact that digital piracy is a more recent type of cyber-deviance, studies prior to this date lacked such a digital component. Instead, it would focus on analogue piracy;

- $\quad$ as this realist synthesis was initially done to provide an answer for why individuals pirate content digitally, studies that did not examine the behavioural aspect of this phenomenon were excluded. This meant, for instance, that studies on purely technical aspects of digital piracy were not incorporated;

- following a similar line of reasoning, studies were also excluded if they did not ground their analysis on empirical data (either primary or secondary data). Purely anecdotal studies were thus excluded;

- given the definition of digital piracy as used in this study, only studies that dealt with individual end-users were selected for further analysis.

The realist synthesis functions through two types of criteria: the relevance and the rigour of the study. Collectively, both relevance and rigour can be seen as dimensions through which the 'fitness' of a study can be determined. Relevance refers to whether or not a study can contribute to the research, while rigour refers to whether or not the method used in the study is credible and trustworthy (Wong et al., 2013). The relevance criteria have been discussed above, but it is also necessary to be clear on the criteria that were used to assess the rigour of the studies. Rigour refers to, as Pawson et al. (2004, p. 22) state: '[...] whether a particular inference drawn by the original researcher has sufficient weight to make a methodologically credible contribution [...].' Each study was examined on three aspects in order to determine their rigour (Wong et al., 2016):

1. the degree of clarity on the design (in a broad sense) of the study, more so than the quality of the design. This could include information on the usage of theory, hypotheses or models, the research design of the study and whether or not the study was piloted or tested;

2. whether the study provided insights into which population was sampled, how many respondents the study used and what the response rate was, whether or not this sample was suitable to study the research question or hypothesis posed in the study and whether the study reflected on the usage of the population (if necessary);

3. whether the data analysis was sufficiently clear. This refers to both the measurements that were used in the study and whether these were sufficiently articulated and understandable, as well as whether or not the study explained the plan of analysis and the tools used to perform this analysis. 
Together, these three aspects allowed for an assessment of whether or not a) the study and choices made in the study were understandable to the researcher and b) whether these choices enabled the study to answer the research questions. This meant that the focus was on whether or not the study was sufficiently transparent in their approach to the research, as well as whether or not there was sufficient information to allow for replication of the study. The studies as a whole were scrutinized rather than individual elements. Thus, a low response rate or a small sample alone was not sufficient for a study to be excluded. Such an exclusion would reflect that the study was unclear as to how the research was conducted. Nor was the lack of an articulated research design an immediate reason for exclusion. Many studies neglected to discuss their research design in an explicit manner. This is due to the fact that most of the examined studies, at least those who only attempted to explain digital piracy, did not aim to make statements about causal relationships or changes over time. It was also determined whether each individual study came from a peer-reviewed journal. Studies published in peerreviewed journals can be regarded as having better standing than those published in non-peer-reviewed journals. The fact that a study did not originate from a peerreviewed journal was not an immediate reason for exclusion, but it would influence the overall assessment of the study.

The literature that was used to answer (parts of) the sub-questions has been examined through the relevance- and rigour-criteria. ${ }^{16}$

Beyond this primary review, more specific (secondary) literature searches were done to obtain information on other aspects of digital piracy (such as the economic consequences of this behaviour or the part of the population that acts in this manner), as well as literature that was instructive on how to analyse the interventions. These latter insights were obtained from mainstream and contemporary criminological, evaluation and policy studies.

A total of 9,156 articles were found. After the application of the inclusion and exclusion criteria that were used to determine the relevance of each study, 168 remained to answer the first sub-question, which all originated from 88 peerreviewed journals. All of these studies had examined variables that explain why individuals pirate content digitally. By applying the criteria related to the rigour of the studies, 6 studies were further excluded, bringing the total number of studies down to 162. Appendix I (infra, p. 317) provides insights into which studies were selected.

${ }^{16}$ Records have been kept of the realist synthesis process. These can be requested by contacting the author. 
Given the variation in the findings of the 162 studies examined, it was necessary to structure these findings in a comprehensive manner. After considering various theoretical frameworks, the Situational Action Theory (SAT) was selected as the framework to organize and structure the findings derived from the academic literature, as was previously stated in $§ 1.7$. (supra p. 16). It therefore served as a lens. The main reason for selecting the SAT is that it allows for the integration and synthetization of a large number of variables. This is due to the fact that the theory explains acts of crime by how individuals see their action alternatives and make their choices when confronted with the particularities of a setting. Individual characteristics (like morality) and the features of the environment in which the individual acts (such as the moral context) can influence the decision to engage in deviant or criminal behaviour (Wikström, 2006; Wikström, 2009; Wikström \& Sampson, 2006; Wikström \& Treiber, 2007). The structure of the SAT allowed for a broad and rich integration of the variables that other studies on digital piracy have uncovered. Secondly, the SAT understands crime and deviance to be an issue of morality first and foremost (Wikström, 2006). Given the sometimes moral ambiguity of digital piracy, focusing in part on the morality of this behaviour offered an interesting and relevant avenue for explaining this behaviour. A third and final reason for selecting the SAT as the framework for analysis was the fact that it is a novel theory and has not yet been used in any way in relation to digital piracy.

The SAT will be dealt with in more detail in §4.1. (infra p. 78). For now, it suffices to discuss how the SAT was used as a lens to structure the findings from the literature. In the context of this research, the SAT was not tested directly. To use the SAT to structure the findings, it was necessary to identify the key individual characteristics and the environmental features in the literature that are conducive to digital piracy. These influence whether an individual is motivated to pirate content digitally. The next step was to focus on the process of choice. This step determines whether or not any motivation to pirate content digitally will be translated into an intention to act in this manner. In turn, this intention will influence whether the individual will actually pirate content digitally. Each of these steps (or clusters) was populated with variables that emerged from the found studies. Collectively, this led to useful and necessary insights into how the behaviour of digital pirates can be explained, providing an answer to the first subquestion. Chapter 4 does not focus on individual studies, since the aim of this aspect of the literature review was to identify trends and patterns that underlined the relevance of specific variables. This implies that a variable could not be included or excluded based on the findings reported in a single or smaller number of studies. 


\section{Research Methodology}

The literature review was firstly necessary to answer the first sub-question ('how can the behaviour of digital pirates be explained?'). Some of the other subquestions were also dependent (sometimes in part) on the insights derived from the academic literature. In order to answer the second sub-question ("which interventions, both from governmental and other (public and private) organisations, are currently applied in the context of digital piracy? '), the basis for the overview was also found in the realist synthesis, as many studies examined in the review made explicit references to and provided information on interventions. In total 85 studies were used. To complete the overview of the antipiracy interventions, information was also sought outside the scope of the academic literature. This primarily consisted of using Internet searches to look for and find information on these interventions. This information was derived from governmental websites, websites belonging to the creative industry and other stakeholders, websites dedicated to specific anti-piracy interventions and more informal sources such as news sites and blogs. These Internet searches were carried out partially via snowballing techniques, using insights from the literature as the initial point of departure.

To answer the third sub-question ("which (behavioural) mechanisms are applied in the design of the various anti-piracy interventions and what are the requirements for their proper functioning?'), the studies examined had to examine the design of the anti-piracy interventions. Insights from the realist review (and additional mainstream criminological literature and evaluation studies) were examined to obtain information on the workings and requirements of each mechanism. This allowed for a contextualization of the mechanisms of which the interventions consist. This led to an additional relevance-criterion for the realist synthesis. 87 studies on digital piracy were used in order to answer the third sub-question.

The fourth sub-question ('to what extent do the underlying mechanisms contribute to reductions in digital piracy?') could not be fully answered by the literature review, in contrast to the first three sub-questions. Subsequently, evidence needed to be gathered to better assess whether or not each mechanism contributes to reductions in digital piracy (Pawson, Greenhalgh, Harvey, \& Walshe, 2005). The first step was to look for studies that had measured the changes in digital piracy behaviour following the implementation of a (hypothetical) intervention. In turn, each intervention used a particular mechanism. 44 studies were used from the realist synthesis to examine this matter. These studies were divided across 34 journals, 32 of which were peer-reviewed. ${ }^{17}$ Since the studies that have examined

${ }^{17}$ Three studies are working papers and three studies are conference papers. 


\section{$\underline{\text { Punish, Seduce or Persuade }}$}

specific interventions (which are reported on in Chapter 6) varied more often in their research design, it was possible to contrast the studies to a greater degree. Such information was used to better evaluate the merits of individual mechanisms.

However, the contribution to reductions and the extent thereof could not be established solely by reviewing existing literature, as the literature did not provide a clear answer to this question. The first empirical study was used to fill this gap.

\subsection{The first empirical study: the stated preference method}

The objective of the first empirical study was to expose respondents to various anti-piracy interventions and uncover how they would respond to these interventions. As interventions are all dependent on various mechanisms, this exposure also generated insights into the functioning of these mechanisms.

As it was important to understand the choices individuals make when confronted with different options (anti-piracy interventions), a method was derived from the field of choice experiments. Choice experiments allow the researcher to present the respondents with a sequence of choice sets and the individual is asked to choose their preferred alternative in each of the choice sets presented. As Bryan, Gold, Sheldon, and Buxton (2000, p. 385) state: ... [choice experiments] refer to a number of different approaches, all of which use peoples' statements of how they would respond to different hypothetical situations [...]. [In that way] respondents rate, rank or choose between alternatives. Each choice set contains several alternatives defined by a set of attributes and attribute levels. Individuals' preferences are revealed by their choices in this manner (Carlsson \& Martinsson, 2003). ${ }^{18}$ The fact that the respondents are asked to choose between alternatives differentiates the choice experiments from other types of conjoint analysis, where the respondent is only asked to rank the alternatives in order of preference (Adamowicz et al., 1998). Rose and Bliemer (2009, p. 587) express why choice experiments earn the label 'experiment':

\footnotetext{
'The purpose behind conducting experiments is to determine the independent influence of different variables (attributes or factors depending on the literature cited) on some observed outcomes. In stated choice (or choice experiments) studies, this translates into the desire to determine the influence of the design attributes upon the choices that are observed to be made by sampled respondents undertaking the experiment.'
}

The choice experiments allow researchers to forecast as to how individuals will receive and value new policies, products or services (Breustedt, Müller-Scheeßel, \& Latacz-Lohmann, 2008; Mark \& Swait, 2003). This means that choice

\footnotetext{
${ }^{18}$ See also Adamowicz, Boxall, Williams, and Louviere (1998), Carlsson and Martinsson (2001) and Louviere, Hensher, and Swait (2000) on a further discussion on choice experiments.
} 


\section{Research Methodology}

experiments were used to determine how changes to the mechanisms used in the anti-piracy interventions have an influence on how the respondents react to them and how they 'choose' between the different 'interventions'.

The specific variant of choice experiment used in this research is known as the 'stated preference' method (Kroes \& Sheldon, 1988). It requires that respondents are exposed to scenarios which depict a situation that an individual could be confronted with in real life. Thus, the scenarios are typically descriptions of (realistic) situations or interventions (Kroes \& Sheldon, 1988). These scenarios presented a discrete choice for the respondents (i.e. the selection of one alternative from two options), with the scenarios being altered based on their attributes (Bryan et al., 2000). Each developed scenario was presented to the respondent as a proposed anti-piracy intervention, resulting in more realistic and believable scenarios. The respondents were exposed to a number of scenarios in order to measure the contribution of the mechanisms and, in turn, the interventions. The choice for the stated preference method lies primarily in the fact that it allowed for an understanding of the choices individuals make. In this way, respondents informed the researcher which intervention they 'preferred', meaning which intervention they found to have the largest impact on their own behaviour. In this way, the respondents informed the researcher about what they intended to do (the stated preference) in a given (hypothetical) situation. The experiment was implemented via a self-administrated questionnaire, as other studies using the stated preference method have also done (Colombo, Calatrava-Requena, \& Hanley, 2006; Ryan \& Farrar, 2000). It was cross-sectional in nature, meaning that measurements were taken at one point in time. As this study was mostly interested in the contributions of specific mechanisms rather than the long-term effects of the various anti-piracy interventions, the usage of a cross-sectional design was suitable. In addition, this approach is often used for practical reasons, as it is less time- and resource consuming than cohort or longitudinal studies (Lindell \& Whitney, 2001).

There are clear strengths associated with the stated preference method as used in the first empirical study. It presented respondents with a defined set of choices (or scenarios) from which to choose. The respondents were continuously given a choice between two anti-piracy 'interventions' to determine which of these interventions is most likely to make them reconsider their acts of digital piracy (e.g., which of these is the 'preferable' choice). Furthermore, the researcher had control over the variables on which the presented scenarios were based, compared to the situation where the researcher only observes the choices made in real life 


\section{$\underline{\text { Punish, Seduce or Persuade }}$}

(known as the revealed preference method ${ }^{19}$ ) (Earnhart, 2001). This meant that, in the context of digital piracy, specific anti-piracy interventions and their associated mechanisms could be focused on since the researcher could design the choices in such a way to reflect the interventions and mechanisms (Whitehead, Pattanayak, van Houten, \& Gelso, 2008).

The stated preference method is not without its weaknesses. One often cited criticism is the fact that this method uses questions and choices that are hypothetical in nature (Earnhart, 2001; Kroes \& Sheldon, 1988; Whitehead et al., 2008). This can mean that the respondents do not answer these questions truthfully or make choices that would not be reflective of their actual behaviour when confronted with this choice in real life (giving trivial answers). This issue can be exacerbated if scenarios are designed poorly or if there is too great a gap between the scenarios and reality. The scenarios used in this study were therefore designed to be as realistic as possible. This was attempted, for instance, by not presenting penalties for digital piracy that are clearly unrealistic (such as significant prison sentences) or by stating that no one else but the respondent pirates content digitally.

A second way to better insure a sufficient degree of realism was to explore and test some of the scenarios beforehand. In this way, a smaller number of scenarios, and how the respondents could respond to them, was examined. This was a necessary condition for the development of additional scenarios. It would have been a waste of resources to develop a larger number of scenarios and find out that their design or presentation was flawed. The exploration took the form of a small self-administrated questionnaire, which was administrated at the start of a tutorial in a criminological course. The outcome of the exploration $(\mathrm{N}=23)$ enabled the fine-tuning of the scenarios and paved the way for the development of additional scenarios.

The exploration revealed that the presentation of the scenarios could be improved. This was accomplished by making the attributes of each scenario more overt to the respondent. For instance, the certainty of punishment would now be presented numerically instead of textually. Following this exploration, addition scenarios were developed. In total, 24 scenarios were developed. The number of scenarios used in this study is double the number of scenarios used in an earlier study on digital piracy that applied a similar methodology (Jeong \& Lee, 2010) and equal to the number used by De Graaf, van den Putte, and van der Werff $(2011) .{ }^{20}$ The

\footnotetext{
${ }^{19}$ Although it should be understood that the revealed preference method is not without flaws. Limited variation in important variables and strong correlations between the variables often make it difficult to measure the impact of individual variables on the choice outcome (Madden, 1995).

${ }^{20}$ The effects of enforcement messages in relation to various misdemeanours were examined in this study.
} 


\section{Research Methodology}

24 scenarios were divided evenly across the three mechanisms, meaning that there were three groups of scenarios. Each group consisted in total of eight scenarios. To test the realism of the scenarios, certain respondents were exposed to a few scenarios and asked to indicate how realistic they found the scenarios to be (on a scale of one to five). The results from this realism check demonstrate that the respondents found the scenarios to be reasonably realistic, with scores mostly being three and four (on a scale from one to five). This signals that the scenarios themselves were at least not designed in such a way that respondents reacted to them as being unrealistic.

Each of the 24 scenarios consisted of one mechanism and each mechanism allowed for some variation. Section §7.2. (infra p. 183) discusses in detail the design of each scenario. To keep the length of the questionnaire manageable but still be able to obtain sufficient insights into the functioning of each mechanism, respondents were exposed to 12 of the 24 scenarios. Two different versions of the questionnaire thus existing, each containing 12 different scenarios.

\subsubsection{Data collection procedure}

The scenarios were accompanied with questions on the respondents' sociodemographic background, their content consumption and their past and intended future acts of digital piracy. A few of these questions were open ended, such as the question asking about the income of the respondent. Together, these questions formed the first part of the questionnaire. Subsequently, depending on whether or not the respondent had pirated content digitally in the past, they could be routed to the scenarios. If routed to the scenarios, the respondent was exposed to 12 scenarios presented in pairs of two. The respondent had to indicate, per pair:

- his inclination to pirate content digitally in the context described by the scenario, which could be scored on a Likert-scale of 1 to 7 ;

- which of the two scenarios in each pair he found to be most convincing; and

- the degree by which the selected scenario was found to be the most convincing, which could be scored on a scale of 1 to 5 .

The questionnaire was initially implemented in the Netherlands. It focused on the behaviour of students, as students are consistently identified as being a dominant group of digital pirates (Al-Rafee \& Rouibah, 2010). As the aim of this research is to better understand what might bring about changes to individuals who already pirate content digitally, it was necessary that the respondents did indeed engage in this behaviour. Selecting students as the population of choice ensured that a sufficiently large number of respondents indeed pirated content digitally, which 
meant that the usage of students was appropriate for this first empirical study. This led to the usage a sample consisting of students.

In April 2013, the questionnaire was distributed among second year law students at Maastricht University. The tone of the questionnaire was matched with the sample population (students) prior to its implementation. Therefore, while some may argue that using students as respondents is a weakness of this empirical study, the impact that this will have on the validity of the findings is likely to be limited.

In line with the above, the question is whether the data obtained via these questionnaires is sufficiently reliable and valid for the purpose of this research. In other words, are the questions used in the questionnaire sufficiently precise, does they measure consistently and do they measure what was intended (Huizinga \& Elliot, 1986; Norland, 1990)? With regard to the validity, the fact that most of the questions were directly linked to the topic of digital piracy contributes to a more valid questionnaire, as these questions are relevant for the research at hand (content validity). A degree of theoretical validity is present, as it was possible to determine whether the results are consistent with the researcher's intuition, although this only tests the theoretical validity indirectly (Ryan \& Gerard, 2003). Given the fact that there are no recorded official statistics on digital piracy, it was not possible to compare the hypothetical behaviour of the scenarios with actual behaviour, meaning that the questionnaire could not be tested for external validity (Ryan \& Gerard, 2003). It was more difficult to assess if the questionnaires are also reliable. It was not possible to expose the same respondents to the questionnaire twice in order to determine whether their responses would still be similar (known as the 'test/retest procedure'). The composition of the sample has likely had an influence on the population validity of the first empirical study (Kam, Wilking, \& Zechmeister, 2007). In addition, the way that the study was performed can have influenced the ecological validity of the study (Schmuckler, 2001). This means that generalization of the results should be avoided, since it may be that the respondents belonging to the sample do not represent the general population and that circumstances of the study (such as the fact that the study was conducted in a class room) might not necessarily reflect real life.

The data collection commenced at the start of a lecture. Students were informed on the purpose of the questionnaire and the importance of the study. This was followed by some statements on the confidentiality of their responses as well as the fact that their participation was voluntary and greatly appreciated by the researcher. The manner in which the questionnaire itself had to completed was also explained. The questionnaire was accompanied by a cover letter that also explained the manner in which the questionnaire had to be completed and restated 


\section{$\underline{\text { Research Methodology }}$}

the overall goals of the questionnaire. The data collection resulted in 67 usable questionnaires.

Since the data collection yielded a relatively small number of usable questionnaires, the questionnaire was also disseminated in Belgium for reasons of convenience. The tone and language of the questionnaire was adjusted for the Belgian setting, as this provided a better match with the previous experiences of these respondents. ${ }^{21,22}$ This questionnaire was distributed among students of a third-year criminology course in May 2013 at the University of Antwerp, also at the beginning of the lecture. A procedure similar to the one used in the Netherlands was used to explain the questionnaire in Belgium. This second questionnaire resulted in 110 usable questionnaires. The two data sets were kept separate for analysis, as the differences in context can have had an influence on the responses. This precluded the grouping of the two datasets.

\subsubsection{Data analysis}

Data-cleaning was a first step prior to the analysis of the data. Incomplete questionnaires were removed from the dataset as part of the data-cleaning. Responses that were outside the expected range were labelled as outliers and were Winsorized when possible. ${ }^{23}$ The dataset was double checked for double entries, incorrect entries and entries that were left blank. The data-cleaning was done manually (Van den Broeck, Cunningham, Eeckels, \& Herbst, 2005).

To analyse the contribution of each mechanism, the mean scores for each mechanism were compared. To do so, it was necessary to dummy code variables for the scenarios, their mechanisms and their variations (based on the requirements for each mechanism). This led to the creation of so-called 'dummy variables'. As Suits (1957, p. 548) explains: 'The dummy variable is a simple and useful method of introducing [...] information contained in variables that are not conventionally measured on a numerical scale, e.g., race, sex, region, occupation, etc.' These dummy variables can be seen as being 'artificial' variables which can be used for further statistical analysis. As the designs of the scenarios themselves

\footnotetext{
${ }^{21}$ Some minor adjustments were made to the questionnaire prior to distributing it in Belgian. These focused the frequency, future likelihood and future effort respondents were willing to make with regard to digital piracy; respondents firstly had to indicate (through simple 'yes' or 'no' answers) whether they had downloaded or were intending to do so in first place before answering the questions regarding their frequency of pirating content.

${ }^{22}$ It was decided against using a second Dutch sample as concerns were raised that such a second sample would also yield a low $N$, similar to the first questionnaire.

${ }^{23}$ The criteria for using this method were whether or not whether the amount of extreme outliers is outside the range of $5 \%$ of the entire sample.
} 


\section{$\underline{\text { Punish, Seduce or Persuade }}$}

were not presented on a numerical scale, the creation of dummy variables was necessary in order to statistically analyse which aspects of the mechanisms used in the scenarios led to which particular outcome. Each scenario was dummy coded based on their applicable requirements and the variations applied to them. Table 2.2 presents an example of how the dummy variables were used in this first empirical study.

Table 2.2: Example of dummy coding for scenarios that use the deterrent mechanism

\begin{tabular}{|c|c|c|c|}
\hline Mechanism & Requirement & Variation & Dummy Coding \\
\hline \multirow[t]{9}{*}{ Deterrence } & \multirow[t]{3}{*}{ Severity of punishment } & Low $(€ 25)$ & 1 \\
\hline & & Medium (€100) & 2 \\
\hline & & High $(€ 250)$ & 3 \\
\hline & \multirow[t]{3}{*}{ Certainty of punishment } & Low $(1: 100)$ & 1 \\
\hline & & Medium $(1: 25)$ & 2 \\
\hline & & High (1:10) & 3 \\
\hline & \multirow[t]{3}{*}{ Social disapproval } & Low (3 out of 10$)$ & 1 \\
\hline & & Medium (5 out of 10$)$ & 2 \\
\hline & & High (7 out of 10$)$ & 3 \\
\hline
\end{tabular}

A scenario that used a deterrent mechanism that had a low severity of punishment, a medium certainty of punishment and a high degree of social disapproval would thus be coded as ' $1-2-3$ '. The coding allowed for the analysis of the responses on the level of the variation. For instance, it was possible to select all instances where the certainty of punishment was low (coded as ' 1 '). Through the dummy coding, it was possible to attribute changes in responses to the specific absence or presence of mechanisms and the requirements.

The data analysis also enabled an overview of which scenarios resulted in the largest changes, which was determined via their associated effect sizes. The focus was thus on comparing the various responses based on the scenarios. In this manner, it was feasible to determine the influence of each mechanism and its requirements on the choice that the respondents made as to which of the scenarios they perceived as being more capable of reducing their inclination to future acts of digital piracy. This meant that the responses measured a cognitive aspect of the respondents' attitude towards digital piracy (Pickens, 2011).

The purpose of the analysis was to identify which scenario was selected by respondents as being the one that constrained their future acts of digital piracy the most, per pair. The responses were tested for statistical significance. The tests for significance were carried out via one-sample T-tests. Cohen's d was used to determine the effect size. This test provided information on the size of the differences of the various scenarios and was used to determine the extent of the possible contributions to reductions in digital piracy. 


\section{$\underline{\text { Research Methodology }}$}

\section{Samples}

It is necessary to give a brief overview of the socio-demographic characteristics of both samples. Table 2.3 presents an overview of the socio-demographic characteristics of the Dutch sample. This overview makes it clear which respondents took part in the Dutch questionnaire. It also makes it quite clear whether the characteristics of the respondents match the characteristics that would have been expected given the sampling frame.

Table 2.3: Socio-demographic overview (Dutch sample)

\begin{tabular}{|c|c|c|c|c|c|c|}
\hline Variable & Amount & Percentage & Mean & SD & Min & Max \\
\hline $\begin{array}{l}\text { Usage of IT-products (hours } \\
\text { per day) }\end{array}$ & & & 4.93 & 2.798 & 1 & 14 \\
\hline Experience with the Internet & & & 5.58 & 1.103 & 3 & 7 \\
\hline Income (in euros) & & & 532.20 & 433.316 & 0 & 2,100 \\
\hline \multicolumn{7}{|l|}{ Residence } \\
\hline $\begin{array}{lll}\text { At home with } \\
\text { parents }\end{array}$ & 27 & $40.3 \%$ & & & & \\
\hline $\begin{array}{c}\text { Student housing } \\
\text { with roommates }\end{array}$ & & $31.3 \%$ & & & & \\
\hline Student housing & 6 & $9.0 \%$ & & & & \\
\hline Independent & 11 & $16.4 \%$ & & & & \\
\hline Other & 1 & $1.5 \%$ & & & & \\
\hline
\end{tabular}

The Dutch sample contained slightly more females $(55.2 \%)$ and the average age of the respondents was $21.8( \pm 1.81)$. These are characteristics that are expected given the context in which the questionnaire was implemented.

Table 2.4 depicts the socio-demographic variables for the Belgian sample.

Table 2.4: Socio-demographic overview (Belgian sample)

\begin{tabular}{|c|c|c|c|c|c|c|}
\hline Variable & Amount & Percentage & Mean & SD & Min & Max \\
\hline $\begin{array}{l}\text { Usage of IT-products (hours } \\
\text { per day) }\end{array}$ & & & 2.75 & 1.335 & 1 & 6 \\
\hline Experience with the Internet & & & 4.88 & 1.194 & 2 & 7 \\
\hline Income (in euro's) & & & 134.38 & 173.315 & 0 & 650 \\
\hline \multicolumn{7}{|l|}{ Residence } \\
\hline $\begin{array}{l}\text { At home with } \\
\text { parents }\end{array}$ & & $75.5 \%$ & & & & \\
\hline $\begin{array}{r}\text { Student housing } \\
\text { with roommates }\end{array}$ & & $12.7 \%$ & & & & \\
\hline Student housing & 9 & $8.2 \%$ & & & & \\
\hline Independent & 4 & $3.6 \%$ & & & & \\
\hline
\end{tabular}




\section{$\underline{\text { Punish, Seduce or Persuade }}$}

This sample is mostly female (65.5\%) and the average age of the respondents is $21.3( \pm 0.76)$. The characteristics of both samples are indeed what would be expected, given the fact that the sampling frame consisted of $2^{\text {nd }}$ year students in the Netherlands and $3^{\text {rd }}$ year students in Belgium.

Nonetheless, there are a few differences between the Dutch and Belgian respondents that can be identified. For instance, the Dutch respondents spend, on average, almost twice as much time using IT-products, such as computers or smart phones compared to their Belgian counterparts. This may influence their exposure to the opportunities to pirate content digitally. Dutch respondents also indicated that they have more disposable income than their Belgian counterparts. This may have an influence on whether or not the respondents are willing and able to purchase content legally and for what price. However, the difference in income could also have been the result of a different way in which both groups of respondents interpreted the question. It is possible that the Belgian respondents understood the question differently (e.g., by thinking about income as what they earn via a job rather than what resources they have available to them via scholarships or parental support).

It is also possible that the domestic situation that students find themselves has influenced their tendency to pirate content digitally. The data shows that most Belgian respondents live at home with their parents, while many Dutch respondents live with roommates (fellow students). This difference can influence the moral context that an individual finds himself in as well as his exposure to pirating peers. For instance, it is possible that living with fellow students exposes the individual to peers who are more supportive to the act of digital piracy, as opposed to a situation where an individual still lives at home and experiences (some degree of) parental supervision. Whether these differences have influenced the respondents' past and future of acts of digital piracy remains to be seen.

\subsection{The second empirical study: Big Data and online search behaviour}

A different source of data was used to answer the fifth sub-question ('which changes can be observed in the online behaviour of digital pirates after the implementation of a specific anti-piracy intervention? '). This allowed for insights to be obtained on the usage of a specific mechanism through a specific implemented anti-piracy intervention. Whereas the fourth sub-question examined the choices that respondents make following exposure to hypothetical anti-piracy interventions (scenarios), the focus in answering this fifth sub-question is placed on how collective, digital piracy-related, online behaviour has changed over time after the implementation of an anti-piracy intervention. Such analysis does not 


\section{Research Methodology}

only look at what happened to the online behaviour after the implementation but also looks at the behaviour before this implementation. This allows for a better assessment of how the behaviour has changed, if at all.

In order to map and understand changes to digital piracy before and after the implementation of a specific anti-piracy intervention, the focus of the second empirical study was on search behaviour related to digital piracy. The collection and analysis of this online search behaviour is an example of using 'Big Data' ${ }^{24}$ as a way to evaluate (digital) policy (Leeuw, 2016, 2017) and allows researchers to study behaviour in a different way without the possibility that the respondents give socially desirable answers (as can be the case with many questionnaires).

The main premise of this approach is that online search behaviour that individuals apply to find pirated digital content is an important indicator of their actual acts of digital piracy (MillwardBrown Digital, 2013). Changes in these patterns can be indicators of changes in actual digital piracy, which may be caused by the introduction of specific anti-piracy interventions. The usage of Big Data in this manner is an innovative and exciting way to use electronic and user-generated data. As Petersson, Leeuw, Breul, and Leeuw (2017, p. 2) state:

\footnotetext{
'When Big Data is anonymized, aggregated, and analyzed, it can reveal significant new insights and trends about human behavior. The basic idea is that Big Data makes it possible to learn things that we could not comprehend with smaller amounts of data, creating new insights and value in ways that change markets, organizations, the relationship between citizens and government, and more [...] We can also learn about phenomena that have been previously difficult to capture, for example, personal connections, such as those within Facebook, and geolocation, such as the place from which a "tweet" was sent via Twitter [...].'
}

Thus, when the opportunity arose to study digital piracy by using Big Data, the decision was made to expand this research into that direction.

Using Big Data has both strengths and weaknesses. The ease of use and the speed of the data collection, as well as the ability to observe online search behaviour both prior to and after implementation of a specific intervention and select data based on the location of the individual are all clear strengths (Leeuw, 2017), which this second empirical study benefits from. Weaknesses that are identified are the lack of forecast-ability and the need for Internet access (Ayers, Althouse, Ribisl, \& Emery, 2014), which are not likely to be a concern here as the first weakness

\footnotetext{
${ }^{24}$ Big Data consists of (call) logs, mobile-banking transactions, online user-generated content such as blog posts, social media, sensor apps, online searches, and satellite images, including information gathered by drones, and including all the data one holds in emails, social media Communications, Weblogs, intranets, extranets, etc. Big Data is characterized by five V's: 'high-volume, high-velocity, high-variety information, high-veracity and high-volatility.' (Haav, Kalja, \& Robal, 2014).
} 


\section{$\underline{\text { Punish, Seduce or Persuade }}$}

is not relevant and the second does not apply, since the selected intervention is implemented in a Western country with a high degree of broadband penetration. The attribution issue is more problematic. As other, potentially relevant, variables are not controlled for, an observed change can be the consequence of this intervention, but it might also be the result of any other variable. This matter will be reflected on in more detail in Chapter 8 via the examination of a natural experiment. A prelude to this is presented in \$2.3.3. (infra p. 45), where a discussion on why and how the natural experiment was examined is presented. A further limitation is that the results are only directly informative on the search behaviour itself and can therefore only be used as an indicator of changes in actual digital piracy, and only for those instances of digital piracy where search engines are used (Leeuw, 2017). The search behaviour did not reflect whether a subscriber has actually pirated content digitally if he found a pirated copy. This meant that changes to the online search behaviour do not automatically reflect changes to digital piracy itself. Nonetheless, there is evidence to assume that (online) search behaviour can be indicative of actual behaviour. For instance, individuals who have a high risk of suicide are also more likely to search for online information on suicide (Masango, Rataemane, \& Motojesi, 2008). Similar observations were made in relation to adolescent self-harm, where individuals who are at greater risk of self-harm are also more likely to search for information on this behaviour (Mars et al., 2015). These matters will be reflected on in more detail in Chapter 8 via the examination of a natural experiment.

Despite the aforementioned limitations, there are good reasons for using Big Data in the study of anti-piracy interventions. Firstly, it was the closest this research could come to examining actual rather than hypothetical acts of digital piracy, even if searching for pirated content does not equate with digital piracy directly. Secondly, the speed and ease of use made it possible to obtain this data relatively late in the research process. Thirdly, the attribution issue could be contextualized by comparing the findings from the Big Data study to insights from the literature study and the first empirical study. Finally, such a study had not yet been performed in the context of digital piracy, which meant that this was a new approach to this topic.

\subsubsection{Data collection procedure}

First, the search queries most closely related to digital piracy had to be identified. As the number of search queries essentially is infinite, a sample was needed, as otherwise it was impossible to analyse the queries properly due to the size of the dataset. The selected search queries reflect the terms or keywords that individuals used in order to search for and download pirated content via Google. This 


\section{Research Methodology}

narrowed down the volume of data. As Google was and is the dominant search engine for many Internet users (Google had a market share of around $88 \%$ in early 2016 (Ripberger, 2011; Statista, 2016)) and provides free and easily accessible tools to map and measure search queries for researchers (Google Trends), this search engine was selected. Google Trends keeps a record of every search query inputted by its users, meaning that the 'response rate' is essentially $100 \%$. Google Trends is an indicator of the public attentiveness to a specific topic. It allows researchers to track how frequently a term is used as compared to the total number of searches done on Google across specific regions, categories or time frames. After inputting certain key words (or queries), Google Trends generates results that are scaled, normalized and visualized (Ripberger, 2011). Google Trends is a tool that can be used to explore and expose the search patterns for various types of (online) behaviour, which can include behaviours such as digital piracy (Ficetola, 2013). Google Trends will be used to measure the changes to digital piracy-related search patterns following the implementation of a specific antipiracy intervention.

A second decision that assisted in keeping the volume of data manageable was the selection of a specific implemented anti-piracy intervention. This led to a clear delineation both in terms of the location of the users (as most interventions are only implemented in specific jurisdictions) as well as a temporal delineation (as interventions are implemented at a specific moment in time). The implementation of a graduated response scheme in the USA was selected as the intervention that would offer this delineation; the Copyright Alert System (CAS) (which was implemented nationwide in the USA in the beginning of 2014). This intervention consists of monitoring online behaviour by the various ISPs, which warn and sanction subscribers that are found to (repeatedly) pirate content digitally. The reasons for this selection was firstly that it is an intervention that had not yet been the subject of any empirical research and that it was implemented in a jurisdiction with a language that the researcher was familiar with. The data collected (the 'search queries') are attempts of users to search for pirated content. This allowed for important observations to be made about the relationship between the introduction of anti-piracy interventions and changes to online behaviour.

The next step was to identify and capture the relevant search queries. To do so, so-called 'root terms' ${ }^{25}$ were first selected. These are the terms that were most

\footnotetext{
${ }^{25}$ A root term refers to an initial search query, from which further search queries can be generated. For example, the root term 'The Pirate Bay' would generate related queries such as 'pirate bay torrent' or 'free torrent movies'. The other root queries selected were 'Free music download', 'Free movie download', 'Free video games download', 'Free software download', 'Torrent', 'Free ebook download', 'Free online streaming', 'Piracy', 'P2P file sharing', 'Six Strikes', 'Netflix', 'Spotify', 'Steam', 'iTunes' and 'Piracy illegal'.
} 


\section{$\underline{\text { Punish, Seduce or Persuade }}$}

often used by individuals to search for pirated content via Google. Insights from the literature review were helpful in identifying these terms and were subsequently directly inputted into Google Trends. Google Trends used these root terms to generate additional and related search queries, which resulted in a large volume of search queries. In line with the study by Ayers et al. (2014), 16 queries were initially inputted. Subsequently, the top ten search queries of each of these root terms were downloaded. For each of these $154^{26}$ queries, the next ten most related queries were selected. This resulted in a total of 1,637 potential queries. Such a large number of queries needed to be cleaned in order to remove unrelated, unclear or duplicate queries that would have affected the data analysis. To present the concept of queries, and how to obtain and select more of these clearly, a visual example is given of how one root term can result in up to 111 individual queries (see Figure 2.1).

Figure 2.1: Example of a root query and related queries

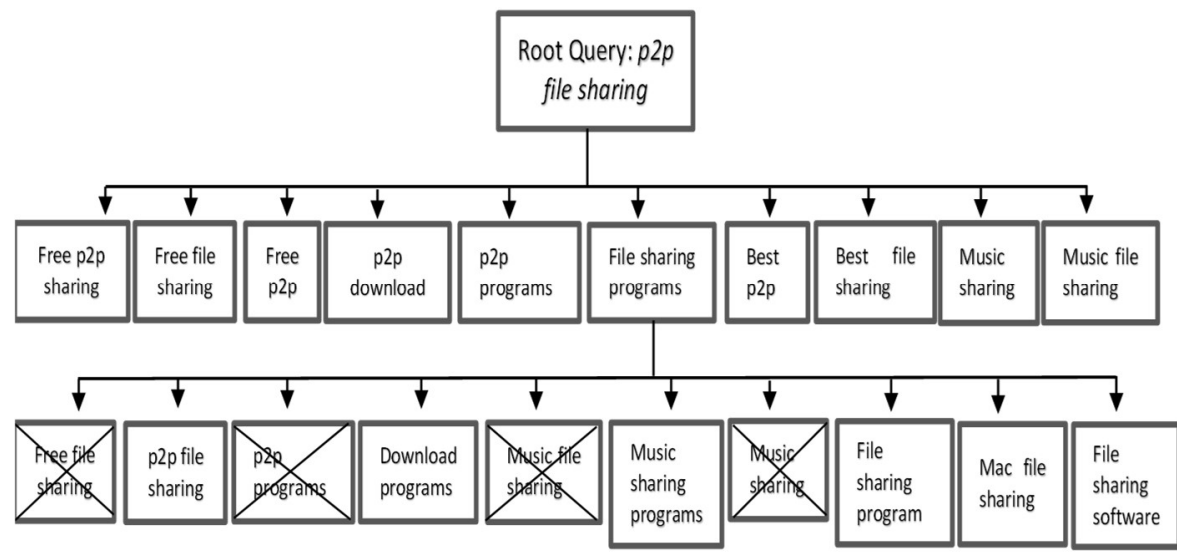

Inputting the root query ' $\mathrm{p} 2 \mathrm{p}$ file sharing' in Google Trends led to the top ten related search queries. In Figure 2.1, one of these related queries was again inputted into Google Trends, which resulted in another top ten queries. The figure also depicts that duplicate queries were quite common, which were crossed out in Figure 2.1. Chapter 8 will explain in depth how many queries were used in the analysis.

${ }^{26} \mathrm{~A}$ few of the root queries did not generate ten related search queries, resulting in slightly less queries than 160 


\title{
$\underline{\text { Research Methodology }}$
}

\subsubsection{Data analysis}

The second step was to map the way in which the search queries changed over time after the implementation of an anti-piracy intervention. Thanks to Google Trends, the relative search volume (RSV) of the various search queries, rather than absolute search volumes could be captured and examined. As Ayers, Ribisl, and Brownstein $(2011$, p. 2) explain:

\begin{abstract}
'[Google Trends] produces relative search volume (RSV) indicators scaled to the highest search proportion week $(\mathrm{RSV}=100)$ with lesser values demonstrating how other proportions compared to the highest proportion. For example, if during the highest search proportion week 400 of every $1,000,000$ searches were related to cessation this would be RSV $=100$. For another week, if 200 of every 1,000,000 searches were related to cessation this would be RSV $=50$, interpreted as $50 \%$ of the highest search proportion. RSV indirectly corrects for variation in population size and Internet access, where both are increasing during the study period and would bias any absolute search volume measure.'
\end{abstract}

This approach corrects for trending. Spikes in the RSV of a specific query indicated that other queries did not also spike simultaneously (Ayers et al., 2014). Simply put, RSV volume depicted the increases or decreases in the search queries used over time. Figure 2.2 illustrates what the changes to the RSV can look like for a single search query ('The Pirate Bay').

Figure 2.2: Example of changes to RSV

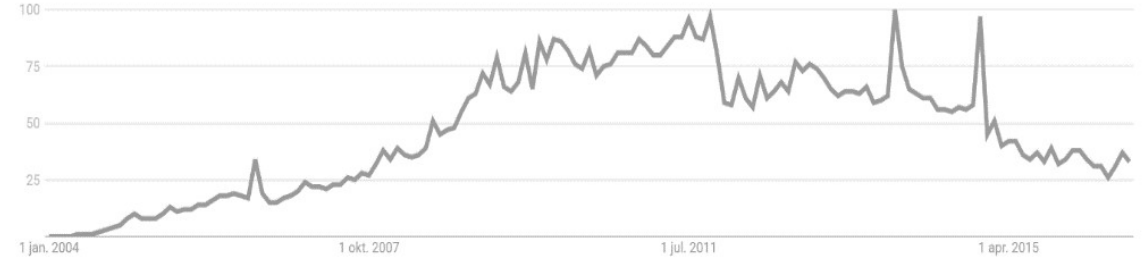

The figure clearly demonstrates that the volume of search behaviour spikes and decreases over time. The focus of the analysis was on similar changes to the RSV. This is reported on a scale from 0 to 100 , with 100 being the moment in time with the highest proportion of searches for the term relative to all queries in the period of time examined. The RSV was used to estimate the mean relative search volume both for the month and year leading up to and after the implementation of the intervention. The goal was to compare how an outcome (the RSV) changed during the implementation of an intervention. To depict the changes over time, time- 


\section{$\underline{\text { Punish, Seduce or Persuade }}$}

trends were used. By examining these trends, observations about the potential contributions of the mechanisms underlying the specific anti-piracy intervention were made. Observations on both the short term (one month prior to and after implementation) and longer term (a year prior to and after implementation) contributions of the intervention are presented in Chapter 8. The followed approach does not allow for the establishment of causal relationships. ${ }^{27}$

\subsubsection{Attributing the changes to the anti-piracy intervention}

Though the Big Data study offered insightful information as to whether or not the online search behaviour of digital pirates had changed after the implementation of the CAS, these changes cannot directly be attributed to the implementation of this anti-piracy intervention. Therefore, a natural experiment was carried out in order to better reflect on the likelihood that the implemented intervention could have led to any observed changes in online search behaviour. This was done by comparing the changes in online search behaviour in the USA from those that originated from a different jurisdiction. This comparison was made possible via a second Big Data study. Through it, it was possible to see whether the changes in the USA were unique. If that was the case, than the likelihood that the CAS had contributed to the changes increased. Thus, the goal was to reflect on whether or not the findings could be attributed to the CAS in earnest. This comparison took the form of a natural experiment, since data from two jurisdictions were compared, one where the CAS has been implemented and one where such an intervention is not implemented. According to Robinson, McNulty, and Krasno (2009, p. 345) '...natural experiments are often the best way for researchers in the social sciences to approximate the counterfactual.' The natural experiment therefore allowed for possibility to examine what might have happened had the CAS not been implemented in the USA.

The natural experiment is different when compared to other types of experiments. Researchers do not have the ability to assign participants to treatment and control groups. Instead, differences in law or policy provide the researcher with the opportunity to analyse populations as if they had been part of an experiment. This means that one population has received an intervention while the other has not (Leeuw \& Schmeets, 2016).

The above means that the possibility to attribute any of the found changes in online search behaviour the CAS (the 'treatment' jurisdiction) could be examined better if the findings were compared to findings from a population (or, more aptly put, a jurisdiction) where such an intervention was not implemented (the 'control'

${ }^{27}$ For a discussion on the concept of causation and the difference with correlation, see Choi and Tran (2016) and Cowls and Schroeder (2015). 


\section{Research Methodology}

jurisdiction). The second Big Data study enabled this comparison. The changes to online search behaviour were compared across the longer period of time in a 'treatment' jurisdiction, where the CAS was implemented, and a 'control' jurisdiction, that had not implemented this or a similar measure (Dunning, 2008; Kirk, 2015; Montalvo, 2011). The treatment jurisdiction was straightforwardly established, since this was the jurisdiction where the anti-piracy intervention was implemented (the USA). To select a 'control' jurisdiction, a unit of analysis had to be configured that was similar to the unit where the CAS had been implemented, with the obvious diffidence that the CAS (or a similar measure) was not implemented in this second unit (Gallo-Riveria, Mancha-Navarro, \& GarridoYserte, 2013) ${ }^{28}$ First and foremost, this meant that the list of possible 'control' jurisdictions solely consisted of jurisdictions that did not have a CAS-like antipiracy intervention. Beyond that, a jurisdiction had to meet a number of requirements in order to be considered as the 'control' jurisdiction (Gallo-Riveria et al., 2013; Staras, Livingston, \& Wagenaar, 2016).

Firstly, the first language of a jurisdiction had to be English so that identical root queries could be used. Secondly, since the topic of analysis is an anti-piracy intervention, the control jurisdiction should have a rate of digital piracy that is close to the rate in the USA in order for a comparison to be valid. Thirdly, it should have an entertainment market similar to the USA, so that there are sufficient legal alternatives available for users to obtain the desired content, as otherwise the changes to the studied queries might not be comparable since Internet users may have no way to obtain the content legally via online venues or platforms. This meant that countries with still developing entertainment markets were excluded. Fourthly, a potential 'control' jurisdiction must have access to high-speed Internet, as this can also influence online search behaviour in relation to digital piracy.

\subsection{Conclusion}

The three different methods all serve to answer the research question. The realist synthesis provides a number of building blocks that are necessary to answer parts of the research question. It firstly uncovers how digital piracy can be explained. By understanding the causes of digital piracy, it becomes possible to understand what anti-piracy interventions can do about this behaviour. The realist synthesis next provides insights that aid in determining whether anti-piracy interventions can succeed in contributing to reductions in digital piracy, since it also allows for an overview of which anti-piracy interventions are applied in practice. Finally, the

\footnotetext{
${ }^{28}$ Google Trends easily allows for a selection of different jurisdictions, as it can determine where each user originates from. This can be accomplished via the user's IP address. In this manner, a researcher can simply select only those search queries from a specific country or even region.
} 


\section{$\underline{\text { Punish, Seduce or Persuade }}$}

synthesis also uncovers which mechanisms are used and what their requirements are for their proper functioning. In the end, the realist synthesis provides a rich and broad basis to further build on via the two empirical studies.

The functioning of the mechanisms and their contributions to reductions in digital piracy are studied via the first empirical study. This fills the gap that the realist synthesis has left. Though there are some studies that had measured how digital piracy has changed following (hypothetical) anti-piracy interventions, this is an insufficient body of evidence to fully answer the fourth sub-question. Via the stated preference study, it was possible to understand how respondents react to and perceive the scenarios, as well as what which choices they make as to the scenarios that influence these matters. This first empirical study exposes the cognitive aspect of the respondents in relation to digital piracy and anti-piracy interventions.

As the first empirical study focuses on perceptions and attitudes, there is still a noticeable gap between the attitude towards anti-piracy interventions and actual changes in digital piracy after the implementation of an anti-piracy intervention. The second empirical study partially bridges this gap as it examines how online search behaviour of digital pirates has changed after the implementation of an anti-piracy intervention. This process is an example of using Big Data as a way to map changes to online search behaviour and is instrumental in answering the fifth sub-question. A second Big Data study aids in the attribution of any found changes to the anti-piracy intervention.

Together, the three-pronged approach provides a broad and balanced effort to better understand anti-piracy interventions and answer the research question. Text box 2.1 presents an overview of the five sub-questions and the used methods in answering them.

Text Box 2.1: Overview of sub-questions and associated methods

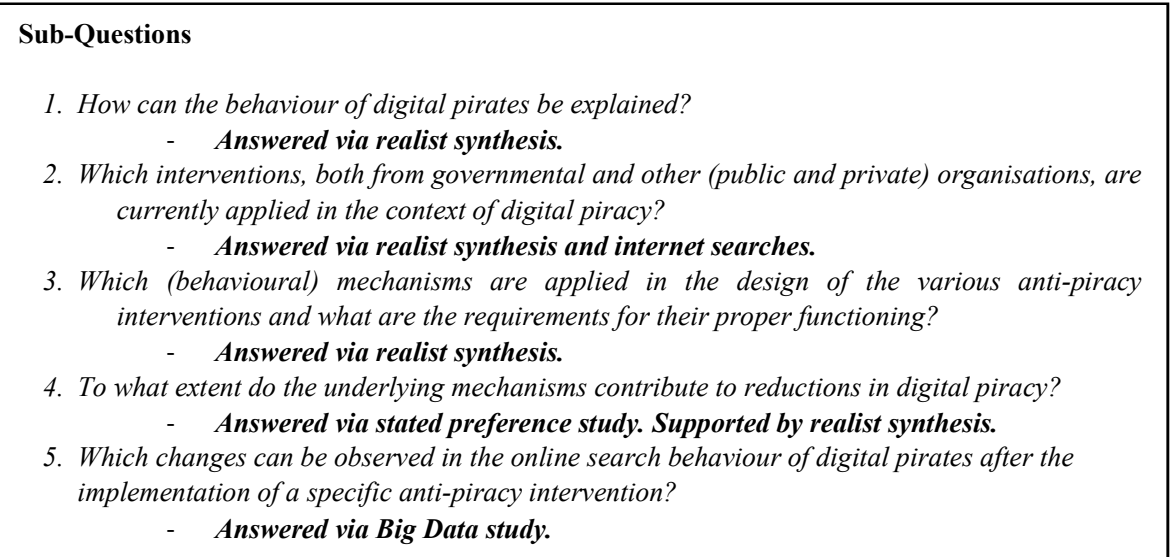




\section{Research Methodology}

From the next chapter onwards, the substantive aspects of this research are presented. The starting point is a more detailed examination of the phenomenon of digital piracy itself. So far, the assumption has been that anti-piracy interventions are needed as digital piracy is both widespread and has consequences for the creative industry as it may cause losses in sales and revenues. But this assumption can be challenged. Therefore, a detailed examination of the scope and potential consequences of digital piracy will be presented in the next chapter. This allows for a firmer grasp of the subject matter and can be used to better understand why governments and the creative industry feel that anti-piracy interventions are needed in the first place. In turn, this paves the way for an analysis of the anti-piracy interventions themselves. 



\section{The Scope and Consequences of Digital Piracy}

It is often indicated that digital piracy is common and has clear consequences for society as a whole and specifically for the creative industries. These statements are used by governments and the creative industry to justify the development and implementation of various anti-piracy interventions. A closer look at the (academic) literature reveals that these statements are more disputable than initially might seem. This is particularly evident when the spotlight is placed on how common digital piracy really is and which economic consequences this behaviour truly causes. In this chapter, industry reports and academic studies are used to gain a better understanding of how wide-spread digital piracy really is and what the consequences are of this behaviour. ${ }^{29}$ The aim of this chapter is not to prove that digital piracy has consequences for the creative industry and society as a whole. Instead, it aims to provide an overview of the various arguments and insights that are presented when discussing digital piracy and its potential consequences.

In this research, 'scope' refers to the segment of a population that pirates content digitally. To establish this scope, findings from industry reports and academic studies that reflect the percentage of the examined population that has pirated content digitally in the past are used. When such findings are unobtainable, the volume or percentage of the content that is pirated on P2P-networks (or other networks that are used to pirate content digitally) is used as an alternative indicator. This alternative indicator is informative not so much with regard to how many individuals engage in this activity but it is nonetheless insightful for how much digital piracy 'is out there'. Both allow for an assessment of how common digital piracy really is in modern society. A starting point for the 'scope' is an examination of just how popular a specific website is that individuals can use to search for, find and download pirated content: 'The Pirate Bay'. This examined by looking at the traffic that this website attracted at specific points in time for specific content. While this is anecdotal evidence, it does present a preliminary outline of how large the scope of digital piracy could be.

\footnotetext{
${ }^{29}$ There are some inherent difficulties in measuring the consequences of digital piracy. Some concerns have been raised on the methodology used in industry reports for instance. Some researchers therefore label these as 'guestimates' (Yar, 2005) adding to the difficulty of establishing these consequences. In addition, some academic studies use data derived from the industry reports (for example, the yearly reports of the BSA), adding to these difficulties (Kariithi, 2011).
} 


\section{$\underline{\text { Punish, Seduce or Persuade }}$}

Consequence refers to the influence digital piracy has (or can have) on the sales and revenues of the creative industry. Any consequences discussed in this research are therefore economic in nature. ${ }^{30}$ The question if and why instances of digital piracy can lead to any consequences is discussed from a theoretical vantage point prior to the presentation of the findings of the industry reports and academic studies on the scope and consequences of digital piracy. This allows for a more balanced position when the findings are discussed. It is clear that there is discussion on whether digital piracy indeed influences these sales and revenues. On the one hand, content owners and the creative industry argue that digital piracy does have consequences for the creative industry, as observed losses in revenue are attributed to digital piracy. Others reach different conclusions and argue that digital piracy does not cause these losses and might even have contributed to increased sales and revenues. Due to these contradicting views, this chapter aims to provide an overview of the various arguments and studies in support of or counter to the statement that digital piracy has specific consequences but also strives to understand why digital piracy might cause such consequences. The explorative nature of this chapter, explains why a broad structured approach to literature review was used, instead of the (more focused) realist synthesis approach.

This chapter analyses both the scope and consequences of the three major types of digital piracy: 1) music piracy, 2) movie and television piracy and 3) video game and software piracy. A few more specific types of digital piracy are excluded in this analysis, among others digital pornography piracy (Brown, 2014b) and e-book piracy. Such types of digital piracy are excluded in this chapter since they are understudied. This means that little, if any, information is available on either the scope or consequences of these types of digital piracy.

\subsection{The Pirate Bay: a demonstration of scope}

'The Pirate Bay' is only one of the many websites through which Internet users can gain access to pirated content. The website provides information on the number of users who are downloading content (the so-called leechers), as well as those individuals who are uploading content (seeders) at any point in time. It is clear that the number of individuals who use this single website is vast. In the past years (2010-2016), the number of simultaneous online users ranged from over 21 million to over 31 million users. On average, there were nine million uploaders at any given time (The Pirate Bay, n.d.). The traffic on this website was examined

\footnotetext{
${ }^{30}$ Other terms used to refer to the consequences of digital piracy are 'impact' (Andersen \& Frenz, 2010) and 'effect' (Barker, 2012). These two terms, like the term 'consequence', refer to the reduction of sales and revenues due to the presence of digital piracy.
} 


\section{The Scope and Consequences of Digital Piracy}

by periodically identifying the file (per content category) that attracted the greatest number of users at that specific moment in time. In this manner, some initial observations on the scope of digital piracy were made, although it concerned the number of files being pirated rather than the segment of the population that is engaged in this behaviour. Figure 3.1 shows the number of users that were downloading a specific content belonging to one of the categories, measured from autumn 2010 until the winter of 2016.

Figure 3.1: Number of downloading individual users (leechers) on The Pirate Bay, per content type ${ }^{31}$

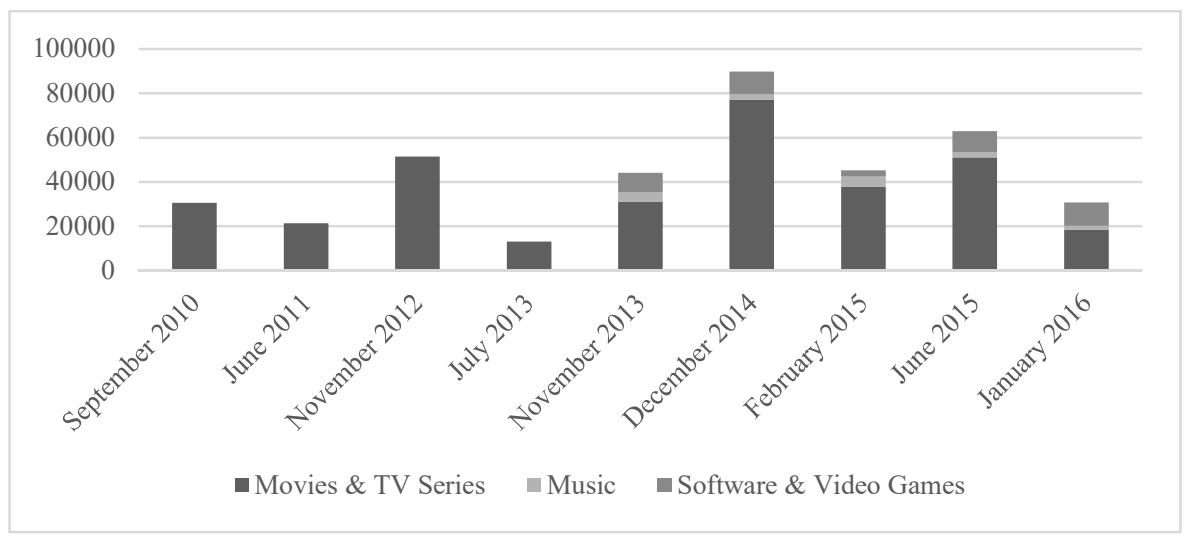

The figure demonstrates that the amount of downloaded pirated content is substantial, ranging to tens of thousands downloads. Movies and television series consistently accounted for the majority of the shared content. The figure also shows that the number of leechers varies continuously. This variation can be explained by changes to the availability and popularity of certain types of content. For example, a season finale of the television series 'The Walking Dead' attracted a large number of downloaders (almost 60,000 individual downloaders immediately after its release) (Rawden, 2016). Another reason for the variance is the moment of the observations. It is likely that the peak in December 2014 is partially attributable to the fact that more individuals have more free time during the holidays, increasing the demand for (pirated) content.

While these numbers might initially not seem to be too immense, recall that this figure refers to one specific file at one moment in time on one website. Indeed, this number becomes more relevant in light of the realisation that there are many websites (and other venues) from which users can digitally pirate content. Each

\footnotetext{
${ }^{31}$ Data taken from The Pirate Bay website (The Pirate Bay, n.d.)
} 


\section{$\underline{\text { Punish, Seduce or Persuade }}$}

website will have links to tens of thousands of individual files or more. This continues non-stop, 24 hours a day, seven days per week.

For uploaded content, a similar reasoning applies. Figure 3.2 shows the number of uploaders from autumn 2010 until the winter of 2016 on The Pirate Bay.

Figure 3.2: Number of uploading individual users (peers) on The Pirate Bay, per most uploaded file

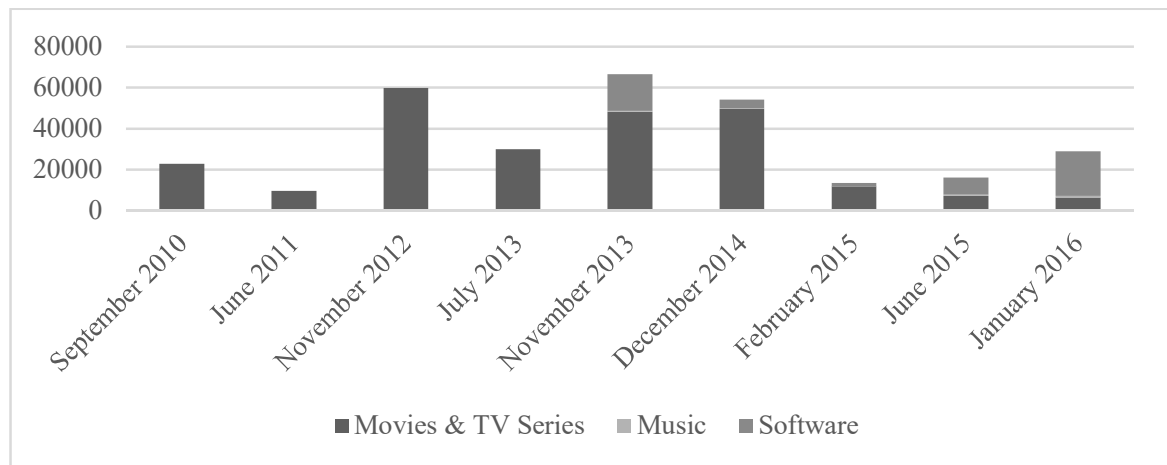

A large number of users upload content via The Pirate Bay. The type of content that is uploaded can again vary over time but movies and television series are most frequently uploaded. Various reasons for these differences over time can be identified. For instance, the increase in uploaded software in January 2016 is likely due to the fact that the popular and long expected video game 'Fallout 4' was released in late 2015, possibly fuelling demand for this content.

While these numbers are mostly anecdotal in nature, they seem to support the creative industries claim that digital piracy is common. If this estimation is correct, would these pirated copies reduce the creative industry's legal sales and revenues? The next section evaluates the merit of this assumption from a theoretical perspective.

\subsection{Understanding the consequences of digital piracy}

The creative industries have repeatedly claimed that digital piracy has led to losses in sales and revenues. On face value, this seems to be a straightforward statement: if an individual pirates content digitally, he will not be likely to purchase this content legally as well. ${ }^{32}$ However, it would be too naïve to assume automatically that every instance of digital piracy equates to a loss in sales and, in turn, a loss in revenue. Following this line of reasoning would lead to the straightforward

${ }^{32}$ With one possible exception being that the individual purchases content legally as a gift for someone else, even if he himself has pirated the content digitally. 
conclusion that digital piracy indeed has consequences and that these in turn are negative and very considerable. The 47 million times (ABC, 2015) the movie 'Interstellar' was pirated in 2015 would be equated with 47 million unsold tickets or DVDs, which, with an average ticket price of \$US 8.34, would have resulted in losses of around \$US 390 million for that movie alone. However, the fact that an individual has pirated this content digitally does not mean that he would have purchased it legally if the pirated copy was not available. The relevant question for this section is to determine when such losses can be attributed to digital piracy in earnest and when an act of digital piracy indeed reduces legal sales and revenues.

Any losses in sales and revenues due to digital piracy are caused by the so-called substitution effect, where the purchase of legal content is precluded by the availability and usage of pirated content. At the same time, there are a number of other effects that can possibly provide balance to this substitution effect. As the following sections will make clear, the substitution effect is just one of the three effects that determine whether digital piracy indeed causes losses in sales and revenues. Two other effects influence this potential outcome: the sampling effect and the complementary consumption effect. The next sections discuss these three effects further in order to better understand if the consequence of a loss in sale and revenue is to be expected in the context of digital piracy.

\subsubsection{The substitution effect}

The substitution effect hypothesis argues that, once an individual has obtained pirated content, he will no longer have an incentive to purchase it legally. The pirated copy is thus a substitute for the legal content. According to this hypothesis, individuals with a low willingness to pay for content may prefer to consume the illegal, and free, copy instead of the legal one. Therefore, the pirated copy competes with the original content (Belleflamme \& Peitz, 2010; Belleflamme \& Picard, 2007). But not every pirated copy will automatically trigger the substitution effect, as it is dependent on the quality of the copy. The closer the quality of the copy comes to the original legal content, the more likely it is that the substitution effect will come into play (Liebowitz, 2005). The lower the quality of this copy, the more incentive the individual may have to purchase the legal product, regardless of the possibility of obtaining a pirated copy. In the case of video games, this low quality takes the form of buggy gameplay or an inaccessible multiplayer component. Thanks to the increase of Internet speeds, pirated copies can be just as good in terms of quality as the legal copy, as the size (in terms of disk storage) of pirated content (which increases with increases in quality) is no longer an issue. In cases where the quality of the pirated copy is 


\section{$\underline{\text { Punish, Seduce or Persuade }}$}

(nearly) equal to the original copy, substitution becomes more pronounced, as the attractiveness of the pirated copy is increased. Huygen et al. (2009) demonstrate that the pirated copy is sometimes considered superior in some aspects, such as with regard to the ease of use. In those instances, substitution becomes more likely.

However, attributing a decrease in sales and revenues solely to the substitution effect would be unwise. As Goel, Miesing, and Chandra (2010) state, a number of other reasons might explain this decrease, such as a perceived decrease in the quality of the legal content or new ways that individuals use and experience content (such as by streaming music through Spotify). Furthermore, it is only possible to 'blame' the substitution effect in those instances where the users would have been willing to pay for legal content if the pirated copy would not have been available in the first place. When this is not the case, an individual pirates content that he would never have purchased legally in the first place, meaning that he does not substitute a legal purchase with a pirated copy. Substitution is thus not a given fact, even if an individual pirates content digitally. It is also highly unlikely that the effect functions in a one-on-one rate.

\subsubsection{The sampling effect}

Most types of digital content are 'experience goods', meaning that individuals use these more than once. Individuals may want to sample the product before purchasing it legally. This allows the individual to better ascertain the quality of the product. If an individual can 'try out' content by first pirating it for free, he can decide to purchase the content legally if he feels that this content is worth buying. (Belleflamme \& Peitz, 2010). Hence, piracy websites can function as a gateway for consumers to sample new types of music, movies or software. Gopal, Bhattacharjee, and Sanders (2006) suggest that the sampling effect can be decisive for consumers who are uncertain about the quality of the product. They state that some consumers will buy the legal content only if a pirated one is available with which the consumer can first test the quality of the content. The pirated copy then becomes a 'trial version' and digital piracy may therefore even improve sales through the sampling effect. Still, there is no guarantee that the individual will purchase the product after sampling it, especially since some individuals might not experience a moral inclination to do so. Just as it is naive to assume that every pirated copy results in substitution, it is also unlikely that each of these pirated copies leads to sampling.

In addition, the sampling effect requires a number of prerequisites for it to take place. The main issue is whether the individual will purchase the legal content 


\section{The Scope and Consequences of Digital Piracy}

after he has pirated it. This firstly means that he needs to be able to buy the content through a legal venue. If the product is not (yet) available, no sampling effect will occur. For instance, in the context of movies, the distribution of both theatrical releases and home video tends to differ depending on the geographical region. For example, movies in cinemas, DVDs and Blu-Ray are often first released in the USA, while they are released later in other regions after some time. The same also happens with regard to video games, where the game might already be available for some platforms (e.g. Xbox) but not for others (e.g. PlayStation), with games sometimes being 'timed exclusives' (Pereira, 2015). However, the pirated copy is often available immediately after the first release or sometimes even prior to this official release, making sampling less likely (as there is in essence nothing to purchase even if the sample is appreciated by the individual). But even if the content is legally available, the positive effect of sampling is not guaranteed. It is important that the individual is willing and able to purchase the legal content legally. If the individual is not willing to pay at all, no sampling effect will take place. If the product is too expensive for the individual, again there will be no sampling.

The final aspect which determines whether a sampling effect will take place depends on the manner in which the individual perceives the (a)morality of the act of digital piracy (Liebowitz, 2005). After obtaining the pirated copy, an individual may or may not feel morally obliged to pay for a product he already has obtained, especially if the pirated copy is of equal or near equal quality. These factors all influence the likelihood of the sampling effect taking place.

\subsubsection{The complementary consumption effect}

The consumption of content, legal or otherwise, can cause individuals to become interested in purchasing or using complementary content and products. Live concerts, for example, can be seen as being complimentary to the downloaded digital copy, as individuals might go to a concert after having listened to pirated music (Peitz \& Waelbroeck, 2006) or an individual might decide to purchase the soundtrack of a movie he has pirated. Digital piracy may therefore result in more sales of related goods such as merchandise (Huygen et al., 2009). This means that complementary consumption is (in)directly caused by the consumption of content, legal or otherwise. Peitz \& Waelbroeck (2006) suggest that through this mechanism, copyright holders may reclaim some of the losses caused by substitution, especially when the complimentary goods are physical or controlled (for example concert tickets, merchandise or MP3-players) (Belleflamme \& Peitz, 2010). Creative industries can recover some of their losses by increasing the price of this related content, which can become popular partially thanks to the many pirated copies that individuals have obtained. Indeed, there are clear indications 
that live concerts have become more popular than ever, possibly due to the fact that such an experience cannot be pirated (Brown, 2014a; Wang, 2016).

\subsubsection{Taking stock of the three effects}

When these three effects are considered in concordance with one another, it is likely that they will be present in various combinations and to various degrees, depending on the specific context. For instance, if substitution occurs, the size of this effect can be mediated by the presence of the sampling effect. The sampling and complementary effects may balance out the more harmful consequences (e.g., losses in sales and revenues) of the substitution effect. The question is whether this assessment can also be seen in practice, and this can be determined by examining both the industry reports and academic studies. To that end, the following three sections each focus on one of the three types of digital piracy that this chapter examines. The next step is to look for more data in order to substantiate or refute the claims of the creative industries. This means that it is necessary firstly to examine whether digital piracy is indeed common, before the (potential) consequences can be determined. This will be discussed in detail in the coming sections and is structured along the lines of the type of content involved (music, movies and television series, and software and video games).

\subsection{Music piracy}

Music piracy is one of the older forms of digital piracy. As the size of a music file is relatively small, even the slower Internet speeds of the late 1990s allowed users to pirate files through services such as Napster or Kazaa. Music files are also the easiest type of content to pirate, as they often do not require any additional software, unlike other types of digital piracy and they are often free from technical restrictions. Finally, music is a type of content that attracts the greatest number of users, as there are many (sub)genres of music, each with its own fans and aficionados. Given these characteristics, it would not be unsurprising to find that music piracy is a common type of digital piracy. At the same time, the cost of purchasing music legally, as well as the production costs associated with this content, is the lowest of the three types of content examined. This fact can influence the consequences of this type of digital piracy.

\subsubsection{The scope of music piracy}

The assumption that music piracy is common or widespread seems to be confirmed by the various industry studies (see Table 3.1). 
The Scope and Consequences of Digital Piracy

Table 3.1: Scope of music piracy according to industry reports

\begin{tabular}{|c|c|c|c|}
\hline Organisation & Country/Region & Year & Results \\
\hline \multirow{2}{*}{$\begin{array}{l}\text { The British Recorded } \\
\text { Music Industry (2013) }\end{array}$} & \multirow{2}{*}{$\mathrm{UK}$} & 2010 & $76 \%$ of music downloads are illegal \\
\hline & & 2013 & $59 \%$ of music downloads are illegal \\
\hline \multirow[t]{6}{*}{ Nielsen Music (2011) } & Asia-Pacific & \multirow[t]{6}{*}{2011} & $43 \%$ download music for free \\
\hline & EU & & $21 \%$ download music for free \\
\hline & Middle East \& Africa & & $41 \%$ download music for free \\
\hline & North America & & $11 \%$ download music for free \\
\hline & Latin America & & $45 \%$ download music for free \\
\hline & Global & & $35 \%$ download music for free \\
\hline IFPI (2011) & EU & 2011 & $23 \%$ visit unlicensed services \\
\hline Envisional (2011) & Global & 2011 & $\begin{array}{l}2.9 \% \text { of all BitTorrent traffic } \\
\text { consisted of music }\end{array}$ \\
\hline \multirow[t]{6}{*}{ Ipsos (2012) } & Asia-Pacific & \multirow[t]{6}{*}{2012} & $39 \%$ download music without paying \\
\hline & EU & & $24 \%$ download music without paying \\
\hline & Middle-East \& Africa & & $37 \%$ download music without paying \\
\hline & North America & & $14 \%$ download music without paying \\
\hline & Latin America & & $48 \%$ download music without paying \\
\hline & Global & & $32 \%$ download music without paying \\
\hline Kantar Media (2013) & UK & 2013 & $\begin{array}{l}22 \% \text { of all content consumed is } \\
\text { infringing }\end{array}$ \\
\hline
\end{tabular}

Table 3.1 suggests that three out of four downloads are pirated. When it comes to the proportion of respondents that pirate music, the range is mostly between $20 \%$ and $40 \%$. As Table 3.2 demonstrates, this might even be a conservative assessment according to certain studies.

Table 3.2: Academic studies examining the scope of music piracy

\begin{tabular}{|lll|}
\hline Study & Population examined & Findings \\
\hline $\begin{array}{l}\text { Levin, Dato-on, and Rhee } \\
\text { (2004) }\end{array}$ & 210 undergraduate students (USA) & $\begin{array}{l}63 \% \text { of the respondents have } \\
\text { pirated music. }\end{array}$ \\
\hline Taylor (2004) & 375 businesses majors (USA). & $\begin{array}{l}69 \% \text { of the respondents have } \\
\text { pirated music. }\end{array}$ \\
\hline Chiang and Assane (2008) & 456 sample of university students & $\begin{array}{l}62 \% / 54 \% \text { of males/females } \\
\text { admits to using file-sharing } \\
\text { technology, } 44 \% / 36 \% \text { of the } \\
\text { music collection belonging to } \\
\text { males/females is acquired via } \\
\text { file-sharing. }\end{array}$ \\
\hline Huygen et al. (2009) & 1,464 Dutch (general population) & $\begin{array}{l}40 \% \text { of the respondents had } \\
\text { pirated music. }\end{array}$ \\
\hline $\begin{array}{l}\text { Lysonski and Durvasula } \\
\text { (2008) }\end{array}$ & 364 university students (USA). & $\begin{array}{l}94 \% \text { of the respondents had } \\
\text { pirated music at one point in }\end{array}$ \\
\hline
\end{tabular}


$\underline{\text { Punish, Seduce or Persuade }}$

\begin{tabular}{|c|c|c|}
\hline & & $\begin{array}{l}\text { time. } 70 \% \text { have done so in the } \\
\text { past six months. }\end{array}$ \\
\hline Morris and Higgins (2009) & 585 US University students & $\begin{array}{l}57.4 \% \text { of the sample had } \\
\text { pirated music in the previous } \\
\text { year. }\end{array}$ \\
\hline $\begin{array}{l}\text { Gunter, Higgins, and Gealt } \\
\text { (2010) }\end{array}$ & $\begin{array}{l}6,2498^{\text {th }} \text { grade and } 5,47011^{\text {th }} \text { grade } \\
\text { high-school students (USA) }\end{array}$ & $\begin{array}{l}\text { For } 8^{\text {th }} \text { grade students, } 52.2 \% \\
\text { have pirated in their lifetime, } \\
44.0 \% \text { have pirated in the last } \\
\text { year, } 35.1 \% \text { have pirated in } \\
\text { the last month and } 16.1 \% \\
\text { pirate daily. For } 11^{\text {th }} \text { grade } \\
\text { students, these rates are } \\
72.3 \%, 63.8 \%, 52.8 \% \text { and } \\
25.0 \% \text { respectively. }\end{array}$ \\
\hline Popham (2011) & $\begin{array}{lll}13,351 & \text { Canadians } & \text { (general } \\
\text { population) }\end{array}$ & $\begin{array}{l}56.5 \% \text { of young individuals } \\
\text { (16-34) pirated music in the } \\
\text { last year, as opposed to } 29.4 \% \\
\text { and } 15.3 \% \text { for middle-aged } \\
\text { and elderly individuals. }\end{array}$ \\
\hline $\begin{array}{l}\text { Wang, Yang \& } \\
\text { Bhattacharjee }(2011-2012)\end{array}$ & $\begin{array}{l}665 \text { undergraduate students at a large } \\
\text { university in southern USA. }\end{array}$ & $\begin{array}{l}\text { A large portion of participants } \\
\text { engaged in both sharing and } \\
\text { obtaining unauthorized } \\
\text { materials }(82.71 \%) \text {. }\end{array}$ \\
\hline Hinduja (2012) & 2,032 undergraduate students (USA). & $\begin{array}{l}\text { Only } 14 \% \text { of the sample has } \\
\text { never pirated music. }\end{array}$ \\
\hline $\begin{array}{l}\text { Jeong, Zhao, and Khouja } \\
\text { (2012) }\end{array}$ & 510 undergraduate students (USA). & $\begin{array}{l}81.7 \% \text { of the sample has } \\
\text { experience with file sharing } \\
\text { (single or multiple songs). }\end{array}$ \\
\hline Poort and Leenheer (2012) & 2009 Dutch (general population) & $\begin{array}{l}21.7 \% \text { of the sample had } \\
\text { engaged in illegal } \\
\text { downloading in the past year. }\end{array}$ \\
\hline $\begin{array}{l}\text { Robertson, McNeill, Green } \\
\text { \& Roberts (2012) }\end{array}$ & $\begin{array}{l}196 \text { students at a New Zealand } \\
\text { university. }\end{array}$ & $\begin{array}{l}\text { The majority of participants } \\
\text { engaged in music piracy } \\
(74.5 \%) \text {. }\end{array}$ \\
\hline Aguiar and Martens (2013) & $\begin{array}{l}16,290 \text { individuals from the five } \\
\text { largest EU countries. }\end{array}$ & $\begin{array}{l}73 \% \text { of the sample has clicked } \\
\text { at least once on an illegal } \\
\text { music website during } 2011 \text {. }\end{array}$ \\
\hline Larsson et al. (2014) & $\begin{array}{l}3,575 \text { respondents from Australia } \\
\text { (general population) }\end{array}$ & $\begin{array}{l}67.7 \% \text { of the sample pirated } \\
\text { music. }\end{array}$ \\
\hline
\end{tabular}

Table 3.2 shows that the assessments of the industry may be conservative. For example, Jeong et al. (2012) demonstrated that more than $80 \%$ of the respondents pirated music and Lysonski and Durvasula (2008) even indicated that over 90\% of the respondents did so.

All studies considered, the occurrence of reported music piracy varies between $15.3 \%$ up to $94 \%$. Most studies placed the scope in the range of $40 \%-70 \%$. This indicates that music piracy is probably as common as the industry reports or perhaps even more so. A final observation is that the scope of music piracy tends to reduce once the general public, which includes older individuals and more socio-demographically varied respondents, is examined rather than students 


\section{The Scope and Consequences of Digital Piracy}

(Poort et al., 2014; Popham, 2011). This was also reflected in those studies that measured the scope for different age groups, where the percentage of older individuals engaged in digital piracy was smaller when compared to younger ones (Popham, 2011). The exception is the study by Larsson et al. (2014) who demonstrated that the number of older individuals who pirate music still falls within this $40 \%-70 \%$ range.

\subsubsection{The consequences of music piracy}

A few industry reports have attempted to estimate the consequences of music piracy. The industry reports state that losses in revenues in the music industry are caused by digital piracy. The Recording Industry Association of America (RIAA) reported a supposed loss of \$US 4.5 billion in revenue in 2005 due to music piracy (Coyle, Gould, Gupta, \& Gupta, 2009). The US music industry claims to have suffered declining sales due to music piracy, from US\$ 13.7 billion in 1998 to US\$ 8.5 billion in 2008 (Sinha, Machado, \& Sellman, 2010). The Institute for Policy Innovation (IPI) goes a step further and suggests that global and US-based music piracy costs the US economy $\$ 12.5$ billion annually and causes around 70,000 job losses (Siwek, 2007). Insights into the effects of music piracy on European countries also exist. For example, music piracy has supposedly cost the German economy $€ 524$ million in 2010 (Martens, Herfert, \& Karbe, 2012). An interesting finding is that, beyond these often reported figures, not many other industry-based reports offer more details on the losses caused by music piracy. Instead, the findings are recycled repeatedly in both the popular press and academic studies. Can these claims be sustained when contrasted with findings from academic studies? Table 3.3 provides an answer to this question.

Table 3.3: Consequences of music piracy

\begin{tabular}{|c|c|c|}
\hline Study & Consequence & Direction and size \\
\hline $\begin{array}{l}\text { Hui and Png } \\
(2003)\end{array}$ & Yes & $\begin{array}{l}\text { The demand for music CDs decreased with piracy. The } \\
\text { industry lost no more than } 6.6 \% \text { of revenue to piracy. }\end{array}$ \\
\hline Blackburn (2004) & Yes & $\begin{array}{l}\text { File sharing reduces sales. If files available online were } \\
\text { reduced by } 30 \% \text {, industry sales would have been approximately } \\
\mathbf{1 0 \%} \text { higher in } 2003 \text {. }\end{array}$ \\
\hline $\begin{array}{ll}\text { Peitz } \quad \& \\
\text { Waelbroeck } \\
(2004)\end{array}$ & Yes & $\begin{array}{l}\text { Music downloading could have caused a } \mathbf{2 0 \%} \text { reduction in } \\
\text { music sales worldwide in } 1998 \text { to } 2002 \text {. }\end{array}$ \\
\hline $\begin{array}{l}\text { Rob \& Waldfogel } \\
\text { (2006) }\end{array}$ & Yes & $\begin{array}{l}\text { Each album downloaded reduces purchases by about } \mathbf{0 . 2} \text {. } \\
\text { Downloading reduces the per capita expenditure from } \$ 101 \text { to } \\
\$ 126 \text {. }\end{array}$ \\
\hline Zetner (2006) & Yes & $\begin{array}{l}\text { P2P usage reduces the probability of buying music by } \mathbf{3 0 \%} \text {. } \\
\text { Sales in } 2002 \text { would have been around } \mathbf{7 . 8 \%} \text { higher if not for } \\
\text { digital piracy. }\end{array}$ \\
\hline
\end{tabular}




\section{$\underline{\text { Punish, Seduce or Persuade }}$}

\begin{tabular}{|c|c|c|}
\hline $\begin{array}{l}\text { Wu \& Sukoco } \\
(2007)\end{array}$ & Yes & $\begin{array}{l}\text { Only } \mathbf{2 . 1} \% \text { of the decrease of music sales in the USA can be } \\
\text { attributed to the Internet. }\end{array}$ \\
\hline Liebowitz (2008) & Yes & $\begin{array}{l}\text { File sharing appears to have caused the entire decline in } \\
\text { record sales and appears to have mitigated what otherwise } \\
\text { would have been growth in the industry. }\end{array}$ \\
\hline Liebowitz (2016) & Yes & $\begin{array}{l}\text { The impact of file-sharing was sufficient to have caused the } \\
\text { entire decline in record sales that occurred from the advent of } \\
\text { Napster up to about } 2005 \text {. }\end{array}$ \\
\hline Zentner (2009) & Yes & $\begin{array}{l}\text { P2P file-sharing can explain half the reduction in music sales } \\
\text { that has occurred. }\end{array}$ \\
\hline $\begin{array}{l}\text { Adermon \& Liang } \\
\text { (2010) }\end{array}$ & Yes & $\begin{array}{l}\text { Their estimates imply that physical music sales would be } \mathbf{7 2 \%} \\
\text { larger in the absence of piracy; this would account for } \mathbf{4 3} \% \text { of } \\
\text { the drop between } 2000 \text { and } 2008 \text {. }\end{array}$ \\
\hline $\begin{array}{l}\text { Waldfogel } \\
(2010 \mathrm{~b})\end{array}$ & Yes & $\begin{array}{l}\text { The rate of sales displacement is between } \mathbf{- 0 . 1 5} \text { and } \mathbf{- 0 . 3} \text {. Each } \\
\text { additional song pirated reduced paid consumption by between } \\
\text { a third and a sixth of a song. }\end{array}$ \\
\hline Barker (2012) & Yes & $\begin{array}{l}\text { P2P file-sharing is a substitute for legitimate music purchases } \\
\text { and has strong negative effects on legitimate music purchases. } \\
\text { The displaced sales amounted to \$CAD } 179 \text { per downloader. }\end{array}$ \\
\hline $\begin{array}{l}\text { Danaher, Smith, } \\
\text { Telang \& Chen } \\
\text { (2014) }\end{array}$ & Yes & $\begin{array}{l}\text { iTunes single and albums sales increased by } \mathbf{2 2 . 5 \%} \text { and } \mathbf{2 5 \%} \\
\text { respectively, after implementation of the graduated response. }\end{array}$ \\
\hline $\begin{array}{l}\text { Gopal, } \\
\text { Bhattacharjee \& } \\
\text { Sanders }(2006)\end{array}$ & Yes & $\begin{array}{l}\text { Decreasing sampling costs not only cause more potential } \\
\text { consumers to sample music but also cause more consumers to } \\
\text { buy these music items. }\end{array}$ \\
\hline $\begin{array}{l}\text { Aguiar \& Martens } \\
(2013)\end{array}$ & Yes & $\begin{array}{l}\text { A } 10 \% \text { increase in clicks on illegal downloading websites leads } \\
\text { to a } \mathbf{0 . 2 \%} \text { increase in clicks on legal purchases websites. }\end{array}$ \\
\hline $\begin{array}{l}\text { Barker and } \\
\text { Maloney (2015) }\end{array}$ & Yes & $\begin{array}{l}\text { The range of these estimated correlations is between-0.047 } \\
\text { and- } 0.061 \text {. This implies that a } 10 \% \text { growth in P2P downloads } \\
\text { is associated with between a } \mathbf{0 . 4 7} \text { and } \mathbf{0 . 6 1 \%} \text { decline in CD } \\
\text { purchases. }\end{array}$ \\
\hline Hong (2004) & Unclear & $\begin{array}{l}\text { Around } 33 \% \text { of the decline of music expenditure can be } \\
\text { attributed to the Internet and possibly Napster. } 80 \% \text { of the } \\
\text { music sales decrease might have been the result from other } \\
\text { factors. }\end{array}$ \\
\hline $\begin{array}{l}\text { Peitz \& } \\
\text { Waelbroeck } \\
(2006)\end{array}$ & Unclear & $\begin{array}{l}\text { The negative effect of piracy may be overcompensated by a } \\
\text { positive effect due to sampling. }\end{array}$ \\
\hline Poddar (2006) & Unclear & $\begin{array}{l}\text { Although piracy displaces some legitimate demand, it also } \\
\text { facilitates sampling. This mitigates the piracy effect somewhat. }\end{array}$ \\
\hline $\begin{array}{l}\text { Bhattacharjee, } \\
\text { Gopal, } \\
\text { Lertwachara, } \\
\text { Marsden, and } \\
\text { Telang (2007) }\end{array}$ & Unclear & $\begin{array}{l}\text { The study found no significant impact of sharing for top debut } \\
\text { ranked albums; file sharing had a significant negative for lower } \\
\text { ranked debut albums. }\end{array}$ \\
\hline $\begin{array}{l}\text { Ahn and Yoon } \\
(2009)\end{array}$ & Unclear & $\begin{array}{l}\text { Although the producers' profits have probably shrunk, the } \\
\text { decrease may not be as severe as the observed sales decline. The } \\
\text { consumer surplus has increased. Third, the social welfare may } \\
\text { have increased. }\end{array}$ \\
\hline $\begin{array}{l}\text { Bender \& Wang } \\
\text { (2009) }\end{array}$ & Unclear & $\begin{array}{l}\text { It is estimated that a } 1 \% \text { increase in piracy rate would result in } \\
\text { a } 0.6 \% \text { decrease in music sales. However, a } 1 \% \text { increase in } \\
\text { the Internet penetration rate led to a more than } 1 \% \text { decrease } \\
\text { in record sales. }\end{array}$ \\
\hline
\end{tabular}


The Scope and Consequences of Digital Piracy

\begin{tabular}{|lll|}
\hline $\begin{array}{l}\text { Mortimer, Nosko } \\
\text { \& Sorensen } \\
(2010)\end{array}$ & Unclear & $\begin{array}{l}\text { File-sharing reduces album sales but increases live } \\
\text { performance revenues for small artists. }\end{array}$ \\
\hline $\begin{array}{l}\text { Andersen \& Frenz } \\
(2010)\end{array}$ & Unclear & $\begin{array}{l}\text { There is both a significant negative substitution effect and a } \\
\text { positive significant market creation effect; these two cancel one } \\
\text { another out, leading to no association between the number P2P } \\
\text { files downloaded and sales. }\end{array}$ \\
\hline $\begin{array}{l}\text { Oberholzer-Gee \& } \\
\text { Strumpf (2007) }\end{array}$ & No & $\begin{array}{l}\text { Downloads have an effect on sales that is statistically } \\
\text { indistinguishable from zero. }\end{array}$ \\
\hline McKenzie (2009) & No & $\begin{array}{l}\text { Evidence suggests no discernible consequences of download } \\
\text { activity on legitimate sales. }\end{array}$ \\
\hline Hammond (2014) & No & $\begin{array}{l}\text { The effect is essentially zero; the elasticity of sales with respect } \\
\text { to illegal downloads is one tenth of one percentage point } \\
(\mathbf{0 . 1 \% )} \text {. }\end{array}$ \\
\hline
\end{tabular}

Table 3.3 demonstrates that most studies (16 out of 27) do clearly indicate that there are consequences of music piracy. Most of these studies (14) found that music piracy has decreased or reduced sales, while a few (2) indicate that digital piracy has increased these sales. There are also some studies that failed to find any consequence at all or the consequence is so small that it is essentially nonexistent (Hammond, 2014). Others failed to reach a definitive conclusion, meaning that found decreases and increases mostly balance each other out (Poddar, 2006). When the findings are taken together, it becomes clear that almost half of the examined studies (14 out of 27) concluded that music piracy causes losses in revenues or displaces legal sales. Only two out of 27 studies concluded the opposite, that music piracy increases revenues or sales. Given the findings, it seems apparent that music piracy indeed has consequences for the creative industry and that this type of digital piracy likely reduced sales and revenues of this content. The statements of the various industries on the presumed consequences therefore appear to be confirmed by these examined academic studies.

However, the academic studies do not state that these consequences are as large as the industry has reported. Only the studies of Liebowitz $(2008 ; 2016)$ provide support for the creative industries' claim that the entire losses can be attributed to digital piracy. The studies by Adermon and Liang (2010) and Zentner (2009) also observe noticeable losses. Most other studies found that the effect is moderate (Blackburn, 2004; Peitz \& Waelbroeck, 2004) or even small (Barker \& Maloney, 2015; Waldfogel, 2010b; Wu \& Sukoco, 2007). The immense losses advocated by the industry studies are thus likely to be farfetched. It is therefore unlikely that music piracy is to blame for the entire reductions in sales and revenues reported by the music industry. However, music piracy likely is one of the factors contributing to these reductions. Other factors, such as increased usage of streaming services that offer less revenues or the decreased popularity of buying 


\section{$\underline{\text { Punish, Seduce or Persuade }}$}

physical rather than digital media are also likely to have influenced the revenues of the music industry.

\subsection{Movie and television piracy}

As with music, it is expected that a considerable number of individuals digitally pirate movies and/or television series, as there is still a large variation of this type of content. Most, if not all, individuals will enjoy watching some kind of visual media. Doing so in a legal manner carries with it a higher price tag when compared to music, while the production costs of movies in particular can be enormous. For instance, the most expensive movie in 2015 cost almost US\$ 280 million to produce. ${ }^{33}$ This means that instances of movie piracy could quickly add up to losses higher than those found in relation to music piracy.

\subsubsection{The scope of movie and television piracy}

A smaller number of industry reports have examined the scope of movie and television piracy, as Table 3.4 illustrates. These figures suggest that around a quarter to a third of the population engages in movie or television piracy.

Table 3.4: Scope of movie and television piracy according to industry reports

\begin{tabular}{|llll|}
\hline Organization & Country/Region & Year & Results \\
\hline $\begin{array}{l}\text { Ipsos and Oxford } \\
\text { Economics (2011b) }\end{array}$ & Australia & 2011 & $\begin{array}{l}\text { A third of the adult population is } \\
\text { engaged in some form of movie piracy. }\end{array}$ \\
\hline Envisional (2011) & Global & 2011 & $\begin{array}{l}35.2 \% / 12.7 \% \text { of all BitTorrent traffic } \\
\text { consisted of movies. }\end{array}$ \\
\hline Wiggin (2013) & UK & 2013 & \begin{tabular}{l}
$24 \%$ pirated movies and TV series. \\
\hline Kantar Media (2013)
\end{tabular} \\
\end{tabular}

This demonstrates that movie and television piracy is common, although it is not as common as music piracy. To give a concrete example of the scope of digital piracy in the case of television piracy, the HBO series 'Game of Thrones' had around 5.5 million 'legal' viewers for the first episode. However, the episode was downloaded illegally 5.2 million times (Laird, 2013). This means that, under certain circumstances, the legal and illegal audiences closely match each other. This series has since then only become more popular for digital pirates. In 2016, following the premiere of its sixth season, the first episode was pirated a million times in 12 hours (Curtis, 2016). Movies are pirated by even greater numbers. For example, both the movies 'Frozen' and 'The Wolf of Wall Street' were pirated

${ }^{33}$ The movie 'Avengers: Age of Ultron' (Wikipedia, n.d.-f). 


\section{The Scope and Consequences of Digital Piracy}

30 million times in 2014 (Spangler, 2014). In 2015, the movie 'Interstellar' was pirated almost 47 million times. In that year, the top 10 of the most pirated movies accumulated almost 400 million downloads (Wallenstein, 2015), compared to around 280 million downloads in 2014. Arguably, 2015 was a particularly good year for movie pirates.

Although the number of industry reports is limited, the table indicates that between one out of four to one out of three individuals are engaged in various forms of movie or television piracy. Similar to the industry studies, the number of academic studies on the scope of movie and television piracy is somewhat limited (Table 3.5).

Table 3.5: Scope of movie and television piracy according to academic studies

\begin{tabular}{|lll|}
\hline Study & Population examined & Findings \\
\hline $\begin{array}{l}\text { Bounie, Bourreau, and } \\
\text { Waelbroeck (2006) }\end{array}$ & $\begin{array}{l}\text { University members of a French } \\
\text { university. }\end{array}$ & $\begin{array}{l}33.4 \% \text { of the respondents pirate } \\
\text { movies either monthly or } \\
\text { weekly. }\end{array}$ \\
\hline Huygen et al. (2009) & 1,405 Dutch (general population). & $\begin{array}{l}13 \% \text { of the sampled individuals } \\
\text { had pirated movies. }\end{array}$ \\
\hline Morris and Higgins (2009) & 585 university students (USA) & $\begin{array}{l}26.9 \% \text { of the sample had } \\
\text { engaged in video piracy in the } \\
\text { previous year. }\end{array}$ \\
\hline Poort and Leenheer (2012) & 1,500 Dutch (general population) & $\begin{array}{l}11.2 \% \text { of the sample had } \\
\text { engaged in illegal downloading } \\
\text { of movies in the past year. }\end{array}$ \\
\hline Poort and Weda (2015) & 2,009 Dutch (general population) & $\begin{array}{l}18.3 \% \text { of the sample had } \\
\text { engaged in illegal downloading } \\
\text { of movies in the past year. }\end{array}$ \\
\hline Bai and Waldfogel (2012) & 372 Chinese university students & $\begin{array}{l}\text { Downloading pirated movies } \\
\text { consists of over half the overall } \\
\text { movie consumption. }\end{array}$ \\
\hline Larsson et al. (2014) & $\begin{array}{l}7,575 \text { respondents from Australia } \\
\text { (general population) }\end{array}$ & $\begin{array}{l}\text { movies while 80.6\% shared } \\
\text { television shows. }\end{array}$ \\
\hline
\end{tabular}

Based on this table, the conclusion can be drawn that movie and television piracy is less common than music piracy, as around one out of five to one out of four respondents indicated that they have pirated movies or television series, supporting the observations made by the industry studies. Only Larsson et al. (2014) found that the vast majority of the respondents had pirated movies or television series. Additionally, the piracy rates of movie and television piracy seem to be on the rise (Poort \& Weda, 2015). This is in contrast with music piracy, where the piracy rates appear to have stabilized or even decreased according to certain studies (Poort \& Leenheer, 2012). Whether this increase will persist is difficult to predict. 


\section{$\underline{\text { Punish, Seduce or Persuade }}$}

It is unclear whether these numbers can be attributed to a small number of persistent pirates or a larger number of individuals who download occasionally. The findings of the academic studies can be interpreted to support the first line of reasoning, as movies are still reported to be pirated in substantial quantities, as the presented examples illustrated. This means that it is likely that there are not as many individuals who pirate movies or television series but, if they do, they are likely to do so frequently and in greater quantities.

\subsubsection{The consequences of movie and television piracy}

Compared to the potential consequences of music piracy, the consequences of movie piracy are thought to be even more considerable. In the US, the total lost revenue due to movie piracy has been reported at around \$US 20.5 billion yearly, as well as costing 140,000 jobs (Siwek, 2007).The MPA suggests that the US motion picture industry lost \$US 6.1 billion in 2005 alone (MPA/LEK, 2006). Similar findings are found in different parts of the world. Germany reported that the loss of revenue was estimated around $€ 156$ million in 2010 (Martens et al., 2012), which interestingly is lower than the losses attributed to music piracy. The Australian Federation Against Copyright Theft (AFACT) reports that AUD\$ 1.3 billion was lost in sales in 2010 due to movie piracy. This resulted in a loss of AUD\$ 551 million throughout the Australian economy, which allegedly led to 6,100 job losses (Ipsos \& Oxford Economics, 2011b). In Canada, movie piracy supposedly costs \$CAD 1.8 billion in revenues and 12,600 full time jobs and (Ipsos \& Oxford Economics, 2011a). The foregoing are bold statements, suggesting that movie piracy results in losses for the movie industry and the economy as a whole. In relation to television piracy, even less is known. Titles akin to: 'Piracy cancer will kill Australian film, TV industry' (Judd, 2014) or 'TV and Film Piracy: Threatening an Industry?' (Strauss, 2013) suggest that movie and television piracy has inherent negative consequences, but there is no data available to quantify these statements.

It seems farfetched that movie and television piracy can truly have such a severe impact on a country's job market and the economy as a whole. Such consequences for the economy are quite unlikely. While individuals may not spend their money on movies by pirating this content digitally, they save it for later use and are likely to spend it elsewhere in the economy. Suggesting that piracy equates with direct losses for the economy as a whole is an observation that is arguably ill-founded when following this line of reasoning. The available academic evidence focuses on the question of what the consequences are for the movie industry directly rather than society as a whole. The statement that movie piracy causes job losses, for instance, can therefore not be verified or falsified. At most, if the losses for the 


\section{The Scope and Consequences of Digital Piracy}

movie industry are severe, it might result in the bankruptcy of several movie studios, which would cause employees of the studios to become unemployed. But the losses have to be vast before this occurs, to the extent that various movies need to fail in recovering their development and production costs. And while certain movies can fail to reach this break-even point (often known as a 'box-office bomb'), attributing this to instances of movie piracy is difficult. After all, a movie might simply not be good enough for people to want to go and see it in theatre or buy the DVD or Blu-Ray. ${ }^{34}$ Movie piracy should not be used as an excuse for movie studios to deflect the fact that some movies simply fail to draw a crowd due to poor quality or lack of marketing.

What can be examined, however, is the possibility that movie or television piracy has consequences for the creative industry itself, in that revenue losses can be attributed to acts of movie or television piracy. The findings of the academic studies that have examined this matter are presented in Table 3.6.

Table 3.6: Consequences of movie and television piracy

\begin{tabular}{|c|c|c|}
\hline Study & Consequence & Direction and sizes \\
\hline $\begin{array}{l}\text { Hennig-Thurau, } \\
\text { Henning, and } \\
\text { Sattler (2007) }\end{array}$ & Yes & $\begin{array}{l}\text { This suggests substantial cannibalization of theatre visits, DVD } \\
\text { rentals and DVD purchases responsible for annual revenue } \\
\text { losses of US\$300 million in Germany. }\end{array}$ \\
\hline $\begin{array}{l}\text { Rob } \quad \& \\
\text { Waldfogel } \\
(2007)\end{array}$ & Yes & Unpaid consumption has reduced paid consumption by $\mathbf{3 . 5 \%}$. \\
\hline $\begin{array}{l}\text { De Vany \& } \\
\text { Walls }(2007)\end{array}$ & Yes & $\begin{array}{l}\text { Internet downloads of a major study movie accelerated its box- } \\
\text { office revenue decline and caused the movie industry to lose } \\
\text { about } \mathbf{\$ 4 0} \text { million in revenue. }\end{array}$ \\
\hline Zentner (2010) & Yes & $\begin{array}{l}\text { In the absence of file sharing, global video sales would have } \\
\text { experienced an increase larger than observed. }\end{array}$ \\
\hline $\begin{array}{l}\text { Danaher and } \\
\text { Smith (2014) }\end{array}$ & Yes & $\begin{array}{l}\text { The shutdown of Megaupload caused digital revenues for three } \\
\text { major studies to increase by } 6.5 \%-8.5 \% \text {, suggesting that illegal } \\
\text { file sharing does displace digital movie sales. }\end{array}$ \\
\hline $\begin{array}{l}\text { Ma, } \\
\text { Montgomery, } \\
\text { Singh \& Smith } \\
(2014)\end{array}$ & Yes & $\begin{array}{l}\text { It is estimated that box office revenue would increase by } \mathbf{2 4 \%} \text { if } \\
\text { no piracy were to occur. }\end{array}$ \\
\hline $\begin{array}{l}\text { Smith \& Telang } \\
(2010)\end{array}$ & Yes & $\begin{array}{l}\text { Increased broadband penetration accounts for } \mathbf{9 . 3 \%} \text { of the } \\
\text { increase in DVD sales rather than a reduction. }\end{array}$ \\
\hline $\begin{array}{l}\text { McKenzie and } \\
\text { Walls (2016) }\end{array}$ & & $\begin{array}{l}\text { Although a statistically significant negative impact from file } \\
\text { sharing on box office sales was detected, the economic } \\
\text { significance of these effects is relatively small. }\end{array}$ \\
\hline $\begin{array}{l}\text { Bounie, } \\
\text { Bourreau \& } \\
\text { Waelbroeck } \\
(2006)\end{array}$ & Unclear & $\begin{array}{l}\text { No consequences of piracy on theatre attendance. A strong } \\
\text { consequence on video rentals and purchases is present. }\end{array}$ \\
\hline
\end{tabular}

${ }^{34}$ Famous 'box-office bombs' are 'The Adventures of Pluto Nash', 'Gigli' and 'Cutthroat Island' (Wikipedia, n.d.-d) 
Punish, Seduce or Persuade

\begin{tabular}{|lll|}
\hline $\begin{array}{l}\text { Bai } \begin{array}{l}\text { Waldfogel } \\
(2012)\end{array} \\
\text { Peukert, }\end{array}$ & Unclear & $\begin{array}{l}\text { Each instance of unpaid consumption displaces 0.14 paid } \\
\text { consumption for university students. This displacement rate is } \\
\text { roughly zero in the case of consumers. }\end{array}$ \\
$\begin{array}{l}\text { Kretschmer } \\
(2013)\end{array}$ & Unclear & $\begin{array}{l}\text { Box office revenues of a majority of movies did not increase } \\
\text { following the shutdown of Megaupload. For a mid-range of } \\
\text { movies, the effect is even negative. Only large blockbusters could } \\
\text { benefit from the absence of Megaupload. }\end{array}$ \\
\hline $\begin{array}{l}\text { Smith \& Telang } \\
(2009)\end{array}$ & No & $\begin{array}{l}\text { A movie's availability on BitTorrent at the time of broadcast does } \\
\text { not reduce the post-broadcast increase in DVD sales. }\end{array}$ \\
\hline $\begin{array}{l}\text { Adermon and } \\
\text { Liang (2010) }\end{array}$ & No & $\begin{array}{l}\text { Movie piracy has no substitution effect on movie sales and } \\
\text { attendance. }\end{array}$ \\
\hline $\begin{array}{l}\text { Martikainen } \\
(2014)\end{array}$ & No & The file-sharing elasticity is not statically different from zero. \\
\hline
\end{tabular}

The first step is again to determine whether digital movie piracy has economic consequences for the creative industry. Seven of the examined studies concluded that there is indeed such a consequence and six of these found clear evidence that digital movie piracy reduces sales or revenues. It is thus unlikely that positive consequences are to be expected, as only one study found evidence for this (Smith \& Telang, 2010) and even then only indirectly, as the study concluded that it was the introduction of broadband technologies that had increased the legal sales. With regard to the size of the consequences, it is apparent that the losses due to movie piracy are nowhere near as voluminous as reported by the industry itself. The exception to this conclusion is the study by Hennig-Thurau et al. (2007) who reported losses that even exceed the German industry figures. The remaining studies give reason to further doubt the size of the negative economic consequences of movie piracy, as the findings demonstrated that pirated copies do displace legal sales but this displacement is far from absolute. In fact, the displacement is relatively small. Although negative, the consequences of movie piracy are unlikely to be as worrisome as the industry itself has stated repeatedly in the past.

\subsection{Software and video game piracy}

The final category of digital piracy focuses on software and video games. It is expected that the scope of this type of piracy is the smallest of the three, due to two reasons. Firstly, the content itself is more specific. Almost all individuals enjoy listening to some kind of music and the same can be said for movies. This does not necessarily apply to video games. Not every individual has a need or desire to play video games and would therefore not be likely to pirate such content. The same reasoning applies to software. Although most of us use software on a daily basis, few individuals tend to obtain this content with any frequency (e.g., we all use Microsoft Word but not many individuals would purchase or acquire every new version released). This means that a smaller portion 


\section{The Scope and Consequences of Digital Piracy}

of the population is likely to be interested in obtaining software or video games, legal or otherwise. Secondly, the usage of pirated software and video games requires more technical knowledge and skills. The content cannot be enjoyed as easily as music or movies. Instead, additional tools or specific software are needed to use this pirated content. This can influence the scope of software and video game piracy, as fewer individuals are willing or able to put the effort into pirating this content.

\subsubsection{The scope of software and video game piracy}

In contrast to movie and television piracy, industry reports have examined the scope of software piracy with recurring frequency and greater detail. The focus here is placed on software rather than on video games, with the Business Software Alliance (BSA) being the primary source of the industry reports. Their reports state that global software piracy rates were at $43 \%$ in 2013 , an increase of $2 \%$ from the previous year (BSA, 2014). In the past years, the rate of software piracy has been stable and is in the range of $40 \%-45 \%$ worldwide (BSA, 2014; BSA \& IDC, 2011). There are large differences between the various regions of the world. The region with the lowest piracy rate is North-America, with a consistent rate of $20 \%$ of the software used having been pirated. On the other end of the scale, the Central/Eastern European region ${ }^{35}$ has a piracy rate of around 64\% (BSA \& IDC, 2010, 2011). Figure 3.3 illustrates the scope of software piracy per region over time.

\footnotetext{
${ }^{35}$ The manner in which the BSA has structured the way through which the findings on software piracy are reported is somewhat inconsistent. Sometimes, the BSA-reports present the piracy rates based on continents (such as North-America), while other geographic units that are used are regional (such as Central/Eastern Europe) and intercontinental regions are also used (Asia-Pacific, which includes both the continents of Asia and Australia). Furthermore, the BSA-reports even make a political distinction as they also report the piracy rates in the European Union. This consistency is likely due to the fact that there may be significant differences within a continent, which is certainly the case in Europe, where WesternEurope has consistently reported low piracy rates while Central/Eastern Europe have in fact reported high piracy rates.
} 
Figure 3.3: Software Piracy Rates (\%) per Region (2008-2013) (BSA, 2014; BSA \& IDC, 2008, 2010, $2011,2012)^{36}$

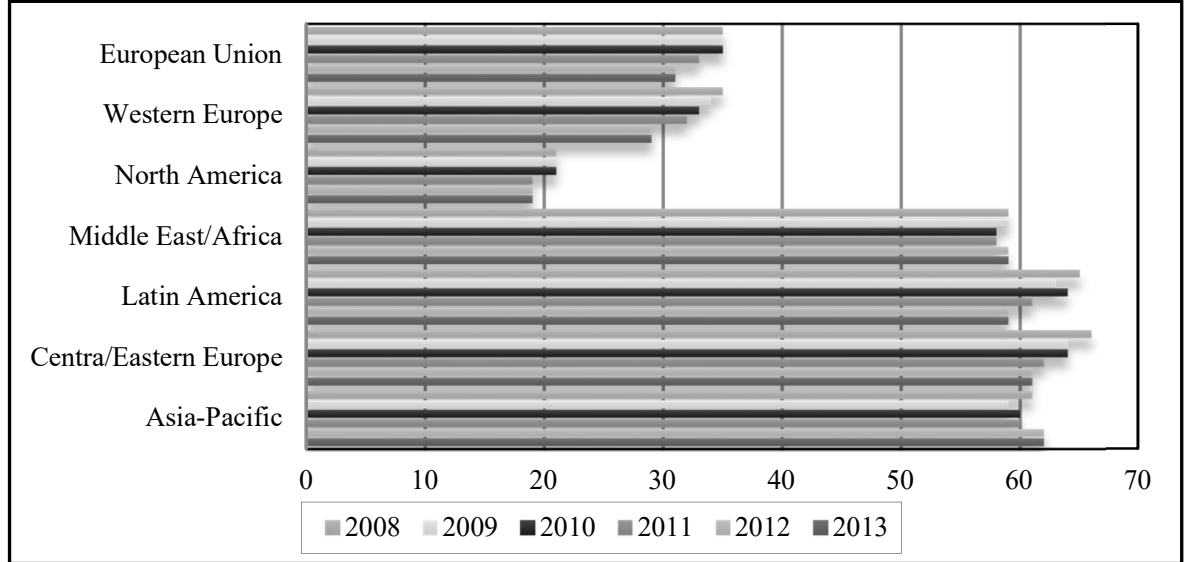

The differences become more apparent when the piracy rates are examined on a national level, showing that piracy rates range from $90 \%-95 \%$ (Georgia) to $18 \%$ $20 \%$ (USA) (BSA, 2014). Since 2013, the piracy rate has been increasing and is the highest since 2009. As the software industry relies on the data from the BSA, these statistics are often repeated by other reports. Contrasting or competing industry reports are lacking, due to the fact that the BSA is the primary stakeholder for the software industry with regard to digital piracy.

In the context of video game piracy, such detailed data are not available. Only rarely is video game piracy examined directly. Kantar Media (2013) suggested that $25 \%$ of all video games consumed online are infringing in nature and that $17 \%$ of Internet users that use such video games pirated them. Within BitTorrent networks, it is stated that $6.7 \%$ of the tracked traffic consisted of video games (both for the PC and consoles) (Envisional, 2011). Beyond this rather meagre harvest, a number of anecdotal comments can be found that suggest that the scope of the problem is enormous. Some suggest that $90 \%$ of the video games used in Europe are pirated (Purchese, 2011). Video game publishers, such as THQ and Ubisoft, suggest that certain games are selling 1 to 10 , meaning that for every sold product, ten pirated copies are used (Oxford, 2010), with publisher Ubisoft suggesting that $93 \%$ to $95 \%$ of all games are pirated (Senior, 2012). Table 3.7 illustrates the size of the problem by looking at the number of downloaded pirated copies of video games through BitTorrent in 2011 and 2012. These figures only relate to video games pirated via BitTorrent-systems. Other types of piracy, such

\footnotetext{
${ }^{36}$ No studies were published focusing on 2014, 2015 or 2016.
} 
as cyberlockers or direct download websites, are not included. The scope might therefore be more sizable than the table data indicates.

Table 3.7: Top 5 game downloads 2011-2012 (Coolpctips, 2012; TorrentFreak, 2011c)

\begin{tabular}{|llll|}
\hline Games 2011 & $\begin{array}{l}\text { Estimated } \\
\text { downloads }\end{array}$ & Games 2012 & $\begin{array}{l}\text { Estimated } \\
\text { downloads }\end{array}$ \\
\hline Crysis 2 & $3,920,000$ & Call of Duty: Black Ops & $4,420,000$ \\
\hline Call of Duty: Modern Warfare 3 & $3,650,000$ & $\begin{array}{l}\text { Call of Duty: Modern } \\
\text { Warfare 3 }\end{array}$ & $4,380,000$ \\
\hline Battlefield 3 & $3,510,000$ & Crysis 2 & $3,960,000$ \\
\hline FIFA 12 & $3,390,000$ & Battlefield 3 & $3,590,000$ \\
\hline Portal 2 & $3,240,000$ & Mafia 2 & $3,340,000$ \\
\hline Total & $17,710,000$ & & $19,960,000$ \\
\hline
\end{tabular}

Collectively, over 17 million copies of these five games were downloaded in 2011 alone. In 2012, this number had increased to almost 20 million downloads. This is a sizable amount and demonstrates the volume of video game piracy. However, it is unlikely that $95 \%$ of the consumption is illegal. In the case of Crysis 2, this would indicate that only 196,000 legal copies would have been sold. In reality, the sales figures are closer to three million, though this includes sales for the PS3 and Xbox 360 versions as well (Wikipedia, n.d.-c). This means that pirated and purchased copies might be matched one-to-one, similar to popular television series. Thus, the $95 \%$ claim seems to be farfetched. But this analysis has not truly revealed what the scope of either software or video game piracy is. How common is this type of digital piracy? Table 3.8 is insightful in answering this question.

Table 3.8: Scope of software and video game piracy according to academic studies

\begin{tabular}{|c|c|c|}
\hline Study & Population examined & Findings \\
\hline \multicolumn{3}{|c|}{ Software piracy } \\
\hline $\begin{array}{l}\text { Al-Jabri and Abdul- } \\
\text { Gader (1997) }\end{array}$ & $\begin{array}{l}278 \text { university students } \\
\text { (Saudi Arabia). }\end{array}$ & $14 \%$ of the sample shared pirated software. \\
\hline $\begin{array}{l}\text { Seale, Polakowski, and } \\
\text { Schneider (1998) }\end{array}$ & $\begin{array}{l}589 \text { university employees } \\
\text { (USA). }\end{array}$ & $\begin{array}{l}44 \% \text { of university employees reported having } \\
\text { copies of pirated software, while } 31 \% \text { said } \\
\text { they have made pirated copies. }\end{array}$ \\
\hline $\begin{array}{l}\text { Rahim, Seyal, and } \\
\text { Rahman (1999) }\end{array}$ & $\begin{array}{l}91 \text { university students } \\
\text { (Brunei). }\end{array}$ & $\begin{array}{l}64 \% \text { of the respondents admitted to having } \\
\text { used pirated software. }\end{array}$ \\
\hline $\begin{array}{l}\text { Moores and Dhillon } \\
(2000)\end{array}$ & $\begin{array}{l}243 \text { university students } \\
\text { (Hong Kong). }\end{array}$ & $\begin{array}{l}93 \% \text { had bought pirated software in the past } \\
\text { year. }\end{array}$ \\
\hline $\begin{array}{l}\text { Peace, Galletta, and } \\
\text { Thong (2003) }\end{array}$ & $\begin{array}{l}201 \text { working adults } \\
(\text { USA). }\end{array}$ & $\begin{array}{l}59.2 \% \text { stated that they had pirated software at } \\
\text { least once. }\end{array}$ \\
\hline $\begin{array}{l}\text { Gupta, Gould, and Pola } \\
(2004)\end{array}$ & $\begin{array}{l}689 \text { respondents from the } \\
\text { general public (USA). }\end{array}$ & $\begin{array}{l}42.5 \% \text { of the respondents indicated that they } \\
\text { engaged in software piracy. }\end{array}$ \\
\hline $\begin{array}{l}\text { Moores and Dhaliwal } \\
(2004)\end{array}$ & $\begin{array}{l}462 \text { university students } \\
\text { (Singapore). }\end{array}$ & $\begin{array}{l}48 \% \text { of the respondents claimed to have } \\
\text { purchased pirated content on a regular basis. }\end{array}$ \\
\hline
\end{tabular}


$\underline{\text { Punish, Seduce or Persuade }}$

\begin{tabular}{|c|c|c|}
\hline $\begin{array}{l}\text { Wang, Zhang, Zang, and } \\
\text { Ouyang (2005) }\end{array}$ & $\begin{array}{l}314 \text { university students } \\
\text { (China). }\end{array}$ & $\begin{array}{l}75.2 \% \text { of the sample had purchased pirated } \\
\text { software. }\end{array}$ \\
\hline $\begin{array}{l}\text { Woolley and } \text { Eining } \\
(2006)\end{array}$ & $\begin{array}{l}481 \text { university students } \\
\text { (USA). }\end{array}$ & $54 \%$ of the respondents pirated software. \\
\hline Hinduja (2007) & $\begin{array}{l}507 \text { university students } \\
\text { (USA). }\end{array}$ & $\begin{array}{l}34.4 \% \text { of those surveyed had pirated software } \\
\text { at least once. }\end{array}$ \\
\hline $\begin{array}{l}\text { Cronan and } \text { Al-Rafee } \\
(2008)\end{array}$ & $\begin{array}{l}280 \text { university students } \\
\text { (USA) }\end{array}$ & $\begin{array}{l}\text { The responses indicate that } 76.5 \% \text { of the } \\
\text { subjects in this study have previously pirated } \\
\text { software. }\end{array}$ \\
\hline Hinduja (2008) & $\begin{array}{l}433 \text { university students } \\
\text { (USA) }\end{array}$ & $\begin{array}{l}55 \% \text { of the respondents reported to have } \\
\text { experience with pirating software. }\end{array}$ \\
\hline $\begin{array}{l}\text { Morris and Higgins } \\
(2009)\end{array}$ & $\begin{array}{l}585 \text { university students } \\
\text { (USA) }\end{array}$ & $\begin{array}{l}24.5 \% \text { of the respondents had pirated } \\
\text { software. }\end{array}$ \\
\hline $\begin{array}{l}\text { Konstantakis, } \\
\text { Palaigeorggiou, Siozos, } \\
\text { and Tsoukalas (2010) }\end{array}$ & $\begin{array}{ll}56 & \text { university } \\
\text { (Greece) }\end{array}$ & $\begin{array}{l}\text { All of the respondents used pirated software, } \\
\text { while } 33 \% \text { of the respondents exclusively } \\
\text { used such software. }\end{array}$ \\
\hline Liao, Lin, and Liu (2010) & $\begin{array}{l}305 \text { respondents from the } \\
\text { general public (Taiwan) }\end{array}$ & $\begin{array}{l}79 \% \text { of the respondents had experience with } \\
\text { using pirated software. }\end{array}$ \\
\hline $\begin{array}{l}\text { Drachen and } \text { Veitch } \\
\text { (2013) }\end{array}$ & $\begin{array}{l}\text { The BitTorrent P2P file } \\
\text { sharing protocol was } \\
\text { monitored. } 127 \text { games } \\
\text { were traced over three } \\
\text { months. }\end{array}$ & $\begin{array}{l}12.6 \text { million unique peers accessed pirated } \\
\text { content. The major commercial titles attracted } \\
\text { the most peers, as the top } 10 \text { most pirated } \\
\text { titles encompass } 41.8 \% \text { of the total traffic. }\end{array}$ \\
\hline $\begin{array}{l}\text { Suki, Ramayah, and Suki } \\
\text { (2011) }\end{array}$ & $\begin{array}{l}289 \text { university students } \\
\text { (Malaysia) }\end{array}$ & $\begin{array}{l}\text { At least three types of software had been } \\
\text { copied recently by } 67 \% \text { of the respondents. }\end{array}$ \\
\hline $\begin{array}{l}\text { Burrus, Bossler, and Holt } \\
\text { (2013) }\end{array}$ & $\begin{array}{l}574 \text { university students } \\
\text { (USA) }\end{array}$ & $\begin{array}{l}\text { Around } 20 \% \text { of the sample had pirated } \\
\text { software. }\end{array}$ \\
\hline \multicolumn{3}{|c|}{$\begin{array}{l}\text { Video game piracy } \\
\end{array}$} \\
\hline Huygen et al. (2009) & $\begin{array}{l}778 \text { Dutch } \\
\text { population). }\end{array}$ & $\begin{array}{l}9 \% \text { of the sampled individuals had pirated } \\
\text { video games. }\end{array}$ \\
\hline Phau and Liang (2012) & 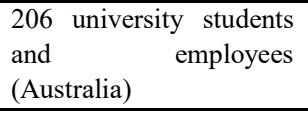 & $44.8 \%$ of the sample had pirated video games. \\
\hline $\begin{array}{lll}\text { Poort and Leenheer } \\
(2012)\end{array}$ & $\begin{array}{l}2,009 \text { Dutch (general } \\
\text { population) }\end{array}$ & $8.2 \%$ of the sample had pirated video games. \\
\hline Larsson et al. (2014) & $\begin{array}{ll}3,575 & \text { Australians } \\
\text { (general population) }\end{array}$ & $\begin{array}{l}49.6 \% \text { pirated either software or video game } \\
\text { files. }\end{array}$ \\
\hline Poort and Weda (2015) & $\begin{array}{l}2,009 \text { Dutch (general } \\
\text { population) }\end{array}$ & $6.0 \%$ of the sample had pirated video games. \\
\hline
\end{tabular}

The findings of the studies reported in Table 3.8 range from a piracy rate of $14 \%$ to $76.5 \%$. Most of these studies presented piracy rates between $40 \%$ and $60 \%$. The rates reported by the industry studies, which are currently $43 \%$ worldwide, are within this range. Interestingly, most Western studies are higher than the $20 \%$ $25 \%$ that the BSA has reported in the past. This also indicates that software piracy might be as common as movie and television piracy, as opposed to what was expected at the beginning of this section. A final observation is that very few studies have specifically examined video game piracy and those studies that have done so are not in consensus, as some studies concluded that video game piracy 


\section{The Scope and Consequences of Digital Piracy}

is engaged in by a relatively small group of individuals (Huygen et al., 2009; Poort \& Leenheer, 2012; Poort \& Weda, 2015), while others stated that this act is common (Larsson et al., 2014; Phau \& Liang, 2012).

\subsubsection{The consequences of software and video game piracy}

As software and video games are among the most expensive content to purchase as well as to produce, it would be expected that the industry would report significant losses to their revenues. The BSA has reported in detail about the consequences of software piracy. Globally, around \$US 60 billion is lost in revenues each year due to software piracy. Different regions in the world contribute to these losses in varying degrees. This is not only dependent on the software piracy rate per region but also the size of the software market. The larger this market is and the higher the price rate, the more a region will add to these losses (BSA, 2014). In recent years, the Asian-Pacific region has contributed the most to these losses, as Figure 3.4 illustrates.

Figure 3.4: Value of illegally acquired software, 2008-2013 (in \$US billions) (BSA, 2014; BSA \& IDC, 2010, 2011, 2012).

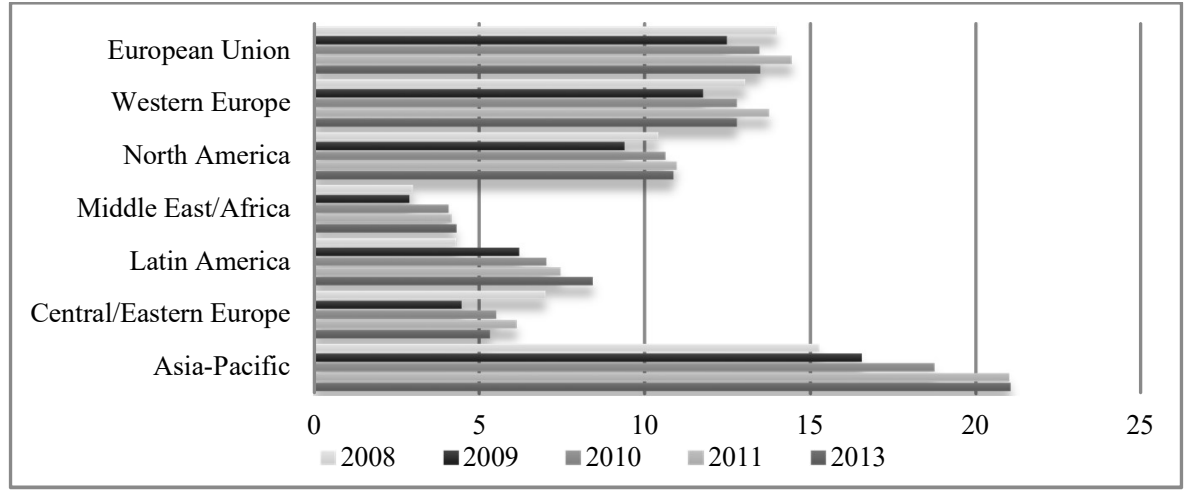

The software market in that region is still growing yet already sizable; combined with high piracy rates (of around 62\%), over US\$ 20 billion is lost in revenue in this region per year. Western-Europe and North America are also significant contributors, but the growth in losses is small, as the software market has stabilized in this part of the world. Latin-America and the Middle-East/Africa are currently relatively small contributors but they exhibit substantial growth. The overall trend is that, while the software rates are stable around the $40 \%$ mark, the value of the illegally acquired software is rising steadily over the last few years in the growing markets, meaning that the consequences are become more pronounced as the markets develop further. Table 3.9 illustrates that over half 
(around US\$ 34 billion) of the total reported losses can be attributed to the 'top ten' countries.

Table 3.9: Top 10 countries with the highest value of pirated software, 2007-2013 (in \$US million) (BSA, 2014)

\begin{tabular}{|llll|}
\hline Country & \$ Value 2007 & \$ Value 2013 & $\begin{array}{l}\text { Change in \% } \\
\mathbf{2 0 0 7 - 2 0 1 3}\end{array}$ \\
\hline USA & 8,040 & 9,737 & $+21.11 \%$ \\
\hline China & 6,664 & 8,767 & $+31.56 \%$ \\
\hline India & 2,025 & 2,911 & $+43.75 \%$ \\
\hline Brazil & 1,617 & 2,851 & $+76.31 \%$ \\
\hline France & 2,601 & 2,685 & $+3.23 \%$ \\
\hline Russia & 4,123 & 2,658 & $-35.53 \%$ \\
\hline Germany & 1,937 & 2,158 & $+11.41 \%$ \\
\hline UK & 1,873 & 2,019 & $+7.80 \%$ \\
\hline Italy & 1,779 & 1,747 & $-1.80 \%$ \\
\hline Japan & 1,791 & 1,349 & $-24.68 \%$ \\
\hline Total & 32,450 & 36,882 & \\
\hline
\end{tabular}

This top ten represents a mixture of developed and developing countries. Most countries (except Russia and Japan) have experienced an increase in the value of pirated software in the past years. This increase is most pronounced in China, India and Brazil. Given this growth, it is to be expected that China will overtake the USA in reporting the largest piracy losses in the near future.

Based on the BSA studies, it is possible that software piracy has the most serious consequences of the three types of piracy examined. Other industry reports even suggest that the estimated US $\$ 60$ billion is low. For example, a recent study by the International Data Corporation (IDC), sponsored by Microsoft, ${ }^{37}$ suggests that, yearly, the direct losses due to pirated and counterfeited software are US\$ 114 billion (Gantz et al., 2013). ${ }^{38}$ The consequences of software piracy are also illustrated at a societal level. For instance, according to a BSA report, a $10 \%$ reduction of the worldwide software piracy rate would contribute US\$140 billion in growth to the GDP, create 600,000 new jobs and generate US\$ 24 billion in tax revenue in the US alone (BSA \& IDC, 2008). Given the findings obtained through the academic analyses of music and movie piracy, it seems unlikely that such enormous losses are realistic however.

Are the consequences of video game piracy equally serious according to the industry? Both the average development cost of a video game and the average retail price of such a product are often substantially higher than a music file or movie. For example, the video game Destiny cost \$US 500 million to develop

${ }^{37}$ This report can be seen as a clear example of the creative industry directly sponsoring reports dealing with the consequences that can be attributed to digital piracy.

${ }^{38}$ However, as this amount is also derived from counterfeited software, which refers to a subset of pirated software that is deliberately presented as being genuine when it is not, we cannot attribute this amount fully to just software piracy. 


\section{The Scope and Consequences of Digital Piracy}

(Wikipedia, n.d.-g). This is also why video games are quite expensive when released ( $€ 49.99$ on average). This could mean that the consequences of video game piracy can be substantial.

However, no industry reports exist that clearly depict the consequences of digital piracy of video games. Only some statements, often ambiguous with regard to their source, exist. For example, in the United Kingdom (UK) it was reported that video game piracy cost around $£ 1.45$ billion due to lost sales (Deleon, 2011). This number only includes console piracy (excluding PC-based piracy). In the case of portable consoles (such as the Nintendo 3DS or Sony PSP), video game piracy has reportedly cost the video game industry $\$ 41.5$ billion between the years 2004 and 2009 (Caoili, 2010). However, beyond these rather incidental statements, there are no proper industry reports that offer more detailed information on the consequences of video game piracy.

Are the consequences of software piracy really so severe that it might cause losses of up to US\$ 60 billion per year (or even more)? Table 3.10 depicts the few academic studies that have attempted to provide insights into this matter.

Table 3.10: Consequences of software and video game piracy according to the academic studies

\begin{tabular}{|lll|}
\hline Study & Consequence & Examined effect \\
\hline Leung (2010) & Yes & $\begin{array}{l}\text { If all sources of piracy were to be shut down, the true gain } \\
\text { would be \$6 per person, 15\% of the BSA estimation, } \\
\text { suggesting that digital piracy of software causes } \$ 6 \text { in } \\
\text { displacement of legal sales. }\end{array}$ \\
\hline Andrés \& Goel (2012) & Unclear & $\begin{array}{l}\text { The findings suggest that software piracy reduces } \\
\text { economic growth over the medium term but the } \\
\text { relationship is non-linear. }\end{array}$ \\
\hline Jain (2008) & Unclear & $\begin{array}{l}\text { There are conditions under which copying can increase } \\
\text { firms' profits, lead to better quality products and increase } \\
\text { social welfare. }\end{array}$ \\
\hline
\end{tabular}

Based on the small number of academic studies that have examined software piracy, it is not possible to establish, with any certainty, whether there are any consequences and what the consequences are for the creative industry, let alone what the extent of the potential consequences is. The industry reports can therefore not be contrasted with the academic studies. Although software piracy is common, it cannot be ascertained whether it has any economic consequences and, if so, what the extent of these consequences are. None of the studies focus on video game piracy, meaning that no conclusions can be drawn for this type of piracy. 


\subsection{Conclusion}

This chapter examined both the scope and consequences of digital piracy in order to better understand the phenomenon itself. When the insights from §3.3. (supra p. 56), §3.4. (supra p. 62) and §3.5. (supra p. 66) are combined, a relatively clear image on the scope and economic consequences of digital piracy emerges. Both the industry reports and academic studies reveal that the scope of the three types of digital piracy examined is quite broad. The academic studies present a range of the scope of each type of digital piracy and the findings of the creative industry itself often fall within this range. Some academic studies indicate that this behaviour is even more common than the industry studies suggest. The statement that digital piracy is widespread and persistent in modern society is valid, especially when younger individuals are involved. Some studies report that more than two-thirds of the respondents pirate music (Wang, Yang, \& Bhattacharjee, 2012) movies (Jeong et al., 2012; Larsson et al., 2014) or software (Cronan \& AlRafee, 2008; Liao et al., 2010; F. Wang et al., 2005). But this does not automatically mean that digital piracy has negative economic consequences for the creative industry.

When the consequences of digital piracy are examined more closely, a schism between claims of the industry and the findings of the academic studies becomes apparent. While both music and movie piracy are likely to result in losses in sales and revenues, the size of these consequences is unlikely to be as extensive as the creative industries have argued. For software piracy, no conclusion can be drawn on the size and direction of the economic consequences given the limited body of evidence available.

Music and movie piracy seem to have negative economic consequences for the creative industry, but on a smaller scale than what the creative industries have reported. The discussion presented in §3.2. (supra p. 52) helps to understand why this is the case. It is likely that the three effects discussed in that section (substitution, sampling and complementary compensation) are present in the context of (at least) music and movie piracy. Given the overall observation that digital piracy, for those two types of content, has led to some loss of revenues and sales, it is likely that the substitution effect is the most persistent of the three, although the sampling and complementary consumption effects are likely to present a counterweight to the substitution effect. At the same time, the findings also reveal that the academic debate on the potential consequences of digital piracy is still on-going. Therefore, not every instance of digital piracy will result in losses in sales and revenues for the creative industry. 


\section{The Scope and Consequences of Digital Piracy}

Still, the findings of this chapter offer insights as to why governments and the creative industries have indeed designed and implemented a variety of interventions meant to stop individuals from pirating content digitally. There are a noticeable number of studies that underline that significant parts of society pirate.

As will become apparent in the fifth chapter, a wide range of anti-piracy interventions are currently used in order to attempt to reduce the number of digital pirates, and by extension, the limit possible consequences that this behaviour has on the creative industry. Prior to depicting this range, the next chapter will present information on the motivations and intentions that underlie piracy behaviour. It answers the question as to how digital piracy can be explained, which is necessary in order to begin to understand the link between the behaviour in question and the anti-piracy interventions. 



\section{How can the Behaviour of Digital Pirates be Explained? A Synthesis through the Lens of the Situational Action Theory}

Governments and creative industries have implemented various anti-piracy interventions and such implementations are often justified by referring to the consequences of digital piracy. Thus, irrespective of how the act of digital piracy is perceived, the fact is that various measures have been taken to prevent individuals from pirating content digitally. However, whether such measures are capable of contributing to reductions in digital piracy remains to be seen. In order to establish that, an answer to the first sub-question 'how can the behaviour of digital pirates be explained?' must be given. A realist synthesis of the relevant literature was undertaken to answer this sub-question, resulting in the collection of a large body of studies that can be used to answer this question.

In order to analyse these studies systematically, the Situational Action Theory (SAT) served as a tool to cluster the findings from the literature, improving the overall quality of the explanation, as it allowed for the integration of a wide range of insights that emerged from the studies into an explanatory narrative. In other words, the SAT served as a lens to analyse the various explanations of digital piracy. The SAT uses three clusters which can aid in explaining why individuals pirate content digitally: the individual's propensity and the conduciveness of the environment towards digital piracy as well as the process of choice (also known as the decision-making process or the perception-choice process (Svensson, Pauwels, \& Weerman, 2010)). The findings were positioned within each of these clusters. By examining the literature carefully, the evidence for and relevance of each finding was assessed and it was determined which findings aid in explaining digital piracy. In each cluster, various explanations take the form of trends or patterns, a process that was explained previously in §2.1. (supra p. 23).

Before discussing the findings of the realist synthesis in detail, this chapter provides an explanation of how the SAT was used as a lens to analyse digital piracy, expanding on the description in §2.1. (supra p. 23). This is important as this clarifies the way in which the findings were structured. 
4.1. The three main 'clusters' of the SAT: the individual's characteristics, the environmental features and the process of choice

The SAT questions why individuals behave in ways that are in conflict with the moral rules of society. ${ }^{39}$ To answer this question, it assumes that people are moved to acts of crime by how they see their action alternatives and make their choices when confronted with the particularities of a certain setting. Put differently, people will make different choices depending on who they are and on the features of the environment that they find themselves in. The benefit of using this theory as a lens to structure and analyse the studies on digital piracy is that it allows for an integration of many different explanatory perspectives. In order to explain deviant behaviour in line with the SAT, it is necessary to identify the individual's characteristics as well as the environmental features that influence the individual's process of choice (Wikström, 2006). The SAT was introduced in 2004 and the most detailed explanation of this theory can be found in the work of Wikström (2006). The theory, like many others, has developed over time. Most applications of the SAT have focused on explicitly testing parts of this theory. For instance, Bruinsma, Pauwels, Weerman \& Bernasco (2015) test what they identify as the 'core propositions' of the SAT and Weerman, Bernasco, Bruinsma \& Pauwels (2015) speak of a "partial test' ${ }^{40}$ of the SAT. As a final example, the studies of Gallupe \& Baron (2014) and Wikström \& Svensson (2010) have tested specific variables belonging to the SAT such as morality, self-control and deterrence. A full revision of this theory has not yet been performed. This means that the work of Wikström (2006) is the most detailed explanation of the main concepts of the SAT and still serves as the primary source for information on this theory.

The SAT focuses on three aspects of human behaviour: the individual characteristics, the environmental features and the process of choice. These aspects can be seen as 'clusters' that aid in explaining crime and deviance. The first two clusters are instrumental in determining whether the individual possesses a motivation to act in the first place. This motivation to offend arises from the interaction between the individual and the setting. The third cluster is needed to understand the situational mechanism under which this motivation is translated into an intention, potentially leading to a (deviant) act. ${ }^{41}$

${ }^{39}$ Thus, the SAT allows for a broader focus than simply the concept of 'crime'.

${ }^{40}$ 'We regard this as a partial test, since we do not investigate the interaction effects that are posited in the theory.' (Weerman et al, 2015, p. 7).

${ }^{41}$ Most applications of the SAT have used the SAT to explain past behaviour (Bruinsma et al, 2015; Gallupe \& Baron, 2014) in addition to focusing on intention. As this research could not use past acts of digital piracy in combination with the various scenarios, the decision was made to stop at an individual's intention to engage in digital piracy. 


\section{How can the Behaviour of Digital Pirates be Explained?}

The first requirement is that an individual has a propensity to act in a deviant manner. Propensity is defined as the general tendency for individuals to choose deviant or criminal acts as the way to fulfil a desire (Weerman et al, 2015; Hirtenlehner \& Hardie, 2016). Certain individual characteristics influence this propensity. It is precisely for that reason that the first cluster focuses on the differences in characteristics between the individuals, as this will explain their differences in propensity.

\subsubsection{Individual characteristics}

The SAT makes a distinction between characteristics, which have a causal link with (deviant) behaviour and attributes, which do not. The SAT states that individuals differ in their propensity towards deviance as they possess different characteristics. Socio-demographic and biological variables that have been examined in 'traditional' criminological research (age, gender, education etc.) are regarded by Wikström (2006) as attributes rather than causes of behaviour. His arguments go back to the work of Holland (1986, p. 955) who states that:

\footnotetext{
'An attribute cannot be a cause [...], because the notion of potential exposability does not apply to it. The only way for an attribute to change its value is for the unit to change in some way and no longer be the same unit. Statements of "causation" that involve attributes as "causes" are always statements of association between the values of an attribute and a response variable across the units in a population.'
}

Therefore, attributes generally cannot be causes of behaviour. The SAT states that, for example, being male, being young or old, being of a certain race or even the individual's immigrant status in itself do not cause him to act in a specific manner. Such attributes are considered to be the background of action and not of direct causal importance (Pauwels, 2011). This does not mean, however, that these attributes are never useful. In fact, they can be used to determine which individuals act in a deviant manner, enabling policy makers to develop interventions that reach those individuals who indeed act in this manner, perhaps akin to an offender profile. ${ }^{42}$

In contrast, the characteristics aid in explaining differences in behaviour as individuals act differently when faced with the same setting. The differences in characteristics allow for the identification of individuals who possess a greater propensity towards crime and deviance. The most relevant individual characteristics are, according to the SAT, desires, morality, and beliefs.

\footnotetext{
${ }^{42}$ In addition, it is suggested that such attributes might indirectly shape behaviour by some scholars (Pauwels \& Svensson, 2009).
} 


\section{$\underline{\text { Punish, Seduce or Persuade }}$}

Desires are addressed explicitly by Wikström (2006) and are the starting point of an individual's behaviour. They are wishes directed towards particular ends or goals. Individuals differ based on the desires they possess.

The second individual characteristic is the individual's morality. Morality refers to an individual's values regarding whether particular acts are the right or wrong thing to do in order to fulfil a particular desire (hence desires come first) in a particular situation (Wikström, 2006). Individuals will vary in their moral values as well as the strength thereof. As Gallupe \& Baron (2014, p. 285) explain: 'those who hold moral beliefs that are consistent with the moral rules of a situation are thought to have stronger morality and will exhibit a degree of shame or guilt if they violate a moral rule or demonstrate some satisfaction by abiding by a moral rule.' Thus, individuals with stronger morality (as described in the previous sentence) are unlikely to consider deviant behaviour as an acceptable way to fulfil a particular desire. Conversely, if an individual does not consider the behaviour in question to be morally wrong, he will more likely to act in this manner (Wikström \& Treiber, 2007). It has been argued that morality is the main factor in the explanation of crime, since it influences whether the individual will see crime as a suitable action to fulfil a desire (Pauwels \& Svensson, 2013).

The third individual characteristic is the beliefs of the individual. Beliefs are an individual's assessment of whether desires can be fulfilled successfully and it refers to the degree of confidence in having the capacity and means available to carry out the act needed to fulfil a particular desire. Individuals who believe themselves to be capable of fulfilling the desire through a particular action are more prone to act in this manner (Wikström, 2006). ${ }^{43}$

There is some debate on whether or not self-control should be added as a fourth characteristic in determining an individual's propensity. Some recent applications of the SAT have in fact done so (Hirtenlehner \& Hardie, (2016); Haar \& Wikström (2010)). In fact, in those studies, the individual's propensity consists solely of his morality and his ability to exercise self-control. This is in contrast to the manner in which self-control was initially positioned by Wikström (2006), as it was placed within the context of the individual's process of choice. The role of self-control in the context of this research is further discussed in §4.1.3. (infra p. 82).

\footnotetext{
${ }^{43}$ In addition to desires and beliefs, Wikström also discusses the role of commitments as a motivating factor. These are desire-independent and consist of doing 'what you have to do regardless of what you want'. These often consist of promises (not to smoke for instance) (Wikström, 2006). As commitments, in this sense of the word, are not applicable in the context of digital piracy, this additional pathway towards motivation is not used hereafter.
} 


\section{How can the Behaviour of Digital Pirates be Explained?}

\subsubsection{The environmental features}

The environment is external to the individual and influences and shapes the individual's motivation to act in a criminal or deviant manner (or not). Certain environments possess features that are conducive to such behaviour (Wikström, 2006). One feature is that the environment can expose the individual to opportunities to act in a deviant manner. These opportunities present the individual with temptations, which are perceived opportunities to satisfy particular desires. The connection between an opportunity and a desire in a particular setting causes a temptation (Wikström, 2006). This means that an individual's exposure to temptations will vary depending on the environment(s) that he encounters in his daily life as well as his own desires. This also means that certain environments are more criminogenic than others as they will vary in the degree to which they offer opportunities (Wikström, 2003). Exposure to environments that are high in temptations to offend increases an individual's level of offending (Bruinsma et al, 2015), adding to the conduciveness of the environment. ${ }^{44}$

The second feature is that the environment can also provide obstacles to the intended action, which take the form of frictions. These may result in provoking the individual into action. Such provocations are the second environmental feature and consist of frustrations directed at the source of the friction. ${ }^{45}$ Provocations can also motivate an individual to act in a particular manner (Wikström \& Treiber, 2009).

The third environmental feature is the moral context. This feature consists of three separate elements: 1) the moral rules that apply in the environment, 2) the enforcement of these moral rules and 3) the degree of sanctioning of these moral rules (Wikström, 2006) ${ }^{46}$ The moral context is independent of the individual and will guide him in his decision to act in a certain manner. If an individual who operates in an environment in which there is a high correspondence between his morality and the moral rules of the setting in which he takes part, he will rarely

\footnotetext{
${ }^{44}$ Bruinsma et al (2015, p. 367) give an example of such an environment and describe it as follows: 'Spending time with peers in an unstructured environment and without supervision of adults may seduce adolescents to take opportunities to offend for symbolic rewards like status and reputation.'

${ }^{45}$ Wikström \& Treiber (2009, p. 85) present an example of a friction: 'people become sources of friction when they interfere with another person or that person's course of action, for example, when a police officer stops a burglar from escaping the scene, or a drunk hassles a couple on a train.'

${ }^{46}$ The moral context should therefore not be focused on the individual's morality, which refers to beliefs regarding whether particular acts are the right or wrong thing to do in order to fulfil a particular desire in a particular circumstance (Wikström, 2006). See also $\$ 4.1 .1$. (supra p. 79).
} 


\section{$\underline{\text { Punish, Seduce or Persuade }}$}

perceive a deviant act as a suitable alternative to fulfil a desire. ${ }^{47}$ Thus, he does not become motivated to act in a criminal or deviant manner. Moral rules, in the context of the SAT, are rules of the environment that delineate what is the right or wrong thing to do (or not do) in a given environment (Wikström, 2006; Gallupe $\&$ Baron, 2014). These can be in conformity with the law but also deviating from it (Weerman et al, 2015). Low risks of both enforcement and sanctioning of these moral rules contribute to the potential criminogenic nature of the environment (Wikström, 2003). The focus on the enforcement and sanctioning of the moral rules reflects the presence or absence of deterrent measures in the environment. There is some overlap on the placing of the concept of deterrence in the framework of the SAT, as it is discussed both as belonging to the environment (through the moral context) as well as in relation to the process of choice that an individual undergoes. Hirtenlehner \& Hardie (2016) position deterrence within the context of the environment, which is also done in this study as an integral part of the moral context. In contrast, Hirtenlehner, Pauwels, and Mesko (2015) position the deterrent measures outside of the moral context.

When these three elements of the moral context come together, it can be determined whether or not moral contexts contribute, together with temptations and provocations, to the conduciveness of the environment, meaning that the environment encourages, or at least does not discourage, the involvement in deviant behaviour (Weerman et al, 2015; Wikström \& Svensson, 2010).

Some recent studies have added a fourth environmental feature: exposure to peer delinquency. Here, the focus is on whether deviant behaviour becomes more likely if the individual interacts with peers that (also) violate social norms and laws (Bruinsma et al, 2015; Hirtenlehner \& Hardie, 2016). Peers are important as an environmental feature as they aid in shaping the moral context of the setting (Hirtenlehner et al., 2015). It is a relevant environmental feature that aids in assessing the conduciveness of the environmental for acts of crime and deviance and was therefore used in this chapter.

\subsubsection{The process of choice}

For a deviant act to occur, it must be perceived by the individual as being a suitable way to fulfil his desires. Without the perception that a particular deviant act is a suitable way to fulfil his desire, the individual is unlikely to act in a deviant manner (Wikström, 2006), as the perceptions determine which acts (e.g., compliance or deviance) are taken into consideration by the individual during the process of choice (Hirtenlehner \& Hardie, 2016; Hirtenlehner et al., 2015).

${ }^{47}$ This is referred to as the principle of moral correspondence (Wikström, Ceccato, Hardie, \& Treiber, 2010). 


\section{How can the Behaviour of Digital Pirates be Explained?}

Perceptions are dependent on the features of the environment in which the individual takes part as well as his individual characteristics. Perceptions are suggested to precede the process of choice and Wikström (2006) argues that perceptions are more fundamental in the explanation of deviance than the process of choice. The individual will, depending on his own characteristics and the environmental features, perceive different behavioural alternatives. Following this perception, the process of choice will cause the individual to deliberate on his behaviour. When no behavioural alternatives are perceived, the individual can act out of habit, as there is in essence nothing to deliberate about, transforming the motivation to act into an intention to do so (Hirtenlehner \& Hardie, 2016).$^{48}$ Using perceptions to explain digital piracy is essential. In §4.1.4. (infra p. 84), it will be elaborated in more detail how perceptions were used to explain digital piracy.

Depending on the individual-setting interplay and his perceptions thereof, an individual can come to behaviour through one of two ways: via moral habits or moral judgements (Wikström, 2006). ${ }^{49,50}$ Moral habits lead to actions that lack deliberation on the part of the individual. Whether a choice is the result of habit will depend on the familiarity of the environment and their features. Familiar environments and features will tend to result in choices based upon moral habit (Wikström, 2007). Moral judgements, instead, occur when an individual encounters an unfamiliar environment (or feature thereof), causing him to deliberate and make a choice. This means that the individual is consciously considering more than one alternative for action (Wikström \& Treiber, 2009). Wikström (2006, p. 99) defines a moral judgement as: 'the deliberation over the moral implications of acting, or not acting, or acting in a particular way, upon a particular motivation in a particular setting.' In turn, Hirtenlehner et al. (2015, p. 533) define choice as: '[...] the selection of the best alternative based on subjective assessments of the pros and cons of the considered alternatives. 'In his work, Wikström identifies some components of the process of choice, one of them being self-control. The role that self-control can play in the context of the SAT was already briefly discussed in $§ 4.1 .1$. (supra p. 79). Interestingly, Wikström places the concept of self-control in the deliberative process rather than in the

\footnotetext{
${ }^{48}$ It must be underlined that individuals who do not see crime as an acceptable way of fulfilling one's desires will be unlikely to deliberate on his behavioural choice (Wikström \& Treiber, 2007). For these individuals, compliance comes 'naturally', which again underlines that morality is an important characteristic in the context of the SAT and comes early in the explanation of crime and deviance.

${ }^{49}$ Admittedly, many choice processes may involve elements of habits and deliberation. However, most choices are predominantly habitual or deliberative (Wikström \& Treiber, 2009).

${ }^{50}$ The addition of 'moral' to habitual or judgement-based behaviour is a direct consequence of the relevance of the individual's morality in the context of the SAT (\$4.1.1. (supra p. 79)). This morality will determine whether or not the individual perceives certain behavioural alternatives in the first place. In a sense, morality screens the range of the alternatives for the individual.
} 


\section{$\underline{\text { Punish, Seduce or Persuade }}$}

characteristics of the individual, his reasoning being that self-control is only activated when the individual deliberates on his behaviour and identifies a conflict between fulfilling his desire in a specific manner and his morality (Wikström, 2006; Wikström, 2007). If the individual does not deliberate on his behaviour (meaning that he does not perceive a conflict between his morality and his desired behaviour), self-control will not matter in explaining his behaviour (Gallupe \& Baron, 2014) ${ }^{51}$ In the context of the SAT, self-control refers to, as Hirtenlehner et al. (2015, p. 533) explain, '[...] an individual's ability to inhibit perceived action alternatives that collide with one's personal moral attitudes when faced with situational incentives to break rules of conduct, or, in brief, the ability to resist current temptations and provocations.' Self-control can be relevant in understanding how an individual reacts to his environment. Self-control will come into play when there is a moral conflict between the morality of the individual and the moral context (Hirtenlehner et al., 2015). ${ }^{52}$ Thus, the individual characteristics and environmental features need to be understood before the role of self-control can be examined, being a component of the process of choice.

\subsubsection{Usage of the SAT in the context of digital piracy}

When the various insights from the previous sections are taken together, Wikström arrives at the deceptively straightforward basic model of the SAT (Wikström \& Svensson, 2010, p. 398):

$$
\mathbf{P} \times \mathbf{E} \rightarrow \mathbf{C}
$$

In this model, ' $\mathrm{P}$ ' stands for crime propensity (of the individual, which is established via an assessment of the individual's characteristics); ' $E$ ' stands for criminogenic exposure (determined by the environmental features) and ' $\mathrm{C}$ ' for crime involvement (which is the result of the process of choice). It was this model that was used as a lens in order to structure the studies on why individuals pirate content digitally, resulting in a general explanation of digital piracy. This means that explanations for digital piracy were taken from studies that examined the individual, the environment or the process of choice (or combinations thereof), forming the three clusters of the SAT.

\footnotetext{
${ }^{51}$ It has been stated that there are interaction effects between morality and self-control. As Svensson et al (2010, p. 733) propose: 'More precisely, we expect that self-control has a more important effect on offending for individuals with low levels of morality than for individuals with high levels of morality. In the same study, they found evidence of such an interaction effect. They also observe in that study there is some support to the SAT argument that morality is a more important variable than self-control.

52 This role of self-control is also known as 'conditional relevance' (Hirtenlehner et al., 2015).
} 


\section{How can the Behaviour of Digital Pirates be Explained?}

With regard to the first step, the individual characteristics, three characteristics needed to be examined in line with the SAT. Desires, morality and beliefs are clearly part of any attempt at explaining digital piracy through the lens of the SAT and were focused on. Individual attributes were also discussed, if evidence emerged of their relevance in relation to explaining digital piracy. These attributes were used in particular to identify the appropriate target population that antipiracy interventions should reach.

The next step was to identify the environmental features. The focus was on the four main features: temptations, provocations, the moral context (which consists of three elements) and the presence of deviant peers. Opportunities and frictions needed to be attuned specifically to digital piracy and it remained to be seen which opportunities and frictions were identified by the relevant literature and what their roles were. A possible example of a friction in the context of digital piracy could be the high costs that content owners charge for legal content. Opportunities may take related forms (such as the opportunity to quickly and easily download pirated content). The moral context does not solely consist of the moral rules themselves but also the enforcement of these moral rules and the sanctioning of acting against these rules. These aspects were incorporated by looking at the role deterrence (or the lack thereof) played explaining digital piracy. The role of peer delinquency was added to the conduciveness of the environment, similar to later applications of the SAT (Bruinsma et al, 2015; Hirtenlehner \& Hardie, 2016).

The above means that certain individuals can be said to have a greater propensity to pirate content digitally. Depending on the environment, this propensity can lead to an individual who is motivated to pirate content digitally. Whether this will result in the individual having the intention to do so is dependent on the process of choice that the individual will go through. As perceptions connect the individual characteristics with the environment and form an important preamble to this process of choice, they were focused on first. The aim was to identify those perceptions that contributed to the translation of the individual's motivation to digitally pirate content into an intention to do so. These perceptions focus on the individual himself, his environment and the potential outcomes of the act of digital piracy. In line with the later revisions of the SAT, perceptions and the choice process were used in concordance with one another and analysed in that order. The roles of the self-control, neutralizations (which from part of the deliberative process as the individual deliberates over the (moral) implications of the act of digital piracy) and moral habits were examined under the heading of the process of choice. Collectively, the individual characteristics, the environmental features and the components of the process of choice are all 'variables' that aided in 


\section{$\underline{\text { Punish, Seduce or Persuade }}$}

explaining digital piracy. Thus, when later chapters refer to the term variables, they refer to this overarching concept which incorporates all parts of the SAT.

In order to explain why individuals pirate content digitally, the 162 studies selected were analysed through the lens of the SAT. This selection process was discussed in \$2.1. (supra p. 23). The SAT allowed for the clustering of the findings from these studies into a synthesis. Evidence was therefore sought for each aspect of the SAT as discussed previously. The realist synthesis thus unearthed the data that enabled three analytical steps: 1) to provide an overview of the 'variables' that have been studied in the various studies, 2) to find out whether the 'variable' indeed aids in explaining digital piracy and, if so, 3) to analyse the direction of the relationship found between each 'variable' and digital piracy. To do so, the findings were grouped and analysed in patterns. Not all patterns are described in this chapter; only those for which sufficient evidence was found are discussed.

\subsection{A snapshot of the studies}

In total, 162 studies were used to answer the sub-question 'how can the behaviour of digital pirates be explained?' To help with the contextualization of the findings that these studies put forward, this section provides a brief overview of some of the aspects that these studies possess. Specifically, the following three characteristics are addressed: 1) the type of respondents used in the study, 2) the origin or location of the study and 3) the type of digital piracy examined.

With regard to the type of respondents used, the majority of the studies $(68 \%)$ focused on the behaviour of university students. High school students are only rarely examined (5\%) and around one third (27\%) of the studies used respondents from the general population. This is not surprising, as younger individuals are often assumed and found (Gunter et al., 2010) to be the most frequent digital pirates, making them the main focus of past and present research. The finding that the majority of the examined empirical studies focused on student populations was therefore expected and not problematic in this realist synthesis. It is also apparent that many studies originated from the USA (43\%). In total, over half of the studies $(56 \%)$ originated from a Western country. A small portion of the studies failed to specify where they were performed (11\%). This meant that approximately one third of the studies were performed in non-Western countries (33\%). This allowed for the findings of the synthesis to be used in the context of this research, which took place in a Western context. Finally, most of the studies examined either music (33\%) or software piracy (34\%). Some studies $(29 \%)$ either examined digital piracy from a general perspective (not specifying the type 


\section{How can the Behaviour of Digital Pirates be Explained?}

of digital piracy studied) or studied a combination of different types of digital piracy. Movie piracy is understudied, with only $4 \%$ of the studies having focused on that type of digital piracy. None of the studies examined television or video game piracy. As this research does not make a distinction between different types of digital piracy, all findings can be used to answer the first sub-question.

Following this brief overview of the studies, the studies will be analysed more in detail. In the coming sections, numbers will be used to refer to each of the studies for the readability of this chapter. Appendix I (infra p. 317) identifies which study belongs to which number. ${ }^{53}$ The findings of the realist synthesis commences with the characteristics of the individual.

\subsection{The propensity of the individual: which characteristics seem to matter?}

Desires, morality and beliefs are discussed in this cluster under the heading of an individual's propensity. A number of individual attributes are also discussed in this section, as this aids in identifying the appropriate target population. Gender, age, computer experience, education, and income are attributes that are examined in this section following the discussion of the characteristics.

\subsubsection{Desires}

Desires are understood as a wish directed towards a particular end or goal (Wikström, 2006). In the context of digital piracy, desires refer to an individual's need to enjoy, obtain or share (digital) content. Fulfilling this desire (through the act of digital piracy) is important in understanding an individual's propensity towards this behaviour. There is evidence that a greater desire towards content aids in explaining an individual's digital piracy behaviour [1-5], meaning that individuals who possess this desire are indeed more likely to engage in digital piracy. Further support for this pattern emerges from studies that have observed that individuals who have an affinity with certain types of music or obtain more joy and pleasure from this content are more likely to pirate this content [6-11]. Only a few studies [12-14] negate the influence of desire on digital piracy. Thus, most studies acknowledge that desire influences an individual's propensity towards digital piracy and it is rightfully identified as a characteristic that aids in explaining this behaviour.

${ }^{53}$ When a range of numbers is presented, such as [1-5], study 1 up to and including study 5 are referred to. 


\subsubsection{Morality}

The individual's morality affects whether or not he is likely to act upon his desire to obtain content through the act of digital piracy. It is therefore important to determine what role morality plays in explaining digital piracy. Many studies have examined whether or not individuals who consider digital piracy as an immoral act are less likely to pirate content digitally. There is substantial evidence to conclude that this is indeed the case [9, 15-29, 153-156]. Only one study [30] failed to find evidence for this relationship. There is also some evidence that suggests that individuals are more likely to pirate content digitally if they consider this behaviour to be morally acceptable [31-34], but not all studies share this assessment [35]. Individuals who experience guilt if they violate a rule are said to possess stronger moral values and there is some evidence to conclude that individuals who experience such feelings in relation to digital piracy are less likely to do so again [24, 36-45]. Clearly, individuals who do not see digital piracy as immoral or wrong have a greater propensity for fulfilling a desire in this manner.

\subsubsection{Beliefs}

The third characteristic influencing an individual's propensity to pirate content digitally is the individual's beliefs, which the SAT refers to as the individual's assessment of whether his desire(s) can be fulfilled. It also refers to the individual's degree of confidence in his capacity and means available to carry out the act in order to fulfil a particular desire. Applied to digital piracy, the question is whether an individual possesses a greater propensity to pirate content digitally if he believes that he is capable doing this successfully. There is a large body of evidence to conclude that, if the individual believes that he is indeed capable of successfully pirating content digitally, it becomes more likely that this individual will actually do so [4, 9, 20, 28, 36, 39, 40, 42, 46-58, 153, 155-157]. Only some studies do not share this conclusion $[38,41,59,60]$.

Collectively, the three characteristics identified in the SAT as forming an individual's propensity are confirmed in the context of digital piracy. The evidence is in fact quite clear, as only a few studies failed to find evidence for the role of these characteristics. Before moving on to the features of the environment, this section briefly focuses on the individual attributes that can be used to identify the target population for the anti-piracy interventions. 


\section{How can the Behaviour of Digital Pirates be Explained?}

\subsubsection{Gender}

The question is whether gender can be used to identify digital pirates and which gender pirates content digitally more frequently or with greater intensity. There is little evidence to conclude that women pirate more content digitally than men [61]. In contrast, the majority of the studies that have examined the role of gender state that males are more likely to pirate content $[6,12,19,56,63-71,73,158$ $160]$ and there is some evidence that males do so in greater quantities [12, 74]. A number of studies have failed to find evidence of the role of gender [11, 35, 39, $75-82,161]$. Still, being male can be seen as an attribute which can be used to identify individuals who are more likely to pirate content digitally.

\subsubsection{Age}

A second attribute potentially relevant is the individual's age. It has been repeatedly suggested that younger individuals are more likely to pirate content digitally and that older individuals are less likely to do so. This suggestion is confirmed by a large body of evidence $[6,11,19,21,33,35,61,65,70,78,82$ $85,158,159,161]$. It is stated that individuals become more likely to pirate content digitally as they reach adolescence [11, 61]. After this peak, this likelihood will start to decrease. Only a few studies failed to find evidence for the role of age as an attribute $[67,71,75-77,86]$. That older individuals are more likely to pirate content digitally is only concluded by one study [73]. This suggests that age can be used to identify the appropriate target population and, more specifically, that being younger (adolescent) is an attribute.

\subsubsection{Computer experience}

The third attribute focuses on individuals who are more likely to pirate content digitally due to their experience with computers and related technologies. It is thought that individuals who use computers more often are also more likely to pirate content digitally as they have obtained the skills and resources needed to do so successfully. It is clear from the various studies that individuals who possess such experience are indeed more likely to do so [32, 67-69, 83, 85, 87-90, 161]. There is little evidence to conclude otherwise [81,91]. Experience with computers and, particularly, more experience is therefore an attribute of individuals who are likely to pirate content digitally.

\subsubsection{Education}

A next possible attribute is whether or not a specific level of education is an attribute for individuals who are more likely to pirate content digitally. The 


\section{$\underline{\text { Punish, Seduce or Persuade }}$}

evidence regarding the relevance of this attribute is unclear. Some studies state that individuals with a lower level of education are more likely to do so [63, 64, $68,84,162]$, while others conclude the opposite: individuals with higher levels of education are more likely to pirate content digitally [66, 67, 73, 78, 159]. Most studies fail to find evidence of any role that education might play $[1,19,76,82$, $89,161]$. Given this lack of conclusive evidence, education will not be considered to be an attribute that can be used to identify those individuals who are more likely to pirate content digitally.

\subsubsection{Income}

As with education, there is no clear conclusion to be drawn on the role that income plays in identifying individuals who pirate content. Although it might be tempting to assume that individuals with lower income are also those individuals who are more likely to pirate the content they desire digitally, this line of reasoning is not supported by the literature, as only a few studies have reached this conclusion [11, 91, 92], meaning that not being able to afford the content is not useful as an attribute. Some studies conclude that individuals with a higher income are in fact more likely to pirate content $[64,75,158]$. Most studies fail to find any evidence for the role of income in determining which individuals are more likely to pirate content digitally $[19,65,78,86,89,161]$. This indicates that income is not a useful attribute in determining the appropriate target population.

\subsection{The environmental features: which features seem to matter?}

The environmental features will determine whether the environment is conducive to the act of digital piracy. This conduciveness, together with the individual's propensity, will influence whether an individual has a motivation to pirate content digitally. Four environmental features are examined: the presence of temptations and provocations, the moral context and the presence of delinquent peers.

\subsubsection{The presence of temptations}

Temptations can be emerge due to the opportunities that the environment provides for the individual. One temptation that has been studied in the context of digital piracy is the ability to have access to high speed Internet. Having this access allows individuals to download large quantities of pirated content quickly and easily. For individuals who have this access, it can act as a temptation to do so. This raises the question whether or not this temptation increases the likelihood that an individual will pirate content digitally. Most studies support the assumption that this access does add to the likelihood to pirate content digitally $[56,68,93-97]$. Only one study failed to find evidence of the relationship between 


\section{How can the Behaviour of Digital Pirates be Explained?}

access to high speed Internet and digital piracy [98]. This would normally mean that this environmental feature would be useful in explaining digital piracy. It is excluded nonetheless due to the fact that access to high speed Internet is essentially a given in Western society, which is the context in which this research in undertaken. This means that there is no real variation in this temptation in dayto-day practice, meaning that it will fail to explain any changes in digital piracy. Arguably, all individuals are equally tempted by this access. Due to this consideration, it is a temptation that is not included when explaining digital piracy.

While it is conceivable that other temptations can be relevant in explaining digital piracy (such as the quality and variation of the pirated content that individuals have access to), they have not been examined by the synthesised studies on digital piracy, with the exception of the low cost of pirated content. If the digitally pirated content has to be purchased from an illegal source, it is thought that the cheaper this pirated content is, the more likely it is that the individual will pirate the content digitally, which presents the individual with a temptation. The low cost of pirated digital content could therefore be a temptation. However, no evidence is found to support this proposition. This type of temptation is thus not included in the explanation of digital piracy.

\subsubsection{The presence of provocations}

The 'counterpart' to the presence of temptations is the presence of provocations. Provocations are caused by frustrations present in the environment that the individual experiences. One provocation that emerges repeatedly in the context of digital piracy is the high cost of legal content. Several studies have demonstrated that, as the price of legal content increases, piracy becomes more likely [3, 44, 45, $95,97,100,104]$. Likewise, individuals who think that the legal content is too expensive $[56,74,88]$ or priced unfairly $[76,90,105]$ are also more likely to pirate content digitally, also supporting the assessment that the cost of content can be clear a provocation for an individual to act. Highly priced legal content is therefore a provocation that can motivate an individual to pirate the content instead of purchasing it.

\subsubsection{The moral context}

The moral context consists of three elements: 1) the moral rules that apply in the environment, 2) the enforcement of these moral rules and 3) the degree of sanctioning of these moral rules. In the context of digital piracy, the concept of moral rules concerns both formal and informal rules. The formal rules refer to the role that the law plays in establishing these moral rules. In §1.4. (supra p. 11), it 


\section{$\underline{\text { Punish, Seduce or Persuade }}$}

was made clear that copyrights serve to protect the owner's content and foster innovation. In turn, the infringement of copyright law can often be sanctioned through criminal law (\$5.2.2. infra p. 110). Many Western countries have, on paper at least, criminalized the act of copyright infringement, which can include digital piracy as defined in this research. This act of criminalization underlines the fact that most Western countries have moral rules in place. The question is whether these formal rules aid in explaining digital piracy. Following the reasoning of the SAT, it would be expected that the presence of these formal moral rules would reduce the likelihood that an individual pirates content digitally. The evidence that emerged from the examined studies is unclear however. Some studies found that the individual's knowledge of copyright law decreases the likelihood of digital piracy [3, 45], while others failed to find similar evidence $[59,106,158]$. Likewise, the evidence on whether or not individuals who agree with these laws are less likely to pirate content digitally is inconclusive. A few studies reached this conclusion $[45,153]$, while the others fail to do so $[27,86$, 89]. Collectively, this means that there is insufficient evidence to conclude that the formal part of the moral rules has an influence on digital piracy through the moral context.

The informal moral rules are reflected by the level of (dis)approval of digital piracy by peers such as friends, parents and colleagues. ${ }^{54}$ Based on the SAT, it would be expected that the approval of digital piracy makes it more likely that an individual will act in this manner, as it adds to the conduciveness of the environment, since these informal rules would then be in favour of the act of digital piracy. There is ample evidence to conclude that, when this act is approved, individuals are more likely to pirate content digitally [3,21, 106-114]. The reverse is not necessarily true: while there is some evidence to support the statement that disapproval makes individuals less likely to pirate content digitally [39, 44, 52, $115]$ and that this disapproval may make the individual more willing to purchase legal content [7], other studies have failed to find similar evidence for the role of disapproval $[15,27]$. This means that, regarding the role of the moral rules in explaining digital piracy, only the social approval of digital piracy is further considered, as it is clearly demonstrated that this influences the conduciveness of the environment.

The second and third elements of the moral context are the enforcement of the moral rules and the sanctioning thereof. The lack of enforcement or sanctioning

\footnotetext{
${ }^{54}$ Studies sometimes differ in the manner in which they look for the source of the (dis)approval of digital piracy. Some studies do not look for a specific source of this (dis)approval, often presenting it in a rather general manner $[3,21]$, while others are more specific in identifying this source, which can be parents [108], colleagues [109], (other) students [113, 114], or friends [106].
} 


\section{How can the Behaviour of Digital Pirates be Explained?}

of the formal moral rules adds to the conduciveness of the environment. An issue emerges when attempting to link this part of the SAT with the studies on digital piracy. As was made clear, the moral context separates the enforcement of the (formal) moral rules from the sanctioning of their infringement. However, most, if not all, studies on digital piracy that have examined these elements have failed to separate them. Instead, they are often discussed together in relation to the certainty and severity of the punishment. The focus in this section is thus on the sanctioning of the infringement of the formal moral rules.

The evidence is indeed quite clear that, as the punishment becomes more certain and severe, an individual is less likely to pirate content digitally [21, 27, 40, 44, $45,49,54,63,64,87,108,116-120,153,156,158,161]$. Conversely, there is little evidence to conclude that formal deterrence has no impact on digital piracy $[24,53]$. The lack of formal deterrence thus makes the environment more conducive and is an element that is useful in explaining digital piracy, especially when combined with informal moral rules approving of the act of digital piracy.

\subsubsection{The presence of deviant peers}

The fourth environmental feature focuses on the role of deviant peers. Recent additions to the SAT state that deviant behaviour becomes more likely if the individual interacts with peers that also violate social norms and laws. In the context of digital piracy, the role of pirating peers has been examined frequently. With regard to this role, the evidence is quite clear. A large body of evidence demonstrates that having friends or peers that also pirate content digitally has a direct and positive impact on the individual's likelihood to pirate content digitally himself. Associating with such individuals means that digital piracy becomes more likely $[17,18,77,79,85,108,121-129,158,163,164]$. Only one study did not find evidence for the role of deviant peers [153]. Collectively, having these peers makes the environment more conducive, adding to the explanation of digital piracy.

\subsection{The process of choice: which components seem to matter?}

As perceptions connect the individual characteristics with the environment, they form a link with the process of choice, and are thus focused upon first in this section. Perceptions precede intentions and in turn intentions precede behaviour. Those perceptions that contribute to the translation of the individual's motivation to pirate content digitally into an intention to do so will be identified in the coming sections. The roles of self-control, deliberation and neutralizations and moral habit are also examined as components of the process of choice. They also influence the translation from motivation to intention, as they determine which of the different action alternatives is selected as the appropriate way to fulfil a certain 
desire. They also aid in understanding whether an individual will act upon this motivation to pirate content digitally.

\subsubsection{Perceptions}

A variety of perceptions can be identified in the context of digital piracy: the perceptions on the individual's own characteristics, the environmental features and the possible outcomes of the act of digital piracy are the three variants of perceptions that are discussed in this section. The perceptions of the possible outcomes of the act of digital piracy are particularly relevant as they influence the choice process by weighing the pros and cons of both compliant and deviant actions.

With regard to the individual's perception of himself, one perception is examined very frequently by the studies on digital piracy: the individual's own attitude towards digital piracy. It is clear that a positive attitude towards digital piracy makes it more likely that the individual will act in this manner, $[2,9,17,28,36$ $41,46,47,49,51,53-55,57,58,60,77,78,88,105,106,114,130-134,154,156$, $157,162]$, though a few studies failed to find evidence for the role of attitude $[155,160,165]$. Simply put, if an individual perceives digital piracy in a positive way, the individual is more inclined to obtain content in this manner. ${ }^{55}$

The second group of perceptions focuses on the environment and on how it is perceived by the individual. One perception is the manner in which the individual perceives the creative industry and artists, who are the source of the desired content. Individuals can have positive and negative perceptions of this industry. However, there is little evidence available to conclude that either positive [57, $135,166]$ or negative perceptions $[19,32,161]$ have an influence on the likelihood of digital piracy. In fact, most studies that have examined the role of this kind of perception failed to find evidence of its relevance $[6,92,115,117,136]$. Thus, this perception is not used to explain digital piracy.

An additional environmental perception focuses on the way the individual perceives the content itself. Some studies examined whether the likelihood of digital piracy increases if the content itself is perceived as being highly valuable by the individual (meaning that the content is perceived as being convenient or fashionable). A few studies $[16,30,76]$ have indeed reached this conclusion but,

\footnotetext{
${ }^{55}$ There might appear to be some overlap between the individual's morality and his attitude towards the act of digital piracy. The difference here is that the first is more general as it refers to the overall morality of the individual, whereas attitude is more specific and only refers to the individual's perception of the act of digital piracy.
} 


\section{How can the Behaviour of Digital Pirates be Explained?}

given their limited volume, there is insufficient evidence available to conclude that this perception is relevant.

A third environmental perception focuses on the perceived pressure to pirate content digitally that an individual may experience. If an individual experiences this pressure, will he be more inclined to pirate content digitally? There is ample evidence that confirms that, if there is such pressure, this is indeed the case $[4,35$, $42,47,49,51,53-55,57,58,60,90,92,105,130,137,153,155-157,161,165]$. This variable is thus used to explain digital piracy. Other studies have examined the reverse: that such pressure does not influence digital piracy. There are a number of studies that find support for this assumption $[9,28,36,38,41,50,82$, 167] , but there is simply more evidence to conclude that the perceived peer pressure indeed influences the likelihood that an individual will pirate content digitally.

The final group of perceptions focuses on the act of digital piracy itself or, more specifically, the perceived outcomes of this behaviour. These can either be positive or negative. Positive outcome expectations means that an individual expects the act of digital piracy to have a positive outcome for him. It is thought that such expectations increase the likelihood of digital piracy. For certain outcome expectations, this is indeed the case. Expectations that have been found to be relevant include the expectation of saving money [59, 97, 137-140, 153, 158] learning new skills [31], better social standing [13, 19, 20, 28, 41, 97, 138], obtaining a more complete content collection $[59,153]$, simply perceiving the content itself as useful [37, 168], or enjoying the act of digital piracy $[160,165]$. There is also evidence that expected negative outcomes can reduce the likelihood of digital piracy. The most often confirmed negative outcome expectations include the expectation of being punished [20, 26, 47, 92, 132, 138, 162], expected negative outcomes for the artists or creative industry $[6,19,76,109,115,141$, $158,167]^{56}$, expected stress and regret caused by digital piracy $[4,51,120]$ or the risk that the pirated content will not function properly [167].

Specific perceptions of the individual himself (the individual's attitude), his environment (the perceived pressure to pirate content digitally) and the perceived outcomes of digital piracy (positive or negative) can all influence the process of choice and are relevant in explaining digital piracy and are therefore used in this research.

\footnotetext{
${ }^{56}$ The difference between this perception and the perception of the creative industry is that the latter perception concerns the general outlook on that industry, whereas the latter focuses on how the negative consequences of digital piracy for the wider society (the artist and the industry) are perceived. The findings indicate that there is little evidence that the general outlook on the industry matters in explaining digital piracy, but that perceived negative consequences for artists and the industry do influence whether or on an individual perceives the act of digital piracy to be a suitable way to fulfil a specific desire.
} 


\subsubsection{Self-Control}

Even if an individual has a motivation to pirate content digitally, he might still be able to resist the urge to do so if he is capable of choosing long-term over shortterm gratifications. Deviant and criminal acts are often immediately gratifying and persons with low self-control are more likely to choose the behaviour associated with this gratification when exposed to an opportunity to do so [142]. Digital piracy might be gratifying in the short term (e.g., obtaining content without having to pay for it) but it can have negative consequences for the individual in the long term (exposing himself to various anti-piracy interventions). The low self-control can make the individual more likely to act upon his desires and pirate content digitally. The individual's ability to exercise self-control can be a factor that reduces the likelihood of this behaviour. While there is some evidence that suggests that low self-control can aid in explaining digital piracy [43, 69, 77, 143], most studies have examined the role that self-control plays in inhibiting digital piracy. The evidence is clear that higher levels of self-control are negatively related to digital piracy $[17,18,59,66,85,112,120-123,126,143-148,159]$. Only a few studies failed to confirm this assumption [79, 127]. When taken together, it is apparent that a lack of self-control thus contributes to the explanation of digital piracy, as it influences the process of choice.

\subsubsection{Deliberation and neutralization}

If an individual deliberates on whether to pirate content digitally or not, he can still recognize that this behaviour is infringing in nature. Digital piracy is often seen as not being immoral, but digital pirates often do acknowledge that this act is illegal (§1.6. supra p. 14)). This might prevent some individuals from pirating content digitally, as they might be inhibited from this act purely by the fact that the behaviour is illegal. Still, in order to fulfil his desire to obtain and enjoy the content, he might still deliberate on acquiring it via digital piracy, as he may be unwilling or unable to purchase it in a legal manner yet wants to fulfil his desire nonetheless. This means that the individual may need to neutralize his deviant behaviour in order to lessen the effectiveness of the formal and informal social controls that he is exposed to while deliberating on whether or not to pirate content digitally. Sykes and Matza (1957) have identified various 'techniques' of neutralization that aid in understanding why individuals can act deviant. These techniques imply that individuals who are capable of neutralizing their acts (more) successfully are more likely to act in this manner. In fact, these techniques of neutralization allow individuals to go on a 'moral holiday'. During such a moral holiday, individuals tend to suspend conventional norms (Eindstadter \& Henry, 2006; Marcum et al., 2011; Matza, 1964). It has also been suggested that 


\section{How can the Behaviour of Digital Pirates be Explained?}

individuals can 'drift' from their moral constraints. Such a process of drift can enable deviant or even criminal acts (Hindelang, 1970). This process reveals that the usage of the techniques of neutralization can influence an individual's deliberation on whether or not to act deviant or criminal.

There is evidence that neutralizations are used in the context of digital piracy [1, $24,61,100,140,149]$. The most frequently applied neutralizations are the 'denial of injury', 'denial of the victim' and 'the claim of normalcy'. ${ }^{57}$ However, it is more interesting whether the use of these neutralizations makes digital piracy more likely. There are studies that confirm the relevance of these neutralizations $[14,50,94,112,150,151,167]$. Furthermore, the usage of neutralization techniques results in more positive attitudes towards digital piracy [29, 152], explain past digital piracy $[79,127]$ and predict future digital piracy [81]. Only one study [59] failed to find evidence of the role of neutralizations. Neutralizations can thus be used to explain digital piracy, as they enable individuals to justify or neutralize their own acts of digital piracy and influence their deliberation on whether to pirate content or not.

\subsubsection{Habit}

An act of digital piracy can also be the result of an individual's habitual behaviour, as was discussed in §4.1.3. (supra p. 82). The individual therefore does not deliberate on his behaviour and does not consciously choose between the various action alternatives available to him. This means that the individual does not even consider an alternative way to fulfil his desire other than to pirate the content digitally. Habits can be formed if an individual repeatedly and successfully pirates content digitally. Past digital piracy can thus be important in explaining digital piracy. Some studies indicate that past piracy indeed makes future piracy more likely $[37,71,93,98,167]$ This is based on the observation that past piracy positively influences both the attitude [12, 36, 41, 42, 47, 94, 119, 133, 139] towards piracy and the intention $[4,6,36,132]$ to pirate content (again). Only one study [9] failed to find evidence of the role of past piracy. Overall, the role of habitual or past piracy is therefore validated. It presents a separate, nondeliberative manner through which individuals can pirate content digitally, meaning that the individual pirates content in an automatic manner and does not 'weigh' his various options to fulfil his desires.

\footnotetext{
${ }^{57}$ The neutralization 'denial of injury' means that the individual argues that no harm has been done at all ('I would not have purchased the content legally anyway'); while the 'denial of the victim' neutralization argues that there is no victim ('The music industry makes plenty of money anyway'). Finally, the 'claim of normalcy' neutralization states that the behaviour is acceptable as more individuals engage in the behaviour in question ('Everybody is pirating content anyway').
} 


\subsection{Conclusion}

This chapter answered the question 'how can the behaviour of digital pirates be explained?' by synthesising the relevant academic literature through the lens of the SAT. The SAT allowed for the clustering of the findings of these studies into an integrative approach that includes the individual, the environment and the process of choice. The examined literature sought to identify those characteristics, features and variables that aid in explaining digital piracy, as well as the direction of their relationship to digital piracy.

It is clear that the studies on digital piracy examined are supportive of the three characteristics proposed by the SAT: desires, morality and beliefs. More specifically, an individual who has a desire to obtain and enjoy content, who understands digital piracy to be a morally acceptable way of fulfilling this desire and believes himself to be capable of fulfilling this desire successfully in this manner can be said to have a propensity towards digital piracy.

Identifying the attributes was necessary in order to determine the target population and, in a later chapter, to determine whether the anti-piracy interventions reach the appropriate population. The target population is likely to consist of individuals who are male, younger and have more experience with computers. Insufficient evidence was found to conclude that education and income are suitable as attributes.

Four environmental features were examined in this chapter: the presence of temptations and frustrations, the moral context and the presence of pirating peers. When referring to the temptations, access to high-speed Internet could be seen as a temptation based on the studies examined. However, this feature is not used to determine the conduciveness of the environment, as access to (high speed) Internet is a given factor in Western society. A clear provocation that was identified was the (high) cost of legal content. If legal content is expensive, this feature contributes to the likelihood of digital piracy as it may provoke an individual to fulfil his desire through the act of digital piracy. The moral context contributes to the conduciveness of the environment in multiple ways. While there is insufficient evidence that the more formal aspects of the applicable moral rules add to this conduciveness, it is clear that the informal moral rules are relevant. If digital piracy is socially approved, digital piracy becomes more likely. Although the studies examined did not study enforcement and the sanctioning of digital piracy in a manner that was fully in line with the notions of the SAT, it is clear that the presence or lack of enforcement actions and sanctioning measures has an influence on the conduciveness of the environment. A final relevant feature is the 


\section{How can the Behaviour of Digital Pirates be Explained?}

presence of pirating peers. When these peers are present in the individual's environment, digital piracy becomes more likely.

Together with the individual characteristics, it is possible to state which individuals are likely to be motivated to pirate content digitally and in which environment. This is likely when the individual has a desire to obtain and enjoy content, does not see digital piracy as a moral issue and when he believes he is capable of fulfilling this desire through the act of digital piracy. If the environment is conducive, meaning that the cost of legal content is high, digital piracy is socially approved, this act is not punished and when the individual's peers are also themselves pirating content digitally, both clusters come together and result in an individual that is certainly motivated to pirate content digitally. But whether this motivation will translate into intention depends on his process of choice.

The analysis of the process of choice allowed for an assessment how an individual's motivation is translated into his intention to pirate content digitally. Perceptions are an important part of this process. Various perceptions were identified. These perceptions focused on the individual himself, his environment or the possible expected outcomes of the act of digital piracy. An individual's positive attitude towards digital piracy, perceived peer pressure and both perceived positive and a lack of negative expected outcomes of digital piracy are all relevant in understanding how motivation translates into intention. This is due to the fact that they influence which action alternative (§4.1.1. (supra p. 79)) is perceived as the most suitable way to fulfil the desire to obtain and enjoy content. Other components of the process of choice determine whether the perceptions are followed through. A lack of self-control and the ability to neutralize one's behaviour also add to the formation of this intention. Habit are also relevant. Through them, an individual can, almost automatically, opt to pirate content digitally without having to deliberate on this behaviour.

When the findings are taken together, it is clear that evidence has been found for the relevance of most of the variables proposed by the SAT. Figure 4.1 illustrates how the individual comes to the act of digital piracy. 
Figure 4.1: Digital piracy through the lens of the SAT

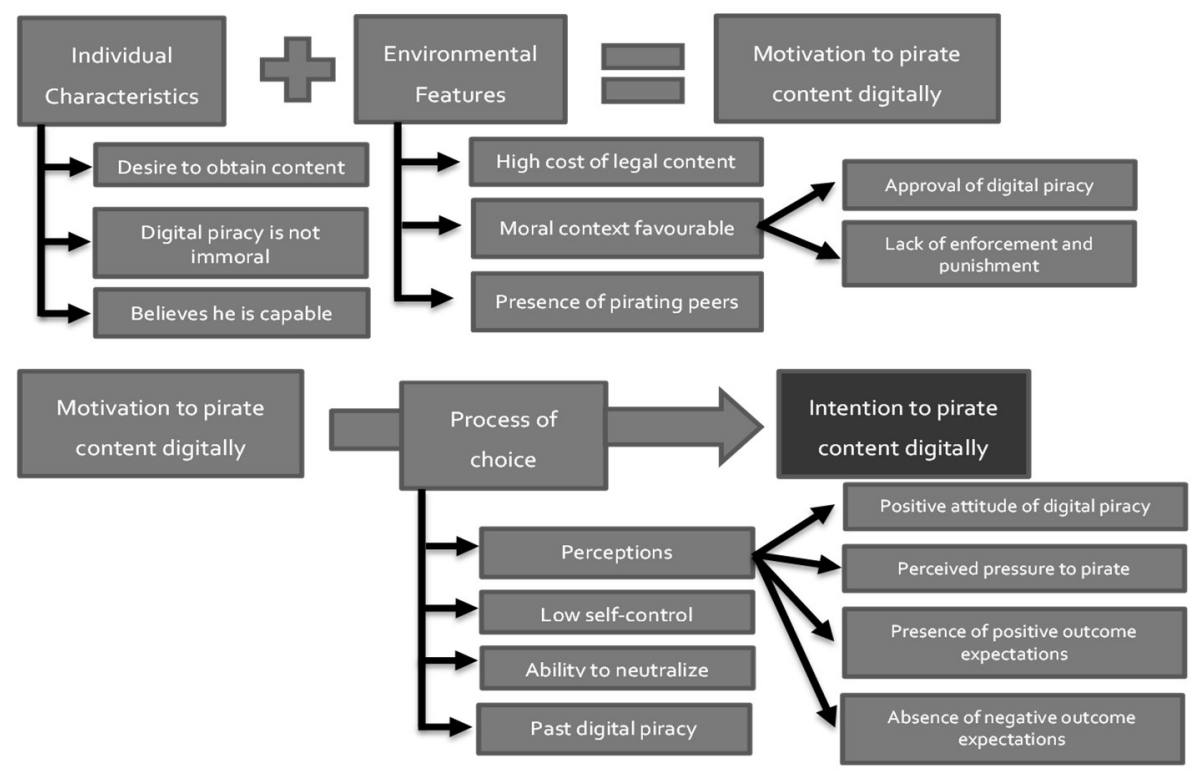

If the individual's characteristics make him more prone to act in this manner, and if the environment is conducive to this act, he can be said to possess a motivation to pirate content. The process of choice will determine whether this motivation is translated into intention (and possibly action). When characteristics, features or components are absent, the likelihood that an individual will pirate content digitally changes. Why individuals pirate content digitally can thus be answered by understanding that: 1) an individual needs to have a propensity for digital piracy, 2) the environment needs to be sufficiently conducive to the act of digital piracy and 3) the process of choice needs to be favourable for the decision to pirate content digitally. Each of these three clusters is dependent on the variables that populate them. Therefore, 'how can the behaviour of digital pirates be explained?' is dependent on these three clusters and the presence or absence of the variables that were found during the review process.

This exercise shows that, although the SAT has not been empirically tested in this research, there appear to be merits to clustering the various findings of the realist synthesis through the lens of this theory. These merits include the fact that a broader range of variables, both individual and situational ones, could be included, especially when compared to theories that are more focused or narrow in their explanation of (deviant) behaviour. 


\section{How can the Behaviour of Digital Pirates be Explained?}

The chapter also uncovered a number of attributes that can be used to identify those individuals who are more likely to pirate content digitally: younger males that have more experience with computers are identified via these attributes as the target population. Creative industries can focus on such individuals as the target population and attempt to reach them via anti-piracy interventions. If these individuals are reached, it becomes more likely that the appropriate target population feels addressed by the intervention, increasing its chances for success. This also aids in using limited resources in the most efficient manner (Zhang, Cohen, \& O'Conner, 2014). Failure to reach the appropriate target population conflicts with the goal of reducing digital piracy, as the individuals who are the possible recipients of such a flawed intervention are not those individuals who are engaged in the behaviour (en masse).

This chapter also exposes which aspects of digital piracy the anti-piracy interventions can focus on in order to contribute to reductions in this behaviour. The individual's propensity, the conduciveness of the environment and his process of choice can possibly be modified via the anti-piracy interventions. For example, when focusing on the environmental cluster, it is apparent that a lack of deterrent measures contributes to the conduciveness of the environment. By introducing more deterrent measures (by either making the enforcement more likely or the sanctions more severe) into a specific environment, the environment can become less conducive to the act of digital piracy. The other identified characteristics, features or variables can likewise be modified by the anti-piracy interventions. It is this modification that will allow the interventions and their associated mechanisms to contribute to reductions in digital piracy.

To determine whether the anti-piracy interventions indeed attempt and potentially succeed in this modification, it is first important to know which interventions are used and how they attempt to change this behaviour. In addition to providing an overview of the various anti-piracy interventions, the next chapter will also discuss the applied mechanisms and indicate whether or not the interventions are capable of reaching and addressing those individuals who possess the attributes identified in this chapter. 



\section{How to Discourage Digital Pirates: Focusing on Anti-Piracy Interventions and Their Mechanisms}

Various anti-piracy interventions have been implemented by the creative industries and governments in order to discourage digital pirates. When examining the variety of anti-piracy interventions - on the basis of the primary mechanism that each intervention uses - three different categories can be distinguished. The mechanisms 1) deter digital pirates, 2) incentivize individuals to obtain content in a legal manner, or 3) persuade users that digital piracy is immoral, harmful or wrong. Each anti-piracy intervention uses at least one of these mechanisms. This allowed for a categorization of the various anti-piracy interventions into 'Sticks (deterrence), Carrots (incentivization) and Sermons (persuasion)' (Vedung, 1998). This is a categorization that flows from the field of evaluation studies, but 'Sticks' and 'Carrots' are concepts that are also well known in the field of law and economics (De Geest \& Dari-Mattiacci, 2012).

This categorization provides a neat and clear-cut division between the various anti-piracy interventions in theory, but in reality many of these interventions will be of a more hybrid character. For instance, most stick-based interventions will also possess aspects of the sermon-based ones, as they also try to inform, persuade or convince individuals of the threat of punishment. Other interventions try to incentivize users by informing them of the variety of ways through which content can be acquired legally (Center for Copyright Information, 2014), combined with punishing those who continue to pirate content digitally. In order to still categorize and analyse the interventions in a structured manner, the focus was placed on the mechanism through which these interventions primarily try to reduce digital piracy. The chapter thus discusses and reviews the various ways through which these three mechanisms are used in the form of numerous anti-piracy interventions.

By examining the interventions on the basis of their mechanisms, the question which interventions, both from governmental and other (public and private) organisations, are currently applied in the context of digital piracy?' will be answered in a more structured way. As a prelude to this examination, §5.1. (infra p. 104) illustrates some of the ways through which the creative industries and governments have used the identified mechanisms to shape anti-piracy interventions. Following this prelude, the categories of anti-piracy interventions are examined and discussed in turn. This will reveal a number of types of antipiracy interventions through which each mechanism is applied in practice. Therefore, each intervention found is positioned based on the mechanism used. 


\section{$\underline{\text { Punish, Seduce or Persuade }}$}

Each type will be explored in detail, with the purpose of not just depicting them but also understanding their aims and objectives, as well as the tools used to accomplish these interventions. Text boxes are at times used to focus on the implementation of a specific anti-piracy intervention, which further illustrates how such an intervention can function in practice.

Beyond describing the interventions and illustrating how they attempt to cause a reduction in digital piracy (or contribute to this), this chapter also determines which of the identified individual attributes are focused on by the various interventions in order to assess whether they reach the target population. For an anti-piracy intervention to be able to influence the behaviour of digital pirates, it is also necessary that the intervention reaches the target population (Ingram \& Schneider, 1991; Leeuw \& Bogaerts, 2009). Whether the anti-piracy interventions succeed in doing so is reflected upon in this chapter. The previous chapter identified three attributes that can be used to identify the target population: individuals who are male, younger and have more experience with computers are more likely to pirate content digitally. If this population can be reached by the various anti-piracy interventions, a first step towards determining whether or not anti-piracy interventions are capable of contributing to reductions in digital piracy is made. Beyond determining whether the interventions can reach the target population, a second matter that is reflected on is whether or not the target population feels addressed by it. This is important, since a reached target population does not automatically mean that they feel addressed by it, which is supports the functioning of the anti-piracy intervention.

\subsection{Some examples of anti-piracy interventions}

In order to sketch the general outlines of each category of anti-piracy interventions and how the three identified mechanisms are applied in practice, this section presents some concrete examples of anti-piracy interventions.

Figure 5.1: FBI anti-piracy warning seal (FBI, The first mechanism, used in stick-based n.b.)

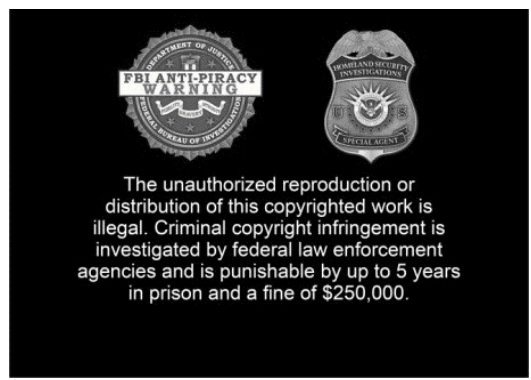
interventions, is to deter individuals from pirating content. By making it more likely that an act of digital piracy is punished more certainly or severely, individuals considering pirating digital content might refrain from doing so. This category of interventions has been used extensively in the past, despite noticeable criticism (Alexander, 2007; Bitton, 2012; Moohr, 
How to Discourage Digital Pirates: Focusing on Anti-Piracy Interventions and Their Mechanisms

2003; Yar, 2008) on their effectiveness or the consequences for the (potential) digital pirates. The threat of civil law suits and criminal law-based interventions have been used for some time now, especially in the USA. More recently, there has been a shift towards the so-called 'graduated response schemes' (also known as the three strikes rule). §1.6. (supra p. 14) already briefly discussed this intervention. This intervention is placed in the stick-based category due to the fact that subscribers can be penalized following their repeated acts of digital piracy. France, the UK, Ireland, New Zealand, the USA, and Taiwan all use variations of the graduated response scheme.

A second category of anti-piracy interventions attempts to change behaviour by using a mechanism that makes the legal content more attractive, which is done by offering incentives. These efforts originate from the creative industries and belong to the 'carrot' category. For instance, during the launch of the iPhone 6 , the band ' $\mathrm{U} 2$ ', in collaboration with Apple, made their new album available for free on iTunes (Williams, 2014). Apple did not only want to reward current iTunes users but also Figure 5.2: Announcement of a free $\mathrm{U} 2$ album (Apple, 2014) wanted to tempt individuals who did not yet use this service by offering them free legal content. Apple hoped that through this incentive, new users would find their way towards this platform and current users would continue to use it. ${ }^{58}$ Incentives are widely applied as anti-piracy interventions and can be found across many platforms, in most countries and in various forms and shapes. For instance, there is a wide range of digital distribution channels (such as Steam (Valve, n.d.), Origin (Electronic Arts, n.d.), Spotify (Spotify, n.d.-b), or iTunes (Apple, n.d.)) which allow individuals quicker and easier access to a wide range of content, often offering content at reduced prices.

\footnotetext{
${ }^{58}$ Ironically, this action was met with significant negative backlash. iTunes and iPhone users were less than thrilled to find this album installed on their iTunes without their permission (Sherwin, 2014).
} 


\section{$\underline{\text { Punish, Seduce or Persuade }}$}

The third category uses persuasion as a mechanism. These interventions persuade, educate or attempt to inform individuals who digital piracy is immoral, illegal, harmful, or wrong or that it is simply better to obtain legal content. Most of these interventions take the form of public information and awareness campaigns. A well-known example of this type of approach was the 'Piracy, it's a crime' campaign. Here, digital piracy was compared to actual crimes, such as stealing a purse or a car (MPAA, 2005). In this way, the campaign hoped to dissuade individuals from pirating content digitally. Other types of campaigns stress that digital piracy is not a victimless act and that it results in the loss of jobs and income, harming society. This informs pirates on the consequences of their behaviour and illustrates where these consequences are felt in society. Yet again other efforts portray that purchasing content legally is the 'right thing to do', as seen in the UK, where Blu-Rays and DVDs are accompanied with a 'thank you' bumper. The individual is thanked for the purchase of the product and it is stated that this supports the local entertainment industry, potentially reinforcing this behaviour.

Figure 5.3: Blu-Ray 'Thank You' bumper (Universal, n.d.)

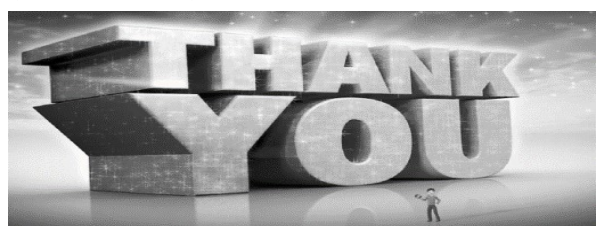

Thanks to this prelude, it is clear that there exists a multitude of different antipiracy interventions. The aim of the main part of this chapter is to explore these various interventions in depth.

\subsection{Stick-based interventions: an exploration}

Stick-based anti-piracy interventions attempt to influence behaviour by deterring individuals. In other words, such interventions require a payment by the individual if the individual has violated the law (De Geest \& Dari-Mattiacci, 2012). This deterrence is enabled via the threat of punishment and through the punishment itself (Paternoster, 2010). Deterrence, in the context of this research, refers to both aspects. The presence of deterrent measures influences the individual's decision to act in a deviant manner as the environment is no longer as conducive to this act. This is due to the fact that the moral context has changed in a way that it is no longer favourable to the act of digital piracy (\$4.4.3. (supra p. 91)).

Stick-based interventions pressure individuals to change their behaviour. Not changing one's behaviour exposes the individual to (the threat of) punishment. The stick can also have a symbolic function, reminding individuals of the applicable rules and norms in society (Grabosky, 1995), further adding to their potential influence on behaviour. These effects do not necessarily have to be 
How to Discourage Digital Pirates: Focusing on Anti-Piracy Interventions and Their Mechanisms

triggered by a formal or legal response. Instead, extra-legal consequences, such as embarrassment or shame, can also trigger a deterrent effect (Nagin \& Pogarsky, 2001). In the context of digital piracy, however, deterrence will typically be of a formal nature, as none of the interventions found and examined confronted the digital pirate with a threat of informal punishment. ${ }^{59}$

Four types of deterrence-based interventions are identified in this research: 1) civil lawsuits, 2) enforcement through the criminal law, 3) the graduated response, and 4) various technological measures. ${ }^{60}$ The first three have a legal basis, while the latter is a measure that copyright owners can directly implement themselves.

Of the three categories of interventions discussed in this chapter, the stick-based interventions are most often reliant on legal instruments, frameworks or treaties. Treaties, such as the Universal Copyright Convention, ${ }^{61}$ the World Intellectual Property Organization Copyright Treaty ${ }^{62}$ and the Agreement on Trade-Related Aspects of Intellectual Property Rights ${ }^{63}$ all provide a legal basis for stick-based interventions and sometimes even require such measures to be taken by the signatory parties. The European Community Directive on Copyright in the Information Society (InfoSoc Directive, 2001/29/EC) ${ }^{64}$ and the Intellectual Property Rights Enforcement Directive (IPRED, 2004/48/EC) ${ }^{65}$ likewise provide a basis for stick-based anti-piracy interventions for EU Member States. The

${ }^{59}$ The reason that 'naming and shaming' has not been used extensively in the context of digital piracy is the fact that the pirates and their peers are likely to be immune to this shame. Simply put, outing an individual as a digital pirate is not likely to have a shaming effect, as this act is often not considered immoral (see $§ 1.5$. (supra p. 13)). One instance of 'naming and shaming' in the context of digital piracy has been found however. A developer of a smart phone Twitter application programmed this application in such a manner that pirated copies automatically insert an admission in the text field (Ingraham, 2013).

${ }^{60}$ Some other types of stick-based anti-piracy interventions can be imagined in theory but are rarely used in practice. This includes the pillory, which refers to the (digital) shaming of individuals who are caught committing minor crimes or acts of deviance (Hess \& Waller, 2014). However, such an approach is rarely (see the previous footnote) used in the context of digital piracy. Hence, this type of stick-based intervention is not used in this research.

${ }^{61}$ Article X: 'Each State party to this Convention undertakes to adopt, in accordance with its Constitution, such measures as are necessary to ensure the application of this Convention.'

${ }^{62}$ Article 14: 'Contracting Parties shall ensure that enforcement procedures are available under their law so as to permit effective action against any act of infringement of rights covered by this Treaty, including expeditious remedies to prevent infringements and remedies which constitute a deterrent to further infringements.'

${ }^{63}$ Article 41: 'Members shall ensure that enforcement procedures as specified in this Part are available under their law so as to permit effective action against any act of infringement of intellectual property rights covered by this Agreement, including expeditious remedies to prevent infringements and remedies which constitute a deterrent to further infringements. [...]'

${ }^{64}$ Member States are obliged to provide legal protection against circumvention by end-users of any effective technological measures (article 6). Member States provide for appropriate sanctions and remedies against copyright infringements. These sanctions should be effective, proportionate and dissuasive (article 8 ) (Svensson \& Larsson, 2012).

${ }^{65}$ The IPRED proscribes administrative and civil measures for tackling piracy but criminal sanctions can be considered as a means of ensuring the enforcement of intellectual property rights (article 16). 


\section{$\underline{\text { Punish, Seduce or Persuade }}$}

various Member States or signatory parties have applied these legal bases in different ways, resulting in some variety of stick-based anti-piracy interventions, as the scope and exact sanctions applied vary per jurisdiction. In contrast, the technological measures make it more difficult to pirate content digitally and force the digital pirate to spend more of his resources in order to pirate successfully (Gopal \& Sanders, 1997). ${ }^{66}$ This can make the act of digital piracy less likely as the individual is less willing to expend these extra resources, resulting in the individual being deterred from this act.

These four types of interventions are used across the globe and often side-by-side. For example, the USA applies strategies based on criminal sanctions and civil suits, as well as a recently implemented Copyright Alert System (or CAS, a specific variant of the graduated response). Technological interventions are often universal, with their application being dependent on the content itself rather than a jurisdiction. The following sections discuss these types of stick-based interventions in more detail, with specific examples given to make the overview more concrete.

\subsubsection{Civil lawsuits}

The first type of stick-based intervention is the enforcement of copyrights through the civil law. Copyright owners use civil law suits to protect their copyrighted content (Mousley, 2003). Civil suits have been used extensively in the USA. Particularly the RIAA and the MPAA (Motion Picture Association of America) have sued a large number of digital pirates, with between 35,000 (Jeong \& Khouja, 2013) and 250,000 (DeBriyn, 2012) individuals having being the subject of such suits. Non-commercial digital pirates were, and still are, targeted by these efforts (Yim, 2013). In the USA, this has led to damages of up to US\$ 3 million being awarded in an individual case (Sinha \& Mandel, 2008). Most law suits however have been settled for an average of US\$ 3,000 (Fivelsdal, 2005). These individuals have sometimes only shared a few CDs worth of music (Yim, 2013). The SPA (Software Publishers Association) has also taken similar legal actions, both against individuals and organizations (Gopal \& Sanders, 1997). Text Box 5.1 further clarifies the manner through which civil law is used as an enforcement mechanism in the USA.

${ }^{66}$ These technical interventions can be seen as being similar to house owners who put up fences or install locks in order to limit trespassing and burglary (Buccafuso \& Masur, 2013). 
How to Discourage Digital Pirates: Focusing on Anti-Piracy Interventions and Their Mechanisms

Text Box 5.1: The usage of the civil law: a US example

The United States Code allows for significant civil sanctions and remedies when dealing with copyright infringements, which includes digital piracy. The digital pirate is liable for either the actual or statutory damages. The actual damages are difficult to establish however (as seen in the Chapter 3). Instead of actual damages, the copyright owner can elect to recover statutory damages, ranging from a minimum of $\$ 750$ up to $\$ 30,000$ per work. This is increased to $\$ 150,000$ in the case of a wilful infringement or lowered to $\$ 200$ when dealing with a negligent infringer (Section 17 \$504 USC). Mass copyright infringement lawsuits (which are known as 'John Doe' lawsuits) are used to sue a large number of digital pirates. The individual, when confronted with the suit, has a choice between settling and going to court. In practice, settlements are often the goal of using the suits for the copyright holders (Karunaratne, 2012). The strategy of copyright owners is to demand extraordinary damages in court, which more or less forces individuals to agree to settle for a substantially lower price, as they cannot afford to pay the damages if a jury or judge were to rule in favour of the copyright owner (DeBriyn, 2012; Owen, 2012).

The damages that pirates have to pay can indeed be substantial. For example, a woman in Minnesota had to pay \$220,000 in damages for sharing 24 music files. Likewise, a student was ordered to pay over \$675,000 in damages for sharing 30 music files. Both individuals were offered a settlement, which entailed significantly lower damages (Holpuch, 2012) (Holpuch, 2012). These mass litigations tend to come in phases. In 2003 and 2008, the first and second phases took place.

The use of civil lawsuits is increasingly common in Europe as well. In Germany, law firms have followed a similar strategy, earning these firms the label of 'copyright trolls' (DeBriyn, 2012; Sag, 2015). These firms specialize in obtaining settlements from digital pirates and making digital piracy profitable for content owners (Schmitz \& Ries, 2012). Such strategies are most frequently used in the context of pornography piracy, as individuals who pirate such content often do not want this fact being made public. Digital pirates might also not be able or willing to hire an attorney, as the cost of legal representation is often greater than the cost to settle (DeBriyn, 2012), again pushing the individual to accept these settlement offers. 'Copyright trolling' has recently become a popular strategy in the USA, possibly driven by a desire to monetize copyright infringement rather than to deter instances of digital piracy (Sag, 2015).

The threshold for such legal actions is quite low in certain countries. For example, in Germany, uploading one film or music album is deemed to be a sufficiently serious infringement to allow for further legal action (Schmitz \& Ries, 2012). Given the fact that many digital pirates tend to upload pirated content while simultaneously downloading when they use P2P-based network (being one of the main methods to pirate content digitally (see §1.2. (supra p. 6)), a large number of individuals are potentially exposed to such actions, especially since the EU IPRED allows content owners to request ISPs to disclose the identity of the individuals behind a specific IP address. This makes it easier for content owners to gather evidence and sue offenders in civil court (Adermon \& Liang, 2014). Similar to Germany, creative industries in Italy (Frosio, 2011), Finland (Jones, 2014) and the UK (TorrentFreak, 2015a) have started to use such strategies. 


\subsubsection{Enforcement through the criminal law}

Copyrights are also enforced through the criminal law. Advocates of such an enforcement style suggest that civil remedies, even with punitive damages (possible in some jurisdictions), do not deter pirates sufficiently and that criminal law allows for a greater degree of deterrence (Buccafuso \& Masur, 2013). Due in part to lobbying efforts by the creative industries, the enforcement of copyrights through criminal law has become a preferred intervention type when others, such as civil sanctions, are either deemed to be too costly or ineffective. This has led to an expansion of the scope of criminal law enforcement (Buccafuso \& Masur, 2013). In the USA, even infringement without the aim of monetary gain can be investigated by the FBI and can be punished with up to five years in prison or a fine of \$250,000 (Mirghani, 2011). Although this style of enforcement seems to be a very 'American' policy choice, criminal sanctions are also possible in some European countries, such as Sweden (Svensson \& Larsson, 2012), Germany and Austria (Frosio, 2011). Enforcement via the IPRED can have a greater deterrent effect, as it simplifies the prosecution of digital pirates (Adermon \& Liang, 2014). This means that being criminally sanctioned for acts of digital piracy is not just a theoretical option in parts of Europe (Larsson et al., 2012). Similar developments can be observed in Hong Kong, where the criminalization and conviction of individual pirates clearly demonstrates the use of this intervention type (Fung \& Lakhani, 2013). Alternative sanctions, such as prohibitions or limitations in the use of computers or tablets, are also suggested as measures meant to deter digital pirates. These sanctions are believed to 'incapacitate' the digital pirate for a time (Buccafuso \& Masur, 2013). Similar to individuals who get an ignition-interlock device for repeated drunken driving, reoffending digital pirates could be sanctioned with a 'downloading lock' on their computer. Text Box 5.2 clearly illustrates the manner through which criminal law is used in Sweden to combat digital piracy. 
How to Discourage Digital Pirates: Focusing on Anti-Piracy Interventions and Their Mechanisms

Text Box 5.2: The use of the criminal law: a Swedish example

Since the implementation of the IPRED, Swedish criminal law has been used in cases of end-user digital piracy. Although Swedish law had previously indicated that digital piracy was illegal, the law did not provide the tools to actually enforce this ban (Svensson \& Larsson, 2012). The IPRED has provided these tools. Individual digital pirates now run the risk of imprisonment in the more serious instances of digital piracy. The chance of being caught and punished has increased. More resources have become available for public prosecutors and police to deal with instances of digital piracy. A dedicated office has been created to investigate and prosecute instances of digital piracy (Larsson, Svensson, \& de Kaminski, 2012). The sanctions range from imprisonment of up to two years or a fine (article 53 of the Act on Copyright in Literary and Artistic Works of 1960). This does not mean that every digital pirate is at risk of being prosecuted and punished. Swedish courts will only order an ISP to provide information which can be used to identify infringers when the individual has uploaded materials or has downloaded a large amount of such materials (Adermon \& Liang, 2010). Given the manner in which most P2P-networks function, it is still likely that a significant segment of digital pirates upload materials and/or download a large amount of content, as the following example illustrates.

In 2010, an individual was caught sharing 57 movies through uTorrent. In both the first and second instance, he was found guilty of this act and given a fine (€900 in first instance, €1,200 in second instance). The public prosecutor had requested a prison sentence in both instances (TorrentFreak, 2013). Likewise, a man was fined approximately $€ 1,500$ in 2011 for sharing 44 music tracks (TorrentFreak, 2011b). Although fines are the preferred enforcement tool, other sanctions are used as well. For example, a Swede who had shared 517 movies was handed a suspended jail sentence and ordered to serve 160 hours of community service (Gibbs, 2013). Perhaps even more severe are the possible sanctions that a fifteen-year-old boy faced. He had been caught downloading and sharing 24 movies, for which he could receive a prison sentence of up to two years (TorrentFreak, 2011a).

\subsubsection{The graduated response scheme}

A third way to use the deterrent mechanism is by implementing a so-called graduated response scheme. Here, repeated instances of digital piracy result in the application of various warnings and sanctions, such as fines, Internet disconnection or bandwidth throttling. This intervention is based on both the monitoring and sanctioning of undesired behaviour. Although the approach itself is not entirely new (universities in the USA have used a similar system for some time now (Meyer, 2012)), it is a new addition to national copyright regimes. The graduated response focuses more on repeat infringements than on cases of incidental digital piracy (Bridy, 2012), meaning that more frequent digital pirates are more at risk of being sanctioned via this type of intervention. Graduated response schemes all follow a similar process following the detection of infringing behaviour. The ISPs or governmental agency ${ }^{67}$ notify subscribers of the detection of their act of digital piracy. After repeated warnings, various countermeasures are taken if the subscriber does not change his behaviour. Limitation of the bandwidth speed and service suspension are among the two most commonly used

${ }^{67}$ This will differ per jurisdiction. 
measures (Garstka, 2012), although some countries opt for a fine instead. The basis for these schemes is found in specific laws, such as the French HADOPI law and the UK Digital Economy Act 2010 or in civil agreements, such as the agreement on which the USA-based CAS is based (Quist, 2010; Yim, 2013). These private agreements are more flexible and can quickly be adjusted if necessary (Owen, 2012). Not all ISPs in a country are always part of these private agreements, possibly resulting in safe havens for digital pirates. Clear objectives are given to the graduated response schemes: the Digital Economy Act, for instance, is supposed to reduce digital piracy by $70 \%$ to $80 \%$ (Garstka, 2012). The goal of most of these responses is to reduce digital piracy to an acceptable level and to ensure adequate and reasonable compensation for the copyright holders (Owen, 2012; Yu, 2010).

In addition to France, the USA and the UK, countries such as New Zealand, South Korea and Taiwan have also implemented (or are in the process implementing) graduated response schemes. Other countries are likewise considering the implementation of this type of anti-piracy intervention (Meyer, 2012; Sinclair \& Green, 2016). At the same time, the usage of the graduated response in France has undergone some changes in the past years and lost some support. Of particular note is the fact that Internet disconnection is now replaced by a fine. The high cost of the initial program, doubts on its effectiveness and the controversial nature of the initial Internet disconnection are reasons given for this change (Datoo, 2013). These changes underline that the graduated response is still undergoing development. Text Box 5.3 provides additional insights into the French implementation of the graduated response scheme (HADOPI), as well as the changes to the interventions following the implementation. 
How to Discourage Digital Pirates: Focusing on Anti-Piracy Interventions and Their Mechanisms

Text Box 5.3: The graduated response: a French example

The basis for the French graduated response is found in the HADOPI-law (Haute Autorite pour la Diffusion des Oeuvres et la Protection des droits sur Internet). Content owners initiate the process by filing a report of infringement by a subscriber to the HADOPI authority, which is charged with the enforcement of the graduated response. After identifying the infringer, the authority will send a series of warning notices, each becoming stricter if the individual infringes again after these warnings. After the third registered infringement, the subscriber would be disconnected from the Internet (Ranaivoson \& Lorrain, 2012). Following the implementation of the intervention, a debate arose on the proportionality and effectiveness of this specific measure and, as a consequence of this debate, it is no longer used in practice. The Constitutional Council of France even found that part of the intervention to be unconstitutional. However, fines of from $€ 60$ up to $€ 1,500$ are still possible following repeat infringement (Geiger, 2011). Subscribers who failed or neglected to secure their internet access also initially risked a suspension of their Internet connection of up to one month (Meyer \& van Audenhove, 2010). A year after implementation, the HADOPI agency reported that it had sent up 750,000 first notices (Bridy, 2012). By December 2011, over 800,000 warnings had been sent by the administrative agency. Only 165 subscribers had reached the third stage, but there were no cases in which a user was disconnected from the Internet. As such, while a large number of warnings had been sent, very few cases reached the final stage of the HADOPI-scheme. Four years after the first implementation, almost 2 million first warnings and 186,000 second warnings had been sent to users (Dejean \& Suire, 2014)

As access to the Internet has become, for most individuals, a basic need, disconnecting users could be an effective deterrent (Haber, 2010). The current need for Internet access also underlines why some critics perceive graduated response schemes to be controversial, since the impact on the individual's personal life can be severe. ISPs are essentially charged with increasing the perceived probability of being sanctioned and often execute the punishment themselves (Ranaivoson \& Lorrain, 2012). Copyright owners therefore do not have to enforce the copyrights themselves, as opposed to instances where they use civil law suits, making such interventions attractive to them (Giblin, 2014). However, most graduated responses only focus on digital piracy through P2Pnetworks, such as BitTorrents (Bridy, 2012).

Some argue that the graduated response scheme is primarily pedagogic in nature (Ranaivoson \& Lorrain, 2012), but Geiger (2011) states that such an educational label is merely presented to make the graduated response scheme more acceptable to the public. The pedagogic nature would be found in the fact that the early warnings are informative rather than punitive. These early warnings stress that digital piracy is illegal, that there are various legal methods to obtain the content and that continued infringement will result in further warnings or sanctions.

Should a subscriber persist in his behaviour, more deterrent measures are taken, although the exact measure will depend on the ISP and the specific graduated response scheme. In the USA, for example, Optimum Online can suspend (or even terminate) an account after continued infringement (Optimum, n.d.), while 


\section{$\underline{\text { Punish, Seduce or Persuade }}$}

Verizon reduces Internet speeds to a mere 256kbs for up to three days (Verizon, n.d.). An Internet disconnection is the most severe measure possible under most graduated responses, although not all variants apply it (Bridy, 2012; Garstka, 2012). Some, like the French HADOPI-scheme, now use fines instead (Storch, 2013; Yim, 2013) although it originally used an Internet disconnection.

The graduated response scheme is a type of intervention with inherent limitations or drawbacks. IP addresses can be faked or masked, which can result in the wrong subscriber receiving the warning or no one receiving a warning at all. At the same time, entire households may be sanctioned for the behaviour of one of its members. Also, not all methods of digital piracy are monitored by these schemes, meaning that digital pirates might move on to alternative illegal options instead of legal ones. In addition, while it is cost effective for the copyright holders themselves, the ISPs or governments would end up paying most of the costs of this system, due to the required monitoring and enforcement of the intervention $(\mathrm{Yu}, 2010)$. Due to these various concerns, it has been labelled the 'digital guillotine' by some, reflecting the manner in which it severs an individual's connection to the world ( $\mathrm{Yu}, 2010)$. Nonetheless, more countries are considering using this intervention and it is also likely that other types of digital piracy (such as direct downloading and illegal streaming) will fall under the umbrella of this intervention in the future (Meyer, 2012). The relative popularity of this intervention was reflected in the fact that it was incorporated in the draft text of the Anti-Counterfeit Trade Agreement (ACTA) (Haber, 2010), even if it did not make the final text of this agreement.

\subsubsection{Designed to frustrate: deterrence through technical restrictions}

The three anti-piracy interventions discussed so far suffer from two major limitations. They lack universality and are applied post fact, e.g. the 'damage is already done' when they are used (Cronin, 2002). The fourth type of stick-based interventions can be applied universally and preventively as the intervention is part of the 'design' of the content (for instance, by embedding the intervention in the programming code of the software). This allows copyright owners to implement an anti-piracy intervention directly, as they themselves manage, design and protect their content. There are no legal constraints that inhibit the content owners from protecting their content. The restrictions themselves are technical in nature and are 'designed to frustrate' the digital pirate (Gillespie, 2006). While the precise technicalities of this approach are beyond the scope of this research, its various forms are discussed in order to understand how these technical restrictions can contribute to reductions in digital piracy. For example, if the 
How to Discourage Digital Pirates: Focusing on Anti-Piracy Interventions and Their Mechanisms

pirated content becomes more difficult to obtain or fails to function properly, digital piracy becomes a less attractive way to obtain that content. This means that there are fewer opportunities for the digital pirate to obtain his desired content in this manner. Various methods are used to deter individuals from downloading and using pirated content, such as network poisoning, (software) aging, introducing game-breaking bugs in pirates' copies of video games (Nazario, 2011), using Digital Rights Management (DRM) technologies and by simply making the pirated content inaccessible altogether. Three specific types of technological measures are discussed in this section: various methods of network poisoning, 'notice and take-down' measures and the use of DRM techniques. Collectively, these measures can deter the individual from pirating content digitally and they present common ways through which content owners seek to protect their content from digital pirates preventively. ${ }^{68}$

\section{Network poisoning}

The goal of network poisoning is to deter digital piracy by 'poisoning' the file sharing network used to pirate content. Digital pirates will receive poisoned chunks of the content they try to digitally pirate, making the content unusable. They are therefore penalized as they cannot successfully download the desired content via the act of digital piracy (Lou \& Hwang, 2009) and have wasted time and efforts to do so. This process pollutes the network, which decreases the proportion of reliable and useable content on these networks (Christin, Weigend, \& Chuang, 2005). Software aging is related to this approach and is based on the concept of required registration. Software requires periodic updates, but pirated versions are unable to be successfully updated as they lack a certain quality, such as a legitimate product key (which the user can only obtain by obtaining the content legally). This decreases their utility for the digital pirate. This approach benefits legitimate users at the same time as it penalizes digital pirates, as legitimate users can enjoy a continuously updated product (Jakobsson \& Reiter, 2002). Related concepts, such as product registration or activation, are also technical tools that can be used to penalize digital pirates and essentially poison or disable pirated content (Djekic \& Loebbecke, 2007).

\section{Notice and take-down}

Take-down measures refer to the removal of unauthorized content from the Internet whenever it is detected by content owners (Sudler, 2013). Sometimes, content owners target the individuals behind a digital piracy service, as was the case in the Swedish Pirate Bay Trial. While site owners can be punished or imprisoned, this does not automatically mean that the website is no longer

${ }^{68}$ These measures have also been labelled as being a form of 'self-help'-strategies employed by the creative industries themselves (Holm, 2014). 


\section{$\underline{\text { Punish, Seduce or Persuade }}$}

accessible, as the Pirate Bay example demonstrates (Fung \& Lakhani, 2013; Lauinger et al., 2013), since the website itself continued to function after the site owners were convicted. It is instead preferable to disable the website or service altogether. Take-down notices are often presented to search engines such as Google who are charged with removing the web links to this pirated content. In this manner, web links containing pirated content are removed, making it more difficult for individuals to find pirated content. In the UK alone, over 100 million take down notices have been sent to Google in the context of music piracy in recent years (Reijerman, 2014). Cyberlockers, such as Megaupload, are often targeted for take-downs or shutdowns (Danaher \& Smith, 2014). A different version of this approach is the blocking of piracy-related websites by ISPs. While take-down notices attempt to remove the pirated content directly (or, at least, the link to this content), website-blocking attempts to block access to websites containing such content. A recent example of this approach can be seen in the Netherlands, where, after two court orders, $80 \%$ of the Dutch Internet subscribers could no longer access the website 'The Pirate Bay' (Poort et al., 2014). Such a technical measure can reduce the likelihood of digital piracy by also making it more difficult or even impossible for individuals to find and download pirated content.

Digital Rights Management

Digital Rights Management (DRM) technologies are the most difficult intervention to categorize properly as belonging to the stick category, as DRM technologies can be seen as having both deterrent and incentive aspects. DRM technologies allow copyright holders to control how music, movies and software are used and distributed by users. For example, they can restrict the number of times a user can play or install a certain file, but they can also prevent a file from being copied in the first place. This means that DRM technologies are a clear example of a hybrid anti-piracy intervention. The deterrent aspect refers to the fact that introducing DRM technologies can penalise users of the pirated content, as it cannot be used. The incentive-based variant refers to the removal or relaxation of DRM, making the legal product more attractive, as users can essentially share and copy the content freely or without (or with fewer) limitations. The introduction or usage of DRM technologies (which restricts usages) is placed under the heading of the stick-based interventions, while the removal thereof (allowing easier and more flexible access) is placed under the heading of the carrot-based interventions.

The attractiveness of initially implementing DRM technologies is that it allows a greater degree of control over the behaviour of content users. The proponents of this intervention suggest that imposing DRM restrictions can reduce digital 
How to Discourage Digital Pirates: Focusing on Anti-Piracy Interventions and Their Mechanisms

piracy, as they make it more difficult and costly (Vernik, Purohit, \& Desai, 2011). In addition, it is cheap, easy to create, implement and maintain (Buccafuso \& Masur, 2013). But DRM can be compromised. No matter the level of protection, there will always be non-protected or DRM-disabled copyrighted content available. DRM technologies can also annoy users of legal content and can instead motivate them to digitally pirate the content DRM-free, due to the usagelimitations these technologies impose on the user (Jaisingh, 2007). This has led to the development of a so-called 'digital arms race' meaning that, as DRM techniques became more restrictive, digital pirates continuously find ways to avoid or disable them (Gillespie, 2006). This has led to the understanding by the creative industry that this is not necessarily a suitable intervention. This has, in certain instances, led to a gradual relaxation of existing DRM policies (as will be discussed in \$5.3.4. (infra p. 127)). At the same time, content owners have recently started to use more nuanced DRM measures to track and trace the pirated content. Such measures, which are similar to watermarks on bank notes, can be used by the content owners to trace the source of the illegal copy. This allows the content owners to tackle to supply-side of digital piracy. As the supply of pirated copies becomes disrupted, it becomes more difficult for digital pirates to obtain a pirated copy (Hurley, 2016; Spangler, 2016).

5.2.5. Do stick-based interventions reach the appropriate target population?

In order for these various stick-based interventions described above to be able to contribute to reductions in digital piracy, it is required that they reach those individuals who pirate digital content frequently or in large quantities. This maximizes the exposure of the target population to these interventions. Thus, the question is whether the stick-based anti-piracy interventions reach young and experienced (with computers and related technologies) males? And do they feel addressed by these measures?

By their nature, most stick-based interventions are reactive, the exception being the interventions that implement technological restrictions. As males are more likely to pirate than females from the outset (\$4.3.4. (supra p. 89)), the stick-based interventions that function through a legal instrument can be said, to be able to reach males. However, no evidence is found that these measures intentionally attempt to reach males. Technological stick-based interventions are gender neutral, affecting all who use the content. As males are twice as likely to use content such as video games (Greenberg, Sherry, Lachlan, Lucas, \& Holmstrom, 2010), they are more likely to be affected by such measures, meaning that such measures can reach individuals with this attribute. However, the fact that these 
interventions do not focus specifically on males can have an influence on whether or not this target population feels addressed. A more specific focus can aid in triggering this feeling.

Reports of younger or even underage individuals having to pay excessive penalties or being confronted with imprisonment sanctions are quite common (France-Presse, 2013; Geuss, 2014; Humphries, 2011; McMillan, 2013) underlining attempts to reach younger individuals. This is reflected in the website of the CAS. This website (see Figure 5.4) makes it clear that the intervention focuses on adolescents or students, increasing their ability to reach such individuals. A similar tone and style can be seen on the website of the French HADOPI intervention (HADOPI, n.d.). The stick-based technological measures are age neutral, as every user of content that is protected in this manner is Figure 5.4: Young users and the CAS (Center for Copyright Information, n.d.)
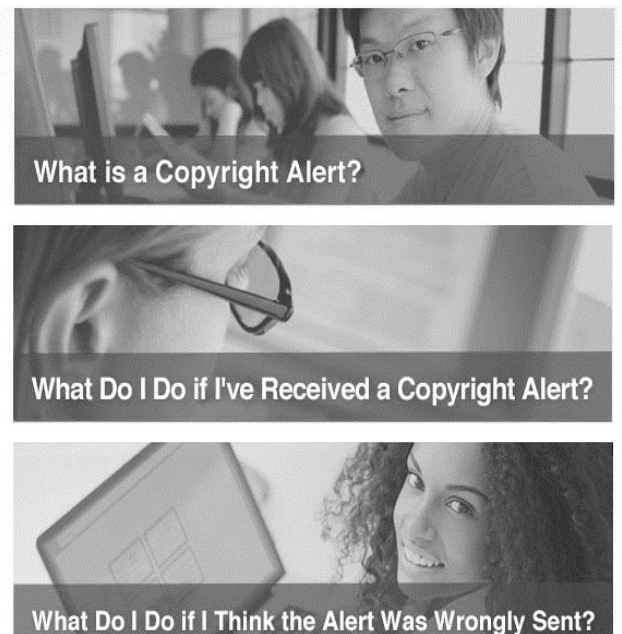
reached by such interventions. Younger users can be reached the most, since content such as videogames (which are often protected by DRM measures) is predominantly used by this demographic group (Greenberg et al., 2010; Nagygyörgy et al., 2013). Overall, the stick-based anti-piracy interventions focus on young individuals and are able to make them feel addressed.

It is not clear if the stick-based interventions reach experienced individuals. In order for most of the discussed stick-based interventions to have any effect, a digital pirate needs to be at risk of being detected. Without this risk, interventions such as the graduated response are hampered, as detection is required for any deterrent effect. It is quite easy for some individuals to attempt to avoid detection and reduce this risk, as was observed in Sweden. There, those individuals who managed to avoid being detected were more experienced computer users (Larsson et al., 2012). ${ }^{69}$ Individuals who did not have such experience failed to use methods to avoid detection and were more likely to be detected and punished. A similar reasoning applies to the technical measures, which can also be easily avoided by

${ }^{69}$ Following the criminalization of (digital) piracy, certain users used evasive techniques such as proxies and encryption methods to avoid detection by the authorities. 
How to Discourage Digital Pirates: Focusing on Anti-Piracy Interventions and Their Mechanisms

experienced individuals, but not by those that have little experience with such matters. This raises concerns not just on whether the target population is reached but also on whether or not they feel addressed. The fact that the more experienced individuals are capable of evading detection and punishment can inhibit the degree to which they feel addressed by the intervention.

Collectively, the stick-based interventions manage to reach the target population to some degree. This applies specifically to the gender- and age-attributes. It is less likely that experienced digital pirates are reached since it is precisely this attribute that allows individuals to avoid exposure to the interventions. There are also some doubts as to whether or not the target population will feel addressed by the stick-based anti-piracy interventions. This applies in particular to the experienced and male digital pirates.

\subsection{Carrot-based interventions}

The central idea behind carrot-based interventions can be neatly summed up by a quote attributed to Steve Jobs: 'You'll never stop [piracy]. What you have to do is compete with it.' (Clement, Rangaswamy, \& Vadali, 2012, p. 20). Instead of exposing digital pirates to (the threat of) punishment, this approach tries to tempt them to purchase the content legally. The goal is to convince all individuals, both those who have and who have not (yet) pirated content digitally, to purchase it legally. In a sense, it involves 'payment' to an individual, by a government or organization (De Geest \& Dari-Mattiacci, 2012). To compete with the pirated copy successfully, the creative industry offers various incentives. These incentives can consist of instances where a (material) resource is offered to the target population if a particular type of behaviour is performed (Vedung, 1998). This can increase the likelihood that individuals will act in the desired manner (Balch, 1980). Market forces, stakeholders and non-governmental institutions can all implement carrot-based interventions (Grabosky, 1995). In the context of digital piracy, most of these interventions originate from the creative industry itself and take the form of the so-called 'in-kind incentives' (Vedung, 1998). Examples of these 'in-kind incentives' include adding additional features to the legal content or quicker and easier access to it, as well as making the content cheaper to purchase. The 'payment' therefore focuses on these 'in-kind incentives'. The concept of 'incentive', as used in this research, focused specifically on offering rewards and is not used in the context of deterrence. This is arguably in contrast to the concept of deterrence as discussed within the mainstream literature from the field of law and economics, where stick-based interventions are expected to function by offering both disincentives and incentives (Becker, 1968; Kramer, 1990; Mocan \& Rees, 2005; Thomas, 2015). 


\section{$\underline{\text { Punish, Seduce or Persuade }}$}

Instead, deterrence, as used in this research, focuses on the usage of the threat of punishment, as was seen in the previous sections (Grabosky, 1995). And while it can be argued that the usage of the threat of punishment provides an incentive for a digital pirate to change his behaviour, it is clear that the stick-based interventions discussed previously do not offer the pirate any 'payment' (or 'in-kind incentives') as a motivator to change his behaviour. Since this is the interpretation of the concept of incentives as used in this research, it is not surprising that this mechanism is only discussed in the context of carrot-based anti-piracy interventions.

Carrot-based interventions see digital piracy as a challenge for the more traditional business models, rather than just as a deviant act. The creative industry is challenged through the 'competition' that digital piracy presents. Digital piracy is a contemporary way to consume content according to this position. The traditional model was based on a high dependence on street shops (Bustinza, Vendrell-Herrero, Parry, \& Myrthianos, 2013), ${ }^{70}$ but this model has undergone significant changes due to the emergence of digital distribution methods. The music industry was the initial innovator in this regard. The other industries (movie and software, for example) took some time to catch up with these developments, due to the greater Internet speed requirements needed to digitally distribute this content in this manner (Papies \& Clement, 2008). Central to these various incentives is the concept of 'anytime, anywhere and anyhow' (Swatman, Kruegel, $\&$ van der Beek, 2006), which changes the manner through which content can be enjoyed by the public and can also mean that content is offered for free.

Strategies that provide access to content for free are not without risk: instead of converting the digital pirates themselves, they can cannibalize part of the market, as individuals who previously purchased content legally can decide to, for example, legally stream their content for free as opposed to purchasing it (Danaher, Dhanasobhon, Smith, \& Telang, 2010; Papies, Eggers, \& Wlömert, 2011).

Collectively, four intervention types are identified that attempt to incentivize users: 1) lowering prices of legal content (or even offering it for free), 2) new ways of distributing legal content, 3) the introduction of streaming services, and 4) offering DRM-free content.

\footnotetext{
70 This traditional model consisted of brick-and-mortar stores which consumers had to visit in order to physically purchase and obtain the content. Given the inherent limitations of such a physical store, content can be out of stock or altogether unavailable, which might frustrate the consumer.
} 
How to Discourage Digital Pirates: Focusing on Anti-Piracy Interventions and Their Mechanisms

\subsubsection{Pricing strategies}

The most straightforward intervention in this category is the reduction of the cost of the legal content. By lowering the price of this content, users are encouraged to buy the content instead of digitally pirating it. Cheaper, or even free, content is the greatest incentive that can be offered by content owners (Holm, 2014). This approach is made partially possible by the emergence of the digital distribution methods, which has reduced production costs, making it possible for content owners to likewise reduce their prices while still making a profit (Jeong \& Khouja, 2013).

With regard to music, a clear downward trend in the cost of this content was noted in the past decade. This trend is quite apparent since the introduction of digital singles and albums, which have significantly decreased the product price. Singles can cost between $€ 0.69$ and $€ 1.29$, while albums can cost between $€ 4.99$ and $€ 14.99$ on average. iTunes prices content through so-called 'price classes', with individual songs costing from $€ 0.69$ up to $€ 1.29$, while most albums cost around $€ 9.99$ (Apple, n.d.). Slightly older music is offered at a

Figure 5.5: Decrease in the cost of music (Degusta, 2011)

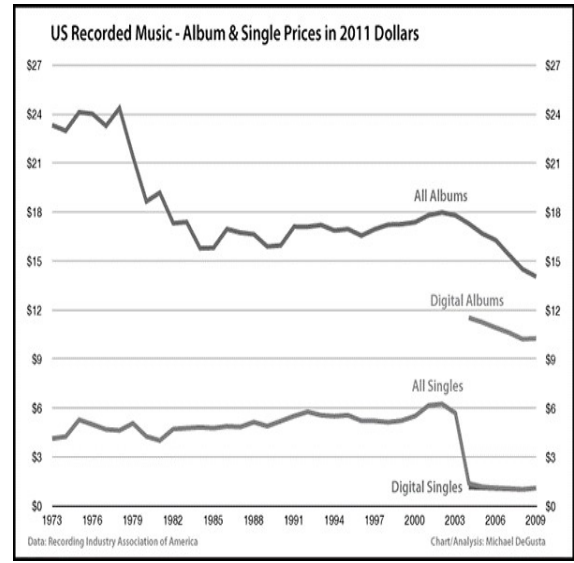
lower price (with prices as low as $€ 4.99$ for a complete album).

Figure 5.6: Example of a video game sale (Valve, n.d.)

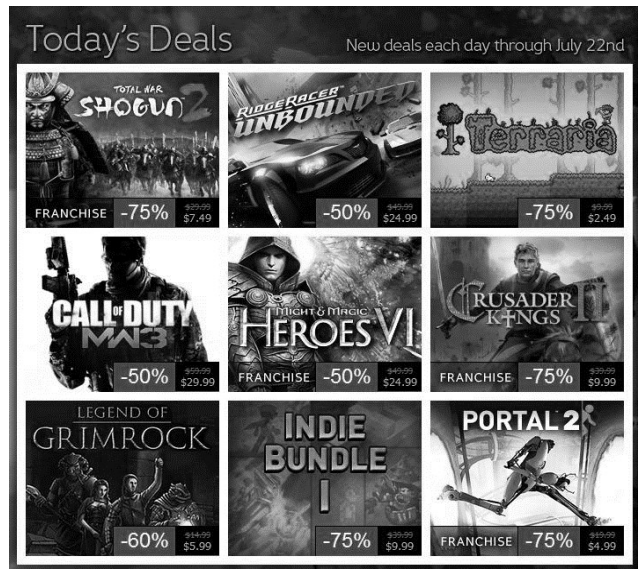

But prices have also begun to become more flexible in other content areas as well. While the price of video games has been rather stable (ranging between $€ 39.99$ and $€ 59.99$ for new, triple-A titles), prices for these products tend to decrease quite rapidly following their release. In addition, a number of venues offer special 'sales' or discounts, temporarily reducing the price of these products by up to $80 \%$. A sudden decrease might change the perception of price in a 


\section{$\underline{\text { Punish, Seduce or Persuade }}$}

positive manner. This might also have a perverse side effect. Once users know that most products (at times) can be offered for significantly lower prices, they may be no longer be willing to pay the full price. 'Pay-what-you-want' models can also be seen in the context of video games (Humble Bundle) and music (bandcamp). Humble Bundle (Humble Bundle, n.d.) allows users to determine exactly what they want to pay for the content; individuals who purchase content in this manner can also determine what goes to the game developer, to charity and to the service itself. This is distinct feature of Humble Bundle.

The movie industry seems to be less flexible in reducing the cost of content. New movies (on DVD or Blu-Ray) are often priced at least $€ 15$, a price that has only somewhat decreased in recent years. At the same time, movie theatres have increased prices in the past years. In the Netherlands, ticket prices have increased by over $25 \%$ in the past five years between 2009 and 2014 (CBS, 2014). This is partially due to the addition of extra features, such as 3D or IMAX movies.

But even in the context of movies, some positive changes can be observed. As traditional video rental stores are now nearly extinct, some content providers now allow users to rent a movie for a lower price (often between $€ 2.99$ and $€ 5.99$ ). Thanks to these changes, it has never been easier to have access to legal content quickly through services such as Amazon, Netflix or Pathé Thuis. Specific institutions also contribute to these pricing strategies. Universities often encourage copyright compliance by providing students and staff with websites offering legal content at a reduced price (Gerlach et al., 2009). Staff members and students of Dutch educational institutions have access to Surfspot, which is a website offering affordable licensed software (Surfspot, n.d.).

Beyond simply having lower prices, copyright holders can also opt to apply the concept of 'versioning'. This concept means that there are multiple versions of the same product (a no-frills version and a more expensive luxury version, for example) (Jaisingh, 2007). Simultaneously, right holders can offer other features that are attractive to some users, such as trying out the content (by offering demos), reward programs and customization options (Jeong \& Khouja, 2013, p. 2746; Papies \& Clement, 2008). For example, the luxury version of the video game 'Far Cry 4' for PC came with a statue of one of the game's characters;

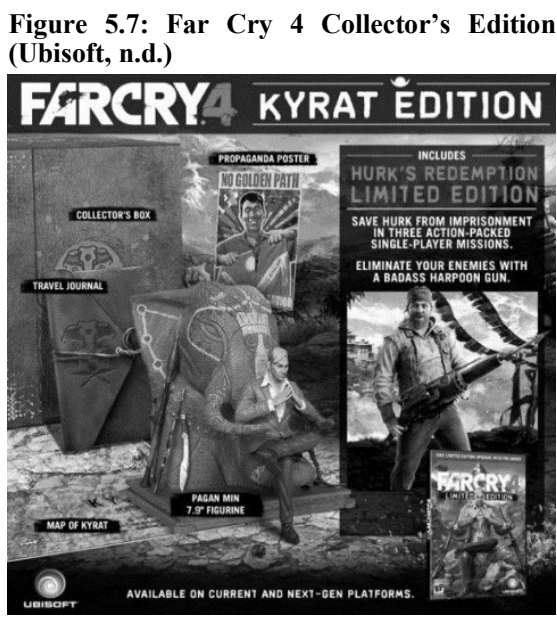


How to Discourage Digital Pirates: Focusing on Anti-Piracy Interventions and Their Mechanisms

a journal, a map, and a poster (see Figure 5.7). Clearly, this legal product comes with features that an illegal download does not contain and might be attractive to some users.

Some content, such as music and movies, is offered in stripped-down versions, offering no additional features beyond the content itself. These versions are often cheaper than the expanded or deluxe versions. This is done to attract potential consumers who are not willing to pay for features that they are not interested in. If such consumers only have access to a premium but more expensive version, they might be more likely to digitally pirate this content. In the context of movies, many content providers now allow users to choose between a one-time rental of a movie and the purchase of this product (as can be seen Pathé Thuis service). The former will obviously be cheaper, while the latter allows users to enjoy the product more frequently and at any time. This allows for a greater degree of product differentiation for different consumer segments. The product price is seen as more 'fair', as there is a better balance between the cost of the content and its quality.

It is also possible that content owners (such as Sony Music, Disney or Electronic Arts) bundle content (Mousley, 2003). For example, a legally purchased album will be bundled with a registration of a live performance of the band or artist (Columbia, n.d.), or a video game that comes with a complementary album containing the game's sound track (Bockstedt, Kauffman, \& Riggins, 2006). Perhaps the most far-reaching suggested strategies are the so-called 'global licenses' (also known as 'flat rates'). Under such a system, downloading content is subject to a compulsory license; users simply pay a fee on top of their regular Internet subscription fees in order to compensate the various copyright owners for any content that is not purchased legally (Clement et al., 2012; Geiger, 2011). Arguably this is not an incentive for the individual to purchase content but rather an ex-post business model for the content owners to reclaim some of their losses. It might even lead to the situation that individuals start to pirate more content digitally as they 'are paying for it anyway'.

Finally, a business model analogous to TV and radio broadcasts is also considered by some content owners, where content is free and the revenues are generated by, primarily, advertisements (Swatman et al., 2006, p. 58). Such a model is adapted by Spotify and similar services, although their premium memberships are still subscription based. Yet it is also possible to offer content for 'free' in this manner. An example of 'free' content is the fact that Windows allowed existing Windows 7 and 8 users to upgrade for free to the new Windows 10 version (up to the end of July 2016). 
5.3.2. New ways to distribute content as a way to make the content more attractive

There are new and innovative ways through which legal content can be acquired and enjoyed by users, beyond having to go to a physical store to purchase it. The attractiveness of the legal content can be improved by making access to this content easier, quicker or more flexible. This section focuses on the ease of use of these ways to distribute content, rather than the cost of content itself. Certain venues or platforms are discussed again in this section, since they also offer an easier, quicker or more flexible way to obtain content, in addition to offering content at reduced prices. For instance, iTunes represents both a way to offer content at a lower price (as was discussed previously) as well as a way for its users to gain access to the content quickly and easily. iTunes therefore also influences the manner in which content is distributed and therefore touches upon both the size of the incentive and the ease of obtaining the legal content.

The digitalization of content, heralded by the development of the MP3 audio format, has contributed to the way in which content is distributed. Easier and quicker distribution of content can also reduce digital piracy (Bockstedt et al., 2006), as content no longer has to be sold through physical media or brick-andmortar stores (Koh, Murthi, \& Raghuanathan, 2014). Content owners have attempted to launch alternative (and attractive) distribution methods to mimic the ease of pirating content. These distribution methods are digital in nature, meaning that content can be downloaded legally. Obtaining this legal content should be just as quick and easy as pirating it. iTunes is an example of this approach, but other options also exist, such as the Amazon Digital Music Store (Amazon.com, n.d.) and Google Play Music (Google, n.d.). In the case of television series and movies, in addition to (again) iTunes and Google Play, other platforms such as Pathé Thuis (Pathé, n.d.) and Netflix (Netflix, n.d.) demonstrate that this market has also started to embrace this approach. The same certainly applies to video games (with services such as Steam, Origin, GOG (Gog.com, n.d.), and Humble Bundle).

These various distribution methods also attempt to limit the impact of digital piracy by offering different versions for different market sections (Sinha \& Mandel, 2008). For example, iTunes allows users to purchase single songs (unbundling), but also entire albums or whatever the user prefers (Bustinza et al., 2013). The reverse is also possible, in which copyright holders can offer an entire set of content at once. For example, iTunes now offers the complete collection of the Beatles' music in its digital store. This is known as 'pure bundling' (Waldfogel, 2010a). Users can quickly and easily obtain this entire collection, without having to spend time and effort to search for and locate individual pirated 
How to Discourage Digital Pirates: Focusing on Anti-Piracy Interventions and Their Mechanisms

content of comparable quality. Apple has proven to be particularly clever in the manner in which they use iTunes, as it is linked to the iPod, iPhone or iPad devices, making iTunes a particularly attractive option for users of Apple products to obtain content (Owen, 2012). Overall, these methods attempt to make the acquisition of legal content as easy as possible or even increase the perceived value of the content through 'bundling' practices.

In addition to having more flexible ways of accessing legal content thanks to these new distribution methods, some carrot-based interventions also make the content available more quickly and of better quality than what was possible in the past decade (Fung \& Lakhani, 2013). For example, in the context of movies, DVDs and Blu-Ray are sometimes made available more rapidly following the theatre release, as was the case with Disney's 'Alice in Wonderland', which was released after only 12 weeks, instead of the usual 17 weeks. A more recent example is $20^{\text {th }}$ Century Fox's movie 'The Martian', which could be purchased on DVD or BluRay around four months after it was released in the cinemas. Netflix tends to make entire seasons of their television series available to their subscribers. This enables these subscribers to 'binge-watch' their favourite series, meaning that they watch an entire season's worth of episodes in one (or a few) sittings (Netflix Media Center, 2016). This means that Netflix's subscribers thus do not have to wait a week at a time before the subsequent episode is released.

Making legal content more rapidly available may increase the attractiveness of the legal content (Edwards, Klein, Lee, Moss, \& Philip, 2012). In addition, websites such as 'www.findanyfilm.com' or 'www.thecontentmap.nl' allow users to find the various options to obtain content legally, also making the legal content more attractive (Edwards et al., 2012). Such efforts are important, as different countries will often have different services available. For example, Amazon Instant Video is not available in Europe. This means that not all users have equal access to the content placed on this service. Content might already be available in certain countries but not in others. This inequality can also contribute to digital piracy, as illegal content is universally available. A lack of globally available legal content can raise the indirect cost of acquiring it: the user has to figure out where and when the content is available, for what price and with which features. It is therefore important that content owners try to make the content available to the largest number of users consistently and as quickly as possible.

\subsubsection{Streaming services}

The use of streaming services is the third carrot-based intervention examined in this section. It focuses on users who value ease of access to the degree that they 


\section{$\underline{\text { Punish, Seduce or Persuade }}$}

are willing to become paying members or at least are willing to listen to or watch advertisements in order to use these services. The incentive of the streaming services is that such services allow the user to access content as often as they want and at any point in time, present the user with a large library of legal content (in the context of music and movies at least) and that the streaming service is designed to be very user friendly. Such services often use tiered plans, varying from paid subscriptions to (often free) advertisement-supported programs that offer more limited features. Certain streaming models, such as Spotify, present their premium users with a range of additional features for a monthly fee. This includes an improved sound quality, off-line listening and no advertisements. Offering content for free also adds to the attractiveness of the legal content. Most of these streaming options are cloud-based services, allowing users to synchronize content between all of their devices (Owen, 2012), again improving the convenience or ease of access to content. In turn, this makes the legal content more attractive. There are differences to the interventions discussed in \$5.3.2. (supra p. 124). Most important is the fact that the features discussed in that previous section do not come free, whereas many streaming services do tend to offer access to content for free. In addition, this section focuses specifically on streaming services, as opposed to a wider range of methods used to make the incentive more attractive to the target population.

This model was made popular for music by Spotify. In the spring of 2015, Spotify was available in a substantial number of countries, covering most of Europe, the Americas and parts of Asia-Pacific (see Figure 5.8). Other services also exist. Deezer (Deezer, n.d.), Pandora (Pandora, n.d.), and Google Play Music are all involved in the streaming business. These music streaming services are collectively known as Music as a Service (MaaS), differentiating this service from the download-to-own or download-torent services of, for example, iTunes or Pathé Thuis (Dörr, Wagner, Hess, \& Benlian, 2013). There are also

Figure 5.8: Availability of Spotify (Spring 2015)

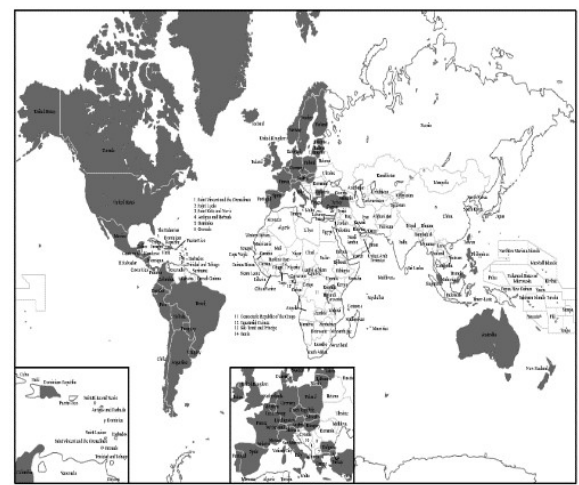
streaming services in the context of movies and television shows. Netflix, Hulu (Hulu, n.d.), and HBO Go (HBO, n.d.) are popular examples of these services. Hulu is currently only available in the USA, which limits the impact of these types of interventions. These offerings are contrasted with the streaming services for video games, where only small and exploratory initiatives such as Gakai 
How to Discourage Digital Pirates: Focusing on Anti-Piracy Interventions and Their Mechanisms

(Gaikai.com, n.d.) are found. Although streaming services contain elements of both previously carrot-based interventions, the combination of a pricing strategy and new distribution methods make it a third type of carrot-based intervention.

\subsubsection{DRM-free content}

As indicated in $\$ 5.2 .4$. (supra p. 114), DRM-measures can have both a deterrenceand an incentive-based component. Over the past years, some copyright owners concluded that DRM alone is not capable of deterring digital piracy and is counterproductive (Owen, 2012), as this restrictive DRM is imposed on all users, legal or otherwise. In fact, the legal users even suffer more restrictions when DRM measures are in place, as pirated versions are often DRM-free, since these measures are often removed by those that make the pirated content available in the first place. In fact, removing DRM will improve the value of the product for legal users and can increase their willingness to pay (Vernik et al., 2011). This led to a gradual relaxation of DRM technologies for certain content.

Although the link with the incentives might not be apparent immediately, the relaxation (or altogether removal) of DRM restrictions provides an incentive to acquire the product legally (Clement et al., 2012). Without such restrictions, users can use content more freely. For example, without DRM, users can install legal software multiple times on different computers, a feat that is not always possible when DRM restrictions are in place. The content has become more attractive for some users due to this relaxation.

5.3.5. Do carrot-based interventions reach the appropriate target population?

Most carrot-based interventions attempt to reach a rather broad population in order to serve two distinct goals: the conversion of digital pirates into legal consumers and the stimulation of legal demand from other users. From this position, it would not be expected that carrot-based interventions specifically attempt to reach only those individuals who are identified as having a greater propensity towards digital piracy. This is apparent as carrot-based interventions do not focus on a particular gender. All efforts are equally applicable to both genders, with the exception of any 'natural' differences in the consumption of content. Whether the male digital pirates feel addressed by the described interventions is doubtful however. 


\section{$\underline{\text { Punish, Seduce or Persuade }}$}

Carrot-based interventions do Figure 5.9: Spotify's younger target population specifically attempt to reach younger individuals. Spotify, for example, is presented both in an informal manner and as a 'hip' service. In its marketing materials, no person over (most likely) 30 can be seen, similar to services such as Steam and Netflix. Selling different versions of the same game is a strategy that is used to reach younger individuals, although indirectly. The way through which the interventions are presented increases the likelihood (Spotify, n.d.-b)

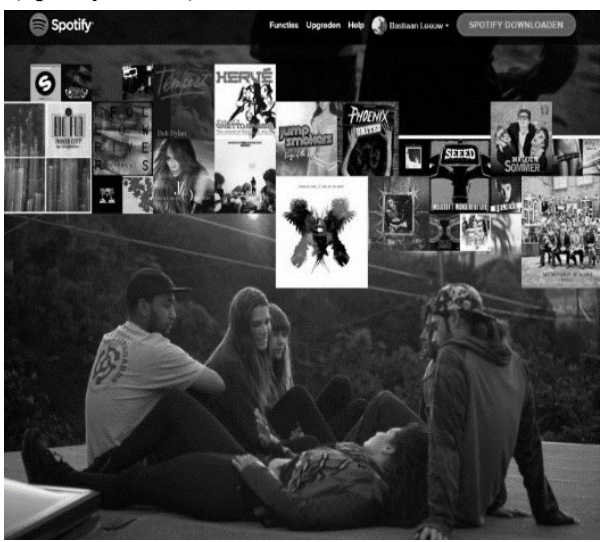
that younger individuals also feel addressed by these interventions.

With regard to whether or not carrot-based interventions can reach experienced individuals, it is difficult to assess whether this is indeed the case. The interventions discussed would benefit from requiring as little technological expertise as possible, as this lowers the threshold for individuals who want to obtain content legally via the options presented by the interventions. This also hampers the degree with which the experienced individuals feel addressed by them.

These carrot-based anti-piracy interventions are likely to be able to reach individuals who possess at least two of the three identified characteristics. The interventions directly attempt to reach younger individuals. In contrast, the interventions belonging to this category appear to be gender neutral. Thus, while not specifically targeting males, the outcome of the interventions is likely that they are reached nonetheless. However, this general neutral approach may hamper the degree with which the male digital pirates feel addressed by the described interventions. Whether the carrot-based interventions succeed in reaching the experienced digital pirates is more difficult to ascertain, but it is possible that such individuals do not feel addressed by the interventions.

\subsection{Sermon-based interventions}

Sermon-based interventions strive to reduce digital piracy through persuasion, which is attempted by informing the target population on the immorality, harmfulness or other consequences of this behaviour. It is thought that, through this information, an individual will begin to think differently about his (intended) act of digital piracy, possibly preventing him from doing so. Any planned effort 
How to Discourage Digital Pirates: Focusing on Anti-Piracy Interventions and Their Mechanisms

that disseminates messages to produce awareness or to cause a change in behaviour among an intended population is labelled a sermon. (Abroms \& Maibach, 2008). The main assumption behind this type of intervention is that, if a message is presented to individuals, they will either change their behaviour based on the new knowledge or the message will promote a change in attitudes about the issue, which can lead in turn to a change in behaviour (Campbell \& Manganello, 2006).

One feature that clearly sets the sermon apart from other types of instruments is the fact that, in addition to being an instrument in its own right, it is a 'metapolicy' intervention. This means that it can be used to disseminate knowledge on the existence, meaning and availability of other interventions, which is the foundation of the hybrid nature of sermon-based interventions. This means that the presence of sermon-based interventions can aid the success of the other two categories of interventions, since they are also dependent on information. Simply put, if an individual does not know that he can be punished for engaging in digital piracy, he cannot be deterred by such a measure. A similar reasoning applies to carrotbased interventions. This suggests that the sermon can sometimes be used to pave the way (or might even be required) for the proper functioning of interventions belonging to the other two categories (Grabosky, 1995).

However, persuasion itself is also a specific intervention-category. Three types of interventions fall under the heading of the 'sermon': 1) efforts to inform the target population on the benefits of purchasing and using legal content, 2) educational campaigns on the immorality of digital piracy, and 3) fear appeals and harm attribution strategies pointing towards the risks and harms of digital piracy (Edwards et al., 2015b). Collectively, these strategies attempt to change the attitudes and misconceptions (according to the copyright holders) of users and digital pirates (Moon, Kim, Feeley, \& Shin, 2015).

\subsubsection{Benefits of legal content}

Some interventions focus on the benefits of using legal content. These are often 'promotion focused', as they address the legal content rather than the pirated copy. Such messages inform the target population that, by acquiring and using content legally, they are more likely to have their desires fulfilled, which plays into one of the core characteristics that aid in explaining the act of digital piracy. Such interventions do not state that the desire to obtain or enjoy content is the problem, but rather the way through which one does so is problematic. The fact that the benefits are exclusive to the legal content is often stated clearly (Jeong \& Yoon, 2014). 
For instance, in the context of software, the possibility to receive the latest product features, technical support and updates are clearly stated as benefits of acquiring legal content (Gopal \& Sanders, 1997). The 'No Piracy' campaign is an example of a message that depicts the benefits of legal content. In these messages, licensed software is presented as being hassle free and enjoys the support of the copyright holder (No Piracy, n.d.). A different example is the 'Watch Real DVDs and BluRay' campaign (Twentieth Centry Fox Home Entertainment, n.d.). Here, the benefits of legally purchased movies are compared to the downsides of pirated copies, which can be of poor quality and functionality (Edwards et al., 2012). The campaign 'Moments Worth Paying For' tries to convey that purchasing content legally is a way to ensure the creation of future content, again conveying that the user benefits when using content legally. Such approaches also try to thank the public or audience for purchasing content legally (Edwards, Klein, Lee, Moss, \&

Figure 5.10: Example of identifying the benefits of legal content (FICCI, n.d.)

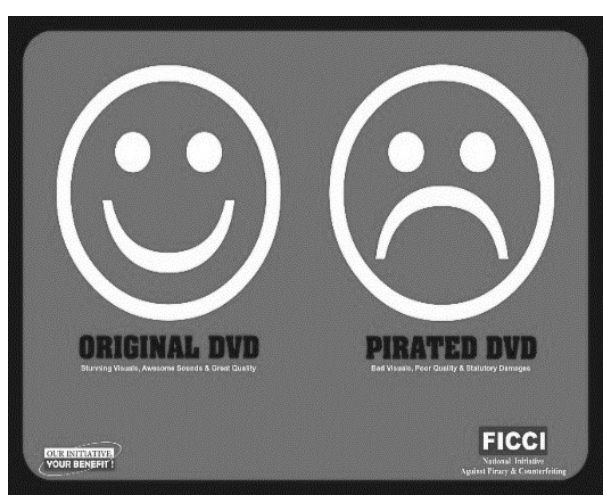
Philip, 2015a). A different approach is the campaign 'Knock-off Nigel', where a digital pirate is portrayed as 'cheap', 'a creep' and 'grubby' (Edwards et al., 2015b), underlining how the benefits of using legal content can go beyond the merely material. Finally, the Creative Content UK (CCUK) is a campaign that was launched in the summer of 2015 that relies heavily on highlighting the benefits of legal content, indicating that these interventions are used continuously (Cable \& Javid, 2014; TorrentFreak, 2015b). Persuading individuals who using legal content is beneficial to them means that there is a link between the content itself and the persuasive effort. This means that this type of sermon-based antipiracy intervention is partially dependent on carrot-based ones. If those latter interventions succeed in making the legal content more attractive for the individual (by incentivizing the behaviour), then the sermon-based anti-piracy interventions discussed in this section can benefit from this attractiveness. Simply put, the more attractive the content is, the easier it will be to convince individuals who using such content is beneficial to them.

\subsubsection{Educational campaigns}

The overall goal of educational campaigns is to make users think critically about the manner in which they acquire copyrighted content, to condition society to be less tolerant of digital piracy and to raise awareness on the content and scope of 
How to Discourage Digital Pirates: Focusing on Anti-Piracy Interventions and Their Mechanisms

the applicable copyright laws (Jeong \& Yoon, 2014; Mousley, 2003). Users are made more aware of their (deviant) behaviour in this manner and can decide not to pirate content digitally. An attempt is therefore made to influence the social norm to be less acceptable of digital piracy (Vernik et al., 2011). Rather than focusing directly on the negative aspects of digital piracy, these interventions attempt to persuade users that using content legally is simply the right thing to do. Other educational campaigns are based on the concept of respect. These suggest that respecting copyrights by not pirating content digitally is the 'right thing to do' (Gillespie, 2009). Such campaigns often ask the target population to consider whether or not pirating content is 'fair' (Gates, 2006). These campaigns often take the form of websites, brochures and (social) media campaigns. Some attempt to inform the public on how they can recognize illegal copies and avoid pirated content, such as the Music Matters Trustmark (Edwards et al., 2015a) or the Digital File Check (Pro Music, n.d.).

These sermon-based interventions also inform the target population on the content and scope of applicable copyright laws. It is thought that if individuals are better informed on what these laws entail, they are less likely to pirate content digitally, especially if the laws are presented as being reasonable and important to society. This does not necessarily mean that such a sermon focuses on informing the target population on the punitive aspects of these laws. Therefore, while information on the applicable laws can aid stick-based interventions, this information can also be used in its own right. A similar reasoning applies in relation to consensus for these laws, as greater consensus can potentially translate into greater compliance (Li \& Nergadze, 2009). A wide range of campaigns (across a wide range of jurisdictions) also attempt to raise awareness about the costs, time and efforts that go into the production of content. This is particularly the case in relation to movies (European Union Intellectual Property Office, n.d.).

\subsubsection{Fear appeals and harm attribution}

The sermons that use information in a more negative manner are the fear appeals and the harm attribution-efforts. The fear appeal tries to invoke fear by clearly stating the negative outcomes of engaging in unsafe (or undesired) behaviour. The link with stick-based interventions is clear here as there seems to be a connection between the deterrent measures that such interventions use and the fear appeals that attempt to make the target population 'afraid' of such deterrent measures. Fear appeals try to influence the act of digital piracy by influencing the perceived outcome expectations of this act, by pointing at the risks involved in this 


\section{$\underline{\text { Punish, Seduce or Persuade }}$}

behaviour. In this way, an individual's process of choice can be modified, possibly resulting in the decision not to pirate content digitally. ${ }^{71}$

Fear appeals attempt to arouse fear in order to promote precautionary behaviour and self-protective action (Ruiter, Abraham, \& Kok, 2001). It is a variant of the sermon that is, in fact, frequently used to 'help people help themselves'. The intervention functions by making the target population afraid and subsequently showing them how to reduce this fear by acting in a prescribed manner. By focusing on the negative consequences, it is thought that individuals will become more likely to change their behaviour. It is not so much the fear itself that results in behavioural change but, rather, the suggested precautions (Ruiter et al., 2001).

Campaigns that fall within this type often attempt to inform users on the risks associated with digital piracy (Jeong \& Yoon, 2014). The goal of these threat appeals is that individuals stop pirating content digitally in order to avoid the negative outcomes that these fear appeals identify for the individual. The suggested precautionary measures are straightforward: simply obtain the content in a legal manner. Various fear appeals present the digital pirate with alternative behaviour in order for him to avoid the negative outcomes. A good illustration of this is the 'Respect Copyrights' approach (MPAA, 2013). Fear appeals also announce upcoming anti-piracy actions to the wider public. Metaphors such as 'war on piracy' or 'piracy blitz' are used to convey a sense of seriousness in this manner (Mirghani, 2011). A well-known example of the fear appeal was the longrunning 'Piracy - it's a crime' campaign, where digital piracy was presented as being analogous to theft, meant to increase the fear of punishment in the target population (Giblin, 2014; Gillespie, 2009). This process can also alter an individual's moral understanding of digital piracy as Figure 5.11: 'Piracy. It's a Crime' (MPAA, 2005)

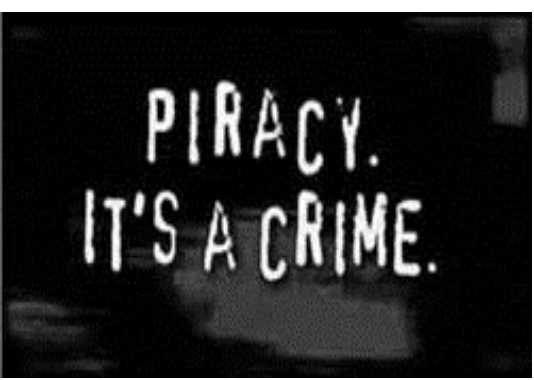
equating the act of digital piracy with theft carries with it a moral component (Rendas, 2015). Most fear appeals tend to vilify or stigmatize digital pirates (Edwards et al., 2012). A different type of fear appeal does not focus on the possible punishments, but rather at other risks associated with such acts. For instance, the risk of downloading a virus through engaging in digital piracy can also be used as a fear appeal (Gillespie, 2009; Wolfe, Higgins, \& Marcum, 2008).

\footnotetext{
${ }^{71}$ As fear appeals themselves do not formalize and shape the (threat of) punishment, such interventions cannot be said to influence the conduciveness of the environment, as opposed to the stick-based interventions, that are capable of doing so.
} 
Harm attributions, on the other hand, are Figure 5.12: 'Don't Copy that Floppy' (Software thought to work by making pirates more aware of the harm that their actions cause, which can influence them to stop their acts of digital piracy. The depiction of who is harmed by digital piracy matters. Users have more positive attitudes towards artists than copyright holders, meaning that they are more sensitive to the harm that the artists experience (Levin, Dato-on, \& Manolis, Publishers Association, 1992)

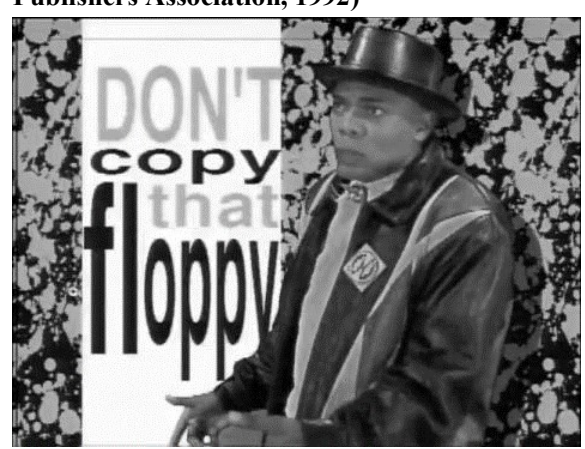
2007). Often, the message is conveyed that digital piracy hurts the creative industry and even the (global) economy. The harm appeal, in the context of analogue software piracy, dates back at least to 1992, when the campaign 'Don't Copy that Floppy' was launched. This campaign focused on the impact of analogue software piracy and urged individuals to respect copyrights (Castro, Bennet, \& Andes, 2009). Other attempts at harm attribution focus on the loss of income, jobs or even creativity. More recent campaigns take the concept of harm attribution quite far. Some state that purchasing pirated content can, in addition to job losses, aid various crimes: drug trafficking, child labour and gang violence are all mentioned (National Crime Prevention Council, 2011b). Other campaigns attempt to convey a similar message (National Crime Prevention Council, 2013). Some governmental agencies such as the FBI have also underlined the supposed link between copyright infringement and organized crime and even terrorism, as a way to 'motivate' individuals to act differently (Mirghani, 2011).

In contrast, the 'It Hurts' campaign attempts to illustrate the harm of digital piracy in a more personal and individual manner. Here, individuals are seen taking money from a street busker, which is obviously intended to be a metaphor for digital piracy (National Crime Prevention Council, 2011a). Certain campaigns show that not only the creators are affected by digital piracy but also those individuals working in the industry. An older MPAA campaign depicted five individuals involved in the creation of movies (such as the technical staff) who were all supposedly affected by acts of digital piracy (Gillespie, 2009). The goal of these harm attribution campaigns is to convince users that digital piracy is not a victimless crime (Edwards et al., 2015a). By focusing on the impact digital piracy has on individuals working in the creative industry, as well as the creative industry itself, policy makers attempt to divert the attention away from the content owners and major publishers towards these more relatable 'victims' of digital piracy (Gates, 2006). Harm attribution is also used as a strategy when proceeds of the legally purchased content would normally go to a charitable cause (Grolleau, 


\section{$\underline{\text { Punish, Seduce or Persuade }}$}

Mzoughi, \& Sutan, 2008). Examples of this approach are 'Do They Know It's Christmas' by Band Aid, 'Download to Donate', many War Child CDs, and so on (Wikipedia, n.d.-e). It is believed that such a strategy may work, as it is associated with the altruistic act of giving to a good cause and that pirating the content digitally would strip those in need of these donations. In addition, the impact on the victims is presented differently; instead of the wealthy copyright holder, those individuals who have suffered a natural disaster now become the victims of digital piracy (Grolleau et al., 2008).

5.4.4. Do sermon-based interventions reach the appropriate target population?

As with the carrot-based interventions, sermons often try to reach a broader group of individuals compared to the stick-based interventions. Sermons attempt to reach and persuade individuals even before they have formed a desire to obtain and enjoy specific content, meaning that sermon-based interventions will tend to reach many individuals early on. Sermon-based interventions seem to be gender neutral and sometimes even focus on females. For example, in the 'Piracy, it's a crime' campaign, the main 'pirate' is a young woman, while the other 'criminals' in the video are all male. Most other sermon-based interventions are gender neutral, depicting both males and females alike. This means that these interventions run the risk of not being able properly address the male digital pirates.

Of the three attributes related to the target population, only the age of the individual is used directly, as they tend to focus younger Internet users. This can be seen in the framing of the message, where young individuals are often depicted as pirates. Younger users are the target of these efforts and an attempt is made to motivate them to stop pirating content digitally, perhaps before it becomes a habit. The focus on younger individuals is based on the understanding that children and teenagers often pirate content digitally (Gillespie, 2009). For instance, in 2006, Boy Scouts in Los Angeles could receive the 'Respect Copyrights' merit badge after reading information on copyright law and digital piracy (Anderson, 2006). Campaigns that target younger individuals often use familiar imagery, such as superheroes. An example of this approach is 'Captain Copyright', a superhero meant to inform children on copyright law and copyright infringement. This reflects earlier

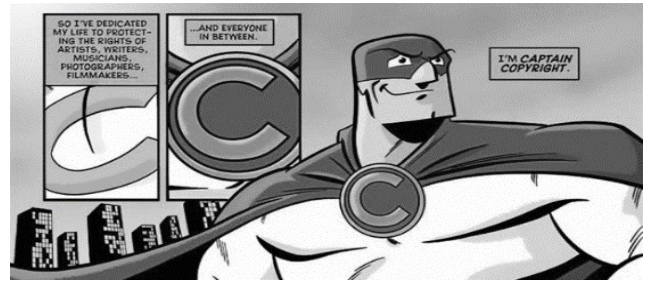


How to Discourage Digital Pirates: Focusing on Anti-Piracy Interventions and Their Mechanisms

efforts, as even the 'Don't Copy that Floppy'-campaign targeted teenagers. A second observation related to age is that the venues used to expose users to these sermons are often used by younger individuals. Social media, such as Facebook and Twitter are being used to convey the sermons, as well as schools and universities. University policies are posted on their websites and educational presentations are part of the students' orientation programmes (Gerlach et al., 2009). Overall, most of the sermons are focused on teenagers and students, meaning that young individuals are likely to be reached by these efforts and are also likely to feel addressed by these efforts.

Exceptions exist however: in some instances, parents seem to be focused upon (Jeong \& Khouja, 2013). In this manner, parents are informed about the legal and illegal consumption behaviour of their children or students. Suggestions are given that make it easier for parents to understand the actions of their children, with technical jargon being explained. A proper example of this approach is the Childnet International information brochure (Pro Music, 2012). Adolescents are also frequently targeted by information-based interventions. These have attempted to use social media to a greater degree, as can be seen in the BSA's Facebook campaign 'No Piracy' (Jeong et al., 2012).

Finally, there is little evidence to conclude that sermon-based interventions reach experienced computer users. Experienced users will likely be able to avoid exposure to the various sermons. While movies are often accompanied by such sermons (often prior to the movie itself), experienced digital pirates can often skip or remove these messages altogether, meaning that their exposure to these sermons is far from guaranteed (Patowary, 2011). Being able to make them feel addressed is thus also unlikely.

As with the stick- and carrot-based interventions, the sermon also does not seem to be able to fully reach the target population, which can influence the contribution that this intervention category can have on reducing digital piracy. Likewise, it is doubtful whether or not the target population will feel fully addressed by the interventions.

\subsection{Conclusion}

This chapter focused on the second sub-question: which interventions, both from governmental and other (public and private) organisations, are currently applied in the context of digital piracy? Anti-piracy interventions were divided into three global categories of anti-piracy interventions; the Sticks, Carrots and Sermons. Of the various interventions, stick-based interventions often include measures that have their basis in civil, criminal or administrative law. This category is the most coercive and attempts to either deter or punish individuals. Carrot-based 
interventions try to tempt (potential) pirates by making the legal content more attractive, an approach applied by content owners. Finally, sermon-based interventions have attempt to persuade (potential) digital pirates of the immorality, wrongfulness or harmfulness of digital piracy.

These insights are also informative for answering part of the third sub-question ("which (behavioural) mechanisms are applied in the design of the various antipiracy interventions and what are the requirements for their proper functioning?'). Each of the found mechanisms attempts to influence digital piracy by changing the individual's propensity to engage in digital piracy, by making the environment less conducive to digital piracy or by influencing components of the process of choice. This chapter answers the first half of the third sub-question by identifying that the stick-based interventions use deterrence as a mechanism; carrot-based interventions attempt to incentivize the users, while sermon-based interventions persuade individuals who digital piracy is immoral, wrong, risky or harmful.

This chapter also answered a small aspect of the fourth sub-question (to what extent the underlying mechanisms contribute to reductions in digital piracy), as it identified whether or not the three categories of anti-piracy interventions succeed in reaching the appropriate target population and whether they make the target population feel addressed. It seems that this is not necessarily the case.

None of the three intervention categories seem to succeed fully in reaching the experienced digital pirates or making them feel addressed. This can have a negative effect on the contribution of these anti-piracy interventions to the reductions in this behaviour. Such a finding was somewhat expected for the carrot- and the sermon-based interventions, as they are likely to try to reach as broad an audience as possible. The reason why the stick fails to reach the experienced individuals is due to the fact that these individuals are better equipped to shield themselves from detection and punishment (Larsson \& Svensson, 2010; Larsson et al., 2012). With regard to gender, stick-based interventions focus to some degree on males but carrot-based ones appear to be gender neutral. This can still mean that males are reached, but this does not mean that those individuals also feel addressed. Some sermon-based interventions target women, who do not frequently engage in digital piracy, which makes it less likely that males are reached. Age-wise, all interventions target and reach younger individuals, particularly the carrot and sermon interventions. It is also likely that those individuals also feel addressed by the interventions.

To answer the second half of the third sub-question, it is important that it is clear with which requirements these interventions are confronted with when applied in 
How to Discourage Digital Pirates: Focusing on Anti-Piracy Interventions and Their Mechanisms

practice. In order to understand whether the found and examined interventions can indeed contribute to reductions in digital piracy, it is necessary to establish whether the interventions meet these requirements and whether there is any empirical evidence to conclude that meeting these requirements indeed influences this contribution to reductions in digital piracy. This will be accomplished in the next chapter. 



\section{An Assessment of Anti-Piracy Interventions: Requirements for the Three Mechanisms}

Anti-piracy interventions use various mechanisms in order to (attempt to) reduce digital piracy. While the previous chapter examined the types of anti-piracy interventions, in this (and the subsequent) chapter, the focus is placed on the mechanisms that these interventions use. References to the stick-, carrot- or sermon-based anti-piracy interventions take a backseat from this point onward. The three identified mechanisms (deterrence, incentives and persuasion) will be examined further in this chapter in order to determine to what extent they might contribute to such reductions. For a mechanism to be able to have such a contribution, it must meet a number of requirements. For each of the three mechanisms, different requirements apply. It is firstly determined in this chapter whether the various requirements are met. Interventions that use mechanisms that are better designed (e.g., succeed in meeting the identified requirements) are more likely to contribute to reductions in digital piracy

Secondly, this chapter examines those studies that have empirically studied the effects of the mechanisms on digital piracy. Special attention is paid to whether or not mechanisms that meet their respective requirements are indeed capable of influencing digital piracy (to a greater degree).

Thus, to obtain these insights, the analysis in this chapter consists of three steps: 1) the requirements for the proper functioning of each mechanism are identified in the relevant literature, 2) it is determined whether each mechanism meets or exceeds each requirement in the context of digital piracy and 3) the empirical findings of each mechanism and its associated requirement(s) are examined, when available.

This chapter completes the answer to the third sub-question (which (behavioural) mechanisms are applied in the design of the various anti-piracy interventions and what are the requirements for their proper functioning?) and provides further insights needed to answer the fourth sub-question (to what extent the underlying mechanisms contribute to reductions in digital piracy).

To answer part of the fourth sub-question, 44 empirical studies were used. When conflicting evidence on the usage of a particular intervention or mechanism was found, the robustness (or rigour) of the studies was taken into consideration in 


\section{$\underline{\text { Punish, Seduce or Persuade }}$}

order to better understand these findings. The 44 studies varied in their research designs in sufficient degree to allow for such an assessment. ${ }^{72}$

\subsection{Requirements for interventions using the deterrent mechanism}

The requirements identified in the literature are important in determining whether anti-piracy interventions, via their respective mechanisms, are capable of influencing the behaviour of digital pirates. Stick-based interventions are dependent on three requirements: 1) the certainty of the punishment (which includes the repetition of the (threat of) punishment) (Apel, 2013; Balch, 1980; Ehrlich, 1975; Grasmick \& Bryjak, 1980; Jacobs \& Piquero, 2012; Nagin \& Pogarsky, 2001; Piquero, Piquero, Gertz, Bratton, \& Loughran, 2012), 2) the severity of the deterrent measure (Balch, 1980) and 3) the stimulation of alternative behaviour (Balch, 1980).$^{73}$ The third requirement demonstrates the link between stick- and carrot-based interventions, underlying the hybrid nature of some interventions.

In practice, the first and second requirements are communicating vessels. Both are necessary, to a certain degree, for deterrence to take place, as an individual needs to know that he can be caught and punished for his deviant or criminal behaviour before any deterrent effect can be triggered (Piquero et al., 2012). This demonstrates that certainty and severity should be seen as a 'package' and that both should be not considered in a vacuum (Mendes \& McDonald, 2001). If individuals believe that the probability of being caught is zero or low, then the severity of the punishment does not influence behaviour. The reverse is also true: if the severity of the punishment is (close to) zero, a high certainty of punishment also does not influence the individual's behaviour (Grasmick \& Bryjak, 1980).

\footnotetext{
${ }^{72}$ This process of weighing is distinct from the way in which the systematic review-style of literature review examines literature. There, the robustness of the studies is a clear inclusion-criteria.

${ }^{73}$ The certainty and severity originate from classical research into deterrence. The origin of the classical research on deterrence can be found in the work of Becker (1968), who examined the matter of deterrence from an economical perspective. Since then, deterrence has been a recurrent theme in the field of criminology and beyond. In the research on deterrence, the celerity of the punishment is often identified as the third requirement needed for a deterrent effect. Celerity has been understudied however and, when studied, there is inconclusive evidence on its relevance (Nagin \& Pogarsky, 2001). This fact, combined with the observation that deterrence-based interventions do not appear to focus on the speed of the punishment led to its exclusion as a requirement. Moving beyond the field of criminology, the other two requirements emerged from the literature: repetition of the punishment and the stimulation of alternative behaviour. Integrating these into the analysis provided a better understanding of when deterrence-based mechanisms can indeed contribute to reductions in digital piracy.
} 
An Assessment of Anti-Piracy Interventions: Requirements for the Three Mechanisms

\subsubsection{Certainty of punishment}

Any stick-based intervention needs to express some degree of certainty that the threat of punishment can be effectuated (meaning that the individual will be punished) in order for it to have any deterrent effect. This means that the individual who is considering a criminal or deviant act needs to be faced with a significant expectation that he will be detected and punished for his non-compliant behaviour. A 'tipping point' of when the certainty of punishment is sufficiently high has been identified in the academic literature. A $30 \%$ to $40 \%$ certainty of being punished forms this threshold. Reaching it makes it more likely that an individual will be deterred, according to the literature (Brown, 1978; Chamlin, 1991; Loughran, Pogarsky, Piquero, \& Paternoster, 2012; Tittle \& Rowe, 1974; Yu \& Liska, 1993). ${ }^{74}$ Does the deterrent mechanism, as applied in the design of the various stick-based anti-piracy interventions, meet this proposed threshold? This is unlikely. In fact, it is unlikely that any other criminal law measure reaches this proposed threshold ( $\mathrm{Yu} \&$ Liska, 1993). Yet, despite the fact that many criminal law measures do not reach this threshold, individuals can still be deterred in practice (Jacobs, 2010; Maxwell \& Gray, 2000; Nagin, Solow, \& Lum, 2015). This suggests that the use of such a threshold is unrealistic. However, it is still plausible that, as the certainty of punishment increases, the likelihood of deterrence increases as well. Thus, anti-piracy interventions with a higher certainty of punishment are more likely to deter digital pirates, but they are not required to reach the $30 \%-40 \%$ certainty of punishment.

The more traditional enforcement through civil law is unlikely to have a high(er) certainty of punishment. In the USA, around 35,000 Internet users have been subjected to lawsuits between 2003 and 2008 (Jeong \& Khouja, 2013), meaning that, on average, around 7,000 users per year have been on the receiving end of a law suit. On an Internet population of around 220 million in 2008, this comes down to around a $0.003 \%$ chance of being detected and punished in that specific jurisdiction. If the findings on the number of individuals who pirate music digitally are considered (which, as seen in Chapter 3 (\$3.3.1. (supra p. 56)), is around $60 \%$ in the USA) the average digital pirate has a $0.005 \%$ chance of being detected and punished in the USA. With the advent of the 'copyright troll' strategy in certain countries (such as the USA and Germany), an increase in the number of settlements is observed, also increasing the certainty of punishment. In the USA, around 250,000 users were asked to settle in 2011 alone. On an Internet population of around 240 million in that year, the certainty of punishment is only $0.1 \%$ or, again considering the percentage of digital pirates, a bit less than $0.2 \%$.

${ }^{74}$ The concept of diminishing returns also applies to the certainty of punishment. After a certain point, increases in the certainty of being punished yield diminishing deterrent effects (Loughran et al., 2012) 
Criminal law has traditionally been the main source of deterrence, but the certainty of punishment is even more complex to establish when compared to civil law measures. Not only must the infringing action be detected and reported, police and public prosecutors also need to determine whether or not to investigate the case and decide if there is sufficient evidence to press charges. Furthermore, a judge (or jury) will rule on the case. Even if a guilty verdict is reached, it is up to this judge to determine the sanction to be applied, if any. Finally, a sanction needs to be executed. At every step, a case can be dismissed. This reduces the certainty of punishment and increasing the certainty of punishment, by preparing and processing more cases, is expensive. Even if extra resources are invested, the certainty of punishment still tends to remain low. For example, Sweden has increased criminal law enforcement in the past years (Larsson et al., 2012). Between 400 and 800 cases are now prepared annually. With an Internet population of around 8.5 million (in 2012), in the 'best case scenario' (e.g. 800 cases are handled per year and these all result in a conviction), the certainty of punishment would be around $0,009 \%$. The Swedish police resources available to deal with digital piracy have doubled since 2012 (Larsson et al., 2012), hypothetically resulting in up to 1,600 cases being prepared annually. However, even in those circumstances, the certainty of punishment is only around $0.02 \%$. With $78.4 \%$ of Swedish Internet users pirating content digitally (Larsson et al., 2012), this means that Swedish digital pirates have a $0.025 \%$ chance of being detected. Rochelandet and Le Guel (2005) suggest that digital pirates know that the actual likelihood of being caught and punished is very small, suggesting that how individuals perceive this certainty matters and may hamper the deterrent measures.

The graduated response seems, in theory, to yield a greater certainty of punishment. The systems that are used for the graduated response are often (semi)automated, meaning that it has become easier and less resource-consuming to monitor computer networks and data traffic, as well as to send notices to infringers. This can lead to a greater number of cases being processed (Bridy, 2010-2011; Strowel, 2009). Furthermore, there are often fewer administrative hurdles to be overcome, making the process more streamlined, quicker and having fewer stages in which a case may be dropped. The biggest advantage may be that once a subscriber has been noticed by the monitoring system, infringements by the same subscriber will also be noticed, as he is monitored from the first infringement onwards. This increases the certainty of punishment once detected. This means that the graduated response schemes allow governments and content owners to send out a large number of warnings. This influences the certainty of punishment. The French and USA practices seem to confirm this expectancy. 
Whether this results in a higher certainty of punishment remains to be seen however.

In France, it was initially expected that around 10,000 first notices would be sent per month (up to 120,000 notices per year) (Bomsel \& Ranaivoson, 2009; Ranaivoson \& Lorrain, 2012). On an Internet population of around 44 million in 2009 , this represents around a $0.27 \%$ likelihood of receiving such a notice. In France, 33.4\% had pirated movies and television series (Bounie et al., 2006), resulting in a chance of detection of $0.8 \%$ for these types of digital piracy. Four years after their implementation of the graduated response scheme in France, around 2 million notices had been sent. 500,000 notices are sent per year, resulting in $1.13 \%$ chance of receiving a notice or sanction or a $3.4 \%$ chance for that part of the population that pirates content digitally. Thus, in France, digital pirates have around a one in 30 chance of receiving a notice and, if infringement persists, of being sanctioned. In the USA, during the first ten months after the implementation of the CAS, around 1.3 million alerts were sent (Center for Copyright Information, 2014 ) and around 1.5 million notices are sent yearly. On an Internet population of around 254 million in 2013 , this is still low $(0.59 \%$ or almost a $1 \%$ chance for the pirating segment of the US population), but it is higher than the other stick-based measures applied in the USA. The CAS hopes to double the number of notices in the coming years (Center for Copyright Information, 2014), leading to a $1.18 \%$ chance (or almost $2 \%$ chance for pirating individuals) that an infringing subscriber will receive a notice and will be exposed to future sanctions. While small, such a certainty is at least concrete for the digital pirates in both France and the USA.

Technological interventions inherently carry with them a high certainty of punishment. DRM protections, for example, are a given fact for certain types of content, such as video games. Users are almost certainly to be 'sanctioned' if they pirate this content digitally (e.g., not being able to use the product), although these sanctions can be avoided by experienced digital pirates. Likewise, website blocking is almost certainly encountered by users. For instance, when the Pirate Bay blockade was enacted in the Netherlands, around $80 \%$ of the Internet users in this jurisdiction were exposed to this intervention (Poort et al., 2014). However, such a blockade can be avoided if the digital piracy has sufficient experience with technologies such as 'Virtual Private Networks' (VPN) or browser extensions (Egan, 2016). Therefore, the certainty of punishment is high for technological interventions, in contrast to the other types of anti-piracy interventions using this mechanism, but likely only for the less experienced digital pirates.

To conclude this more theoretical discussion on the certainty of punishment, it can be argued that most of the stick-based interventions do not present a higher certainty of punishment (or even detected and caught). The various graduated 


\section{$\underline{\text { Punish, Seduce or Persuade }}$}

response schemes do come closer to having a higher certainty. The technological measures form a clear exception, which can be used in such a way that they make it very certain that a digital pirate or user will be exposed to such measures (as long as the pirates do not evade or bypass detection). In addition, through a variety of sermon-based interventions, the perception of the certainty of punishment can perhaps be increased. This underlines that this perception also influences whether or not an individual will be deterred.

To determine whether increases in the certainty of punishment or even the individual's perception thereof can contribute to reductions in digital piracy, studies are discussed that empirically studied this requirement in some detail. Is it sensible for governments and content owners to invest in increasing (the perception of individuals on) the certainty of being punished? Table 6.1 depicts the findings of these studies that have attempted to examine this matter and makes a distinction between studies that have focused on the certainty of being caught (which is part of the certainty of punishment) and those that have focused on the certainty of punishment directly. ${ }^{75}$ The studies discussed below (Table 6.1) examined the outcomes of hypothetical anti-piracy interventions. ${ }^{76}$

Table 6.1: Studies on the certainty of being caught or punished

\begin{tabular}{|c|c|c|}
\hline Study & Measure & Outcome \\
\hline \multicolumn{3}{|c|}{ Certainty of being caught } \\
\hline $\begin{array}{l}\text { Sinha and Mandel } \\
(2008)\end{array}$ & $\begin{array}{l}\text { Two studies were performed, both } \\
\text { of which varied in the certainty of } \\
\text { being caught by } 5 \%, 45 \% \text { or } 100 \% \text {. }\end{array}$ & $\begin{array}{l}\text { A } 10 \% \text { increase in the certainty of } \\
\text { being caught increased the } \\
\text { willingness to pay for legal content } \\
\text { by } \$ \mathbf{0 . 0 3} \text {. The willingness to pay } \\
\text { does increase as the risk of being } \\
\text { punished increased; from } \$ 0.34 \text { to } \\
\$ 0.48 \text { and } \$ 0.62 \text { respectively. }\end{array}$ \\
\hline $\begin{array}{l}\text { Chiang and Assane } \\
(2007)\end{array}$ & $\begin{array}{l}\text { Perceived chance of being sued by } \\
\text { the RIAA for a copyright violation } \\
\text { was examined. }\end{array}$ & $\begin{array}{l}\text { When the perceived risk of being } \\
\text { apprehended (chance of being sued) } \\
\text { is below } 25 \% \text {, nearly } 50 \% \text { of the } \\
\text { music collection of the respondents } \\
\text { consisted of pirated content. This } \\
\text { percentage is reduced by half } \\
\text { when the perceived risk is increased } \\
\text { to the range of } 75-100 \% \text {. }\end{array}$ \\
\hline
\end{tabular}

75 This distinction is important, as these studies do not measure the exactly the same thing. The certainty of being caught will consist of the detection of infringing behaviour while the certainty of punishment goes one step further and also seems to entail detection and punishment (Williams \& Hawkins, 1986). This means that the certainty of being detected and punished might have a greater influence on the respondents' intention to pirate content digitally.

${ }^{76}$ Results of studies that are presented in italics reflect that that particular study did not find evidence for the role of examined requirement or even that it has had the opposite effect from what was expected. 
An Assessment of Anti-Piracy Interventions: Requirements for the Three Mechanisms

\begin{tabular}{|c|c|c|}
\hline $\begin{array}{l}\text { Rochelandet and Le } \\
\text { Guel (2005) }\end{array}$ & $\begin{array}{l}\text { Four levels of risk were examined } \\
\text { that influenced the perceived } \\
\text { certainty of being caught. }\end{array}$ & $\begin{array}{l}\text { The expected negative impact of the } \\
\text { risk of being caught was not found. }\end{array}$ \\
\hline \multicolumn{3}{|c|}{ Certainty of punishment } \\
\hline Li and Nergadze (2009) & $\begin{array}{l}\text { The perceived certainty of } \\
\text { punishment was studied, which was } \\
\text { measured with regard to three } \\
\text { aspects of certainty of being caught } \\
\text { and punished. }\end{array}$ & $\begin{array}{l}\text { Certainty of punishment has a } \\
\text { negative relationship with current } \\
\text { digital piracy practices }(\boldsymbol{\beta}=-\mathbf{0 . 3 7}) \text {, } \\
\text { the volume thereof }(\boldsymbol{\beta}=\mathbf{- 0 . 4 2}) \text { and } \\
\text { intended future digital piracy }(\beta=- \\
\mathbf{0 . 3 8}) \text {. Therefore, individuals who } \\
\text { perceive more certainty are less } \\
\text { likely to pirate content digitally. }\end{array}$ \\
\hline Jeong and Lee (2010) & $\begin{array}{l}\text { The likelihood of the punishment } \\
\text { ranged between } 0 \%, 5 \% \text { and } 10 \% \text {. In } \\
\text { this experiment, either the } \\
\text { government or content owners } \\
\text { would bring legal action against the } \\
\text { infringers. }\end{array}$ & $\begin{array}{l}\text { A } 1 \% \text { increase in the certainty of } \\
\text { punishment for file sharing } \\
\text { reduced the price users were } \\
\text { willing to pay for a pirated copy by } \\
\mathbf{\$ 0 . 9 6 .}\end{array}$ \\
\hline d'Astous et al. (2005) & $\begin{array}{l}\text { Deterrent information consisted of } \\
\text { informing the respondent that a } \\
\text { special police division from the } \\
\text { Royal Canadian Mounted Police had } \\
\text { been set up to identify and prosecute } \\
\text { pirates, increasing the certainty of } \\
\text { punishment. }\end{array}$ & $\begin{array}{l}\text { Higher levels of perceived personal } \\
\text { consequences have a negative } \\
\text { impact on attitudes towards music } \\
\text { piracy }(\boldsymbol{\beta}=-\mathbf{0 . 1 7}) \text { and the intention } \\
\text { to engage in piracy }(\boldsymbol{\beta}=\mathbf{- 0 . 1 8}) \text {. }\end{array}$ \\
\hline $\begin{array}{l}\text { Depoorter, van Hiel, } \\
\text { and Vanneste (2011) }\end{array}$ & $\begin{array}{l}\text { The experiment varied in the } \\
\text { certainty of punishment (low: } 0.01 \% \\
\text { and high: } 20 \% \text { ). }\end{array}$ & $\begin{array}{l}\text { Respondents in the high } \\
\text { severity/low certainty condition } \\
\text { reported that they would pirate less } \\
\text { than the respondents in the low } \\
\text { severity/high certainty condition. }\end{array}$ \\
\hline $\begin{array}{l}\text { Chiu, Hsieh, and Wang } \\
\text { (2008) }\end{array}$ & $\begin{array}{l}\text { Private industries taking action and } \\
\text { investigating piracy was examined, } \\
\text { as well as the fact that industry } \\
\text { would consult the government in } \\
\text { relation to this. They all had the goal } \\
\text { of increasing the (perceived) } \\
\text { certainty of punishment. }\end{array}$ & $\begin{array}{l}\text { It is demonstrated that such a legal } \\
\text { strategy increases the users' } \\
\text { intentions to purchase legal content } \\
(\boldsymbol{\beta}=\mathbf{0 . 1 5}) \text {. }\end{array}$ \\
\hline
\end{tabular}

Of the eight studies that examined the role of certainty, three studied the certainty of being caught while five focused on the certainty of punishment. All five of these latter studies demonstrate that an increase in the certainty of punishment (or perception thereof) reduces the likelihood of digital piracy. One studied found that this increased certainty also increases the likelihood that digital pirates will purchase the content legally instead (Chiu et al., 2008). Two of the three studies that focused on the certainty of being caught also indicate that an increase in this certainty reduces the likelihood of digital piracy, with one also indicating that this can also make respondents more likely to purchase the desired content legally (Sinha \& Mandel, 2008). The dissenting study of Rochelandet and Le Guel (2005) seems to follow a cross-sectional design but provides only limited information on 


\section{$\underline{\text { Punish, Seduce or Persuade }}$}

the research design used. In contrast, the studies of Sinha and Mandel (2008) and Chiang and Assane (2007) provide more information on the research design. Both studies use a research design that can be identified as a 'pre-experimental design' ${ }^{77}$ The size of the body of knowledge remains limited however. Together, the findings show that influencing the certainty of punishment can be of use in the context of contributing to reductions to digital piracy, though the body of evidence is not overwhelming with regard to the certainty of being caught.

Thus, the results indicate that increasing the (perceived) certainty of punishment is a requirement that needs to be met if anti-piracy interventions using the deterrent mechanism are to contribute to reductions in digital piracy. If met, some reductions in digital piracy are to be expected.

The findings presented in Table 6.1 have to be contextualized however. The studies often presented the respondents with a certainty of being caught or punished that was significantly higher than what tends to be found in practice. Based on the previous discussion, it seems unlikely that implemented anti-piracy intervention that uses the deterrent mechanism would be capable of accomplishing certainties of $20 \%$, let alone $45 \%$. This means that the suggested effects of an increased certainty of punishment on digital piracy might not be as substantial as these studies state. The effects can also be quite small, even if the presented increase in certainty is substantial (Sinha \& Mandel, 2008): an increase in the objective certainty of being caught by $10 \%$ increases the willingness to pay just by US $\$ 0.03$. Thus, certainty matters but it is difficult to predict exactly how large the reductions will be in practice. Overestimating the potential changes in behaviour after implementing measures that are meant to increase the certainty of being caught or punished should thus be avoided.

Other studies have examined the effects of increasing the certainty of punishment by focusing on implemented stick-based anti-piracy interventions. Three specific stick-based interventions are examined in this way: the lawsuits by the RIAA, the implementation of IPRED in Sweden and the implementation of the French HADOPI law. Table 6.2 shows how these implementations have influenced digital piracy. In contrast to most of the studies discussed so far, some of these studies examined actual online behaviour (Adermon \& Liang, 2010, 2014; Danaher et al., 2014), adding to the relevance of their findings. Thus, most of these studies follow a research design that resembles a natural experiment.

\footnotetext{
${ }^{77}$ Pre-experimental designs are arguably the weakest experimental design that can be used, but can be positioned above cross-sectional designs. These are studies that do not use a control group or a pre- and post-measurement (Sackett \& Mullen, 1993)
} 
An Assessment of Anti-Piracy Interventions: Requirements for the Three Mechanisms

Table 6.2: Studies on implemented anti-piracy interventions: a focus on the certainty of punishment

\begin{tabular}{|c|c|}
\hline Study & Outcome \\
\hline \multicolumn{2}{|r|}{ Lawsuits by the RIAA } \\
\hline $\begin{array}{l}\text { La Roche, Flanigan, and } \\
\text { Marks (2004) }\end{array}$ & $\begin{array}{l}\mathbf{4 3 \%} \text { of the sample was more hesitant about pirating content digitally. } \\
\text { Since becoming aware of these lawsuits, } \mathbf{3 5 \%} \text { of the sample who had } \\
\text { previously pirated music had refrained from illegal file sharing. Of the } \\
\text { respondents who knew someone who had been sued for copyright } \\
\text { infringement, only } \mathbf{4 4 \%} \text { admitted to continuing to digitally pirate music. } \\
\text { Moreover, once respondents knew someone who had been sued, } \mathbf{9 2 \%} \\
\text { changed their downloading habits by ceasing, becoming more selective, } \\
\text { or more hesitant to swap files peer-to-peer. }\end{array}$ \\
\hline $\begin{array}{l}\text { Bhattacharjee, Gopal, } \\
\text { Lertwachara, and Marsden } \\
(2006)\end{array}$ & $\begin{array}{l}\text { The majority of digital pirates decreased the number of files shared, } \\
\text { typically by more than } \mathbf{9 0 \%} \text {. However, an upsurge of frequency is } \\
\text { detected at a later stage, from users who continue to use the file-sharing } \\
\text { network. }\end{array}$ \\
\hline \multicolumn{2}{|r|}{ Implementation of the IPRED in Sweden } \\
\hline $\begin{array}{l}\text { Svensson and Larsson } \\
(2012)\end{array}$ & $\begin{array}{l}\text { Before the implementation of IPRED, } 21.6 \% \text { of the respondents reported } \\
\text { that they never pirated and, six months after IPRED, this figure was } \\
\text { almost } \mathbf{3 8 . 9 \%} \text {. At the same time, the percentage of respondents who } \\
\text { claimed to be file sharing on a daily basis decreased from } \mathbf{1 0 . 6 \%} \text { to } \\
\mathbf{6 . 4 \%} \text {. }\end{array}$ \\
\hline $\begin{array}{l}\text { Adermon and Liang } \\
(2010)\end{array}$ & $\begin{array}{l}\text { A decrease of Internet traffic by } \mathbf{1 8 \%} \text { is noted during the first six months } \\
\text { after implementation. The sale of both physical and digital music } \\
\text { increased (by } \mathbf{2 7 \%} \text { and } \mathbf{4 8 \%} \text { ). }\end{array}$ \\
\hline $\begin{array}{l}\text { Adermon and Liang } \\
\text { (2014) }\end{array}$ & $\begin{array}{l}\text { An initial decrease in Internet traffic by } \mathbf{1 6 \%} \text { is noted. The effect is } \\
\text { reduced over time. Likewise, initially, there are increases in both digital } \\
\text { and physical music sales but, over time, these effects vanish, except for } \\
\text { the increase in digital music sales. }\end{array}$ \\
\hline \multicolumn{2}{|r|}{ Implementation of the HADOPI in France } \\
\hline Danaher et al. (2014) & $\begin{array}{l}\text { iTunes sales data demonstrates that single and album sales increased by } \\
\mathbf{2 2 . 5 \%} \text { and } \mathbf{2 5 \%} \text { respectively. Other countries do not demonstrate such } \\
\text { an increase. }\end{array}$ \\
\hline $\begin{array}{l}\text { Arnold, Darmon, Dejean, } \\
\text { and Penard (2014) }\end{array}$ & $\begin{array}{l}\text { It is indicated that a graduated response fails to deter individuals from } \\
\text { pirating content. There is likewise no effect on users who already pirate } \\
\text { content. It is also suggested that some users now use methods that are } \\
\text { unmonitored in order to obtain pirated content. }\end{array}$ \\
\hline $\begin{array}{l}\text { Dejean, Penard, and Suire } \\
\text { (2010) }\end{array}$ & $\begin{array}{l}\text { Digital piracy habits are unlikely to change in a significant manner due } \\
\text { to the graduated response. }\end{array}$ \\
\hline Dejean and Suire (2014) & $\begin{array}{l}\text { Instead of a decrease in digital piracy, it is indicated that different modes } \\
\text { of piracy, such as offline file swapping, have become dominant. This } \\
\text { suggests that pirates have begun to innovate to cope with the graduated } \\
\text { response. }\end{array}$ \\
\hline
\end{tabular}

In contrast to the studies discussed in Table 6.1 (where student samples were used), the studies below vary somewhat with regard to the respondents examined. Some studies used students or young Internet users (La Roche et al., 2004; Svensson \& Larsson, 2012), others focused on users of P2P-networks (Bhattacharjee et al., 2006), general Internet users (Arnold et al., 2014; Dejean et 


\section{$\underline{\text { Punish, Seduce or Persuade }}$}

al., 2010; Dejean \& Suire, 2014), Internet traffic (Adermon \& Liang, 2010, 2014) and sales data (Danaher et al., 2014). As the target population of anti-piracy interventions are young and experienced males, those studies that have used younger respondents are especially insightful. Likewise, using data from a P2Pnetwork is equally relevant, as the users of this service are likely to be digital pirates. In contrast, insights obtained from general Internet users might be less attuned to identifying smaller changes in digital piracy. Sales data, while insightful, might suffer from attribution issues, meaning that it cannot always be established that any changes are indeed due to the implemented intervention.

Table 6.2 suggests that the lawsuits of the RIAA and the IPRED can contribute to more certainty, deterring individuals from pirating content digitally. The results underline the gap that exists between the objective certainty of punishment, which is far too low to solicit a deterrent response, and the perception of this certainty when specific anti-piracy interventions are implemented in real life. Certain aspects, such as previous successful offences or an individual's low self-control, influence the perceptions of the certainty of punishment (Schoepfer, Carmichael, \& Piquero, 2007). Content owners attempt to influence these perceptions in various ways, including using fear appeals (§6.3.7. (infra p. 173)). Piquero et al. (2012) argue that such efforts are important for deterrence to work, as this increases the individual's assessment of the possibility that he will be caught engaging in this behaviour.

An additional element influencing the certainty of punishment is, according to Balch (1980), the fact that punishment must be repeated (or the individual must at least run the risk of being punished repeatedly). Piquero et al. (2012) demonstrate that, once punished, part of the population will re-evaluate their likelihood of being punished as being lower than it initially was, underlining the need for repetition (see also Krawczyk (2009)). Being able to (quickly) repeat the punishment adds to the deterrent effect of such a measure. ${ }^{78}$

'Repeat offenders' in the context of digital piracy also need to be repeatedly met with punishment (or the threat thereof) if they are to be deterred from such actions in a more persistent manner. Monitoring of (online) behaviour (or the perception thereof) is therefore necessary (Balch, 1980). Technological interventions, as long as they are implemented, inherently allow for this repetition. Both civil and criminal law enforcement also allow for some degree of repetition, as new acts of digital piracy can lead to new measures being taken against the individual. But

\footnotetext{
${ }^{78}$ Arguably, there is some overlap between the repetition and certainty of punishment. However, certainty focuses specifically on the individual chance or likelihood that an act of digital piracy is detected and punished. Repetition, in contrast, refers to the likelihood that this punishment can be repeated quickly if the infringing behaviour persists.
} 
this process takes time and repetition is not automatic. The graduated response specifically uses the repetition of the (threat of) punishment as a way to change behaviour, as the subscriber is repeatedly warned about the possible consequences of his actions. After a user has entered the final phase of such a scheme and is penalized, it might take a while before a repeated punishment is possible, somewhat limiting the degree of repetition. It is not clear yet what will be done with subscribers that continue to infringe after regaining access to the Internet. It is expected that they will be given a 'clean slate' and that they will start receiving first notices again. Frequent repetition of the punishment is met, to some degree, by most examples of stick-based interventions, but only technical measures allow for truly frequent and consistent repetition, since they are always present in certain content. This adds to their certainty of being caught or punished.

Two important limitations of the findings presented in this section are observed. Firstly, while it was previously stated that graduated responses might have the highest degree of certainty of the various stick-based interventions, there is limited evidence that this type of intervention can reduce digital piracy, as only one of the four studies that examined this type of intervention reached this conclusion (Danaher et al., 2014). However, if the research designs of these four studies are examined, concerns can be raised on whether some of these studies really add meaningful insights to this discussion. While the study of Danaher et al. (2014) follows, as a research design, the natural experiment, the other studies appear to follow less robust designs. The study of Arnold et al. (2014) tries to approximate a natural experiment but lacks a number of aspects of that particular design (such as a comparison or control group and a pre- and post-measurement). The remaining two studies articulate their design in such a manner that it is difficult to assess their relevance and rigour in the discussion on the effects of the implementation of the HADOPI-intervention (Dejean et al., 2010; Dejean \& Suire, 2014). This makes it challenging to establish the merits of these studies and their findings. Such observations lead to the assessment that the evidence on the graduated response is currently limited and that its functioning has not been demonstrated.

However, only one variant of graduated response has been examined in detail (the French HADOPI). The effects of other implemented variants of this type of intervention have not yet been studied (such as the CAS). As these differ in the way in which they attempt to influence the perceived certainty of punishment, their results might be different. ${ }^{79}$ Secondly, the findings sometimes indicate that, over time, the effect of the implementation on the (perceived) certainty of punishment decreases, reducing the deterrent effect. This is due to the fact that

${ }^{79}$ The CAS will be studied in detail in Chapter 8 , which will provide information that can be used to bridge this existing gap in the knowledge on the graduated responses. 


\section{$\underline{\text { Punish, Seduce or Persuade }}$}

users become aware that they initially overestimated the certainty of being caught or punished. The effects of these stick-based interventions might be relatively short lived.

What may also influence the perception of certainty is the perception of the severity of the punishment. If this severity is perceived as very low or even nihil, the target population can become less worried about the certainty of being caught or punished. This further underlines that both certainty and severity are communicating vessels in the context of deterrence (Paternoster \& Iovanni, 1986).

\subsubsection{Severity of the punishment}

Thus, a deterrent measure needs to be accompanied with a sufficiently severe punishment if the deterrent effect is to take place. The assumption here is that a more severe (or greater) punishment aids the emergence of this deterrent effect to a greater degree (Balch, 1980). As Weinrath and Gartrell (2001) note, most research dealing with the severity of a deterrent measure (in general) have not examined the effect of specific increases in severity but instead tend to generalize their findings (Apel, 2013; Weinrath \& Gartrell, 2001). The more serious crimes obviously incur more severe sanctions (long-term imprisonment), but most legal systems are unlikely to allow such severe sanctions in the context of digital piracy (as defined in this research) (Hansen, 2015). Thus, the severity of the punishment is dependent on the type of stick-based anti-piracy intervention assessed. The legal framework thus presents a maximum sanction for the conduct in question. An exact threshold as to when a measure is sufficiently severe cannot be identified, however, as the body of literature has not established this level for digital piracy. If a more economic approach were to be followed (Kramer, 1990), it could be argued that the costs of the act of digital piracy need to outweigh its benefits for the individual digital pirate. This would result most likely in relatively small fines. If the legal content costs $€ 59.99$ higher than these costs. In fact, since only the digital pirates who are convicted will probably have to pay the fine, price discrimination occurs. The 'costs' of the act of digital piracy should be higher than its 'benefits' (Becker, 1968). The fine should be beyond $€ 59.99$. Of course, given the fact that individual digital pirates tend to pirate large quantities of content, even relatively small fines can quickly add up to substantial fines.

A threshold as to when a deterrent measure is sufficiently severe has been established for other types of deviance, such as for driving under the influence of alcohol. It was found that imprisonment of six months resulted in having the greatest deterrent effect for that type of deviance. Lower sanctions meant that individuals were more likely to reoffend, while higher sanctions did not contribute 
to a greater deterrent effect (Weinrath \& Gartrell, 2001). What is also clear is that individuals tend to under- or over-estimate the severity of a sanction (Kleck, Sever, Li, \& Gertz, 2005; Piquero et al., 2012), meaning that they perceive the severity of the sanction to be lower or higher than they are in practice. ${ }^{80}$ The research on digital piracy has focused on the matter of whether increases in the severity reduce the likelihood of this act occurring, again underlining the importance of the individual's perception in determining whether there will be a deterrent effect. Before these studies are discussed, it is necessary to focus on how objectively severe the punishment is in the context of digital piracy.

In the context of the various civil sanctions some exorbitant sanctions are reported, of up to \$US 3 million in fines in the USA. ${ }^{81}$ The media often reports that the recipients of these sanctions are not very wealthy. Mention is made of cases in which a student or single mother pirated a limited amount of content yet they were fined (up to $\$ 675,000$ in certain cases). These exorbitant fines are often imposed by making a reference to their supposed deterrent effects, the idea being that digital piracy can be sanctioned with fines that, essentially, no individual can pay. This might lead the individual to overestimate the severity of the punishment,

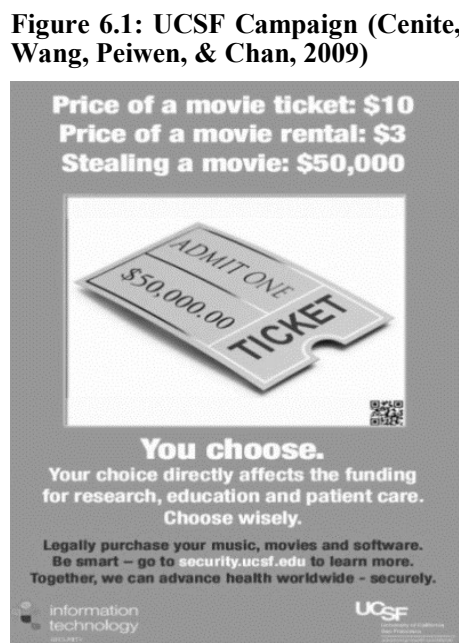
which can increase the likelihood of the individual being deterred, since his perception of the severity is modified.

Since the introduction of the 'copyright troll' strategy in the USA, settlements between \$US 3,000 and \$US 4,000 are the norm (DeBriyn, 2012). This is still quite severe in relation to the act of digital piracy. Other sanctions, such as imprisonment, can be said to be the most severe and can, in theory, be used in certain jurisdictions. However, it is unlikely that judges would apply such a sanction in most of these cases and no study has empirically examined the possible effects of prison sentences on digital piracy. This means that monetary fines are the most severe sanctions that these more classical legal interventions allow.

\footnotetext{
${ }^{80}$ Informing digital pirates on the actual sanctions used against them might therefore have the side-effect of actually reducing their perceived severity of the sanction if they had previously overestimated this severity, as the sanctions used might be lower than what the pirates had expected (Piquero et al., 2012). At the same time, it may also reduce the underestimation of this severity.

${ }^{81}$ These sanctions are often mediated in a later stage by judges, suggesting that these civil sanctions might not be as severe as indicated.
} 


\section{$\underline{\text { Punish, Seduce or Persuade }}$}

In contrast, graduated response schemes use various sanctions. The most severe of these are those measures that disconnect the subscriber from the Internet. ${ }^{82}$ This not only makes repeat instances of digital piracy nearly impossible, but it is also a significant sanction in its own right. Access to the Internet has become a basic need for many and, according to some, has become a human right (Tully, 2014), underlining the severity of this punishment. And while technical interventions often possess a higher level of the certainty of punishment, the sanctions themselves are often quite trivial as they can be avoided, disabled or removed altogether. Blocked websites can easily be reached through proxies, mirrors or alternative web pages. A corrupted file will need to be re-downloaded from a different source but that is also quite easily and quickly done. At best, most of these measures might be seen as inconveniences by most digital pirates, especially by experienced ones.

Can any evidence be found to support the assessment that increasing the severity of the punishment contributes to a reduction in digital piracy? Table 6.3 gives an answer to this question by presenting the findings of those studies that have directly examined the changes to the severity of a measure and its consequences for digital piracy.

Table 6.3: Studies on the severity of the punishment

\begin{tabular}{|c|c|c|}
\hline Study & Intervention & Outcome \\
\hline $\begin{array}{l}\text { Gopal and Sanders } \\
\text { (1997) }\end{array}$ & $\begin{array}{l}\text { Copyright infringement can be } \\
\text { sanctioned with a fine of up to } \$ 1,000 \\
\text { and/or a prison sentence of up to one } \\
\text { year. }\end{array}$ & $\begin{array}{l}\text { Individuals who receive deterrent } \\
\text { information will participate in } \\
\text { smaller piracy peer groups, } \\
\text { meaning that they are less engaged } \\
\text { in digital piracy. }\end{array}$ \\
\hline $\begin{array}{l}\text { Al-Rafee and Rouibah } \\
(2010)\end{array}$ & $\begin{array}{l}\text { Information on new laws, regulations } \\
\text { and the enforcement of laws dealing } \\
\text { with digital piracy. Harsher penalties } \\
\text { and tougher enforcements were } \\
\text { specified. }\end{array}$ & $\begin{array}{l}\text { No statistical difference was found } \\
\text { between pre- and post-exposure } \\
\text { answers. }\end{array}$ \\
\hline $\begin{array}{l}\text { Feldman and Nadler } \\
\text { (2006) }\end{array}$ & $\begin{array}{l}\text { The sanction in this study originated } \\
\text { from the university. Sanctions } \\
\text { became more severe after repeat } \\
\text { infringements, and included } \\
\text { warnings, account suspensions, leave } \\
\text { of absence, and, most severe, } \\
\text { permanent separation from the } \\
\text { university. }\end{array}$ & $\begin{array}{l}\text { These formal sanctions led to a } \\
\text { significant decrease in the } \\
\text { individual's intention to pirate } \\
\text { content digitally }(\mathbf{M = 5 . 2 0} \\
\text { compared to } \mathbf{M = 6 . 6 1 )} \text { when no } \\
\text { such sanction is in place. }\end{array}$ \\
\hline Depoorter et al. (2011) & $\begin{array}{l}\text { Respondents were exposed to low or } \\
\text { high severities of punishment for }\end{array}$ & $\begin{array}{l}\text { Respondents in the high } \\
\text { severity/low certainty condition } \\
\text { reported that they would pirate less }\end{array}$ \\
\hline
\end{tabular}

${ }^{82}$ Most severe in comparison to the other measures that the graduated responses typically allow, such as reduced Internet speeds or the usage of pop-ups. 
An Assessment of Anti-Piracy Interventions: Requirements for the Three Mechanisms

\begin{tabular}{|c|c|c|}
\hline & $\begin{array}{l}\text { each pirated song, with the former } \\
\text { being } \$ 20 \text { and the latter } \$ 20,000 \text {. }\end{array}$ & $\begin{array}{l}\text { than the respondents in the low } \\
\text { severity/high certainty condition. }\end{array}$ \\
\hline $\begin{array}{l}\text { De Corte and Van } \\
\text { Kenhove (2015) }\end{array}$ & $\begin{array}{l}\text { Respondents read an article from a } \\
\text { local newspaper covering the house } \\
\text { searches, arrests, and hardware } \\
\text { confiscations of website hosts and the } \\
\text { shutdown of two websites, although a } \\
\text { fictitious paragraph was added } \\
\text { stating that a number of end users } \\
\text { also faced administrative fines. }\end{array}$ & $\begin{array}{l}\text { Although this strategy was effective } \\
\text { in changing perceptions of } \\
\text { illegality and impunity in most } \\
\text { segments, it did not significantly } \\
\text { lower pirating intentions in any } \\
\text { segment. Moreover, it actually } \\
\text { resulted in an increase in pirating } \\
\text { intentions for certain digital } \\
\text { pirates. }\end{array}$ \\
\hline
\end{tabular}

Surprisingly few studies have examined this requirement and there are some differences in the findings. The study of De Corte and Van Kenhove (2015) found some evidence that increasing the severity of the punishment might be counterproductive, while the study of Al-Rafee and Rouibah (2010) found no evidence of the role of severity. Still, the remaining studies underline that there are merits to meeting this requirement and their research designs are relatively robust. Two of these studies followed the pre-experimental design (Feldman \& Nadler, 2006; Gopal \& Sanders, 1997). However, the study of Al-Rafee and Rouibah (2010) used a quasi-experimental design while the study of De Corte and Van Kenhove (2015) also uses a pre-experimental design, meaning that their findings are not without merit. When taken together, it seems that a more severe punishment alone not necessarily contributes to a reduction in digital piracy, in contrast to what was expected.

In fact, it is not just a matter of having sufficiently severe deterrent measures in place, as increases in objective severity do not necessarily increase the perceived severity of the measures, as some studies have demonstrated (Jacobs \& Piquero, 2012; Kleck \& Barnes, 2008; Kleck et al., 2005; Paternoster, 2010). ${ }^{83}$ As Jacobs and Piquero (2012) note, little is known about this kind of perception and how it is formed by individuals, as the focus has been on the objective aspect of severity. Fear appeals can be used to influence the perceived severity of the punishment (Pogarsky, Piquero, \& Paternoster, 2004).

What can also affect the severity of the sanction or the perception thereof are issues with regard to the execution of the punishment. As was reported, the fines that digital pirates may end up paying can be exorbitant in certain jurisdictions, sometimes ranging in the hundreds of thousands of US dollars. A college student is unlikely to be able to pay this. But even concerning the smaller fines and settlements of around $\$ 3,000$, the question remains whether or not these fines are

${ }^{83}$ Some go even further and suggest that there might not even be a relationship between the actual risks of punishment and the perceptions thereof by individuals (Kleck \& Barnes, 2008). Others however do find evidence for the suggested effects of the objective aspect of deterrence (Scheider, 2001). 


\section{$\underline{\text { Punish, Seduce or Persuade }}$}

paid by the digital pirate. This connects to a limitation of the concept of deterrence: wealth constraints. Wealth constraints refer to the notion that the deterrent effects of fines (in particular) will decrease if the individual simply does not have the means to pay the fine. When using fines to deter individuals, the size of the fine should be matched (as far as possible) with the wealth of the offender, but not beyond what the individual can pay (Emons, 2003). When using fines in the context of digital piracy, it may be beneficial to make a distinction between low-wealth and high-wealth offenders and differentiate the fines based on this distinction (Polinsky, 2006). In the context of digital piracy, it is likely that many digital pirates (particularly those that are students) do belong to the low-wealth category. Having (very) high fines might therefore be counterproductive as this hampers the deterrent effect. At the same time, the fine must still be sufficiently high so that the 'costs' of digital piracy outweigh the 'benefits'. This might be a challenge for governments and the creative industry alike.

In addition to the inability of certain digital pirates to pay the fines, it is also possible that the governments or the creative industry is not always actively trying to execute the sanction. This can also negatively influence the effect of the stickbased measures. If some of the fines are not paid, either wholly or partially, the deterrent effect can be reduced as the (perceived) severity of the measure decreases. There are currently no insights available that illustrate the part or portion of the fines or settlements which are paid in the context of digital piracy. However, not executing a sanction fully or even partially is not an uncommon issue when it comes to the enforcement of fines in a general sense (Hillsman \& Mahoney, 1988; Olson \& Ramker, 2001).

A few examples can be used to illustrate this problem further and support the assumption that it can also be present in the context of digital piracy. In the Netherlands, the enforcement tool known as asset confiscation (voordeelsontneming) ${ }^{84}$ is used to reclaim the financial gains obtained by convicted criminals via their criminal acts. Between 1995 and 2011, there were almost 3,000 cases in which the confiscated amount consisted of $€ 10,000$ or more. These various asset confiscations resulted in almost $€ 300$ million in outstanding 'accounts' for convicted criminals, but only around $20 \%$ was received in payment. Around $€ 230$ million had not yet been received by the government by 2012 and may never be recouped (Van Duyne, Kristen, \& de Zanger, 2015). With regard to the collection of municipal penal orders ${ }^{85}$, it is clear that around $25 \%$ of the fines imposed between 2009 and 2012 have not yet been executed, despite the fact that

\footnotetext{
${ }^{84}$ Article $36 \mathrm{e}$ of the Criminal Code of the Netherlands.

${ }^{85}$ These orders deal with minor infringements, such as consuming alcohol in public, urinating in public or not having one's dog on a leash.
} 
the fines issued were often small (maximum of $€ 390,-)$ and the cases were simple (Flight, Hartmann, \& Nauta, 2012). A final example comes from the enforcement of tax law. Here, the documented gap between the taxes owed and taxes received by the government is known as the 'tax gap'. Although part of this gap is caused by the fact that individuals underreport their income (or simply fail to do so altogether), part of it is attributed to the fact that tax agencies simply fail to collect the taxes owed. Such gaps are common in most countries (Hochman, 2009). From these three examples, clear problems exist with regard to the execution of sanctions, criminal or otherwise.

This discussion leads to the observation that some interventions do not possess 'implementation fidelity', e.g., evidence that the intervention (in this case, the punishment) has been implemented as it was designed (by succeeding in executing the sentence fully) (Carrol et al., 2007). The fact that there can be a gap between the sanction imposed and the execution thereof has an influence on the deterrent effect of a measure. If individuals are aware of the fact that, even if they are sanctioned officially, there is a substantial chance that they will not have pay the whole fine, they are less likely to be deterred as the severity of the measure decreases. It is quite possible that such an issue also emerges in the context of digital piracy. Recalling the $\$ 675,000$ fine imposed on some individuals, it seems unlikely that this amount will ever be paid fully, negatively influencing the severity of the deterrent measure and the perception thereof, given the issues inherent in the collection and enforcement of monetary fines.

What also adds to the severity of the punishment is the ability to vary the punishment. This means that a deterrent measure should not repeatedly use the exact same punishment, as repetition can result in habituation which will hamper the deterrent effect (Brons, Hilhorst, \& Willemsen, 2008; Van der Laan, 2004). If this aspect of the severity of the punishment is not considered, the deterrent effect will become less persistent over time. Habituation is possible in relation to certain anti-piracy interventions that use the deterrent mechanism. As punishment such as prison sentences are rare and sanctions such as community service or conditional punishments have not been found in the inventory discussed in Chapter 5, the variation in imposed punishments is inherently limited, as fines tend to be tool of choice. More variation is likely in the context of the graduated response schemes, as each phase of these schemes comes with different warnings and punishments, cumulating in the most severe punishment: disconnection from the Internet. In contrast, technical measures vary least as the punishment used for specific content is always the same: DRM techniques will always mean that a file is not usable, nothing more and nothing less. This makes the issue of habituation more pressing in the context of those anti-piracy interventions. Digital pirates 


\section{$\underline{\text { Punish, Seduce or Persuade }}$}

come to expect that they will be unable to use certain pirated content and accept this as a possible outcome of their activities. Being deterred in this way becomes less likely.

It is possible that these identified problems not only have an influence on the severity of the deterrent measure but also influence the (perception of the) certainty of being punished. If individuals become aware of the fact that a measure, although severe on paper, is in practice 'toothless', is might render the certainty of the punishment inert, as individuals may have a chance of being caught but not of being punished. This further illustrates that severity, on its own, is unlikely to trigger a deterrent effect.

\section{Text Box 6.1: Empirical assessment of technical anti-piracy interventions}

Technical anti-piracy interventions modify both the certainty and severity of punishment simultaneously. Certainty, as these technical interventions are almost always encountered by users (such as DRM technologies) and severity as they carry with them a specific sanction, such as being unable to access a specific website. Instead of separating these matters, these interventions and their contribution to reductions in digital piracy are discussed together.

Two types of technical stick-based interventions have been studied empirically: the usage of DRM technologies and the blocking of digital piracy-affiliated websites. With regard to DRM techniques, studies state that the likelihood of digital piracy even increases when such techniques are implemented (Choi, Bae, \& Jun, 2010; Djekic \& Loebbecke, 2007; Jaisingh, 2007; Petrick, 2004).

The result of shutting down websites is more mixed. Danaher and Smith (2014) demonstrate that shutting down a popular digital piracy website (Megaupload) may have led to an increase in legal sales. On the other hand, Lauinger et al. (2013) state that such a takedown only affects a small fraction of the available pirated content, limiting the overall impact of such a measure. Finally, Poort, Leenheer, van der Ham, and Dumitru (2014) indicate that a large segment (around 70\%) of digital pirates is nonresponsive to such a blockade or takedown and will instead look elsewhere for pirated content. The amount of digital piracy has remained stable or even increased, despite this blockade. Collectively, the technical measures, though possessing both a high degree of certainty and severity of the punishment in theory, seem to fail to contribute to reductions in digital piracy.

6.1.3. Complementary with the carrot: the stimulation of alternative behaviour

While stick-based interventions are primarily used to deter individuals, they function best if the desired behaviour is simultaneously stimulated, as the suppression of undesired behaviour is most likely to occur when the alternative desired behaviour is reinforced (Balch, 1980). This reinforcement is accomplished by offering rewards or incentives to the recipients of stick-based interventions to purchase the content legally instead of pirating the digital content (Akers, Krohn, Lanza-Kaduce, \& Radosevich, 1979). While these rewards themselves are discussed in the following sections, the deterrent mechanism 
clearly benefits from stimulating acceptable or desired behaviour, as this improves the likelihood that stick-based interventions can contribute to reductions in digital piracy. This is due to the fact that the alternative behaviour is presented as an acceptable way to fulfil the individual's desire to obtain and enjoy the content. Put differently, if an individual is punished (or exposed to the threat thereof), he needs to be aware of which alternative behavioural options are desired by the content owners or governments in order to avoid future punishment. This stimulation is linked to the reinforcement of behaviour. If an individual anticipates a particular reward that is associated with his behaviour, he might be more likely to act in this manner in the future. Carrot-based interventions obviously directly stimulate this behaviour, but some stick-based interventions can also guide individuals towards the desired behaviour. Stick-based interventions can directly inform the digital pirates on alternative ways to obtain content in a legal manner. This stimulation has been demonstrated in relation to tax law, where rewarding tax payers for 'good' behaviour increased their tax compliance (Feld \& Frey, 2007).

However, not all stick-based interventions succeed in guiding individuals towards the desired behaviours. Technological interventions are rather one-dimensional, as they are embedded in the content itself and come without messages or information for its users. They thus fail to stimulate alternative behaviour. A similar conclusion can be drawn from the more traditional methods used for the enforcement of copyrights. Criminal law is not concerned with stating which behaviour is desired but only identifying what is not allowed. Most civil law enforcement techniques, likewise, are not interested in stimulating desired behaviour. This is especially true for settlements sought after by the so-called 'copyright trolls', who claim that digital piracy can be made into profit (DeBriyn, 2012; Schmitz \& Ries, 2012). For these strategies, there might be no benefit of informing users about the alternative, legal ways to acquire content, as individuals who cease to pirate content digitally are no longer a source of revenue for these firms. 
Other stick-based interventions clearly do stimulate alternative behaviour, such as the various graduated response schemes. The educational messages of these responses come into play here: in addition to the fact that the subscriber is warned that his infringing behaviour has been detected, he is also informed about the legal alternatives

Figure 6.2: Stimulation of alternative behaviour by the

\section{CÂS (Sinclair \& Green, 2016)}

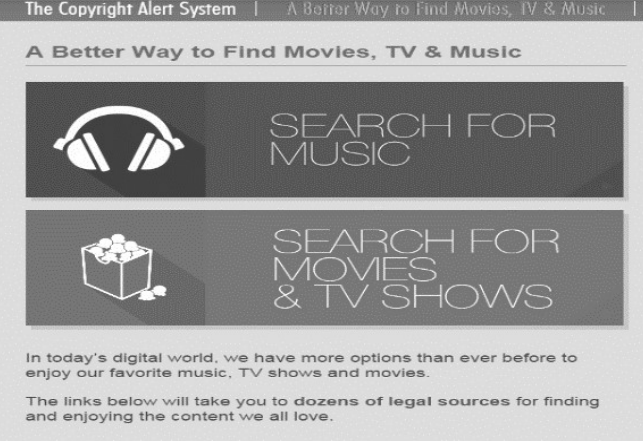
through which the content can be acquired, which is meant to stimulate obtaining this content in alternative ways (see Figure 6.2).

In sum, most (empirical) evidence points to the relevance of the (perceived) certainty, though there is less clarity on the role that the severity of punishment plays in this regard. There is some theoretical merit to the stimulation of alternative behaviour, but not all stick-based anti-piracy interventions succeed in meeting this requirement. There is also no empirical validation that meeting this requirement would have increased the contribution of stick-based anti-piracy interventions to the reduction in digital piracy.

\subsection{Requirements for interventions using the incentive-mechanism}

Carrot-based interventions function by offering an incentive. This incentive can take various forms, one of them being the price that content owners ask for legal content. This price needs to be sufficiently attractive in order for the individual to consider the incentive to be tempting. Lower prices will increase the attractiveness of the incentive. In addition to (1) price, three other identified and important requirements are examined; 2) the consideration of non-financial incentives, 3 ) the complexity of the behaviour and 4) the avoidance of bad news perceptions. The second requirement means that if other types of incentives (beyond simply price-related ones) are present, the attractiveness of the legal content will increase. Furthermore, the easier (or less complex) the desired behaviour is to perform, the more likely it is that individuals will act in this manner. Finally, the framing of the incentive is important. The discussed incentives can be framed positively or negatively. However, framing the incentive in a negative manner does not make the legal content more attractive to the target population. A positive framing is therefore preferred. 


\section{An Assessment of Anti-Piracy Interventions: Requirements for the Three Mechanisms}

6.2.1. The attractiveness of the incentive: introducing lower prices

Balch (1980) states that increasing the size and certainty of the incentive will increase the attractiveness of the incentive, which in turn makes the desired behaviour more likely (Adams, Giles, Robalino, McColl, \& Sniehotta, 2012). The main way through which the size of the incentive is determined in the context of digital piracy is decreasing the price that users have to pay in order to obtain and enjoy the legal content, as was discussed in detail in §5.3.1. (supra p. 121). The question is whether these reductions in price are sufficiently large to contribute to reductions in digital piracy. One way to answer this question is by examining the price that users are willing to pay for legal content and contrast this with what this content actually costs. ${ }^{86}$ On average, a digital single will cost around $€ 0.99$ and a full digital album around $€ 9.99$. Table 6.4 demonstrates that the average price users are willing to pay for music content is close to this price. Some of the price reductions or sales might even surpass the price users are willing to pay for legal content, especially when prices are discounted during sales. The size of the incentive might be sufficient for some users, considering the Table below.

Table 6.4: Willingness to pay for (digital) music

\begin{tabular}{|c|c|c|}
\hline Study & Singles & Albums \\
\hline Chiang and Assane (2009) & $\$ 0.66$ & $\mathrm{n} / \mathrm{a}$ \\
\hline \multirow{2}{*}{$\begin{array}{l}\text { Makkonen, Haltunnen, and Frank } \\
\text { (2011) }\end{array}$} & Males: $€ 0.82$ & Males: $€ 7.75$ \\
\hline & Females: 0.99 & Females: €9.18 \\
\hline Sinha and Mandel (2008) & $\$ 0.47$ & $\mathrm{n} / \mathrm{a}$ \\
\hline Dutch respondents in empirical study ${ }^{87}$ & $€ 0.69$ & $€ 7.50$ \\
\hline $\begin{array}{llll}\begin{array}{l}\text { Belgian } \\
\text { study }\end{array}{ }^{88} & \text { respondents in empirical } \\
\end{array}$ & $€ 0.65$ & $€ 7.45$ \\
\hline Rob and Waldfogel (2006) & $\mathrm{n} / \mathrm{a}$ & $\$ 12.70-\$ 15.25$ \\
\hline Sinha et al. (2010) & $\$ 0.69-\$ 0.85$ & $\mathrm{n} / \mathrm{a}$ \\
\hline Regner and Barria (2009) & $\mathrm{n} / \mathrm{a}$ & $\$ 8.20$ \\
\hline Sandulli (2007) & $€ 0.46$ & $\mathrm{n} / \mathrm{a}$ \\
\hline
\end{tabular}

The average willingness to pay hides the fact, however, that some respondents are not willing to pay anything for legal content at all. Even if the price is close to the amount users are on average willing to pay, it is questionable whether or not the pricing strategy will work for these individuals. Regardless of how low the price of legal content is, the price some users are willing to pay will be lower or even zero.

\footnotetext{
${ }^{86}$ As most insights on the willingness to pay focus on music, this type of content is used to examine this

${ }^{87}$ See $\$ 2.2 .2$. (supra p. 35) for a more in-depth discussion.

${ }^{88}$ See $\$ 2.2 .2$. (supra p. 35) for a more in-depth discussion.
} 


\section{$\underline{\text { Punish, Seduce or Persuade }}$}

Only limited information on the price users are willing to pay for other types of content is available. Hsu and Shiue (2008) report that the willingness to pay for software packages such as Microsoft Office was around US\$ 54. However, such packages can cost up to US\$ 149 or even more when purchased legally, there is a clear discrepancy between the price asked by the content owners and the individuals' willingness to pay for this legal content.

A different way to examine the relevance of the size of the incentive is by measuring whether a reduction in the price would also reduce digital piracy. Table 6.5 presents the findings of studies that have attempted to measure these reductions.

Table 6.5: Studies on the introduction of pricing strategies

\begin{tabular}{|c|c|c|}
\hline Study & Change in price & Outcome \\
\hline Chiu et al. (2008) & $\begin{array}{l}\text { It is examined whether a } \\
\text { lower price of content } \\
\text { (software) makes it more } \\
\text { likely that legal content is } \\
\text { purchased. }\end{array}$ & $\begin{array}{l}\text { Pricing strategies have significant } \\
\text { positive impact on the purchasing } \\
\text { intentions for legal products }(\boldsymbol{\beta}=\mathbf{0 . 2 5}) \\
\text { although it is suggested that the } \\
\text { impact of this intervention is } \\
\text { dependent on the type of piracy. }\end{array}$ \\
\hline Chiang and Assane (2007) & $\begin{array}{l}\text { Lower prices of legal fee- } \\
\text { based music services. }\end{array}$ & $\begin{array}{l}\text { A low willingness to pay for music } \\
\text { results in a high proportion of pirated } \\
\text { music, and vice versa. When students } \\
\text { exhibit willingness to pay that is less } \\
\text { than } \$ 0.25 \text { per song, about } 50 \% \text { of } \\
\text { individual music collections are } \\
\text { acquired via digital piracy; this } \\
\text { percentage drops to roughly } \mathbf{1 0} \% \\
\text { when the value is above } \$ 1.50 \text {. A } 10 \% \\
\text { increase in willingness to pay leads to } \\
\text { between a } 0.7 \% \text { and } 0.8 \% \text { decrease in } \\
\text { file-shared music. }\end{array}$ \\
\hline Maffioletti and Ramello (2004) & $\begin{array}{l}\text { A decrease in the price of } \\
\text { legal content. Both the } \\
\text { effect of full and lower- } \\
\text { priced content on digital } \\
\text { piracy was examined. }\end{array}$ & $\begin{array}{l}\text { The price users are willing to pay is } \\
\text { lower }(€ 9-€ 11) \text { than the full price of a } \\
\text { product }(€ 18-€ 20) \text {. At prices lower } \\
\text { than the full price, but which still } \\
\text { allow for profits, the legal market } \\
\text { should increase while copying and } \\
\text { digital piracy decrease. }\end{array}$ \\
\hline Veitch and Constantiou (2012) & $\begin{array}{l}\text { Both the product } \\
\text { desirability and the price } \\
\text { perception of the product } \\
\text { were examined. This } \\
\text { refers to the positive or } \\
\text { negative difference } \\
\text { between one's reference } \\
\text { price for a film or music }\end{array}$ & $\begin{array}{l}\text { If the price perception is positive, } \\
\text { meaning that the cost of content is } \\
\text { within the limits of what a user is } \\
\text { willing to pay, it is positively related } \\
\text { to the decision to use each of the legal } \\
\text { access modes. }\end{array}$ \\
\hline
\end{tabular}


An Assessment of Anti-Piracy Interventions: Requirements for the Three Mechanisms

\begin{tabular}{|c|c|c|}
\hline & $\begin{array}{l}\text { title and one's } \\
\text { willingness to pay for it. }\end{array}$ & \\
\hline Sandulli (2007) & $\begin{array}{l}\text { Price is directly } \\
\text { examined. }\end{array}$ & $\begin{array}{l}\text { Higher prices of legal content make it } \\
\text { less likely that the content is } \\
\text { purchased instead of pirated ( } \beta=- \\
\mathbf{0 . 5 7} \text { ). }\end{array}$ \\
\hline Bhattacharjee et al. (2003) & $\begin{array}{l}\text { It is examined whether } \\
\text { higher prices result in } \\
\text { more digital piracy. }\end{array}$ & $\begin{array}{l}\text { An elastic relationship between price } \\
\text { and digital piracy is depicted. Higher } \\
\text { prices therefore lead to more piracy. } \\
\text { As more content becomes available } \\
\text { illegally, it is necessary for the price } \\
\text { of legal content to decrease in order to } \\
\text { positively impact the purchase } \\
\text { decision. }\end{array}$ \\
\hline Dörr et al. (2013) & $\begin{array}{l}\text { The availability of } \\
\text { services based on a 'flat } \\
\text { rate } 89 \text { is examined. }\end{array}$ & $\begin{array}{l}\text { Flat rates are regarded as an attractive } \\
\text { pricing model by music pirates and } \\
\text { this constitutes a suitable alternative } \\
\text { to pay-per-download, which is often } \\
\text { considered to be too expensive. }\end{array}$ \\
\hline $\begin{array}{l}\text { Camarero, Antón, and } \\
\text { Rodríguez (2014) }\end{array}$ & $\begin{array}{l}\text { The role of the price of e- } \\
\text { books and the acceptance } \\
\text { of this price is examined } \\
\text { in the context of digital } \\
\text { piracy. }\end{array}$ & $\begin{array}{l}\text { The less e-reader owners are willing } \\
\text { to pay for e-books, the greater their } \\
\text { tendency to pirate this content ( } \beta=- \\
\mathbf{0 . 1 5 2} \text { ). }\end{array}$ \\
\hline
\end{tabular}

From Table 6.5, the observation emerges that reducing the cost of legal content to what users are willing to pay is a strategy worth considering for content owners. Lower prices do seem to attract more legal content consumption and less digital piracy. The fact that the perception of the price (e.g., whether the individual subjectively believes that the content is too expensive or, conversely, acceptably priced) is also relevant in making the content more attractive means that content owners also need to consider how they promote the content.

A different price-related development is the emergence of streaming services such as Spotify. Content can be enjoyed for free on these services, as most revenue is generated by advertisements (Aguiar \& Waldfogel, 2015). As it is often stated: 'you cannot compete with free', (Miller, 2004-2005) but providing free legal content is the closest the creative industry can get to truly competing with digital piracy and provides the greatest incentive possible to use legal content. This can convert those digital pirates that have become frustrated with the unreliability of pirated digital content (Mousley, 2003). This approach is not an option for all markets equally. Not all content can therefore be offered for free. And even if the price is zero, individuals might still not opt to stream the content legally, as having to listen to frequent and repetitive advertisements can frustrate users (Delikan,

${ }^{89}$ A usage-independent cost that is incurred during the selection of the service rather than during consumption. 


\section{$\underline{\text { Punish, Seduce or Persuade }}$}

2011). This demonstrates that even offering content for free might not always tempt individuals to use and enjoy content in a legal manner.

\subsubsection{Consideration of non-financial incentives}

Certain carrot-based interventions use non-financial incentives to persuade users to obtain content legally (Balch, 1980). Overall, there are a few different types of non-financial incentives in the context of digital piracy. One of these is the additional features offered by services such as Spotify. It offers a number of services 'especially for you' (the user). This also personalizes the incentive. Users can use Spotify to discover new music they will 'love'; 'your new favourite songs are waiting for you', shows that listening to music is also an emotive experience. Finally, Spotify is also a social platform that connects the user to other users. Similar features can be found in, for example, iTunes, Steams and Pathé Thuis services. The removal of DRM technologies is also a non-financial incentive. A different non-financial incentive is the new distribution methods used by the creative industry. Many of the carrot-based anti-piracy interventions discussed use these methods to make the incentive available in an easy, swift and certain manner. This is meant to improve the attractiveness of these incentives. This raises the question as to whether or not such non-financial incentives can contribute to reductions in digital piracy. Table 6.6 provides an overview of various non-financial incentives.

Table 6.6: Studies on the various non-financial incentives

\begin{tabular}{|c|c|c|}
\hline Study & Intervention & Outcome \\
\hline \multicolumn{3}{|c|}{$\begin{array}{c}\text { Availability of legal content } \\
\end{array}$} \\
\hline Kunze and Mai (2007) & $\begin{array}{l}\text { Access to online retail } \\
\text { services. }\end{array}$ & $\begin{array}{l}\text { Particularly non- and light-downloaders } \\
\text { indicated that they are more likely to use } \\
\text { such a distribution service. However, it is } \\
\text { also likely that a segment of heavy } \\
\text { downloaders would also adopt this service. } \\
\text { It is not indicated whether this would also } \\
\text { result in a decrease in digital piracy. }\end{array}$ \\
\hline $\begin{array}{l}\text { Veitch and } \\
\text { Constantiou (2012) }\end{array}$ & $\begin{array}{l}\text { It was examined whether the } \\
\text { direct availability of content } \\
\text { has an influence on the } \\
\text { decision to purchase content. }\end{array}$ & $\begin{array}{l}\text { The availability of legal content was } \\
\text { positively related to the decisions to legally } \\
\text { acquire content. }\end{array}$ \\
\hline Danaher et al. (2010) & $\begin{array}{l}\text { The impact of the removal of } \\
\text { such content from legal } \\
\text { venues on having access to } \\
\text { content (movies) is } \\
\text { examined. }\end{array}$ & $\begin{array}{l}\text { After the removal of this content from the } \\
\text { legal venues, the pirating of this content } \\
\text { increased. After the reintroduction of this } \\
\text { content on these legal venues, digital piracy } \\
\text { rates reduced. }\end{array}$ \\
\hline Sandulli (2007) & $\begin{array}{l}\text { A larger assortment of legal } \\
\text { content offered, the ease of }\end{array}$ & $\begin{array}{l}\text { Larger assortments of music on P2P- } \\
\text { networks result in more digital piracy, }\end{array}$ \\
\hline
\end{tabular}


An Assessment of Anti-Piracy Interventions: Requirements for the Three Mechanisms

\begin{tabular}{|c|c|c|}
\hline & $\begin{array}{l}\text { use of this content, the } \\
\text { flexibility of use (selecting } \\
\text { individual songs instead of } \\
\text { full albums), and a way to } \\
\text { sample and discover new } \\
\text { content are factors that are } \\
\text { examined in the context of } \\
\text { content consumption. }\end{array}$ & $\begin{array}{l}\text { suggesting that, if legal services also offer } \\
\text { greater degrees of assortment, it might } \\
\text { motivate individuals to purchase content. } \\
\text { Improving the amount of new content can } \\
\text { also influence purchase decisions. In } \\
\text { addition, it is also demonstrated that the } \\
\text { discovery of new content is a contributor to } \\
\text { digital piracy, meaning that, if new } \\
\text { distribution methods allow for an easier way } \\
\text { to discover such content, it can positively } \\
\text { influence the individual's decision to access } \\
\text { this content legally. }\end{array}$ \\
\hline $\begin{array}{lll}\text { Poort } & \text { and } & \text { Weda } \\
(2015) & & \end{array}$ & $\begin{array}{l}\text { Greater availability of legal } \\
\text { content over time. }\end{array}$ & $\begin{array}{l}\text { Pirated music declined from } 35 \% \text { of the } \\
\text { population to } 22 \% \text {. For movies and series, it } \\
\text { increased from } 11 \% \text { to } 18 \% \text { over this time } \\
\text { span. It is not clear, however, what causes } \\
\text { these opposing trends. It is indicated that the } \\
\text { decrease in digital music piracy is due to the } \\
\text { fact the legal options are perceived } \\
\text { favourably, while this is not the case for } \\
\text { movies. }\end{array}$ \\
\hline Chiu et al. (2008) & $\begin{array}{l}\text { Examined whether } \\
\text { additional features of legal } \\
\text { content, such as extended } \\
\text { services, free updates and } \\
\text { better security, influence the } \\
\text { respondents' willingness to } \\
\text { purchase such content. }\end{array}$ & $\begin{array}{l}\text { They find positive and significant results for } \\
\text { this strategy }(\boldsymbol{\beta}=\mathbf{0 . 2 5}) \text {. The removal of } \\
\text { technical measures is also a non-financial } \\
\text { incentive for users to purchase and use legal } \\
\text { content. }\end{array}$ \\
\hline $\begin{array}{l}\text { Sinha and Mandel } \\
(2008)\end{array}$ & $\begin{array}{l}\text { The removal of DRM } \\
\text { measures on content. }\end{array}$ & $\begin{array}{l}\text { They find that the removal of DRM } \\
\text { measures can convert some digital pirates } \\
\text { into paying customers and increases the } \\
\text { willingness to pay for legal content. This } \\
\text { suggests that these removals do not cause an } \\
\text { increase in digital piracy but rather a } \\
\text { possible increase in sales. }\end{array}$ \\
\hline \multicolumn{3}{|c|}{ Manner of distribution } \\
\hline Koh et al. (2014) & $\begin{array}{l}\text { The impact of legal, iTunes- } \\
\text { like, channels on music } \\
\text { sales. }\end{array}$ & $\begin{array}{l}\text { The availability of legal channels for digital } \\
\text { music weakens the negative effect of online } \\
\text { music digital piracy. }\end{array}$ \\
\hline Clement et al. (2012) & $\begin{array}{l}\text { The impact of the } \\
\text { introduction of new legal } \\
\text { services was examined. Both } \\
\text { a subscription (a legal } \\
\text { version of Napster) and an } \\
\text { ad-based model (Ruckus) } \\
\text { were examined. }\end{array}$ & $\begin{array}{l}\text { The introduction of legal music downloaded } \\
\text { services reduced the extent of favourable } \\
\text { attitudes towards digital piracy. }\end{array}$ \\
\hline Dörr et al. (2013) & $\begin{array}{l}\text { It was examined whether } \\
\text { implementing a distribution } \\
\text { system (Music as a Service, } \\
\text { or MaaS) that allows for } \\
\text { easier, cheaper and quicker } \\
\text { access makes it more likely }\end{array}$ & $\begin{array}{l}\text { Although the study does not indicate that } \\
\text { MaaS can decrease digital piracy in general, } \\
\text { it is suggested that music pirates consider a } \\
\text { free, ad-based, version of Maas to be an } \\
\text { alternative to digital piracy. }\end{array}$ \\
\hline
\end{tabular}


$\underline{\text { Punish, Seduce or Persuade }}$

\begin{tabular}{|c|c|c|}
\hline & $\begin{array}{l}\text { that individuals will } \\
\text { consume content legally. }\end{array}$ & \\
\hline $\begin{array}{l}\text { Quiring, von Walter, } \\
\text { and Atterer (2008) }\end{array}$ & $\begin{array}{l}\text { Various } \text { distribution } \\
\text { methods were examined, } \\
\text { ranging from classical } \\
\text { methods to methods where } \\
\text { levels of revenue are split } \\
\text { between the downloaders } \\
\text { and the right holders is } \\
\text { possible. }\end{array}$ & $\begin{array}{l}\text { Even experienced digital pirates are willing } \\
\text { to change their acts of digital piracy when } \\
\text { confronted with distribution methods that } \\
\text { allow for a degree of revenue splitting. }\end{array}$ \\
\hline Papies et al. (2011) & $\begin{array}{l}\text { Various free, ad-based, } \\
\text { business models were } \\
\text { examined, which varied with } \\
\text { respect to the price or } \\
\text { subscription fees, the usage } \\
\text { of DRM, the presence of } \\
\text { advertisement and the size of } \\
\text { the catalogue. }\end{array}$ & $\begin{array}{l}\text { The advertising-based model has the } \\
\text { potential to attract new customers who } \\
\text { previously did not obtain content in this } \\
\text { manner, thus increasing the market size. The } \\
\text { subscription model is unattractive for most } \\
\text { consumers. A dislike for advertising appears } \\
\text { to strongly impact consumer preferences. }\end{array}$ \\
\hline \multicolumn{3}{|c|}{ Introduction of streaming services } \\
\hline Borja et al. (2015) & $\begin{array}{l}\text { It was examined whether } \\
\text { respondents who used legal } \\
\text { streaming services for music } \\
\text { pirated more or less than } \\
\text { those who did not. }\end{array}$ & $\begin{array}{l}\text { It is indicated that using streaming services } \\
\text { is a strong predictor of digital music piracy. }\end{array}$ \\
\hline Bustinza et al. (2013) & $\begin{array}{l}\text { The introduction of new } \\
\text { business models (such as } \\
\text { unbundling, streaming and } \\
\text { pay as you go). }\end{array}$ & $\begin{array}{l}\text { Newer business models allow for some } \\
\text { recovery of users from digital piracy, } \\
\text { demonstrating that providing access to } \\
\text { content in a way that better suits the } \\
\text { requirements of the users can be effective. }\end{array}$ \\
\hline $\begin{array}{l}\text { Borja and Dieringer } \\
(2016)\end{array}$ & $\begin{array}{l}\text { The introduction of music } \\
\text { streaming services. }\end{array}$ & $\begin{array}{l}\text { Using streaming services increases the } \\
\text { likelihood of piracy by about } 11 \% \text {. College } \\
\text { students do not view streaming as a low- } \\
\text { price substitute to piracy. Most of them } \\
\text { reported that other alternatives to listening } \\
\text { to music are still too expensive and } \\
\text { inaccessible, increasing the likelihood of } \\
\text { piracybehaviour. }\end{array}$ \\
\hline
\end{tabular}

Table 6.6 shows that there are merits to making more content available and to changing the ways in which this content is distributed in the first place. In this manner, the legal content appears to be capable of competing with the pirated copy, which makes it more likely that some individuals decide not to pirate content digitally. The one study that did not find evidence for the role of the availability of legal content used a cross-sectional design (Kunze \& Mai, 2007), while the remaining studies used a natural experiment (Danaher et al., 2010), preexperimental (Sinha \& Mandel, 2008), longitudinal (Poort \& Weda, 2015) or cross-sectional (Chiu et al., 2008; Sandulli, 2007; Veitch \& Constantiou, 2012) designs. The collective findings of these studies underline the relevance of the availability of legal content, namely that offering legal content in a flexible and 
easy manner can influence digital piracy in a manner desired by the creative industry.

Few studies have examined the impact of streaming services on digital piracy, perhaps due to the fact that such services are still relatively new. Of these, the studies of Borja et al. (2015) and Borja and Dieringer (2016) indicate that that individuals who use legal streaming services are also more likely to pirate content digitally, casting doubt on the usage of such services. All three studies that have examined the role of legal streaming services follow a similar cross-sectional design, making it more difficult to contrast the studies in this regard. A possible explanation, according to these scholars, is that individuals who make intensive use of streaming services are also experienced with using digital technologies and therefore feel comfortable with acts of music piracy (Borja et al., 2015). Thus, they use both methods to consume and enjoy content.

\subsubsection{Complexity of the desired behaviour}

Gneezy, Meier, and Rey-Biel (2011) state that the desired behaviour should not be too complex to perform for the individual. The simpler the desired behaviour is, the more likely it is that individuals will follow through with it. This is due to the fact that individuals are more likely to believe that they are capable of being compliant if the behaviour is easy to carry out. In the context of digital piracy, the desired behaviour, purchasing legal content, is quite simple to perform from the outset. It simply requires that an individual stops pirating content (digitally) and instead finds and uses legal content. Through search engines such as Google and services such as iTunes, many options are quickly and easily found. In addition, some services such as Spotify also use commercials to make them better known among the target population. Most legal services are quite user friendly and are 'one-click'-based, often requiring little more than a registered membership and a bank account. Still, there will be some individuals who are unable to access this legal content due to their lack of technological experience.

\subsubsection{Avoidance of negative framing}

Incentives need to be framed positively, as this signals to the target population that the desired behaviour is risk free and beneficial to them. In contrast, presenting the desired behaviour through reference to what has happened to individuals who did not change behaviour (the negative framing) makes it less likely that individuals will change their behaviour. Simply put, incentives can best be presented by referencing to their benefits (positive framing) rather than to the costs of not using the incentives (Gneezy et al., 2011; Rothman \& Salovey, 1997). 


\section{$\underline{\text { Punish, Seduce or Persuade }}$}

This requirement is clearly met by all the carrot-based interventions, as the act of obtaining content in a legal manner is, by its nature, easy to perform.

\subsection{Requirements for interventions using the persuasive mechanism}

Sermon-based interventions present information to the target population and this information is meant to persuade the target population to act differently. All sermon-based interventions share four requirements: 1) the ease of the desired behaviour (Fujii, 2006), 2) the introduction of novel content or information (Abroms \& Maibach, 2008), 3) the believability of the message (Weiss \& Tschirhart, 1994), and 4) the use of positive symbols in the message (Schneider \& Ingram, 1990). In addition, each of the three forms of persuasion (see $§ 5.4$. (supra p. 128)) has one specific requirement. Sermons that inform individuals on the benefits of legal content need to present benefits that are sufficiently clear and large enough. Attempts to educate the target population on the scope and content of copyright laws need to present a message that is in alignment with the norms of the target population. Finally, fear and harm appeals need to present a fear or harm that is meaningful to the target population.

\subsubsection{Ease of the desired behaviour}

A requirement for the success of any sermon-based intervention is that the desired behaviour is easy to accomplish. If the desired behaviour is perceived by the individual as being difficult to perform, he might not attempt to do so, even if he is motivated to do so (Fujii, 2006). The behaviour that sermon-based interventions prescribe (not doing something and/or obtaining content in a legal manner) is specific and easy to perform (§6.2.3. (supra p. 165)), especially if the user is somewhat experienced with the use of the Internet and related technologies. Therefore, the various sermon-based interventions fulfil this requirement. No studies have examined the empirical validation of this requirement in the context of digital piracy, however.

\subsubsection{Introduction of novel information}

Abroms and Maibach (2008) state that sermons have a greater degree of success if they contain novel information for the target population, the reason being that newer information is noticed more easily and considered more seriously by the target population. Yet the information contained in most sermon-based anti-piracy interventions is not new. Campaigns in the context of analogue piracy have used similar information as those of today: piracy is harmful, a type of theft, illegal and immoral and it is better to obtain the content legally. Sermon-based anti-piracy interventions have been applied at least since the 1980s, starting with the 'Home 
Taping is Killing Music' campaign in the UK (see Figure 6.3), which clearly attempted to attribute harm to the act of piracy (Drew, 2014). This underlines that many sermons use messages with information that is not novel. Arguably, none of the examined sermon-based anti-piracy interventions succeed in meeting this requirement. As with the previous requirement, however, no studies examined whether this is relevant in reducing digital piracy.

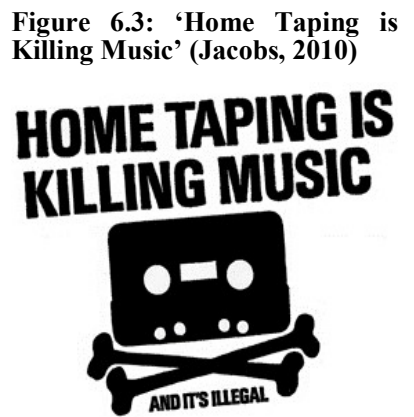

\subsubsection{The believability of the message}

In order for the target population to believe the message, they need to be able to understand it. The message should be clear, credible and easy to understand. More complex messages are more likely to fail to cause behavioural changes (Weiss \& Tschirhart, 1994). Ideally, the message should fit with the prior knowledge of the target population. This is due to the fact that messages are interpreted by target audiences in light of what they already know (Weiss \& Tschirhart, 1994). The message that is presented by sermon-based anti-piracy interventions is quite simple and sufficiently clear: do not pirate content digitally. The language used is often not ambiguous but instead understandable. Messages often directly refer to the (supposed) harmfulness of digital piracy, both for the industry as a whole and for individuals such as artists. The suggested damages are often claimed to be very sizable and are sometimes quantified.

The next step is whether or not the message itself is really believable for the target population. The source of the message affects this believability, especially in relation to the more negatively framed messages. As the source often is the creative industry itself, the credibility of the message is negatively affected, since the source is not perceived as being neutral (Hashim, Kannan, Maximiano, \& Rees, 2014). This possibly fuels the neutralization of the behaviour of the target population. In the Chapter 3 , it was shown that the alleged negative consequences of digital piracy are not uncontested (§3.3.2. (supra p. 59), §3.4.2. (supra p. 64) and \$3.5.2. (supra p. 71)). The fact that the more negatively framed sermons depend upon such depictions of harm does not necessarily contribute to their believability. Of the three types of sermon-based anti-piracy campaigns, only those that point towards the benefits of using legal content are likely to meet this requirement, as users are likely to know some of these benefits already and are more prone to believe them, but there is no empirical validation available to confirm this assumption. 


\subsubsection{The use of positive symbols}

For sermons to be more likely to change the behaviour of the target population, the information used in the sermon needs to be associated with positive symbols, labels and images in order to avoid negative labelling (Schneider \& Ingram, 1990). Individuals who are labelled in a negative manner (e.g., using terms such as 'crime' or 'criminal') are more likely to act according to this label, due to the so-called 'self-fulfilling prophecy' that is often reported in criminological studies (Schultz, 2014). In addition, the message itself should be framed in a polite manner, as impolite messages are less likely to be accepted by the target population (Whittam, Dwyer, Simpson, \& Leeming, 2006) and messages that are too harsh can have undesired side effects (Peters, Ruiter, \& Kok, 2013). In the field of health sciences, positive symbols are often used in promotional-focused messages. Such messages can result in a target population that is more responsive to its content (Bauman et al., 2003; Grigg, Waa, \& Bradbrook, 2008; Updegraff \& Rothman, 2013).

Not all of the sermon-based anti-piracy interventions frame their messages in positive ways. The fear appeals clearly fail to do so. Some digital pirates are vilified or labelled as criminals. Harm attributions likewise are framed negatively in terms of losses and harms. In these instances, digital piracy is often equated with job losses in the creative industries or loss of income for the creators. Some campaigns, such as the 'Piracy - It's a Crime' can be said to be somewhat aggressive in their tone. Due to the fact that fear-based sermons often link digital piracy with a number of serious crimes, these are also often phrased in a somewhat negative manner.

On the other hand, more positively framed messages also frame the issue in a more polite way. Most educational-based campaigns are focused on informing the target population on the applicable copyright laws and proper digital behaviour. These efforts are often framed in more positive ways. The most 'positive' sermons are those that inform users on the benefits of legal content or those that attempt to persuade the users that legal content is 'worth it'. These types of sermons are more about facts and insights instead of 'scaring them straight' with negative symbolism. Moon et al. (2015) examined the different variations in the wording of sermon-based interventions (both positive and negative and combinations thereof) and found that the positively worded messages were more influential than negatively worded ones. This means that content owners clearly do not just need to consider the content of the sermons but also the framing of this content. 


\subsubsection{Identifying the benefits of legal content}

Sermon-based anti-piracy interventions can clearly identify the benefits of legal content in order to persuade the target population to use such content rather than the pirated counterparts. A clear example of this approach is the 'Watch Real DVD's and Blu-Ray' campaign. The message states that content is made to be enjoyed legally, given the benefits that the legal copy possesses compared to the pirated copy, such as better audio or video quality. With regard to this requirement, it is important that the benefits of the legal content are present, sufficiently attractive for users and clearly communicated to them (Vedung, 1998). If the target population lacks information on the benefits of the legal content, individuals belonging to this group may lack the motivation to acquire the content legally. Increasing the knowledge about these benefits is therefore important (Bandura, 2004; Hirvonen, Huotari, Niemelä, \& Korpelainen, 2012). The aim is to make the legal content appear as attractive as possible. Otherwise, the sermon would not be able to convince the target population to act differently. The link with carrot-based interventions therefore becomes apparent. The sermon cannot determine what the benefit is; it can only identify and express it. It is still a separate requirement to persuade individuals to act differently, as individuals need to be aware of the existence of these benefits in the first place. The question is whether various sermon-based interventions convey these benefits and whether this contributes to reductions in digital piracy. The benefits are sometimes presented very concretely, while other sermons are somewhat vague in relation to what the benefits are, simply stating that legal content is 'better'. As was stated in \$5.4.1. (supra p. 129), some sermon-based interventions focus on these benefits and Table 6.7 demonstrates whether this truly contributes to the desired reductions in the context of digital piracy.

Table 6.7: Studies on the effects of identifying the benefits of legal content

\begin{tabular}{|lll|}
\hline Study & Presented benefits & Outcome \\
\hline Jeong and Yoon (2014) & Benefits were clearly stated, Anti-piracy messages that \\
& including receiving the latest emphasize a promotion focus \\
& product features, updates and and use positive framing are \\
& technical support. This more persuasive than messages \\
& intervention therefore focused using negative framing $(\mathbf{M}=\mathbf{5 . 2}$ \\
& on the promotion of legal vs $\mathbf{M = 4 . 6 1 ) .}$ \\
& content rather than the \\
& prevention of digital piracy. \\
& The intervention states that legal & \\
& versions of content bring with it and significant impact on the \\
Chiu et al. (2008) & certain advantages, are more users purchase intentions for \\
& trustworthy and reliable. & legal content $(\boldsymbol{\beta}=\mathbf{0 . 2 0})$.
\end{tabular}




\section{$\underline{\text { Punish, Seduce or Persuade }}$}

Only two studies examined the role of identifying the benefits of legal content but both suggest that meeting this requirement can contribute to reductions in digital piracy, perhaps more so than using a more negative approach (Jeong \& Yoon, 2014). The body of evidence is quite small however, limiting the overall strength of this observation.

\subsubsection{Aligning the desired behaviour with those of the target population}

This requirement consists of two parts. Firstly, the desired behaviour is presented as being important by content owners and governments. Individuals are more likely to act in support of policy goals if these acts are promoted by the government or stakeholders as being important and high priority issues (Schneider \& Ingram, 1990). This is not problematic, as the various sermon-based interventions clearly stress this importance.

The second part is more problematic however. It is also important that the desired behaviour is consistent (or aligned) with the values, beliefs and preferences of the target population (Schneider \& Ingram, 1990). A lack of this alignment will negatively affect the contribution that these sermon-based anti-piracy interventions have on reducing digital piracy. It is clear that the content of the sermon-based anti-piracy interventions do not necessarily align with the values, beliefs and values of the target population. The manner in which the target population perceives the behaviour in question is important in determining whether this type of sermon-based anti-piracy intervention can offer any contribution (as was discussed in §4.5.1. (supra p. 94), a positive attitude of digital piracy will increase the likelihood that an individual will act in this manner and that such attitudes are common, possibly making alignment more difficult). Other issues can also make it more difficult to accomplish this alignment, such as the ability to neutralize the act of digital piracy ( $\$ 4.5 .3$. (supra p. 96)), the social approval of this act (\$4.4.3. (supra p. 91)) or even the individual's morality (\$4.3.2. (supra p. 88)). This all depicts that a gap between the desired behaviour and the target population is present. Nonetheless, these types of sermon-based anti-piracy interventions attempt to instil in individuals the notion that digital piracy is immoral and infringes on the rights of the creator (as was discussed in \$5.4.2. (supra p. 130). They also tend to focus on the illegality of the behaviour by informing the target population on the content, scope and importance of the applicable copyright laws in an effort to persuade them to act differently.

The majority of digital pirates do not perceive their behaviour as being unethical or immoral (Bhal \& Leekha, 2008; Glass \& Wood, 1996; Moohr, 2003; Moore \& 
McMullan, 2004; Siegfried, 2004; Yu, 2012) (§1.5. (supra p. 13). There may be other competing values as well, further hampering this alignment. One often heard argument is that information, knowledge and ideas are free for all to use and enjoy on the Internet, an argument that is supportive of digital piracy (Papacharissi, 2002). If such a norm is entrenched in (community) values, it will compete with the norm that one has to pay for these goods or products (Feldman \& Nadler, 2006; Moohr, 2003, p. 771). Here, a clash between the message of the stakeholder ('digital piracy is a crime, immoral or wrong') and the values or beliefs of the community ('digital piracy is okay, normal and not a problem) occurs. This makes it more difficult for the target population to accept the messages presented, possibly reducing the effect of these sermon-based interventions. Various studies have examined the impact of these educational approaches on digital piracy behaviour. Table 6.8 gives an overview of the results of these studies.

Table 6.8: Studies on the education or awareness efforts

\begin{tabular}{|c|c|c|}
\hline Study & Educational information & Outcome \\
\hline Hashim et al. (2014) & $\begin{array}{l}\text { Advice on digital piracy and } \\
\text { purchasing decisions as presented to } \\
\text { teens. The source of the advice } \\
\text { varied along two dimensions: the } \\
\text { existence of social ties between the } \\
\text { advisor and advisee, and whether or } \\
\text { not the source of the advice has a } \\
\text { stake in the outcome of the } \\
\text { consumption decisions. The advice } \\
\text { consisted of the earnings of the } \\
\text { record companies, the average } \\
\text { amount of digital piracy and the } \\
\text { moral opinion of the source. }\end{array}$ & $\begin{array}{l}\text { From the outset, offering this advice } \\
\text { clearly influenced the behaviour of } \\
\text { the respondents. It is most effective } \\
\text { (purchasing increased, digital piracy } \\
\text { decreased) when the advisor has a } \\
\text { social connection. A parent has, for } \\
\text { example, such a connection and this } \\
\text { type of advice can mitigate digital } \\
\text { piracy. Direct advice from the } \\
\text { stakeholders has no effect on digital } \\
\text { piracy and might even reduce legal } \\
\text { purchases. }\end{array}$ \\
\hline d'Astous et al. (2005) & $\begin{array}{l}\text { Music piracy was described as } \\
\text { socially unacceptable behaviour that } \\
\text { was inconsistent with ethical or } \\
\text { moral social values. }\end{array}$ & $\begin{array}{l}\text { No significant effect was } \\
\text { demonstrated after the introduction } \\
\text { of this construct. }\end{array}$ \\
\hline $\begin{array}{l}\text { Al-Rafee and Rouibah } \\
(2010)\end{array}$ & $\begin{array}{l}\text { Respondents were informed about a } \\
\text { religious edict that considers digital } \\
\text { piracy to be immoral from a } \\
\text { religious point of view. }\end{array}$ & $\begin{array}{l}\text { Results demonstrate that exposure to } \\
\text { such a religious edict (which is a } \\
\text { specific type of sermon-based } \\
\text { intervention) decreased the intention } \\
\text { to pirate content digitally (M=4.64 vs } \\
\mathbf{M = 3 . 8 6} \text { after exposure). }\end{array}$ \\
\hline $\begin{array}{l}\text { Feldman and Nadler } \\
(2006)\end{array}$ & $\begin{array}{l}\text { One group of respondents received } \\
\text { information on the applicable } \\
\text { copyright regulations. In addition, a } \\
\text { second group of respondents } \\
\text { received information which was } \\
\text { designed to trigger the respondent's } \\
\text { moral duty not to pirate. }\end{array}$ & $\begin{array}{l}\text { Presenting information on the law } \\
\text { alone was not sufficient to trigger } \\
\text { any behavioural changes. Likewise, } \\
\text { confronting the respondents with this } \\
\text { moral duty did not influence piracy } \\
\text { behaviour. }\end{array}$ \\
\hline
\end{tabular}


$\underline{\text { Punish, Seduce or Persuade }}$

\begin{tabular}{|c|c|c|}
\hline $\begin{array}{l}\mathrm{Li} \text { and Nergadze } \\
(2009)\end{array}$ & $\begin{array}{l}\text { Both the awareness of the law and } \\
\text { the consensus of the law were } \\
\text { examined in the context of digital } \\
\text { piracy behaviour. }\end{array}$ & $\begin{array}{l}\text { The respondent's consensus with the } \\
\text { copyright law was negatively } \\
\text { related to both current }(\boldsymbol{\beta}=-\mathbf{0 . 4 2}) \\
\text { and future ( } \boldsymbol{\beta}=-\mathbf{0 . 2 7}) \text { digital piracy. } \\
\text { Awareness of the copyright law had } \\
\text { a weak negative relationship only } \\
\text { with future piracy ( } \boldsymbol{\beta}=-\mathbf{0 . 1 0}) \text {. }\end{array}$ \\
\hline $\begin{array}{l}\text { Yang and Wang } \\
(2015)\end{array}$ & $\begin{array}{l}\text { The effects of five major } \\
\text { socialization agents - namely } \\
\text { parents, peers, traditional media, the } \\
\text { Internet, and music industry - on } \\
\text { emerging adults' attitudes and } \\
\text { behaviour toward music piracy in } \\
\text { the form of unauthorized } \\
\text { downloading are examined. }\end{array}$ & $\begin{array}{l}\text { All socialization variables (peers, } \\
\text { parents, traditional media, the } \\
\text { Internet and music industry), except } \\
\text { for traditional media, have a } \\
\text { significant impact on digital piracy } \\
\text { attitudes and/or behaviour. Peers and } \\
\text { the Internet exert a direct impact on } \\
\text { both attitudes and behaviour. Parents } \\
\text { and the music industry, however, } \\
\text { only have an indirect impact on } \\
\text { emerging adults' digital piracy habits } \\
\text { through shaping their attitudes. }\end{array}$ \\
\hline $\begin{array}{l}\text { Brown and } \\
\text { MacDonald (2014) }\end{array}$ & $\begin{array}{l}\text { Positive messages were tested. } \\
\text { Vignettes were tested which were } \\
\text { meant to reflect to positive effects of } \\
\text { purchasing music, such as the fact } \\
\text { that legal sales encourage future live } \\
\text { performances. }\end{array}$ & $\begin{array}{l}\text { The results suggest that anti-piracy } \\
\text { messages, even framed in a positive } \\
\text { way, are not a valid resource to } \\
\text { amend piracy attitudes and } \\
\text { behaviours. }\end{array}$ \\
\hline
\end{tabular}

Four of the seven studies indicate that various ways of persuading individuals to act differently by offering (various types of) information has an influence on their acts of digital piracy. These four studies used the pre-experimental (Hashim et al., 2014), quasi-experimental (Al-Rafee \& Rouibah, 2010) or cross-sectional (Li \& Nergadze, 2009; Yang \& Wang, 2015) research designs. In contrast, studies that failed to find evidence for the relevance of educational or awareness efforts used the pre-experimental design (Brown \& MacDonald, 2014; d'Astous et al., 2005; Feldman \& Nadler, 2006). Since both groups of studies used relatively robust research designs, it is somewhat difficult to indeed establish that fulfilling this requirement can contribute to reductions in digital piracy.

Two further issues emerge from this table that also make it difficult to state that meeting this requirement can contribute to reductions to digital piracy: 1) most studies examined different parts of the educative approach, meaning that the evidence is rather scattered and 2) the studies question who should provide the information that the sermon relies on. It is possible that parents and peers can have a greater influence on behaviour than the creative industry itself or governments. Interventions emerging from the creative industry will likely struggle to meet the discussed requirement, meaning that they are less likely to succeed in bridging the alignment gap. The fact that most sermon-based anti-piracy campaigns originate from and speak on behalf of the creative industry can mean that their possible contribution is limited (Gillespie, 2009; Hashim et al., 2014; Yar, 2008). This 
means that anti-piracy interventions that attempt to use parents and teachers as intermediaries can be more likely to contribute to reductions in digital piracy than sermons that directly come from these industries.

\subsubsection{Meaningful fear appeals and harm attributions}

The third way through which sermon-based anti-piracy interventions are applied is to attempt to persuade the target population that their acts of digital piracy will 'get them into trouble'. This is done in two different ways. The fear appeals focus on the individual and state that an individual will be punished if he pirates content digitally. ${ }^{90}$ In contrast, the harm attributions focus more on society and present the individual with statements that acts of digital piracy have consequences for society as a whole. Both require either a meaningful threat or harm in order for them to be able to persuade the target population to act differently. The question is what 'meaningful' means in this context.

In the context of fear appeals, this meaningfulness comes from the seriousness of the presented threat: the threat level. The exact level to be used requires careful consideration on the side of the policy maker. Threat levels that are too high will decrease the acceptance or believability of the message or may even cause denial or resistance in the target population. This means that the target population simply does not believe that the presented 'threat' is as serious or as likely as the sermon presents, making it less likely that the individual will change his behaviour. A second way through which fear appeals can fail to cause behavioural change is when the recommended precautions result in inadequate fear reduction given the seriousness of the threat (Ruiter et al., 2001; Sternthal \& Craig, 1974). This is due to the fact that the recipients of the fear appeal become overwhelmed by the content of the message and do not believe that the recommended responses can properly alleviate the presented threat. Simply put, there is a mismatch between the seriousness of the presented 'threat' and the solutions presented as to how to prevent this threat from taking place. ${ }^{91}$ Due to this mismatch, the individual will not change his behaviour, since he believes that, given the severe threat, acting in the prescribed manner is pointless as it is, in his eyes, insufficient to evade the threat (Leventhal, 1971). Too low levels of fear are also unlikely to persuade the target population to change its behaviour (Williams, 2012). Here, the target

\footnotetext{
${ }^{90}$ As was discussed in §5.4.3. (supra p. 131), the difference between a fear appeal and a deterrent measure is that the latter directly makes it more likely that an individual will be punished for his act of digital piracy (by influencing the certainty and severity of punishment), while the former can only inform the target population of this risk of punishment. It cannot, on its own, increase the risk objectively, although it may be able to influence the perceived certainty and severity of punishment.

${ }^{91}$ For instance, instructing an at-risk for cancer target population to eat one apple daily is unlikely to 'scare' individuals belonging to this population to act differently.
} 


\section{$\underline{\text { Punish, Seduce or Persuade }}$}

population is not sufficiently worried about the presented threat to change its behaviour. A curvilinear relationship between fear appeals and persuasion exists. To improve the impact of the threat, policy makers need to consider two important dimensions: the perceived susceptibility and the perceived severity of the threat (Witte \& Allen, 2000). This is somewhat similar to the discussion on the interventions that use deterrence as a mechanism.

By presenting and informing the users on the possible sanctions of pirating content digitally, users can be made aware of both the certainty and severity of the punishment. These fear appeals can also inflate both this certainty and severity; even if this is not necessarily grounded in reality (meaning that, for example, the chance of being caught is portrayed as more certain than it really is). Does this mean that there is a meaningful threat in the context of digital piracy? Not necessarily. The 'threat' presented is often vague; digital piracy is presented as a crime, but what sanctions await infringers exactly? In practice, it is rather difficult to conclude whether these fear appeals are meaningful for the individual. Most DVDs and Blu-Ray (and other content) are accompanied by various 'warning seals'. These warning seals often refer to sanctions such as fines of up to $\$ 250,000$ or imprisonment terms of up to five years. Given the relatively harmlessness nature of digital piracy (when compared to other crimes that can result in imprisonment of five years), it is possible that the target population views these warnings as having too high a threat level, meaning that the threat might be too severe. In addition, none of the sermon-based interventions directly address the certainty of the threat. This leads to the conclusion that there probably is not a meaningful threat when these sermon-based anti-piracy interventions are considered.

Only a few studies have examined the effects of fear appeals and the appropriate level of the threat in the context of digital piracy. Levin et al. (2007) examined three levels of the fear appeal, varying in relation to the indicated severity of the punishment. A low level of fear appeal was having to delete the music files one pirated digitally, while community service of up to 25 hours and a fine of $\$ 2,500$ for each downloaded file represented the medium and high levels of threat respectively. The latter threat resulted in reduced intentions to download in the future when compared to 'weaker' threats. A different type of fear appeal was examined by Jeong and Yoon (2014), where the threat consisted of warnings that downloading pirate content could expose one's computer to viruses. Respondents exposed to this message exhibited a more negative attitude towards digital piracy, reducing the likelihood of engaging in digital piracy. But the empirical evidence is limited on the use of this type of sermon-based anti-piracy intervention, 
meaning that it is not possible to reach a clear conclusion on the effects of fear appeals in the context of digital piracy.

Sermons using the harm attribution approach focus on the (potential) harm of digital piracy. These are designed to raise awareness on the potential harm and portray the outcomes of digital piracy in a negative manner. These outcomes are often framed as losses in revenues and job losses, as was seen in \$5.4.3. (supra p. 131). These outcomes can also be presented as being felt by individual content creators, considering that the time and effort that individuals have put into creating this content is wasted thanks to digital piracy (Yar, 2008). In practice, many harm attribution interventions do try to be somewhat specific on the harm of digital piracy, such as the 'It Hurts' campaign. Table 6.9 presents the findings of those studies that have examined the harm appeal.

Table 6.9: Studies on the attribution of harm

\begin{tabular}{|c|c|c|}
\hline Study & Manner of harm attribution & Outcome \\
\hline Grolleau et al. (2008) & $\begin{array}{l}\text { Digital piracy means that the } \\
\text { copyright holders are unable to } \\
\text { donate part of the proceeds to } \\
\text { charity. }\end{array}$ & $\begin{array}{l}\text { Overall, the level of digital piracy } \\
\text { is lower when a donation } \\
\text { mechanism is present and when } \\
\text { individuals are made aware of this } \\
\text { fact ( } 33 \% \text { of the respondents' } \\
\text { pirated content compared to } \\
80 \%) \text {. }\end{array}$ \\
\hline d'Astous et al. (2005) & $\begin{array}{l}\text { The negative consequences for } \\
\text { the artists were stressed, such as } \\
\text { the loss of revenue or job } \\
\text { insecurity. }\end{array}$ & $\begin{array}{l}\text { The experimental condition did } \\
\text { not have a significant impact on } \\
\text { the intention to pirate. }\end{array}$ \\
\hline Al-Rafee and Rouibah (2010) & $\begin{array}{l}\text { Respondents were informed } \\
\text { about the current and future } \\
\text { consequences of digital piracy. }\end{array}$ & $\begin{array}{l}\text { Results demonstrate that the } \\
\text { awareness of the consequences of } \\
\text { digital piracy significantly } \\
\text { decreased the respondent's } \\
\text { digital piracy intention after } \\
\text { exposure }(\mathbf{M}=\mathbf{3 . 7 6} \mathbf{~} \mathbf{M}=\mathbf{4 . 6 1}) \text {. Of } \\
\text { the various interventions } \\
\text { examined, this type of sermon had } \\
\text { the largest effect. }\end{array}$ \\
\hline Levin et al. (2007) & $\begin{array}{l}\text { Subjects were informed that } \\
\text { downloading individual songs } \\
\text { caused the artist or company to } \\
\text { lose income. In a follow-up } \\
\text { study, it was indicated that, } \\
\text { overall, downloading resulted in } \\
\text { a significant loss to the artist } \\
\text { and industry. }\end{array}$ & $\begin{array}{l}\text { In the initial assessment of the } \\
\text { concept of harm attribution, no } \\
\text { significant effects could be noted. } \\
\text { Likewise, no effect is recorded in } \\
\text { the second operationalization of } \\
\text { the concept of harm attribution. }\end{array}$ \\
\hline $\begin{array}{l}\text { De Corte and Van Kenhove } \\
(2015)\end{array}$ & $\begin{array}{l}\text { Respondents were exposed to a } \\
\text { brochure from the Belgian Anti- } \\
\text { Piracy Federation } \quad \text { (BAF) } \\
\text { informing consumers about }\end{array}$ & $\begin{array}{l}\text { The educating strategy } \\
\text { significantly increased } \\
\text { perceptions of harm caused by } \\
\text { piracy. The strategy was effective }\end{array}$ \\
\hline
\end{tabular}




\begin{tabular}{|c|c|c|c|}
\hline & & $\begin{array}{l}\text { intellectual property rights and } \\
\text { the detrimental consequences of } \\
\text { piracy on the entertainment } \\
\text { industry. The brochure } \\
\text { explicitly referred to piracy as } \\
\text { stealing and emphasized that the } \\
\text { creative sector was losing jobs } \\
\text { and revenue for innovation } \\
\text { because of piracy. }\end{array}$ & $\begin{array}{l}\text { in lowering pirating intentions for } \\
\text { certain pirates. For the heavy- } \\
\text { downloaders, however, the } \\
\text { educational strategy, although } \\
\text { successful in significantly } \\
\text { increasing perceived harm, } \\
\text { remained insufficient for } \\
\text { generating an effect on pirating } \\
\text { intentions. }\end{array}$ \\
\hline
\end{tabular}

There is conflicting empirical evidence on the effect of harm attribution in the context of digital piracy. The results of these few studies are mixed. Three studies come to the conclusion that harm attribution can contribute to reductions in digital piracy, while two others fail to do so. When the research design of these studies is examined, the three studies that found support for the usage of harm attribution use the pre-experimental (De Corte \& Van Kenhove, 2015; Grolleau et al., 2008) or quasi-experimental (Al-Rafee \& Rouibah, 2010) research design. The two studies that did not find this kind of support both used a pre-experimental research design. This fact, combined with the fact that the number of studies is relatively small, makes it difficult to conclude whether or not using harm attribution is useful in reducing digital piracy.

\subsection{Conclusion}

This chapter further answered the third sub-question (which (behavioural) mechanisms are applied in the design of the various anti-piracy interventions and what are the requirements for their proper functioning?) by identifying the applicable requirements for their functioning. This chapter also provided a partial answer to the fourth sub-question (to what extent the underlying mechanisms contribute to reductions in digital piracy). A better understanding of the various requirements that each of the three mechanisms need to meet allowed for a more fine-tuned assessment of if and when anti-piracy interventions, based on the deterrent, incentivizing and persuasive mechanisms, are capable of contributing to reductions in digital piracy. To do so, the requirements for their functioning had to be identified, as well as the empirical evidence available as to whether or not meeting those requirements can contribute to the reduction in digital piracy.

A deterrent mechanism needs to meet the following requirements: 1) the certainty of punishment 2) the severity thereof, and 3) the intervention promotes the alternative (and desired) behaviour. The main issue found is that most deterrencebased interventions are overly severe, yet they are unlikely to amount to a sufficiently certain punishment (or the threat thereof). The studies that have examined the deterrent anti-piracy interventions have found more consistent 
support for the relevance of certainty than for severity, although both are necessary for reductions in digital piracy to take place. The findings are mixed with regard to the remaining requirement. The stimulation of alternative behaviour is a requirement that not all types of stick-based interventions fulfil. The graduated response likely meets this requirement while the others do not.

For an incentive mechanism to contribute to reductions in digital piracy, the legal content must be sufficiently attractive. Such content becomes more attractive if 1) the incentive is sufficiently large and certain to obtain, 2) non-financial incentives are used, 3) the desired behaviour is not too complex, and 4) bad news perceptions are avoided. Overall, carrot-based interventions mostly succeed in meeting these requirements. There is evidence to conclude that larger incentives (e.g., cheaper priced content) make the incentive more attractive, especially if the individual is certain he will obtain this incentive. It is important, however, that the size of the incentive is close to what some individuals are willing to pay for legal content. For some, there will still be a gap between what content owners ask for their content and what users are willing to pay for legal content. The remaining requirements are all met and there is empirical evidence that using non-financial incentives (such as easy access to content) can contribute to reductions in digital piracy. There is, however, no empirical validation of the other two requirements. On the whole, anti-piracy interventions that use the incentive mechanism manage to meet most of the requirements identified in the literature, improving their chances of contributing to reductions in digital piracy.

All usages of the persuasive mechanism need to meet four requirements: 1) the desired behaviour should be easy to perform, 2) the content of the sermon should be novel and 3) believable and 4) use positive symbols and a positive tone. Of these four, only the first requirement is fulfilled by all the described interventions. Some of these sermon-based requirements also use a positive tone, although most do not. The remaining two requirements, the believability of the message and the usage of novel content, are not met by any sermon-based interventions.

Next, each different usage of the persuasive mechanism needs to fulfil one specific requirement. When identifying the benefits of legal content, they need to be sufficiently clear and attractive for the individual. This requirement is met, but only two studies examined this requirement, although they did present some evidence for the relevance of this requirement. When using information to educate, the message used to present this information needs to be consistent with the target population's norms and values on digital piracy. Given the nature of digital piracy, it is likely that this requirement will not be met. There is, however, some empirical validation that using information to inform the target population can indeed contribute to reductions. Interventions meant to scare digital pirates 


\section{$\underline{\text { Punish, Seduce or Persuade }}$}

need to present a threat or harm that is 'meaningful': not too little or too much fear or harm is needed. It is doubtful that the threat is indeed meaningful in the examined interventions, as the presented sanctions are too grave, while statements on the likelihood of being punished are rarely included or vague, if included at all. There is also only limited empirical evidence to conclude that using fear appeals in the context of digital piracy indeed reduces this behaviour. The insights derived from harm appeals are also unclear, as the evidence is conflicting and the harm presented might not be believable for the target population.

This chapter clarified which requirements need to be fulfilled in order to increase the likelihood that a mechanism can contribute to a reduction in digital piracy. It also provided insights into which of the mechanisms are better equipped to contribute to reductions in digital piracy and how this is reflected in empirical studies. But the possible extent of this reduction has not yet been examined in depth. To fully answer the matter of the extent of the contribution to reductions in digital piracy, Chapter 7 examines, by presenting the first empirical study, whether the three mechanisms indeed contribute to reductions if (some of) the discussed requirements are met. 


\section{Measuring the Contributions of Anti-Piracy Interventions and Their Mechanisms}

The various mechanisms used in anti-piracy interventions function through a number of requirements. The mechanisms and the requirements are examined in detail in this chapter in order to fully answer the sub-question 'to what extent do the underlying mechanisms contribute to reductions in digital piracy?' This chapter aims to obtain a better understanding of when reductions in digital piracy, brought about by the mechanisms and their associated requirements, are to be expected, as well as what the extent of these reductions can be.

A specific variant of choice experiment was selected in this research to determine how people react to these mechanisms and their associated requirements: the 'stated preference' method. This method was informative as it allowed respondents to indicate which 'intervention' they 'preferred'. This informed the researcher on what the respondents intended to do (the stated preference) in a given (hypothetical) situation. Respondents were asked how they would act when exposed to certain anti-piracy interventions. More specifically, they had to choose between scenarios. Each scenario was based on one of the three mechanisms (deterrence, incentives and persuasion). ${ }^{92}$ The scenarios varied based on some of the specific requirements associated with each mechanism identified in the previous chapter. Perceptions played a central role in understanding how individuals can react to the mechanisms used in the anti-piracy interventions. This can be informative as to which anti-piracy intervention is most likely to influence the individual digital pirate to reduce his acts of digital piracy. The role of perceptions was incorporated into this study by consistently giving the respondent a choice between two different scenarios. Each respondent's 'preference' for one of the mechanisms surfaced in this manner. For a more detailed discussion on the data collection itself, see §2.2. (supra p. 30). The method was implemented using two self-administrated questionnaires, one in the Netherlands and one in Belgium.

The first section of this chapter briefly explores the past and potential future acts of digital piracy of both groups of respondents as well as their willingness to pay for legal content, information which was used to better understand the findings. The second section discusses the design of the examined scenarios. As it was not possible to examine all the requirements associated with the three mechanisms, a

\footnotetext{
92 As will be discussed later, the decision was made to avoid the usage of hybrid or combined scenarios. Focusing one mechanism per scenario allowed for a purer examination of each of these three mechanisms.
} 


\section{$\underline{\text { Punish, Seduce or Persuade }}$}

selection was made with regard to the requirements that were incorporated into the scenarios. The second section describes this selection process. It depicts the design of each scenario and the variation within the selected requirements. In the third section, the responses to the various scenarios are examined in detail. By using a baseline to depict the respondents' inclination to pirate content digitally prior to having been exposed to the hypothetical anti-piracy interventions (the scenarios), it became possible to contrast the responses to each scenario (and its encapsulated mechanism and requirements) with this baseline. This allowed for observations on the contribution that each scenario had on the respondents' reported inclination to pirate content digitally. The fourth section goes one level deeper and analyses the requirements themselves. This section illustrates which changes to mechanisms (through the associated requirements) also influence the inclination of the respondents to pirate content digitally. The fifth section examines the differences in responses between men and women in order to determine whether these two subgroups reacted differently to the various scenarios. All these findings demand critical reflection and contextualization on both the used methodology and the findings, which are presented in the sixth and seventh sections of this chapter.

\subsection{Past content consumption and digital piracy}

The socio-demographic background of both samples were discussed previously in Chapter 2 (\$2.2.2. (supra p. 35)). ${ }^{93}$ The general content consumption of the respondents, as well as their previous and intended acts of digital piracy, was not discussed in that section however. Such insights are informative with regard to how much the respondents had pirated content digitally in the past, their inclination do so in the future and the degree of effort that the respondents were willing to exert in order to pirate successfully. This illustrates the general tendencies of the respondents to act in this manner. The analysis also offers information on what respondents are willing to pay for legal content, if anything at all. As this study uses a sample from both the Netherlands and Belgium, the findings are separated in order to properly depict them.

\footnotetext{
${ }^{93}$ It bears repeating that the characteristics of both samples are more or less what would have been expected given the sampling frame; the respondents are relatively young (on average around 21 years), often female and quite experienced with the Internet and related technologies.

There were important differences in the two populations, however. The proportion of males in the Dutch sample was greater than compared to the Belgian sample. A second difference was that Dutch are more likely to live in student housing rather than with their parents. Thirdly, Dutch respondents had slightly more experience with using the computer and related technologies. Finally, the Dutch respondents indicated that they had more disposable income than their Belgian counterparts.
} 


\subsubsection{The Dutch sample}

The discussion of the Dutch sample concerns the data obtained using both questionnaire A and B. Table 7.1 illustrates, in turn, what these respondents are willing to pay for legal content (music), how frequently they had pirated content (music) digitally in the past, their inclination to do so again, and the effort they will devote to this behaviour.

Table 7.1: Content consumption, past and future digital piracy (Dutch sample) $\mathrm{N}=69$

\begin{tabular}{|lllll|}
\hline Variable & Mean & SD & Min & Max \\
\hline WTP for single & 0.6803 & 0.89770 & 0 & 3 \\
\hline WTP for album & 7.5072 & 7.40738 & 0 & 30 \\
\hline Frequency of past digital piracy (six months) & 3.73 & 2.233 & 1 & 7 \\
\hline $\begin{array}{l}\text { Frequency of past digital piracy (six months), non- } \\
\text { downloaders excluded }\end{array}$ & 4.59 & 1.857 & 2 & 7 \\
\hline Inclination to pirate digitally in the future & 4.60 & 2.216 & 1 & 7 \\
\hline Degree of effort to put into future digital piracy & 3.57 & 2.183 & 1 & 7 \\
\hline
\end{tabular}

On average, the Dutch respondents are willing to pay $€ 0.68$ for an individual single and $€ 7.51$ for a complete album. At a first glance, it seems that the average WTP is not far removed from the price content owners charge; $€ 0.68$ compared to, on average, $€ 0.99$ for an individual single and $€ 7.50$ compared to, on average, $€ 9.99$ for a complete album. Respondents appear to be willing to pay for legal content. A closer examination of the results warrants a more nuanced conclusion. Some Dutch respondents are not willing to pay anything for legal content. In fact, almost half of the sample is unwilling to pay for individual singles $(41.8 \%)$ and almost a third is unwilling to pay for a complete album (29.9\%). This suggests that there are respondents that might not be sensitive to changes in the price of legal content.

The frequency of past digital piracy is indicated to be $M=3.73$. Interestingly, almost $25 \%$ of the respondents indicated that they had never pirated content digitally during this time period. This suggests that certain individuals might never do so, making them naturally compliant (Bottoms, 2002). If respondents that indicated to have never pirated content digitally are excluded, the respondents' inclination increases $(M=4.59)$. The respondents also indicated that they are somewhat inclined to pirate content digitally in the near future $(M=4.6){ }^{94}$ This is very close to the frequency of past digital piracy, once the non-pirates are

${ }^{94}$ Based on a Likert-scale of 1 to 7 . Respondents were asked to indicate whether they agreed with the following statement: 'I plan to download music in the future from a source that I suspect to be illegal, without paying for this content.' A score of 1 indicated that the respondent did not agree with this statement at all, while a score of 7 indicated that the respondent strongly agreed with it. This reflects the respondent's assessment on his inclination to pirate content digitally in the future. 


\section{$\underline{\text { Punish, Seduce or Persuade }}$}

removed from this analysis. When asked whether they would put any effort into this, respondents indicated that they were not too inclined to do so $(\mathrm{M}=3.57) .{ }^{95}$ This suggests that there may be a gap between what respondents desire, contentwise, and the amount of effort they are willing to put into this act. This perhaps suggests that the more effort individuals need to exert to pirate content successfully, the less inclined they are to actually do so.

The above illuminates the acts of digital piracy of the Dutch respondents. A similar overview can be given for the respondents belonging to the Belgian sample.

\subsubsection{The Belgian sample}

Table 7.2 depicts an overview of the responses from the Belgian respondents.

Table 7.2: Content consumption, past and future digital piracy (Belgian sample) $\mathrm{N}=110$

\begin{tabular}{|lllllll|}
\hline Variable & Amount & Percentage & Mean & SD & Min & Max \\
\hline WTP for single & & & 0.6394 & 0.7064 & 0 & 3 \\
\hline WTP for album & & & 7.4568 & 5.2031 & 0 & 20 \\
\hline Piracy & 75 & $68.2 \%$ & & & & \\
\hline Yes & 35 & $31.8 \%$ & & & & \\
\hline No & & 3.96 & 1.645 & 1 & 7 \\
\hline $\begin{array}{l}\text { Frequency of past digital } \\
\text { piracy (six months) (n=76) }\end{array}$ & & & & & & \\
\hline $\begin{array}{l}\text { Inclination to pirate digitally } \\
\text { in the future }\end{array}$ & & & & & & \\
\hline Yes & 77 & $70.0 \%$ & & & \\
\hline No & 33 & $30.0 \%$ & & & \\
\hline $\begin{array}{l}\text { Degree of effort to put into } \\
\text { future digital piracy }\end{array}$ & & & & & \\
\hline Yes & 50 & $45.5 \%$ & & \\
\hline No & 60 & $54.5 \%$ & & & \\
\hline
\end{tabular}

The Belgian respondents are, on average, willing to pay similar prices for legal content ( $€ 0.63$ and $€ 7.46$ respectively). The large majority of the respondents were willing to pay something for legal content. Only $21.8 \%$ of the respondents were unwilling to pay anything for a single, whereas only $11 \%$ is likewise unwilling to pay anything for a full album. Two-thirds of the respondents had previously pirated content digitally, indicating that $31.8 \%$ of the respondents are naturally compliant. Those that did pirate content digitally did so a bit more

95 Based on a Likert-scale of 1 to 7 . Respondents were asked to indicate whether they agreed with the following statement: 'I will put effort into the act of downloading music from a source that I suspect to be illegal, without paying for this content.' A score of 1 indicated that the respondent did not agree with this statement at all, while a score of 7 indicated that the respondent strongly agreed with it. 
Measuring the Contributions of Anti-Piracy Interventions and Their Mechanisms

frequently than their Dutch counterparts $(\mathrm{M}=3.96) .{ }^{96}$ A similar segment of the respondents intends to pirate digitally in the future but the majority indicates that they are not willing to put effort into this behaviour (54.5\%).

Collectively, these findings allow for a better understanding of the differences between the Dutch and Belgian respondents, especially in relation to their frequency of past digital piracy and their inclination to engage in this activity in the future. From these two sections, it also appears as though both the Dutch and Belgian respondents are equally willing to pay for legal content. There are some differences in relation to the acts of digital piracy of both samples. The Belgian respondents appear to be a bit more compliant than their Dutch counterparts. Collectively, the differences in the socio-demographic background of the respondents (supra p. 37) seems not to be paired with substantial differences in their acts of digital piracy.

Regardless of the potential differences between the samples, it is possible to use the insights to determine how the respondents' inclination to pirate content digitally changes after they are exposed to the various scenarios. A first step to determine this is to expand on how the various scenarios were developed in the first place.

\subsection{Developing the scenarios}

Anti-piracy interventions attempt to influence behaviour through one of three main mechanisms: deterrence, incentivization and persuasion. Each scenario was based on one of these three mechanisms. As exposing the respondents to all 24 scenarios would have unduly burdened the respondents, they were randomly divided into two groups. Each group was exposed to twelve scenarios in total. ${ }^{97}$ This led to a questionnaire which was balanced between not wanting to overburden the respondents and still having a sufficient variation in the mechanisms to allow for a proper analysis. With 24 scenarios and three mechanisms, it was logical to have eight scenarios per mechanism. This threeway division also reflected the variance in practice, as the three categories of antipiracy interventions are equally common. In turn, each mechanism was shaped by its related requirements, such as the degree of certainty or the severity of the (threat of) punishment. Between three and four requirements were used to further shape each scenario. The requirements that were selected are those that form the core of each mechanism. Before the respondents were exposed to these scenarios, they were confronted with the so-called 'scenario zero', which would serve as a

\footnotetext{
${ }^{96}$ The question posed was similar to the one posed to the Dutch respondents.

${ }^{97}$ At least those that had previously pirated content digitally. Those that had not done so were routed to a different part of the questionnaire.
} 


\section{$\underline{\text { Punish, Seduce or Persuade }}$}

baseline with which responses to the various scenarios could be compared. The decision was made to design the scenarios around digital music piracy, as this is the most common type of digital piracy and would be most recognizable and applicable for the majority of the respondents.

\subsubsection{Finding a baseline: the role of 'scenario zero'}

The ability to compare the responses to a baseline was important for this empirical study. Without such a baseline, it would have been difficult to establish which scenarios (and thus, mechanisms and requirements) contribute the most to reductions in digital piracy. The reported inclination in 'scenario zero' reflects the respondents' inclination to pirating content digitally in a context that is as close as possible to the reality in both the Netherlands and Belgium. Deviations from this baseline are insightful as to whether or not a particular scenario has reduced (or even increased) the respondent's assessment to pirate content digitally or whether it has had no effect on this assessment. Figure 7.1 depicts this 'scenario zero'.

The 'scenario zero', needed to be based on the current state of affairs (at the time of this empirical study) of digital piracy in both the Netherlands and Belgium. This meant that the characteristics of this scenario needed to be stated clearly. For instance, in both jurisdictions, there was no chance that an individual would be punished for the act of digital piracy (Gerkens, Smeets, Teeven, \& van Vroonhoven-Kok, 2009). Social disapproval in both jurisdictions is low, as the social norms governing this act are rarely in favour of copyright compliance (Depoorter, Parisi, \& Vanneste,

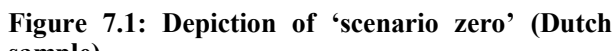
Figure 7.1: Depiction of 'scenario zero' (Dutch sample)

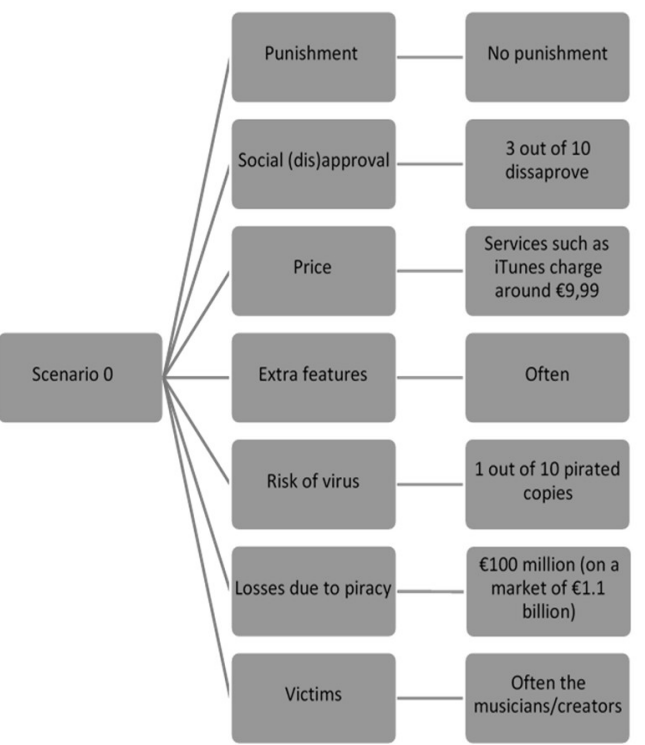
2005; Jensen, 2003; Larsson et al., 2014; Sinclair \& Green, 2016). After examining the current (at that time) supply of services such as iTunes, it was clear that the average price of a full album was around $€ 9.99$. As these albums often come with extra features (bonus or alternative tracks, digital booklets or video 
clips), the presence of extra features was integrated into scenario zero. The risk of obtaining a virus via digital piracy is dependent on the type of content available. For instance, a large proportion of pirated software contains viruses or malware (Kammerstetter, Platzer, \& Wondracek, 2012), more so than is the case for pirated movies or music files. A one out of ten chance of contracting a virus of was selected for scenario zero, since these scenarios focused on music content (Gantz, Christiansen, \& Gillen, 2006; Gantz et al., 2013). The next aspect of 'scenario zero' was to depict the harm to the Dutch and Belgium entertainment markets respectively. The total size of the Dutch entertainment market is around $€ 1.1$ billion (NVPI, 2014). The next step was to establish how great the harm of digital piracy was, for which the findings discussed in §3.3.2. (supra p. 59) were useful. In that section, the losses to the German music industry due to digital piracy were reported to be over $€ 500$ million (Martens et al., 2012). Given the fact that the Dutch economy is around one fifth the size of the German economy, the decision was made to depict a level of harm at around $€ 100$ million. ${ }^{98}$ The final feature of scenario zero reflected where this harm is felt. The emphasis was placed on the musicians and creators themselves, rather than the creative industry as a whole, as this particular strategy is currently often used in practice.

It is possible that this scenario is not entirely realistic, which is also influenced by how the respondents will perceive it. Both may have had an influence on how the respondents reacted to it. Such concerns are not uncommon in the field of social sciences, especially when laboratory experiments are used (Berkowitz \& Donnerstein, 1982; Falk \& Heckman, 2009). This makes the issue of realism an inherent concern in the type of research conducted in this first empirical study. Fully excluding this concern is not possible. At the same time, there is no reason to automatically assume that the scenario is wholly unrealistic. By attempting to frame the scenario in such a way that it was familiar the respondent (by referring to services such as iTunes, depicting prices for legal content that are common or by indicating that there was no risk of punishment), it was attempted to make the scenario as realistic as possible. How this scenario has been perceived by the respondents cannot be assessed however, nor can it be ruled out that such perceptions have influenced the response to this scenario.

Earlier in the questionnaire, the respondents were confronted with a few questions on their past and intended acts of digital piracy. ${ }^{99}$ This meant that the respondents were not yet informed on the context presented by 'scenario zero' when they

\footnotetext{
${ }^{98}$ As the Belgian economy is smaller than its Dutch counterpart, the presented harm in scenario zero was reduced to $€ 90$ million.

${ }^{99}$ To avoid socially desirable answers, the term 'digital piracy' was not used in the questionnaires. This act was instead described as 'downloading music from an illegal source'.
} 


\section{$\underline{\text { Punish, Seduce or Persuade }}$}

answered these questions. Although the findings of these questions were already discussed in \$7.1. (supra p. 180), one outcome is positioned here again: the individual's inclination whether he would pirate content in the future, which can be contrasted with the reported inclination established through scenario zero. The closer both scores are, the more likely it becomes that this scenario indeed reflected the reality that the respondents experience on a daily basis. The difference between the baseline $(\mathrm{M}=4.8)$ and the inclination to pirate content digitally in the future for the Dutch sample is small $(\mathrm{M}=4.6){ }^{100}$ This validates the usage of scenario zero as a baseline to which the findings derived from the scenarios can be compared. The responses of the Belgian sample led to a similar baseline ( $\mathrm{M}=4.61)$.

With the establishment of the scenario used to identify the baseline, the next step was to develop and design the make-up of the 24 scenarios used in the first empirical study. The following three sections discuss the design of each group of scenarios based on the selected mechanism.

\subsubsection{Requirements used to generate a deterrent effect}

The stick-based scenarios were based on three requirements associated with the deterrent mechanism: the 1) certainty and 2) severity of the (threat of) punishment and 3) the degree of social disapproval of digital piracy, which forms the informal moral rules of a specific environment. All three are part of the moral context an individual finds himself in and thus belong to the environment (see §4.4.3. (supra p. 91)). Each requirement varied on three levels. Eight different combinations were made through these three requirements, ${ }^{101}$ which is illustrated in Figure 7.2.

Figure 7.2: The eight stick-based scenarios
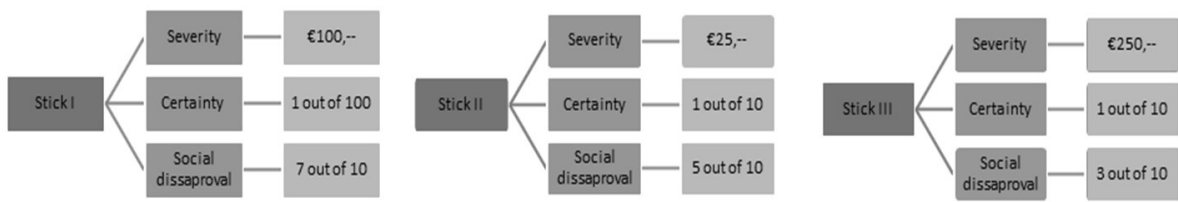

${ }^{100} \mathrm{M}=4.8, \mathrm{SD}=1.69(\mathrm{t}(49)=5.44, \mathrm{p}<0.001)$ compared to $\mathrm{M}=4.6, \mathrm{SD}=2.23(\mathrm{t}(66)=4.05, \mathrm{p}<0.001, d=-0.09)$.

${ }^{101}$ Not all requirements are incorporated into the design of the scenarios meant to test the deterrent mechanism. The repetition of the (threat of) punishment is not explicitly stated, as the focus was on once-off sanctions. The stimulation of alternative behaviour is likewise not used in the design of these scenarios. Testing these requirements is therefore not possible. 


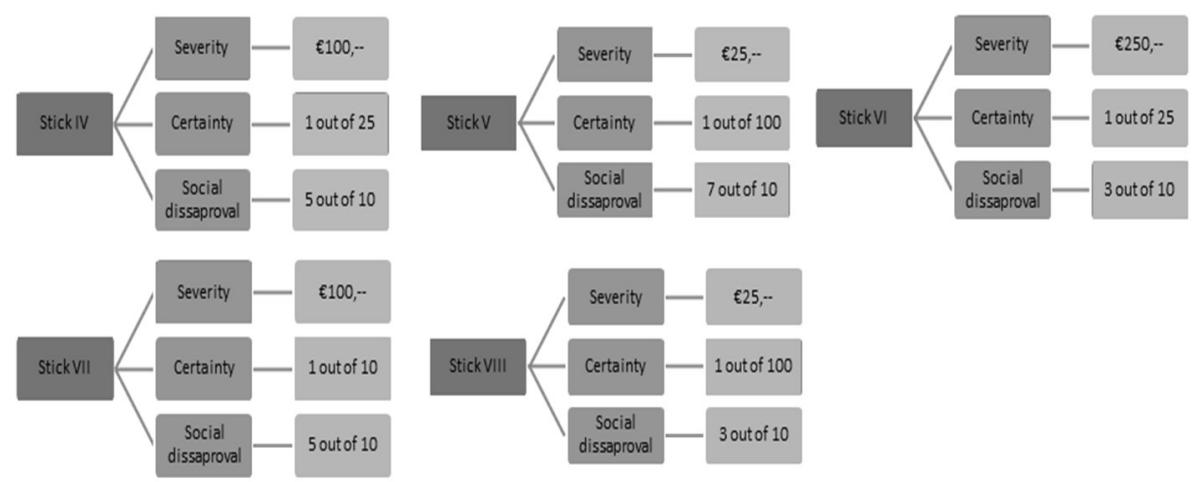

The focus in relation to the certainty and severity of the scenarios was on whether more certain or more severe sanctions are more capable of contributing to reducing digital piracy. Since the findings in \$6.1.2. (supra, p. 150) were somewhat conflicting, there was extra merit to also examining the effect that a more severe punishment can have on the reported intention of the respondents. To assess this, the scenarios depicted low, medium or high levels of both requirements. A low level referred to either a $1 \%$ chance of being sanctioned or a fine of $€ 25$. Fines were selected as opposed to prison sentences, as they are more realistic, given the Dutch and Belgian contexts. ${ }^{102}$ A medium level referred to a $4 \%$ sanctioning chance or a fine of $€ 100$, while high levels referred to a $10 \%$ chance and a fine of $€ 250$, respectively. ${ }^{103}$ The decision was made to have a range of certainty of punishment from $1 \%-10 \%$, instead of from $30 \%-40 \%$. This decision was based on the fact that the $30 \%-40 \%$ range might be unrealistic, which could have made the scenarios unrealistic. A lower threshold was therefore needed, and the $1 \%-10 \%$ range reflects this lower threshold.

The third selected requirement (the degree of social disapproval) reflects the role of informal moral rules as a way to deter individuals from engaging in the act of digital piracy (Grasmick \& Green, 1980). By including statements on the number of individuals who disapprove of digital piracy, respondents may change their

${ }^{102}$ Imprisonment for acts of digital piracy, as defined in this research, is highly unlikely in either of these jurisdictions.

${ }^{103}$ These values are lower than what might be expected based on the previous chapters and it is certainly low compared to the deterrent measures used in the USA (see §6.1.1. (supra p. 141) and §6.1.2. (supra p. 150)). However, higher values would have resulted in unrealistic scenarios, given the context of the study. This unrealism would have hampered the reliability of the responses to the questionnaires. This sets this study apart from studies where unrealistically high levels of certainty were tested, such as the study by Sinha and Mandel (2008) who examined certainties of punishment of $45 \%$ and $100 \%$. 


\section{$\underline{\text { Punish, Seduce or Persuade }}$}

assessment on the applicable moral rules, which in turn can influence whether or not the individual will act in this manner. It was therefore measured whether or not more intense social disapproval results in changes in the reported scores. Three levels of social disapproval were used, each identifying the part of the society that believes that digital piracy is wrong. This ranged from three out of ten (low), and five out of ten (medium) to seven out of ten (high). ${ }^{104}$ Collectively, eight different combinations were made based on these three requirements, each with three associated varying levels.

\subsubsection{Requirements needed to make the incentive attractive}

The carrot-based scenarios relied on three requirements: 1) offering a greater incentive by reducing the cost of content, 2) the addition of extra features included in the purchase of the content and 3) stating the risk of contracting a computer virus or malware via the act of digital piracy. These first and third requirements varied on three levels, while the second requirement varied on two levels. The resulting eight scenarios are illustrated in Figure 7.3.

Figure 7.3: The eight carrot-based scenarios
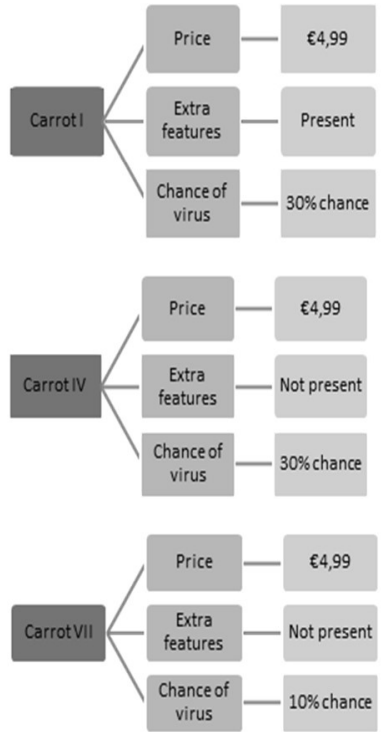
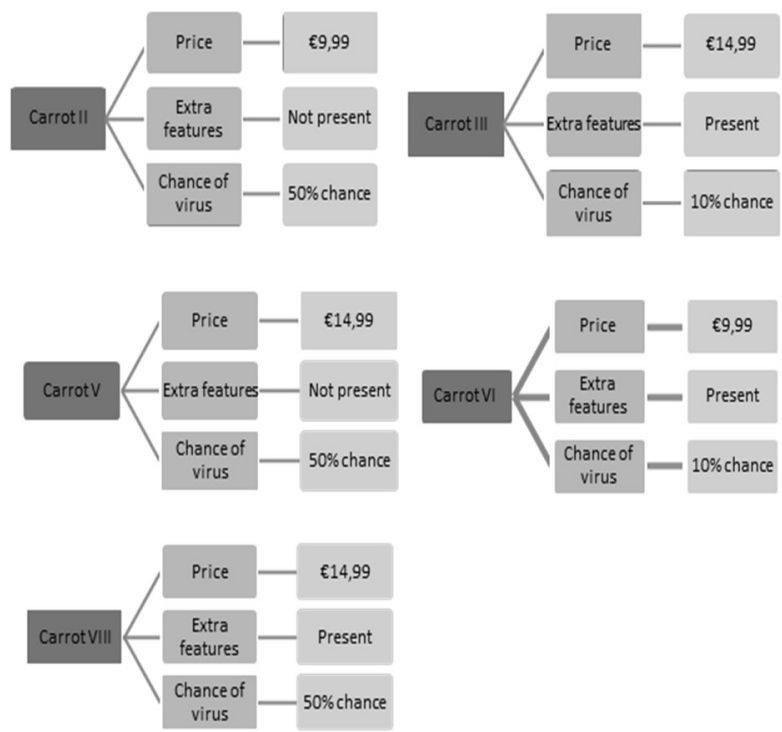

104 This range reflects the number of individuals who were found to pirate music digitally in Chapter 3 , which was between $30 \%$ to $70 \%$ 
Measuring the Contributions of Anti-Piracy Interventions and Their Mechanisms

The price for a complete (digital) music album varied between $€ 4.99, € 9.99$ and $€ 14.99$, being the low, medium and high variants of this requirement. ${ }^{105}$ In this way, the size of the incentive was modified. The second requirement focused on whether or not the legal content came with free extra features. Offering these free extras can improve the perceived benefits of the presented incentive. This requirement consisted of two variations: the content was either present or it was not. The extra features specifically referred to the addition of a free digital copy, in addition to the purchased one. The third requirement increased the attractiveness of legal content by identifying the risks associated with using pirated content. By clearly identifying the benefits of legal content, the legal content becomes more attractive for the user compared to the pirated version. This can occur if users are made aware of the fact that using pirated content carries the risk of obtaining a computer virus or other malware. It also, simultaneously, can increase the perceived expected negative outcomes of the act of digital piracy. The low variation of this requirement stated that users have a $10 \%$ chance of downloading an infected pirated copy, whereas the medium and high levels indicated this chance to be at 30\% and 50\% respectively. ${ }^{106}$ Arguably, the chance of being infected by a virus cannot always be expressed in this manner, but these percentages were used to reduce the role that each respondent's perception could play in this regard (over- or underestimating it).

\subsubsection{Requirements in order to persuade the target population}

The decision was made to focus on one of the three types of the sermon-based anti-piracy interventions: the harm appeal. The reason for this selection had to do with the fact that the other variants might be too similar to the scenarios based on the deterrent or incentive mechanisms, causing too great a degree of overlap between the scenarios (e.g. are the effects of raising awareness on a deterrent intervention measured or rather the effects of the persuasive intervention itself?). ${ }^{107}$ This is the reason that it is the harm appeal rather than the fear appeal

${ }^{105}$ It might have been expected that the scenarios would have examined the streaming of content (and thus, for free) as an incentive. This was not done for two reasons. First and foremost, when the questionnaires and scenarios were developed, streaming services were still relatively new and not as widespread as they are today. Secondly, testing both the more traditional content-model and the streaming model would have expanded the size of the questionnaires and have further burdened the respondents.

${ }^{106}$ Gantz et al. (2006) indicate that between $11 \%$ and $59 \%$ of pirated content contained malware. Although this content only included software such as key generators or crack tools, using a range between $10 \%$ and $50 \%$ is deemed to be sufficiently realistic.

${ }^{107}$ Selecting a similar type of the usage of the persuasive mechanism would have been interesting to determine whether its outcomes would have been similar to the findings associated with either the deterrent or incentive mechanisms. This could be used to determine whether differences in the presentation and the framing of the message influence how respondents would have reacted to a, content-wise, similar message. In the end, the necessity to examine the effects of informing respondents 


\section{$\underline{\text { Punish, Seduce or Persuade }}$}

that has been selected for analysis. Four requirements were used to design the scenarios using the harm appeal, three of which were meant to present a sufficiently meaningful harm to the respondent: 1) the size of the negative consequences, 2) where the consequences are felt in society, 3) the personal consequences of digital piracy, and 4) the social disapproval of digital piracy. The fourth requirement was linked to the believability of the sermon (a requirement that applies to all sermon-based interventions). If the act of digital piracy is presented as being disapproved of by others, the message that digital piracy is not the appropriate way to obtain content can become more believable. Figure 7.4 presents the variations within the eight sermon-based scenarios.

Figure 7.4: The eight sermon-based scenarios
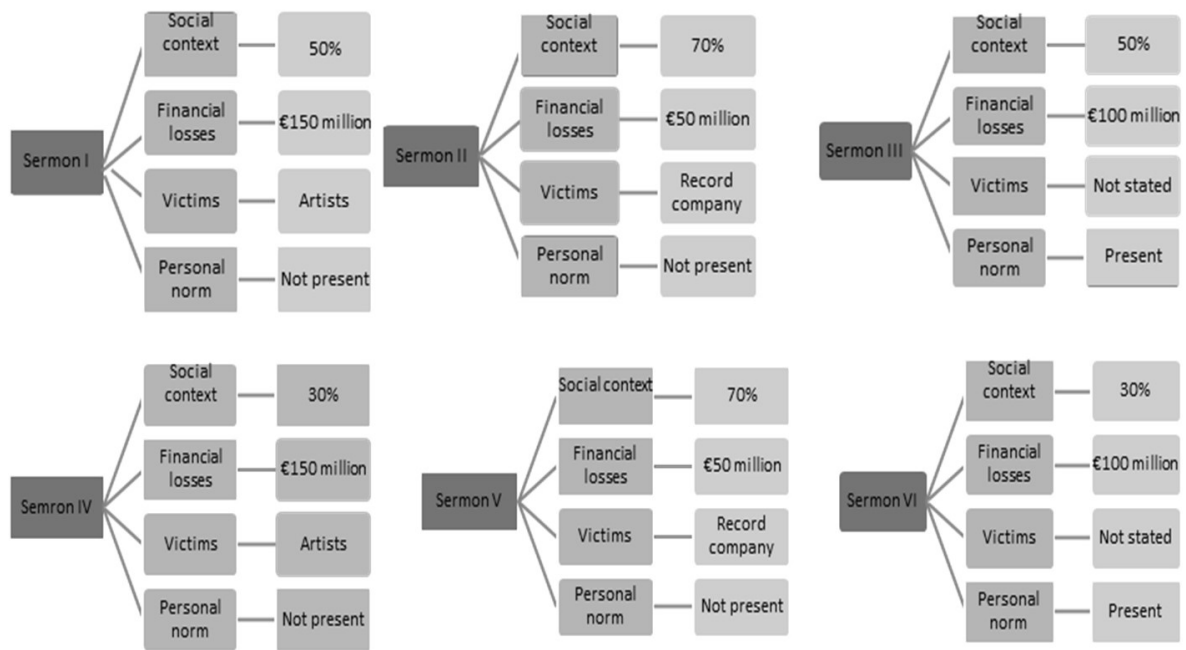

on the effects of digital piracy was deemed to be more important than to check the outcomes of using the persuasive mechanisms as a way to support the other two mechanisms. 

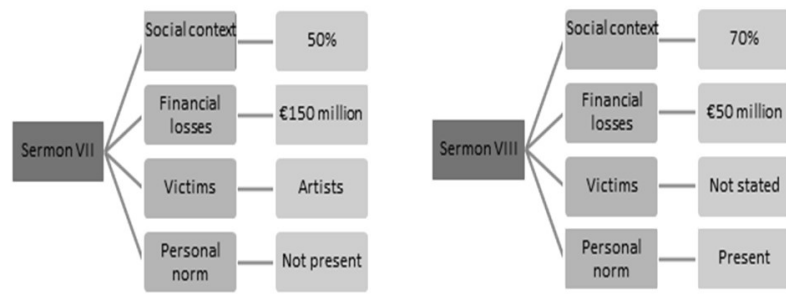

The extent of the consequences of digital piracy was expressed in financial losses and ranging from $€ 50$ million (low), to $€ 100$ million (medium) to $€ 150$ million (high). ${ }^{108}$ The second requirement focused on where the

harm was felt and varied in three ways: the 'victim' was portrayed as either the artist or the record company or, thirdly, the victim was not stated or identified. The third requirement made the harm more concrete for the respondent by stating that the quality and variety of legal content would decrease if digital piracy continued. This meant that the respondent was exposed to another negative consequence of his behaviour, framing the harm appeal differently. This aspect varied in two levels: it was either present or not. The fourth and final requirement varied on three levels and depicted the percentage of the population that believes that people should never pirate content digitally. This percentage varies from 30\% (low), to $50 \%$ (medium) to $70 \%$ (high).

\subsubsection{The 12 pairs of scenarios}

As discussed in §2.2. (supra p. 30), scenarios were presented to the respondents in pairs. Each pair consisted of two scenarios, with each scenario being based on a different mechanism (e.g., deterrence and incentives, incentives and persuasion or persuasion and deterrence). The reason for this pairing can be found in the fact that digital pirates are exposed to a multitude of different anti-piracy interventions in daily life. By asking the respondents to choose between scenarios using different mechanisms, it became possible to rank these by order of 'preference'. Table 7.3 gives an example of what a pair of scenarios looked like for the respondent. The first pair, which consisted of Stick I and Carrot I, is presented in this figure. ${ }^{109}$

\footnotetext{
${ }^{108}$ For the Belgian questionnaire, these figures were changed to $€ 35$ million, $€ 85$ million and $€ 140$ million respectively to reflect the smaller economy of this country.

${ }^{109}$ See Appendix II (infra, p. 325) for a textual overview of the 24 scenarios.
} 
Punish, Seduce or Persuade

Table 7.3: Example of a pair of scenarios (translated from Dutch)

\begin{tabular}{|ll|}
\hline Scenario A & Scenario B \\
\hline $\begin{array}{l}1 \text { out of a } 100 \text { individuals who download music } \\
\text { from an illegal source receives a fine, which is } \\
\text { imposed by The BREIN Foundation. }{ }^{110}\end{array}$ & $\begin{array}{l}\text { The average price one has to pay to obtain a music } \\
\text { album legally is } € 4.99 .\end{array}$ \\
\hline $\begin{array}{l}\text { On average, this fine is } € 100.00 \text { per downloaded } \\
\text { music file. }\end{array}$ & $\begin{array}{l}\text { These albums come with a free digital copy and } \\
\text { other extras. }\end{array}$ \\
\hline $\begin{array}{l}7 \text { out of } 10 \text { Internet users believe that one should } \\
\text { never download music from an illegal source. }\end{array}$ & $\begin{array}{l}\text { On average, } 3 \text { out of } 10 \text { music files that have been } \\
\text { downloaded from an illegal source contain a } \\
\text { virus. }\end{array}$ \\
\hline
\end{tabular}

12 of these pairs were made, containing the 24 scenarios in total. These 12 pairs were divided into two groups. Each group of six pairs of scenarios formed a separate self-administrated questionnaire (version A and version B). The overview of the pairs is presented in Figure 7.5.

Figure 7.5: The 12 pairs of scenarios

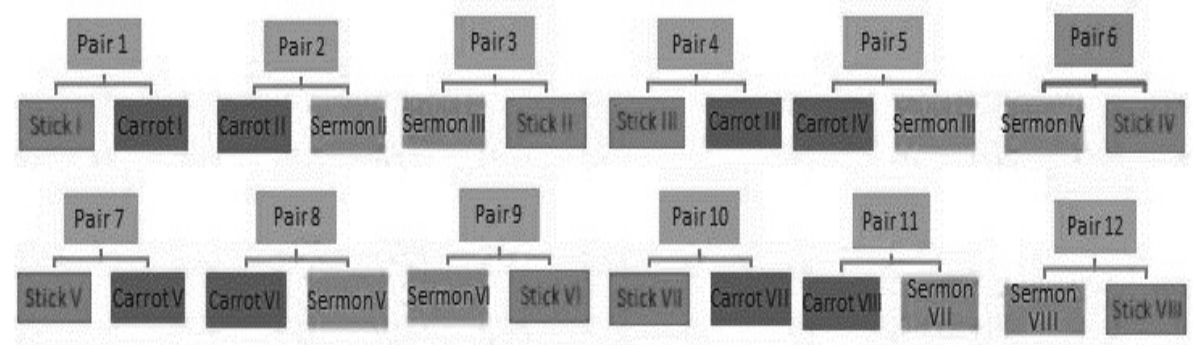

Version A of the questionnaires consisted of pairs one to six, while version B was populated with pairs seven to twelve. Both groups contained an equal number of mechanisms: four scenarios based on deterrence, four were based on incentives and the remaining four on persuasion. ${ }^{111}$

Collectively, the 24 scenarios allowed for insights into how respondents reacted to specific mechanisms and their associated requirements. The scenarios led to three measurements that are insightful in understanding the extent that the mechanisms can contribute to reductions in digital piracy. Firstly, the respondent was asked to indicate, per scenario, his inclination to pirate content digitally in the context presented by both scenarios in each pair. In this manner, insights into the respondent's assessment as to whether or not he would pirate content digitally were obtained. For the second question, respondents were asked to indicate which

${ }^{110}$ The BREIN Foundation (Stichting BREIN) is the joint anti-piracy program of authors, artists, publishers, producers, and distributors of music, film, games, interactive software, and books in the Netherlands (Grasmick \& Green, 1980).

111 The division of the scenarios remained identical in both the Netherlands and Belgium. 
Measuring the Contributions of Anti-Piracy Interventions and Their Mechanisms

of the two scenarios they found to be more convincing. This was followed by a final question asking the respondent to indicate the strength of this conviction. ${ }^{112}$

\subsection{The mechanisms at work: their contributions to reductions in digital piracy}

The choices made by the respondents as to which of the two scenarios were found to be more convincing, as well as the strength of this conviction, are insightful in determining which of the three mechanisms the respondents themselves perceived to influence their behaviour to the greatest degree. This section focuses on identifying which mechanism is more capable of contributing to reductions in digital piracy. By also reporting the strength that the respondents have attributed to their choices, the relevance of each mechanism is further underlined. The second analysis compared the baseline presented previously to the reported score per scenario. This was done to obtain further insights as to the extent of each mechanisms' possible contribution and rank the scenarios based on this extent. Scenarios that resulted in a score that is lower than the baseline are more capable to contribute to reductions in digital piracy in real life, compared to those scenarios that failed to do so. As previously discussed (\$7.2.1. (supra p. 184)), the scores from this baseline was sufficiently close to the respondents' frequency of past digital piracy for it to be used in such a way. A later section will examine how specific requirements influenced the scores in both samples.

7.3.1. Most convincing mechanism and strength of conviction (Dutch sample)

Respondents were asked to indicate which of the two scenarios (per pair) they found most convincing. The choices of the Dutch sample are depicted in Figure 7.6. Respondents were asked to select the scenario they found to be most convincing and also to indicate the strength of this conviction (on a scale of 0 to 5). This means that the respondents always had to make a choice and compare both scenarios. ${ }^{113}$ The figure presents the assessment of both scenarios, per pair, made by the respondents.

\footnotetext{
${ }^{112}$ Respondents that had not pirated content digitally (and who had also indicated that they were not inclined to do so in the future) were routed to a different part of the questionnaire and were presented with a few questions about the believability and realism of the questionnaire. As this study is interested in the contributions that anti-piracy interventions can have on reducing digital piracy, analysing the responses from those individuals who are naturally compliant to the various scenarios would likely have overstated this contribution, as they would not have been inclined to pirate content digitally in any of the scenarios. This could have influenced the outcomes of this study.

${ }^{113}$ In order to limit, as far as possible, the potential influence of the ordering of these scenarios, the scenarios were designed in such a way that the variance was not predictable for the respondent. For example,
} 


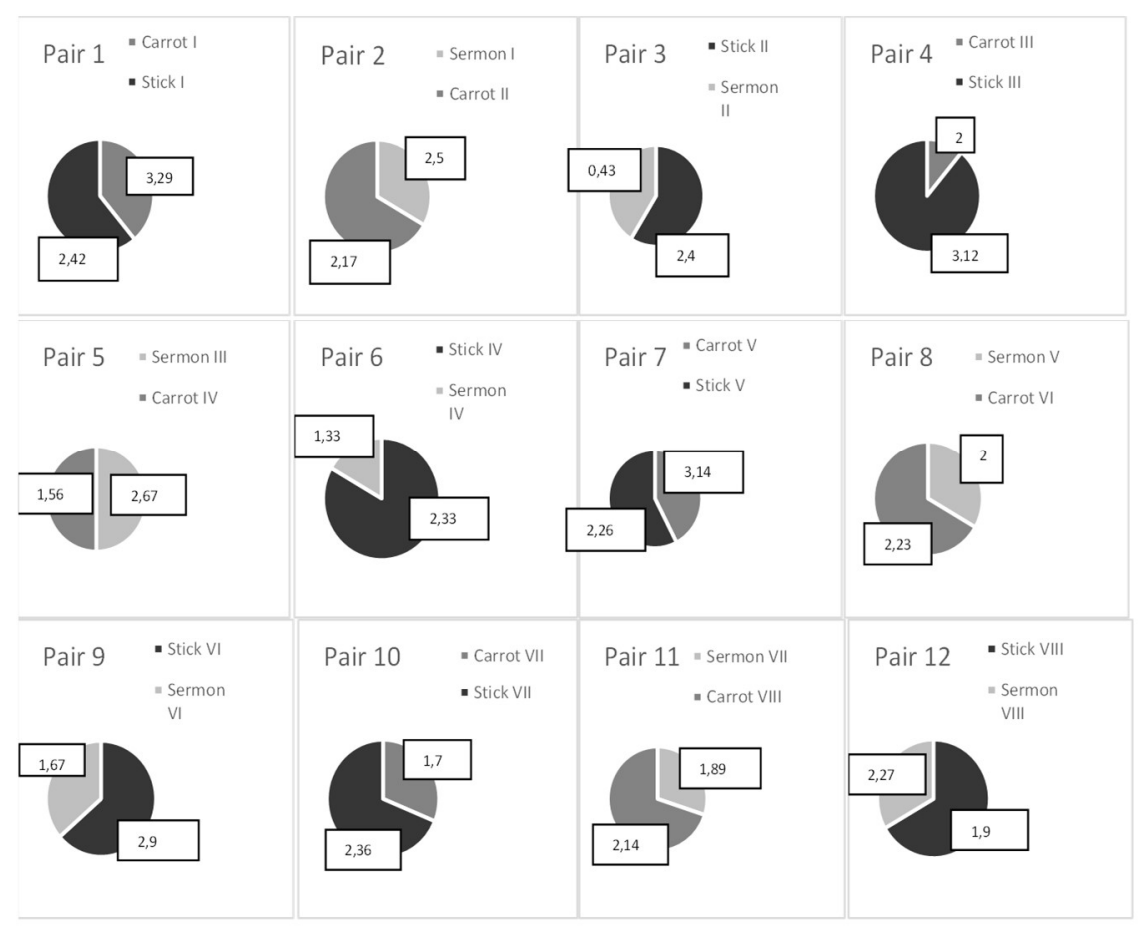

Patterns emerge when the figure above is examined in detail. Of the eight times that the respondents were confronted with a stick-based scenario, they chose those the stick-based scenarios every time. Stick-based scenarios are thus preferred over carrot- or sermon-based scenarios. Three out of the four times that the carrotbased scenarios were paired with sermon-based scenarios, the carrot-based scenarios were preferred. The sermon-based scenarios were never preferred. But even if a scenario was not selected by the majority, this does not mean that it is not convincing at all, as the scores associated with those scenarios reflect. For instance, Carrot I scores 3.29, even though it was not the scenario that the majority selected as being the most convincing. ${ }^{114}$

instead of gradually increasing the certainty of punishment as the later scenarios were presented, this requirement both increased and decreased in subsequent scenarios.

${ }^{114}$ It is not unlikely however that the mean scores for the strength of the conviction for those scenarios that are not selected as often are skewed. This is possibly an artefact from the fact that the group of respondents who selected the overall less convincing scenario is smaller in size, meaning that significantly higher or lower scores likely influence the mean. 
Measuring the Contributions of Anti-Piracy Interventions and Their Mechanisms

7.3.2. How the scenarios influence the respondents' inclination to pirate content digitally (Dutch sample)

The preference for certain scenarios is thus apparent. The next matter is to determine how certain scenarios influenced the respondents' scores on their inclination to pirate content digitally. Based on the previous section, the most often selected scenarios in the Dutch sample were scenarios 'Stick III', 'Stick IV' and 'Carrot VIII', while the strongest conviction was apparent in scenarios 'Carrot I', 'Carrot V' and 'Stick III'. ${ }^{115}$ Whether specific requirements explain these outcomes will be discussed later in this chapter, but for now it suffices to determine whether these scenarios also had the greatest influence (reduction) on the respondent's inclination to pirate content digitally or not.

Recall that 'scenario zero' led to a score $\mathrm{M}=4.8$ ( $\mathrm{p}<0,001)$. This is the baseline to which the responses to the scenarios will be compared. Scores that are lower than this baseline are indications that a scenario, and the associated requirements, can contribute to reductions in digital piracy. A larger difference between this baseline and the scores for certain scenarios is indicative of a scenario that has modified the respondents' inclination to pirate content digitally in the context described in the scenario, provided that this difference is statistically significant. Scenarios that have resulted in scores higher than the baseline might not contribute in this manner at all. Instead, these might even be counterproductive, as respondents indicated that they are more inclined to pirate content digitally in that context.

The results of this analysis on the level of each scenario are depicted in Figure 7.7. The black line represents the mean score for scenario zero. Red bars refer to stick-scenarios, while green and orange bars refer to carrot- and sermon-based scenarios respectively. The results have been tested for statistical significance, the results of which are reported in the figure below. Cohen's $d$ is used to express the effect size of the various changes (Rice \& Harris, 2005). ${ }^{116}$

\footnotetext{
${ }^{115}$ It cannot be excluded that the way in which the scenarios were paired, as well as the order thereof, has influenced the responses to some degree.

${ }^{116}$ The tests for significance were carried out via one-sample T-tests. Cohen's $d$ was used to determine the effect size.
} 
Figure 7.7: Scores after exposure to scenario (Dutch sample)

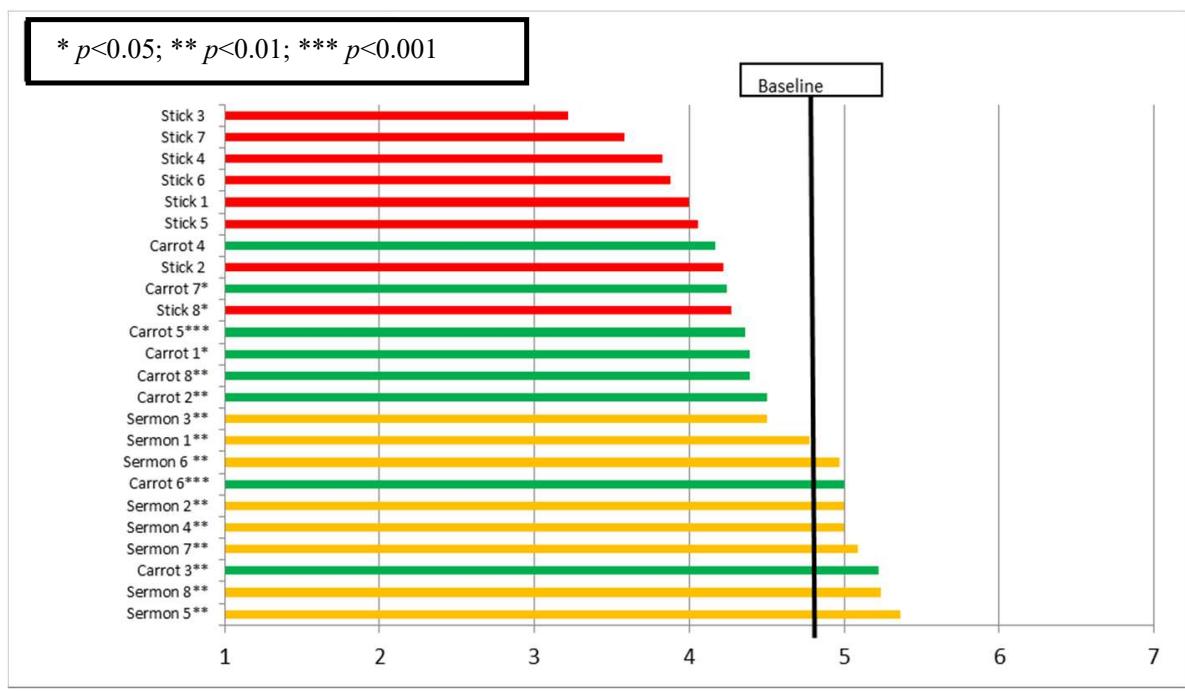

The sole statistically significant result for the stick-based scenarios was paired with the 'smallest' scores for stick-based scenarios: Stick VIII, which is accompanied with a small effect size. ${ }^{117}$ Stick III and IV, in contrast, were identified as being most often selected by the respondents, while Stick III was also one of the scenarios with a strong degree of conviction. And while both result in low scores, these findings are not statistically significant.

Most of the carrot-based scenarios led to the results that were statistically significant. Carrot VII led to a reduction, also having a small effect size. ${ }^{118}$ Still, two of these scenarios resulted in scores higher than the baseline: Carrot VI ${ }^{119}$ and Carrot III. ${ }^{120}$ The effect sizes accompanied with both scenarios are small however. Carrot VIII ${ }^{121}$ was among the most often selected, while Carrot ${ }^{122}$ and Carrot $\mathrm{V}^{123}$ were among the scenarios that had strong degrees of convictions. All led to scores that were below the baseline but were accompanied with small effect sizes.

Most sermon-based scenarios have resulted in scores that are beyond the baseline. These findings are consistently statistically significant. Only two scenarios led to

${ }^{117} \mathrm{M}=4.27, \mathrm{SD}=1.79$ compared to the baseline $(\mathrm{t}(32)=2.48, \mathrm{p}<0.05, \mathrm{~d}=-0.29)$

${ }_{118} \mathrm{M}=4.24, \mathrm{SD}=1.86$ compared to the baseline $(\mathrm{t}(32)=2.3, \mathrm{p}<0.05, \mathrm{~d}=-0.3)$.

${ }^{119} \mathrm{M}=5, \mathrm{SD}=1.39$ compared to the baseline $(\mathrm{t}(32)=6.19, \mathrm{p}<0.001, \mathrm{~d}=0.14)$.

${ }^{120} \mathrm{M}=5.22, \mathrm{SD}=1.43$ compared to the baseline $(\mathrm{t}(17)=5.08, \mathrm{p}<0.01, \mathrm{~d}=0.31)$.

${ }^{121} \mathrm{M}=4.39, \mathrm{SD}=1.73$ compared to the baseline $(\mathrm{t}(32)=2.97, \mathrm{p}<0.01, \mathrm{~d}=-0.23)$.

${ }^{122} \mathrm{M}=4.39, \mathrm{SD}=1.54$ compared to the baseline $(\mathrm{t}(17)=2.45, \mathrm{p}<0.05, \mathrm{~d}=-0.27)$.

${ }^{123} \mathrm{M}=4.36, \mathrm{SD}=1.32$, compared to the baseline $(\mathrm{t}(32)=3.76, \mathrm{p}<0.001 . \mathrm{d}=-0.33)$. 
lower scores: Sermon III ${ }^{124}$ and I. ${ }^{125}$ The latter scenario has an effect size that is so small that it means that its effect is close to zero. The remaining six all resulted in scores beyond the baseline, with Sermon V having the greatest effect size. ${ }^{126}$

\subsubsection{Most convincing scenarios and strength of conviction (Belgian sample)}

The next question is whether the Belgian sample reflects the findings found in the Dutch sample. The first matter is again to determine whether a similar order of choices can be seen, which Figure 7.8 illustrates.

Figure 7.8: Choices per pair and strength of conviction (Belgium sample)

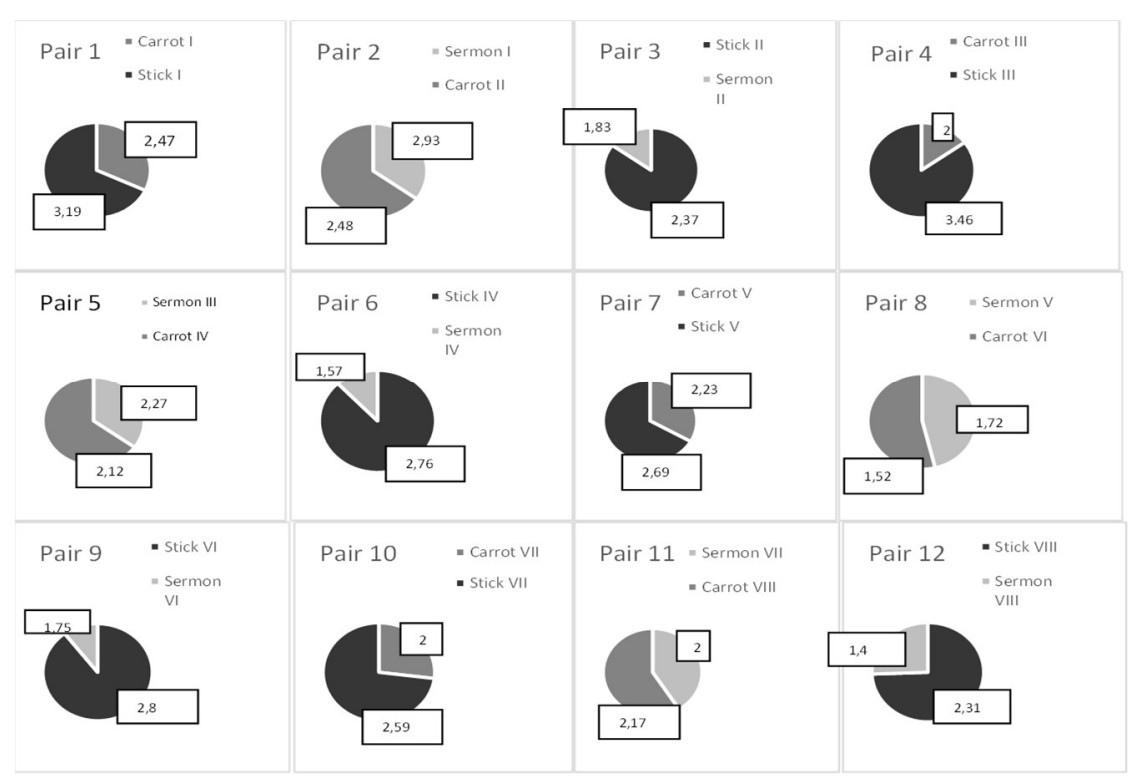

The findings mirror those from the Dutch sample. Again, the eight times that the respondents were confronted with stick-based scenarios, they always chose stickbased scenarios over carrot- or sermon-based scenarios. The preference of the carrot over the sermon is also clear, as it was preferred in all four possible choices. The sermon was never preferred.

Taken together with the preferences of the Dutch respondents, a ranking emerges where stick-based interventions are preferred over carrot-based ones and carrot-

\footnotetext{
${ }^{124} \mathrm{M}=4.5, \mathrm{SD}=1.38$ compared to the baseline $(\mathrm{t}(17)=3.07, \mathrm{p}<0.01, \mathrm{~d}=-0.22)$.

${ }^{125} \mathrm{M}=4.78, \mathrm{SD}=1.56$ compared to the baseline $(\mathrm{t}(17)=3.49, \mathrm{p}<0.01, \mathrm{~d}=-0.01)$

${ }^{126} \mathrm{M}=5.36, \mathrm{SD}=1.50$ compared to the baseline $(\mathrm{t}(32)=7.12, \mathrm{p}<0.01, \mathrm{~d}=0.38)$.
} 


\section{$\underline{\text { Punish, Seduce or Persuade }}$}

based ones are preferred over sermon-based ones. But scenarios that are selected less often are again not necessarily accompanied by very low scores in the strength of the conviction. This is indicative of what the respondents 'prefer' and both samples indicate that the preferences of both groups of respondents are largely similar.

7.3.4. How the scenarios influence the respondents' inclination to pirate content digitally (Belgian sample)

Based on the choices made by the Belgian sample, certain scenarios emerged as being either the most often selected or having the strongest degree of conviction. Stick-based scenarios dominated both categories in the Belgian sample. 'Stick VI' 'Stick IV', 'Stick II', and 'Stick III' were selected most often (the latter two being tied) while 'Stick III', 'Stick I' and 'Stick VI' led to the strongest conviction.

The question is whether these choices are reflected in how the respondents scored the various scenarios. By again comparing 'scenario zero' to the reported score per scenario, it becomes possible to present more detailed findings. The baseline in the Belgian sample was $M=4.61(\mathrm{p}<0.005)$, to which the reactions to the scenarios were compared. Figure 7.9 depicts the scores per scenario.

Figure 7.9: Scores after exposure to the scenarios (Belgian sample)

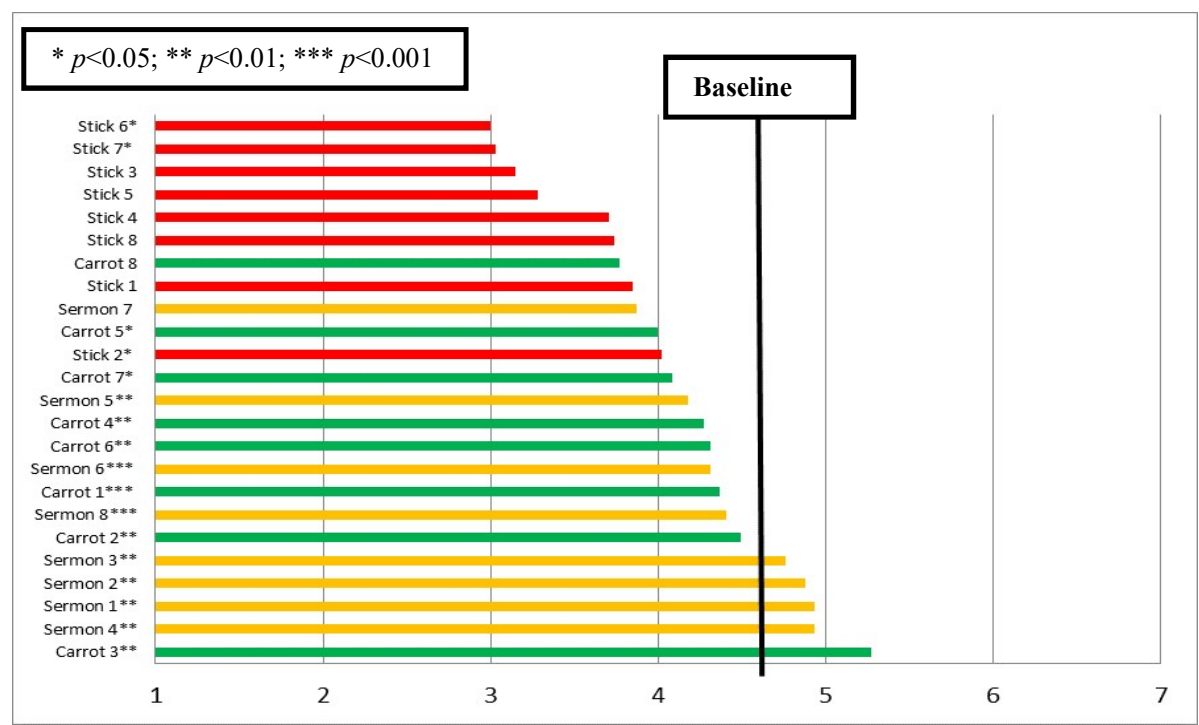


In the Belgian context, the stick-based scenarios have also led to lower scores, with Stick VI resulting in the lowest score ${ }^{127}$, while Stick II led to the score closest to the baseline of this category. ${ }^{128}$ The relevance of Stick VI, with a large effect size, is thus reflected in both the choices made by the respondents as well as the way through which this has led to lower scores. Interestingly, Stick II led to the scores that are relatively close to the baseline (which can be seen in the effect size), even though it was one of the scenarios that was selected most often. In contrast, Stick VII led to a score that is almost as low and an effect size as large compared to Stick VI ${ }^{129}$, but it did not emerge previously as a scenario that was most often selected or judged to be highly convincing.

Certain carrot-based scenarios also led to lower scores. Carrot V has the largest effect size of those carrot-based scenarios that resulted in lower scores. ${ }^{130}$ Interestingly, of all the examined scenarios, a carrot-based scenario had the highest score and the largest effect size of those that end up beyond the baseline: Carrot III. ${ }^{131}$ Most of the other carrot-based scenarios resulted in statistically significant reductions.

Finally, some of the sermons depict increases in the respondent's inclination to pirate content digitally. Of these, Sermon IV has the largest effect size. ${ }^{132}$ In total, four of these scenarios led to scores higher than the baseline. The other four scenarios led to scores slightly smaller than the baseline, with Sermon V having the largest effect size that was also statistically significant. ${ }^{133}$ Combined with the fact that these results are statistically significant, for the most part, there appears to be an additional confirmation that sermon-based scenarios (and its associated mechanism) are least likely to contribute to reductions in digital piracy behaviour, with Sermon V being the exception to this observation.

The findings in these two sections demonstrate that the deterrent mechanism is preferred over the incentive and that the incentive is preferred over persuasive efforts. This preference however does not mean that stick-based scenarios will always lead to the lowest scores in the respondent's inclination to pirate content digitally in the context present by the scenario. Nor does it mean that sermonbased scenarios are completely incapable of contributing to reductions. Still, the ranking proposed based on the choices made in both samples, as well as the

${ }^{127} \mathrm{M}=3, \mathrm{SD}=1.34$ compared to the baseline $(\mathrm{t}(38)=-2.33, \mathrm{p}<0.05, \mathrm{~d}=-1.2)$.

${ }^{128} \mathrm{M}=4.02, \mathrm{SD}=1.41$ compared to the baseline $(\mathrm{t}(40)=2.39, \mathrm{p}<0.05, \mathrm{~d}=-0.42)$.

${ }^{129} \mathrm{M}=3.03, \mathrm{SD}=1.46$ compared to the baseline $(\mathrm{t}(37)=-6.68, \mathrm{p}<0.01, \mathrm{~d}=-1.08)$.

${ }^{130} \mathrm{M}=4, \mathrm{SD}=1.43$ compared to the baseline $(\mathrm{t}(38)=2.66, \mathrm{p}<0.05, \mathrm{~d}=-0.43)$.

${ }^{131} \mathrm{M}=5.27, \mathrm{SD}=1.32$ compared to the baseline $(\mathrm{t}(40)=8.56, \mathrm{p}<0.01, \mathrm{~d}=0.5)$.

${ }^{132} \mathrm{M}=4.93, \mathrm{SD}=1.42$ compared to the baseline $(\mathrm{t}(40)=6.43, \mathrm{p}<0.01, \mathrm{~d}=0.22)$.

${ }^{133} \mathrm{M}=4.18, \mathrm{SD}=1.57$ compared to the baseline $(\mathrm{t}(38)=2.7, \mathrm{p}<0.01, \mathrm{~d}=-0.27)$. 


\section{$\underline{\text { Punish, Seduce or Persuade }}$}

reported scores, provides a basis for subsequent analyses. What these two sections also demonstrate is that the effect size of the scenarios is, with a few exceptions, quite small. This observation carries with it the possibility that anti-piracy interventions in real life might also only trigger relatively small changes.

The next analysis focuses on the requirements that were used to shape the scenarios. This is informative on the role that the various requirements play in influencing the respondents' inclination that he will pirate content digitally in the context presented by the various scenarios. The goal of that section is to identify which requirements, and which variations thereof, can contribute the most to reductions in digital piracy.

\subsection{A closer look at the requirements}

As discussed in $§ 7.2$. (supra p. 183), the 24 scenarios were all designed around a number of requirements (which were identified in Chapter 6). Variations for each requirement were used in order to differentiate the scenarios. Scenarios that meet the requirements are expected to be more capable of contributing to reductions in digital piracy. For example, making content increasingly affordable (e.g., cheaper) would increase the contribution of the incentive mechanism to reductions in digital piracy. Giving the findings in the previous chapters, this would be expected at least. This section focuses on these and other requirements in order to determine whether this assumption is valid. The respective baselines of both samples were again used to contrast the responses to the mechanisms.

\subsubsection{Responses to the requirements in the Dutch sample}

The requirements are analysed per each mechanism that they belong to, starting with the deterrent-mechanism. The scenarios based on this mechanism use three requirements: the certainty and the severity of the sanction and the degree of social disapproval. Figure 7.10 demonstrates how these requirements and their variations have influenced the respondents' inclination to pirating content digitally. 


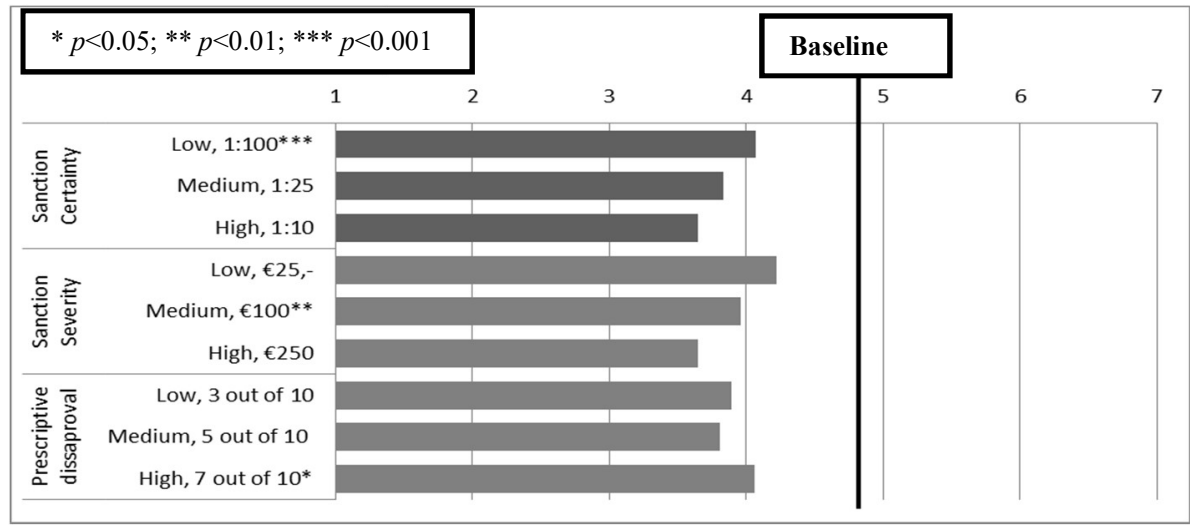

As the certainty increases (moving from a likelihood of one out of a hundred to one out of ten), scores continue to decrease. Only the lowest degree of the certainty of punishment is statistically significant however, which leads to a small reduction in scores. ${ }^{134}$ In a similar manner, the medium severity of the (threat of) punishment also reduces the scores, though the effect size is a bit larger. ${ }^{135}$ The highest level of social disapproval also contributed to a reduction in scores. ${ }^{136}$ Next, Figure 7.11 presents how the respondents reacted to the various requirements related to the carrot-based scenarios.

Figure 7.11: Changes in scores based on carrot-related requirements (Dutch sample)

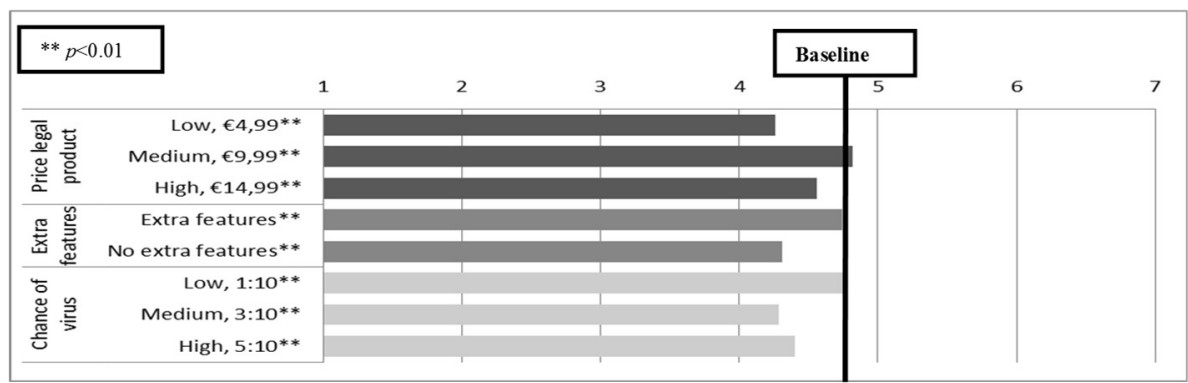

The figure shows that, firstly, the lowest score and largest effect size for this group of requirements is found in those scenarios where the price of legal content was lowest. ${ }^{137}$ As content becomes more expensive, the scores come closer to the

${ }^{134} \mathrm{M}=4.07, \mathrm{SD}=1.75$, compared to the baseline $(\mathrm{t}(116)=3.51, \mathrm{p}<0.001, \mathrm{~d}=-0.42)$.

$135(\mathrm{M}=3.96, \mathrm{SD}=1.7$, compared to the baseline $(\mathrm{t}(134)=1.7, \mathrm{p}<0.01, \mathrm{~d}=-0.49)$

${ }^{136} \mathrm{M}=4.06, \mathrm{SD}=1.74$ compared to the baseline $(\mathrm{t}(50)=2.9, \mathrm{p}<0.05, \mathrm{~d}=-0.43$

${ }^{137} \mathrm{M}=4.26, \mathrm{SD}=1.7$ compared to the baseline $(\mathrm{t}(68)=3.71, \mathrm{p}<0.01, \mathrm{~d}=-0.32)$. 


\section{$\underline{\text { Punish, Seduce or Persuade }}$}

baseline and the effect size shrinks. ${ }^{138}$ While the reduction for low cost content is not overly large, given the small effect size, the fact that the other prices lead to scores closer to the baseline is important as it underlines that making content more expensive can influence the respondent's assessment on whether or not he should pirate the content digitally.

With regard to the remaining requirements, adding extra features (the addition of a free digital copy) does not have the expected effect on the scores, as these lead to increases rather than decreases when these features are added, though the effect sizes remain small in both instances. ${ }^{139}$ At the same time, the role of identifying the risks of pirated content (exposure to viruses) has an impact on the scores, particularly if the risk is sufficiently concrete at medium ${ }^{140}$ or high levels. ${ }^{141}$ Identifying the 'cleanliness' of the legal content can be supportive of whether or not individuals perceive the content to be sufficiently attractive, though the effect sizes indicate that the changes in behaviour might be small.

Finally, Figure 7.12 focuses on the sermon-related requirements.

Figure 7.12: Changes in scores based on sermon-related requirements (Dutch sample)

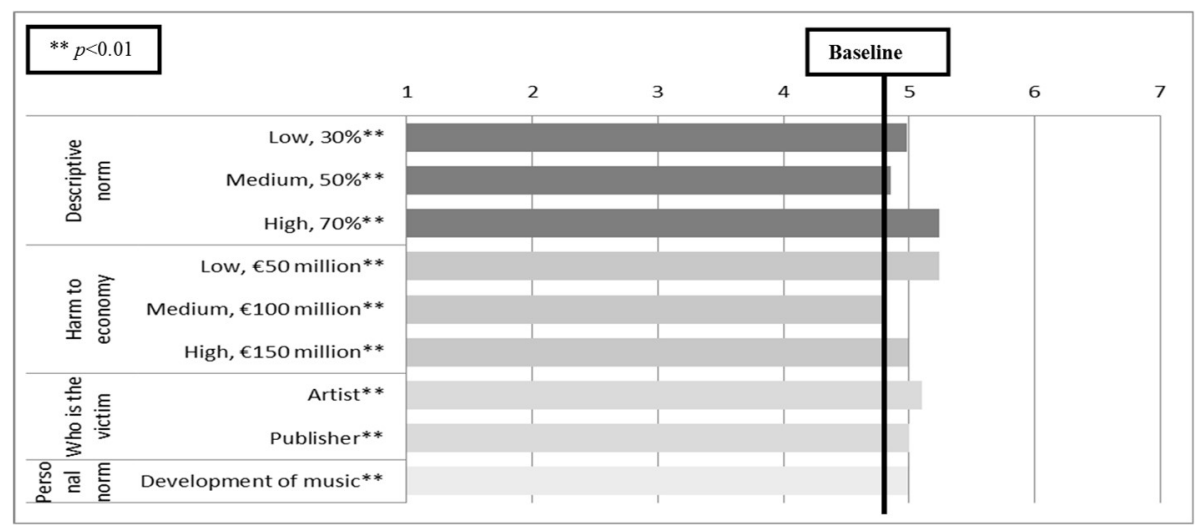

The figure clearly illustrates that none of the requirements manage to contribute to reductions beyond the established baseline. In fact, most of the requirements have resulted in a small increase in scores. Only the medium level of the harm of digital piracy meets the baseline. ${ }^{142}$ Given the fact that the findings are all statistically significant, the observation that, in the Dutch context at least, sermon-

${ }^{138} \mathrm{M}=4.82, \mathrm{SD}=1.42$ compared to the baseline $(\mathrm{t}(50)=6.64, \mathrm{p}<0.01, \mathrm{~d}=0.02)$ and $\mathrm{M}=4.56, \mathrm{SD}=1.54$ compared to the baseline $(\mathrm{t}(83)=6.31, \mathrm{p}<0.01, \mathrm{~d}=-0.16)$

${ }^{139} \mathrm{M}=4.74, \mathrm{SD}=1.56$ compared to the baseline $(\mathrm{t}(101)=7.99, \mathrm{p}<0.01, \mathrm{~d}=-0.04)$ and $\mathrm{M}=4.31, \mathrm{SD}=1.58$ compared to the baseline $(\mathrm{t}(101)=5.22, \mathrm{p}<0.01, \mathrm{~d}=-.31)$.

${ }^{140} \mathrm{M}=4.28, \mathrm{SD}=1.58$ compared to the baseline $(\mathrm{t}(35)=2.96$, $) \mathrm{p}<0.01, \mathrm{~d}=-0.35$.

${ }^{141} \mathrm{M}=4.4, \mathrm{SD}=1.41$ compared to the baseline $(\mathrm{t}(83)=5.51, \mathrm{p}<0.01, \mathrm{~d}=-0.26)$.

${ }^{142} \mathrm{M}=4.8, \mathrm{SD}=1.36$, compared to the baseline $(\mathrm{t}(50)=6.86, \mathrm{p}<0.01, \mathrm{~d}=0.003)$. 
based scenarios fail to contribute to reductions in digital piracy becomes more concrete.

\subsubsection{Responses to the requirements in the Belgian sample}

Recall that the baseline for the Belgian sample is slightly lower than the one in the Dutch sample $(M=4.61)$, meaning that the changes in scores are relative to this baseline (see \$7.2.1. (supra p. 184)) for the differences in past and intended digital piracy between the Dutch and Belgian sample). Figure 7.13 starts with the stickrelated requirements.

Figure 7.13: Changes in scores based on stick-related requirements (Belgian sample)

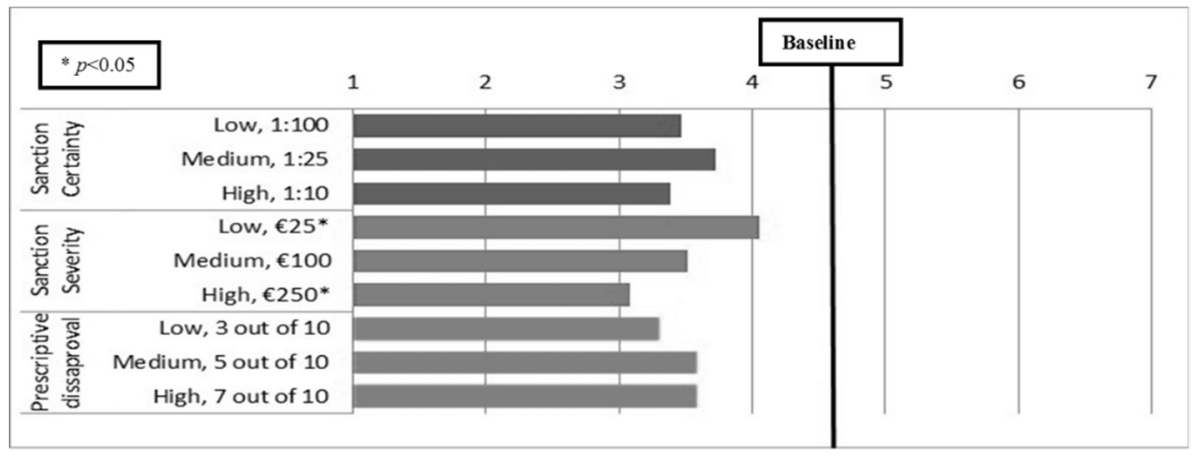

While all three requirements result in scores well below the baseline, few of these are statistically significant. Only the lowest and highest variations of the severity of punishment are in fact statistically significant. This is also the requirement that contributes to reductions in digital piracy in the expected direction, as the scores decrease step-by-step as the severity of the sanction increases. This leads to a large effect size when the sanction is very severe. ${ }^{143}$ The low variation of this requirement yields scores with a smaller effect size. ${ }^{144}$

${ }^{143} \mathrm{M}=3.08, \mathrm{SD}=1.5$ compared to the baseline $(\mathrm{t}(78)=-2.51, \mathrm{p}<0.05, \mathrm{~d}=-1.02)$.

${ }^{144} \mathrm{M}=4.05, \mathrm{SD}=1.41$ compared to the baseline $(\mathrm{t}(39)=2.46, \mathrm{p}<0.05, \mathrm{~d}=-0.4)$. 
Figure 7.14: Changes in scores based on carrot-related requirements (Belgian sample)

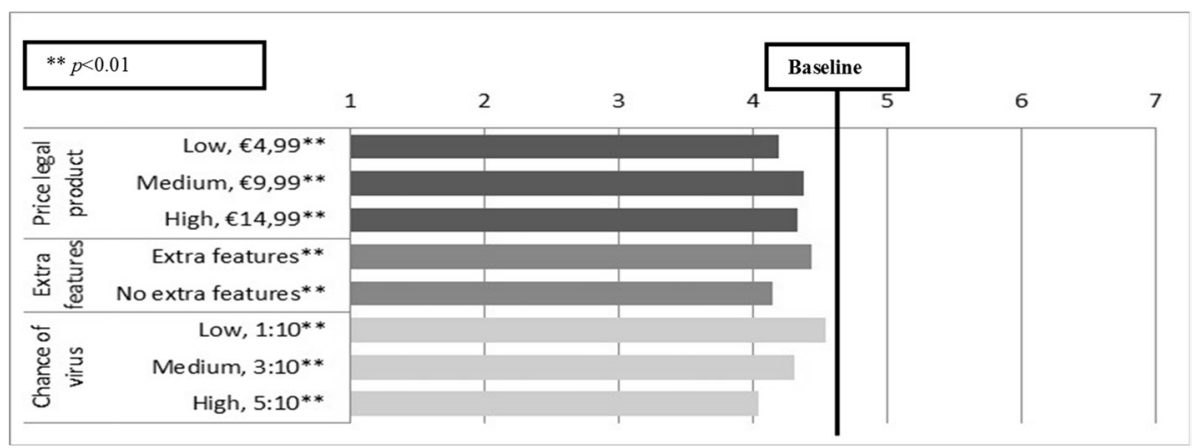

Figure 7.14 shows that reducing the price of content contributes to reducing the respondent's inclination that he will pirate content digitally. The reduction is statistically significant but the effect sizes are small for both the lowest ${ }^{145}$ and medium price. ${ }^{146}$ Introducing additional features to the legal content does not result in an expected reduction in scores. In fact, the scores indicate that the respondents estimate that they are more inclined to pirate content digitally when extra features are present ${ }^{147}$ then when they are not. ${ }^{148}$ This opposite to what was expected. Given the fact that a similar result was found in the Dutch sample, adding extra features to legal content does not seem to be able to contribute to reductions in digital piracy. Of the three requirements examined here, the chance of being infected by a virus through piracy functions in the expected manner, as greater risks result in lower scores. ${ }^{149,150}$ Overall, although the scores carry small effect sizes with them, the fact that they are statistically significant does indicate that the incentive mechanism can be useful in contributing to reductions in digital piracy if some of these requirements are met, though the reductions are likely to be small. Particularly the size of the incentive and the risks that the pirate copy carries with it are relevant. Little evidence is found for the role of adding extra features. Finally, Figure 7.15 concludes with the requirements for the sermonbased scenarios.

${ }^{145} \mathrm{M}=4.2, \mathrm{SD}=1.52$ compared to the baseline $(\mathrm{t}(117)=5.02, \mathrm{p}<0.01, \mathrm{~d}=-0.27)$.

${ }^{146} \mathrm{M}=4.34, \mathrm{SD}=1.55$ compared to the baseline $(\mathrm{t}(117)=5.89, \mathrm{p}<0.01, \mathrm{~d}=-0.16)$.

${ }^{147} \mathrm{M}=4.44, \mathrm{SD}=1.55$ compared the baseline $(\mathrm{t}(157)=7.63, p<0.01, d=-0.11)$.

${ }^{148} \mathrm{M}=4.15, \mathrm{SD}=1.45$ compared to the baseline $(\mathrm{t}(157)=5.64, p<0.01, d=-0.31)$.

${ }^{149} \mathrm{M}=4.54, \mathrm{SD}=1.53$ compared to the baseline $(\mathrm{t}(116)=7.32, p<0.01, d=-0.05)$.

${ }^{150} \mathrm{M}=4.05$, SD1.43 compared to the baseline $(\mathrm{t}(117)=4.2, \mathrm{p}<0.01, \mathrm{~d}=-0.39)$. 
Figure 7.15: Changes in scores based on sermon-related requirements (Belgian sample)

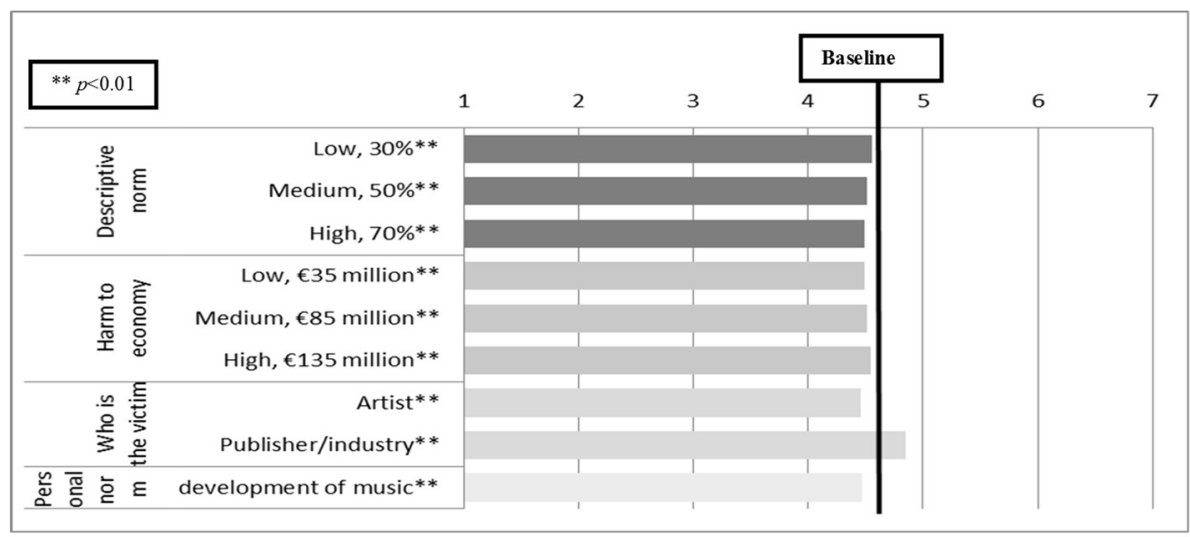

The findings for these requirements are all statistically significant. They depict that all requirements applied for the persuasive mechanism have very little effect on the scores. When compared to the baseline of $\mathrm{M}=4.61$, the reductions have a very small effect size. This leads to the assessment that the use of these requirements does not enable the mechanism to contribute to reductions in digital piracy, especially when combined with the findings in the Dutch sample.

\subsection{Differences in responses between men and women}

In $\S 4.3$ (supra p. 87), a number of attributes were discussed that allowed for the identification of the target population for anti-piracy interventions. Gender is one of these attributes and it was proposed that males more were inclined to pirate content digitally. This gender difference means that men and women are likely to act differently in the context of digital piracy. This first empirical study has found additional merit to examining the role of gender, since being female is negatively correlated with both the frequency of past digital piracy $(\mathrm{r}=-0.326, p=0.01)$ and the inclination to pirate content digitally in the future $(r=-0.356, p<0.01)$. In turn, this may also mean that both genders can react differently to anti-piracy interventions and mechanisms. This section sets out to understand how men and women reacted to the various scenarios and whether these reactions are different. Such an additional analysis allows for a better estimation of the role that gender plays in explaining and inhibiting digital piracy. ${ }^{151}$

At a first glance, differentiating on the basis of gender seems to depict that women indeed respond differently. In Figure 7.16, the pink area depicts the responses of

${ }^{151}$ This analysis was only carried out based on the data that originated from the Dutch sample. 


\section{$\underline{\text { Punish, Seduce or Persuade }}$}

the female respondents to each variation of each requirement. The red area depicts the responses of the males.

Figure 7.16: Gender differences and the requirements

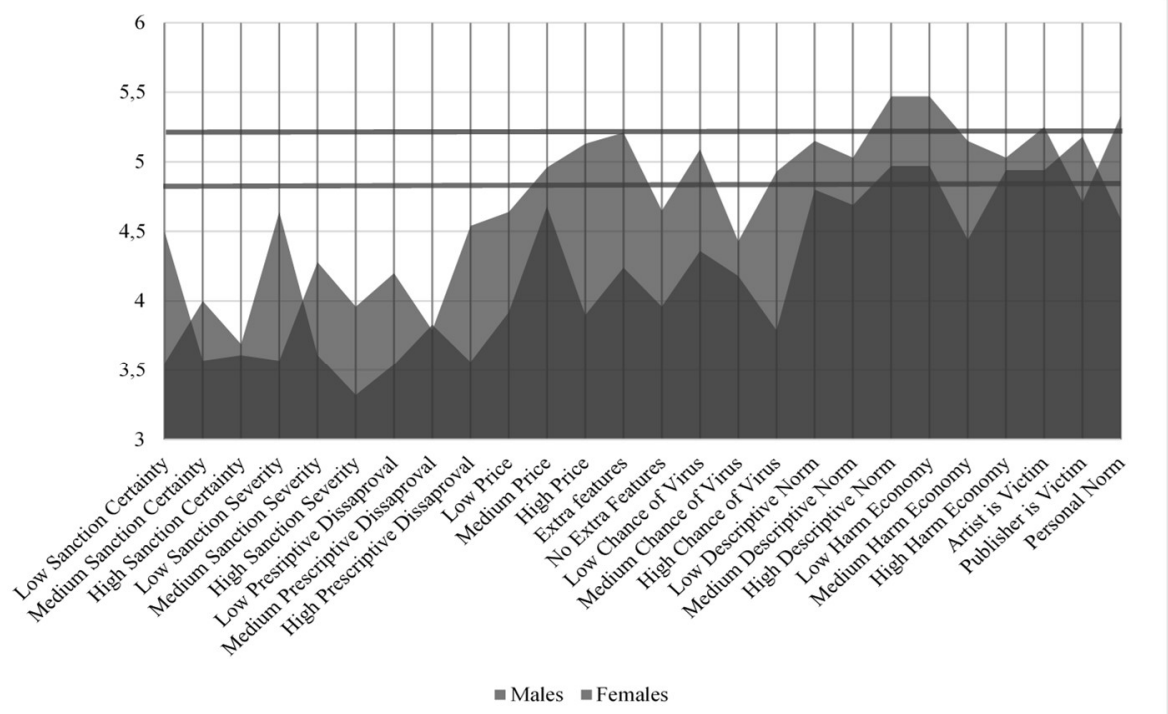

Overall, the scores from women are lower compared to men. But this does not necessarily mean that women indeed react differently to the requirements. The previously established baseline of $\mathrm{M}=4.8$ is derived from the overall sample, which includes both males and females. If a separate baseline is calculated for males and females respectively, the differences become less apparent. Male respondents have scored their inclination of pirating content digitally at $\mathrm{M}=5.2$ $(p<0.01)$ in 'scenario zero', while females scored this at $\mathrm{M}=4.4(p<0.05)$.

If these baselines are used, some differences emerge. First, the results of the female respondents are more often beyond their respective baseline. This is most visible in relation to the sermon-based requirements. This suggests that men and women do seem to respond differently to different mechanisms and associated requirements. At the same time, no gender is totally insensitive to these mechanisms and requirements. In addition, both genders appear to respond to stick-based requirements. These differences and similarities underline the need for policy makes to consider the attributes of the target population when developing and implementing ant-piracy interventions. 
Measuring the Contributions of Anti-Piracy Interventions and Their Mechanisms

\subsection{Methodological limitations and their consequences for the findings}

The previous sections focused on presenting the findings. The coming two sections take these findings and attempts to contextualize them in two manners. This first section will examine how the methodological choices made in this empirical study may have influenced the findings.

7.6.1. The findings contrasted with the background of the sample

The first matter that needs to be discussed is whether and how certain characteristics (or perhaps indirectly even certain attributes) of the samples can have influenced the general findings discussed. Specifically, the question is whether the findings can be better understood by framing these in relation to the make- up of the two samples. Of special interest is the fact that both the Dutch and Belgian samples were made up of students.

A relevant finding is the fact that the severity of the punishment was more often statistically significant than the certainty of punishment. In addition, the effect sizes for this severity were larger, in contrast to the findings presented in Chapter 6. One reason for this latter observation may be found in the sample itself: it has been suggested that the severity of punishment can be more relevant for some populations in some circumstances (Jacobs \& Piquero, 2012). In fact, deterrence might even only work for certain individuals (Jacobs, 2010; Strelan \& Boeckmann, 2006). It could be argued that the samples consisted of individuals who are more sensitive to deterrent measures, which would explain why the deterrent scenarios are selected as often as they are. Students may be more responsive to severity compared to the general population, as they react differently to risk (Anderson \& Stafford, 2003; Block \& Gerety, 1995). In addition, women are often identified as being more risk aversive than men (Booth, Cardona-Sosa, \& Nolen, 2014; Borghans, Golsteyn, Heckman, \& Meijers, 2009; Charness \& Gneezy, 2012). Since the majority of both samples (and even the large majority in Belgium) of the respondents were female, this may have influenced how the respondents valued and assessed the presented risk. In addition, it has been stated that individuals who are more risk aversive are more sensitive to changes to the severity of punishment (Mendes, 2004). In this context, it might not be so surprising that severity was identified as more relevant in this empirical study.

With regard to the examination of the attractiveness of legal content, it may be that the (some) respondents belonging to the sample are less sensitive to 


\section{$\underline{\text { Punish, Seduce or Persuade }}$}

reductions in price (also known as price consciousness) (Alford \& Biswas, 2002; Erdem, Keane, \& Sun, 2008; Goldsmith, Flynn, \& Kim, 2010). Such individuals are more likely to be interested in products or content due to emotional or entertainment reasons, which can make them less sensitive to a monetary incentive. Perceptions play an important role in estimating the effect of price reductions. An objective decrease does not automatically result in changes in behaviour. This may have made the presented incentive less attractive for certain respondents than what was initially assumed. In addition, whether a monetary incentive can tempt individuals to purchase content legally instead of pirating it is also dependent on the disposable income of the target population. The limited disposable income of the students, being the respondents in this first empirical study, can also have influenced the attractiveness of the incentive presented by specific scenarios. ${ }^{152}$ Studies have demonstrated that students who have more disposable income have a greater willingness to pay for digital content (Chiang \& Assane, 2009; Makkonen et al., 2011), services (Wang, Ye, Zhang, \& Nguyen, 2005 ) or products (Yadav, 1994). Studies examining the role of income often consider a yearly income of $€ 15,000$ to be the lowest level of income. Generally speaking, the income of both the Dutch and Belgian students do not come close to such a level. This perhaps explains why even the lowest variation of the cost of legal content led to relatively limited reductions in scores.

What may also have been observed, in relation to the presented incentive, is the fact that certain respondents consume both pirated and legal content and are, as a result of this fact, willing to pay more for content yet will pirate content digitally nonetheless (see the discussion on the sampling effect). This means that some individuals are willing to purchase content legally but only after they have experienced the quality of the content, which is often accomplished via digital piracy (Huygen et al., 2009). Their willingness to pay for content therefore does not conflict with their efforts to pirate content digitally. In addition, Huygen et al. (2009) state that pirates do not necessarily purchase less content than individuals who do engage in digital piracy. Digital pirates are even more inclined to purchase a video game than individuals who do not pirate content (67\% compared to $51 \%$ ). This finding, and those from other studies, underline that some digital pirates will still purchase content even if they already pirated it and sometimes they will purchase even more than individuals who did not pirate content previously (Cenite et al., 2009; Levin et al., 2004). This means that individuals can have both a high willingness to pay for content and a high willingness to pirate content digitally. This can aid in explaining why the reductions were relatively minor in relation to the carrot-based scenarios.

152 Though the differences in income in both samples were not analysed, it is a well-known fact that students simply have less disposable income available to them. 
7.6.2. Influence of the design on the responses to the scenarios

In addition to the make-up of the sample, it is also possible that the design of the scenarios themselves has also had an influence on the responses. The scenarios were carefully designed but it is nonetheless possible that some of the responses are a consequence of the wording or phrasing of the scenarios rather than the addition or exclusion of specific requirements. Various matters can be raised to further reflect on the possible design issues.

Firstly, as opposed to what would have been expected, the relevance of the severity of the punishment, rather than the certainty thereof, seems to be established more clearly in this study. One possible reason for this finding has to do with the design of the scenarios: the fact that severity was always combined with a certain level of certainty meant that a minimum level of certainty was always present. This can have influenced the relevance of severity, as the respondents considered the severity more seriously since there was always a concrete chance of being detected and punished. This points to the potentially contingent nature of both the certainty and severity of the punishment (Stafford, Gray, Menke, \& Ward, 1986). This contextualization finds support in the SAT, where deterrence always consists of both the enforcement of the law and the punishment of infringements.

Secondly, the pairing the scenarios can also have influenced how the respondents selected their preferential scenario (per pair). Also, the fact that a scenario was selected as being preferred in a particular pair did not automatically mean that it resulted in large reductions in scores. Still, as a total of eight scenarios per mechanism was examined, the general observation that deterrence is preferred still stands, even if some of these scenarios did not reduce the scores in a statistically significant manner.

Thirdly, the wording or phrasing of the scenarios can have contributed to the observed outcomes. Research has shown that persuasive interventions are better able to change behaviour if they are more emotional or affective rather than objective or factual (DeSteno, Petty, Rucker, Wegener, \& Braverman, 2004). The tone of the scenarios was rather factual, which means that this may have contributed to the lack of an effect after exposure. Furthermore, the credibility of the source also influences the persuasiveness of a message. Low credibility sources are less likely to result in persuasion (Tormala \& Petty, 2004). The question can be raised how credible the source (the researcher) was perceived in the context of the first empirical study. 


\subsection{Contextualizing the findings}

Beyond reflecting on the findings from a methodological vantage point, it is also necessary to look at the findings themselves in more detail. In the previous sections, the main findings of the first empirical study were presented, but what do these findings mean? How can they be situated and compared to the findings of the previous chapters? And how can these findings be placed in the context of other insights from various academic disciplines? These matters will be discussed in the coming sections.

7.7.1. The preference for the deterrent scenarios and the relevance of formal deterrence

Respondents tend to select stick-based scenarios over carrot-based scenarios and carrot-based scenarios over sermon-based scenarios. The question can be raised why stick-based scenarios are so clearly preferred by the respondents. Based on what was discussed previously, this finding was not that surprising. By introducing deterrent measures, the moral context becomes less favourable for the act of digital piracy, which influences the environmental conduciveness towards this act. Furthermore, as opposed to other explanatory factors of digital piracy, the absence of deterrent measures can be quite easily remedied by policy makers. One other explanation for this consistent choice has to do with the fact that there is a persistent belief, also held by the respondents' themselves, that punishment works. Common sense dictates that harsher punishment results in more deterrence and therefore less crime (Pratt, 2008), which is why it has become so dominant in the field of criminal justice policy (Tyler, Schulhofer, \& Huq, 2010). For the respondents, the stick-based scenarios influence the perceived expected positive outcomes of the act of digital piracy. Perhaps that is why deterrent measures are preferred: the gains of digital piracy are relatively small, making it more likely that a sanction will influence this balance. This is reflective of the relevance of the perceived positive and negative outcome expectations established earlier.

The role of informal deterrence (in the form of social disapproval) could not statistically be demonstrated since only one of the variations in this requirement led to results that were statistically significant. Based on the SAT and the previously presented explanation of digital piracy, this finding is somewhat unexpected. One environmental feature that was identified as being conducive for digital piracy was the social approval of digital piracy. Together with (the lack of) formal deterrence, this determines the moral context in which an individual finds himself. At the same time, however, studies found that the presence of social disapproval does not necessarily make digital piracy less likely (Bateman et al., 
Measuring the Contributions of Anti-Piracy Interventions and Their Mechanisms

2013; Wingrove et al., 2011). Therefore, while the approval of digital piracy might explain why an individual pirates content digitally in the first place, the reverse might not be true in relation to the disapproval thereof. Given the nature of digital piracy, individuals can ignore or neutralize this social disapproval more easily, inhibiting the effect of this disapproval. The source of the social disapproval may also be relevant, as each source differs in its credibility. Sources that are perceived to be more credible tend to be better able to change behaviour (Pornpitakpan, 2004). The scenarios left the source of the disapproval rather abstract, perhaps enabling the respondents to set aside the disapproval easier and neutralize this behaviour. This underlines that the perception of such matters is also relevant in the explanation as to why this requirement has not led to the expected outcome.

\subsubsection{The relevance of the severity of the punishment}

The finding that the severity of the punishment reduced scores with larger effect sizes than the certainty thereof seems to indicate that the respondents attributed greater value to the severity. This finding goes against the common assessment that certainty is the more relevant of the two examined aspects of deterrence, one that was also established in Chapter 6. In fact, the established relevance of the certainty of punishment has led to what has been called the 'certainty principle' (Apel, 2013; O'Connell, Visher, Martin, Parker, \& Brent, 2011). As Jacobs and Piquero (2012, p. 795) put it: 'Certainty appears to be more important than severity because regardless of how steep the sanction threat, if would-be offenders think they can evade it, the threat generally will not deter.' One reason as to why severity is found to be relevant in the context of this empirical study was already discussed in relation to the characteristics of the sample. A different reason emerges from academic literature. This reveals that the finding that severity can be more relevant than certainty is not as uncommon as might initially be assumed. There have been studies in the past in which severity was also identified as being more relevant than certainty (Friesen, 2012; Grasmick \& Bryjak, 1980). Studies that have found none or limited support for the relevance of the severity of the punishment may have suffered from the way they measured deterrence. This has to do with the way in which both the certainty and severity are positioned in such studies (Mendes \& McDonald, 2001). Studies that isolate the components of certainty and severity tend to fail to find support for the severity of punishment. When studies take these components together instead (as this study has done), they are more likely to find that severity does matter. 


\section{$\underline{\text { Punish, Seduce or Persuade }}$}

7.7.3. The cost of content and the attractiveness of the incentive

One of the environmental features that influences conduciveness of the environment with regard to the act of digital piracy is the high cost of content, which can be seen as a provocation within the context of the SAT. It was expected that removing or reducing this provocation would contribute to the reduction in digital piracy. This expectation was maintained when the mechanism underlining this type of intervention was (theoretically) examined, as interventions that use such a mechanism are capable of influencing this environmental feature directly. While the scenarios did lead to some reductions scores, the effect sizes for these reductions were small. If the individual requirements are examined, the requirement that focused on the cost of content did not really result in the expected changes in scores. This means that it is likely that the provocation was not removed from the environment. Some possible explanations can be given for this finding.

There is evidence to assume that it is not just the objective reduction in price that the respondent considered (which was examined in this first empirical study), but also the manner in which the reduction was presented (which is known as "price framing'). Different framing strategies can result in different choice outcomes (d'Astous \& Landreville, 2003; Friesen, 2012). In fact, it is clear that a discount in price entails significantly more than just simply reducing the price, such as the situational effects ('brand' preference or the type of good involved) (Anderson \& Stafford, 2003). Presenting the size of the incentive as a fixed price rather than a temporary sale may also have influenced the outcome. Reducing prices as 'everyday-low-price' can negatively influence the perception of the product or content that the respondent has (Darke \& Chung, 2005).

\subsubsection{The relevance of the role of viruses}

The findings suggest that a greater risk of being infected by a virus via the act of digital piracy reduces the inclination of an individual to obtain content in this manner. This is an effect that was expected, as this can directly increase the perceived expected negative outcome expectations of this act and the absence of such an outcome is one of the reasons that an individual will be motivated to pirate content digitally in the first place. Some studies confirmed this finding previously (Bachman, 2007; Hennig-Thurau et al., 2007; Koklic et al., 2014; Wolfe et al., 2008).

The question is why the introduction of computer viruses or malware contributes to the reduction in digital piracy. It is possible that the fear of viruses will not always inhibit an individual from pirating content digitally. Digital pirates can use 
antivirus programs as protection and may even be able to identify and avoid those files that are likely malicious (Holt \& Copes, 2010). This means that it is possible to increase the objective negative outcomes of digital piracy in this manner by introducing viruses into the P2P-network, but the question is whether this affects all digital pirates and whether the effect will be persistent. Perhaps certain individuals, those who are less experienced with computers and related technologies, are unable to avoid the technological risks associated with digital piracy. They may be more likely to obtain the content in a legal manner or stop pirating content digitally. Others, the more experienced individuals, might be able to take proper countermeasures to avoid 'infection' and can continue to engage in digital piracy.

This variety of responses to the technological risks of digital piracy can be understood better by looking at studies from the field of STDs, unprotected sex and the use of condoms. When confronted with the risks of STDS, individuals can either opt to stop having sex altogether, take protective measures (using condoms) or continue to engage in unprotected sex. ${ }^{153}$ Research has shown that individuals who are aware of the risks associated with unprotected sex are more likely to use condoms to limit the risk of being infected with such a disease (Dancy \& Berbaum, 2005; Ellis, 2014; Fritz, 1998; Green, Fulop, \& Kocsis, 2000; Minchiello, Mariño, \& Browne, 2001). However, even then, some individuals are unwilling to use condoms for various reasons, such as intimacy and trust (Corbett, Dickinson-Gómez, Hilario, \& Weeks, 2009), pleasure (Geter \& Crosby, 2014) or even impulsivity (Adefuye, Abiona, Balogun, \& Lukobo-Durell, 2009). Other studies report that individuals opt to abstain after being exposed to information on the risks of unprotected sex (Kabiru \& Ezeh, 2007; Long-Middleton et al., 2013; Morrison-Beedy, Carey, Côté-Arsenault, Seibold-Simpson, \& Robinson, 2008). Thus, different individuals will respond differently to the perceived risk of being infected by a virus.

Extending this line of reasoning to the issue of digital piracy entails that some individuals will become 'abstinent' by simply not pirating content digitally any longer. Instead, they may decide to purchase the content legally. Others may react differently to the risk of being infected by a virus (Akbulut, 2014; Sheehan et al., 2010). However, these different reactions to 'digital STDs' cannot be established directly based on the available data. The scenarios asked what the respondent's inclination to pirating content digitally would be given the context of each scenario. It was not asked whether they would take certain precautions to avoid

\footnotetext{
${ }^{153}$ Obviously the seriousness of being infected with a computer virus is very different than the seriousness of contracting a sexual transmitted disease, but the way in which digital pirates may react to the risk of the computer virus can be similar.
} 


\section{$\underline{\text { Punish, Seduce or Persuade }}$}

the negative aspects of this behaviour or whether they would displace their acts of digital piracy to other venues, websites or software. Nonetheless, it would be interesting for future research to study how individuals pirate content digitally when confronted with technological risks.

\subsubsection{Why the sermon fails to contribute to reductions}

The responses from both the Dutch and Belgian samples demonstrate that the sermon-based scenarios did not reduce the respondents' scores. Instead, these scores seemed to have increased in some instances. Given the findings of the previous chapter, where the persuasive mechanism was found to meet the least requirements in theory and the empirical evidence was divided, this finding was not unexpected.

It still raises the question as to why persuading the respondents is so difficult. Are there inherent difficulties or limitations in using persuasion as a mechanism to change behaviour? The literature presents some of these difficulties. Renes et al. (2011) note that sermon-like interventions (that are meant to persuade) are less likely to change behaviour if it involves existing behaviour or preventing undesired behaviour, instead of enabling the target population to learn and enact new types of behaviour. Digital piracy is an example of existing behaviour for many, while at the same time being an example of undesired behaviour.

A related issue is that these interventions are also less capable of behavioural change, as this change is meant to be more persistent. Sermon-based interventions are in fact less capable of enabling more persistent behavioural changes (Wakefield, Loken, \& Hornik, 2010).

A different explanation of the difficulties found when using the sermon is related to the social environment that an individual can find himself in. Environmental features (i.e. the moral context and the perceived approval of the act of digital piracy) do not just influence the individual's inclination to pirating content digitally, but they also influence whether persuasive efforts lead to changes in behaviour. Postmes, Steg, and Keizer (2009) demonstrate that social surroundings can also make it more difficult for the individual to be persuaded. If the social surroundings are not also changed by such an intervention, it becomes less likely that an individual will change his own behaviour. The persuasive scenarios have focused on the individual rather than the group, possibly also explaining the lack of behavioural change. 
Measuring the Contributions of Anti-Piracy Interventions and Their Mechanisms

\subsubsection{Considering the benefits of a more hybrid approach}

Although this chapter opted to focus on the three mechanisms in a separate manner (meaning that no hybrid scenarios were developed and tested), the findings from the carrot-based scenarios do seem to point to the potential merit of such an approach. The goal of these scenarios was to make the legal content as attractive as possible to the respondents. Two requirements examined in each scenario did so directly by making the content cheaper or by adding extra features. The third requirement did so in a different manner. Instead of just making the legal content more attractive, it instead attempted to also make the pirated copy less attractive by stating the risk of being infected by a virus or malware. This also increased the attractiveness of the legal copy. This requirement also carries with it a deterrent aspect, perhaps not dissimilar to the technological measures identified previously, since it clearly adds to the risk of digital piracy. As already reported, it was this particular requirement that seemed to have a larger effect on the respondents' inclination to pirate content digitally when confronted with the various carrot-based scenarios. This indicates that adding this requirement, which incentivizes legal consumption while simultaneously making the pirated content less attractive, is perhaps supportive to the overall aim of the interventions. There may be merit to further developing and implementing anti-piracy interventions that carry with them such hybrid mechanisms or requirements. By having interventions in place that touch upon more than one mechanism, more of the variables that explain digital piracy can be modified, which increases the intervention's chance of contributing to reductions in digital piracy.

\subsection{Conclusion}

This chapter uncovered a number of interesting and relevant findings. Firstly, a clear preference for one of the three mechanisms has become apparent. In both samples, stick-based scenarios were consistently preferred over the other types of scenarios. In turn, carrot-based scenarios were preferred over the sermon-based ones. When the individual scenarios are examined, certain stick-based scenarios led to lower scores. This was most pronounced in the Belgian sample, where the two scenarios that led to the largest reductions were based on the deterrent mechanism. Most of the carrot-based scenarios led to reductions as well, although these were not always as large as their stick-based counterparts. What further emerges from the findings is that the sermon-based interventions were never selected as being the most convincing and often led to only small reductions or even increases in the scores. This means that the doubts expressed in the previous chapter on the usability of this type of intervention are fortified, as there is now clear empirical evidence that this mechanism is not ideally equipped to influence 
digital piracy. Overall, when it comes to the extent of the changes, the findings demonstrate that the effect sizes are relatively modest.

The requirements for each mechanism are an important part of understanding why specific mechanisms influence digital piracy as well as which interventions are capable of contributing to reductions in digital piracy. Such insights enable an estimation of the role of each of these requirements and determine how they support the mechanism. In relation to the deterrent-mechanism, the findings reveal that the severity of the punishment is more supportive to this mechanism than the certainty thereof. In addition, the size of the reductions was more sizeable when severity was examined. Stick-based interventions that focus on increasing the severity of the punishment result in a more noticeable extent of the contribution, provided that a minimum level of certainty is present.

The evidence for the requirements related to the incentive mechanism is less clear. The first requirement, the size of the incentive, does seem to contribute to reductions but the size of the contribution is relatively small. Adding extra content or features to the legal content might not have the desired effect of contributing to reductions in digital piracy. The clearest findings are linked to the role of viruses. A greater risk of contracting a computer virus reduces the inclination to pirate content digitally. None of the requirements for the sermon-based mechanism are supportive to the mechanism however.

Although insightful, the findings presented in this chapter are limited in one specific way: the stated preference method used reflects the respondents' inclination to pirate content digitally in the context of a specific scenario, rather than actual behaviour. Therefore, it is not clear which changes an implemented anti-piracy intervention can bring about in practice as the examined scenarios were hypothetical. Such matters are addressed via the fifth sub-question: 'which changes can be observed in the online search behaviour of digital pirates after the implementation of a specific anti-piracy intervention?', a question that is answered in the next chapter. 


\section{Changes in Online Search Behaviour after the Implementation of an Anti-Piracy Intervention: the Copyright Alert System as a Case Study ${ }^{154}$}

Insightful information was gathered in the previous chapter on how individuals respond to hypothetical anti-piracy interventions. However, those insights were obtained used the respondents' own assessment of their inclination to pirate content digitally. This means that the changes observed do not necessarily reflect actual changes to digital piracy. This is also known as the 'intention-behaviour gap' and is commonly identified in the context of behavioural interventions (Allom, Mullan, \& Sebastian, 2013; Carrington, Neville, \& Whitwell, 2010; Hassan, Shiu, \& Shaw, 2014). This means that the findings of the first empirical study do not necessarily explain how individuals respond to real-life implemented anti-piracy interventions. To observe how digital pirates search for online pirated content and how this (real-life) search behaviour changed after the implementation of a specific anti-piracy intervention, a second empirical study was conducted. Based on the findings of the previous chapter, the decision was made to select an intervention that uses a deterrent mechanism. This study was used to answer the fifth sub-question: "which changes can be observed in the online search behaviour of digital pirates after the implementation of a specific anti-piracy intervention?'

The starting point for this second empirical study was the Internet itself. Individuals often use search engines to search for and download pirated content. Search engines, such as Google, store each of these individual search actions (known as queries), which can be accessed by researchers for analysis and research purposes. These queries can be used to map the online search behaviour of individuals searching for pirated content. Changes to the queries reflect changes in how individuals search for and find pirated content in the online environment. As opposed to the data obtained via the stated-preference method, this data consisted of actual search behaviour instead of purely intended behaviour. The data discussed in this chapter is thus closer to real-life digital piracy, since it is not just informative with regard to how individuals feel about digital piracy but also with regard to whether they take actions (e.g., search for content) in order to obtain pirated content. This Big Data-study thus measures factual changes. This is insightful for the likelihood that an individual will actually go ahead with his act of digital piracy, as (often strong) correlations are found

${ }^{154}$ The findings presented in this chapter have previously been published (Leeuw, 2016, 2017) and were made possible thanks to a grant by the Horowitz Foundation for Social Policy. 


\section{$\underline{\text { Punish, Seduce or Persuade }}$}

between search query data and the emergence or likelihood of various behaviour such as influenza (Dugas et al., 2012), economics behaviours such as car purchases (Choi \& Varian, 2012), tobacco consumption (Cavazos-Regh et al., 2015) and even tourism (Park, Lee, \& Song, 2016). These studies have demonstrated that online search behaviour can perhaps predict, or at least signal, changes to the actual behaviour of individuals, even when the behaviour itself is not digital in its nature. In fact, using Big Data in this way might even be as useful as the more classical methods of measuring behaviour. For instance, in the case of private consumer spending, forecasting based on Google Trends appeared to outperform classical survey-based indicators of the same behaviour (Schmidt \& Vosen, 2009). This means that online search behaviour used to find pirated content is indicative of acts of digital piracy, although it cannot directly measure changes to the behaviour itself. Using such an approach to the topic of digital piracy can offer insights into how this online search behaviour has changed over time.

The data used in this chapter is an example of 'Big Data' and allowed for the usage of an innovative and flexible approach in the study of a specific anti-piracy intervention (Leeuw, 2016, 2017). The search queries were used to analyse the changes after the implementation of a specific anti-piracy measure in a specific jurisdiction: the Copyright Alert System (CAS), which was implemented in the USA. ${ }^{155}$ By mapping online search behaviour prior to the implementation of the CAS, it became possible to see whether changes were found after the implementation of this intervention. As the CAS uses a specific mechanism (deterrence), insights obtained in this chapter are also indirectly insightful for a further reflection on this mechanism.

The chapter will firstly briefly identify the key characteristics of the CAS and how they are supposed to reduce digital piracy. This is informative with regard to which changes in search behaviour are to be expected. In order to determine whether this influence is likely and whether this led to changes in actual search behaviour, the subsequent section discusses how Big Data was used to obtain insights into the (potential) changes in the online search behaviour of digital piracy after the implementation of the CAS. That section elaborates on what was previously discussed in §2.3. (supra p. 38). The two main sections of this chapter focus on the changes in online search behaviour, as well a discussion on the

155 The selection of the CAS was based on the need to delineate the second empirical study in terms of location and time. As the CAS was only implemented in the USA, it offered the first important delineation. Furthermore, the intervention was implemented at a specific point in time, which made it possible to measure search behaviour prior, during and after the implementation (see also $§ 2.3 .1$. (supra p. 40). 
attribution of these changes to the CAS. As will become apparent, even if changes in online search behaviour are observed, this finding cannot be automatically attributed to the implementation of the CAS. An inherent limitation of Big Data as used in this second empirical study means that such an attribution is impossible given the fact that other confounding variables cannot be excluded from the analysis. The tool used for the analysis of the search queries (Google Trends) simply does not allow the research to exclude any variable. This means that any observed change could have been caused by a multitude of factors, the implementation of the CAS being one of them. Nonetheless, there are possibilities to reflect on this attribution and estimate how likely it is that the CAS has indeed caused the observed changes. This reflection is accomplished through a natural experiment.

\subsection{The CAS and its assumed influence on digital piracy}

In early 2013, the CAS was implemented in the USA in order to reduce digital piracy, or at least attempt to do so (Jeffries, 2013). The CAS is a graduated response scheme, where notices, warnings and mitigation measures are sent to repeat infringers, with the aim of deterring infringing individuals. In total, six measures (or alerts) can be sent to an infringing individual. As discussed previously ( $\$ 6.1 .2$ (supra p. 150)), the graduated response is a stick-based intervention that allows (theoretically at least) for the greatest certainty of punishment of the interventions belonging to this category, aside from those that are technological in nature.

The CAS functions by monitoring P2P-networks. The subscriber's downloads are inspected and the CAS matches the file signature against a set of known signatures of pirated files. When an infringement is detected, the respective ISP is informed of the copyright violation. Subsequently, the ISP will inform its subscriber on the alleged infringement (Depoorter \& van Hiel, 2015). Thus, the ISPs alert their own subscribers of alleged infringement, with the CAS only informing the ISPs of the alleged infringement by one of their subscribers. Direct enforcement is therefore placed in the hands of the ISPs. The alerts will gradually become more stern and severe if the subscriber continues to pirate content via monitored P2P-networks. The first two alerts are informative and explain that digital piracy is illegal, that there are lawful ways of obtaining content and that continued infringement will result in further measures. These alerts require no response from the subscriber. The next two alerts are known as 'acknowledgement measures'. Here, the subscriber needs to acknowledge receiving the notice. These clearly attempt to motivate the subscriber to stop pirating content digitally (see Figure 8.1). Finally, the last two alerts, the 'mitigation measures', require acknowledgement of 


\section{$\underline{\text { Punish, Seduce or Persuade }}$}

receiving the notice and also result in measures being taken to prevent digital piracy in the future. These measures can include, amongst others, bandwidth throttling, account suspension and account downgrading. The CAS-scheme resets once an ISP no longer receives infringements notices related to a specific subscriber's account within twelve months from the last notice (Yim, 2013).

Figure 8.1: Example of a mitigation measure (Farivar, 2013)

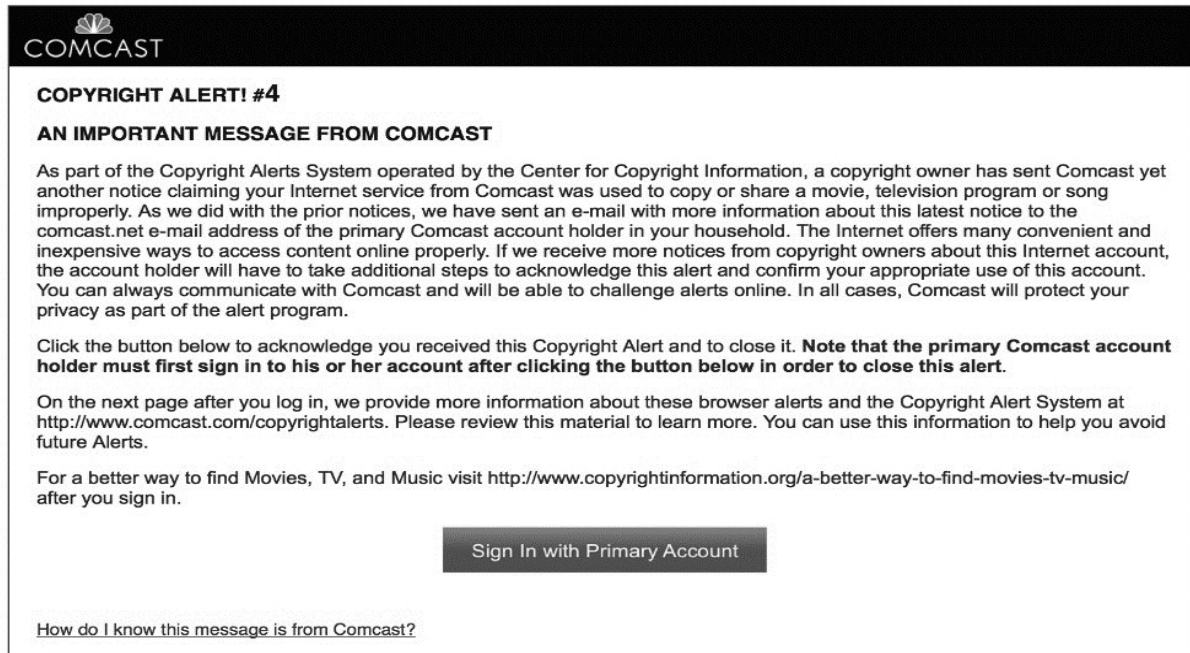

The certainty of punishment is modified since the intervention uses a monitoring and detection system. This makes it more likely that infringing individuals are detected following their act of digital piracy. With regard to the severity of the punishment, while the CAS does not use fines as a method to sanction digital pirates, quite severe measures such as bandwidth throttling or account suspension are possible. For most Internet users, who consider access to (high speed) Internet as a basic need (Tully, 2014), such measures can be quite severe. Through the warnings that the ISPs send to their infringing subscribers, the intervention also expresses that the behaviour is disapproved of socially. By using the deterrent mechanism, the CAS attempts to reduce digital piracy (Bridy, 2010-2011, 2012; Yim, 2013). ${ }^{156}$

The CAS has two features that inherently limit its potential. Firstly, it only targets P2P-piracy (Bridy, 2012). Thus, other modus operandi of digital piracy, such as

156 Although the data gathered in this chapter does not allow for an analysis on the level of these requirements, they are still relevant with regard to whether or not the intervention is capable of contributing to reductions in digital piracy. Observations from Chapters 6 and 7 therefore still stand, such as the concerns as to whether or not the certainty is sufficiently high. 
direct downloading, are excluded. Secondly, since the CAS is a technological measure, it is possible that individuals, who are more experienced in the usage of IT-related tools and products, can avoid detection. There are already dedicated websites that explain how individuals can do so (Seedbox Guide, 2016; Storm, 2013). Thus, it is possible that this second empirical study only uncovers the online search behaviour of less experienced digital pirates. Nonetheless, if this contributes to a reduction of the number of lesser-experienced digital pirates, these efforts still contribute to the overall goal of the intervention.

Little information is currently available on whether the CAS succeeds in meeting its set goals. Proponents of this intervention claim that it is successful in reducing digital piracy and that initial outcomes are encouraging (Center for Copyright Information, 2014). However, empirical evidence has been presented on the contributions of the CAS to reducing digital piracy. ${ }^{157}$ In addition, the studies that have examined similar graduated response schemes provide only limited evidence for the functioning of such a measure (Arnold et al., 2014; Danaher et al., 2014; Dejean et al., 2010; Dejean \& Suire, 2014). This study presents an innovative way of mapping the changes to digital piracy after the implementation of the CAS. This is done by examining online search behaviour prior to and after the implementation of the CAS. This is insightful since, in order for an individual to be able to download pirated content, he must first be able to find it. And while some individuals will have specific venues they turn to in order to do so (dedicated websites such as the Pirate Bay) others use search engines. Around $20 \%$ of the infringing users use such search engines (such as Google) to find pirated content (MillwardBrown Digital, 2013). As indicated, the lesser-experienced digital pirates are probably overrepresented in this group, but they still make up a sizeable part of the entire population. If the CAS has had an effect on digital piracy, this will be reflected in changes to underlying search behaviour. Individuals who previously searched for pirated content might no longer do so out of fear of being punished. The overall expectation is that search queries used to search for and download pirated content have declined after the implementation of CAS. Since the method followed in this second empirical study allowed for the selection of search queries that only had a bearing on the topic of digital piracy (see §2.3.1. (supra p. 40)), it is possible to make statements on the changes to online search behaviour related to digital piracy. This was ensured by selecting specific root queries. ${ }^{158}$

157 Although Depoorter and van Hiel (2015) presented empirical evidence that the design of the CAS underestimated the robustness (e.g., persistence) of social norms and have failed to anticipate the negative reactions to a copyright information system, in particular as it relates to perceived privacy harms.

${ }^{158}$ The following root queries were used: 'Pirate Bay', 'Free music download', 'Free movie download', 'Free video games download', 'Free software download', 'Torrent', 'Free ebook download', 'Free 


\subsection{Mapping online search behaviour}

In §2.3.1. (supra p. 40) it was explained how root terms were used to gather a sufficient volume of search queries in order to analyse (the changes in) search behaviour. This process led to a total of 1,637 search queries, not all of which were used in this second empirical study. Of this total number, 445 queries were either unrelated to digital piracy or unclear. Furthermore, 1,028 queries were duplicates. Of the 160 remaining queries, 45 had failed to generate a sufficient volume to allow for a proper analysis, as there were gaps in their sequence of data. This meant that these queries were missing weeks or even months of data points. For a query to be used in this analysis it had to have continuous data points during selected the period of time. This process of elimination led to 115 queries that did have a sufficient volume, were relevant and were not duplicates. All 115 queries were usable to measure the longer-term effects of the intervention. Only 72 of these queries were sufficiently specific to be used on the daily level as only these had daily data points available as opposed to just weekly data points. Both the daily and weekly measurements were necessary to map the changes in online search behaviour. The daily measurements were used to understand the short-term changes of the implementation, while the weekly measurements were used to understand the long(er)-term changes. The short-term change could be indicative of the expressive function of the measure (e.g., that the interventions send a message) (Beale, 2000; Cooter, 1998). In contrast, the longer-term changes can point towards persistence of the changes in behaviour. Persistent changes after anti-piracy interventions are not a given fact. As was discussed in §6.1.1. (supra p. 141), it is not unlikely for an anti-piracy intervention to have an immediate effect, but that this effect decreases over time (Adermon \& Liang, 2014; Bhattacharjee et al., 2006). This makes it relevant to also look at changes over a longer period of time.

All queries were divided among three clusters: P2P-piracy, legal content consumption and alternative forms of digital piracy. Each of these clusters represents a group of queries that was expected to be influenced by the implemented intervention in some way. Changes to the queries were reported by referring to the 'relative search volume' or RSV (\$2.3.2. (supra p. 43)). The relative search volume is automatically generated by Google Trends itself. The $\mathrm{RSV}$ indicates the highest search proportion $(\mathrm{RSV}=100)$ during the selected time period. Lower scores in RSV indicate that the volume in search behaviour is smaller compared to the point in time where the volume is highest (Ayers et al., 2011). Scores close to 100 show that the interest in particular queries peaked

online streaming', 'Piracy', 'P2P file sharing', 'Six Strikes', 'Netflix', 'Spotify', 'Steam', 'iTunes' and 'Piracy illegal'. 
during the selected period of time. Low scores, in contrast, reflect that the use of the search query reduced during the selected period of time. For example, peaks in RSV related to the Tour de France would be expected during the period of time that this competition takes place. Decreases in interest after its conclusion are relative to the highest 'peak' established.

Three clusters of queries reflect the way through which the implementation of the CAS can be expected to influence the search behaviour linked to digital piracy. The first cluster consists of search queries that are used to search directly for pirated content on P2P-networks. As the CAS only directly focuses on this type of piracy (Bridy, 2012), a reduction in these queries would certainly be expected if the CAS has had an influence on this behaviour. The hypothesis in relation to this first cluster is that its related queries have reduced after the implementation of the CAS.

The second cluster focused on search queries that reflected an interest in legal content (through venues such as iTunes, Netflix or Spotify). If the individuals' desire to obtain content remains unchanged (as the CAS does not set out to change this individual characteristic), it can be that these individuals search more often for this content in a legal manner, after the implementation of the CAS. Therefore, the hypothesis that belongs to this cluster is that related search queries increased after the implementation of the CAS.

The third cluster involves queries that are indicative of the changes to other variants of digital piracy. It is possible that the implementation of the CAS reached beyond P2P-piracy, meaning that the search queries for other types of digital piracy also have decreased (such as the usage of cyberlockers). An explanation for such an extended reach can be found in the concept of the 'diffusion of benefits' (Johnson, Guerette, \& Bowers, 2014). The reverse might also occur and individuals might start looking for other ways to obtain the content without having to pay for it after the implementation of the CAS. This can be the case if an increase in the queries belonging to this third cluster is observed. In those circumstances, P2P-piracy has become too risky, but the motivation and intention to obtain content in this manner remains unchanged. This forces individuals to look for other venues and opportunities to obtain the content. This is not just a theoretical possibility, as this effect has been reported in the context of other anti-piracy interventions. For instance, the more experienced Swedish digital pirates started to use anonymity software in order to avoid detection following the implementation of the IPRED in that jurisdiction (Larsson \& Svensson, 2010; Larsson et al., 2012). If such changes are observed, this can mean that the implementation of the CAS has had certain unwanted side effects, calling for a more critical look at the usage, design and implementation of the CAS (and similar interventions). But it is also possible that the RSV related to these queries 


\section{$\underline{\text { Punish, Seduce or Persuade }}$}

has not changed but has instead remained stable, meaning that the status quo has been maintained. If paired with decreases in search behaviour related to P2Ppiracy, the outcome of such a status quo is that the net changes are positive. The position that the queries for alternative digital piracy have remained unchanged is taken as the starting position, as the CAS does not set out to decrease the alternative variations of digital piracy. To assess this, the third hypothesis in this second empirical study is that the queries belonging to this cluster have not changed after the implementation of the CAS.

The online search behaviour was mapped using two different time periods. This was done to map the changes to online search behaviour both immediately after the implementation of the CAS as well as the changes in the long run. The mapping of behaviour on the short term consisted of queries of one month prior and one month after the implementation of the CAS. The goal here was to examine the changes immediately before the implementation and determine what happened immediately after the proclamation and implementation of this intervention. Data on the search queries was gathered and analysed on a day-today level.

In order to map the changes for a longer time period, queries were captured one year prior and one year after the implementation. Here, the data was captured on a week-to-week level. The process of the data capture of the CAS was initiated in the middle of 2014. Changes in search behaviour were measured immediately after the implementation of the CAS (the first of March 2013). This means that the findings are especially insightful for the effects of the declaration and implementation of the CAS, as well as the initial changes in online search behaviour. Given the limited timespan that was available, the decision was made not to wait with starting the measurements.

One point of concern is whether these short-term measurements can actually reflect changes in online search behaviour after the implementation of the CAS. After all, for the CAS to have changed digital piracy, the target population must be aware of the interventions and the consequences of being caught (Nagin, 1998). This is not too big an issue when analysing the longer-term changes, since information on the CAS was available at that point and the first warnings had already been sent (Center for Copyright Information, 2014). For shorter-term changes in search behaviour to have any connection with the implementation of the CAS, it was necessary that awareness was raised on the intended implementation of this intervention. Some information on the scope and nature of the CAS was available before its implementation (Lesser, n.d.; Nazer, 2013; Newman, 2012). But a fully-fledged awareness campaign did not seem to have 
taken place. This underlines the relevance of also looking at the longer-term changes to online search behaviour.

\subsection{Observed changes in online search behaviour}

\subsubsection{Short-term observed changes}

Short-term changes are observed directly after the implementation of the CAS (see Figure 8.2).

Figure 8.2: Short-term changes to the RSV of all search queries

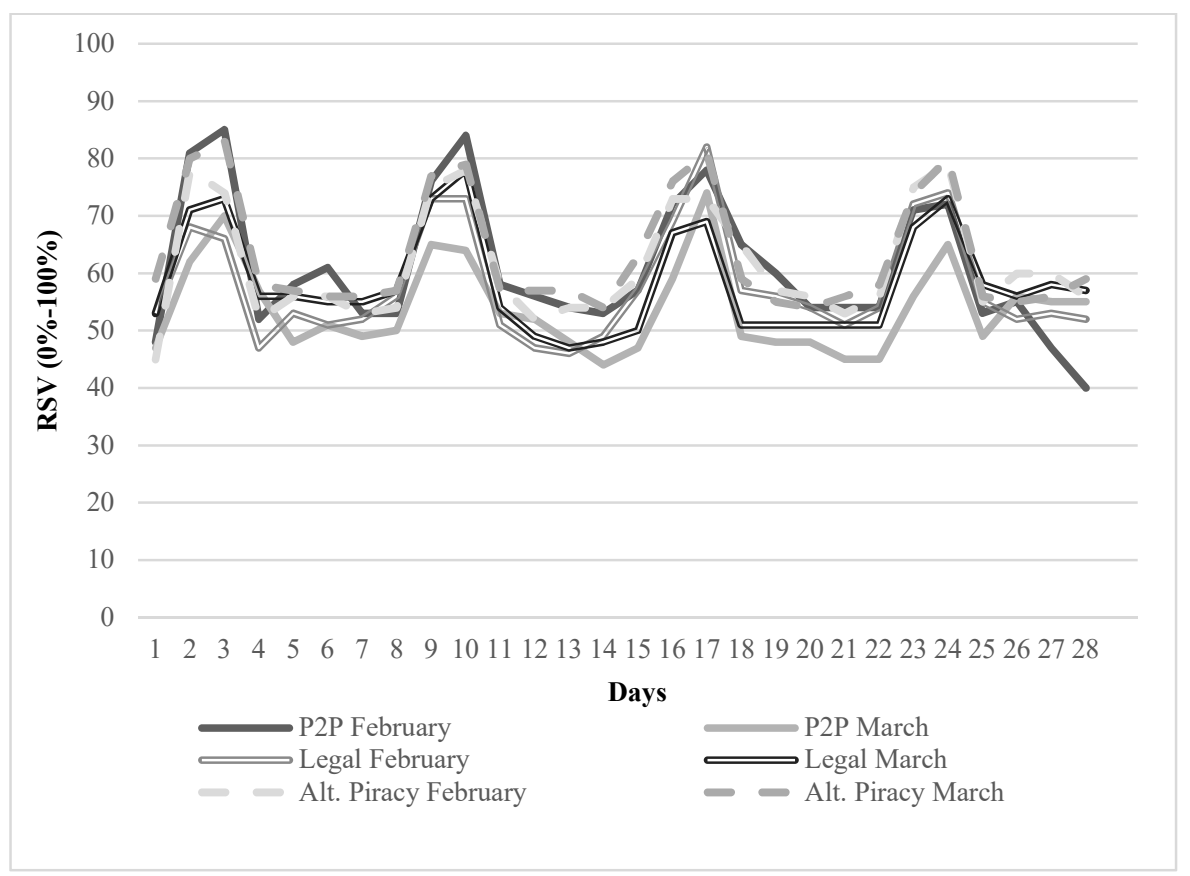

The RSV of search queries for P2P-piracy was lower in the month of March, particularly during the first half of this month, when compared to the queries recorded in February. While search queries dealing with legal content initially depicted an increase, the difference seemed to decrease as the month progressed. By the end of the month, these search queries no longer depicted either a decrease or an increase. Simply put, the status quo seemed to have been maintained. The trends for search queries related to the alternative types of piracy did not demonstrate any substantial change after the implementation of the CAS. Overall, it seems that the search queries dealing with P2P-piracy have reduced somewhat after the implementation, especially in the first week after the implementation. 


\section{$\underline{\text { Punish, Seduce or Persuade }}$}

The recurring spikes that are observed are the days of the weekend, suggesting that, when individuals have more time on their hands, they are more likely to search for content (both pirated and legal content, as the spikes also apply to the queries related to legal content).

From this figure, a slight decrease in P2P-piracy related search queries followed the implementation of the CAS, at least in the short term. A difference is thus observed. The figure, however, only presents the general overview of the changes and visualizes the trends. It is also possible to focus on the short-term changes per examined query. This allows for more fine-tuned statements on the changes in online search behaviour. Figure 8.3 illustrates how each query has changed, with the bars to the left representing an increase (which is not desired) and the bars to the right representing a decrease (which is desired). ${ }^{159}$ This was done by mapping the percentile increases or decreases per query over the 28 days and the figure presents the average increase or decrease for this period of time.

Figure 8.3: Short-term changes to the queries 'P2P-Piracy' (RSV of Feb-March 2013)

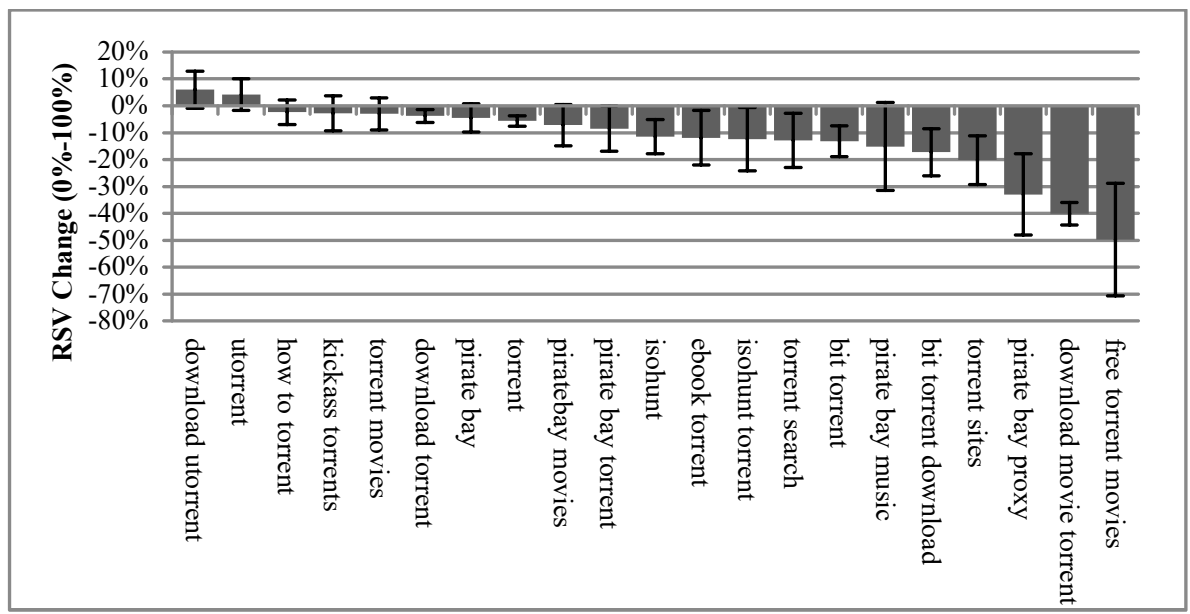

Overall, of the 21 queries belonging to the P2P-piracy cluster, the RSV decreased by $12.6 \%$. Only two of these queries showed a slight increase. In particular, movie-related P2P piracy seems to have changed $(-49.78 \%$ and $-40.17 \%$ for these two queries). The Pirate Bay website seems to be a digital piracy venue for piracy that is somewhat out of fashion after the implementation of the CAS $(-32.9 \%)$. Search behaviour for other P2P-venues, such as uTorrent, has slightly increased $(+5.97 \%)$.

${ }^{159}$ The error bars present the $95 \%$ confidence level of the range of where any changes in search behaviour should fall. 
The next step is to examine whether queries dealing with legal content also changed after the implementation of the CAS. Figure 8.4 presents these findings, with the bars to the left being increases (a trend that is desired in relation to this cluster) and the to the right bars being decreases. At a first glance, it seems that those queries dealing with legal content have, overall, seen an increase in volume, which would be indicative of changes that are welcome.

Figure 8.4: Short-term changes to the queries 'Legal Content' (RSV of Feb-March 2013)

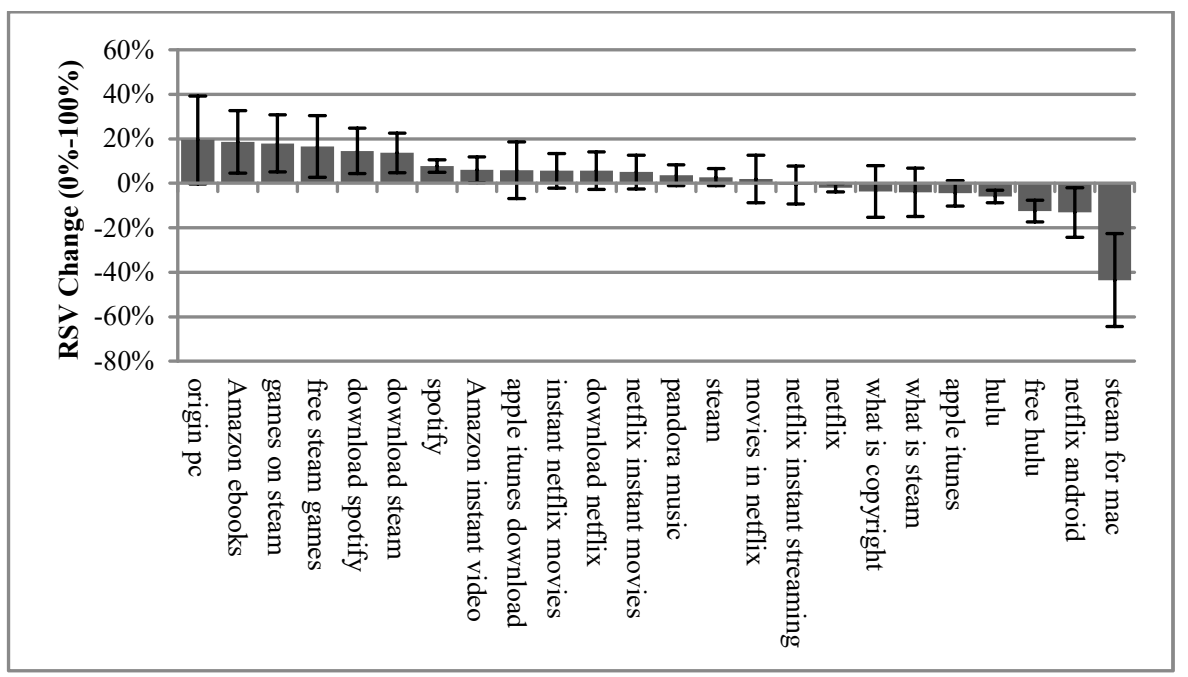

On average, however, the increase is quite small: $+2.33 \%$, which was reflected in the trend line of Figure 8.2. This might mean that something of an equilibrium is present in relation to these queries. Still, these findings suggest that the introduction of the CAS has at least not resulted in a decrease in interest in these queries. It is interesting to note however that some rather specific channels for legal content, such as Steam for Mac (Apple) and Netflix for Android, do exhibit a decrease in search volume (-43.48\% and $-13.03 \%)$. At the same time, the queries that have a significantly increased RSV are also quite specific, such as the Origin and Steam services for PC $(+19.51 \%$ and $+17.98 \%)$. This finding suggests that consumption patterns with regard to such services can change rapidly and that users look for specific venues rather than general ones.

The third cluster is reflective of the changes to alternative ways to pirate content digitally. Figure 8.5 shows that the RSV for these queries did not reduce after the implementation of the CAS. Again, the left bars are increases while the right bars reflect decreases. As the focus is on alternative ways to pirate content digitally, 
decreases would be desired after the implementation of the CAS. At the very least, the changes should not reflect increases in these queries.

Figure 8.5: Short-term changes to the queries 'Alternative Digital Piracy' (RSV of Feb-March 2013)

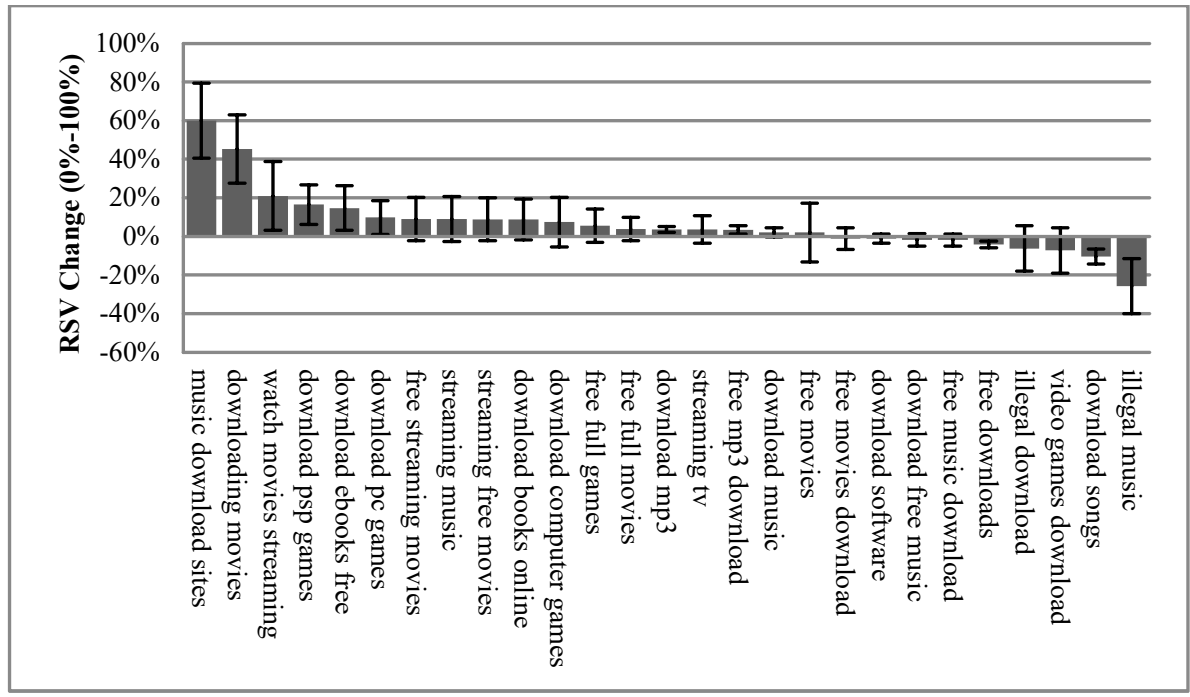

It seems that there has been a small increase overall $(+6.49 \%)$, which was hinted at during the discussion of Figure 8.2, although it is a relatively small change. Whether this change is a consequence of the reduction in P2P-related search queries cannot be ascertained directly. The displacement of digital piracy could be an explanation for this finding however (Guerette \& Bowers, 2009). As already indicated (§8.2. (supra p. 222)), some evidence for the presence of displacement has been found in the context of digital piracy and other anti-piracy interventions (Larsson \& Svensson, 2010; Larsson et al., 2012). In addition, the findings in the previous chapters underline that no anti-piracy intervention is capable of reducing the inclination of all individuals to pirate content digitally. In situations where certain individuals remain determined to obtaining content via the act of digital piracy, these individuals can use different methods to avoid exposure to interventions such as the CAS. Some degree of displacement is therefore to be expected, but additional research would be needed to demonstrate that the CAS has led to such an outcome. If the increase in alternative piracy queries is subtracted from the decrease in P2P-piracy queries, the overall reduction for the queries that are informative for digital piracy as a whole is still $6.11 \%$. 
The short-term changes after the implementation of the CAS seem to be promising. The question is whether these findings are still valid when search behaviour on the longer term is taken into account.

\subsubsection{Longer-term observed changes}

Ideally, the implementation of the CAS has had a persistent change over a longer period of time, in addition to any short-term changes. This section maps the changes to the online search behaviour for up to a year after the implementation. In order to establish this, the goal is to determine how the various search queries (or their clusters) have changed over the selected period of time. It is difficult to identify the specific point in time when the changes start to become more pronounced, given the fact that changes in search queries do not necessarily appear instantaneously but instead tend to emerge gradually. In order to determine how the changes in search behaviour were present over a longer period of time, a second set of data was captured for the 115 queries previously identified. Figure 8.6 reveals the changes over a longer period.

Figure 8.6: Longer-term changes to the RSV of all search queries

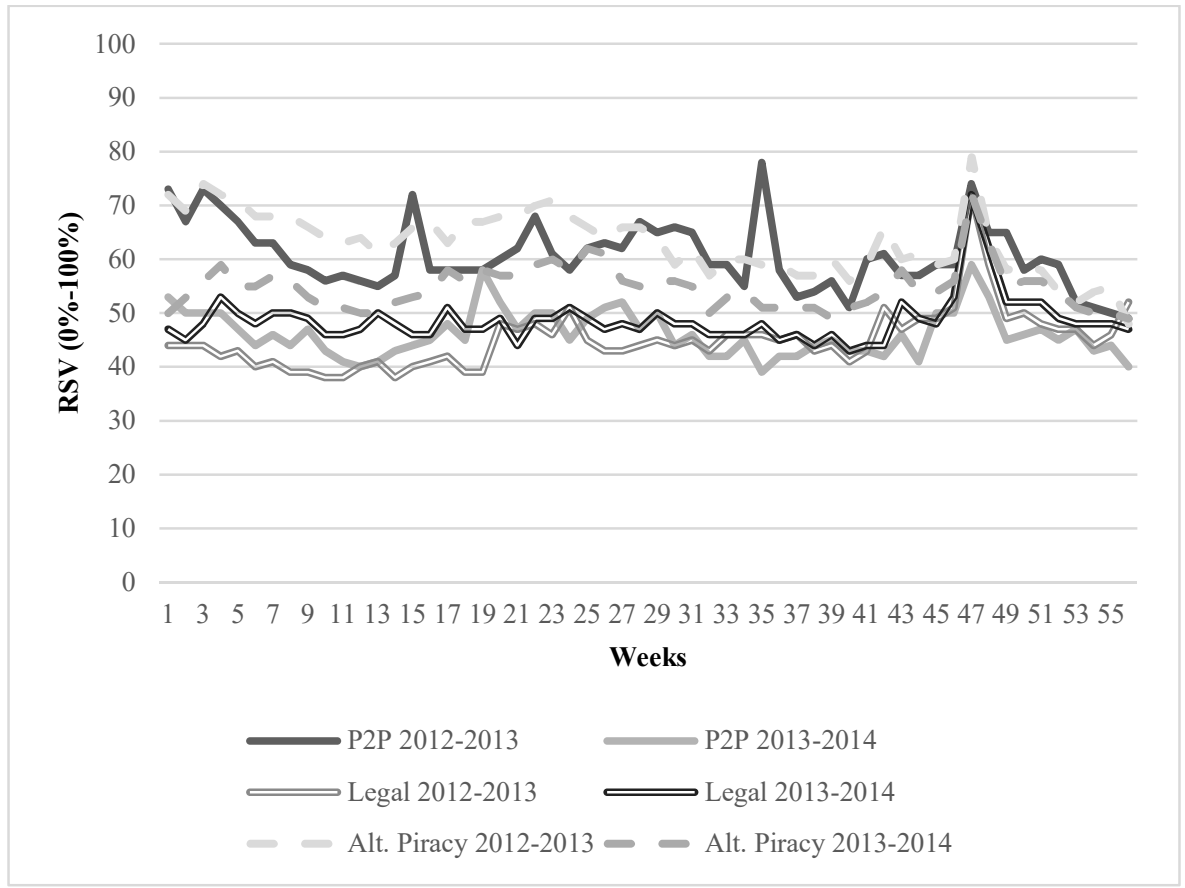

The differences between the search queries for P2P-piracy in 2012-2013 compared to 2013-2014 seems to be noticeable (as the straight lines demonstrate). 


\section{$\underline{\text { Punish, Seduce or Persuade }}$}

The queries dealing with P2P-piracy in 2013-2014 are lower than the 2012-2013 comparison, indicating that users used these types of queries to a lesser degree after the implementation of the CAS. The differences between these periods do become smaller as time passes. A full year after the implementation of the CAS, the differences are relatively small. This finding indicates that there has been an initial change after the CAS implementation. While an exact point in time cannot be identified as to when changes are most pronounced, the changes seem to be most noticeable shortly after the implementation of the CAS. The queries for legal content consumption and alternative piracy also depict more pronounced changes immediately after the implementation of the CAS.

The changes per cluster of queries are also insightful, which Figure 8.7 illustrates for P2P-piracy. This figure suggests that there has been a decrease in the queries after the implementation.

Figure 8.7: Long-term changes to the queries 'P2P-Piracy' (RSV of Feb 2012- Feb 2014)

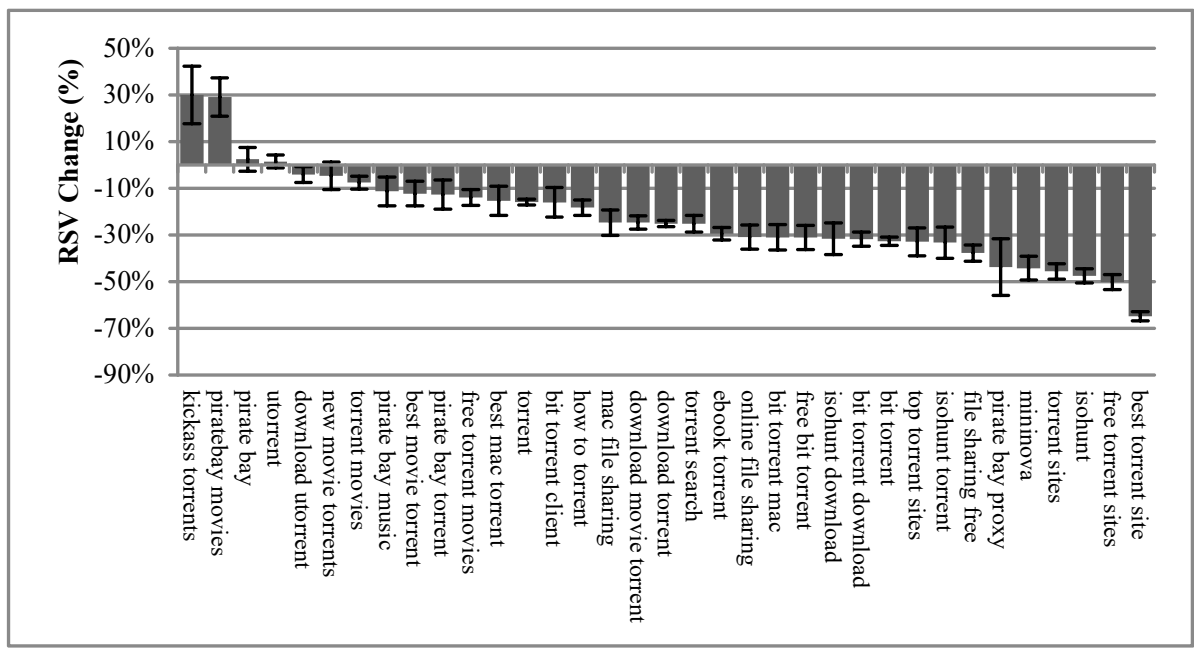

The decreases for those queries that deal with various torrent search websites are the most notable $(-64.86 \%$ and $-50.21 \%$ being the largest decreases). Only two noteworthy increases are present: the queries 'Kickass Torrents' $(+29.98 \%)$ and 'Piratebay Movies' $(+29.16 \%)$. This finding suggests that websites that link directly to other $\mathrm{P} 2 \mathrm{P}$-websites have become less popular overall. When all of these queries are considered, P2P-piracy related search behaviour has decreased by $-22.51 \%$.

Queries belonging to the second cluster present a more mixed picture, as Figure 8.8 demonstrates. While there are noticeable increases to certain queries, others seem to have also decreased substantially. 


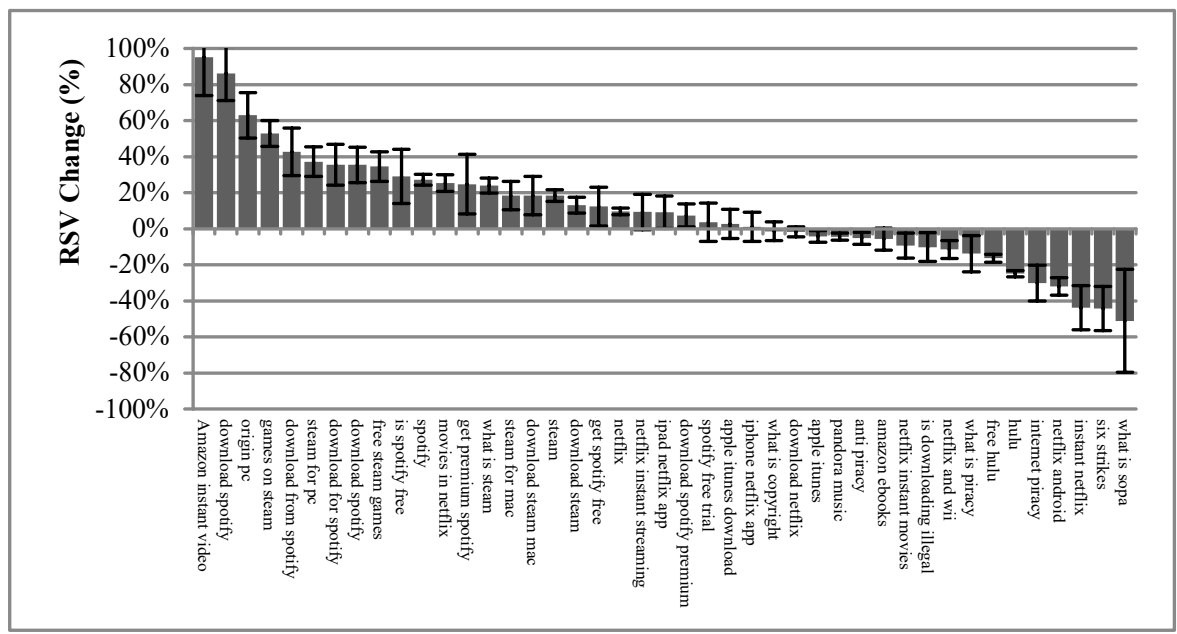

The popularity of some services has clearly reduced. This is particularly the case for Netflix, but Hulu has likewise failed to maintain its search volume. It is quite interesting to note, however, that the search volume of particular types of legal content has increased. For example, Steam $(+52.78 \%)$, Amazon $(+95.12 \%)$, and Spotify $(+86.20 \%)$ are services that contribute to this overall increase. Specific decreases are also observed in the context of queries related to certain anti-piracy interventions such as 'What is SOPA ${ }^{160}$ ' $(-51.09 \%)$ and 'Six Strikes (-44.23\%). It is interesting that search behaviour for these queries decreased. This might be reflective of reduced concern for the CAS (which is unofficially known as 'Six Strikes') and might explain why the changes are not as persistent as would be expected. On the whole, the RSV towards legal content has increased by $+9.92 \%$.

When focusing on the changes to queries for alternative methods to pirate content digitally, more differences between the short- and long(er) term changes emerge. Here, the majority of the queries actually decreased, as Figure 8.9 illustrates.

${ }^{160}$ SOPA refers to the Stop Online Piracy Act, which was a United States Bill that was meant to expand the ability to tackle digital piracy and the enforcement of copyright laws. The Bill could have had significant consequences for digital pirates, but it never became law. The fact that queries emerged on this topic altogether does underline that individual users were concerned about this Bill. See also Belleville (2012). 
Figure 8.9: Long-term changes to the queries 'Alternative Digital Piracy' (RSV of Feb 2012-Feb 2014)

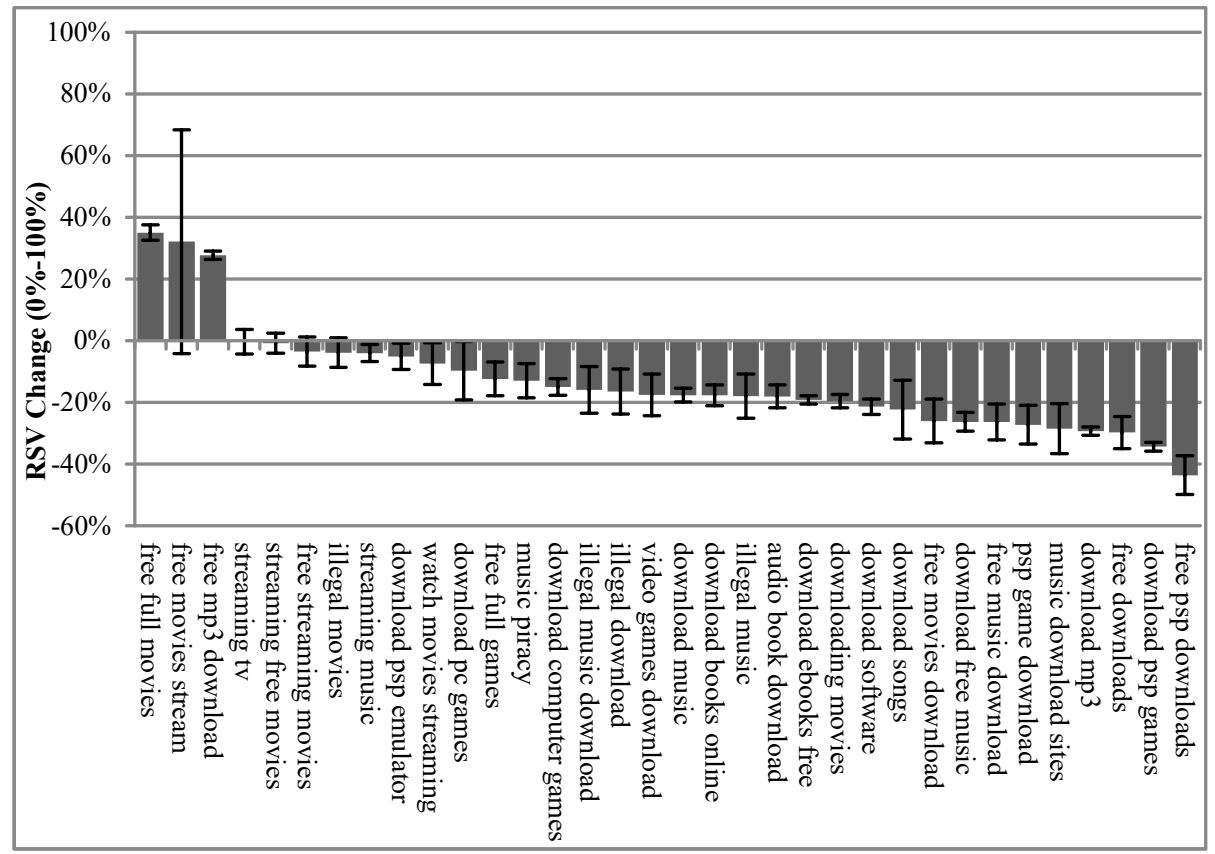

The overall decrease is $-11.65 \%$, clearly different from the increase noted in the short-term search queries (which was $+6.49 \%$ ). Many of the downloading-related queries decreased $(-43.54 \%$ and $-34.34 \%)$. On the other hand, streaming-related queries remained nearly stable $(-0.8 \%$ and $-0.29 \%)$ or even increased $(+32.13 \%)$.

With these combined insights on both the short- and long(er)-term changes to online search behaviour after the implementation of the CAS, it is tempting to state that these observed changes, which are mostly in the direction desired by the CAS and its proponents, are the result of its implementation. However, reaching that conclusion is not as easy as it initially seems. As was discussed in \$2.3.1. (supra p. 40), the attribution issue is inherently present in the method used to obtain and analyse the findings present in this chapter. Simply put, because this method does not allow the researcher to control any variables that might have had an effect on the online search behaviour, it is impossible to attribute the findings solely to the CAS. This attribution issue becomes more prominent if the investigated time period is longer, as more variables come into play over this longer period of time. 
In order to attempt to make more concrete statements on whether the observed changes indeed followed the implementation of the CAS, the remainder of this chapter will reflect on this attribution issue in detail.

\subsection{Observing the counterfactual: what if the CAS had not been implemented?}

The findings from the previous sections do not mean that the CAS did not contribute to the observed changes. It only means that the method used up to this point is incapable of unearthing such a potential causal link. By reflecting on this matter, it is possible to take a closer look at this attribution issue. One way to do so is to start from the fact that the CAS was implemented in a specific jurisdiction, the USA. Many other jurisdictions lack such an anti-piracy intervention. There is merit in comparing how online search behaviour has changed in jurisdictions with and without the CAS (or a similar intervention). Such an approach would take the form of a natural experiment. The overall method used to reflect on the attribution issue has been discussed in $§ 2.3 .3$. (supra p. 44). The focus here is on reporting on the attribution of the findings in more detail, as well as a clear statement on what the natural experiment entailed. The first step to do so is to explain how the 'control' jurisdiction was selected.

\subsubsection{Selecting the 'control' jurisdiction}

As was discussed in §2.3.3. (supra p. 44), for the comparison to be made, a 'control' jurisdiction needed to be selected based on the requirements discussed in that section. The list of possible 'control' jurisdictions was initially composed of most Western countries, as well as a few counties that belong to the Commonwealth of Nations. The starting point that a CAS-like intervention had not been implemented (yet) led to the exclusion of a number of jurisdictions, including the UK, France, Ireland, New Zealand and South Korea (Giblin, 2014; Kelly, 2016).

When the four requirements were applied, the list of candidates for the 'control' jurisdiction quickly became smaller. The first requirement required that a potential 'control' jurisdiction had English as it first language. This meant that a large number of potential 'control' jurisdictions were excluded, such as the Netherlands, Germany, but also jurisdictions such as Japan and Argentina. The second requirement focused on the rate of digital piracy, which should be similar in both jurisdictions. This led to the exclusion of Australia, which had a digital piracy rate substantially higher than the USA (BSA \& IDC, 2012). South Africa was excluded since the entertainment market there is too dissimilar to the one in the USA. From these three requirements, only one jurisdiction remained: Canada. This jurisdiction also met the fourth requirement, since it is a jurisdiction where 


\section{$\underline{\text { Punish, Seduce or Persuade }}$}

citizens have access to high-speed Internet. This led to the selection of Canada ${ }^{161}$ as being the 'control' scenario as it met these various requirements. ${ }^{162}$

Since the goal was to compare changes to online search behaviour in both the USA and Canada, the question examined in the natural experiment was: "what happened to the online search behaviour in Canada?' The online search behaviour originating from both jurisdictions was compared during the period of time. The Big Data-analysis in Canada used the same queries as the American counterpart. Canadian data was captured solely for a longer period of time, as the longer-term search queries are arguably most relevant to understand the implementation of the CAS and the persistence of changes in search behaviour. This means that the queries were captured one year prior and one year after the implementation of the CAS in the USA. These pre- and post-measurements provide an estimate of the counterfactual, since the changes noted in the 'control' jurisdiction demonstrate what might have happened in the USA had the CAS not been implemented there (Leeuw \& Schmeets, 2016).

\subsubsection{Analysing the Canadian results}

Now that it is clear which 'control' jurisdiction was selected, the changes to online search behaviour from both the USA and Canada can be compared.

The results show that the changes observed, at least in relation to the changes in P2P-piracy related queries, are not exclusively seen in to the USA-context, as Figure 8.10 demonstrates.

\footnotetext{
${ }^{161}$ Even more specifically, Canada has expressly rejected the use of a graduated response scheme in favour of other types of interventions (Suzor \& Fitzgerald, 2011).

${ }^{162}$ One important nuance is that French Canadians may have searched for pirated content using French terms. Such search behaviour is not examined in this study.
} 
Figure 8.10: Comparison of the RSV of 'P2P Piracy' queries between the USA and Canada

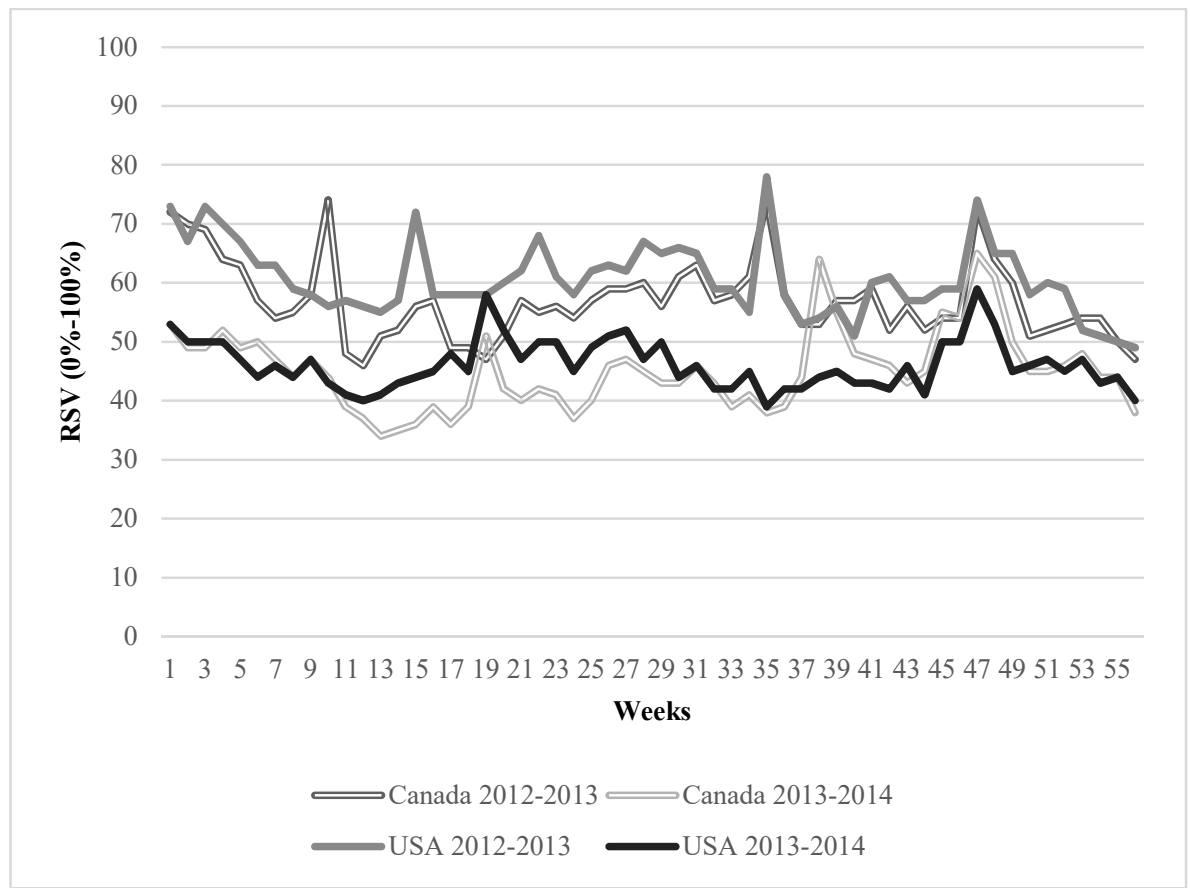

While the RSV in Canada (double lines) is slightly lower from the start, a clear decrease is noted, seemingly matching the decrease observed in the USA (straight lines). As in the USA, the reduction in Canada decreases over time. Analysing the individual queries shows that the decrease is somewhat smaller when compared to the USA (-15.97\% compared to $-22.51 \%)$.

The search queries dealing with legal content depict a similar image (see Figure 8.11). 
Figure 8.11: Comparison of the RSV of 'Legal Content' queries between the USA and Canada

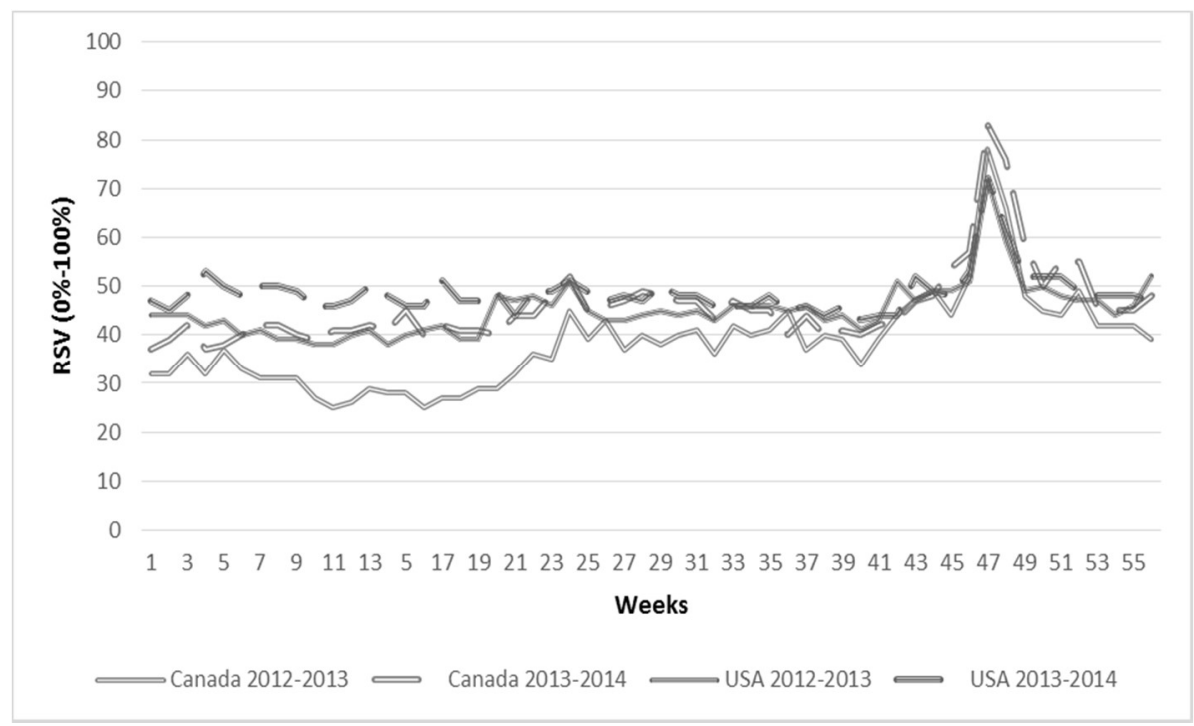

In both countries, an initial increase is noted, but over time the change becomes less pronounced. The analysis of the individual queries reveals that the overall increase in RSV in Canada is greater than in the USA ( $+24.31 \%$ compared to $+9.92 \%)$.

With regard to alternative queries, the changes in RSV again follow a similar pattern in Canada (see Figure 8.12).

Figure 8.12: Comparison of the RSV of 'Alternative Piracy' queries between the USA and Canada

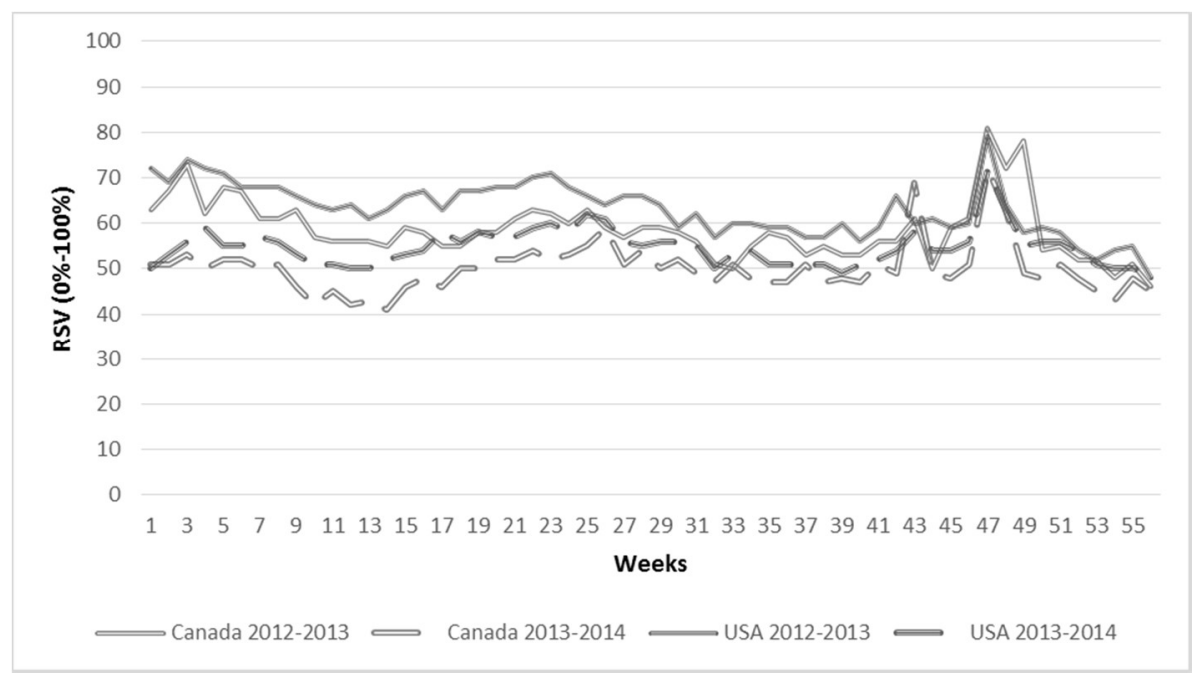


Initially it seems that the decrease is larger in Canada, despite the fact that no CAS-like intervention is in place. As in the USA, the change becomes smaller over time but, as opposed to the USA, the change seems to be somewhat more persistent. The change is slightly smaller than in the USA however $(-9.78 \%$ compared to $-11.65 \%$ ).

This natural experiment depicts that search behaviour dealing with P2P-piracy also decreased in Canada in the same period of time. The two remaining clusters also change in a manner similar to the USA. Interestingly, the legal content queries increased to a larger degree in Canada. Due to the fact that similar changes to the various search queries have been observed in Canada, it has become more difficult to conclude that changes followed the implementation of the CAS. What may have happened is that the changes in online search behaviour occurred naturally, but that the CAS acted as a catalyst to further aid in some of these reductions, particularly in relation to the reductions in P2P-related queries, which were more noticeable in the USA. Alternatively, perhaps there has been some degree of diffusion of benefits, which means that the Canadian digital pirates have also become more cautious in their efforts to obtain content (Guerette \& Bowers, 2009; Johnson et al., 2014).

\subsection{Conclusion}

The focus of this chapter was on the changes in the online search behaviour of digital pirates after the implementation of a specific anti-piracy intervention (the CAS). Big Data on this behaviour was used to obtain the required insights, which was an innovative way to study digital piracy. At first glance, the results of the empirical study moved in the direction that was expected beforehand. The first two hypotheses were confirmed. P2P-related search queries decreased while queries related to legal content increased. Conversely, the third hypothesis is seemingly false: the search queries for alternative methods to pirate content digitally seem to have changed, but the direction of the change seems to support the usage of the CAS, as these queries also seem to have been reduced.

A more critical reflection on these findings relativizes this preliminary conclusion. By using a natural experiment, the second half of this chapter asked 'what happened to the online search behaviour in Canada?' The result of this examination was that the implementation of the CAS was most likely not directly followed by changes in online search behaviour, as similar changes were also observed in the Canadian context. For policy makers and content owners, this means that some caution is required when deciding to implement such a graduated response scheme. Thus, to answer the fifth sub-question in a more concrete 


\section{$\underline{\text { Punish, Seduce or Persuade }}$}

manner: changes are observed but these changes are probably not the result of the implementation of the CAS. This is striking and not what was expected initially. This warrants further research as to why no real differences are observed.

One possible explanation is that, in line with what was discussed in Chapter 6, implemented graduated response schemes (like the CAS) fail to offer a sufficiently certain chance of being punished, in contrast to the scenarios tested in the Chapter 7. As stated in §6.1.1. (supra p. 141) and §6.1.2. (supra p. 150), two important requirements must be met for the deterrent effect to take place: the severity and the certainty of punishment. If these requirements are objectively lacking or perceived to be too low by the target population, it is unlikely that individuals will be deterred, as the low certainty or severity of punishment means that a deterrent response is not triggered. It was also found in Chapter 6 (supra p. 149) that only limited empirical evidence exists that a graduated response schemes (like the CAS) can indeed change behaviour. This limited evidence however appears to conflict. Although this second empirical study does not offer straightforward answers as to whether or not the CAS, or similar interventions, 'work', it is at present the first empirical assessment of the CAS.

A different explanation might be found on the other side of the US-Canadian border. Canadian digital pirates, being unsure of the reach and scope of the CAS, may have been somewhat deterred as well? Though this is speculation, it would be interesting to examine both countries in more detail in a follow-up research project.

This chapter also adds to the scientific debate by being a test case for the use of Big Data. In that regard, it is concluded that it allowed for the detection of changes in online search behaviour, but that it cannot be used to draw conclusions on the attribution or causality of these changes. This underlines that pairing such a Big Data study with other approaches is beneficial to the quality of the conclusions drawn.

Overall, this chapter mapped the changes in online search behaviour after the implementation of one specific anti-piracy intervention, while the previous chapters focused more on the design of various interventions and how this influenced the inclination of individuals to pirate content digitally. Requirements on the proper functioning of the mechanisms used in the design of the anti-piracy interventions have also been established. An earlier chapter also established why individuals pirate content digitally in the first place. It is the aim of the final and concluding chapter to draw these insights together and to present a clear answer to the research question that has guided the research so far. The final chapter will also focus on what these findings mean, how they can be contextualized as well 
$\underline{\text { Changes in Online Search Behaviour after the Implementation of an Anti-Piracy Intervention }}$

as what the implications of the findings are. Finally, it will also sketch some of the challenges that the creative industries and governments may be confronted with in the near future and how the insights obtained in research are useful to tackle these challenges. 



\section{Conclusion and Future Outlook}

Regardless of how the act of digital piracy is morally perceived, the fact is that it is an act which is common in Western society. It is also clear that various antipiracy interventions have been implemented by both governments and the creative industries. Empirical research on these interventions aids in better understanding whether they can succeed in limiting the scope and consequences of the act of digital piracy.

An examination of this scope and the consequences of digital piracy confirmed that it is indeed a common type of cyber-deviance and that some displacement of legal sales is to be expected. Some studies report that more than two-thirds of the respondents pirate music (Jeong et al., 2012; Wang et al., 2012), movies (Larsson et al., 2014) or software (Cronan \& Al-Rafee, 2008; Liao et al., 2010; F. Wang et al., 2005). The primary contributor to any losses due to digital piracy is the substitution mechanism. ${ }^{163}$ In addition to these economic consequences, the act of digital piracy also inherently infringes upon the copyright of the creator of the content. Such consequences have aided in the development and implementation of a wide variety of anti-piracy interventions, all of which strive to reduce digital piracy and its impact on society.

Two goals lie at the root of this research. The first goal is to determine which mechanisms, as the (behavioural) 'building blocks' of anti-piracy interventions, are activated when organizations and stakeholders implement anti-piracy interventions. The second goal is to assess whether these mechanisms enable interventions to contribute to reductions in digital piracy.

In order to reach these goals, this research set out to critically examine which mechanisms can contribute to reducing digital piracy, when and why such an outcome is to be expected and what the extent of such a contribution will be. This led to the following research question: 'Which mechanisms, used in the designs of various anti-piracy interventions, contribute to reductions in digital piracy and to what extent?'

As a starting point to answer this question, it was necessary to explain why people pirate content digitally. This allowed for the identification of what the anti-piracy interventions need to influence in order to be able to contribute to reductions in digital piracy. Since various anti-piracy interventions exist, a categorization and

${ }^{163}$ Which refers to the assumption that an individual will no longer have an incentive to obtain legal content once he has obtained this content via the act of digital piracy. For a more detailed discussion, see $\$ 3.2 .1$. (supra p. 53). 


\section{$\underline{\text { Punish, Seduce or Persuade }}$}

inventory of various anti-piracy interventions was made. This categorization reflected the mechanisms that are used by the interventions that are meant to reduce digital piracy. It was determined to what extent these mechanisms are used to influence variables contributing to the likelihood of digital piracy, as well as which requirements need to be met in order for these mechanisms to be able to succeed in doing so. Following this theoretical analysis, two empirical studies examined 1) whether and how the mechanisms (and requirements) allow the interventions to reduce digital piracy, and to what extent, and 2) whether and how online search behaviour changed after the implementation of a specific anti-piracy intervention. Text box 9.1 presents the five sub-questions on which this sequence of steps was based and which were answered during the course of this research.

Text Box 9.1: The five sub-questions

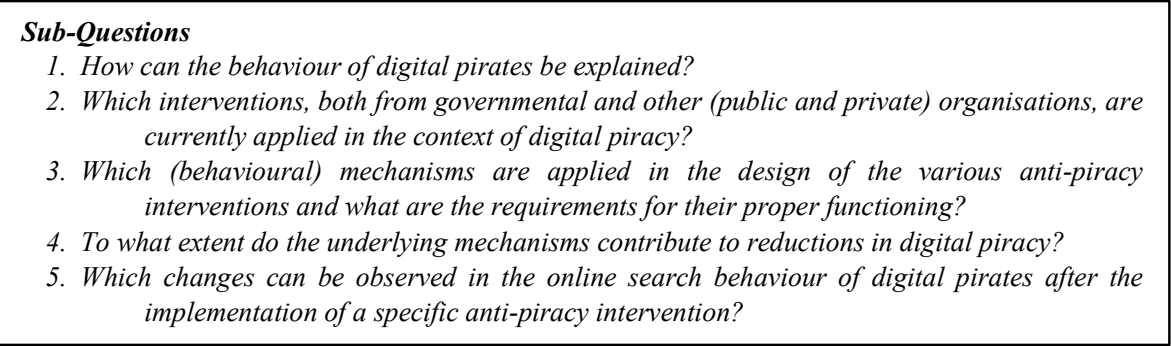

It was found that individuals in general are inclined to pirate content digitally if they possess individual characteristics that make them more prone to engaging in this act, if the environment is conducive to it and if their deliberation (through the process of choice) permits it. For example, the individual's morality makes the individual more prone to pirating content digitally, while the moral context influences the conduciveness of the environment that this individual finds himself in. Finally, perceptions and past digital piracy are examples of components of the process of choice and aid in understanding whether the individual will act upon his propensity when confronted with a digital piracy-conducive environment. The Situational Action Theory (SAT) was used as the lens through which these and other aspects could be clustered and framed.

Three categories of anti-piracy interventions were identified, which led to the identification of three types of mechanisms used by these interventions: deterrence, incentivization and persuasion. Though this categorization is somewhat artificial, since in practice a number of hybrid anti-piracy interventions exist, it did allow for a better assessment and understanding of the mechanisms used to influence the act of digital piracy. Hybrid anti-piracy interventions allow governments and the creative industries to combine or intertwine mechanisms in an attempt to improve the likelihood that such interventions will contribute to 


\section{$\underline{\text { Conclusion and Future Outlook }}$}

reductions in digital piracy. Thus, they are interventions in which a primary mechanism is supported by a second mechanism. Often, the persuasivemechanism, which can be used to inform the target population, serves as this second mechanism. The information is used, for instance, to create more awareness of the content, scope or consequences of other mechanisms used in the intervention.

This research has shown that interventions which use deterrence or incentivization are more capable of contributing to reductions in digital piracy than interventions that use persuasion as a mechanism. The extent of these contributions is likely to be relatively small however. The empirical study that focused on observing potential changes to online search behaviour after the implementation of the CAS unearthed various changes. However, attributing these observed changes to the CAS proved challenging: it is unlikely that the CAS alone has indeed influenced this online behaviour.

The aim of this concluding chapter is to examine some of the relevant patterns present in the findings and express their importance for the anti-piracy interventions themselves. In addition, this chapter will also explore a number of future outlooks, which illustrate the coming challenges in the field of digital piracy and how the examined interventions can cope with these challenges.

\subsection{A closer look at the most important findings}

Seven findings are examined in some detail in this section. These patterns focus on what the findings mean for the interventions and mechanisms themselves as well as which avenues remain to possibly improve the contribution of the various mechanisms to the reduction of digital piracy.

9.1.1. The link between the mechanisms and variables explaining digital piracy

The explanation of digital piracy is based on three clusters: the individual's propensity, the conduciveness of the environment and the process of choice. Antipiracy interventions, through the mechanisms incorporated in their design, attempt to modify the variables in these three clusters in order to reduce the likelihood of digital piracy.

Each mechanism focuses on specific variables. The deterrent mechanism directly tries to make it more certain that the act of digital piracy is punished or that this act is punished more severely. By doing so, it attempts to modify the moral context of the environment. The incentive-mechanism also directly attempts to 


\section{$\underline{\text { Punish, Seduce or Persuade }}$}

modify an environmental feature: the cost of content. The high cost of legal content is one of the features that make it more likely that an individual will pirate the content digitally rather than purchase it legally. Both mechanisms are thus focused on specific variables that influence the likelihood that an individual will pirate content digitally. The sermon, as a mechanism, does not enjoy the benefits of such a focus. This is due to the fact that this mechanism is used in three different ways: 1) inform individuals on the benefits of using legal content, 2) educate individuals on the immorality of digital piracy, and 3) 'scare' individuals by using fear appeals and harm attribution strategies. Each different usage of this mechanism attempts to influence different variables. Identifying the benefits of legal content can have an influence on the perceptions of digital piracy. This applies in particular to the perceived positive outcome expectations of this act, which can be reduced if the individual is made aware of what he will 'miss out on' when he uses the pirated copy. In other words, this information is meant to cause the individual to compare the pirated copy with the benefits and features of the legal content, which the pirated copy lacks. If used well, this comparison should lead the individual to conclude that the legal content is superior to pirated copy. In turn, the fear appeal and harm attribution approaches have an influence on the perceived negative outcome expectations of the act of digital piracy, which are increased for both the individual and society in this manner. Using the sermon as a way to focus on the immorality of digital piracy is meant to influence those 'variables' that are linked to morality of this act.

The differences in the way the mechanisms focus on variables that explain digital piracy can aid in better understanding why both the stick- and carrot-based interventions appear to be more capable of contributing to reductions in digital piracy than the sermon-based ones. Policymakers and the creative industries have more direct control over the degree of deterrence in a specific context, and even more control over what they ask for legal content. In contrast, morality is less easily influenced by outside intervention. Thus, the specific link between a mechanism and certain variables aids in assessing the likelihood that an antipiracy intervention that uses such a mechanism can contribute to reductions in digital piracy.

The stick-mechanism can also benefit from the expressive function of the (criminal) law, which is a feature that the other mechanisms do not enjoy (Sunstein, 1996). This expressive function is linked to the immorality (or the lack thereof) of digital piracy. The usage of the criminal law expresses a degree of condemnation (Dau-Schmidt, 1990; Hart Jr, 1958; Harvard Law Review, 2003; Kahan, 2000), while also confirming existing (social) norms (Cooter, 2000; Jakobs, 2004; Posner, 2000). This can indirectly influence the individual's moral outlook on digital piracy. However, the question should be posed whether this 


\section{$\underline{\text { Conclusion and Future Outlook }}$}

expressive function of the law plays a pivotal role in the context of digital piracy. As was established previously, the fact that many individuals see digital piracy as an act which is not immoral or wrong is quite persistent.

\subsubsection{What can the mechanisms really modify in terms of behaviour?}

The previous section demonstrated that the three mechanisms differ in the way through which they attempt to contribute to reductions in digital piracy. They clearly focus on different variables. However, the fact that these mechanisms attempt to influence certain variables does not mean that these are easily modified in practice or that such a modification will lead to a change in behaviour. This section discusses the modification of the variables and whether there are any practical issues that may influence this process.

As aforementioned, the stick- and carrot-mechanisms focus specifically on modifying environmental features that are conducive to the act of digital piracy. This focus is quite understandable. After all, the environmental features are more modifiable via outside intervention, especially when compared to individual characteristics and components of the process of choice. For instance, certain individual characteristics are not meant to be modified by the interventions. Desires are an example of such a characteristic, since it will also determine whether or not an individual will try to obtain content in a legal manner. Changing this characteristic may be counterproductive for the intervention. It is also difficult to directly influence the individual's belief that he is capable of pirating content digitally, as only the technological measures that belong to the stick-based interventions directly set out to influence this belief. There is also some evidence that this belief is linked to deterrence, in the sense that individuals who perceive a lower certainty of detection also have a higher belief that they are successfully capable of pirating content digitally (Zhang, Smith, \& McDowell, 2009), indicating that deterrent measures can indirectly influence this characteristic. Of the remaining individual characteristics, only the individual's morality is directly focused on by the sermon-based anti-piracy interventions. Given the importance of morality as both an explanatory factor and a reason for the persistence of digital piracy, the role of this characteristic is discussed separately in section (\$9.1.4. (infra p. 249)).

Components of the process of choice are also not focused on as frequently. These components tend to be outside the direct control of the policy makers and creative industries. However, sermon-based anti-piracy interventions do strive to influence some of these components, such as the individual's ability to neutralize his acts of digital piracy. The findings from both Chapter 6 and the first empirical study 
underline that these interventions struggle to succeed in influencing digital piracy in this manner. This suggests that, once an individual is motivated to obtain content via the act of digital piracy, it becomes more difficult to inhibit an individual from doing so. For the creative industry and governments, intervening before an individual has formed this motivation is important.

In addition to whether or not the mechanisms are capable of focusing on certain variables, certain practical issues emerge when attempting to influence the environmental features via the anti-piracy interventions. This adds to the difficulty in reducing digital piracy in practice. For instance, it is difficult to reach the certainty and severity of punishment examined in the first empirical study in practice. As was discussed in §6.1. (supra p. 140), increasing the available resources for stick-based interventions does not automatically mean that the certainty and severity of punishment are increased to a level where digital pirates are actually deterred. In fact, given the large amount of digital pirates and Internet users, perhaps only the technological anti-piracy measures can be really said to be able to deter digital pirates in practice. Given the technological nature of these measures, content owners can implement them relatively cheaply and quickly and are used to increase the certainty of 'punishment'. Implementing and maintaining traditional legal interventions, in contrast, tends to be resource-consuming. In addition, making more resources available does not necessarily result in a higher certainty of punishment. As was seen in Sweden, even a doubling of available resources did little to increase the certainty of punishment.

Furthermore, there is some reluctance to using stick-based interventions in certain jurisdictions, including the Netherlands. It has been repeatedly stated that prosecuting individual digital pirates is not the aim of the Dutch copyright enforcement policy (Teeven, 2011). However, more recently, the Dutch film industry has indicated that it is also considering focusing on individual digital pirates (The Post Online, 2016). Fines or settlements would be used in such an approach. In Belgium, an approach similar to what was found in Germany (the so-called 'copyright trolls' practices) has emerged (Feys, 2014; Luyten, 2014), although this kind of enforcement seems to focus on the 'heavy downloaders' rather than on all digital pirates. Such developments suggest that a more deterrent approach, with the creative industry itself as its vanguard, has become more likely in the past years, although enforcement through criminal law still seems unlikely. Thus, perhaps some of the reluctance to use such measures has disappeared. Based on the findings discussed in this research, such stick-based interventions are only able to influence behaviour if the degree of certainty and severity of punishment is sufficiently high. If this degree can be accomplished, stick-based interventions are more capable of contributing to reductions to digital piracy than their carrotand sermon-based counterparts. 


\section{$\underline{\text { Conclusion and Future Outlook }}$}

Practical issues are not unique to interventions that use the deterrent-mechanism, since carrot-based interventions may also encounter certain practical issues. The main concern here is that there needs to be a balance between offering an incentive that is both attractive for the target population and yet also profitable for the content owners. The largest incentive is offering content for free, via streaming models. However, there are doubts as to whether or not streaming models such as Spotify can be profitable, despite their popularity (Willins, 2016), although other streaming services such as Netflix are likely to become profitable in the near future (Williams, 2016). §6.2.2. (supra p. 162) also revealed that there is limited evidence that streaming models will contribute to reductions in digital piracy, as some studies found that individuals who use such services were more inclined to pirate content digitally.

Some of this profit can be obtained via other, related content, such as concert tickets or merchandise. These experiences cannot be pirated as easily, if at all. Perhaps content owners can offer albums and singles cheaply or even for free for them to function as a gateway for such other types of content. A different practical issue is that the findings suggest that adding extra content is counterproductive. This is not just a theoretical issue, as the backlash following Apple's decision to make the latest $\mathrm{U} 2$ album available for free for users who used their iTunes service illustrates (Booth, 2014; Selby, 2014; Sherwin, 2014). ${ }^{164}$

\subsubsection{Changing perceptions}

It became clear that perceptions are important in the context of digital piracy, antipiracy interventions and the mechanisms used in these interventions. The way in which individuals belonging to the target population perceive themselves and their environment was found to be important in explaining the act of digital piracy. In turn, whether or not anti-piracy interventions are capable of influencing these perceptions is relevant in estimating their likelihood of reducing this behaviour.

Various findings show that interventions, through their mechanisms, can indeed influence these perceptions. For instance, concerning the deterrence mechanism, a relation between objective and perceived risks of punishment has been found. As Apel, Pogarsky, and Bates (2009, p. 220) state: 'Not only was there a sanctions-perceptions correlation [...], individual perceptions were also responsive to a change in the strictness of the sanctioning regime.' The relation between perceived risk of punishment and objective risk of punishment had previously been established in a number of studies (Horney \& Marshall, 1992; Matsueda, Kreager, \& Huizinga, 2006; Paternoster, Saltzman, Waldo, \& Chiricos, 1985).

${ }^{164}$ Some iTunes users have compared this marketing technique to 'waking up with herpes' (Selby, 2014). 


\section{$\underline{\text { Punish, Seduce or Persuade }}$}

The first empirical study revealed that the respondents' inclination to pirate content digitally did change after exposure to a more certain or more severe deterrent measure. This underlines the likelihood of a relationship between objective and perceived risks of punishment. However, that study exposed the respondents to quite high certainties of being detected and punished. This degree of certainty was certainly higher than what can be accomplished in practice currently, particularly since the certainty of punishment tends to be very low in real life. Thus, while there may very well be a pathway to influence the perceptions via the deterrent measures in theory, it is unlikely that such influence manifests itself in the day-to-day practice of digital piracy. The exception is the usage of technological measures, which have a higher certainty of punishment.

Perceptions are also relevant for the carrot-based interventions as the incentive must be sufficiently attractive for the target population. The way through which the incentive is perceived influences this attractiveness. Following the first empirical study, the question was raised as to whether the incentive presented in that study was indeed perceived as being sufficiently attractive. Simply reducing the cost of content is not sufficient. How the artist (or creator), the content itself and the creative industry are perceived by individuals is also important (Coyle et al., 2009; Ouellet, 2007). This means that, above all, the creative industry should strive to market content that is of high quality, as this will directly determine how the incentive is perceived by the target population. It should also avoid fostering perceptions that the target population feels 'ripped off'.

Using the persuasive-mechanism as a way to inform the target population can play a role in influencing the various perceptions, as they offer clear information on the various aspects of digital piracy, the benefits of legal content and the risks of pirated content. This means that sermon-based anti-piracy interventions should be primarily applied to manage the perceptions of the target population (Olney \& Brockelman, 2003). To that end, it is a type of intervention (and in turn, a mechanism) that can be supportive to other interventions and mechanisms. This underlines the relevance of using hybrid interventions, e.g., interventions which have characteristics of two types of interventions. Thus, while Chapter 7 demonstrated that the persuasive-mechanism on its own is unlikely to contribute to reductions in digital piracy, this mechanism can be supportive to the other two mechanisms, provided that the information is presented in a believable and positive manner.

The role of the persuasive-mechanism as a way to inform the target population can be better understood by looking, for instance, at the cost of content and how this feature influences the likelihood of digital piracy. It was found that it is important to reduce this cost directly but also to influence how this cost is 


\section{$\underline{\text { Conclusion and Future Outlook }}$}

perceived by the target population. In that regard, there is a clear role for the informative role that certain sermon-based interventions play, as they can be used to inform the target population on the existence of specific incentives. In turn, this can influence the target population's perception of the presented incentive.

The persuasive-mechanism can also be used to inform the target population on the content of stick-based interventions. Using information in this way, interventions can present clear information on the certainty and/or severity of the punishment following an act of digital piracy. For instance, warning messages presented at the beginning of a movie tend to mention the potential penalty for the act of digital piracy. As research has shown that the average individual does not know the certainty and severity of a deterrent measure (Apel, 2013; Kleck \& Barnes, 2008; Maccoun, Liccardo Pacula, Chriqui, Harris, \& Reuter, 2009), efforts to increase this knowledge and thus influence these perceptions can be useful, especially in the context of digital piracy. But such an approach can be a double-edged blade. If these efforts inform the target population on the real-life certainty of punishment for digital piracy, which is very low, the interventions may very well have the opposite effect. Individuals might be more inclined to pirate content digitally than before. At the same time, presenting the certainty (and the severity) of punishment as (very) high is likely to hamper the believability of the message. This will influence whether or not the target population will seriously considers the content of the message. Thus, prudence is called for when using the persuasive-mechanism as a way to support interventions that use the deterrent-mechanism.

9.1.4. The relevance of morality as both an explanation of digital piracy and an obstacle to behavioural change

One of the recurring themes in this research was the relevance of morality and the moral context in which digital piracy takes place. The fact that many individuals do not see digital piracy as a moral issue contributes to why such individuals are motivated to obtain content in that manner. But, in addition to explaining digital piracy directly, it is also insightful as to why certain anti-piracy interventions are not ideally equipped to influence this behaviour. Changing the moral outlook of individuals is difficult in any case, let alone when behaviour such as digital piracy is involved, which has been seen as acceptable for many years now. A recent study has even demonstrated that individuals feel less guilt and shame when pirating content digitally, compared to stealing the same content physically from a shop. The intangible nature of the digital content may contribute to this reaction (Eres, Louis, \& Molenberghs, 2016). This study from the field of neurosciences illustrates that changing this moral outlook is not easy. 


\section{$\underline{\text { Punish, Seduce or Persuade }}$}

The fact that changing the moral outlook of digital piracy is difficult aids in explaining why the prevalence of digital piracy has been so persistent. It also aids in understanding why the sermon-based interventions struggle to offer a contribution to reductions in digital piracy since they attempt to do so via an attempt to influence the morality of digital piracy (LaRose \& Kim, 2007). Studies on digital piracy have established that morality matters but often treat this as a given, as something that cannot be modified but that is useful in explaining such behaviour. The empirical studies on the relationship between morality and digital piracy focus on how the individual's existing morality can be used in order to inhibit individuals from pirating content digitally (Al-Rafee \& Rouibah, 2010). Some additional insights into the difficulties of changing morality, be it the individual's morality or the moral context of the environment, need to be presented in order to better understand their relevance.

When it comes to the individual's morality, research has shown that is not a construct that appears out of thin air. Instead, it develops over time and a large part of this developmental process takes place during early childhood (Krebs \& Denton, 2005; Turiel, 2008). This means that, when individuals come into contact with digital piracy and anti-piracy interventions, it is likely that a large part of their moral outlook has already been formed. Influencing this outlook, especially by a source as far removed from the individual as an anti-piracy intervention, seems unlikely.

The moral context of the environment is more capable of being modified via outside influence. But even here it is apparent that morality is a stubborn concept, as the social approval of digital piracy influences the favourability of the context. In contrast to the deterrent aspects of the moral context, social approval of digital piracy is difficult to modify as it requires the intervention to influence the norms and morality of a group of individuals.

The relevance and persistence of the moral aspects of digital piracy (the individual's morality and the moral context) can hamper the anti-piracy interventions, especially the sermon-based interventions. The moral aspects of digital piracy are difficult to influence and, since this intervention category in part functions via attempts to instil in digital pirates with a sense that digital piracy is immoral, it is not surprising that the evidence does not support the use of such interventions. The findings from the first empirical study underlined earlier doubts on the usage of sermon-based interventions as a tool to reduce digital piracy. Instead, the persuasive-mechanism can better be used as a way of informing the target population on the existence and content of other types of interventions. 


\section{$\underline{\text { Conclusion and Future Outlook }}$}

\subsubsection{Reaching and addressing the subgroups of digital pirates?}

This research uncovered a number of attributes which allowed for the identification of those individuals who are more likely than others to pirate content digitally. These attributes do not (directly) aid in explaining the act of digital piracy but can be used to better delineate the target population of the various anti-piracy interventions. This target population consists of individuals who are young males who have more experience with computers and related technologies. These attributes are useful in better understanding the extent of the contributions of the anti-piracy interventions to the reduction in digital piracy: if the interventions fail to reach the appropriate target population, the extent of the contribution will be negatively affected. And even if the target population is reached, this does not guarantee that individuals belonging to this population feel addressed by it and change their behaviour.

Though the findings presented in Chapter 5 underline that the various anti-piracy interventions do seem able to reach individuals who possess (some of) the identified attributes, it is not at all certain that these individuals also feel addressed. In addition, some of the interventions would benefit from a more focused or tailor-made approach that better allows the intervention to reach and address the target population. When the data from the first empirical study, as well as the academic literature on digital piracy, was examined, it became clear that there are different types of digital pirates. Some individuals do not intend to obtain content in this manner at all and seem to be naturally compliant. It is of no extra use if the anti-piracy interventions focus on these individuals. On the other end of the spectrum are individuals who are very persistent in their acts of digital piracy. Such individuals can be seen as being the heavy-downloaders or -pirates. These individuals are more likely to act out of habit, meaning that they are less likely to deliberate on their behaviour. This lack of deliberation means that the individuals belonging to this subgroup are less likely to be influenced by the interventions. In between these two extremes are individuals who can be deterred, tempted or persuaded to act differently, as they may still deliberate on their decision to obtain content via the act of digital piracy. These individuals are more likely to notice and react to changes in the environmental features for instance.

A better differentiation between the various types of digital pirates (non-pirates, deliberative-pirates and habitual-pirates) can aid in improving the contributions that the interventions, through their mechanisms, have on the reductions in digital piracy. In addition, it would also be of added value to examine whether different types of digital pirates react differently to the various mechanisms. The findings from the first empirical study suggest that men and women react differently to the 


\section{$\underline{\text { Punish, Seduce or Persuade }}$}

various hypothetical anti-piracy interventions (the scenarios). Thus, it can be beneficial for anti-piracy interventions to reach and address different sub-groups of digital pirates. Though the first empirical study only examines the differences between how both male and female respondents reacted to the various scenarios, this does not mean that further distinctions between subgroups are not called for. Perhaps most relevant in this regard is the fact that the SAT also makes a distinction between habitual and non-habitual (or deliberative) offenders. Both end up acting in a deviant manner, but are influenced differently by (for instance) environmental variables. Following this line of reasoning, a greater need for differentiation seems apparent, though additional empirical validation is still necessary to further substantiate this claim.

Differentiation is also possible by making intervention more focused. In this regard, certain interventions can be made more focused than others. Arguably, the least focused anti-piracy interventions are the carrot-based interventions, as they are not just meant to tempt digital pirates to purchase the content legally but also to make it easier for legal consumers to obtain content. The application of a carrotbased anti-piracy intervention that would focus on deliberative digital pirates is difficult to imagine. However, this does not mean that these interventions are incapable of reaching these individuals. Instead, it can mean that they do not feel addressed by the intervention, decreasing the possibility that they will seriously consider its content.

Likewise, sermon-based interventions are currently not too focused, as they try to reach a relatively broad audience. However, these can be made more focused by making adjustments to the tone and platform through which the sermon is implemented. For instance, using social media as a way to disseminate the sermon enables the intervention to better reach younger individuals, meaning that individuals who have one of the attributes of the digital pirate are reached (Bolton et al., 2013). Stick-based interventions can be made more focused, especially when considering the use of civil suits, settlements, the criminal law or graduated response schemes. Here, it can be decided, per case, on whom to focus as well as which sanction is appropriate. Still, the day-to-day criminal justice practice shows that stick-based interventions tend to focus on the cases that are relatively easy to investigate. These are cases that, with relatively limited effort, can be investigated and closed. Due to the process of 'creaming', it is unlikely that the experienced digital pirates will bear the brunt of the anti-piracy interventions (Nelen, Leeuw, Bakker, \& Herrenberg, 2012). Instead, it is more likely that the digital 'losers' become the subject of closer investigation, since these individuals are less capable of avoiding detection and punishment. 


\subsubsection{The merits of 'entwined' anti-piracy interventions?}

In addition to a more focused targeting of individuals, there is a different way through which anti-piracy interventions can improve their contribution to reductions in digital piracy: through a further 'entwinement' between the categories of interventions and mechanisms. This means that a combined approach, for instance between stick- and carrot-based interventions, could be the pathway to take in the future. This could be the best of both worlds, as this combined effect might mean that the target population is presented with a clear legal alternative to digital piracy, while at the same time being deterred from this act. This would result in the further development of the so-called 'hybrid' antipiracy interventions or mechanisms that have previously been discussed. An example of such a 'hybrid' mechanism was seen when discussing the requirements for the functioning of the deterrent mechanism, where the stimulation of alternative behaviour was found to add to this functioning (§6.1.3. (supra p. 156). The persuasive-mechanism can be entwined with both the stickand carrot-mechanisms as a way to inform the target population on their existence, scope and content. In addition, the carrot-mechanism can be entwined with the stick-mechanism as a way to present the target population with a legal alternative to obtain the desired content.

If sermon-based interventions are used in the manner described, they would be more informative and less persuasive. Collectively, this means that carrot-based interventions are supportive of the stick-based interventions and the sermon-based interventions are supportive of the other two categories.

Such entwinement can already be found in practice. The CAS, for instance, also informs the infringing subscribers on ways through which the content can be obtained legally. A different example of an entwinement between interventions is seen in the usage of DRM and the protection of video games. Here, users of the pirated content are sometimes confronted with glitches or issues that the legal copy does not possess (such as Figure 9.1: Example of measures taken against video game pirates (Greenheart Games, 2013) not being able to progress past a certain point in the game, see Figure 9.1). The users of this pirated content might not identify the glitch as being the consequence 


\section{$\underline{\text { Punish, Seduce or Persuade }}$}

the pirated copy and ask for the developer's help in solving it. In this, this publicly uncovers the individual as a digital pirate. Thus, an entwinement between punishing the individual for his usage of a pirated copy and attempting to persuade the individual to use the content legally the next time can be observed (Chacos, 2016; Cooper, 2014; Wilbur, 2016). Such entwinement is important as the desire of individuals to obtain and enjoy content will remain and, if digital pirates are not informed on how they might fulfil this desire in a different and suitable manner, they are more likely to continue to pirate content digitally, despite being exposed to stick-based interventions.

9.1.7. The limits of anti-piracy intervention? A balance between input and output

The creative industries, governments and policy makers implement anti-piracy interventions with the primary goal of reducing digital piracy. These various stakeholders put time and effort into developing, implementing and maintaining the various interventions. All in all, it is a costly affair. This carries with it the question whether all these efforts are worth the effort. Put differently, what can be expected in terms of reductions in digital piracy?

The findings lend themselves to the conclusion that the reductions in digital piracy are likely to be quite small. Most of the effect sizes presented in Chapter 7 confirm that some interventions that use the studied mechanisms can contribute to reductions in digital piracy, but that the examined scenarios rarely resulted in large reductions in the respondent's inclination to pirate content digitally. The effects of interventions, even new ones like the CAS, should therefore not be overstated. Some degree of digital piracy may need to be accepted by governments and the creative industry. Putting more effort into reducing digital piracy may even lead to diminishing returns.

This means that governments, policy makers and the creative industries need to consider performing a balancing act. On the one hand, they need to attempt to reduce digital piracy to a certain extent. A total lack of enforcement (or other means used to reduce digital piracy) is likely to result in an increase of this behaviour (Lau, 2006). Just having the laws in place is insufficient. Thus, having some degree of enforcement is necessary (Al-Rafee \& Rouibah, 2010; Hill, 2007). However, implementing too many interventions (or interventions which are stricter, and thus more costly, when it comes to deterring digital piracy) is not the panacea either.

The observations that digital piracy is only partially reducible and that these reductions are likely to be small in practice implies that putting too much efforts 


\section{$\underline{\text { Conclusion and Future Outlook }}$}

into reducing digital piracy is not cost-effective. This is due to the fact that many anti-piracy interventions are expensive to implement and maintain, while the benefits of many interventions are limited. The creative industry and governments need to reflect on what level of digital piracy they consider to be acceptable. This would come down to determining what an 'tolerable' degree of digital piracy is, which may refer to the situation in which the content owners still obtain a fair compensation for their work, despite the presence of some degree of digital piracy.

There are studies that underline the premise that having some degree of tolerance of digital piracy can be 'optimal' (Banerjee \& Poddar, 2015; Fagundes, 2013). In addition, not enforcing the copyrights strictly can have benefits, since the resources that are normally used to enforce the rules can be used elsewhere in society. As Stigler (1974, p. 56) argues: 'There is one decisive reason why the society must forego "complete" enforcement of the rule: enforcement is costly.' The sampling effect, discussed in \$3.2.2. (supra p. 54) also adds merits to allowing some degree of tolerance. This effect states that some digital pirates will also purchase the content legally, even if they have already obtained the pirated content. Such a strategy is already being pursued by the content owners: for instance, the usage of a pirated copy can be tolerated when this serves a promotional purpose for the content owner (Zajko, 2015). This does not mean that no enforcement should take place, but rather, that enforcement should be reserved for the more serious instances of digital piracy or instances where organized crime is involved.

The required balancing act already found in the creative industries in the USA: here, digital piracy is seen as market condition that will remain a problem (United States Copyright Office, 2015). ${ }^{165}$ This is in line with recent observations on the use of stick- and carrot-based interventions, where it is suggested that there is an increase in the usage of carrot-based ones (De Geest \& Dari-Mattiacci, 2012). Whether this indicates the emergence of a more tolerant approach in Europe, where carrot-based interventions are preferred over stick-based ones, remains to be seen. Recent legal rulings have underlined the infringing nature of the act of digital piracy and countries have had to make changes to their efforts to reduce digital piracy. The Netherlands, for instance, where a degree of tolerance was applied in the past, have had to revise their enforcement approach since a verdict of the European Court of Justice (Shahid, 2014). This verdict underlined that the European Union Member States must distinguish between legal and illegal sources of copies for private use. The prior solution applied in the Netherlands, where private copies were tolerated regardless of the legal or illegal nature of the

${ }^{165}$ This means that digital piracy is seen as a continuing challenge that depresses revenues for the creative industry (United States Copyright Office, 2015). 


\section{$\underline{\text { Punish, Seduce or Persuade }}$}

source the copy, could therefore not be maintained (Rosati, 2014). As a consequence, a 'downloading ban' has now become part of the Dutch legal landscape, though it has not yet led to enforcement in the context of individual end-user digital piracy. Regardless, it is now clear that downloading content from an illegal source, even for private use, indeed constitutes a copyright infringement (Quintais, 2015). This underlines the presence of a trend towards greater regulation and control of the issue of digital piracy (Bright \& Agustina, 2013), possibly moving away from the discussed balancing act.

A final related matter is how much further some of the anti-piracy interventions can be expanded beyond their current incarnations and scope. For instance, it seems that most carrot-based interventions have already reached their limits. A lot of content is already offered for free (via streaming) or at least cheaper than what was asked for content in the past. Is there any way left for the creative industry to make the legal content even more attractive while still making a profit? Similarly, how much stricter can stick-based anti-piracy interventions really become? Current approaches, such as the graduated response, have garnered a significant amount of criticism (Bridy, 2010, 2012; Giblin, 2014). Other suggested approaches, such as interventions that were prescribed by the ACTA and SOPA/PIPA, were even more controversial. The limits for certain anti-piracy interventions may have therefore already been reached.

\subsection{A look towards the future: six scenarios to consider}

Despite efforts from content owners, artists, publishers, the creative industry, and governments, digital piracy cannot not be removed from society altogether. Various incarnations of piracy (digital or otherwise) have been part of society for some time and this research does not conclude that (digital) piracy will permanently be excised as a consequence of the anti-piracy interventions currently present in Western society. Society will continue to be confronted with this phenomenon in the future. What can (and will) change are the practicalities of digital piracy, as new technologies become available to the public. This can influence the manner through which individuals pirate content digitally, meaning that new variations of digital piracy can emerge. In addition, changes to the demographics may mean that different individuals will act in this manner. In this section, a few future scenarios will be depicted that are meant to illustrate the coming challenges. 


\section{$\underline{\text { Conclusion and Future Outlook }}$}

9.2.1. The introduction and wide-spread availability of 3D-printers

Up until a few years ago, the industries that were most affected by instances of digital piracy were the music, movie, software, and video game industries. Other industries were mostly shielded from the digital developments that have made digital piracy so widespread (Depoorter, 2014). This is beginning to change due to the emergence of the commercially available 3D-printer. While 3D-printers have been used in the industry for some time now, in the past years, 3D-printers have become available for household use. While initially expensive, the current 3D-printers are sold for prices ranging from $€ 400$ to $€ 8,000$. Prices have been going down, while their quality and usability have increased. And while it will be some time before the average household will start printing their own cars, copyright issues are beginning to emerge.

Lego blocks, for example, are nothing more than plastic blocks that could easily be printed by the current 3D-printers. The table-top game 'Warhammer' consists of plastic or steel figurines with which one can play the game. These too can be printed with a 3D-printer (Fincocchiaro, 2012-2013). A single Warhammer figurine can cost anything between $€ 10$ and $€ 110$. Will Warhammer-aficionados forgo the legal purchase of such toys and print these from the comfort of their homes?

It is possible that these and other developments could lead to a resurgence of digital piracy in a new form: 3D-piracy. This might mean that after the music, film, video game, and book industries, other industries may be forced to deal with the matter of digital piracy. Instead of copyrights, individuals may start to infringe upon patents, as the emergence of the 3D-printer has made it significantly easier to do so (Desai \& Magliocca, 2014). Some scholars suggest that this technological development will trigger the next wave of non-commercial intellectual property infringements, similar to what occurred after large scale file-sharing networks emerged in the late 1990s (Depoorter, 2014; Osborn \& Holbrook, 2015).

Due to the emergence of the 3D-printer, individuals can now scan items which they then subsequently print at home. At the same time, more and more blueprints of existing products are found online, which individuals can download and use to produce copies of the product. Currently, the 3D-printing community is still relatively small and consists mostly of hobbyists, but in the coming years it is likely that this will change and that more households will have access to 3Dprinters (Fincocchiaro, 2012-2013). The Pirate Bay already has a category called 'physibles' on their website, indicating that the availability of blueprints that can be used to print objects has been increasing (Brean, 2012-2013; Macik, 2015). Finally, the 3D-printer raises concerns beyond just the issue of digital piracy, as Text Box 9.2 illustrates. 
These developments go beyond just the sphere of copyrights and patents. Owners and users of 3Dprinters are currently also able to print usable guns, made from plastics. In the context of firearms regulation and the fight against organized crime, the emergence of the 3D-printer is a worrisome development (Desai \& Magliocca, 2014). In fact, the 3D-printing section of The Pirate Bay mostly consists of blueprints and schematics for weapons. Instances of individuals scanning and printing house keys have also been noted, meaning that 3D-printing can also be relevant for other types of crime (Osborn, 2014).

The industry is likely to respond to the challenges posed by the emergence of the 3D-printer. One approach that might be used to prevent individuals from using patents is to use DRM techniques (Desai \& Magliocca, 2014). However, in Chapter 6 it was indicated that this approach is counterproductive, as such measures can be evaded and might irritate legal users. An alternative venue would be to offer legal venues for downloading blueprints legally (for a fee), which can then be subsequently used to print the product from one's home. This also raises the question as to whether or not individual households should enjoy some sort of private use exemption (Desai \& Magliocca, 2014).

The relevant industries should also take note of the role that morality plays in explaining digital piracy. As was demonstrated in this research, once a particular moral outlook on digital piracy has been formed, it can become a source for the persistence of this behaviour. The issue of 3D-piracy can be become more worrisome if this act is seen as not being a moral issue, similar to what is currently thought by many about the types of digital piracy examined in this research. Depoorter (2014) states that users of 3D-printers may form attitudes and beliefs about using these devices and printing patented or copyrighted content. Strict enforcement may trigger resistance among these users, similar to the resistance currently found in the context of the piracy of digital music or movies. Even if such an approach were to be productive, questions are raised about the viability of this approach, which are not dissimilar to some of the objections raised in the current debates on digital piracy. Anonymity remains an issue and enforcement measures will infringe upon the privacy of the users. Due to the decrease in price and the increase in the availability of 3D-printers, it is suggested that there will soon be a large number of infringements and infringers. In turn, this can reduce the chance of being detected and sanctioned, affecting the deterrent effect of enforcement measures (Depoorter, 2014). Such an approach may be inefficient and costly (Macik, 2015).

Some rather extreme measures have been proposed to limit 3D-piracy from becoming an issue. Examples include an outright ban on the devices that enable 


\section{$\underline{\text { Conclusion and Future Outlook }}$}

infringement or pursuing the websites that host the blueprints (Macik, 2015). The former seems somewhat far-fetched, whereas the latter technique has also been applied to digital piracy, with mixed results as new websites tend to pop up as quickly as copyright holders can take them down. Others focus on developing and fostering norms that are opposed to undesired forms of 3D-printing (Osborn, 2014). This research has demonstrated that the latter is quite difficult to achieve. If the industry hopes to accomplish this, it is best to start as soon as possible rather than to wait for norms in favour of 3D-printing to emerge. Furthermore, it would be beneficial if measures used to foster such norms would be carried out in a positive way, rather than in a negative way. Many anti-piracy interventions have used negative framing and this has not been received well by the target population. Perhaps those industries most affected by the emergence of the 3D-printer would benefit most from using the capabilities of these devices, instead of competing with them. Lego, instead of seeing 3D-printing developments as a challenge to their business, sees it as an opportunity for developing new avenues of business, allowing users to customize their Lego bricks through 3D-printing for a fee (Gardner, 2014).

It is therefore clear that the advent of the 3D-printer will confront various industries with existing challenges. It is proposed by some that 3D-piracy will become as mainstream as digital piracy (Depoorter, 2014). Given the fact that this research has examined various anti-piracy interventions and their underlying mechanisms, the relevance of the findings is apparent for industries beyond the music and movie industries. Indeed, Doherthy (2012) suggests that the events and changes that have occurred in the context of the copyright industry can be used to proactively fix the system and use solutions that have already been tested. Likewise, Appleyard (2015) indicates that the industries that are most likely to be affected by the emergence of the 3D-printer would do well to learn from the music and movie industries. The findings from this research are beneficial in that regard.

9.2.2. Changing the demographics of digital piracy: geriatric pirates of the Caribbean?

Current research has identified that most digital pirates are young. The question is whether this will remain so or whether the demographics of digital piracy are going to change. It might very well be that pirates are getting older. Those individuals who began pirating in the late 1990s might not all have stopped pirating content. These individuals are now in their thirties and will continue to experience and adapt to new forms of digital piracy. Even older individuals might be exposed to the benefits of pirating through their children or younger coworkers. This gives these individuals the opportunity to (learn how to) pirate 


\section{$\underline{\text { Punish, Seduce or Persuade }}$}

content digitally at a later stage in life. And, as almost every individual, including older individuals, has access to both a computer and high-speed Internet, there is no real barrier precluding them from doing so.

Initially, the examined studies seem to provide no evidence that such a shift will emerge. Arguably, they were not equipped to find evidence of such a shift. To determine whether individuals continue to pirate content digitally at later stages in their life, a longitudinal study needs to be performed. None of the studies examining the role of age in relation to digital piracy used such a design. In addition, many studies (including the first empirical study in this research) use high school or university students as the sample to study. This means that older individuals are excluded automatically, meaning that, by design, younger individuals are typically identified as digital pirates. This also makes it more difficult to properly identify a potential shift in the age of the digital pirates.

However, it is not unlikely that some older individuals continue to pirate content digitally after they leave university. The finding that digital piracy is mostly the domain of university students can be somewhat challenged by a study by Cesaro, Pastore, and Ugolini (2015). They found that individuals up to 28 years old have a higher positive relationship with digital piracy than older individuals. While this is not close to the age of retirement, it is an age that is older than that which is often depicted in most studies. Similarly, Krawczyk, Tyrowicz, Kukla-Gryz, and Hardy (2015) note that both students and the general population (which, in their sample had an average age of 28 years) had a similar ethical evaluation of digital piracy. It was reported in both the USA and in Germany that around half the individuals aged 30 years or older had copied or downloaded content for free, compared to around $70 \%$ of individuals aged 18-29 (Karaganis \& Renkema, 2013). These indications of older individuals engaging in piracy can best be observed in the context of e-book piracy. It was indicated that one out of eight women aged over 35 pirates such content compared to one in twenty women who have pirated other types of content (Williams, 2011). But this may be a consequence of the fact that older individuals tend to read more books compared to their younger counterparts.

It is likely that many future digital pirates will commence their piracy-career when they are relatively young. Simultaneously, the pirates of today will age, and some of these will likely continue to pirate. Finally, some individuals could begin their digital piracy-career at a later point in their life. If the age of the digital piracy changes, interventions might need to change their tone and approach as well. Further research is necessary to examine digital piracy committed by individuals in the age-groups of 25 years and above. Such research can study whether the age 


\section{$\underline{\text { Conclusion and Future Outlook }}$}

of the digital pirate is indeed changing. If this is found, the 'older' digital pirates could require different approaches in terms of policy. After all, the socioeconomic context of the 'older' digital pirates will likely be different from those of the 'younger' digital pirates.

9.2.3. An abundance of legal content: risk of competition and cannibalization

In Chapter 5, it was made clear that a sizeable number of interventions had been implemented to compete with digital piracy. Especially in the context of music, a large number of initiatives have emerged over the past years, which includes iTunes and Spotify. More and more services have been developed in the past years. This also applies to the movie and TV-series industries. These approaches are sound as they allow content owners to offer content in a flexible manner, even if their contribution to reductions in digital piracy is relatively small. Users can access these services essentially anywhere and content is often offered through a subscription or an advertisement-based model. What was not discussed previously was the risk of oversaturating the market as well as the risk of cannibalization.

Worldwide, there were at least 35 streaming services available for music alone in 2015 (Wikipedia, n.d.-b). Each year, more services are added to this list. For television shows, movies and video games, a large number of services also exists. On the surface, this development is not problematic, as it forces the providers of these services to compete with each other, which benefits the user. This situation becomes more problematic as soon as content begins to be scattered across these services. Artists might be linked to a specific service, meaning that their content is exclusively provided to and controlled by that service. The risk that emerges is that a user will have to use multiple services (subscription or advertisement-based) to be able to obtain the full spectrum of the content he desires. This is both costly and inefficient, meaning that the user might be more inclined to pirate content digitally in order to obtain all the content he desires without having to use multiple legal services. The following example, presented in Text Box 9.3, illustrates this issue. 
Say that an individual wants to watch and follow a few current and popular television series. This individual is unwilling to wait for these series to be made available on regular television and hopes to stream this content legally as soon as it is made available. He wants to watch the HBO show 'Game of Thrones' and the Netflix show 'House of Cards'. The user also wants to stay in touch with a number of Dutch series. HBO and Netflix each have separate streaming services and the Dutch television series are likewise not accessible through their services. Therefore, if this individual intends to enjoy all these series legally, he will have pay around $€ 15$ for access to the HBO-shows, $€ 8.99$ for a Netflix subscription and $€ 7.95$ for the Dutch service 'NL Ziet'. This means that this individual has to pay around $€ 32$ per month in order to enjoy these shows legally, on top of his regular Internet and television subscription.

Such an example applies to other types of content as well. As users do not possess unlimited financial resources, the illegal venues to enjoy this content might become more tempting, especially if they do allow clustering all the content in one place. For example, Popcorn Time (Cox \& Collins, 2014) allows users to stream nearly all TV-series and movies, although the service itself infringes on the copyright of content owners. These various services are clearly competing with each other.

It is also possible that streaming and other services cannibalize the market to some degree. Do users who use such services (particularly the free advertisement-based services) still purchase content? The answer to this question might not be as bleak as some anticipate, as some studies have stated that the use of streaming services does not reduce the sales of CDs and increases the attendance of live music (Aguiar \& Martens, 2013; Nguyen, Dejean, \& Moreau, 2014). Aguiar and Martens (2013) even suggest that music streaming services have a small positive effect on music purchases, perhaps suggesting a degree of complementary consumption rather than substitution. The risk of cannibalization may be limited, though only a few studies have examined this issue empirically.

The issue that remains is whether or not the current streaming models are economically viable for the industry and the artists themselves. There has been quite a bit of debate about whether or not the artists themselves actually generate any income for themselves through services such as Spotify. While Spotify has paid around \$US 3 billion in royalties (Spotify, n.d.-a), this platform is not really clear on how much money artists actually make. The stated pay-out range that Spotify uses is placed at between US\$ 0.006 and US\$ 0.0084 per stream. This means that the more popular artists are more likely to benefit the most from services such as Spotify. In 2014, the most popular song had been streamed 203 million times, resulting in a pay-out of between US\$ 1.2 million and US\$ 1.7 million (Johnson, 2014). Clearly, a large volume of streams is needed before substantial pay-outs are likely. Niche or newer artists are less likely to reach these 


\section{$\underline{\text { Conclusion and Future Outlook }}$}

levels. It is indicated that, for a musician to earn the US minimum wage of US\$ 1,200 , they need over a million streams (McCandless, Quick, Hollowood, \& Slater, 2015). The issue of pay-outs has led some artists to remove their content from services such as Spotify. The musician Taylor Swift removed her content from Spotify in November of 2014 (Dickey, 2015). This again underlines the risk of market dispersion and the scattering of content. Beyond the question of whether or not the artists themselves earn any appreciable revenues through Spotify services, the question has been raised whether the Spotify-model can be profitable at all. Although revenues have steadily increased in the past years (thanks to an increase in paying subscribers), Spotify is still incurring annual losses (Sisaro, 2014). ${ }^{166}$ This casts doubt as to whether or not such business models are sustainable in the longer term. However, Netflix is expected to generate profits in the near future, indicating that such streaming services can be profitable (Salapa, 2015). Perhaps the future for streaming services is not as bleak as some anticipate.

A recent development is the emergence of a second-hand market for certain types of digital content. The sale of second-hand digital games and particularly e-books is on the rise (Brustein, 2015). In addition potentially further cannibalizing the first-hand market, the possibility to obtain second-hand content has started to concern the creative industry (Musiani \& Peserico, 2014; Savič, 2015). This development needs to be considered by governments and the creative industries when designing interventions meant to tackle digital piracy.

9.2.4. Streaming becomes the dominant form of content
consumption

As is apparent from the previous section, more and more content is available for streaming. This does not solely apply to legal content. For quite some time now, users can also stream content from dubious sources. This especially applies to music, television series and movies. Additionally, the issue of sports piracy has emerged in past few years. This type of digital piracy refers to the live streaming of sports events in instances where the user does not have legal access to this content (Krawczyk et al., 2015). This is thus a new type of digital piracy. Streaming this type of content is even easier than downloading it. The user simply needs to find the website hosting the stream. Sometimes, a plug-in should be installed but this is usually the extent of the technological knowledge that the individual needs to possess. As the speed of delivery and the quality of the stream increased over time, it has become a popular alternative to downloading such

\footnotetext{
${ }^{166}$ These losses are the consequence of the fact that a large part of the revenues earned by Spotify are paid to the artists and the music industry. Recently, the revenues have been growing at a greater pace than the losses (Ingham, 2016; Kafka, 2016).
} 


\section{$\underline{\text { Punish, Seduce or Persuade }}$}

content from an illegal source (Wong, 2016). The MPAA has defined 'illegal streaming' as 'a form of online content theft that allows users to view unauthorized copyrighted motion picture and television content on demand, without downloading the illegal file' (Burroughs \& Rugg, 2014, p. 371). It is clear from such a definition that a broad category of behaviours would fall under its scope. Again the familiar association is made between the streaming of content and theft, similar to earlier depictions of illegal downloading. The comparison is even more strained here, however, as the users do not even download the content on their devices.

Due to the differences in the modus operandi of streaming content, it is difficult to estimate how sizeable this problem is (Burroughs \& Rugg, 2014). What can be stated is that enjoying pirated content has never been easier. This raises the question as to whether or not streaming piracy is supplementing instances of 'traditional' digital piracy. There are some indications that streaming in general is increasing at the expense of downloading pirated content, but it is not clear whether the type of streaming that is often examined can truly be labelled as being an instance of illegal streaming (Weijters, Goedertier, \& Verstreken, 2014). What is also noted is that certain anti-piracy measures, such as the French HADOPI approach, may have led to some movement away from downloading towards illegal streaming (Koster, 2012), as they focus on traditional forms of digital piracy. However, the second empirical study did not find evidence that supports this assumption.

Changes to the way through which individuals enjoy pirated content might be reflected in the fact that, in some jurisdictions, a decrease in the traditional forms of digital piracy can be noted. Poort and Weda (2015) indicate that, in the Netherlands, the proportion of the individuals who engage in file sharing has decreased, on the whole, from $38 \%$ to $27 \%$ in the past years. However, they note that, while the consumption of music through illegal channels has decreased, the reverse is noted in the context of movies and television series. In some instances of streaming, users might not be entirely sure whether or not the stream is legal, as the difference can be difficult to note. Anecdotal evidence does point towards the fact that illegal streaming is becoming more popular (TorrentFreak, 2016).

Should it indeed become apparent that increases in illegal streaming are the effect of the displacement of traditional digital piracy, a number of challenges (re)emerge for content owners. For stick-based interventions, the matter of obtaining evidence of infringement becomes more difficult. How are content owners to determine whether or not a user has streamed their content? Can an ITsystem make the distinction between legal and illegal instances of streaming? The 


\section{$\underline{\text { Conclusion and Future Outlook }}$}

application of a graduated response might be made more difficult. The risk is that these approaches become obsolete due to the shifting piracy landscape. For carrotbased interventions, the primary concern might be that illegal streaming services offer a better experience when compared to the legal services (Poort \& Weda, 2015). This might make the legal content less enticing, reducing the effectiveness of these approaches. For sermon-based interventions, trying to persuade pirates that streaming from an illegal source is wrong becomes more difficult, as streaming might allow for easier neutralizations ('I have not downloaded the file, so I have not pirated or downloaded the content').

\subsubsection{Digital piracy in your pocket}

Throughout this research, the focus has been on rather classical types of digital piracy; music, movies and television, and software and video game piracy. It is quite likely that additional types of content and new ways to obtain this pirated content have joined this list in the past few years. Sport piracy and the usage of streaming services to gain access to pirated content were already discussed in the previous section. But the developments do not stop there. One specific type of content that has become more popular in the past years are the so-called mobile apps (or applications), which can be used on a smartphone. With such devices having become increasingly advanced, cheaper and widely available, more types of applications and software has been produced to be used in concert with them. Thus, a wide range of mobile applications exist, which include topics such as healthcare, fitness, banking, social media, and books as well as entertainment applications allowing access to video games, movies and music. Some of this content is available for free but a lot of content has to be purchased. And as more and more individuals have and use such devices, it might not be unexpected that the piracy of mobile applications is on the rise. This is a type of piracy that can be labelled as 'application piracy'.

While application piracy is still a relatively unknown phenomenon, there are some indications that digital piracy is also spreading to these devices. In 2013, it was indicated that over 48,000 pirated applications were available for iOS. For Android-based devices, even more pirated applications are available to its users (Khan, Othman, Ali, Khan, \& Madani, 2014). Furthermore, estimations of the degree of pirated applications range from $60 \%$ to $90 \%$ of all installed applications. Just as with the 'traditional' types of digital piracy, there is some uncertainty on the impact of these pirated copies, but the size of the issue is apparent (Choi et al., 2014). The application-industry is not dealing with minor matters. It is expected that the global revenue for this market will reach US\$ 76.5 billion by 2017 (Choi et al., 2014). The possible consequences of digital piracy can be 
severe. What is apparent however is that very few academics have so far touched upon this issue in detail.

There are also indications that, aside from pirating mobile applications, smart phones are also used to pirate more traditional types of content. 'Mobile music pirating' is nowadays a distinct possibility (Chmielewski, 2014). This type of piracy may soon be more prevalent than traditional types of digital piracy. Indeed, this might already be the case in the context of music piracy (Pankinkis, 2014). Content owners are already pointing towards the danger of mobile piracy. The IFPI indicates that, in the USA, 27 million individuals used mobile applications to obtain access to content in an illegal manner (IFPI, 2015). Technical anti-piracy measures, such as DRM variants, are already in place in the mobile market. Likewise, most carrot-based interventions have mobile applications which serve as counterparts to services such as Spotify or iTunes. These efforts mirror the continuous developments to the topic of digital piracy.

\subsubsection{New and innovative ways to study digital piracy ${ }^{167}$}

There are also developments that are directly relevant for academia itself. For instance, this research has experimented with a new way to map and measure (online) behaviour by using Big Data. A clear benefit of using Big Data as a source of data is that it examines actual (search) behaviour rather than intentions or attitudes. This allowed for some observations to be made on the effects that the CAS might have had on digital piracy-related online search behaviour in the USA. This approach can be evaluated on its merits.

There are clear benefits to using Big Data as a data source in order to determine whether specific types of (online) behaviour have changed after the implementation of an intervention. The ease of use and the speed of the data collection, as well as the ability to observe online behaviour both prior to and after implementation and select data based on the location of the individual are all clear benefits.

Though the method is not without its limitations (particularly in relation the attribution of changes in online behaviour to a specific potential cause), it can be combined with other methods to (partially) alleviate this issue. Perhaps the Big Data study, as performed, in this research can best be understood as taking a position that is similar to the 'Mechanism Experiment' (Ludwig, Kling, \& Mullainathan, 2011). While the methods differ significantly substantially and methodologically, both can arguably be used, to relatively cheaply and quickly, screen specific interventions. If changes in online behaviour are revealed through

${ }^{167}$ Part of this future scenario was published previously (Leeuw, 2016, 2017) 


\section{$\underline{\text { Conclusion and Future Outlook }}$}

the Big Data analysis, a further, more robust, empirical examination may be warranted.

\subsection{Limitations of the research and recommendations for future research}

Though this research has provided an in-depth examination into various aspects of digital piracy, it was not without its limitations. These limitations can be divided between substantive and methodological limitations.

\subsubsection{Substantive limitations}

The focus of this research has been on the more traditional types of digital piracy (music piracy, movie and television piracy and software and video game piracy). In addition, the first empirical study was even more focused since it specifically examined music piracy. While the insights are valuable for these types of digital piracy, they might not necessarily fully apply to the newer types discussed earlier. For instance, e-book and pornography piracy were excluded. Though there were good reasons to exclude those types of digital piracy, future research would benefit from including them. For both types of digital piracy, the body of research is still in its infant stages. Hardly any studies have examined why individuals pirate this particular content digitally (Camarero et al., 2014), let alone whether anti-piracy interventions focused on this type of digital piracy can succeed in reducing this type of behaviour. The digital piracy of online blueprints, used in combination with 3D-printers to download and print all sorts of copyrighted products, has also been neglected in criminological studies.

A second substantive limitation had to do with the modus operandi of digital piracy. Given the definition of digital piracy used in this research, streaming and mobile piracy where excluded from the research. However, many signs point towards the fact that this particular modus operandi will become the dominant form of digital piracy. Though the insights obtained in this research can also be insightful for streaming piracy, it is a topic that warrants specific academic attention.

What could be accomplished in future research is a greater focus on the 'hybrid' anti-piracy interventions. Through the chapters, a categorization was made of the three mechanisms used in anti-piracy interventions. These mechanisms were tested in this manner as well. However, it became clear that, in practice, certain anti-piracy interventions use a second mechanism to support the primary one. This means that examining the functioning of these 'hybrid' interventions can add to the understanding of whether and how the used anti-piracy interventions function. 


\subsubsection{Methodological limitations}

In this research, the various mechanisms were tested via a self-administrated questionnaire. However, it could also be possible to study these mechanisms in a more experimental way, for instance by setting up a computer laboratory and observing directly how respondents react to mechanisms. However, this requires both a substantial amount of resources and specific expertise on behalf of the researcher.

With regard to the first empirical study (the stated preference method), there were some matters that could be improved in future research. These matters are linked to the design and operationalization of the scenarios used to test the mechanisms. For instance, the incentive might simply not have been 'big' enough, hampering the attractiveness of the incentive mechanism. The 'lowest' price that the scenarios presented was $€ 4.99$. Although this was below the level of the average willingness to pay of both samples (which was around $€ 7.50$ ), it might still be too high (or perceived to be as such) for some individuals. 'Free' legal content was not offered as an incentive, which is a limitation given the fact that nowadays, many legal services do offer content of free. In addition, it is possible that the respondents were not interested in extra features included in the scenarios as these were expressed rather abstractly (a free digital copy). Future research would do well to express the extra features more clearly but also vary with the content of these extras, if the relevance of this requirement is to be assessed in more detail.

It is also worth underlining that the first empirical study did not study actual behaviour, but instead assessed the respondents' inclination to pirate content digitally. This means that the findings discussed in Chapter 7 do not necessarily reflect the actual behaviour of digital pirates. While there is evidence that aspects such as attitudes and intentions are important predictors of actual behaviour (Armitage \& Conner, 2001; Webb \& Sheeran, 2006), future research would do well to examine actual instances of digital piracy, in order to examine the relationship between intended acts of digital piracy and actual acts of digital piracy. Technological innovations, such as Big Data, present researchers with innovative and flexible approaches to study digital piracy.

The selection of a type of sermon examined in the first empirical study, the harm appeal, can have influenced the manner in which the respondents reacted to the scenarios using the persuasive-mechanism. O'Keefe and Jensen (2007) state that gain-framed appeals (like those efforts that point towards the benefit of using legal content) tend to be more persuasive than the loss-framed appeals (like the harm appeals examined in the sermon-based scenarios), underlining that the exact type of sermon-based interventions used will also influence whether or not individuals 


\section{$\underline{\text { Conclusion and Future Outlook }}$}

will no longer pirate content digitally. Future studies should look into other types of interventions that use the persuasive-mechanism.

Like many other studies that have studied digital piracy and anti-piracy interventions, the first empirical study used a sample made up of students. In order to properly test the scenarios, it was necessary that a large part of the respondents had indeed pirated content digitally in the past. Selecting students as the population ensured that this was the case. However, one should be careful in automatically generalizing these results to a wider population.

A final inherent limitation in this research is linked to the second empirical study. The fact that the Big Data study was unable to measure the changes in online search behaviour over a longer period of time. This was due to the fact that the data was simply not available. However, as time progresses, more data will be available over a longer period of time. This means that a follow-up study can, with relative ease, re-examine the findings of this second empirical study and focus on the changes over an even longer period of time. Own its own, using Big Data in a manner similar to one used in this research does allow the researcher to map the changes in online behaviour, provided that the researcher is content with not being able to identify the causes of such changes. In that regard, it is valuable on its own.

\subsection{Final remarks}

This research set out to better understand digital piracy and examine the extent to which various anti-piracy interventions are capable of contributing to reductions in this behaviour. To that end, insights were obtained through the use of various methods. The end result is a sequence of steps where each step allowed for a closer analysis of a specific aspect of digital piracy and the various anti-piracy interventions. The findings are promising, as they allowed for a better understanding of the act of digital piracy and present the reader with an in-depth analysis of the various anti-piracy interventions.

This analysis demonstrated that there is merit to the implementation of certain anti-piracy interventions. Interventions can benefit from matching the design as closely as possible to the various characteristics, features and variables that determine whether or not an individual will pirate content digitally. At the same time, the findings also show that the extent of the contribution is relatively small and that different interventions result in different contributions. It is clear that different interventions and mechanisms result in different outcomes.

There appears to be more merit to the usage of anti-piracy interventions that use either deterrence or incentives as a primary mechanism, in contrast to interventions that use persuasion as a primary mechanism. However, the way in 


\section{$\underline{\text { Punish, Seduce or Persuade }}$}

which the mechanisms are used in those interventions will influence their potential contribution to reductions in digital piracy. For instance, for anti-piracy interventions that use deterrence as a primary mechanism, a combination of the certainty and the severity of punishment is necessary. A potential punishment needs to be sufficiently certain and severe for it to take any effect. Regardless of whether some stick-based anti-piracy interventions can accomplish this, some of these interventions are controversial, as the discussion surrounding the various graduated response schemes has illustrated. Another option is to focus on further designing and implementing interventions that make use of the incentive as a primary mechanism. These also appear to be capable of influencing the behaviour of digital pirates, yet are not as likely to experience resistance from society. However, such approaches are less likely to convince the experienced or even hard-core digital pirates to change their behaviour. Perhaps these interventions can best be used to make the legal content more attractive for those individuals who are not yet habitual digital pirates.

The above also demonstrates that a gap exists between how interventions function in theory and how they do so in practice. This means that interventions which contribute to reductions in digital piracy on paper might not succeed in doing so in real life. Even if the mechanisms used in these interventions are applied carefully, the findings underline that digital piracy cannot be excised from society. Instead, the various interventions can be used to make digital piracy manageable, meaning that its effects on society are somewhat limited. Expecting anti-piracy interventions completely reduce digital piracy would mean that policy makers underestimate the persistence of the social norms and morality that govern this behaviour. This would also be a very costly endeavour.

But the 'future' of digital piracy might not be so bleak. Certain types of persistent behaviour, such as speeding, have been reduced successfully in the recent years (Pérez, Marí-Dell'Olmo, Tobias, \& Borrell, 2007). Like digital piracy, speeding has traditionally been seen as behaviour that is difficult to influence or reduce (Bates, Allen, \& Watson, 2016). However, recent technological innovations, such as the average speed or point-to-point cameras (trajectcontroles) have led to substantial reductions in average speed and accidents (De Pauw, Daniels, Brijs, Hermans, \& Wets, 2014; Soole, Watson, \& Fleiter, 2013). The average speed camera is a technological measure that nearly guarantees that drivers who drive above the speed limit will be detected and punished. Thus, this measure increases the certainty of punishment in a substantial manner. Whether technological measures can have a similar effect in relation to digital piracy remains to be seen, as more ways to avoid detection exist. Still, this means that more in-depth research 


\section{$\underline{\text { Conclusion and Future Outlook }}$}

concerning technological anti-piracy interventions can be fruitful to determine the suitability of such measure for tackling digital piracy.

In the end, clear challenges remain for the creative industry, governments and policy makers as to how anti-piracy interventions can be developed, implemented and maintained in order to make digital piracy manageable. The findings in this research can be beneficial for this process, as they clearly allow for a fine-tuning of the interventions themselves. Finally, the future challenges described imply that the act of digital piracy will undergo changes (or evolve) with regard to which individuals pirate what content and how these individuals do so. This will demand flexibility of the creative industry and governments. A proactive approach is warranted, as waiting to respond to these newer types of digital piracy, can mean that they will have become engrained in society, similar to how 'traditional' digital piracy has become so persistent. And once an act of piracy becomes habitual, it becomes even more difficult to influence. Given the findings of this research, it should nonetheless be possible to manage digital piracy, even in contexts described by the various future outlooks, especially if interventions are used in an entwined manner. But individuals will always look for ways to copy, burn, rip, download, or stream content. Anti-piracy interventions must ensure that some individuals also buy the content. 



\section{Bibliography}

Aaltonen, M., \& Salmi, V. (2013). Versatile Delinquents or Specialized Pirates? A Comparison of Correlates of Illegal Downloading and Traditional Juvenile Crime. Journal of Scandinavian Studies in Criminology and Crime Prevention, 14(2), 188-195.

ABC. (2015). Interstellar takes out most pirated movie of 2015, downloaded nearly 47 million times. Retrieved 17-01-2017, from http:/www.abc.net.au/news/2015-12-29/interstellar-the-mostpirated-movie-of-2015/7057848

Abroms, L., \& Maibach, E. (2008). The Effectiveness of Mass Communication to Change Public Behavior. Annual Review of Public Health, 29, 219-234.

Acilar, A. (2010). Demographic Factors Affecting Freshman Students' Attitudes towards Software Piracy: An Empirical Study. Issues in Informing Science and Information Technology, 7, 321-328.

Adamowicz, W., Boxall, P., Williams, M., \& Louviere, J. (1998). Stated Preference Approaches for Measuring Passive Use Values: Choice Experiments and Contingent Valuation. American Journal of Agricultural Economics, 80(1), 64-75.

Adams, J., Giles, E., Robalino, S., McColl, E., \& Sniehotta, F. (2012). A Systematic Review of the use of Financial Incentives and Penalties to Encourage Uptake of Healthy Behaviors: Protocol. Systematic Reviews, 1, 51-55.

Adefuye, A., Abiona, T., Balogun, J., \& Lukobo-Durell, M. (2009). HIV sexual risk behaviors and perception of risk among college students: implications for planning interventions. BMC Public Health, 9(1), 281-294.

Adermon, A., \& Liang, C. (2010). Piracy, Music, and Movies: A Natural Experiment. IFN Working Paper. Research Institute of Industrial Economics. Stockholm.

Adermon, A., \& Liang, C. (2014). Piracy and music sales: The effects of an anti-piracy law. Journal of Economic Behavior \& Organization, 105, 90-106.

Adrian, J. (2009). Piracy: the intellectual property wars from Gutenberg to Gates. Chicago: University of Chicago Press.

Aguiar, L., \& Martens, B. (2013). Digital Music Consumption on the Internet: Evidence from Clickstream Data JRC Technical Reports. Luxembourg: Institute for Prospective Technological Studies.

Aguiar, L., \& Waldfogel, J. (2015). Streaming Reaches Flood Stage: Does Spotify Stimulate or Depress Music Sales? JRC Technical Reports. Luxembourg: Institute for Prospective Technological Studies

Ahn, I., \& Yoon, K. (2009). On the Impact of Digital Music Distribution. CESifo Economic Studies, 55(2), 306-325.

Ajzen, I. (1991). The theory of planned behavior. Organizational Behavior and Human Decision Processes, 50(2), 179-211.

Akbulut, Y. (2014). Exploration of the antecedents of digital piracy through a structural equation model. Computers \& Education, 78(September), 294-305.

Akers, R., Krohn, M., Lanza-Kaduce, L., \& Radosevich, M. (1979). Social Learning and Deviant Behavior: A Specific Test of a General Theory. American Sociological Review, 44(4), 636-655.

Al-Jabri, I., \& Abdul-Gader, A. (1997). Software Copyright Infringements: An Exploratory Study of the Effects of Individual and Peer Beliefs. Omega, 25(3), 335-344.

Al-Rafee, S., \& Cronan, T. (2006). Digital Piracy: Factors that Influence Attitude towards Behavior. Journal of Business Ethics, 63(3), 237-259.

Al-Rafee, S., \& Rouibah, K. (2010). The Fight against Digital Piracy: An Experiment. Telematics and Informatics, 27(3), 283-292.

Aleassa, H., Pearson, J., \& McClurg, S. (2011). Investigating Software Piracy in Jordan: An Extension of the Theory of Reasoned Action Journal of Business Ethics, 98(4), 663-676.

Alexander, I. (2007). Criminalising Copyright: A Story of Publishers, Pirates and Pieces of Eight. Cambridge Law Journal, 66(3), 625-656.

Alford, B., \& Biswas, A. (2002). The effects of discount level, price consciousness and sale proneness on consumers' price perception and behavioral intention. Journal of Business Research, 55(9), 775 783.

Alleyne, P., Soleyn, S., \& Harris, T. (2015). Predicting Accounting Students' Intentions to Engage in Software and Music Piracy. Journal of Academic Ethics, 13(4), 291-309. 


\section{$\underline{\text { Punish, Seduce or Persuade }}$}

Allom, V., Mullan, B., \& Sebastian, J. (2013). Closing the intention-behaviour gap for sunscreen use and sun protection behaviours Psychology and Health, 28(5), 477-494.

Amazon.com. (n.d.). Amazon.com: Digital Music. Retrieved 17-01-2017, from https://www.amazon.com/ MP3-Music-Download/b?ie=UTF8\&node=163856011.

Andersen, B., \& Frenz, M. (2010). Don't blame the P2P file-sharers: the impact of free music downloads on the purchase of music CDs in Canada. Journal of Evolutionary Economics, 20(5), 715-740.

Anderson Jr, H. (2008). "Criminally Minded?" Mixtape DJs, the Piracy Paradox, and Lessons for the Recording Industry. Tennessee Law Review, 76(1), 109-156.

Anderson, L., \& Stafford, S. (2003). Punishment in a regulatory setting: Experimental evidence from the VCM. Journal of Regulatory Economics, 24(1), 91-110.

Anderson, N. (2006). Boy Scouts get MPAA-approved copyright merit badge. Retrieved 17-01-2017, from http://arstechnica.com/gadgets/2006/10/8044/

Andrés, A., \& Goel, R. (2012). Does Software Piracy Affect Economic Growth? Evidence across Countries Journal of Policy Modeling, 34(2), 284-295.

Apel, R. (2013). Sanctions, perceptions, and crime: Implications for criminal deterrence. Journal of Quantitative Criminology, 29(1), 67-101

Apel, R., Pogarsky, G., \& Bates, L. (2009). The Sanctions-Perceptions Link in a Model of School-based Deterrence. Journal of Quantitative Criminology, 25(2), 201-226.

Apple. (2014). Announcement of new U2 Album.

Apple. (n.d.). iTunes - Everything you need to be entertained. Retrieved 17-01-2017, from http://www.apple.com/itunes/

Appleyard, M. (2015). Corporate responses to online music piracy: Strategic lessons for the challenge of additive manufacturing. Business Horizons, 58(1), 69-76.

Arli, D., Tjiptono, F., \& Porto, R. (2015). The impact of moral equity, relativism and attitude on individuals' digital piracy behaviour in a developing country. Marketing Intelligence \& Planning, 33(3), $348-365$.

Armitage, C., \& Conner, M. (2001). Efficacy of the theory of planned behaviour: A meta-analytic review. British Journal of Social Psychology, 40(4), 471-499.

Arnold, M., Darmon, E., Dejean, S., \& Penard, T. (2014). Graduated Response Policy and the Behavior of Digital Pirates: Evidence from the French Three-strike (Hadopi) Law. Retrieved from http://papers.ssrn.com/sol3/papers.cfm?abstract id=2380522

Ayers, J., Althouse, B., Ribisl, K., \& Emery, S. (2014). Digital Detection for Tobacco Control: Online Reactions to the 2009 U.S. Cigarette Excise Tax Increase. Nicotine \& Tobacco Research, 16(5), 576-583.

Ayers, J., Ribisl, K., \& Brownstein, J. (2011). Using Search Query Surveillance to Monitor Tax Avoidance and Smoking Cessation following the United States' 2009 "SCHIP" Cigarette Tax Increase. PLOS ONE, 6(3), 1-7.

Bachman, M. (2007). Lesson Spurned? Reactions of Online Music Pirates to Legal Prosecutions by the RIAA. International Journal of Cyber Criminology, 1(2), 213-227.

Bai, J., \& Waldfogel, J. (2012). Movie piracy and sales displacement in two samples of Chinese consumers. Information Economics and Policy, 24, 187-196.

Balch, G. (1980). The Stick, The Carrot, and Other Strategies: A Theoretical Analysis of Government Intervention. Law \& Policy Quarterly, 2(1), 35-60.

Bandura, A. (2004). Health Promotion by Social Cognitive Means. Health Education \& Behavior, 31(2), 143-164.

Banerjee, D., \& Poddar, S. (2015). Does stricter enforcement prevent copyright infringement and necessarily improve innovation. University of Redlands. Retrieved 17-01-2017, from https://works.bepress.com/sougata poddar/6/.

Barker, G. (2012). Evidence of the Effect of Free Music Downloads on the Purchase of Music CDs in Canada. Review of Economic Research on Copyright Issues, 9(2), 55-78

Barker, G., \& Maloney, T. (2015). The impact of Internet file-sharing on the purchase of music CDs in Canada. Journal of Evolutionary Economics, 25(4), 821-848.

Bateman, C., Valentine, S., \& Rittenburg, T. (2013). Ethical Decision Making in a Peer-to-Peer File Sharing Situation: The Role of Moral Absolutes and Social Consensus. Journal of Business Ethics, $115(2), 229-240$

Bates, L., Allen, S., \& Watson, B. (2016). The influence of the elements of procedural justice and speed camera enforcement on young novice driver self-reported speeding. Accident Analysis and Prevention, 92, 34-42. 


\section{Bibliography}

Bauman, A., McLean, G., Hurdle, D., Walker, S., Boyd, J., van Aalst, I., \& Carr, H. (2003). Evaluation of the national 'Push Play' campaign in New Zealand - creating population awareness of physical activity. The New Zealand Medical Journal, 116(1179), 1-11.

Beale, S. (2000). Federalizing hate crimes: Symbolic politics, expressive law, or tool for criminal enforcement. Boston University Law Review, 80, 1227-1281.

Becker, G. (1968). Crime and Punishment: An Economic Approach. Journal of Political Economy, 76(2), 169-217.

Becker, J., \& Clement, M. (2006). Dynamics of Illegal Participation in Peer-to-Peer Networks: Why Do People Illegally Share Media Files. Journal of Media Economics, 19(1), 7-32.

Belleflamme, P., \& Peitz, M. (2010). Digital Piracy: Theory CESifo Economic Studies (Vol. 3222). Munich: Center for Economic Studies and Ifo Institute.

Belleflamme, P., \& Picard, P. (2007). Piracy and Competition. Journal of Economics \& Management Strategy, 16(2), 351-383.

Belleville, M. (2012). IP Wars: SOPA, PIPA, and the Fight over Online Piracy Temple International \& Comparative Law Journal, 26(2), 303-334.

Bender, M., \& Wang, Y. (2009). The impact of digital piracy on music sales: a cross-country analysis. International Social Science Review, 84(3-4).

Berkowitz, L., \& Donnerstein, E. (1982). External Validity Is More Than Skin Deep: Some Answers to Criticisms of Laboratory Experiments. American Psychologist, 37(3), 245-257.

Bhal, K., \& Leekha, N. (2008). Exploring Cognitive Moral Logics Using Grounded Theory: The Case of Software Piracy. Journal of Business Ethics, 81(3), 635-646.

Bhattacharjee, S., Gopal, R., Lertwachara, K., \& Marsden, J. (2006). Impact of Legal Threats on Online Music Sharing Activity: an Analysis of the Music Industry Legal Actions. Journal of Law and Economics, 49(1), 91-114.

Bhattacharjee, S., Gopal, R., Lertwachara, K., Marsden, J., \& Telang, R. (2007). The Effect of Digital Sharing Technologies on Music Markets: A Survival Analysis of Albums on Ranking Charts. Management Science, 53(9), 1359-1374.

Bhattacharjee, S., Gopal, R., \& Sanders, G. (2003). Digital Music and Online Sharing: Piracy 2.0? Communications of the ACM, 46(7), 107-111.

Bitton, M. (2012). Rethinking the Anti-Counterfeiting Trade Agreement's Criminal Copyright Enforcement Measures. Journal of Criminal Law \& Criminology, 102(1), 67-117.

Blackburn, D. (2004). On-line Piracy and Recorded Music Sales. Department of Economics, Harvard University. Cambridge.

Blankfield, S., \& Stevenson, I. (2012). Towards a Digital Spine: The Technological Methods that UK and US Publishers are Using to Tackle the Growing Challenge of E-Book Piracy. Publishing Research Quarterly, 28(2), 79-92.

Block, M., \& Gerety, V. (1995). Some experimental evidence on differences between student and prisoner reactions to monetary penalties and risk. Journal of Legal Studies, 24(1), 123-138.

Bockstedt, J., Kauffman, R., \& Riggins, F. (2006). The Move to Artist-Lend On-Line Music Distribution: A Theory-Based Assessment and Prospects for Structural Change in the Digital Music Market. International Journal of Electronic Commerce, 10(3), 7-38.

Bolton, R., Parasuraman, A., Hoefnagels, A., Migchels, N., Kabadayi, S., Gruber, T., . . Solnet, D. (2013). Understanding Generation $\mathrm{Y}$ and their use of social media: a review and research agenda. Journal of Service Management, 24(3), 245-267.

Bomsel, O., \& Ranaivoson, H. (2009). Decreasing Copyright Enforcement Costs: The Scope of the Graduated Response. Review of Economic Research in Copyright Issues, 6(2), 13-29.

Bonner, S., \& O'Higgins, E. (2010). Music piracy: ethical perspectives. Management Decision, 48(9), 13411354.

Booth, A., Cardona-Sosa, L., \& Nolen, P. (2014). Gender differences in risk aversion: Do single-sex environments affect their development? Journal of Economic Behavior \& Organization, 99, 126-154.

Booth, R. (2014). U2's Bono issues apology for automatic Apple iTunes album download. Retrieved 17 01-2017, from https://www.theguardian.com/music/2014/oct/15/u2-bono-issues-apology-forapple-itunes-album-download

Borghans, L., Golsteyn, B., Heckman, J., \& Meijers, H. (2009). Gender Differences in Risk Aversion and Ambiguity Aversion. Journal of the European Economic Association, 7(2/3), 649-658.

Borja, K., \& Dieringer, S. (2016). Streaming or stealing? The complementary features between music streaming and music piracy. Journal of Retailing and Consumer Services, 32, 86-95.

Borja, K., Dieringer, S., \& Daw, S. (2015). The effect of music streaming services on music piracy among college students. Computer in Human Behavior, 45, 69-76. 


\section{$\underline{\text { Punish, Seduce or Persuade }}$}

Bottoms, A. (2002). Morality, crime, compliance and public policy. In A. Bottoms \& M. Tonry (Eds.), Ideology, Crime and Criminal Justice: A symposium in honour of Sir Leon Radzinowicz (pp. 20-54). Portland, Oregon: Willan Publishing.

Bounie, D., Bourreau, M., \& Waelbroeck, P. (2006). Piracy and the demand for films: analysis of piracy behaviour in French universities. Review of Economic Research on Copyright Issues, 3(2), 1527.

Brean, D. (2012-2013). Asserting Patents to Combat Infringement via 3D Printing: It's No "Use". Fordham Intellectual Property, Media \& Entertainment Law Journal, 23(3), 771-814.

Breustedt, G., Müller-Scheeßel, J., \& Latacz-Lohmann, U. (2008). Forecasting the Adoption of GM Oilseed Rape: Evidence from a Discrete Choice Experiment in Germany. Journal of Agricultural Economics, 59(2), 237-256.

Bridy, A. (2009). Why pirates (still) won't behave: Regulating P2P in the decade after Napster. Rutgers Law Journal, 40(3), 565-611.

Bridy, A. (2010). ACTA and the Specter of Graduated Response. The American University International Law Review, 26(3), 559-578.

Bridy, A. (2010-2011). Graduated Response and the Turn to Private Ordering in Online Copyright Enforcement. Oregon Law Review, 89, 81-132.

Bridy, A. (2012). Graduated Response American Style: "Six Strikes" Measured Against Five Norms. Fordham Intellectual Property, Media \& Entertainment Law Journal, 23(1), 1-67.

Bright, J., \& Agustina, J. (2013). Mediating Surveillance: The Developing Landscape of European Online Copyright Enforcement. Journal of Contemporary European Research, 9(1), 121-137.

Brons, D., Hilhorst, N., \& Willemsen, F. (2008). Het kennisfundament t.b.v. de aanpak van criminele Marokkaanse jongeren. Den Haag: WODC

Brown, D. (1978). Arrest rates and crime rates: When does a tipping effect occur? Social Forces, 57(2), 671-682.

Brown, S. (2014a). How piracy is changing the music industry landscape. Retrieved 17-01-2017, from $\mathrm{http}: / /$ theconversation.com/how-piracy-is-changing-the-music-industry-landscape-31919

Brown, S. (2014b). Porn piracy: an overlooked phenomenon in need of academic investigation. Porn Studies, 1(3), 326-330.

Brown, S., \& MacDonald, R. (2014). Predictive factors of music piracy: An exploration of personality using the HEXACO PI-R. Musicae Scientiae, 18(1), 53-64.

Bruinsma, G., Pauwels, L., Weerman, F., \& Bernasco, W. (2015). Situational Action Theory: CrossSectional and Cross-Lagged Tests of Its Core Propositions. Canadian Journal of Criminology and Criminal Justice, 57(3), 363-398.

Brustein, J. (2015). Secondhand Downloads: Will Used E-Books and Digital Games Be for Sale? Retrieved 17-01-2017, from https://www.bloomberg.com/news/articles/2015-02 10/secondhand-downloads-will-used-e-books-and-digital-games-be-for-sale-

Bryan, S., Gold, L., Sheldon, R., \& Buxton, M. (2000). Preference Measurement using Conjoint Methods: An Empirical Investigation of Reliability. Health Economics, 9(5), 385-395.

BSA. (2014). The Compliance Gap: BSA Global Software Study. Washington: BSA.

BSA \& IDC. (2008). Piracy Reduction Impact Study. Washington: BSA.

BSA \& IDC. (2010). Seventh Annual BSA/IDC Global Software 09 Piracy Study. Washington: BSA.

BSA \& IDC. (2011). Eight Annual BSA/IDC Global Software 2010 Piracy Study. Washington: BSA.

BSA \& IDC. (2012). Shadow Market: 2011 BSA Global Software Piracy Study, Ninth Edition. Washington: BSA

Buccafuso, C., \& Masur, J. (2013). Innovation and Incarceration: An Economic Analysis of Criminal Intellectual Property Law. Coase-Sandor Institute for Law and Economics Working Paper. Coase-Sandor Institute for Law and Economics. Chicago. Retrieved 17-01-2017, from https://papers.ssrn.com/sol3/papers.cfm?abstract id=2297488

Burroughs, B., \& Rugg, A. (2014). Extending the Broadcast: Streaming Culture and the Problems of Digital Geographies. Journal of Broadcasting \& Electronic Media, 58(3), 365-380.

Burrus, G., Bossler, A., \& Holt, T. (2012). Assessing the Mediation of a Fuller Social Learning Model on Low Self-Control's Influence on Software Piracy. Crime and Delinquency, In press.

Burrus, G., Bossler, A., \& Holt, T. (2013). Assessing the Mediation of a Fuller Social Learning Model on Low Self-Control's Influence on Software Piracy. Crime and Delinquency, 59(8), 1157-1184.

Bustinza, O., Vendrell-Herrero, F., Parry, G., \& Myrthianos, V. (2013). Music business models and piracy. Industrial Management \& Data Systems, 113(1), 4-22.

Cable, V., \& Javid, S. (2014). New education programme launched to combat online piracy. Retrieved 17-01-2017, from https:/www.gov.uk/government/news/new-education-programme-launchedto-combat-online-piracy 


\section{Bibliography}

Camarero, C., Antón, C., \& Rodríguez, J. (2014). Technological and ethical antecedents of e-book piracy and price acceptance: Evidence from the Spanish case. The Electronic Library, 32(4), 542-566.

Campbell, J., \& Manganello, J. (2006). Changing Public Attitudes as a Prevention Strategy to Reduce Intimate Partner Violence. Journal of Aggression, Maltreatment \& Trauma, 13(3-4), 13-39.

Caoili, E. (2010). CESA: Portable Piracy Cost Game Industry \$41.5 Billion. Retrieved 17-01-2017, from http://www.gamasutra.com/view/news/28848/CESA_Portable_Piracy_Cost_Game_Industry_4 15 Billion.php

Carlsson, F., \& Martinsson, P. (2001). Do Hypothetical and Actual Marginal Willingness to Pay Differ in Choice Experiments? Application to the Valuation of the Environment. Journal of Environmental Economics and Management, 41(2), 179-192.

Carlsson, F., \& Martinsson, P. (2003). Design techniques for stated preference methods in health economics. Health Economics, 12(4), 281-294.

Carrington, M., Neville, B., \& Whitwell, G. (2010). Why Ethical Consumers Don't Walk Their Talk: Towards a Framework for Understanding the Gap Between the Ethical Purchase Intentions and Actual Buying Behaviour of Ethically Minded Consumers. Journal of Business Ethics, 97(1), 139-158.

Carrol, C., Patterson, M., Wood, S., Booth, A., Rick, J., \& Balain, S. (2007). A conceptual framework for implementation fidelity. Implementation Science, 2, 40-49.

Casidy, R., Phau, I., \& Lwin, M. (2016). The role of religious leaders on digital piracy attitude and intention. Journal of Retailing and Consumer Services, 32, 244-252.

Castells, M. (2014). The Rise of the Network Society. Hoboken: Wiley-Blackwell.

Castro, D., Bennet, R., \& Andes, S. (2009). Steal These Policies: Strategies for Reducing Digital Piracy. Washington: The Information Technology \& Innovation Foundation.

Cavazos-Regh, P., Krauss, M., Spitznagel, E., Lowery, A., Grucza, R., Caloupka, F., \& Bierut, L. (2015). Monitoring of non-cigarette tobacco use using Google Trends. Tobacco Control, 24(3), 249255.

CBS. (2014). Dagje uit flink duurder. Retrieved 17-01-2017, from https:/www.cbs.nl/nlnl/nieuws/2014/32/dagje-uit-flink-duurder.

Cenite, M., Wang, M., Peiwen, C., \& Chan, G. (2009). More Than Just Free Content: Motivations of Peerto-Peer File Sharers. Journal of Communication Inquiry, 33(3), 206-221.

Center for Copyright Information. (2014). The Copyright Alert System: Phase One and Beyond.

Center for Copyright Information. (n.d.). What Do I Do if I've Received a Copyright Alert.

Cesaro, L., Pastore, A., \& Ugolini, G. (2015). Pirate or subscriber? An exploratory study on Italian consumers' music habits. Italian Journal of Management, 33(96), 153-171.

Chacos, B. (2016). 12 hilarious, brutally devious ways game developers punish pirates. Retrieved 17-012017, from http://www.pcworld.com/article/2602876/software-games/10-hilarious-brutallydevious-ways-pc-game-developers-punish-pirates.html\#slide12

Chamlin, M. (1991). A longitudinal analysis of the arrest-crime relationship: A further examination of the tipping effect. Justice Quarterly, 8(2), 187-199.

Chan, R., \& Lai, J. (2011). Does ethical ideology affect software piracy attitude and behaviour? An empirical investigation of computer users in China. European Journal of Information Systems, 20(6), 659-673

Charness, G., \& Gneezy, U. (2012). Strong Evidence for Gender Differences in Risk Taking. Journal of Economic Behavior \& Organization, 83(1), 50-58.

Chen, Y., Shang, R., \& Lin, A. (2008). The intention to download music files in a P2P environment Consumption value, fashion, and ethical decision perspectives. Electronic Commerce Research and Applications, 7(4), 411-422.

Cheng, H., Sims, R., \& Teegen, H. (1997). To Purchase or Pirate Software: An Empirical Study. Journal of Management Information Systems, 13(4), 49-60.

Chiang, E., \& Assane, D. (2007). Determinants of Music Copyright Violations on the University Campus. Journal of Cultural Economics, 31(3), 187-204.

Chiang, E., \& Assane, D. (2008). Music piracy among students on the university campus: Do males and females react differently? Journal of Socio-Economics, 37(4), 1371-1380.

Chiang, E., \& Assane, D. (2009). Estimating the Willingness to Pay for Digital Music Contemporary Economic Policy, 27(4), 512-522.

Chiang, L., \& Lee, B. (2011). Ethical Attitude and Behaviors Regarding Computer Use. Ethics and Behavior, 21(6), 481-497.

Chiou, J., Cheng, H., \& Huang, C. (2011). The Effects of Artist Adoration and Perceived Risk of Getting Caught on the Attitude and Intention to Pirate Music in the United States and Taiwan. Ethics and Behavior, 21(3), 182-196. 


\section{$\underline{\text { Punish, Seduce or Persuade }}$}

Chiou, J., Huang, C., \& Lee, H. (2005). The Antecedents of Music Piracy Attitudes and Intentions. Journal of Business Ethics, 57(2), 161-174.

Chiu, H., Hsieh, Y., \& Wang, M. (2008). How to Encourage Customers to use Legal Software. Journal of Business Ethics, 80, 583-595.

Chmielewski, D. (2014). Music Piracy Goes Mobile. Retrieved 17-01-2017, from http://www.recode.net/2014/3/24/11624860/music-piracy-goes-mobile

Choi, H., Au, Y., \& Liu, C. (2014). Is Digital Piracy an Enemy of the Mobile App Industry? An Empirical Study on Piracy of Mobile Apps. Paper presented at the Twentieth Americas Conference on Information Systems, Savannah.

Choi, H., \& Varian, H. (2012). Predicting the Present with Google Trends. The Economic Record, 88(1), 2-9.

Choi, P., Bae, S., \& Jun, J. (2010). Digital piracy and firms' strategic interactions: The effects of public copy protection and DRM similarity. Information Economics and Policy, 22(4), 354-364.

Choi, S., \& Tran, D. (2016). Heart attacks prevent chocolate. Or, the differences between correlation and causation. Anaesthesia, 71(5), 586-589.

Christin, N., Weigend, A., \& Chuang, J. (2005). Content Availability, Pollution and Poisoning in File Sharing Peer-to-Peer Networks. Paper presented at the Proceedings of the ACM, Vancouver.

Citron, D., \& Franks, M. (2014). Criminalizing Revenge Porn. Wake Forest Law Review, 49(2), 345-391.

Clement, M., Rangaswamy, A., \& Vadali, S. (2012). Consumer Responses to Legal Music Download Services that Compete With Illegal Alternatives. informs, 4(1), 4-23.

Cluley, R. (2013). Downloading deviance: Symbolic interactionism and unauthorized file-sharing. Marketing Theory, 13(3), 263-274.

Cockrill, A., \& Goode, M. (2012). DVD pirating intentions: Angels, devils, chancers and receivers. Journal of Consumer Behavior, 11(1), 1-10.

Colombo, S., Calatrava-Requena, J., \& Hanley, N. (2006). Analysing the social benefits of soil conservation measures using stated preference methods. Ecological Economics, 58(4), 850-861.

Columbia. (n.d.). The Ties That Bind: The River Collection (CD+DVD). Retrieved 17-01-2017, from $\mathrm{https}: / / \mathrm{www} \cdot$ bol.com $/ \mathrm{nl} / \mathrm{p} /$ the-ties-that-bind-the-rivercollection/9200000050905080/\#product_specifications

Coolpctips. (2012). All Time Best PC Games Record Highest Illegal downloads. Retrieved 17-01-2017, from http:/www.coolpctips.com/2012/05/all-time-best-pc-games-record-highest-illegaldownloads-top-pirated/

Cooper, T. (2014). 8 of the Cruelest/Best Ways Games Are Trolling Pirates. Retrieved 17-01-2017, from http://www.dorkly.com/post/70736/8-surprising-ways-video-games-are-fighting-piracy

Cooter, R. (1998). Expressive Law and Economics. The Journal of Legal Studies, 27(2), 585-608.

Cooter, R. (2000). Three Effects of Social Norms on Law: Expression, Deterrence, and Internalization. Oregon Law Review, 79(1), 1-22.

Corbett, M., Dickinson-Gómez, J., Hilario, H., \& Weeks, M. (2009). A Little Thing Called Love: Condom Use in High-Risk Primary Heterosexual Relationships. Perspectives on Sexual and Reproductive Health, 41(4), 218-224.

Cowls, J., \& Schroeder, R. (2015). Causation, Correlation, and Big Data in Social Science Research. Policy \& Internet, 7(4), 447-472.

Cox, J., \& Collins, A. (2014). Sailing in the same ship? Differences in factors motivating piracy of music and movie content. Journal of Behavioral and Experimental Economics, 50, 70-76.

Coyle, J., Gould, S., Gupta, P., \& Gupta, R. (2009). "To buy or to pirate": The matrix of music consumers' acquisition-mode decision-making. Journal of Business Research, 62(10), 1031-1037.

Cronan, T., \& Al-Rafee, S. (2008). Factors that Influence the Intention to Pirate Software and Media. Journal of Business Ethics, 78(4), 527-545.

Cronin, G. (2002). A Taxonomy of Methods for Software Piracy Prevention. Retrieved from http://citeseerx.ist.psu.edu/viewdoc/download?doi=10.1.1.86.3025\&rep=rep1\&type=pdf

Culiberg, B., Kos Koklic, M., Vida, I., \& Badje, D. (2016). Examining the effects of utilities and involvement on intentions to engage in digital piracy. Computers in Human Behavior, 61, 146154.

Curtis, S. (2016). Game of Thrones season 6 premiere sparks online piracy frenzy - with over a million illegal downloads in 12 hours. Retrieved 17-01-2017, from http://www.mirror.co.uk/tech/game/thrones-season-6-premiere-7835730.

d'Astous, A., Colbert, F., \& Monpetit, D. (2005). Music Piracy on the Web-How Effective Are Anti-Piracy Arguments? Evidence from the Theory of Planned Behavior. Journal of Consumer Policy, 28(3), 298-310. 


\section{Bibliography}

d'Astous, A., \& Landreville, V. (2003). An experimental investigation of factors affecting consumers' perceptions of sales promotions. European Journal of Marketing, 37(11/12), 1746-1761

Danaher, B., Dhanasobhon, S., Smith, M., \& Telang, R. (2010). Converting Pirates Without Cannibalizing Purchasers: The Impact of Digital Distribution on Physical Sales and Internet Piracy. Marketing Science, 29(6), 1138-1151.

Danaher, B., \& Smith, M. (2014). Gone in 60 Seconds: The Impact of the Megaupload Shutdown on Movie Sales. International Journal of Industrial Organization, 33, 1-8.

Danaher, B., Smith, M., Telang, R., \& Chen, S. (2014). The Effect of Graduated Response Anti-Piracy Laws on Music Sales: Evidence from an Event Study in France. The Journal of Industria Economics, 62(3), 541-553.

Dancy, B., \& Berbaum, M. (2005). Condom Use Predictors for Low-Income African American Women. Western Journal of Nursing Research, 27(1), 28-44.

Darke, P., \& Chung, C. (2005). Effects of pricing and promotion on consumer perceptions: it depends on how you frame it. Journal of Retailing, 81(1), 35-47.

Datoo, S. (2013). France drops controversial 'Hadopi law' after spending millions. Retrieved 17-01-2017, from https://www.theguardian.com/technology/2013/jul/09/france-hadopi-law-anti-piracy

Dau-Schmidt, K. (1990). An Economic Analysis of the Criminal Law as a Preference-Shaping Policy. Duke Law Journal, 1990(1), 1-38.

De Corte, C., \& Van Kenhove, P. (2015). One Sail Fits All? A Psychographic Segmentation of Digital Pirates. Journal of Business Ethics(1-25).

De Geest, G., \& Dari-Mattiacci, G. (2012). The rise of carrots and the decline of sticks. University of Chicago Law Revew, 80(1), 341-392.

De Graaf, D., van den Putte, B., \& van der Werff, S. (2011). Het motiverende effect van normatieve en afschrikwekkende boodschappen: een stated preference benadering. Amsterdam: SEO Economisch Onderzoek.

De Pauw, E., Daniels, S., Brijs, T., Hermans, E., \& Wets, G. (2014). Automated section speed control on motorways: An evaluation of the effect on driving speed. Accident Analysis and Prevention, 73, 313-322.

De Vany, A., \& Walls, D. (2007). Estimating the Effects of Movie Piracy on Box-office Revenue. Review of Industrial Organization, 30(4), 291-301.

DeBriyn, J. (2012). Shedding Light on Copyright Trolls: An Analysis of Mass Copyright Litigation in the Age of Statutory Damages. UCLA Entertainment Law Review, 19(1), 130-163.

Deezer. (n.d.). Deezer - Flow my music. Retrieved 17-01-2017, from http://www.deezer.com/

Degusta, M. (2011). US Recorded Music Sales - Album \& Single Prices in 2011 Dollars.

Dejean, S., Penard, T., \& Suire, R. (2010). The French "Three Strikes Law" against digital piracy and the change in usage of pirates. Paper presented at the The Internet, Policy \& Politics Conferences Oxford, UK

Dejean, S., \& Suire, R. (2014). Digital files dealers and prohibition in the context of the French 3 strikes (HADOPI) law. Retrieved from https://papers.ssrn.com/sol3/papers.cfm?abstract_id=2422933

Deleon, N. (2011). UK Video Game Piracy Caused £1.45B In Losses \& 1,000 Jobs Last Year. Retrieved 17-01-2017, from https://techcrunch.com/2011/01/21/uk-video-game-piracy-caused-1-45b-inlosses-1000-jobs-last-year/

Delikan, D. (2011). The streaming music revolution: an empirical study on streaming music service Spotify. Paper presented at the IASPM Benelux Conference, Haarlem.

Depoorter, B. (2014). Intellectual Property Infringements \& 3D Printing: Decentralized Piracy. Hastings Law Journal, 65(6), 1483-1504.

Depoorter, B., Parisi, F., \& Vanneste, S. (2005). Problems with the enforcement of copyright law: is there a social norm backlash. International Journal of the Economics of Business, 12(3), 361-369.

Depoorter, B., \& van Hiel, A. (2015). Copyright Alert Enforcement: Six Strikes and Privacy Harms. The Columbia Journal of Law \& the Arts, 39(2), 233-280.

Depoorter, B., van Hiel, A., \& Vanneste, S. (2011). Copyright Backlash. Southern California Law Review, 84(6), 1251-1293.

Desai, D., \& Magliocca, G. (2014). Patents, meet Napster: 3D printing and the digitization of things. Georgetown Law Journal, 102(8), 1691-1720.

DeSteno, D., Petty, R., Rucker, D., Wegener, D., \& Braverman, J. (2004). Discrete emotions and persuasion: The role of emotion induced expectancies. Journal of Personality \& Social Psychology, 86(1), 43-56

Dickey, J. (2015). Taylor Swift's Spotify Paycheck Mystery. Retrieved 17-01-2017, from http://time.com/3581487/taylor-swift-spotify-borchetta/. 


\section{$\underline{\text { Punish, Seduce or Persuade }}$}

Dilmperi, A., King, T., \& Dennis, C. (2011). Pirates of the web: The curse of illegal downloading. Journal of Retailing and Consumer Services, 18(2), 132-140.

Djekic, P., \& Loebbecke, C. (2007). Preventing application software piracy: An empirical investigation of technical copy protections Journal of Strategic Information System, 16(2), 173-186.

Doherthy, D. (2012). Downloading Infringement: Patent Law as a Roadblock to the 3D Printing Revolution. Harvard Journal of Law \& Technology, 26(1), 353-373.

Donner, C., Marcum, C., Jennings, W., Higgins, G., \& Banfield, J. (2014). Low self-control and cybercrime: Exploring the utility of the general theory of crime beyond digital piracy. Computers in Human Behavior, 34(May), 165-172.

Dörr, J., Wagner, T., Hess, T., \& Benlian, A. (2013). Music as a Service as an Alternative to Music Piracy: An Empirical Investigation of the Intention to Use Music Streaming Services. Business \& Information Systems Engineering, 6(5), 383-396.

Douglas, D., Cronan, T., \& Behel, J. (2007). Equity perceptions as a deterrent to software piracy behavior. Information and Management, 44(5), 503-512.

Drachen, A., \& Veitch, R. (2013). Patterns in the distribution of digital games via BitTorrent. International Journal of Advanced Media and Communication, 5(1), 80-99.

Drassinower, A. (2009). From Distribution to Dialogue: Remarks on the Concept of Balance in Copyrigh Law. Journal of Corporation Law, 34(4), 991-1007.

Drath, R. (2012). Hotfile, Megaupload, and the Future of Copyright on the Internet: What Can Cyberlockers Tells Us about DMCA Reform. John Marshall Review of Intellectual Property Law, 12(1), 205241.

Drew, R. (2014). New Technologies and the Business of Music: Lessons from the 1980s Home Taping Hearings. Popular Music and Society, 37(3), 253-272.

Dugas, A., Hsieh, Y., Levin, S. P., J., Mareiniss, D., Mohareb, A., Gaydos, C., . . Rothman, R. (2012) Google Flu Trends: Correlation With Emergency Department Influenza Rates and Crowding Metrics. Clinical Infectious Diseases, 54(4), 463-469.

Dunning, T. (2008). Improving Causal Inference: Strengths and Limitations of Natural Experiments. Political Research Quarterly, 61(2), 282-293.

Earnhart, D. (2001). Combining Revealed and Stated Preference Methods to Value Environmental Amenities at Residential Locations. Land Economics, 77(1), 12-29.

Edwards, L., Klein, B., Lee, D., Moss, G., \& Philip, F. (2012). Framing the consumer: Copyright regulation and the Public. Convergence: The International Journal of Research into New Media Technologies, 19(1), 9-24.

Edwards, L., Klein, B., Lee, D., Moss, G., \& Philip, F. (2015a). Discourse, justification and critique: towards a legitimate digital copyright regime? International Journal of Cultural Policy, 2l(1), 60-77.

Edwards, L., Klein, B., Lee, D., Moss, G., \& Philip, F. (2015b). ‘Isn't it just a way to protect Walt Disney’s rights?': Media user perspectives on copyright. New Media \& Society, 17(5), 691-707.

Egan, M. (2016). How to download torrents. Retrieved 17-01-2017, from http://www.pcadvisor.co.uk/how-to/internet/how-download-torrents-download-torrent-files-access-pirate-bay-3492629.

Eggerton, J. (2011). Senate Bill Gets Tough on Pirates. Retrieved 17-01-2017, from http://www.multichannel.com/news/policy/senate-bill-gets-tough-pirates/264986

Ehrlich, I. (1975). The Deterrent Effect of Capital Punishment: A Question of Life and Death. The American Economic Review, 65(3), 397-417.

Eindstadter, W., \& Henry, S. (2006). Criminological Theory: An Analysis of its Underlying Assumptions (2nd ed.). Lanham: Rowman \& Littlefield.

Electronic Arts. (n.d.). Origin. Retrieved 17-01-2017, from https:/www.origin.com/nl-nl/store/

Elkin-Koren, N. (1997). Copyright Policy and the Limits of Freedom of Contract. Berkeley Technology Law Journal, 12(1), 93-113.

Ellis, W. (2014). Perceptions of HIV/AIDS-STD Risk Among First-Year African-American College Students: The Decomposition of Self-Esteem to Promote a Positive Behavioral Change in RiskReduction Practices. Social Work in Mental Health, 12(2), 155-173.

Emons, W. (2003). A note on the optimal punishment for repeat offenders. International Review of Law \& Economics, 23(3), 253-259.

Envisional. (2011). An Estimate of Infringing Use of the Internet. Cambridge: Envisonal.

Erdem, T., Keane, M., \& Sun, B. (2008). The impact of advertising on consumer price sensitivity in experience goods markets. Quantitative Marketing and Economics, 6(2), 139-176.

Eres, R., Louis, W., \& Molenberghs, P. (2016). Why do people pirate? A neuroimaging investigation. Social Neuroscience, 1-13. 


\section{Bibliography}

European Union Intellectual Property Office. (n.d.). Public awareness campaigns. Retrieved 17-01-2017, from https:/euipo.europa.eu/ohimportal/en/web/observatory/public-awareness-campaigns

Fagundes, D. (2013). Efficient copyright infringement. Iowa Law Review, 98(5), 1791-1846.

Falk, A., \& Heckman, J. (2009). Lab experiments are a major source of knowledge in the social sciences. Science, 326(5952), 535-538.

Farivar, C. (2013). Here's what an actual "six strikes" copyright alert looks like.

Farrington, D., Gottfredson, D., Sherman, L., \& Welsh, B. (2002). The Maryland Scientific Methods Scale. In L. Sherman, D. Farrington, B. Welsh \& D. MacKenzie (Eds.), Evidence-based Crime Prevention (pp. 13-55). London Routlegde.

Farrington, D., \& Petrosino, A. (2001). The Campbell Collaboration Crime and Justice Group. Annals of the American Academy of Political and Social Science, 578(1), 35-49.

FBI. (n.b.). FBI Anti-Piracy Warning Seal.

Feld, L., \& Frey, B. (2007). Tax Compliance as the Result of a Psychological Tax Contract: The Role of Incentives and Responsive Regulation. Law \& Policy, 29(1), 102-120.

Feldman, Y., \& Nadler, J. (2006). The Law and Norms of File Sharing. San Diego Law Review, 43(3), 577 618.

Feys, S. (2014). Europa legt illegaal downloaden in België voorgoed aan banden. Retrieved 17-01-2017, from http://www.demorgen.be/technologie/europa-legt-illegaal-downloaden-in-belgievoorgoed-aan-banden-bf3ef3c5.

FICCI. (n.d.). Our Initiative, Your Benefit.

Ficetola, G. (2013). Is interest toward the environment really declining? The complexity of analysing trends using internet search data. Biodiversity and Conservation, 22(12), 2983-2988.

Fincocchiaro, C. (2012-2013). Personal Factory or Catalyst for Piracy: The Hype, Hysteria, and Hard Realities of Consumer 3-D Printing. Cardozo Arts \& Entertainment Law Journal, 31(2), $473-$ 508

Fivelsdal, H. (2005). Moving Toward a Balanced and Effective Response to Internet Music Piracy. The International Journal on Media Management, 7(3-4), 121-126.

Flight, S., Hartmann, A., \& Nauta, O. (2012). Bestuurlijke strafbeschikking en bestuurlijke boete overlast: Evaluatie na drie jaar. Amsterdam: DSP Group.

France-Presse, A. (2013). Supreme Court upholds \$220,000 fine for music piracy. Retrieved 17-01-2017, from http://www.rawstory.com/2013/03/supreme-court-upholds-220000-fine-for-musicpiracy/

Friesen, L. (2012). Certainty of Punishment versus Severity of Punishment: An Experimental Investigation. Southern Economic Journal, 79(2), 399-421.

Fritz, R. (1998). AIDS Knowledge, Self-Esteem, Perceived AIDS Risk, and Condom Use Among Female Commercial Sex Workers. Journal of Applied Social Psychology, 28(10), 888-911.

Frosio, G. (2011). Urban Guerrilla \& Piracy Surveillance: Accidental Casualties in Fighting Piracy in P2P Networks in Europe. Rutgers Computer \& Technology Law Journal, 37(1-2), 1-57.

Fujii, S. (2006). Environmental concern, attitude toward frugality, and ease of behavior as determinants of pro-environmental behavior intentions. Journal of Environmental Psychology, 26(4), 262-268.

Fung, W., \& Lakhani, A. (2013). Combating peer-to-peer file sharing of copyrighted material via antipiracy laws: Issues, trends and solutions. Computer Law \& Security Review, 29(4), 382-402.

Gaikai.com. (n.d.). Gaikai.com. Retrieved 17-01-2017, from https://www.gaikai.com/

Gallo-Riveria, M., Mancha-Navarro, T., \& Garrido-Yserte, R. (2013). Application of the counterfactual method to assess of the local economic impact of a nuclear power station. Energy Policy, 62(3), 1481-1492.

Gallupe, O., \& Baron, S. (2014). Morality, Self-Control, Deterrence, and Drug Use: Street Youths and Situational Action Theory. Crime and Delinquency, 60(2), 284-305.

Gantz, J., Christiansen, C., \& Gillen, A. (2006). The Risks of Obtaining and Using Pirated Software. Framingham: IDC.

Gantz, J., Vavra, T., Howard, J., Rodolfo, R., Lee, R., Satidkanitkul, A., . . . Lachawitz, C. (2013). The Dangerous World of Counterfeit and Pirated Software: How Pirated Software Can Compromise the Cybersecurity of Consumers, Enterprises, and Nations.... and the Resultant Costs in Time and Money. Framingham: IDC.

Garbharran, A., \& Thatcher, A. (2009). A case for using a social cognitive model to explain intention to pirate software. Journal of eHealth Technology and Application, 7(2), 87-98.

Garbharran, A., \& Thatcher, A. (2011). A case for using a social cognitive model to explain intention to pirate software. Journal of eHealth Technology and Application. 


\section{$\underline{\text { Punish, Seduce or Persuade }}$}

Gardner, A. (2014). Lego Awarded 3D Printing Patent, May Allow Users to Print Own Bricks. Retrieved 17-01-2017, from https://3dprint.com/1383/lego-awarded-3d-printing-patents-may-allowusers-to-print-own-bricks/

Garstka, K. (2012). The Amended Digital Economic Act 2010 as an Unsuccessful Attempt to Solve the Stand-Alone Complex of Online Piracy. International Review of Intellectual Property and Competition Law, 2012(2), 158-174.

Gates, B. (1976). An Open Letter to Hobbyists. Homebrew Computer Club Newsletter, 2(1), 2.

Gates, K. (2006). Will Work for Copyrights: The Cultural Policy of Anti-piracy Campaigns. Social Semiotics, 16(1), 57-73.

Geiger, C. (2011). Honourable Attempt but (ultimately) Disproportionately Offensive against Peer-to-peer on the Internet (HADOPI) - A Critical Analysis of the Recent Anti-File-Sharing Legislation in France. International Review of Intellectual Property and Competition Law, 42(4), 457-472.

Gerkens, A., Smeets, P., Teeven, F., \& van Vroonhoven-Kok, N. (2009). Auteursrechten: Een Rapport. Den Haag: Tweede Kamer,

Gerlach, J., Kuo, F., \& Lin, C. (2009). Self sanction and regulative sanction against copyright infringement: a comparison between U.S. and China college students. Journal of the American Society for Information Science Technology, 60(8), 1687-1701.

Geter, A., \& Crosby, R. (2014). Condom Refusal and Young Black Men: the Influence of Pleasure, Sexual Partners, and Friends. Journal of Urban Health, 91(3), 541-546.

Geuss, M. (2014). British man sentenced to nearly three years in prison for movie piracy. Retrieved 17 01-2017, from http://arstechnica.com/tech-policy/2014/08/british-man-sentenced-to-nearlythree-years-in-prison-for-movie-piracy/

Gibbs, J., \& Giever, D. (1995). Self-Control and its Manifestations among University Students: An Empirical Test of Gottfredson and Hirschi's General Theory Justice Quarterly, 12(2), 231-256.

Gibbs, S. (2013). Swedish 'pirate' hit with $£ 403,000$ damages for sharing single movie. Retrieved 17-012017, from http://www.theguardian.com/technology/2013/dec/18/bittorrent-pirate-swedenmartin-beck-swebit

Giblin, R. (2014). Evaluating Graduated Response. The Columbia Journal of Law \& the Arts, 37(2), $147-$ 210

Gillespie, T. (2006). Designed to 'effectively frustrate': copyright, technology and the agency of users. New Media \& Society, 8(4), 651-669.

Gillespie, T. (2009). Characterizing Copyright in the Classroom: The Cultural Work of Antipiracy Campaigns. Communication, Culture and Critique, 2(3), 274-318.

Glass, R., \& Wood, W. (1996). Situational Determinants of Software Piracy: An Equity Theory Perspective. Journal of Business Ethics, 15(11), 1189-1198.

Gneezy, U., Meier, S., \& Rey-Biel, P. (2011). When and Why Incentives (Don't) Work to Modify Behavior. Journal of Economic Perspectives, 25(4), 191-210.

Goel, S., Miesing, P., \& Chandra, U. (2010). The Impact of Illegal Peer-to-Peer File-Sharing on the Media Industry. California Management Review, 52(3), 6-33.

Gog.com. (n.d.). Gog.com. Retrieved 17-01-2017, from https://www.gog.com/

Goldsmith, R., Flynn, L., \& Kim, D. (2010). Status Consumption and Price Sensitivity. Journal of Marketing Theory and Practice, 17(3), 199-213.

Goles, T., Jayatilaka, B., George, B., Parsons, L., \& Chambers, V. T., D.

Brune, R. (2008). Softlifting: Exploring Determinants of Attitude Journal of Business Ethics, 77(4), 481499.

Google. (n.d.). Muziek op Google Play. Retrieved 17-01-2017, from https://play.google.com/store/music

Gopal, R., Bhattacharjee, S., \& Sanders, G. (2006). Do Artists Benefit from Online Music Sharing? . Journal of Business, 79(3), 1503-1533.

Gopal, R., \& Sanders, G. (1997). Preventive and Deterrent Controls for Software Piracy. Journal of Management Information Systems, 13(44), 29-47.

Gopal, R., Sanders, G., Bhattacharjee, S., Agrawal, M., \& Wagner, S. (2004). A Behavioral Model of Digital Music Piracy. Journal of Organizational Computing and Electronic Commerce, 14(2), 89-105.

Grabosky, P. (1995). Regulation by Reward: On the use of Incentives as Regulatory Instruments. Law \& Policy, 17(3), 257-282.

Grasmick, H., \& Bryjak, G. (1980). The Deterrent Effect of Perceived Severity of Punishment. Social Forces, 59(2), 471-491.

Grasmick, H., \& Green, D. (1980). Legal Punishment, Social Disapproval and Internalization as Inhibitors of Illegal Behavior. Journal of Criminal Law \& Criminology, 71(3), 325-335. 


\section{Bibliography}

Green, J., Fulop, N., \& Kocsis, A. (2000). Determinants of unsafe sex in women. International Journal of Advertising, 11(12), 777-783.

Greenberg, B., Sherry, J., Lachlan, K., Lucas, K., \& Holmstrom, A. (2010). Orientations to Video Games Among Gender and Age Groups. Simulation \& Gaming, 41(2), 238-259.

Greenheart Games. (2013). What happens when pirates play a game development simulator and then go bankrupt because of piracy? Retrieved 17-01-2017, from http://www.greenheartgames.com/2013/04/29/what-happens-when-pirates-play-a-gamedevelopment-simulator-and-then-go-bankrupt-because-of-piracy/

Grigg, M., Waa, A., \& Bradbrook, S. (2008). Response to an indigenous smoking cessation media campaign - It's about whānau. Australian and New Zealand Journal of Public Health, 32(6), 559-564.

Grolleau, G., Mzoughi, N., \& Sutan, A. (2008). Please do not Pirate it, you will Rob the Poor! An Experimental Investigation on the Effect of Charitable Donations on Piracy. Journal of SocioEconomics, 37, 2417-2426.

Grosheide, W. (1986). Auteursrecht op Maat: beschouwingen over de grondslagen van het auteursrecht in een rechtspolitieke context. Deventer: Kluwer.

Guerette, R., \& Bowers, K. (2009). Assessing the extent of crime displacement and diffusion of benefits: a review of situational crime prevention evaluations. Criminology, 47(4), 1331-1368.

Gunter, W. (2008). Piracy on the High Speeds: A Test of Social Learning Theory on Digital Piracy among College Students. . International Journal of Criminal Justice Studies, 3(1), 54-68.

Gunter, W., Higgins, G., \& Gealt, R. (2010). Pirating Youth: Examining the Correlates of Digital Music Piracy among Adolescents. International Journal of Cyber Criminology, 4(1\&2), 657-671.

Gupta, P., Gould, S., \& Pola, B. (2004). "To Pirate or Not to Pirate": A Comparative Study of the Ethical versus Other Influences on the Consumer's Software Acquisition-Mode Decision. Journal of Business Ethics, 55(3), 225-274.

Haar, D., \& Wikström, P. (2010). Crime Propensity, Criminogenic Exposure and Violent Scenario Responses: Testing Situational Action Theory in Regression and Rasch Models. European Journal of Applied Mathematics, 21(4-5), 307-323.

Haav, H., Kalja, A., \& Robal, T. (Eds.). (2014). Databases and Information Systems VIII. Amsterdam: IOS Press.

Haber, E. (2010). The French Revolution 2.0: Copyright and the Three Strikes Policy. Journal of Sports \& Entertainment Law, 2(2), 297-339.

HADOPI. (n.d.). Haute Autorité pour la diffusion des œuvres et la protection des droits sur internet Retrieved 17-01-2017, from https://www.hadopi.fr/

Hammond, R. (2014). Profit Leak? Pre-Release File Sharing and the Music Industry. Southern Economic Association, 81(2), 387-408.

Hansen, B. (2015). Punishment and Deterrence: Evidence from Drunk Driving. American Economic Review, 105(4), 1581-1617.

Hart Jr, H. (1958). The Aims of the Criminal Law. Law and Contemporary Problems, 23, 401-441.

Harvard Law Review. (2003). Shame, Stigma, and Crime: Evaluating the Efficacy of Shaming Sanctions in Criminal Law Harvard Law Review. Harvard Law Review, 116(7), 2186-2207.

Hashim, M., Kannan, K., Maximiano, S., \& Rees, J. (2014). Digital Piracy, Teens, and the Source of Advice: An Experimental Study. Journal of Management Information Systems, 31(2), 211-244.

Hashim, M., Kannan, K., \& Wegener, D. (2011). Nudging the Digital Pirate: An Extension of the Theory of Planned Behavior. Retrieved from https://www.researchgate.net/publication/228769927_Nudging_the_Digital_Pirate_An_Empir ical Investigation of the Conversion of Digital Pirates to Paying Customers

Hassan, L., Shiu, E., \& Shaw, D. (2014). Who Says There is an Intention-Behaviour Gap? Assessing the Empirical Evidence of an Intention-Behaviour Gap in Ethical Consumption. Journal of Business Ethics, 136(2), 219-236.

HBO. (n.d.). OD GO NEW - HBO Nederland. Retrieved 17-01-2017, from http://www.itshbo.nl/ondemand-go.

Heckert, A., \& Heckert, D. (2002). A new typology of deviance: integrating normative and reactivist definitions of deviance. Deviant Behavior: An Interdisciplinary Journal, 23(5), 449-479.

Helberger, N., \& Hugenholtz, B. (2007). No Place Like Home for Making a Copy: Private Copying in European Copyright Law and Consumer Law. Berkeley Technology Law Journal, 22(3), 1061 1098.

Hendriana, E., Mayasari, A., \& Gunadi, W. (2013). Why Do College Students Buy Counterfeit Movies? International Journal of e-Education, e-Business, e-Management and e-Learning, 3(1), 62-67.

Hennig-Thurau, T., Henning, V., \& Sattler, H. (2007). Consumer File Sharing of Motion Pictures. Journal of Marketing, 71(4), 129-159. 


\section{$\underline{\text { Punish, Seduce or Persuade }}$}

Hess, K., \& Waller, L. (2014). The digital pillory: media shaming of 'ordinary' people for minor crimes. Continuum: Journal of Media \& Cultural Studies, 28(1), 101-111.

Higgins, G. (2004). Can low self-control help with the understanding of the software piracy problem? Deviant Behavior, 26(1), 1-24.

Higgins, G. (2007a). Digital Piracy, Self-Control, and Rational Choice: An Examination of the Role of Value. International Journal of Cyber Criminology, 1(1), 33-55.

Higgins, G. (2007b). Digital Piracy: An Examination of Low Self-Control and Motivation Using ShortTerm Longitudinal Data. Cyberpsychology \& Behavior, 10(4), 523-529.

Higgins, G., Fell, B., \& Wilson, A. (2006). Digital Piracy: Assessing the Contributions of an Integrated Self-Control Theory and Social Learning Theory Using Structural Equation Modeling. Criminal Justice Studies, 19(1), 3-22.

Higgins, G., Fell, B., \& Wilson, A. (2007). Low Self-Control and Social Learning in Understanding Students' Intentions to Pirate Movies in the United States Social Science Computer Review, 25(3), 339-357.

Higgins, G., \& Makin, D. (2004). Does Social Learning Theory Condition the Effects of Low Self-Control on College Students' Software Piracy? Journal of Economic Crime Management, 2(2), 1-22.

Higgins, G., Marcum, C., Freiburger, T., \& Ricketts, M. (2012). Examining the Role of Peer Influence and Self-Control on Downloading Behavior. Deviant Behavior, 33(5), 412-423.

Higgins, G., Wilson, A., \& Fell, B. (2005). An Application of Deterrence Theory to Software Piracy. Journal of Criminal Justice and Popular Culture, 12(3), 229-248.

Higgins, G., Wolfe, S., \& Marcum, C. (2008a). Digital Piracy: An Examination of Three Measurements of Self-Control. Deviant Behavior, 29(5), 440-460.

Higgins, G., Wolfe, S., \& Marcum, C. (2008b). Music Piracy and Neutralization: A Preliminary Trajectory Analysis from Short-Term Longitudinal Data. International Journal of Cyber Criminology, 2(2), 324-336.

High, M. (2015). Dialogic Comedy in Pirate Rhetoric. International Journal of Communication, 9, 925940 .

Hill, C. (2007). Digital piracy: Causes, consequences, and strategic responses. Asia Pacific Journal of Management, 24(1).

Hillsman, S., \& Mahoney, B. (1988). Collecting and Enforcing Criminal Fines: A Review of Court Processes, Practices, and Problems. The Justice System Journal, 13(1), 17-36.

Hindelang, M. (1970). The Commitment of Delinquents to Their Misdeeds: Do Delinquents Drift? Social Problems, 17(4), 502-509.

Hinduja, S. (2001). Correlates of Internet Software Piracy. Journal of Contemporary Criminal Justice, 17(4), 369-382

Hinduja, S. (2003). Trends and Patterns among Online Software Pirates. Ethics and Information Technology, 5(1), 49-61.

Hinduja, S. (2007). Neutralization theory and online software piracy: An empirical analysis. . Ethics and Information Technology, 9(3), 197-204.

Hinduja, S. (2008). Deindividuation and Internet Software Piracy. Cyberpsychology \& Behavior, 11(4), 391-398

Hinduja, S. (2012). General Strain, Self-Control, and Music Piracy. International Journal of Cyber Criminology, 6(1), 339-357.

Hinduja, S., \& Higgins, G. (2011). Trends and Patterns Among Music Pirates. Deviant Behavior, 32(7), 563-588.

Hinduja, S., \& Ingram, J. (2009). Social learning theory and music piracy: the differential role of online and offline peer influences. Criminal Justice Studies, 22(4), 405-420.

Hirtenlehner, H., \& Hardie, B. (2016). On the Conditional Relevance of Control: An Application of Situational Action Theory to Shoplifting. Deviant Behavior, 37(3), 315-331.

Hirtenlehner, H., Pauwels, L., \& Mesko, G. (2015). Is the criminogenic effect of exposure to peer delinquency dependent on the ability to exercise self-control? Results from three countries. Journal of Criminal Justice, 43(6), 532-543.

Hirvonen, N., Huotari, M., Niemelä, R., \& Korpelainen, R. (2012). Information Behavior in Stages of Exercise Behavior Change. Journal of the American Society for Information Sciences and Technology, 63(9), 1804-1819.

Hochman, N. (2009). Tax defiers and the tax gap: stopping "frivolous squared" before it spreads. Stanford Law \& Policy Review, 20(1), 69-84.

Holland, P. (1986). Statistics and Causal Inference. Journal of the American Statistical Association, 81(396), 945-960. 


\section{Bibliography}

Holm, P. (2014). Piracy on the simulated seas: the computer games industry's non-legal approaches to fighting illegal downloads of games. Information \& Communications Technology Law, 23(1), 61-76.

Holpuch, A. (2012). Minnesota woman to pay $\$ 220,000$ fine for 24 illegally downloaded songs. Retrieved 17-01-2017, from https://www.theguardian.com/technology/2012/sep/11/minnesota-womansongs-illegally-downloaded

Holt, T., Bossler, A., \& May, D. (2011). Low Self-Control, Deviant Peer Associations, and Juvenile Cyberdeviance. American Journal of Criminal Justice, 1-18.

Holt, T., \& Copes, H. (2010). Transferring subcultural knowledge on-line: Practices and beliefs of persistent digital pirates. Deviant Behavior, 31(7), 625-654.

Hong, S. (2004). The Effects of Napster on Recorded Music Sales: Evidence from the Consumer Expenditure Survey. SIEPR Discussion Paper. Stanford Institute for Economic Policy Research. Stanford. Retrieved from http://www-siepr.stanford.edu/papers/pdf/03-18.pdf

Horney, J., \& Marshall, I. (1992). Risk perceptions among serious offenders: the role of crime and punishment. Criminology, 30(4), 575-594.

Hsu, J., \& Shiue, C. (2008). Consumers' Willingness to Pay for Non-pirated Software. Journal of Business Ethics, 81(4), 715-732.

Huang, C. (2005). File Sharing as a Form of Music Consumption. International Journal of Electronic Commerce, 9(4), 37-55.

Huang, Y., Lin, C., Su, H., \& Tung, M. (2015). I worship, so I download? Idol worship, music purchase and piracy by young consumers in Taiwan. Asia Pacific Journal of Marketing and Logistics, 27(1), 99-126.

Hui, K., \& Png, I. (2003). Piracy and the Legitimate Demand for Recorded Music. Contributions to Economic Analysis \& Policy, 2(1), 1-22.

Huizinga, D., \& Elliot, D. (1986). Reassessing the Reliability and Validity of Self-Report Delinquency Measures. Journal of Quantitative Criminology, 2(4), 293-327.

Hulu. (n.d.). Hulu - Watch TV, Originals, and Hit Movies. Retrieved 17-01-2017, from http://www.hulu.com/welcome

Humble Bundle. (n.d.). Humble Survive This Bundle (pay what you want and help charity). Retrieved $17-$ 01-2017, from https://www.humblebundle.com/survive-this-bundle

Humphries, M. (2011). 15-year-old facing jail time for downloading 24 movies. Retrieved 17-01-2017, from http://www.geek.com/news/15-year-old-facing-jail-time-for-downloading-24-movies$1415467 /$

Hurley, L. (2016). How The Walking Dead Is Fighting Against Piracy. Retrieved 17-01-2017, from http://www.cinemablend.com/television/How-Walking-Dead-Fighting-Against-Piracy120547.html

Huygen, A., Rutten, P., Huveneers, S., Limonard, S., Poort, J., Leenheer, J., . . Helberger, N. (2009). Ups and Downs: Economische en Culturele Gevolgen van file sharing voor muziek, film en games. Amsterdam: SEO.

IFPI. (2011). IFPI Digital Music Report 2011: Music at the touch of a button. London: IFPI.

IFPI. (2015). IFPI Digital Music Report 2015.

Ingham, T. (2016). Spotify Revenues Topped \$BN Last Year as Losses Hit \$194M. Retrieved 17-012017, from http:/www.musicbusinessworldwide.com/spotify-revenues-topped-2bn-last-yearas-losses-hit-194m/

Ingraham, N. (2013). Tweetbot pirates are naming and shaming themselves on Twitter. Retrieved 17-012017, from http://www.theverge.com/2013/2/27/4035406/tweetbot-pirates-are-naming-andshaming-themselves-on-twitter

Ingram, H., \& Schneider, A. (1991). The Choice of Target Populations. Administration \& Society, 23(3), 333-356.

Ingram, J., \& Hinduja, S. (2008). Neutralizing music piracy: an empirical examination. Deviant Behavior 29(4), 334-366.

Internet World Stats. (2016). World Internet Users Statistics and 2016 World Population Stats. Retrieved 17-01-2017, from http://www.internetworldstats.com/stats.htm

Ipsos. (2012). Connected Music Matters 2012.

Ipsos, \& Oxford Economics. (2011a). Economic Consequences of Movie Piracy - Canada.

Ipsos, \& Oxford Economics. (2011b). Economic consequences of movie piracy: Australia

Jackman, M., \& Lorde, T. (2014). Why buy when we can pirate? The role of intentions and willingness to pay in predicting piracy behavior. International Journal of Social Economics, 41(9), 801-819.

Jacobs, B. (2010). Deterrence and Deterrability. Criminology, 48(2), 417-441. 


\section{$\underline{\text { Punish, Seduce or Persuade }}$}

Jacobs, B., \& Piquero, A. (2012). Boundary-Crossing in Perceptual Deterrence: Investigating the Linkages Between Sanction Severity, Sanction Certainty, and Offending. International Journal of Offender Therapy and Comparative Criminology, 57(7), 792-812.

Jacobs, R., Heuvelman, A., Tan, M., \& Peters, O. (2012). Digital movie piracy: A perspective on downloading behavior through social cognitive theory. Computers in Human Behavior, 28(3), 958-967.

Jain, S. (2008). Digital Piracy: A Competitive Analysis. Marketing Science, 27(4), 610-626.

Jaisingh, J. (2007). Piracy on File-sharing Networks: Strategies for Recording Companies. Journal of Organizational Computing and Electronic Commerce, 17(4), 329-348.

Jakobs, G. (2004). Imputation in Criminal Law and the Conditions for Norm Validity. Buffalo Criminal Law Review, 7(2), 491-511.

Jakobsson, M., \& Reiter, M. (2002). Discouraging Software Piracy Using Software Aging. Lecture Notes in Computer Science, 2320, 1-12.

Jambon, M., \& Smetana, J. (2012). College students' moral evaluations of illegal music downloading. Journal of Applied Developmental Psychology, 33(1), 31-39.

Janssens, J., Vandaele, S., \& vander Beken, T. (2009). The Music Industry on (the) Line? Surviving Music Piracy in a Digital Era. European Journal of Crime, Criminal Law and Criminal Justice, 17(2), 77-96.

Jeffries, A. (2013). Internet providers launch controversial Copyright Alert System, promise 'education' over lawsuits. Retrieved 17-01-2017, from http://www.theverge.com/2013/2/25/4026194/infamous-six-strike-anti-piracy-program-barks-harder-than-it-bites.

Jensen, C. (2003). The More Things Change, The More They Stay the Same: Copyright, Digital Technology, and Social Norms Standford Law Review, 56(2), 531-570.

Jeong, B., \& Khouja, M. (2013). Analysis of the effectiveness of preventive and deterrent piracy contro strategies: Agent-based modeling approach. Computer in Human Behavior, 29(6), 2744-2755.

Jeong, B., \& Yoon, T. (2014). The Role of Regulatory Focus and Message Framing on Persuasion of Antipiracy Educational Campaigns. Paper presented at the Americas Conference on Information Systems, Savannah.

Jeong, B., Zhao, K., \& Khouja, M. (2012). Consumer Piracy Risk: Conceptualization and Measurement in Music Sharing. International Journal of Electronic Commerce, 16(3), 89-118.

Jeong, G., \& Lee, J. (2010). Estimating Consumer Preferences for Online Music Services. Applied Economics, 42(30), 3885-3893.

Johnson, D. (2014). See How Much Every Top Artist Makes on Spotify. Retrieved 17-01-2017, from http://time.com/3590670/spotify-calculator/

Johnson, S., Guerette, R., \& Bowers, K. (2014). Crime displacement: what we know, what we don't know, and what it means for crime reduction. Journal of Experimental Criminology, 10(4), 549-571.

Jones, B. (2014). File-Sharing Copyright Trolls Invade Finland. Retrieved 17-01-2017, from https://torrentfreak.com/file-sharing-copyright-trolls-invade-finland-140326/

Judd, B. (2014). 'Piracy cancer' will kill Australian film, TV industry: Wolf Creek actor John Jarratt. Retrieved 17-01-2017, from http://www.abc.net.au/news/2014-10-15/piracy-cancer-will-killaustralian-film-tv-industry-john-jarratt/5815864

Kabiru, C., \& Ezeh, A. (2007). Factors Associated with Sexual Abstinence among Adolescents in Four Sub-Saharan African Countries. African Journal of Reproductive Health, 11(3), 111-132.

Kafka, P. (2016). Spotify lost more money than ever last year - which is great news for Spotify. Retrieved 17-01-2017, from http://www.recode.net/2016/5/23/11749122/spotify-losses-revenue-2015

Kahan, D. (2000). Gentle Nudges vs. Hard Shoves: Solving the Sticky Norms Problem. The University of Chicago Law Review, 67(3), 607-645.

Kam, C., Wilking, J., \& Zechmeister, E. (2007). Beyond the "Narrow Data Base": Another Convenience Sample for Experimental Research. Political Behavior, 29(4), 415-440.

Kammerstetter, M., Platzer, C., \& Wondracek, G. (2012). Vanity, cracks and malware: insights into the anti-copy protection ecosystem. Paper presented at the ACM Conference on Computer and communications security, New York.

Kantar Media. (2013). OCI Tracker: High volume infringers analysis report. London: Kantar Media.

Karaganis, J., \& Renkema, L. (2013). Copy Culture in the US \& Germany. In T. A. Assembly (Ed.): Columbia University.

Kariithi, N. (2011). Is the Devil in the Data? A Literature Review of Piracy Around the World. The Journal of World Intellectual Property, 14(2), 133-154.

Karunaratne, S. (2012). The Case Against Combating BitTorrent Piracy Through Mass John Doe Copyright Infringement Lawsuits. Michigan Law Review, 111(2), 283-309. 


\section{Bibliography}

Katz, D., Bommarito II, M., \& Blackman, J. (2017). Predicting the Behavior of the Supreme Court of the United States: A General Approach. Retrieved from https://papers.ssrn.com/sol3/papers.cfm?abstract id=2463244

Kelly, G. (2016). A court-ordered graduated response system in Ireland: the beginning of the end? Journal Of Intellectual Property Law \& Practice, 11(3), 183-198.

Khan, A., Othman, M., Ali, M., Khan, A., \& Madani, S. (2014). Pirax: framework for application piracy control in mobile cloud environment. Journal of Supercomputing, 68(2), 753-776.

Khang, H., Ki, E., Park, I., \& Baek, S. (2012). Exploring antecedents of attitude and intention toward Internet piracy among college students in South Korea. Asian Journal of Business Ethics, 1(2), 177-194.

Kim, J., \& Kim, J. (2015). Software Piracy among Korean Adolescents: Lessons from Panel Data. Deviant Behavior, 36(9), 705-724.

Kin-wai Lau, E. (2006). Factors motivating people toward pirated software. Qualitative Market Research, 9(4), 404-419.

Kini, R., Ramakrishna, H., \& Vijayraraman, B. (2003). An exploratory study of moral intensity regarding software piracy of students in Thailand. Behaviour and Information Technology, 22(1), 63-70.

Kini, R., Ramakrishna, H., \& Vijayraraman, B. (2004). Shaping of Moral Intensity regarding Software Piracy: A Comparison between Thailand and U.S. Students. Journal of Business Ethics, 49(1), 91-104.

Kinnally, W., Lacayo, A., McClung, S., \& Sapolsky, B. (2008). Getting up on the download: college students' motivations for acquiring music via the web. . New Media \& Society, 10(6), 893-913.

Kirk, D. (2015). A natural experiment of the consequences of concentrating former prisoners in the same neighborhoods. Proceedings of the National Academy of Sciences of the United States of America, 112(22), 6943-6348.

Kleck, G., \& Barnes, J. (2008). Deterrence and Macro-Level Perceptions of Punishment Risks: Is There a "Collective Wisdom"? Crime \& Delinquency, 59(7), 1006-1035.

Kleck, G., Sever, B., Li, S., \& Gertz, M. (2005). The Missing Link in General Deterrence Research. Criminology, 43(3), 623-659.

Koh, B., Murthi, B., \& Raghuanathan, S. (2014). Shifting Demand: Online Music Piracy, Physical Music Sales, and Digital Music Sales. Journal of Organizational Computing and Electronic Commerce, 24(4), 366-387.

Koklic, M., Kukar-Kinney, M., \& Vida, I. (2016). Three-Level Mechanism of Consumer Digital Piracy: Development and Cross-Cultural Validation. Journal of Business Ethics, 134(1), 15-27.

Koklic, M., Vida, I., Bajde, D., \& Culiberg, B. (2014). The study of perceived adverse effects of digital piracy and involvement: insights from adult computer users. Behaviour \& Information Technology, 33(3), 224-235.

Konstantakis, N., Palaigeorggiou, G., Siozos, P., \& Tsoukalas, I. (2010). What do computer science students think about software piracy? Behaviour and Information Technology, 29(3), 277-285.

Koster, A. (2012). Fighting Internet Piracy: The French Experience With The Hadopi Law. International Journal of Management \& Information Systems, 16(4), 327-330.

Kowalski, R., Morgan, C., Drake-Lavelle, K., \& Allison, B. (2016). Cyberbullying among college students with disabilities. Computers in Human Behavior, 57(3), 416-427.

Kramer, S. (1990). An Economic Analysis of Criminal Attempt: Marginal Deterrence and the Optimal Structure of Sanctions. The Journal of Criminal Law and Criminology, 81(2), 398-417.

Krawczyk, M. (2009). The Role of Repetition and Observability in Deterring Insurance Fraud. The Geneva Risk and Insurance Review, 34(1), 74-87.

Krawczyk, M., Tyrowicz, J., Kukla-Gryz, A., \& Hardy, W. (2015). "Piracy is not theft!" Is it just students who think so? Journal of Behavioral and Experimental Economics, 54, 32-39.

Krebs, D., \& Denton, K. (2005). Toward a More Pragmatic Approach to Morality: A Critical Evaluation of Kohlberg's Model. Psychological Review, 112(3), 629-649.

Kroes, E., \& Sheldon, J. (1988). Stated Preference Methods: An Introduction. Journal of Transport Economics \& Policy, 22(1), 11-25.

Kunze, O., \& Mai, L. (2007). Consumer adoption of online music services: the influence of perceived risks and risk-relief strategies. International Journal of Retail \& Distribution Management, 35(11) 862-877.

Kuo, F., \& Hsu, M. (2001). Development and Validation of Ethical Computer Self-Efficacy Measure: The Case of Softlifting. Journal of Business Ethics, 32(4), 299-315.

Kwong, K., Yau, O., Lee, J., Sin, L., \& Tse, A. (2003). The Effect of Attitudinal and Demographic Factors on Intention to Buy Pirated CDs: the Case of Chinese Consumers. Journal of Business Ethics, $47(3), 223-235$ 


\section{$\underline{\text { Punish, Seduce or Persuade }}$}

Kwong, T., \& Lee, M. (2002). Behavioral Intention Model for the Exchange Mode Internet Music Piracy. Paper presented at the Proceedings of the 35th Annual Hawaii International Conference on System Sciences, Hawaii.

La Roche, C., Flanigan, M., \& Marks, M. (2004). Online Music Piracy: Are Lawsuits The Best Approach? Journal of Business and Economic Research, 2(9), 1-12.

Laird, S. (2013). 'Game of Thrones' Is Most Pirated Show of 2013 So Far. 17-01-2017, from http://mashable.com/2013/06/24/game-of-thrones-most-pirated/\#IyumD1i6PSqX

Landes, W., \& Posner, R. (1989). An Economic Analysis of Copyright Law. Journal of Legal Studies, $18(2), 325-363$

LaRose, R., \& Kim, J. (2007). Share, Steal, or Buy? A Social Cognitive Perspective of Music Downloading. CyberPsychology \& Behavior, 10(2), 267-277.

LaRose, R., Lai, Y., Lange, R., \& Love, B., Wu, Y. (2006). Sharing or Piracy? An Exploration of Downloading Behavior Journal of Computer-Mediated Communication, 11(1), 1-21.

Larsson, S., \& Svensson, M. (2010). Compliance or Obscurity? Online Anonymity as a Consequence of Fighting Unauthorized File sharing. Policy \& Internet, 2(4), 77-105.

Larsson, S., Svensson, M., \& de Kaminski, M. (2012). Online piracy, anonymity and social change: Innovation through deviance. Convergence: The International Journal of Research into New Media Technologies, 19(1), 1-20.

Larsson, S., Wnukowska-Mtonga, S., Svensson, M., \& de Kaminski, M. (2014). Parallel Norms: FileSharing and Contemporary Copyright Development in Australia. The Journal of World Intellectual Property, 17(1-2), 1-15.

Lau, E. (2003). An empirical study of software piracy. Business Ethics: A European Review, 12(3), 233 245.

Lau, E. (2006). Factors Motivating People Toward Pirated Software. Qualitative Market Research, 9(4), 404-419.

Lauinger, T., Szydlowski, M., Onarlioglu, K., Wondracek, G., Kirda, E., \& Kruegel, C. (2013). Clickonomics: Determining the Effect of Anti-Piracy Measures for One-Click Hosting. Retrieved from https://www.cs.ucsb.edu/ chris/research/doc/ndss13 clickonomics.pdf

Law, R., \& Wong, D. (2005). How do Hospitality and Tourism Students View Software Piracy? Asia Pacific Journal of Tourism Research, 10(3), 263-273.

Layton, R., \& Watters, P. (2010). Investigation into the extend of infringing content on BitTorrent networks Ballarat, Australia: Internet Commerce Security Laboratory.

Lee, D., Park, J., Kim, J., Kim, J., \& Moon, J. (2011). Understanding music sharing behaviour on social network services. Online Information Review, 35(5), 716-733.

Leeman, J., Chang, Y., Lee, E., Voils, C., Crandell, J., \& Sandelowski, M. (2010). Implementation of antiretroviral therapy adherence interventions: a realist synthesis of evidence. Journal of Advanced Nursing, 66(9), 1915-1930.

Leeuw, F., \& Leeuw, H. B. M. (2012). Cyber society and digital policies: Challenges to evaluation? Evaluation, 18(1), 111-127.

Leeuw, F., \& Schmeets, H. (2016). Empirical Legal Research: a guidance book for lawyers, legislators and regulators. Cheltenham, UK: EE-Publishers.

Leeuw, H. B. M. (2016). De evaluatie van digitaal beleid: een Big Data case study. Justitiële Verkenningen, $42(1), 22-32$

Leeuw, H. B. M. (2017). Big Data and Evaluation: A Case Study on Digital Piracy, the Copyright Alert System, and Big Data. In G. Petersson \& J. Breul (Eds.), Cyber Society, Big Data, and Evaluation. Piscataway: Transaction, pp. 97-116.

Leeuw, H. B. M., \& Bogaerts, S. (2009). High-Tech Crime en Voorlichting: Een inventarisatie van voorlichtingsinitiatieven in Nederland en een analyse van kansen en mogelijkheden. Leuven: Katholieke Universiteit Leuven.

Lesser, J. (n.d.). The Copyright Alert System: Moving to Implementation. Retrieved 17-01-2017, from http://www.copyrightinformation.org/uncategorized/the-copyright-alert-system-moving-toimplementation/

Leung, T. (2010). What is the True Loss Due to Piracy? Evidence from Microsoft Office in Hong Kong. The Review of Economics and Statistics, 95(3), 1018-1029.

Leventhal, H. (1971). Fear Appeals and Persuasion: The Differentiation of a Motivational Construct American Journal of Public Health, 61(6), 1208-1224.

Levin, A., Dato-on, M., \& Manolis, C. (2007). Deterring illegal downloading: the effects of threat appeals, past behavior, subjective norms, and attributions of harm. Journal of Consumer Behavior, 6(23), 111-122 


\section{Bibliography}

Levin, M., Dato-on, M., \& Rhee, K. (2004). Money for nothing and hits for free: the ethics of downloading music from peer-to-peer web sites. Journal of Marketing Theory and Practice, 12(1), 48-59.

Li, X., \& Nergadze, N. (2009). Deterrent Effect of Four Legal and Extralegal Factors on Online Copyright Infringement. Journal of Computer Mediated Communication, 14(2), 307-327.

Liao, C., Lin, H., \& Liu, Y. (2010). Predicting the Use of Pirated Software: A Contingency Model Integrating Perceived Risk with the Theory of Planned Behavior Journal of Business Ethics, 91(2), 237-252.

Liebowitz, S. (2005). Pitfalls in Measuring the Impact of File-sharing on the Sound Recording Market. CESifo Economic Studies, 51(2-3).

Liebowitz, S. (2008). Testing File Sharing's Impact on Music Album Sales in Cities. Management Science, $54(4), 852-859$

Liebowitz, S. (2016). How much of the decline in sound recording sales is due to file-sharing? Journal of Cultural Economics, 40(1), 13-28.

Lievrouw, L. (2012). The Next Decade in Internet Time: Ways ahead for new media studies. Information. Information, Communication \& Society, 15(5), 616-638.

Limayem, M., Khalifa, M., \& Chin, W. (2004). Factors Motivating Software Piracy: A Longitudinal Study. IEEE Transactions on Engineering Management, 51(4), 414-425.

Lin, T., Hsu, J., \& Chen, H. (2013). Customer Willingness to Pay for Online Music: The Role of Free Mentality. Journal of Electronic Commerce Research, 14(4), 315-333.

Lin, T., Hsu, M., Kuo, F., \& Sun, P. (1999). An Intention model-based Survey of Software Piracy. Paper presented at the $32^{\text {nd }}$ Annual Hawaii International Conference on System Sciences, Hawaii.

Lindell, M., \& Whitney, D. (2001). Accounting for Common Method Variance in Cross-Sectional Research Designs. Journal of Applied Psychology, 86(1), 114-121.

Loader, B., \& Dutton, W. (2012). A Decade in Internet Time: The dynamics of the Internet and society. Information, Communication \& Society, 15(5), 609-615.

Long-Middleton, E., Burke, P., Lawrence, C., Blanchard, L., Amudala, N., \& Rankin, S. (2013). Understanding Motivations for Abstinence among Adolescent Young Women: Insights into Effective Sexual Risk Reduction Strategies. Journal of Pediatric Health Care, 27(5), 342-350.

Lorde, T., Devonish, D., \& Beckles, A. (2010). Real pirates of the Caribbean : socio-psychological traits, the environment, personal ethics and the propensity for digital piracy in Barbados Journal of Eastern Caribbean Studies, 35(1), 1-35.

Lou, X., \& Hwang, K. (2009). Collusive Piracy Prevention in P2P Content Delivery Networks. IEEE Transactions on Computers, 58(7), 970-983.

Loughran, T., Pogarsky, G., Piquero, A., \& Paternoster, R. (2012). Re-Examining the Functional Form of the Certainty Effect in Deterrence Theory. Justice Quarterly, 29(5), 712-741.

Louviere, J., Hensher, D., \& Swait, J. (2000). Stated Choice Methods: Analysis and Applications. Cambridge: Cambridge University Press.

Ludwig, J., Kling, J., \& Mullainathan, S. (2011). Mechanisms Experiments and Policy Evaluations. Journal of Economic Perspectives, 25(3), 17-38.

Luyten, S. (2014). Zware boete voor vader die 'Bambi' en de 'Leeuwenkoning' downloadde. Retrieved 17-01-2017, from http://www.nieuwsblad.be/cnt/dmf20140505 01093357

Lysonski, S., \& Durvasula, S. (2008). Digital piracy of MP3s: consumer and ethical predispositions. Journal of Consumer Marketing, 25(3), 167-178.

Ma, L., Montgomery, A., Singh, P., \& Smith, M. (2014). An Empirical Analysis of the Impact of PreRelease Movie Piracy on Box Office Revenue. Information Systems Research, 25(3), 590-603.

Maccoun, R., Liccardo Pacula, R., Chriqui, J., Harris, K., \& Reuter, P. (2009). Do citizens know whether their state has decriminalized marijuana? Assessing the perceptual component of deterrence theory. Review of Law \& Economics, 5(1), 347-371.

Macik, T. (2015). Global Data Meets 3-D Printing: The Quest for a Balanced and Globally Collaborative Solution to Prevent Patent Infringement in the Foreseeable 3-D Printing Revolution. Indiana Journal of Global Legal Studies, 22(1), 149-173.

Madden, G. (1995). Experimentation in Economics: An Overview of the Stated-Preference Experimental Design Method. Australian Economic Papers, 34(64), 120-135.

Maffioletti, A., \& Ramello, G. (2004). Should we Put them in Jail? Copyright Infringements, Penalties and Consumer Behaviour: Insights from Experimental Data. Review of Economic Research on Copyright Issues, 1(2), 81-95.

makeuseof. (2015). Piracy On Android: How Bad Is It Really? Retrieved 17-01-2017, from http://www.makeuseof.com/tag/piracy-android-how-bad-is-it-really/ 


\section{$\underline{\text { Punish, Seduce or Persuade }}$}

Makkonen, M., Haltunnen, V., \& Frank, L. (2011). The Effect of Gender, Age, and Income on the Willingness to Pay for Music Downloads. Paper presented at the Bled eConference eFuture Bled.

Malin, J., \& Fowers, B. (2009). Adolescent self-control and music and movie piracy. . Computers in Human Behavior, 25(3), 718-722.

Mallough, R. (2013). Why 3D printers could hammer the manufacturing industry. Retrieved 17-01-2017, from http://www.macleans.ca/economy/business/the-new-age-of-piracy/

Maratea, R., \& Kavanagh, P. (2012). Deviant Identity in Online Contexts: New Directives in the Study of a Classic Concept. Sociology Compass, 6(2), 102-112.

Marcum, C., Higgins, G., Wolfe, S., \& Ricketts, M. (2011). Examining the Intersection of Self-control, Peer Association and Neutralization in Explaining Digital Piracy. Western Criminology Review, 12(3), 60-74.

Mark, T., \& Swait, J. (2003). Using Stated Preference Modeling to Forecast the Effect of Medication Attributes on Prescriptions of Alcoholism Medications. Value in Health, 6(4), 474-482.

Mars, B., Heron, J., Biddle, L., Donovan, J., Holley, R., Piper, M., . . . Gunnel, D. (2015). Exposure to, and searching for, information about suicide and self-harm on the Internet: Prevalence and predictors in a population based cohort of young adults. Journal of Affective Disorders, 185(1), 239-245.

Martens, B., Herfert, J., \& Karbe, T. (2012). Auswirkungen digitaler Piraterie auf die Ökonomie von Medien. Berlin: House of Research.

Martikainen, E. (2014). Does File-Sharing Reduce DVD Sales? NETNOMICS: Economic Research and Electronic Networking, 15(1), 9-31.

Masango, S., Rataemane, S., \& Motojesi, A. (2008). Suicide and suicide risk factors: A literature review. South African Family Practice, 50(6), 25-29.

Matsueda, R., Kreager, D., \& Huizinga, D. (2006). Deterring Delinquents: A Rational Choice Model of Theft and Violence. American Sociological Review, 71(1), 95-122.

Matza, D. (1964). Delinquency and drift. New York: Wiley.

Maxwell, S., \& Gray, K. (2000). Deterrence: Testing the Effects of Perceived Sanction Certainty on Probation Violations. Sociological Inquiry, 70(2), 117-136.

McCandless, D., Quick, M., Hollowood, E., \& Slater, T. (2015). Selling out: How mush do music artists earn online? Retrieved 17-01-2017, from http:/www.informationisbeautiful.net/visualizations/how-much-do-music-artists-earn-online-2015-remix/.

McCorkle, D., Reardon, J., Dalenberg, D., Pryor, A., \& Wicks, J. (2012). Purchase or pirate: a model of consumer intellectual property theft. Journal of Marketing Theory and Practice, 20(1), 73-86.

McKenzie, J. (2009). Illegal Music Downloading and its Impact on Legitimate Sales: Australian Empirical Evidence. Australian Economic Papers, 48(4), 296-307.

McKenzie, J., \& Walls, D. (2016). File Sharing and Film Revenues: Estimates of Sales Displacement at the Box Office. The BE Journal of Economic Analysis \& Policy, 16(1), 25-57.

McMillan, G. (2013). Appeals court approves $\$ 675,000$ fine for student who illegally downloaded 30 songs. Retrieved 17-01-2017, from http://www.digitaltrends.com/music/appeals-court-denies-piracypenalty-plea/

Megaupload. (n.d.). Megaupload.

Mendes, S. (2004). Certainty, Severity, and Their Relative Deterrent Effects:Questioning the Implications of the Role of Risk inCriminal Deterrence Policy. The Policy Studies Journal, 32(1), 59-74.

Mendes, S., \& McDonald, M. (2001). Putting Severity of Punishment Back into the Deterrence Package. Policy Studies Journal, 29(4), 588-610.

Meyer, T. (2012). Graduated Response in France: The Clash of Copyright and the Internet. Journal of Information Policy, 2(2), 107-127.

Meyer, T., \& van Audenhove, L. (2010). Graduated response and the emergence of a European surveillance society. info, 12(6), 69-79.

Miller, B. (2004-2005). The War Against Free Music: How the RIAA Should Stop Worrying and Learn to Love the MP3. University of Detroit Mercy Law Review, 82(2), 303-329.

MillwardBrown Digital. (2013). Understanding the Role of Search in Online Piracy. New York: MillwardBrown Digital.

Minchiello, V., Mariño, R., \& Browne, J. (2001). Knowledge, risk perceptions and condom usage in male sex workers from three Australian cities. Aids Care, 13(3), 387-402.

Mirghani, S. (2011). The War on Piracy: Analyzing the Discursive Battles of Corporate and GovernmentSponsored Anti-Piracy Media Campaigns. Critical Studies in Media Communication, 28(2), 113-134.

Mocan, N., \& Rees, D. (2005). Economic Conditions, Deterrence and Juvenile Crime: Evidence from Micro Data. American Law and Economics Review, 7(2), 319-349. 


\section{Bibliography}

Montalvo, J. (2011). Voting after the Bombings: a Natural Experiment on the Effect of Terrorist Attacks on Democratic Elections. . The Review of Economics and Statistics, 93(4), 1146-1154.

Moohr, G. (2003). The Crime of Copyright Infringement: An Inquiry Based on Morality, Harm and Criminal Theory. Boston University Law Review, 83(4), 731-783.

Moon, B., McCluskey, J., \& McCluskey, C. (2010). A General Theory of Crime and Computer Crime: An Empirical Test. Journal of Criminal Justice, 38(4), 767-772.

Moon, S., Kim, K., Feeley, T., \& Shin, D. (2015). A normative approach to reducing illegal music downloading: The persuasive effects of normative message framing. Telematics and Informatics, 32(1), 169-179.

Moore, R., \& McMullan, E. (2004). Perceptions of Peer-to-Peer File Sharing Among University Students. Journal of Criminal Justice and Popular Culture, 11(1), 1-19.

Moore, R., \& McMullan, E. (2009). Neutralizations and Rationalizations of Digital Piracy: A Qualitative Analysis of University Students. International Journal of Cyber Criminology, 3(1), 441-451.

Moores, T., \& Chang, J. (2006). Ethical Decision Making in Software Piracy: Initial Development and Test of a Four-Component Model. MIS Quarterly, 30(1), 167-180.

Moores, T., \& Dhaliwal, J. (2004). A reversed context analysis of software piracy issues in Singapore. Information and Management, 41(8), 1037-1042.

Moores, T., \& Dhillon, G. (2000). Software Piracy: A View from Hong Kong. Communications of the $A C M, 43(12), 88-93$.

Moores, T., \& Esichaikul, V. (2011). Socialization and Software Piracy: A Study. Journal of Computer Information Systems, 51(3), 1-9.

Morris, R., \& Higgins, G. (2009). Neutralizing potential and self-reported digital piracy: A multitheoretical exploration among college undergraduates. Criminal Justice Review, 34(2), 173-195.

Morris, R., Johnson, M., \& Higgins, G. (2009). The role of gender in predicting the willingness to engage in digital piracy among college students. Criminal Justice Studies, 22(4), 393-404.

Morrison-Beedy, D., Carey, M., Côté-Arsenault, D., Seibold-Simpson, S., \& Robinson, A. (2008) Understanding Sexual Abstinence in Urban Adolescent Girls. Journal of Obstetric, Gynecologic, \& Neonatal Nursing, 37(2), 185-195.

Mortimer, J., Nosko, C., \& Sorensen, A. (2010). Supply Responses to Digital Distribution: Recorded Music and Live Performances. NBER Working Paper Series. Retrieved from http://www.nber.org/papers/w16507.pdf

Morton, N., \& Koufteros, X. (2008). Intention to Commit Online Music Piracy and Its Antecedents: An Empirical Investigation. Structural Equation Modeling, 15(3), 491-512.

Mousley, M. (2003). Peer-to-Peer Combat: The Entertainment Industry's Arsenal In Its War on Digital Piracy. Villanova Law Review, 48(2), 667-695.

MPA/LEK. (2006). The cost of movie piracy.

MPAA. (2005). Piracy, It's a Crime.

MPAA. (2013). Respect Copyrights. Retrieved 17-01-2017, from http://www.respectcopyrights.org

Musiani, F., \& Peserico, E. (2014). A second-hand market for digital goods? First Monday, 19(11).

Nagin, D. (1998). Criminal Deterrence Research at the Outset of the Twenty-First Century. Crime and Justice, 23, 1-42.

Nagin, D., \& Pogarsky, G. (2001). Integrating Celerity, Impulsivity, and Extralegal Sanction Threats into a Model of General Deterrence: Theory and Evidence. Criminology, 39(4), 865-892.

Nagin, D., Solow, R., \& Lum, C. (2015). Deterrence, Criminal Opportunities, and Police. Criminology, 53(1), 74-100.

Nagygyörgy, K., Urbán, R., Farkas, J., Griffiths, M., Zilahy, D., Kökönyei, G., . . Demetrovics, Z. (2013). Typology and Sociodemographic Characteristics of Massively Multiplayer Online Game Players. International Journal of Human-Computer Interaction, 29(3), 192-200.

Nandedkar, A., \& Midha, V. (2012). It won't happen to me: An assessment of optimism bias in music piracy. Computers in Human Behavior, 28(1), 41-48.

National Crime Prevention Council. (2011a). It Hurts

National Crime Prevention Council. (2011b). Premonition

National Crime Prevention Council. (2013). The Dangers of Intellectual Property Theft.

Nazario, K. (2011). 6 Hilarious Ways Game Designers Are Screwing With Pirates. Retrieved 17-01-2017, from http://www.cracked.com/article_19162_6-hilarious-ways-game-designers-are-screwingwith-pirates.html

Nazer, D. (2013). The Copyright Alert System FAQ. Retrieved 17-01-2017, from http://www.eff.org/deeplinks/2013/02/six-strikes-copyright-alert-system-faq. 


\section{$\underline{\text { Punish, Seduce or Persuade }}$}

Neagle, C. (2013). 3D printing could trigger intellectual property wars, legal expert says. Retrieved $17-$ 01-2017, from http:/www.networkworld.com/article/2168167/software/3d-printing-could trigger-intellectual-property-wars--legal-expert-says.html

Nelen, H., Leeuw, H. B. M., Bakker, F., \& Herrenberg, T. (2012). In de war en uit de bocht. Ex ante evaluatie van de aanpak van solistische dreigers binnen de pilot Dreigingsmanagement. Den Haag: Boom Juridische Uitgevers.

Netflix. (n.d.). Netflix Nederland - Kijk series online, kijk films online. Retrieved 17-01-2017, from https://www.netflix.com/nl/

Netflix Media Center. (2016). Netflix \& Binge: New Binge Scale Reveals TV Series We Devour and Those We Savor. Retrieved 17-01-2017, from https://media.netflix.com/en/press-releases/netflixbinge-new-binge-scale-reveals-tv-series-we-devour-and-those-we-savor-1

Newman, J. (2012). Downloaders note-ISP Copyright Alert System rollout begins. Retrieved 17-012017, from http://www.techhive.com/article/2012695/downloaders-note-isp-copyright-alertsystem-rollout-begins.html

Nguyen, G., Dejean, S., \& Moreau, F. (2014). On the complementarity between online and offline music consumption: the case of free streaming. Journal of Cultural Economics, 38(4), 315-330.

Nielsen Music. (2011). The hyper-fragmented world of music: Marketing considerations and revenue maximisation. London: Nielsen Music.

No Piracy. (n.d.). No Piracy. Retrieved 17-01-2017, from https://facebook.com/reportsoftwarepiracy.

Norland, E. (1990). Controlling Error in Evaluation Instruments. Journal of Extension, 28(2). Retrieved 17-01-2017, from https://www.joe.org/joe/1990summer/tt2.php.

NVPI. (2014). NVPI Report 2014. Amsterdam: NVPI.

O'Connell, D., Visher, C., Martin, S., Parker, L., \& Brent, J. (2011). Decide your time: Testing deterrence theory's certainty and celerity effects on substance-using probationers. Journal of Criminal Justice, 39(3), 261-267.

O'Keefe, D., \& Jensen, J. (2007). The Relative Persuasiveness of Gain-Framed Loss-Framed Messages for Encouraging Disease Prevention Behaviors: A Meta-Analytic Review. Journal of Health Communication, 12(7), 623-644.

Oblerholzer-Gee, F., \& Strumpf, K. (2007). The Effect of File Sharing on Record Sales: An Empirical Analysis. Journal of Political Economy, 115(1).

OECD. (2005). Digital Broadband Content: The online computer and video game industry Paris: OECD.

OECD. (2009). Piracy of Digital Content. Paris: OECD.

Olney, M., \& Brockelman, K. (2003). Out of the Disability Closet: strategic use of perception management by select university students with disabilities. Disability \& Society, 18(1), 35-50.

Olson, D., \& Ramker, G. (2001). Crime Does Not Pay, But Criminals May: Factors Influencing the Imposition and Collection of Probation Fees. The Justice System Journal, 22(1), 29-46.

Optimum. (n.d.). Copyright Infringement Alerts. Retrieved 17-01-2017, from http://optimum.custhelp.com/app/answers/detail/a id/3592

Osborn, L. (2014). Regulating Three-Dimensional Printing: The Converging Worlds Of Bits And Atoms. San Diego Law Review, 51(2), 553-622.

Osborn, L., \& Holbrook, T. (2015). Digital Patent Infringement in an Era of 3D Printing. UC Davis Law Review, 48, 1319-1385.

Ouellet, J. (2007). The Purchase Versus Illegal Download of Music by Consumers: The Influence of Consumer Response towards the Artist and Music. Canadian Journal of Administrative Sciences, 24(2), 107-119.

Owen, J. (2012). Graduated Response Systems and the Market for Copyrighted Works. Berkeley Technology Law Journal, 27, 559-612.

Oxford, T. (2010). The truth about PC game piracy. Retrieved 17-01-2017, from http://www.techrader.com/news/gaming/the-truth-about-pc-game-piracy-688864.

Padmanabhan, V., Wang, H., Chou, P., \& Sripanidkulchai, K. (2002). Distributing streaming media content using cooperative networking. Paper presented at the International workshop on Network and operating systems support for digital audio and video, New York.

Panas, E., \& Ninni, V. (2011). Ethical Decision Making in Electronic Piracy: An Explanatory Model based on the Diffusion of Innovation Theory and the Theory of Planned Behavior. International Journal of Cyber Criminology, 5(2), 836-859.

Pandora. (n.d.). Pandora Internet Radio - Listen to Free Music You'll Love. Retrieved 17-01-2017, from http://www.pandora.com/

Pankinkis, T. (2014). Mobile music piracy outgrows online torrenting. Retrieved 17-01-2017, from http://www.musicweek.com/news/read/mobile-music-piracy-outgrows-onlinetorrenting/058085 


\section{Bibliography}

Papacharissi, Z. (2002). The Virtual Sphere: The Internet as a Public Sphere. New Media \& Society, 4(1), 9-27.

Papies, D., \& Clement, M. (2008). Adoption of New Movie Distribution Services on the Internet. Journal of Media Economics, 21(3), 131-157.

Papies, D., Eggers, F., \& Wlömert, N. (2011). Music for free? How free ad-funded downloads affect consumer choice. Journal of the Academy of Marketing Science, 39(5), 777-794.

Park, S., Lee, J., \& Song, W. (2016). Short-term forecasting of Japanese tourist inflow to South Korea using Google trends data. Journal of Travel \& Tourism Marketing, 1-12.

Paternoster, R. (2010). How Much Do We Really Know About Criminal Deterrence? Journal of Criminal Law \& Criminology, 100(3), 765-823.

Paternoster, R., \& Iovanni, L. (1986). The Deterrent Effect of Perceived Severity: A Reexamination. Social Forces, 64(3), 751-777.

Paternoster, R., Saltzman, L., Waldo, G., \& Chiricos, T. (1985). Assessments of risk and behavioral experience: an exploratory study of change. Criminology, 23(3), 417-436.

Pathé. (n.d.). Online films kijken - Kijk de nieuwste \& beste films bij Pathé thuis. Retrieved 17-01-2017, from http://www.pathe-thuis.nl/

Patowary, K. (2011). How to Remove Unskippable Anti-Piracy Ads, Region Lock, and Encryption From DVDs. Retrieved 17-01-2017, from http://www.instantfundas.com/2011/08/how-to-removeunskippable-anti-piracy.html

Pauwels, L. (2011). Adolescent Offending and the Segregation of Poverty in Urban Neighbourhoods and Schools: An Assessment of Contextual Effects from the Standpoint of Situational Action Theory. Urban Studies Research, 1-17.

Pauwels, L., \& Svensson, R. (2009). Adolescent Lifestyle Risk by Gender and Ethnic Background: Findings from Two Urban Samples. European Journal of Criminology, 6(1), 5-23.

Pauwels, L., \& Svensson, R. (2013). Violent Youth Group Involvement, Self-reported Offending and Victimisation: An Empirical Assessment of an Integrated Informal Control/Lifestyle Model. European Journal on Criminal Policy and Research, 19(4), 369-386.

Pawson, R. (2002). Evidence-based Policy: The Promise of 'Realist Synthesis'. Evaluation, 8(3), 340-358.

Pawson, R. (2013). The Science of Evaluation: A Realist Manifesto. London: Sage.

Pawson, R., Greenhalgh, T., Harvey, G., \& Walshe, K. (2004). Realist synthesis: an introduction Manchester: University of Manchester.

Pawson, R., Greenhalgh, T., Harvey, G., \& Walshe, K. (2005). Realist review - a new method of systematic review designed for complex policy interventions. Journal of Health Services Research \& Policy, 10(1), 21-34.

Pawson, R., \& Tilley, N. (1997). Realistic Evaluation. London: Sage

Peace, G., Galletta, D., \& Thong, J. (2003). Software Piracy in the Workplace: A Model and Empirical Test. Journal of Management Information Systems, 20(1), 153-177.

Peitz, M., \& Waelbroeck, P. (2004). The Effect of Internet Piracy on Music Sales: Cross-Section Evidence. Review of Economic Research on Copyright Issues, 1(2).

Peitz, M., \& Waelbroeck, P. (2006). Why the Music Industry may Gain from Free Downloading - The role of Sampling. International Journal of Industrial Organization, 24(5), 907-913.

Pereira, C. (2015). PS4, PC Get Xbox Timed Exclusive Rise of the Tomb Raider in 2016. Retrieved 17 01-2017, from http://www.gamespot.com/articles/ps4-pc-get-xbox-timed-exclusive-rise-ofthe-tomb-r/1100-6429137/

Pérez, K., Marí-Dell'Olmo, M., Tobias, A., \& Borrell, C. (2007). Reducing Road Traffic Injuries Effectiveness of Speed Cameras in an Urban Setting. American Journal of Public Health, 97(9), $1632-1637$

Peters, G., Ruiter, R., \& Kok, G. (2013). Threatening communication: A critical re-analysis and a revised meta-analytic test of fear appeal theory. Health Psychology Review, 7(1), 8-31.

Petersson, G., Leeuw, F., Breul, J., \& Leeuw, H. B. M. (2017). Cyber Society, Big Data, and Evaluation: An Introduction. In G. Petersson \& J. Breul (Eds.), Cyber Society, Big Data, and Evaluation. Piscataway: Transaction Publishers, pp. 1-18.

Petrick, P. (2004). Why DRM Should be Cause for Concern: An Economic and Legal Analysis of the Effect of Digital Technology on the Music Industry. Cambridge: The Berkman Center for Internet \& Society.

Peukert, C., Claussen, J., \& Kretschmer, T. (2013). Piracy and Movie Revenues: Evidence from Megaupload. A Tale of the Long Tail? Retrieved 17-01-2017, from https://www.econstor.eu/bitstream/10419/79687/1/VfS_2013_pid_271.pdf

Phau, I., \& Liang, J. (2012). Downloading digital video games: predictors, moderators and consequences. Marketing Intelligence \& Planning, 30(7), 740-756. 


\section{$\underline{\text { Punish, Seduce or Persuade }}$}

Phau, I., Lim, A., Liang, J., \& Lwin, M. (2014). Engaging in digital piracy of movies: a theory of planned behaviour approach. Internet Research, 24(2), 246-266.

Phau, I., \& Ng, J. (2010). Predictors of Usage Intentions of Pirated Software Journal of Business Ethics, 94(1), 23-37.

Phau, I., Teah, M., \& Lwin, M. (2014). Pirating Pirates of the Caribbean: The curse of cyberspace. Journal of Marketing Management, 30(3-4), 312-333.

Pickens, J. (2011). Attitudes and Perceptions. In N. Borkowski (Ed.), Organizational Behavior in Health Care. Sudbury: Jones and Bartlett Publishers.

Piquero, A., Piquero, N., Gertz, M., Bratton, J., \& Loughran, T. (2012). Sometimes Ignorance is Bliss: Investigating Citizen Perceptions of the Certainty and Severity of Punishment. American Journal of Criminal Justice, 37(4), 630-646.

Plowman, S., \& Goode, S. (2009). Factors affecting the intention to download music: quality perceptions and downloading intensity. Journal of Computer Information Systems, 49(4), 84-97.

Poddar, S. (2006). Music Product as a Durable Good and Online Piracy. Review of Economic Research on Copyright Issues, 3(2), 53-66.

Pogarsky, G., Piquero, A., \& Paternoster, R. (2004). Modeling Change in Perceptions about Sanction Threats: The Neglected Linkage in Deterrence Theory. Journal of Quantitative Criminology, 20(4), 343-369.

Polinsky, M. (2006). The Optimal Use of Fines and Imprisonment When Wealth is Unobservable Journal of Public Economics, 90(4-5), 823-835.

Poort, J., \& Leenheer, J. (2012). Filesharing 2@12: Downloaden in Nederland. Amsterdam: Instituut voor Informatierecht.

Poort, J., Leenheer, J., van der Ham, J., \& Dumitru, C. (2014). Baywatch: two Approaches to Measure the Effects of Blocking Access to The Pirate Bay. Telecommunications Policy, 38(4), 384-392.

Poort, J., \& Weda, J. (2015). Elvis is Returning to the Building: Understanding a Decline in Unauthorized File Sharing. Journal of Media Economics, 28(2), 63-83.

Popham, J. (2011). Factors Influencing Music Piracy. Criminal Justice Studies, 24(2), 199-209.

Pornpitakpan, C. (2004). The persuasiveness of source credibility: A critical review of five decades' evidence. Journal of Applied Social Psychology, 34(2), 243-281.

Posner, E. (2000). Law and social norms: The case of tax compliance. Virginia Law Review, 86(8), 1781 1820.

Postmes, T., Steg, L., \& Keizer, K. (2009). Groepsnormen en gedrag: Sturing door sociale identiteit en dialoog. In W. Tiemeijer, C. Thomas \& H. Prast (Eds.), De menselijke beslisser: over de psychologie van keuze en gedrag. Den Haag/Amsterdam: Amsterdam University Press.

Pratt, T. (2008). Rational Choice Theory, Crime Control Policy, and Criminological Relevance Criminology \& Public Policy, 7(1), 43-52.

Pro Music. (2012). 'Music, TV and the Internet - A guide for Parents and Teachers Retrieved 31-10-2016, from http://www.pro-music.org/music-internet.php

Pro Music. (n.d.). Digital File Check. Retrieved 17-01-2017, from http://www.digitalfilecheck.com/

Pryor, A., Dalenberg, D., McCorkle, D. R., J, \& Wicks, J. (2008). Buy or burn?: Empirical tests of models of crime using data from a general population The Social Science Journal, 45(1), 95-106.

Purchese, R. (2011). How Bad is PC Piracy Really? DRM or not to DRM, that is the question. Retrieved 17-01-2017, from http://www.eurogamer.net/articles/2011-09-30-how-bad-is-pc-piracy-reallyarticle

Quintais, J. (2015). Private Copying and Downloading from Unlawful Sources. International Review of Intellectual Property and Competition Law, 46(1), 66-92.

Quiring, O., von Walter, B., \& Atterer, R. (2008). Can filesharers be triggered by economic incentives? Results of an experiment. New Media \& Society, 10(3), 433-453.

Quist, D. (2010). Three Strikes and You're Out: A Survey of Foreign Approaches to Preventing Copyrigh Infringements on the Internet. Business Lawyer, 66(1), 261-270.

Rahim, M., Rahman, M., \& Seyal, A. (2000). Software piracy among academics: an empirical study in Brunei Darussalam. Information Management \& Computer Security, 8(1), 14-26.

Rahim, M., Seyal, A., \& Rahman, M. (1999). Software Piracy Among Computing Students: a Bruneian Scenario. Computers \& Education, 32(4), 301-321.

Ramakrishna, H., Kini, R., \& Vijayraraman, B. (2001). Shaping of moral intensity regarding software piracy in university students: Immediate community effects Journal of Computer Information Systems, 41(4), 47-51.

Ranaivoson, H., \& Lorrain, A. (2012). Graduated response beyond the copyright balance: why and how the French HADOPI takes consumers as targets. info, 14(6), 34-44. 


\section{Bibliography}

Rawden, J. (2016). The 10 Most Pirated TV Shows In 2015. Retrieved 17-01-2017, from http://www.cinemablend.com/television/10-Most-Pirated-TV-Shows-2015-107607-p9.html

Redondo, I., \& Charron, J. (2013). The payment dilemma in movie and music downloads: An explanation through cognitive dissonance theory. Computers in Human Behavior, 29(5), 2037-2046.

Regner, T., \& Barria, J. (2009). Do consumers pay voluntarily? The case of online music. European Journal of Economic Behavior \& Organization, 71(2), 395-406.

Reijerman, D. (2014). Britse muziekindustrie stuurt 100 miljoen takedownverzoeken naar Google. Retrieved 17-01-2017, from https://tweakers.net/nieuws/98599/britse-muziekindustrie-stuurt100-miljoen-takedownverzoeken-naar-google.html

Rendas, T. (2015). Time-shifted morality: a critique of the legal discourse on online copyright infringement. Queen Mary Journal of Intellectual Property, 5(1), 28-45.

Renes, R., van de Putte, B., van Breukelen, R., Loef, J., Otte, M., \& Wennekers, C. (2011) Gedragsverandering via campagnes. Den Haag: Dienst Publiek en Communicatie, Ministerie van Algemene Zaken.

Reyns, B., Henson, B., \& Fishers, B. (2014). Digital Deviance: Low Self-Control and Opportunity as Explanations of Sexting Among College Students. Sociological Spectrum: Mid-South Sociological Association, 34(3), 273-292.

Rhoades, E. (2011). Literature Reviews. The Volta Review, 111(1), 61-71.

Rice, M., \& Harris, G. (2005). Comparing Effect Sizes in Follow-Up Studies: ROC Area, Cohen's $d$, and r. Law and Human Behavior, 29(5), 615-620.

Ripberger, J. (2011). Capturing Curiosity: Using Internet Search Trends to Measure Public Attentiveness. The Policy Studies Journal, 39(2), 239-259.

Rob, R., \& Waldfogel, J. (2006). Piracy on the High C's: Music Downloading, Sales Displacement and Social Welfare in a Sample of College Students. Journal of Law and Economics, 49(1), 29-62.

Rob, R., \& Waldfogel, J. (2007). Piracy on the Silver Screen. The Journal of Industrial Economics, 55(3), 379-395.

Robertson, K., McNeill, L., Green, J., \& Roberts, C. (2012). Illegal Downloading, Ethical Concern and Illegal Behavior. Journal of Business Ethics, 108(2), 215-227.

Robinson, G., McNulty, J., \& Krasno, J. (2009). Observing the Counterfactual? The Search for Political Experiments in Nature. Political Analysis, 17(4), 341-357.

Rochelandet, F., \& Le Guel, F. (2005). P2P Music Sharing Networks: Why the Legal Fight Against Copiers may be Inefficient. Review of Economic Research on Copyright Issues, 2(2), 69-82.

Roettgers, J. (2016). Napster Is Back as Rhapsody Rebrands Its Streaming Service. Retrieved 17-01-2017, from http://variety.com/2016/digital/news/rhapsody-napster-rebrand-1201795439/

Rosati, E. (2014). Private copying exception may only apply to reproductions from licensed sources. Journal Of Intellectual Property Law \& Practice, 9(9), 710-711.

Rose, J., \& Bliemer, M. (2009). Constructing Efficient Stated Choice Experimental Designs. Transport Reviews, 29(5), 587-617.

Rothman, A., \& Salovey, P. (1997). Shaping Perceptions to Motivate Healthy Behavior: The Role of Message Framing Psychological Bulletin, 121(1), 3-19.

Ruiter, R., Abraham, C., \& Kok, G. (2001). Scary Warnings and Rational Precautions: A Review of the Psychology of Fear Appeals. Psychology and Health, 16(6), 613-630.

Ryan, M., \& Farrar, S. (2000). Using conjoint analysis to elicit preferences for health care. Quality and Safety in Health Care, 320(7248), 1530-1533.

Ryan, M., \& Gerard, K. (2003). Using discrete choice experiments to value health care programmes: current practice and future research reflections. Applied Health Economics and Health Policy, 2(1), 55 64

Rycroft-Malone, J., McCormack, B., Hutchinson, A., DeCorby, K., Bucknall, T., Kent, B., .. . Wilson, V. (2012). Realist synthesis: illustrating the method for implementation research. Implementation Science, 7(33), 1-10

Sackett, P., \& Mullen, E. (1993). Beyond Formal Experimental Design: Towards an Expanded View of the Training Evaluation Processs. Personal Psychology, 46(3), 613-627.

Sag, M. (2015). Copyright Trolling, An Empirical Study Iowa Law Review, 100, 1105-1147.

Salapa, G. (2015). Why Netflix's Financials Are Better Than You Think. Retrieved 17-01-2017, from http://www.forbes.com/sites/valleyvoices/2016/01/25/why-netflixs-financials-are-better-thanyou-think/\#413a0380f409

Sandulli, F. (2007). CD music purchase behaviour of P2P users. Technovation, 27(6-7), 325-334.

Sang, Y., Lee, J., Kim, Y., \& Woo, H. (2015). Understanding the intentions behind illegal downloading: A comparative study of American and Korean college students. Telematics and Informatics, 32(2), 333-343. 


\section{$\underline{\text { Punish, Seduce or Persuade }}$}

Savič, M. (2015). The Legality of Resale of Digital Content after UsedSoft in Subsequent German and CJEU Case Law. European Intellectual Property Review, 37(7), 414-429.

Schmidt, T., \& Vosen, S. (2009). Forecasting Private Consumption: Survey-based Indicators vs. Google Trends. In C. Schmidt (Ed.), Ruhr Economic Papers. Bochum: Ruhr-Universität Bochum.

Schmitz, S., \& Ries, T. (2012). Three songs and you are disconnected from cyberspace? Not in Germany where the industry may 'turn piracy into profit'. European Journal of Law and Technology, 3(1), $1-14$

Schmuckler, M. (2001). What Is Ecological Validity? A Dimensional Analysis. Infancy, 2(4), 419-436.

Schneider, A., \& Ingram, H. (1990). Behavioral Assumptions of Policy Tools. Journal of Politics, 52(2), 510-529.

Schoepfer, A., Carmichael, S., \& Piquero, N. (2007). Do perceptions of punishment vary between whitecollar and street crimes? Journal of Criminal Justice, 35(2), 151-163.

Schultz, C. (2014). The Stigmatization of Individuals Convicted of Sex Offenses: Labeling Theory and The Sex Offense Registry. Themis: Research Journal of Justice Studies and Forensic Science, 2(1), 64-81.

Seale, D., Polakowski, M., \& Schneider, S. (1998). It's not really theft!: personal and workplace ethics that enable software piracy. Behaviour \& Information Technology, 17(1), 27-40.

Securethoughts. (2016). BitTorrent Network.

Seedbox Guide. (2016). How to torrent anonymously with the Six Strikes law. Retrieved 17-01-2017, from http://seedboxgui.de/guides/six-strikes-plan-stay-anonymous/

Selby, J. (2014). Tyler, The Creator says having new U2 album automatically downloaded on his iPhone was 'like waking up with herpes'. Retrieved 17-01-2017, from http://www.independent.co.uk/arts-entertainment/music/news/tyoler-the-creator-compares-having-the-new-u2-album-automatically-download-on-his-iphone-was-like-9732091.html.

Selwyn, N. (2008). A Safe Haven for Misbehaving? An Investigation of Online Misbehavior Among University Students. Social Science Computer Review, 26(4), 446-465.

Senftleben, M. (2004). Copyright, Limitations and the Three-Step Test: An Analysis of the Three-Step Test in International and EC Copyright Law. Amsterdam: ITeR.

Senior, T. (2012). PC gaming has "around a 93-95\% piracy rate" claims Ubisoft CEO. Retrieved 17-012017, from http://www.pcgamer.com/pc-gaming-has-around-a-93-95-per-cent-piracy-rateclaims-ubisoft-ceo/

Setiawan, B., \& Tjiptono, F. (2013). Determinants of Consumer Intention to Pirate Digital Products. International Journal of Marketing Studies, 5(3), 48-55.

Shahid, M. (2014). Downloadverbod; einde illegaal downloadgenot? - Het arrest ACI Adam BV e.a. inzake de thuiskopievergoeding. Nederlands Tijdschrift voor Europees Recht, 7, 211-215.

Shanahan, K., \& Hyman, M. (2010). Motivators and enablers of SCOURing: A study of online piracy in the US and UK Journal of Business Research, 63(9-10), 1095-1102.

Sheehan, B., Tsao, J., \& Yang, S. (2010). Motivations for Gratifications of Digital Music Piracy Among College Students. Atlantic Journal of Communication, 18(5), 241-258

Sherwin, A. (2014). Free U2 album: How the most generous giveaway in music history turned PR disaster Retrieved 17-01-2017, from http://www.independent.co.uk/arts-entertainment/music/features/free-u2-album-how-the-most-generous-giveaway-in-music-history-turned-into-a-pr-disaster9745028.html

Shlonsky, A., Noonan, E., Littell, J., \& Montgomery, P. (2011). The Role of Systematic Reviews and the Campbell Collaboration in the Realization of Evidence-Informed Practice. Clinical Social Work Journal, 39(4), 362-368.

Shoham, A., Ruvio, A., \& Davidow, M. (2008). (Un)ethical consumer behavior: Robin Hoods or plain hoods? . Journal of Consumer Marketing, 25(4), 200-210.

Shore, B., Venkatachalam, A., Solorzano, E., Burn, J., Hassan, S., \& Janczewski, L. (2001). Softlifting and piracy: behavior across cultures. Technology in Society, 23(4), 563-581.

Siegfried, M. (2004). Student Attitudes on Software Piracy and Related Issues of Computer Ethics. Ethics and Information Technology, 6(4), 215-222.

Simpson, P., Banerjee, D., \& Simpson, L. (1994). Softlifting: A Model of Motivating Factors. Journal of Business Ethics, 13(6), 431-438.

Sims, R., Cheng, H., \& Teegen, H. (1996). Toward a Profile of Student Software Piraters. Journal of Business Ethics, 15(8), 839-849.

Sinclair, G., \& Green, T. (2016). Download or stream? Steal or buy? Developing a typology of today's music consumer. Journal of Consumer Behaviour, 15(3), 3-14.

Sinha, R., Machado, F., \& Sellman, C. (2010). Don't Think Twice, It's All Right: Music Piracy and Pricing in a DRM-Free Environment. Journal of Marketing, 74(2), 40-54. 


\section{Bibliography}

Sinha, R., \& Mandel, N. (2008). Preventing Digital Music Piracy: the Carrot or the Stick. Journal of Marketing, 72(1), 1-15.

Siponen, M., Vance, A., \& Willison, R. (2012). New insights into the problem of software piracy: The effects of neutralization, shame, and moral beliefs. Information and Management, 49(7-8), 334341.

Sisaro, B. (2014). As Music Streaming Grows, Spotify Reports Rising Revenue and a Loss. Retrieved 17 01-2017, from http://www.nytimes.com/2014/11/26/business/spotify-discloses-revenue-butnot-its-future-plans.html? $\mathrm{r}=0$

Siwek, S. (2007). The True Cost of Sound Recording Piracy to the U.S. Economy. Irving: Institute for Policy Innovation.

Smallridge, J., \& Roberts, J. (2013). Crime Specific Neutralizations: An Empirical Examination of Four Types of Digital Piracy. International Journal of Cyber Criminology, 7(2), 125-140.

Smith, M., \& Telang, R. (2009). Competing with the Free: The Impact of Movie Broadcasts on DVD Sales and Internet Piracy. MIS Quarterly, 33(2), 321-338.

Smith, M., \& Telang, R. (2010). Piracy or promotion? The impact of broadband Internet penetration on DVD sales. Information Economics and Policy, 22(4), 289-298.

Software Publishers Association. (1992). Don't Copy That Floppy.

Soole, D., Watson, B., \& Fleiter, J. (2013). Effects of average speed enforcement on speed compliance and crashes: A review of the literature. Accident Analysis and Prevention, 54, 46-56.

Spangler, T. (2014). Top 20 Most Pirated Movies of 2014 Led by 'Wolf of Wall Street,' 'Frozen, 'Gravity'. Retrieved 17-01-2017, from http://variety.com/2014/digital/news/top-20-most-pirated-moviesof-2014-led-by-wolf-of-wall-street-frozen-gravity-1201388403/

Spangler, T. (2016). AMC Moves to Fight Pirated Leaks of 'Walking Dead,' Other Original Series. Retrieved 17-01-2017, from http://variety.com/2016/digital/news/amc-piracy-walking-deadwatermarking-1201711621/

Spoor, J., Verkade, D., \& Visser, D. (2005). Auteursrecht: Auteursrecht, naburige rechten en databankenrecht. Deventer: Kluwer.

Spotify. (n.d.-a). How is Spotify contributing to the music business? Retrieved 17-01-2017, from https://www.spotifyartists.com/spotify-explained/\#how-is-spotify-contributing-to-the-musicbusiness

Spotify. (n.d.-b). Music for Everybody - Spotify. Retrieved 17-01-2017, from https://www.spotify.com/nl/

Stafford, M., Gray, L., Menke, B., \& Ward, D. (1986). Modeling the deterrent effects of punishment. Social Psychology Quarterly, 49(4), 338-347.

Staras, S., Livingston, M., \& Wagenaar, A. (2016). Maryland Alcohol Sales Tax and Sexually Transmitted Infections: A Natural Experiment. American Journal of Preventive Medicine, 50(3), 73-80.

Statista. (2016). Worldwide desktop market share of leading search engines from January 2010 to January 2016. Retrieved 17-01-2017, from http://www.statista.com/statistics/216573/worldwidemarket-share-of-search-engines/

Steinmetz, K., \& Tunnel, K. (2013). Under the Pixelated Jolly Roger: A Study of On-Line Pirates. Deviant Behavior, 34(1), 53-67.

Sternthal, B., \& Craig, S. (1974). Fear Appeals Revisited and Revised. Journal of Consumer Research, 1(3), 22-34.

Stewart, S., Bing, M., \& Davison, K. (2009). In the Eyes of the Beholder: A Non-Self-Report Measure of Workplace Deviance. Journal of Applied Psychology, 94(1), 207-215.

Stigler, G. (1974). The Optimum Enforcement of Laws. In G. Becker \& W. Landes (Eds.), Essays in the Economics of Crime and Punishment (pp. 55-67). New York: Columbia University Press.

Storch, R. (2013). Copyright Vigilantism. Stanford Technology Law Review, 16(2), 453-483.

Storm, D. (2013). Six ways pirates can get around the coming 'Six Strikes'. Retrieved 17-01-2017, from http://www.computerworld.com/article/2474562/internet/six-ways-pirates-can-get-around-thecoming--six-strikes-.html

Strauss, K. (2013). TV and Film Piracy: Threatening an Industry? Retrieved 17-01-2017, from http://www.forbes.com/sites/karstenstrauss/2013/03/06/tv-and-film-piracy-threatening-anindustry/\#f10eded5e0e7

Strelan, P., \& Boeckmann, R. (2006). Why Drug Testing in Elite Sport Does Not Work: Perceptual Deterrence Theory and the Role of Personal Moral Beliefs. Journal of Applied Social Psychology, 36(12), 2909-2934.

Strowel, A. (2009). Internet Piracy as a Wake-up Call for Copyright Law Makers - Is the "Graduated Response" a Good Reply? The WIPO Journal(1), 75-86.

Sudler, H. (2013). Effectiveness of anti-piracy technology: Finding appropriate solutions for evolving online piracy. Business Horizons, 56(2), 149-157. 


\section{$\underline{\text { Punish, Seduce or Persuade }}$}

Suits, D. (1957). Use of Dummy Variables in Regression Equations. Journal of the American Statistical Association, 52(280), 548-551.

Suki, N., Ramayah, T., \& Suki, N. (2011). Understanding consumer intention with respect to purchase and use of pirated software. Information Management \& Computer Security, 19(3), 195-210.

Sunstein, C. (1996). On the Expressive Function of the Law. University of Pennsylvania Law Review, 144(5), 2021-2053

Surfspot. (n.d.). Surfsport | Smart Deals for Education. Retrieved 17-01-2017, from https://www.surfspot.nl/

Sutherland, E. (2006). White-collar Criminality. In J. Munchie (Ed.), Criminology, Vol.1: The Meaning of Crime. London: Sage.

Suzor, N., \& Fitzgerald, B. (2011). The Legitimacy of Graduated Response Schemes in Copyright Law. UNSW Law Journal, 34(1), 1-40.

Svensson, M., \& Larsson, S. (2012). Intellectual property law compliance in Europe: Illegal file sharing and the role of social norms. New Media \& Society, 14(7), 1147-1163.

Svensson, R., Pauwels, L., \& Weerman, F. (2010). Does the Effect of Self-Control on Adolescent Offending Vary by Level of Morality? A Test in Three Countries. Criminal Justice and Behavior, 37(6), $732-743$.

Swan, M. (2013). The Quantified Self: Fundamental Disruption in Big Data Science and Biological Discovery. Big Data, 1(2), 85-99.

Swatman, P., Kruegel, C., \& van der Beek, K. (2006). The changing digital content landscape: An evaluation of e-business model development in European online news and music. Internet Research, 16(1), 53-80.

Sykes, G., \& Matza, D. (1957). Techniques of Neutralization: A Theory of Delinquency. American Sociological Review, 22(6), 664-670.

Tang, J., \& Farn, C. (2005). The Effect of Interpersonal Influence on Softlifting Intention and Behaviour Journal of Business Ethics, 56(2), 149-161.

Taylor, S. (2004). Music Piracy - Difference in the Ethical Perceptions of Business Majors and Music Business Majors. Journal of Education for Business, 79(5), 306-310.

Taylor, S. (2012). Evaluating digital piracy intention on behaviors. Journal of Services Marketing, 26(7), $472-483$.

Taylor, S., Ishida, C., \& Wallace, D. (2009). Intention to Engage in Digital Piracy: A Conceptual Model and Empirical Test. Journal of Service Research, 11(3), 246-262.

Teeven, F. (2011). Speerpunten Auteursrecht 20@20. Den Haag.

The British Recorded Music Industry. (2013). Digital Music Nation. London: BPI.

The Campbell Collaboration. (n.d.). What is a systematic review? Retrieved 17-01-2017, from http://www.campbellcollaboration.org/what_is_a_systematic_review/index.php

The Pirate Bay. (2016). The Pirate Bay.

The Pirate Bay. (n.d.). The Pirate Bay. Retrieved 17-01-2017, from https://thepiratebay.org/

The Post Online. (2016). Filmdistributeur Dutch Filmworks gaat actief jagen op individuele downloaders Retrieved 17-01-2017, from http://nieuws.tpo.nl/2016/02/20/filmdistributeur-dutch-filmworksgaat-actief-jagen-op-individuele-downloaders/

The Steering Group of the Campbell Collaboration. (2015). Campbell Collaboration Systematic Reviews: Policies and Guidelines. Campbell Systematic Reviews, 1 .

Thom, J. (1988). Digital Sampling: Old-Fashioned Piracy Dressed up in Sleek New Technology. Loyola Entertainment Law Journal, 8(2/4), 297-336.

Thomas, L. (2015). Optimal Marginal Deterrence and Incentives for Precaution. Review of Law \& Economics, 11(3), 409-433

Tittle, C., \& Rowe, A. (1974). Certainty of arrest and crime rates: A further test of the deterrence hypothesis. Social Forces, 54(4), 455-462.

Tjiptono, F., Arli, D., \& Viviea. (2016). Gender and digital privacy: examining determinants of attitude toward digital piracy among youths in an emerging market. International Journal of Consumer Studies, 40(2), 168-178.

Tormala, Z., \& Petty, R. (2004). Source credibility and attitude certainty: a metacognitive analysis of resistance to persuasion. Journal of Consumer Psychology, 14(4), 427-442.

TorrentFreak. (2011a). 15-Year-Old Schoolboy On Trial After Head Teacher Tells Police About FileSharing. Retrieved 17-01-2017, from http://torrentfreak.com/15-year-old-schoolboy-on-trialafter-head-teacher-tells-police-about-file-sharing-110824/

TorrentFreak. (2011b). Appeal Punishes File-Sharer, Fine Increased 6x Over. Retrieved 17-01-2017, from https://torrentfreak.com/appeal-punishes-file-sharer-fine-increased-6x-over-110721/ 


\section{Bibliography}

TorrentFreak. (2011c). The Most Pirated Games of 2011. Retrieved 17-01-2017, from https://torrentfreak.com/top-10-most-pirated-games-of-2011-111230/

TorrentFreak. (2013). Sweden Wants to Jail Pirate Bay User to Strengthen Anti-Piracy Enforcement. Retrieved 17-01-2017, from http://torrentfreak.com/sweden-wants-to-jail-file-sharer-tostrengthen-anti-piracy-enforcement-130514/

TorrentFreak. (2015a). Sky Users Receive Porn Piracy Threats in Time For Christmas. Retrieved 17-012017, from https://torrentfreak.com/sky-users-receive-porn-piracy-threats-in-time-forchristmas-151202/

TorrentFreak. (2015b). UK Anti-Piracy 'Education' Campaign Starts This Summer. Retrieved 17-012017, from https://torrentfreak.com/uk-anti-piracy-education-campaign-starts-this-summer$150720 /$

TorrentFreak. (2016). Pirates Switch From Torrents to Streaming and Download Sites. Retrieved 17-012017, from https://torrentfreak.com/pirates-switch-from-torrents-to-streaming-and-downloadsites-160426/

Tully, S. (2014). A Human Right to Access the Internet? Problems and Prospects. Human Rights Law Review, 14(2), 175-195.

Turiel, E. (2008). The Development of Morality. In W. Damon \& R. Lerner (Eds.), Child and Adolescent Development: An Advanced Course (pp. 473-516). Hoboken: John Wiley \& Sons.

Twentieth Centry Fox Home Entertainment. (n.d.). Watch Real DVDs and Blu-Ray.

Tyler, T., Schulhofer, S., \& Huq, A. (2010). Legitimacy and Deterrence Effects in Counter-Terrorism Policing: A Study of Muslim Americans. Law \& Society Review, 44(2), 365-401.

Ubisoft. (n.d.). Far Cry 4 Kyrat Edition - PC.

Ulsperger, J., Hodges, S., \& Paul, J. (2010). Pirates on the Plank: Neutralization Theory and the Criminal Downloading of Music Among Generation Y in the Era of Late Modernity. Journal of Criminal Justice and Popular Culture, 17(1), 124-151.

United States Copyright Office. (2015). Copyright and the Music Marketplace. Washington DC: United States Copyright Office.

Universal. (n.d.). Blu-ray Thank You Bumper.

Updegraff, J., \& Rothman, A. (2013). Health Message Framing: Moderators, Mediators,and Mysteries. Social and Personality Psychology Compass, 7(9), 668-679.

Valve. (n.d.). Welcome to Steam. Retrieved 17-01-2017, from http://store.steampowered.com/

Van Belle, J., Macdonald, B., \& Wilson, D. (2007). Determinants of Digital Piracy among Youth in South Africa. Communications of the IIMA, 7(3), 47-64.

Van den Broeck, J., Cunningham, S., Eeckels, R., \& Herbst, K. (2005). Data Cleaning: Detecting, Diagnosing, and Editing Data Abnormalities PLoS Medicine, 2(10), 966-970.

Van der Byl, K., \& van Belle, J. (2008). Factors Influencing South African Attitudes toward Digital Piracy. Communications of the IBIMA, 1(1), 202-211.

Van der Hulst, R., \& Neve, R. (2008). High-tech crime, soorten criminaliteit en hun daders: een literatuurinventarisatie. Den Haag: WODC.

Van der Laan, P. (2004). Over straffen, effectiviteit en erkenning: De wetenschappelijke onderbouwing van preventie en strafrechtelijke interventie. Justitiële Verkenningen, 30(5), 31-48.

Van Duyne, P., Kristen, F., \& de Zanger, W. (2015). Belust op misdaadgeld: de werkelijkheid van voordeelsontneming. Justitiële Verkenningen, 4l(1), 103-119.

van Lingen, N. (2002). Auteursrecht in hoofdlijnen. Groningen: Martinus Nijhoff.

Varian, H. (2005). Copying and Copyright. The Journal of Economic Perspectives, 19(2), 121-138.

Vedung, E. (1998). Policy Instruments: Typologies and Theories. In M. Bemelmans-Videc, R. Rist \& E. Vedung (Eds.), Carrots, Sticks \& Sermons: Policy Instruments and Their Evaluation. Piscataway: Transaction.

Veitch, R., \& Constantiou, I. (2012). User Decisions Among Digital Piracy and Legal Alternatives for Films and Music. Paper presented at the Thirty Third International Conference on Information Systems, Orlando.

Vergeer, M. (2015). Twitter and Political Campaigning. Sociology Compass, 9(9), 745-760.

Verizon. (n.d.). Copyrights and Verizon's Copyright Alert Program. Retrieved 17-01-2017, from https://www.verizon.com/support/consumer/account-and-billing/copyright-alert-programfaqs \#04FAQ

Vernik, D., Purohit, D., \& Desai, P. (2011). Music Downloads and the Flip Side of Digital Rights Management. Marketing Science, 30(6), 1011-1027.

Wakefield, M., Loken, B., \& Hornik, R. (2010). Use of mass media campaigns to change health behaviour. Lancet, 376(9748), 1261-1271. 


\section{$\underline{\text { Punish, Seduce or Persuade }}$}

Waldfogel, J. (2010a). The Four P's of Digital Distribution in the Internet Era: Piracy, Pricing Pie-Splitting and Pipe Control. Review of Economic Research in Copyright Issues, 7(2), 3-20.

Waldfogel, J. (2010b). Music file sharing and sales displacement in the iTunes era. Information Economics and Policy, 22(4), 306-315.

Wall, D., \& Yar, M. (2011). Intellectual property crime and the Internet:cyber-piracy and 'stealing' information intangibles. In Y. Jewkes \& M. Yar (Eds.), Handbook of Internet Crime. New York: Routlegde.

Wallenstein, A. (2015). Top 10 Pirated Movies of 2015 See Alarming Increase in Downloads. Retrieved 17-01-2017, from http://variety.com/2015/digital/news/top-10-pirated-movies-of-2015-seealarming-increase-in-downloads-1201667982/

Wang, A. (2016). Recorded music is in trouble, but live concerts are making more money than ever. Retrieved 17-01-2017, from http://qz.com/625934/recorded-music-is-in-trouble-but-liveconcerts-are-making-more-money-than-ever/

Wang, C., Chen, C., Yang, S., \& Farn, C. (2009). Pirate or Buy? The Moderating Effect of Idolatry. Journal of Business Ethics, 90(1), 81-93.

Wang, C., Ye, L., Zhang, Y., \& Nguyen, D. (2005). Subscription to Fee-Based Online Services: What Makes Consumer Pay for Online Content. Journal of Electronic Commerce Research, 6(4), 304311.

Wang, F., Zhang, H., Zang, H., \& Ouyang, Q. (2005). Purchasing pirated software: an initial examination of Chinese consumers. Journal of Consumer Marketing, 22(6), 340-351

Wang, J., Yang, Z., \& Bhattacharjee, S. (2011-2012). Same Coin, Different Sides: Differential Impact of Social Learning on Two Facets of Music Piracy. Journal of Management Information Systems, 28(3), 343-384.

Wang, J., Yang, Z., \& Bhattacharjee, S. (2012). Same Coin, Different Sides: Differential Impact of Socia Learning on Two Facets of Music Piracy. Journal of Management Information Systems, 28(3), 343-384.

Wang, X., \& McClung, S. (2011). Toward a detailed understanding of illegal digital downloading intentions: An extended theory of planned behavior approach. New Media \& Society, 13(4), 663-677.

Wang, X., \& McClung, S. (2012). The immorality of illegal downloading: The role of anticipated guilt and general emotions. Computers in Human Behavior, 28(1), 153-159.

Webb, T., \& Sheeran, P. (2006). Does Changing Behavioral Intentions Engender Behavior Change? A Meta-Analysis of the Experimental Evidence. Psychological Bulletin, 132(2), 249-268.

Weerman, F., Bernasco, W., Bruinsma, G., \& Pauwels, L. (2016). Gender Differences in Delinquency and Situational Action Theory: A Partial Test. Justice Quarterly, 33(7), 1182-1209.

Weijters, B., Goedertier, F., \& Verstreken, S. (2014). Online Music Consumption in Today's Technological Context: Putting the Influence of Ethics in Perspective. Journal of Business Ethics, 124(4), 537550

Weinrath, M., \& Gartrell, J. (2001). Specific Deterrence and Sentence Length: The Case of Drunk Drivers. Journal of Contemporary Criminal Justice, 17(2), 105-122.

Weiss, J., \& Tschirhart, M. (1994). Public Information Campaigns as Policy Instruments. Journal of Policy Analysis and Management, 13(1), 82-119.

Whitehead, J., Pattanayak, S., van Houten, G., \& Gelso, B. (2008). Combining Revealed and Stated Preference Data to Estimate the Nonmarket Value of Ecological Services: An Assessment of the State of the Science. Journal of Economic Surveys, 22(5), 872-908.

Whittam, K., Dwyer, W., Simpson, P., \& Leeming, F. (2006). Effectiveness of a Media Campaign to Reduce Traffic Crashes Involving Young Drivers. Journal of Applied Social Psychology, 36(3), $614-628$.

Wiggin. (2013). Wiggin Digital Entertainment Survey 2013. London: Wiggin

Wikipedia. (n.d.-a). Captain Copyright. Retrieved 17-01-2017, from https:/www.en.wikipedia.org/wiki/Captain Copyright

Wikipedia. (n.d.-b). Comparison of on-demand streaming music services. Retrieved 17-01-2017, from https://en.wikipedia.org/wiki/Comparison of on-demand streaming music services.

Wikipedia. (n.d.-c). Crysis 2. 17-01-2017, from https://en.wikipedia.org/wiki/Crysis_2.

Wikipedia. (n.d.-d). List of box office bombs. Retrevied 17-01-2017, from https://en.wikipedia.org/wiki/List of box office bombs.

Wikipedia. (n.d.-e). List of Charity Albums. Retrieved 17-01-2017, from https://en.wikipedia.org/wiki/Category:Charity albums.

Wikipedia. (n.d.-f). List of most expensive films. 17-01-2017, from https://en.wikipedia.org/wiki/List_of_most expensive films. 


\section{Bibliography}

Wikipedia. (n.d.-g). List of most expensive video games to develop. Retrieved 17-01-2017, from https://en.wikipedia.org/wiki/List_of_most_expensive_video_games_to_develop

Wikström, P. (2006). Individuals, settings, and acts of crime: situational mechanisms and the explanation of crime. In P. Wikström \& R. Sampson (Eds.), The Explanation of Crime: Context Mechanisms, and Development. Cambridge: Cambridge University Press.

Wikström, P. (2009). Crime Propensity, Criminogenic Exposure and Crime Involvement in Early to Mid Adolescence. Monatsschrift für Kriminologie und Strafrechtreform, 92(2/3), 253-266.

Wikström, P., \& Sampson, R. (2003). Social Mechanisms of Community Influences on Crime and Pathways in Criminality. In B. Lahey, T. Moffitt \& A. Caspi (Eds.), Causes of Conduct Disorder and Juvenile Delinquency

Wikström, P., \& Sampson, R. (2006). The Explanation of Crime: Context, Mechanisms and Development (Vol. Cambridge): Cambridge University Press.

Wikström, P., \& Svensson, R. (2010). When does self-control matter? The interaction between morality and self-control in crime causation. European Journal of Criminology, 7(5), 395-410.

Wikström, P., \& Treiber, B. (2007). The Role of Self-Control in Crime Causation: Beyond Gottfredson and Hirschi's General Theory of Crime. European Journal of Criminology, 4(2), 237-264.

Wikström, P., \& Treiber, B. (2009). Violence as Situational Action. International Journal of Conflict and Violence, 3(1), 76-96.

Wilbur, B. (2016). The 13 Most Hilarious Anti-Piracy Traps In Video Games. Retrieved 17-01-2017, from https://www.inverse.com/article/12807-the-13-most-hilarious-anti-piracy-traps-in-videogames

Wilis, C., Riley, B., Stockton, L., Abramowicz, A., Zummach, D., Wong, G., . . . Best, A. (2016). Scaling up complex interventions: insights from a realist synthesis. Health Research Policy and Systems, 14(1), 88-104

Williams, C. (2011). E-books drive older women to digital piracy. Retrieved 17-01-2017, from http://www.telegraph.co.uk/technology/news/8518755/E-books-drive-older-women-to-digitalpiracy.html

Williams, K. (2012). Fear Appeal Theory. Research in Business and Economics Journal, 5(February), 121.

Williams, M. (2014). Half a billion iTunes customers receive latest U2 album for free. Retrieved 17-012017, from https://www.theguardian.com/music/2014/sep/09/u2-songs-of-innocence-itunescustomers-free-album

Williams, T. (2016). Netflix will likely take years to see profits overseas. Retrieved 17-01-2017, from http://www.marketwatch.com/story/netflix-will-likely-take-years-to-see-profits-overseas2016-01-07

Willins, M. (2016). Is Spotify Profitable? 2015 Revenue Doubles, But Music Streaming Service Is Still In The Red. Retrieved 17-01-2017, from http://www.ibtimes.com/spotify-profitable-2015revenue-doubles-music-streaming-service-still-red-2373020

Wingrove, T., Korpas, A., \& Weisz, V. (2011). Why were millions of people not obeying the law? Motivational influences on non-compliance with the law in the case of music piracy. Psychology, Crime \& Law, 17(3), 261-276.

Witte, K., \& Allen, M. (2000). A Meta-Analysis of Fear Appeals: Implications for Effective Public Health Campaigns. Health Education \& Behavior, 27(5), 591-615.

Wolfe, S., Higgins, G., \& Marcum, C. (2008). Deterrence and Digital Piracy: a Preliminary Examination of the Role of Viruses. Social Science Computer Review, 26(3), 317-333.

Wong, D. (2016). The EPL drama - paving the way for more illegal streaming? Digital piracy of live sports broadcasts in Singapore. Leisure Studies, 35(5), 534-548.

Wong, G., Greenhalgh, T., Westhorp, G., Buckingham, J., \& Pawson, R. (2013). RAMESES publication standards: realist syntheses. BMC Medicine, 69(5), 1005-1022.

Wong, G., Westhorp, G., Manzano, A., Greenhalgh, J., Jagosh, J., \& Greenhalgh, T. (2016). RAMESES II reporting standards for realist evaluations. BMC Medicine, 14(1), 1-18.

Woolley, D., \& Eining, M. (2006). Software Piracy among Accounting Students: A Longitudinal Comparison of Changes and Sensitivity. Journal of Information Systems, 20(1), 49-63.

Wu, W., \& Sukoco, B. (2007). The Influence of Internet on Music Market - A Revisited. Paper presented at the Proceedings of the 13th Asia Pacific Management Conference, Melbourne.

Xia, M., Huang, Y., Duan, W., \& Whinston, A. (2012). To Continue Sharing or Not to Continue Sharing? An Empirical Analysis of User Decision in Peer-to-Peer Sharing Networks. Information Systems Research, 23(1), 247-259.

Yadav, M. (1994). How Buyers Evaluate Product Bundles: A Model of Anchoring and Adjustment Journal of Consumer Research, 21(2), 342-353. 


\section{$\underline{\text { Punish, Seduce or Persuade }}$}

Yang, Z., \& Wang, J. (2015). Differential effects of social influence sources on self-reported music piracy. Decision Support Systems, 69(4), 70-81

Yar, M. (2005). The global 'epidemic' of movie piracy: crime-wave or social construction? Media, Culture \& Society, 27(5), 677-696.

Yar, M. (2007). Teenage Kicks or Virtual Villainy?: Internet Piracy, Moral Entrepreneurship, and the Social Construction of a Crime Problem. In Y. Jewkes (Ed.), Crime Online. Portland: Willan.

Yar, M. (2008). The rhetorics and myths of anti-piracy campaigns: criminalizaton, moral pedagogy and capitalist property relations in the classroom. New Media \& Society, 10(4), 605-623.

Yim, T. (2013). Normative Avoision: Revising the Copyright Alert System to Circumvent Normative Backlash. Hastings Science and Technology Law Journal, 6(1), 1-30.

Yoon, C. (2011). Theory of Planned Behavior and Ethics Theory in Digital Piracy: An Integrated Model Journal of Business Ethics, 100(3), 405-417.

Yoon, C. (2012). Digital piracy intention: a comparison of theoretical models. Behaviour \& Information Technology, 31(6), 565-576.

Yu, J., \& Liska, A. (1993). The certainty of punishment: A reference group effect and its functional form. Criminology, 31(3), 447-464.

Yu, P. (2010). The Graduated Response. Florida Law Review, 62(5), 1373-1430.

Yu, S. (2012). College Students' Justifications for Digital Piracy: A Mixed Methods Study. Journal of Mixed Methods Research, 6(4), 364-378.

Zajko, M. (2015). The Copyright Surveillance Industry. Media and Communication, 3(2), 42-52.

Zentner, A. (2006). Measuring the Effect of File Sharing on Music Purchases. Journal of Law and Economics, 49(1), 63-90.

Zentner, A. (2009). Ten Years of File Sharing and Its Effects on International Physical and Digital Music Sales. CAPRI Publication. Retrieved 17-01-2017, from https://papers.ssrn.com/sol3/papers.cmf?abstract id $=1724444$.

Zentner, A. (2010). Measuring the Impact of File Sharing on the Movie Industry: An Empirical Analysis Using a Panel of Countries. Retrieved 17-01-2017, from https://papers.ssrn.com/sol3/papers.cmf?abstract id $=1792615$.

Zhang, B., Cohen, J., \& O'Conner, S. (2014). The Priority Group Index: A Proposed New Method Incorporating High Risk and Population Burden to Identify Target Populations for Public Health Interventions. Journal of Public Health Management and Practice, 20(5), 1-11.

Zhang, L., Smith, W., \& McDowell, W. (2009). Examining Digital Piracy: Self-Control, Punishment, and Self-Efficacy. Information Resources Management Journal, 22(1), 24-44. 


\section{Valorisation Addendum}

Digital piracy refers to the act of digital copyright infringement. Digital piracy is common and has potential consequences for the creative industry and society as a whole. To tackle this problem, various anti-piracy interventions have emerged. Various stakeholders, such as the creative industry and governments, are involved in the management digital piracy. They attempt to reduce the total number of digital pirates via the anti-piracy interventions. The research has examined the inner workings of these interventions, aiming to change the behaviour of digital pirates. This was accomplished by focusing on the mechanisms that are used in the design of these anti-piracy interventions. As this research focuses on a real societal problem, its relevance and worth is immediately underlined. More specifically, many of the anti-piracy interventions will have direct consequences for individual end-users and society at large. Particularly those measures that are meant to deter instances of digital piracy are likely to influence the digital and physical lives of individuals. The findings of this research may influence the design of the anti-piracy interventions, which in turn may influence members of society. For instance, an increase in the technical measures used to counter digital piracy can influence how individuals use their purchased digital content.

\section{Relevance}

This research fills a knowledge gap, from both a scholarly perspective and a societal one. For many years, governments around the globe and the creative industry have attempted to tackle digital piracy, although with limited success. This limited success is likely the result of the selection and design of anti-piracy interventions. Quite possibly, those interventions were designed (solely) on the 'gut feeling' of policy-makers, instead of departing from knowledge on digital piracy. Simply put: evidence-based policy making might not always be the norm, a common problem in the field of policy and evaluation sciences (Nelen, 2008; Sanderson, 2002a, 2002b). This is further influenced by those individuals and organizations who design the policy and how they perceive digital piracy. For instance, the creative industry is clearly worried about digital piracy, which can make them more inclined to use more forceful (or deterrent) measures, in order to project an aura of strength and send a clear message.

A further reason for the limited degree of evidence-based policy is the limited amount of research on anti-piracy interventions. More importantly, the available evidence is scattered across many disciplines. As this research reports on antipiracy interventions in an integrated and cohesive manner, the findings from this research can be beneficial for the development of future interventions. Moreover, 
the focus on the mechanisms ${ }^{168}$ used in the interventions will provide a better insight on the functioning of anti-piracy interventions.

\section{Target group}

The findings of this research can be used to better inform policy makers (in the broadest sense) on which types of anti-piracy intervention are better suited to influence digital piracy, as well as what outcomes can be expected once the interventions are implemented. In addition, the research is also informative on how a selected anti-piracy intervention can be best designed.

Governmental agencies that form the target group in the Netherlands include the Advisory Committee on Copyright and the Directorate of Legalisation and Legal Affairs and at the Ministry of Security and Justice, the Directorate-General Culture and Media at the Ministry of Education, Culture and Science and the Ministry of Economics. In addition to governmental organizations, other organizations also influence the policy on copyright enforcement. These include 'Stichting Brein', 'Buma/Stemra' and 'Bits of Freedom'. Eventhough these organizations have different stances on digital piracy, they can also influence the policy-making process. Similar organisations in Belgium (and beyond) can likewise benefit from the insights obtained in this research, such as BAF in Belgium and the RIAA in the USA. Targets groups can also be found in organisations that surpass the national borders. At the EU level, the 'Digital Single Market' project of the European Commission is such an example as well organisations on a (further) international level such as the OECD and the WIPO.

In addition, the findings of the research are relevant for other organizations that can influence the societal debate on digital piracy but cannot directly influence the enforcement policy. Examples are the mainstream or popular media. These organisations inform the public on the status of digital piracy and copyright enforcement. Insights derived from this research can be used to better inform the general public.

\section{Activities and products}

First and foremost, the guidelines presented in Chapters 6 and 7 can be beneficial for policy-makers when designing new or modifying existing anti-piracy interventions. An even more concrete toolset has been described in Chapter 8, in the form of a Big Data approach, which allows for the mapping of online search behaviour using an easily accessible tool (Google Trends). Such an approach has implications beyond the immediate scope of the research. Policy-makers, but also commercial organizations, can use this method to map changes to online search behaviour and understand the extent of these changes. More specifically, the toolset can be used directly when evaluating (digital) policy. In the field of

${ }^{168}$ Mechanisms are the building blocks of any (anti-piracy) intervention. 
criminology, the Big Data approach holds opportunities the more classical approaches lack. The speed and versatility of data collection are clear benefits, even though the approach requires further fine-tuning. The value of testing the Big Data approach in this research is twofold. Firstly, the results of the Big Data approach found in this research can be expanded and further analysed, possibly with different statistical tools. Secondly and more importantly, the Big Data approach used in this research is not limited to the field of anti-piracy interventions alone, but can be expanded to other fields of research. On the medium to long term, a Big Data approach can be used for various topics, such as the ability to predict legal judgements (Katz, Bommarito II, \& Blackman, 2017), or the prediction of voting behaviour of citizens (Vergeer, 2015).

In addition to these guidelines and toolsets, certain aspects of the research have already been published elsewhere, resulting in concrete (knowledge) products. These publications include reviewed articles on specific aspects of anti-piracy interventions (Leeuw \& Leeuw, 2012; Leeuw, 2012; Leeuw, 2016) as well as a chapter in an edited volume on Big Data, policy evaluations and digital piracy (Leeuw, 2017). This ensures that the knowledge obtained during the $\mathrm{PhD}$ is already accessible to a wider range scholars and organizations. Insights obtained during the research will also be used to create new university courses and modify existing ones. My role as tutor thus ensures that the knowledge obtained in this research is also disseminated to a wider audience.

\section{Innovation}

This research fills a vacuum by focusing on the mechanisms of the anti-piracy interventions, as previous research tends to focus on the interventions as a whole rather than their working mechanisms. Another substantive innovative aspect of the research is the fact that a rather new criminological theory (the SAT) was used to structure the findings derived from the literature (see Chapter 4). The final substantive innovative aspect is the focus on a specific anti-piracy intervention, the Copyright Alert System, which has not yet been the subject of any empirical study so far.

From a methodological stance, the research is also innovative. The use of the stated-preference method is quite rare in the context of digital piracy and antipiracy interventions. Yet, use of the method offered insights on how the various mechanisms can influence responses of respondents. Most innovative is the use of a Big Data approach in order to map the changes to online search behaviour. Such an approach had, prior to this research, not been applied to the topic of digital piracy or to the specific anti-piracy intervention (the Copyright Alert System). Thus, the findings presented in Chapter 8 present an effort to pioneer a new approach to studying online or digital interventions. 


\section{$\underline{\text { Punish, Seduce or Persuade }}$}

\section{Schedule and implementation}

Some steps have already been taken during the $\mathrm{PhD}$ research to valorise it and disseminate the findings to a wider public. These steps include media appearances, both on television (TV Maastricht) and on the radio (NPO 1: Met Het Oog Op Morgen). Certain aspects of the research have also been incorporated into courses that are taught at the Faculty of Law of Maastricht University (The Art of Doing Research, Criminological Perspectives). As previously stated, the research has already led to a number of publications in journals or edited volumes. The aim is to further publish parts of this research. The findings discussed in Chapters 4, 6 and 7 are especially suitable for separate publication. Possible (peerreviewed) journals of interest originate from the fields of criminology, evaluation studies, public policy and media studies. More informal methods of dissemination, such as blogs, can also be used to implement the valorisation.

In addition to these efforts, the aim is also to disseminate the published manuscript to the various members of the direct target group, both within the Netherlands and beyond.

\section{References}

Katz, D., Bommarito II, M., \& Blackman, J. (2017). Predicting the Behavior of the Supreme Court of the United States: A General Approach. Retrieved 17-01-2017, from https://papers.ssrn.com/sol3/papers.cfm?abstract id=2463244.

Leeuw, F., \& Leeuw, H. B. M. (2012). Cyber society and digital policies: Challenges to evaluation? Evaluation, 18(1), 111-127.

Leeuw, H. B. M. (2012). Zin en onzin van het downloadverbod; actuele ontwikkelingen in digitale piraterij nader beschouwd. Justitiële Verkenningen, 38(1), 83-96.

Leeuw, H. B. M. (2016). De evaluatie van digitaal beleid: een Big Data case study. Justitiële Verkenningen, $42(1), 22-32$

Leeuw, H. B. M. (2017). Big Data and Evaluation: A Case Study on Digital Piracy, the Copyright Alert System, and Big Data. In G. Petersson \& J. Breul (Eds.), Cyber Society, Big Data, and Evaluation. Piscataway: Transaction.

Nelen, H. (2008). Evidence maze; het doolhof van het evaluatieonderzoek. Maastricht: Maastricht University.

Vergeer, M. (2015). Twitter and Political Campaigning. Sociology Compass, 9(9), 745-760. 


\section{Nederlandstalige Samenvatting}

\section{Aanleiding tot het promotieonderzoek en vraagstelling}

Centraal in dit promotieonderzoek staat de werking van interventies die digitale auteursrechtschendingen (ook wel bekend als illegaal downloaden of digitale piraterij) tegen zouden moeten gaan. Illegale piraterij is een maatschappelijk fenomeen waarbij individuen auteursrechtelijk beschermd materiaal uit illegale bron downloaden. Recente technologische ontwikkelingen maken het voor vrijwel iedereen mogelijk om via deze weg muziek, films, videogames en andere vormen van content te verkrijgen, vaak kosteloos. Een aanzienlijk deel van de bevolking verkrijgt op deze wijze content. Dit brengt echter met zich mee dat dergelijke individuen zich schuldig maken aan het overtreden van een aantal wettelijke bepalingen, die zich onder andere bevinden binnen het privaat- en het strafrecht. Illegaal downloaden kan, wanneer een voldoende groot deel van de samenleving op deze wijze content verkrijgt, leiden tot bepaalde gevolgen voor de entertainmentindustrie, waaronder een afname in legale aankopen.

Overheden en de entertainmentindustrie hebben een breed scala aan interventies geïmplementeerd die als doel hebben om illegaal downloaden tegen te gaan. Deze interventies komen voor in verschillende 'smaken'. Sommige bestraffen illegaal downloaden en dienen illegale downloaders af te schrikken. Andere pogen juist te verleiden, door het legale aanbod aantrekkelijker te maken. Tenslotte zijn er interventies die illegale downloaders proberen te overtuigen van het feit dat hun gedrag schadelijk, maatschappelijk onwenselijk of onverstandig is. Ondanks deze verschillende pogingen om illegaal downloaden terug te brengen, is niet zeker dat deze interventies ook daadwerkelijk tot een afname in illegaal downloaden hebben geleid. Sterker nog, de vraag die in essentie gesteld dient te worden is, of deze interventies in de eerste plaats wel kunnen werken. Deze vraag stond centraal in dit promotieonderzoek. Van belang is dat de mechanismen waarmee deze interventies gedragsveranderingen proberen teweeg te brengen onderzocht zijn en niet alleen de interventies sec. Deze focus op mechanismen maakt diepgaandere inzichten in het functioneren van de interventies mogelijk. Een dergelijke focus is tevens een innovatieve wijze om interventies te bestuderen. De twee doelen van het promotieonderzoeken onderstrepen de focus op mechanismen:

1. het vaststellen welke mechanismen, zijnde de (gedragskundige) 'bouwstenen' van interventies die gericht zijn op het tegengaan van 


\section{$\underline{\text { Punish, Seduce or Persuade }}$}

illegaal downloaden, worden toegepast wanneer organisaties en belanghebbenden deze interventies implementeren; en

2. het bepalen of deze mechanismen, via de interventies, bijdragen aan een afname van illegaal downloaden.

Deze twee doelen leiden tot de volgende vraagstelling: 'Welke mechanismen, gebruikt in het ontwerp van verschillende interventies die illegaal downloaden moeten tegengaan, dragen bij aan afnames in dit gedrag en in welke mate?'. Vijf deelvragen zijn gebruikt om deze overkoepelende hoofdvraag te beantwoorden. Deze samenvatting zal kort deze deelvragen beantwoorden, alvorens een antwoord te geven op de hoofdvraag. De eerste drie deelvragen ('Hoe kan het gedrag van digitale piraten worden verklaard?', 'Welke interventies, afkomstig van zowel overheden als andere (publiek en private) organisaties, worden toegepast in de context van illegaal downloaden?' en 'Welke (gedragskundige) mechanismen worden gebruikt in het ontwerp van de verschillende interventies die illegaal downloaden moeten tegengaan en wat zijn de voorwaarden voor hun adequaat functioneren?') zijn in hun geheel beantwoord via inzichten die vergaard zijn met behulp van een uitgebreide en gestructureerde literatuurstudie. Deze literatuurstudie geeft de stand van zaken van de wetenschappelijke kennis weer. Aspecten van de vierde deelvraag ('In welke mate dragen de onderliggende mechanismen bij aan afnames in illegaal downloaden?') zijn eveneens verkregen via de literatuurstudie. Een realist synthesis-aanpak is gevolgd bij het zoeken en bestuderen van de literatuur, waarbij de relevantie van de studies samen met de kwaliteit van de studie in ogenschouw is genomen.

De vierde deelvraag kon in zijn geheel beantwoord worden dankzij nieuw empirisch onderzoek. Daartoe zijn zelfrapportagevragenlijsten, opgebouwd op basis van de stated preference-methode, verspreid in Nederland en België onder studentenpopulaties. Via stated preference-methode zijn de respondenten bevraagd naar hun 'voorkeuren' voor wat betreft de verschillende interventies en mechanismen. De voorkeuren werden voorgelegd via een vragenlijst, waarbij elke respondent keuzes moest maken tussen verschillende interventies (vorm gegeven als scenario's). Via deze weg konden inzichten vergaard worden over hoe deze respondenten reageren op interventies en mechanismen, en hoe dit hun voorgenomen pogingen om content illegaal te downloaden heeft beïnvloed. De vijfde deelvraag ('Welke veranderingen worden geobserveerd in het online zoekgedrag van illegale downloaders na de implementatie van een specifieke interventie die illegaal downloaden tegen moet gaan?') is beantwoord via een tweede empirische studie. Hierbij stond de rol van Big Data centraal. Onderzocht werd hoe het online zoekgedrag inzage illegaal downloaden veranderde na implementatie van een specifieke interventie (het Copyright Alert System). De eerste drie hoofdstukken betroffen respectievelijk de inleiding, de methodologie 


\section{Nederlandstalige Samenvatting}

van dit onderzoek en een overzicht van de omvang en mogelijke gevolgen van illegaal downloaden. Deze eerste drie hoofdstukken droegen niet direct bij aan de beantwoording van de deelvragen, maar verschaffen de lezer wel inzichten in de opzet en uitvoering van de studie evenals een duidelijk overzicht van de stand van zaken van illegaal downloaden.

\section{Hoe kan het gedrag van digitale piraten worden verklaard?}

Om te begrijpen wanneer en waarom interventies die illegaal downloaden tegen moeten gaan, kunnen werken, was het noodzakelijk om eerst te weten waarom individuen dit gedrag vertonen. Deze vraag is besproken in hoofdstuk 4. Inzichten die afkomstig zijn uit de literatuur zijn verdeeld over drie clusters, die allen voort komen uit de Situational Action Theory (SAT): individuele eigenschappen, omgevingskenmerken en het keuzeproces. De bevindingen afkomstig uit de 162 bestudeerde studies zijn ondergebracht in een van deze drie clusters. Dit maakte het mogelijk om duidelijk te verklaren wanneer individuen de intentie hebben om content via illegaal downloaden te verkrijgen. Deze inzichten hebben geleid tot een overzicht van variabelen die de verklaring van illegaal downloaden mogelijk maken. De individuele eigenschappen en omgevingskenmerken komen samen en leiden tot een motivatie om illegaal te downloaden, terwijl het keuzeproces bepaalt of deze motivatie ook daadwerkelijk vertaald wordt in een intentie.

Om tot een intentie om illegaal downloaden te komen dient een individu eerst gemotiveerd zijn om op deze wijze content te verkrijgen. Individuen hebben een grotere kans om gemotiveerd te zijn wanneer ze een wens hebben om content te verkrijgen, wanneer ze illegaal downloaden niet als immoreel zien en wanneer ze geloven dat ze in staat zijn om de content succesvol via deze wijze te verkrijgen. Bepaalde omgevingskenmerken dragen bij aan deze motivatie. Hieronder vallen de hoge kosten van legale content, een gunstige morele context en een sociaal netwerk bestaande uit gelijkgezinden die ook op illegale wijze content verkrijgen. Van een gunstige morele context is sprake wanneer: illegaal downloaden geaccepteerd wordt door de omgeving, er een gebrek aan handhaving van auteurswetten is en bestraffing van illegaal downloaden doorgaans uitblijft. Het feit dat een individu gemotiveerd is om content via illegale wijze te verkrijgen maakt niet direct dat hij dit gedrag ook daadwerkelijk zal vertonen. Daarvoor is vereist dat de motivatie vertaald wordt in intentie.

Dit hangt af van het keuzeproces. Dit proces bestaat uit verschillende onderdelen. Percepties nemen hierbij een centrale positie in. Deze bepalen mede of illegaal downloaden wordt gezien als een geschikte wijze voor het individu om zijn behoefte aan content te vervullen. De positieve houding met betrekking tot illegaal downloaden, evenals als de ervaren sociale druk om via deze weg content 


\section{$\underline{\text { Punish, Seduce or Persuade }}$}

te verkrijgen, beïnvloeden deze percepties. De aanwezigheid van verwachte positieve uitkomsten van illegaal downloaden en de afwezigheid van verwachte negatieve uitkomsten van ditzelfde gedrag zijn ook belangrijk. Deze bepalen immers de kosten/basten-analyse van het individu, hetgeen invloed kan hebben op diens keuze. Andere onderdelen van het keuzeproces zijn de mate van zelfcontrole van het individu en de mogelijkheid om zijn deviant gedrag te neutraliseren. Een laatste aspect van het keuzeproces heeft betrekking op het gedrag uit het verleden: individuen die al eerder content via illegaal downloaden hebben verkregen, zijn geneigd om dit ook in de toekomst te doen. De rol van het verleden brengt ook met zich mee dat bepaalde individuen uit gewoonte illegaal downloaden, zonder hier goed over na te denken.

Het is niet mogelijk om aan te geven welke van deze variabelen het belangrijkst is. Wat wel duidelijk is, is dat naarmate er meer van deze variabelen aanwezig zijn in een specifieke context, dit gedrag waarschijnlijker wordt. Het omgekeerde geldt ook, zeker wanneer bepaalde variabelen zich in tegenovergestelde richting voordoen. Interventies die illegaal downloaden willen tegengaan kunnen deze uitkomst bewerkstelligen door zich te richten op het beïnvloeden van de geïdentificeerde variabelen. Hoe meer van deze variabelen worden beïnvloed, hoe eerder een bijdrage aan de afname van illegaal downloaden verwacht kan worden.

Welke interventies, afkomstig van zowel overheden als andere (publiek en private) organisaties, worden toegepast in de context van illegaal downloaden?

Om te kunnen begrijpen of interventies die illegaal downloaden tegen dienen te gaan, hiertoe in staat zijn, was het eerst nodig om een overzicht en categorisering van de verschillende interventies te hebben. Deze deelvraag stond in hoofdstuk 5 centraal. Het werd snel duidelijk dat, hoewel er vele verschillende interventies geïmplementeerd zijn, deze in drie categorieën verdeeld kunnen worden wanneer gekeken wordt naar de primaire wijze waarop gedragsverandering wordt nagestreefd. Interventies proberen personen door afschrikking af te houden van illegaal downloaden, hen te verleiden legale content te kopen of hen te overtuigen dat illegaal downloaden immoreel of schadelijk is. Deze categorisering staat bekend als 'sticks, carrots and sermons'.

Per categorie bestaan verschillende subtypes, die elk op een andere wijze de gedragsverandering proberen te bewerkstelligen. Zo dienen civiele rechtszaken, strafrechtelijke handhaving, de zogeheten graduated response ${ }^{169}$ en verschillende

169 De graduated response is een interventie waarbij het downloadgedrag van internetgebruikers gemonitord wordt. Indien blijkt dat gebruikers content op illegale wijze verkrijgen, worden zij gewaarschuwd. Indien de gebruiker geen gehoor geeft aan deze waarschuwing en nog steeds via deze weg content verkrijgt zullen de waarschuwingen herhaald worden. De toon wordt hierbij steeds 


\section{$\underline{\text { Nederlandstalige Samenvatting }}$}

technologische maatregelen (die illegaal downloaden bemoeilijken of de pakkans aannemelijker maken) elk om illegaal downloaden of te schrikken. Vier verschillende subtypes van de 'carrot' zijn ook geïdentificeerd, die - elk op eigen wijze - een stimulans geven om de content legaal aan te schaffen. Gedacht kan worden aan prijsstrategieën, nieuwe wijze om content te verspreiden, het gebruik van streaming services en de verwijdering van technische beperkingen van de legale content. Veel variatie is te vinden in de interventies die het na streven om individuen te overtuigen van het feit dat zij content op een legale wijze moeten verkrijgen. Zo wordt gewezen op de voordelen van legale content, informatie gegeven over de inhoud en aard van de geldende auteurswetten en gewezen op de risico's en schade van illegaal downloaden voor het individu en de samenleving.

Welke (gedragskundige) mechanismen worden gebruikt in het ontwerp van de verschillende interventies die illegaal downloaden moeten tegengaan en wat zijn de voorwaarden voor hun adequaat functioneren?

Enkel het bestaan van de interventies die illegaal downloaden moeten tegengaan, leidt niet automatisch tot afname van illegaal downloaden. Om deze afname te kunnen vaststellen was als eerste van belang om te begrijpen wanneer deze interventies in theorie 'werken'. Hiervoor was van belang om elk mechanisme te analyseren. Van belang was om het functioneren van deze interventies te begrijpen en ook duidelijk te hebben welke voorwaarden er zijn voor hun adequaat functioneren. Als interventies, via het mechanisme dat gebruikt wordt in hun design, deze voorwaarden niet halen, dan neemt de kans dat ze kunnen bijdrage aan een afname van illegaal downloaden af. Op basis van de interventies die besproken zijn in hoofdstuk 5 zijn er drie mechanismen geïdentificeerd: afschrikking, stimuleren en overtuigen.

Om het afschrikkingsmechanisme goed te kunnen inzetten moet voldaan zijn aan drie voorwaarden: bestraffing via de afschrikkende maatregel moet ten eerste voldoende zeker en, ten tweede, voldoende ernstig zijn. Daarnaast is van belang dat alternatief (legaal) gedrag gestimuleerd wordt. Als er vrijwel geen kans is om bestraft te worden, of als de hoogte van de straf erg laag is, dan zal er geen afschrikkend effect gesorteerd worden door de interventie. De derde voorwaarde heeft met name betrekking op de duurzaamheid van het afschrikkend effect. Indien een legale wijze van verkrijging gestimuleerd wordt, dan kan de afschrikking een langduriger effect hebben.

strenger. $\mathrm{Na}$ een aantal waarschuwingen kunnen bepaalde maatregelen ingezet worden, zoals het beperken van de internetsnelheden of een geldboete. Waarschuwingen en maatregelen escaleren dus zolang de gebruiker illegaal blijft downloaden (vandaar ook de term 'graduated'). 


\section{$\underline{\text { Punish, Seduce or Persuade }}$}

Voor wat betreft stimuleren gaat het er om dat het legaal aanbod zo antrekkelijk mogelijk wordt gemaakt voor de doelgroep. Door het legaal aanbod goedkoper te maken, neemt de omvang van de stimulans toe en wordt het legaal aanbod aantrekkelijker. Ten tweede kan gebruik worden gemaakt van niet-financiële prikkels om de stimulans aantrekkelijk te maken. Sneller toegang kunnen krijgen tot legale content is een voorbeeld van hoe deze tweede voorwaarde vervuld kan worden. De twee overige voorwaarden die legale content aantrekkelijker kunnen maken zijn: onderstrepen dat het verkrijgen van content op deze wijze eenvoudig is en voorkomen dat de stimulans als negatief wordt ervaren door de doelgroep. Overtuigen is het derde mechanisme. Er zijn vier voorwaarden waaraan elke toepassing van dit mechanisme in ieder geval moet voldoen. Deze voorwaarden dragen gezamenlijk bij aan de acceptatie van de boodschap die door de interventie wordt uitgedragen. Dit is van belang, want als een boodschap niet wordt geaccepteerd, wordt de kans kleiner dat de doelgroep zijn gedrag zal aanpassen. Van belang is dat het gewenste gedrag eenvoudig uit te voeren is, dat de boodschap nieuwe informatie presenteert, geloofwaardig is én een positieve toon heeft. Daarnaast zijn er drie specifieke voorwaarden die elk gekoppeld zijn aan de drie manieren waarop bepaalde interventies de doelgroep proberen te overtuigen. Als gewezen wordt op de voordelen van legale content, dan dient nadruk gelegd te worden op deze voordelen. Indien de doelgroep ingelicht wordt over de aard en strekking van de auteurswetten dienen de bestaande normen en waarden van de doelgroep gelijk getrokken te worden met die van de bestaande wet- en regelgeving. Indien gewezen wordt op de risico's en schadelijkheid van illegaal downloaden moeten de risico's of schade voldoende betekenisvol zijn voor de doelgroep. Zodoende moeten de voorgestelde risico's en schade voldoende tastbaar zijn.

\section{In welke mate dragen de onderliggende mechanismen bij aan afnames in illegaal downloaden?}

De beantwoording van de derde deelvraag laat zien dat er een aantal voorwaarden is per mechanisme. Als aan deze voorwaarden wordt voldaan, zou de interventie, in theorie, in staat moeten zijn om te kunnen bijdragen aan een afname van illegaal downloaden. Deze materie staat centraal in de vierde deelvraag. In totaal zijn vier stappen gezet om deze deelvraag te beantwoorden.

Ten eerste is vastgesteld of de verschillende interventies zich wel op de juiste doelgroep richten. In hoofdstuk 4 is een aantal attributen gesignaleerd dat gebruikt kan worden om de doelgroep te identificeren. Hieruit bleek dat jonge mannen met meer ervaring met computers en gerelateerde technieken de voornaamste doelgroep vormen. Het valt op dat de verschillende interventies zich niet volledig 


\section{$\underline{\text { Nederlandstalige Samenvatting }}$}

op deze doelgroep richten. Interventies lijken zich ook te richten op de minder ervaren individuen. Dit kan een invloed hebben op de bijdrage van de verschillende interventies. Van belang is immers dat de individuen die illegaal downloaden zich ook aangesproken voelen door de interventie. Indien deze interventie zich richt op de verkeerde doelgroep, dan neemt de kans dat deze individuen zich aangesproken voelen af.

Van wezenlijk belang is de vraag of de mechanismen in de praktijk wel voldoen aan de reeds geïdentificeerde voorwaarden. Dit was de tweede stap om de vierde deelvraag te kunnen beantwoorden. Hier doen zich problemen voor. Interventies die gebruik maken van het afschrikkingsmechanisme, hebben moeite met het halen van een voldoende grote mate van strafzekerheid. In de praktijk hebben dergelijke interventies te maken met een (zeer) lage kans op detectie en bestraffing. Enkel de technologische maatregelen brengen een hoge zekerheid van bestraffing met zich. Op hun beurt hebben deze maatregelen een lagere strafernst, mede omdat de maatregelen relatief eenvoudig omzeild kunnen worden. Zelfs maatregelen zoals de graduated response hebben moeite om voldoende strafzekerheid te genereren.

Interventies die gebruik maken van het stimulerings-mechanisme lopen tegen minder problemen aan in de praktijk. Hoewel getwijfeld kan worden of de grootte van de prikkel voldoende is, voldoen de interventies grotendeels aan de andere voorwaarden.

De meeste problemen doen zich voor met betrekking tot de interventies die de doelgroep wensen te overtuigen. Deze doen zich met name voor wanneer dit mechanisme gebruikt wordt om de doelgroep te informeren over de inhoud en strekking van de auteursrechten en wanneer er gewezen wordt op de risico's en schade die illegaal downloaden met zich meebrengt voor het individu en de samenleving. Het gelijk trekken van de normen en waarden van de doelgroep met die van overheden en de entertainmentindustrie is lastig te bewerkstelligen, mede omdat illegaal downloaden geworteld is in de samenleving. Het wijzen op risico's lijkt eveneens niet aan de voorwaarden te voldoen, vooral omdat de risico's die worden aangewezen, onvoldoende betekenisvol zijn voor de doelgroep. Dit is een consequentie van het feit dat de ernst van het risico als erg hoog wordt gepresenteerd, maar de kans dat een individu aan dit risico wordt blootgesteld in de praktijk zeer laag is. De werking van dergelijke interventies is dus te betwijfelen. De andere voorwaarden, die gelden voor alle interventies die gebruik maken van dit derde mechanisme, worden ook niet altijd vervuld. De geloofwaardigheid van de boodschap, het presenteren van nieuwe informatie en het gebruik van positieve toon zijn voorwaarden waaraan niet voldaan wordt. Wel wordt voldaan aan de voorwaarde dat het gewenste gedrag makkelijk is uit te voeren. 


\section{$\underline{\text { Punish, Seduce or Persuade }}$}

De derde stap was om te bepalen of er wetenschappelijk bewijs is om vast te stellen dat het voldaan aan deze voorwaarden ook inderdaad kan bijdragen (en zo $\mathrm{ja}$, in welke mate) aan afnames van illegaal downloaden. Bewijs is gevonden voor de rol van (met name) de zekerheid en de ernst van de straf als het gaat om het afschrikkingsmechanisme. Ook is er bewijs voor het bieden van een grotere prikkel (bijv. goedkoper geprijsde content) als het gaat om het stimuleren van het kopen van legale content. Ook het aanbieden van niet-financiële prikkels draagt bij het verleiden van de doelgroep. Er is echter weinig bewijs dat het gebruik van het overtuigingsmechanisme ondersteund. Dit is met name het geval voor wat betreft het identificeren van de voordelen van legale content en het aanwijzen van de risico's van illegaal downloaden. Het bewijs voor de andere manieren van het gebruik van het overtuigingsmechanisme is conflicterend als het gaat om het halen van de overige voorwaarden.

De laatste stap was om een nieuw empirisch onderzoek uit te voeren waarin de voorlopige bevindingen nader getest konden worden via verschillende scenario's. Via deze weg was het ook mogelijk om uitspraken te doen over de grootte van de mogelijke bijdrage van de interventies.

Ten eerste kwam naar voren dat de respondenten aangaven dat zij de scenario's die bestonden uit het afschrikkingsmechanisme meer overredingskracht toebedeelden dan de andere typen scenario's. Op hun beurt werden scenario's gebaseerd op het stimuleringsmechanisme overredender gevonden dan die op het overtuigingsmechanisme. Scenario's gebaseerd op dat laatste mechanisme werden nooit geselecteerd als meest overredend. In de reacties op de individuele scenario's wordt deze voorkeur van de respondenten bevestigd. Wanneer deze reacties worden vergeleken met een vastgesteld referentiekader, dan valt op dat scenario's die gebruik maakten van het afschrikkingsmechanisme de grootste afname in voorgenomen downloadgedrag teweeg brengen. Scenario's die gebruik maakten van het stimuleringsmechanisme brachten relatief kleine afnames te weeg, maar deze resultaten waren wel het meest frequent statistisch significant. Scenario's die poogden de respondenten te overtuigen hadden geen effect of maakten de kans zelfs groter dat de respondenten content op illegale wijze zouden verkrijgen. Dit onderschrijft in ieder geval dat het gebruik maken van interventies met een overtuigingsmechanisme weinig slagingskans heeft.

Wat uit deze eerste empirische studie ook naar voren komt is dat bepaalde van de reeds besproken voorwaarden meer invloed hebben op de reacties dan andere. Zo blijkt de strafernst zwaarder te wegen dan de strafzekerheid. Ook bleek een bepaalde niet-financiële prikkel (de veiligheid van het legale aanbod) meer effect te hebben dan het aanbieden van goedkopere legale content. Daarentegen leidde een andere niet-financiële prikkel (toevoeging van gratis extra features) tot een tegenovergesteld effect: deze prikkel leidde ertoe dat de respondenten meer 


\section{Nederlandstalige Samenvatting}

geneigd waren om content via illegale wijze te verkrijgen. Als er specifiek gekeken wordt naar de voorwaarden voor het overtuigingsmechanisme, dan wordt duidelijk dat hier niets meer 'te redden' valt. Geen van deze voorwaarden droeg bij aan een afname van illegaal downloaden. Al met al blijkt dat de afschrikkingsinterventies een grotere bijdrage kunnen leveren aan afnames in illegaal downloaden, gevolgd door interventies die de doelgroep een stimulans bieden om de content legaal aan te schaffen. Interventies die de doelgroep proberen te overtuigen zijn waarschijnlijk niet in staat om een dergelijke bijdrage te leveren.

Welke veranderingen worden geobserveerd in het online zoekgedrag van illegale downloaders na de implementatie van een specifieke interventie die illegaal downloaden tegen moet gaan?

Hoewel de zojuist besproken bevindingen erg inzichtelijk zijn, reflecteren ze niet noodzakelijk veranderingen in daadwerkelijk gedrag. De vijfde deelvraag poogde dichterbij dit echte gedrag te komen door te bestuderen hoe online zoekgedrag veranderde na implementatie van een specifieke interventie die illegaal downloaden tegen zou moeten gaan: het Copyright Alert System (CAS). Deze interventie is geïmplementeerd in een specifieke jurisdictie: de Verenigde Staten van Amerika (VS). Dankzij Google Trends was het mogelijk om alle zoektermen, die gerelateerd zijn aan illegaal downloaden, in kaart te brengen, zowel voorafgaand en na de implementatie in de VS. Deze aanpak maakt het mogelijk om uitspraken te doen over hoe het zoekgedrag is veranderd, hetgeen op zijn beurt een indicatie kan zijn voor veranderingen in daadwerkelijke gevallen van illegaal downloaden.

De eerste resultaten leken veelbelovend. De verschillende zoektermen zijn, ter analyse, verdeeld over drie clusters en het gebruik van de zoektermen veranderde in de verwachte richting. De omvang van zoektermen die indicatief waren voor illegaal downloaden via P2P-netwerken nam af, interesse in legaal aanbod nam toe en zoekgedrag naar alternatieve wijze om content illegaal te downloaden nam ook enigszins af. Deze effecten waren het meest zichtbaar op korte termijn. De effecten namen ietwat af naar mate de tijd verstreek. Maar zelfs op langere termijn bleven verschillen tussen voor en na de implementatie van het CAS zichtbaar.

Deze veranderingen konden echter niet automatisch worden toegeschreven aan het CAS. De attributie van deze veranderingen aan het CAS bleek lastig. Om daar toch uitspraken over te doen was het nodig om een natuurlijk experiment uit te voeren, waarbij een andere jurisdictie als controle groep werd geselecteerd. Zodoende werd dezelfde analyse uitgevoerd voor zoekgedrag dat afkomstig was van Canada. Deze analyse liet zien dat de veranderingen niet uniek zijn voor de 
VS. Dit maakt het waarschijnlijker dat de geobserveerde veranderingen niet door het CAS zijn veroorzaakt. Ten hoogste heeft het CAS de omvang van de veranderen beïnvloed. Deze bevindingen zaaien twijfel over het gebruik van het CAS en soortgelijke interventies die een afschrikkingsmechanisme gebruiken. Een mogelijke oorzaak hiervan kan liggen in de lage sanctiekans, die inherent blijkt te zijn aan dergelijke interventies.

\section{Afronding}

Al met al laat dit onderzoek zien dat het de moeite waard is om bepaalde interventies te implementeren. Hoe meer rekening wordt gehouden met de verklarende variabelen van illegaal downloaden en de theoretische inzichten betreffende het design van dergelijke interventies, én de voorwaarden waaraan voldaan moet worden, hoe groter de kans is dat deze interventies een bijdrage kunnen leveren aan afnames in illegaal downloaden. Tegelijkertijd zullen deze bijdragen relatief bescheiden blijven en hebben bepaalde interventies meer kans om deze bijdrage te leveren. Wel lijkt dat bepaalde interventies, dankzij hun mechanismen, een grotere bijdrage kunnen leveren dan andere. Ook is duidelijk dat er een gat bestaat tussen hoe de interventies en mechanismen volgens de theorie zouden moeten fungeren en hoe ze dat in de praktijk doen.

De verschillende interventies zullen er niet voor zorgen dat 'illegaal downloaden' geheel zal verdwijnen. Wel kunnen interventies het probleem beter beheersbaar maken, maar daarbij zal ook altijd een balans moeten worden gevonden tussen de maatschappelijke kosten van dit gedrag en de handhavingskosten. Duidelijk is dat er uitdagingen blijven bestaan voor de entertainmentindustrie, overheden en beleidsmakers wat betreft het ontwerp, de implementatie en het in stand houden van interventies om het illegaal downloaden beheersbaar te maken. De bevindingen van dit onderzoek kunnen daaraan bijdragen, omdat de bevindingen het mogelijk maken om beleid aan te passen en aan te scherpen. De toekomstige uitdagingen die het fenomeen 'illegaal downloaden' met zich brengt vereisen een flexibele en proactieve houding van de entertainmentindustrie en overheden. Via die weg kan voorkomen worden dat nieuwe vormen en modaliteiten van illegaal downloaden net zo hardnekkig worden als de huidige. Desalniettemin zullen bepaalde personen altijd blijven zoeken naar manieren om content te verkrijgen zonder hier voor te hoeven betalen. De interventies die illegaal downloaden tegen proberen te gaan dienen er voor te zorgen dat content ook nog via legale wegen gekocht wordt. 


\section{Appendix I: Reference list for the realist synthesis}

The realist synthesis, presented in Chapter 4, was based on an initial body of work that consisted of 168 empirical studies on digital piracy. Of these 168, 6 were excluded, resulting in 162 studies in total that were used for further analysis. ${ }^{170}$ In order for that chapter to remain understandable, the decision was made to refer to studies in a numerical way. This first appendix lists and identifies each of these studies. For reasons of transparency, this appendix consists of all studies that were initially selected.

1. Bonner, S. \& O'Higgins, E. (2010) Music piracy: ethical perspectives. Management Decision, 48(9), 1341-1354.

2. Koklic, M., Vida, I., Bajde, D. \& Culiberg, B. (2014) The study of perceived adverse effects of digital piracy and involvement: insights from adult computer users. Behaviour \& Information Technology, 33(3), 224-235.

3. Lau, E. (2003) An empirical study of software piracy. Business Ethics: A European Review, 12(3), 233-245.

4. Taylor, S., Ishida C. \& Wallace, D. (2009) Intention to Engage in Digital Piracy: A Conceptual Model and Empirical Test. Journal of Service Research, 11(3), 246-262.

5. Taylor, S. (2012) Evaluating digital piracy intention on behaviors. Journal of Services Marketing, 26(7), 472-483.

6. Coyle, J., Gould, S., Gupta, P. \& Gupta, R. (2009) "To buy or to pirate": The matrix of music consumers' acquisition-mode decision-making. Journal of Business Research, 62(10), 10311037.

7. Hsu, J. \& Shiue, C. (2008) Consumers' Willingness to Pay for Non-pirated Software. Journal of Business Ethics, 81(4), 715-732.

8. Jambon, M. \& Smetana, J. (2012) College students' moral evaluations of illegal music downloading. Journal of Applied Developmental Psychology, 33(1), 31-39.

9. Phau, I. \& Liang J. (2012) Downloading digital video games: predictors, moderators and consequences. Marketing Intelligence \& Planning, 30(7), 740-756.

10. Wang, F., Zhang, H., Zang, H. \& Ouyang, Q. (2005) Purchasing pirated software: an initial examination of Chinese consumers. Journal of Consumer Marketing, 22(6), 340-351.

11. Dilmperi, A., King, T. \& Dennis, C. (2011) Pirates of the web: The curse of illegal downloading. Journal of Retailing and Consumer Services, 18(2), 132-140.

12. Kinnally, W., Lacayo, A., McClung, S. \& Sapolsky, B. (2008) Getting up on the download: college students' motivations for acquiring music via the web. New Media \& Society, 10(6), 893 913.

13. Lee, D., Park, J., Kim, J., Kim, J. \& Moon, J. (2011) Understanding music sharing behaviour on social network services. Online Information Review, 35(5), 716-733.

14. Shanahan, K. \& Hyman, M. (2010) Motivators and enablers of SCOURing: A study of online piracy in the US and UK. Journal of Business Research, 63(9-10), 1095-1102.

15. Bateman, C., Valentine, S. \& Rittenburg, T. (2013) Ethical Decision Making in a Peer-to-Peer File Sharing Situation: The Role of Moral Absolutes and Social Consensus. Journal of Business Ethics, 115(2), 229-240.

16. Hendriana, E., Mayasari, A. \& Gunadi, W. (2013) Why Do College Students Buy Counterfeit Movies? International Journal of e-Education, e-Business, e-Management and e-Learning, 3(1), 62-67.

17. Higgins, G. \& Makin D. (2004), Does Social Learning Theory Condition the Effects of Low Self-Control on College Students' Software Piracy? Journal of Economic Crime Management, 2(2), 1-22.

${ }^{170}$ The studies with the number 62, 72,99, 101 and 103 were excluded from the discussion in Chapter 4. 


\section{$\underline{\text { Punish, Seduce or Persuade }}$}

18. Higgins, G., Fell, B. \& A. Wilson, A. (2007) Low Self-Control and Social Learning in Understanding Students' Intentions to Pirate Movies in the United States. Social Science Computer Review, 25(3), 339-357.

19. Kwong, K., Yau, O., Lee, J., Sin, L. \& Tse, A. (2003) The Effect of Attitudinal and Demographic Factors on Intention to Buy Pirated CDs: the Case of Chinese Consumers. Journal of Business Ethics, 47(3), 223-235.

20. LaRose, R., Lai, Y., Lange, R., Love, B. \& Wu, Y. (2006) Sharing or Piracy? An Exploration of Downloading Behavior. Journal of Computer-Mediated Communication, 11(1), 1-21.

21. Pryor, A., Dalenberg, D., McCorkle, D., Reardon, J. \& Wicks, J. (2008) Buy or burn?: Empirical tests of models of crime using data from a general population. The Social Science Journal, 45(1), 95-106.

22. Samtani, A., Kiong, J., Young, L. \& Neo, A. (2001) Software Piracy in Singapore. The Journal of World Intellectual Property, 4(4), 581-604.

23. Shoham, A., Ruvio, A. \& Davidow, M. (2008) (Un)ethical consumer behavior: Robin Hoods or plain hoods? Journal of Consumer Marketing, 25(4), 200-210.

24. Siponen, M., Vance, A. \& R. Willison R. (2012) New insights into the problem of software piracy: The effects of neutralization, shame, and moral beliefs. Information and Management, 49(7-8), 334-341

25. Suter, T., Kopp, S. \& Hardesty, D. (2006) The effects of consumers' ethical beliefs on copying behaviour. Journal of Consumer Policy, 29(2), 190-202.

26. Tan, B., (2002) Understanding consumer ethical decision making with respect to purchase of pirated software. Journal of Consumer Marketing, 19(2), 96-111.

27. Wingrove, T., Korpas, A. \& Weisz, V. (2011) Why were millions of people not obeying the law? Motivational influences on non-compliance with the law in the case of music piracy. Psychology, Crime \& Law, 17(3), 261-276.

28. Yoon, C. (2012) Digital piracy intention: a comparison of theoretical models. Behaviour \& Information Technology, 31(6), 565-576.

29. Yu, S. (2012) College Students' Justifications for Digital Piracy: A Mixed Methods Study Journal of Mixed Methods Research, 6(4), 364-378.

30. Chen, Y., Shang, R. \& Lin, A. (2008) The intention to download music files in a P2P environment: Consumption value, fashion, and ethical decision perspectives. Electronic Commerce Research and Applications, 7(4), p. 411-422.

31. Garbharran, A. \& Thatcher, A. (2011) A case for using a social cognitive model to explain intention to pirate software. Journal of eHealth Technology and Application, 7(2), 87-98.

32. Huang, C. (2005) File Sharing as a Form of Music Consumption. International Journal of Electronic Commerce, 9(4), 37-55.

33. Moores, T. \& Chang, J. (2006) Ethical Decision Making in Software Piracy: Initial Development and Test of a Four-Component Model. MIS Quarterly, 30(1), 167-180.

34. Zentner, A. (2006) Measuring the Effect of File Sharing on Music Purchases. Journal of Law and Economics, 49(1), 63-90.

35. Al-Rafee, S. \& Cronan, T. (2006) Digital Piracy: Factors that Influence Attitude towards Behavior. Journal of Business Ethics, 63(3), p. 237-259.

36. Cronan, T. \& Al-Rafee, S. (2008) Factors that Influence the Intention to Pirate Software and Media. Journal of Business Ethics, 78(4), 527-545.

37. Goles, T., Jayatilaka, B., George, B., Parsons, L., Chambers, V., Taylor, D. \& Brune, R. (2008) Softlifting: Exploring Determinants of Attitude. Journal of Business Ethics, 77(4), 481-499.

38. Hashim, M., Kannan, K. \& Wegener, D. (2011) Nudging the Digital Pirate: An Extension of the Theory of Planned Behavior. Draft.

39. Khang, H., Ki, E., Park, I. \& Baek, S. (2012) Exploring antecedents of attitude and intention toward Internet piracy among college students in South Korea. Asian Journal of Business Ethics, 1(2), 177-194.

40. Panas, E. \& Ninni, V. (2011) Ethical Decision Making in Electronic Piracy: An Explanatory Model based on the Diffusion of Innovation Theory and the Theory of Planned Behavior. International Journal of Cyber Criminology, 5(2), 836-859. 


\section{$\underline{\text { Appendix I: Reference list for the realist synthesis }}$}

41. Setiawan, B. \& Tjiptono, F. (2013) Determinants of Consumer Intention to Pirate Digital Products. International Journal of Marketing Studies, 5(3), 48-55.

42. Yoon, C. (2011) Theory of Planned Behavior and Ethics Theory in Digital Piracy: An Integrated Model. Journal of Business Ethics, 100(3), 405-417.

43. Aaltonen, M. \& Salmi, V. (2013) Versatile Delinquents or Specialized Pirates? A Comparison of Correlates of Illegal Downloading and Traditional Juvenile Crime. Journal of Scandinavian Studies in Criminology and Crime Prevention, 14(2), 188-195.

44. Higgins, G., Wilson, A. \& Fell, B. (2005) An Application of Deterrence Theory to Software Piracy. Journal of Criminal Justice and Popular Culture, 12(3), 229-248.

45. Li, X. \& Nergadze, N. (2009) Deterrent Effect of Four Legal and Extralegal Factors on Online Copyright Infringement. Journal of Computer Mediated Communication, 14(2), 307-327.

46. Chiang, L. \& Lee, B. (2011) Ethical Attitude and Behaviors Regarding Computer Use. Ethics and Behavior, 21(6), 481-497.

47. d'Astous, A., Colbert, F. \& Monpetit, D. (2005) Music Piracy on the Web-How Effective Are Anti-Piracy Arguments? Evidence from the Theory of Planned Behavior. Journal of Consumer Policy, 28(3), 298-310.

48. Kuo, F. \& Hsu, M. (2001) Development and Validation of Ethical Computer Self-Efficacy Measure: The Case of Softlifting. Journal of Business Ethics, 32(4), 299-315.

49. Kwong, T. \& Lee, M. (2002) Behavioral Intention Model for the Exchange Mode Internet Music Piracy. Proceedings of the 35th Hawaii International Conference on System Sciences: Hawaii, 191-200.

50. LaRose, R. \& Kim, J. (2007) Share, Steal, or Buy? A Social Cognitive Perspective of Music Downloading. CyberPsychology \& Behavior, 10(2), 267-277.

51. Liao, C., Lin, H. \& Liu, Y. (2010) Predicting the Use of Pirated Software: A Contingency Model Integrating Perceived Risk with the Theory of Planned Behavior. Journal of Business Ethics, 91(2), 237-252.

52. Lin, T., Hsu, J. \& Chen, H. (2013) Customer Willingness to Pay for Online Music: The Role of Free Mentality. Journal of Electronic Commerce Research, 14(4), 315-333.

53. Morton, N. \& Koufteros, X. (2008) Intention to Commit Online Music Piracy and Its Antecedents: An Empirical Investigation. Structural Equation Modeling, 15(3), 491-512.

54. Peace, G., Galletta, D. \& Thong, J. (2003) Software Piracy in the Workplace: A Model and Empirical Test. Journal of Management Information Systems, 20(1), 153-177.

55. Plowman, S. \& Goode, S. (2009) Factors affecting the intention to download music: quality perceptions and downloading intensity. Journal of Computer Information Systems, 49(4), 8497.

56. Van Belle, J., Macdonald, B. \& Wilson, D. (2007) Determinants of Digital Piracy among Youth in South Africa. Communications of the IIMA, 7(3), 47-64.

57. Wang, C., Chen, C., Yang, S. \& Farn, C. (2009) Pirate or Buy? The Moderating Effect of Idolatry. Journal of Business Ethics, 90(1), 81-93.

58. Wang, X. \& McClung, S. (2012) The immorality of illegal downloading: The role of anticipated guilt and general emotions. Computers in Human Behavior, 28(1), 153-159.

59. Jacobs, R., Heuvelman, A., Tan, M. \& Peters, O. (2012) Digital movie piracy: A perspective on downloading behavior through social cognitive theory. Computers in Human Behavior, 28(3), 958-967.

60. Lin, T., Hsu, M., Kuo, F. \& Sun, P. (1999) An Intention model-based Survey of Software Piracy. 32nd Annual Hawaii International Conference on System Sciences.

61. Ulsperger, J., Hodges, S. \& Paul J. (2010), Pirates on the Plank: Neutralization Theory and the Criminal Downloading of Music Among Generation Y in the Era of Late Modernity. Journal of Criminal Justice and Popular Culture, 17(1), 124-151.

62. Bhattacharjee, S., Gopal, R. \& Sanders, G. (2003) Digital Music and Online Sharing: Piracy 2.0? Communications of the ACM, 46(7), 107-111.

63. Chiang, E. \& Assane, D. (2007) Determinants of Music Copyright Violations on the University Campus. Journal of Cultural Economics, 31(3), 187-204. 


\section{$\underline{\text { Punish, Seduce or Persuade }}$}

64. Chiang, E. \& Assane, D. (2008) Music piracy among students on the university campus: Do males and females react differently? Journal of Socio-Economics, 37(4), 1371-1380.

65. Gopal, R., Sanders, G., Bhattacharjee, S., Agrawal, M. \& Wagner S. (2004) A Behavioral Model of Digital Music Piracy. Journal of Organizational Computing and Electronic Commerce, 14(2), 89-105.

66. Gunter, W., Higgins, G. \& Gealt, R. (2010) Pirating Youth: Examining the Correlates of Digital Music Piracy among Adolescents. International Journal of Cyber Criminology, 4(1-2), 657-671.

67. Hinduja, S., (2003) Trends and Patterns among Online Software Pirates. Ethics and Information Technology, 5(1), 49-61.

68. Hinduja, S. \& Higgins, G. (2011) Trends and Patterns Among Music Pirates. Deviant Behavior, 32(7), 563-588

69. Moon, B., McCluskey, J. \& McCluskey, C. (2010) A General Theory of Crime and Computer Crime: An Empirical Test. Journal of Criminal Justice, 38(4), 767-772.

70. Moores, T. \& Esichaikul, V. (2011) Socialization and Software Piracy: A Study. Journal of Computer Information Systems, 51(3), 1-9.

71. Shore, B., Venkatachalam, A., Solorzano, E., Burn, J., Hassan, S. \& Janczewski, L. (2001) Softlifting and piracy: behavior across cultures. Technology in Society, 23(4), 563-581.

72. Simpson, P., Banerjee, D. \& Simpson L. (1994), Softlifting: A Model of Motivating Factors. Journal of Business Ethics, 13(6), 431-438.

73. Sims, R., Cheng, H. \& Teegen, H. (1996) Toward a Profile of Student Software Piraters. Journal of Business Ethics, 15(8), 839-849.

74. Cheng, H., Sims, R. \& Teegen, H. (1997) To Purchase or Pirate Software: An Empirical Study. Journal of Management Information Systems, 13(4), 49-60.

75. Acilar, A. (2010) Demographic Factors Affecting Freshman Students' Attitudes towards Software Piracy: An Empirical Study. Issues in Informing Science and Information Technology, 7, 321-328.

76. Cockrill, A. \& Goode, M. (2012) DVD pirating intentions: Angels, devils, chancers and receivers. Journal of Consumer Behavior, 11(1), 1-10

77. Higgins, G. (2004) Can low self-control help with the understanding of the software piracy problem? Deviant Behavior, 26(1), 1-24.

78. Lorde, T., Devonish, D. \& Beckles, A. (2010) Real pirates of the Caribbean: socio-psychological traits, the environment, personal ethics and the propensity for digital piracy in Barbados. Journal of Eastern Caribbean Studies, 35(1), 1-35.

79. Morris, R., Johnson, M. \& Higgins, G. (2009) The role of gender in predicting the willingness to engage in digital piracy among college students. Criminal Justice Studies, 22(4), 393-404.

80. Redondo, I. \& Charron, J. (2013) The payment dilemma in movie and music downloads: An explanation through cognitive dissonance theory. Computers in Human Behavior, 29(5), $2037-$ 2046.

81. Smallidge, J. \& Roberts, J. (2013) Crime Specific Neutralizations: An Empirical Examination of Four Types of Digital Piracy. International Journal of Cyber Criminology, 7(2), 125-140.

82. Van der Byl, K. \& Van Belle J. (2008), Factors Influencing South African Attitudes toward Digital Piracy. Communications of the IBIMA, 1(1), 202-211.

83. Gan, L. \& Koh, H. (2006) An empirical study of software piracy among tertiary institutions in Singapore. Information and Management, 43(5), 640-649.

84. Kini, R., Ramakrishna, H. \& Vijayraraman, B. (2003) An exploratory study of moral intensity regarding software piracy of students in Thailand. Behaviour and Information Technology, 22(1), 63-70.

85. Malin, J. \& Fowers, B. (2009) Adolescent self-control and music and movie piracy. Computers in Human Behavior, 25(3), 718-722.

86. Rahim, M., Rahman, M. \& Seyal, A. (2000) Software piracy among academics: an empirical study in Brunei Darussalam. Information Management \& Computer Security, 8(1), 14-26.

87. Becker, J. \& Clement, M. (2006) Dynamics of Illegal Participation in Peer-to-Peer Networks: Why Do People Illegally Share Media Files. Journal of Media Economics, 19(1), 7-32. 


\section{$\underline{\text { Appendix I: Reference list for the realist synthesis }}$}

88. Phau, I. \& Ng, J. (2010) Predictors of Usage Intentions of Pirated Software. Journal of Business Ethics, 94(1), 23-37.

89. Rahim, M., Seyal, A. \& Rahman, M. (1999) Software Piracy Among Computing Students: a Bruneian Scenario. Computers \& Education, 32(4), 301-321.

90. Seale, D., Polakowski, M. \& Schneider, S. (1998) It's not really theft!: personal and workplace ethics that enable software piracy. Behaviour \& Information Technology, 17(1), 27-40.

91. Djekic, P. \& Loebbecke, C. (2007) Preventing application software piracy: An empirical investigation of technical copy protections. Journal of Strategic Information System, 16(2), 173 186.

92. Borja, K., Dieringer, S. \& Daw, S. (2015) The effect of music streaming services on music piracy among college students. Computer in Human Behavior, 45, 69-76.

93. Hinduja, S. (2001) Correlates of Internet Software Piracy. Journal of Contemporary Criminal Justice, 17(4), 369-382.

94. Levin, M., Dato-on, M. \& Rhee, K. (2004) Money for nothing and hits for free: the ethics of downloading music from peer-to-peer web sites. Journal of Marketing Theory and Practice, 12(1), 48-59.

95. McCorkle, D. Reardon, J., Dalenberg, D., Pryor, A. \& Wicks, J. (2012) Purchase or pirate: a model of consumer intellectual property theft. Journal of Marketing Theory and Practice, 20(1), 73-86.

96. Popham, J. (2011) Factors Influencing Music Piracy. Criminal Justice Studies, 24(2), 199-209.

97. Sheehan, B., Tsao, J. \& Yang, S. (2010) Motivations for Gratifications of Digital Music Piracy Among College Students. Atlantic Journal of Communication, 18(5), 241-258.

98. Xia, M., Huang, Y., Duan, W. \& Whinston, A. (2012) To Continue Sharing or Not to Continue Sharing? An Empirical Analysis of User Decision in Peer-to-Peer Sharing Networks. Information Systems Research, 23(1), 247-259.

99. Law, R. \& Wong, D. (2005) How do Hospitality and Tourism Students View Software Piracy? Asia Pacific Journal of Tourism Research, 10(3), 263-273.

100. Bhal, K. \& Leekha, N. (2008) Exploring Cognitive Moral Logics Using Grounded Theory: The Case of Software Piracy. Journal of Business Ethics, 81(3), 635-646.

101. Kin-wai Lau, E. (2006) Factors motivating people toward pirated software. Qualitative Market Research, 9(4), 404-419.

102. Konstantakis, N., Palaigeorggiou, G., Siozos, P. \& Tsoukalas, I. (2010) What do computer science students think about software piracy? Behaviour and Information Technology, 29(3), 277-285.

103. Lau, E. (2006) Factors Motivating People Toward Pirated Software. Qualitative Market Research, 9(4), 404-419.

104. Moores, T. \& Dhaliwal, J. (2004) A reversed context analysis of software piracy issues in Singapore. Information and Management, 41(8), 1037-1042.

105. Suki, N., Ramayah, T. \& Suki, N. (2011) Understanding consumer intention with respect to purchase and use of pirated software. Information Management \& Computer Security, 19(3), 195-210.

106. Woolley, D. \& Eining, M. (2006) Software Piracy among Accounting Students: A Longitudinal Comparison of Changes and Sensitivity. Journal of Information Systems, 20(1), 49-63.

107. Al-Jabri, I. \& Abdul-Gader, A. (1997) Software Copyright Infringements: An Exploratory Study of the Effects of Individual and Peer Beliefs. Omega, 25(3), 335-344.

108. Gunter, W. (2008), Piracy on the High Speeds: A Test of Social Learning Theory on Digital Piracy among College Students. International Journal of Criminal Justice Studies, 3(1), 54-68.

109. Gupta, P., Gould, S. \& Pola, B. (2004) "To Pirate or Not to Pirate": A Comparative Study of the Ethical versus Other Influences on the Consumer's Software Acquisition-Mode Decision. Journal of Business Ethics, 55(3), 225-274.

110. Hinduja, S. \& Ingram, J. (2009) Social learning theory and music piracy: the differential role of online and offline peer influences. Criminal Justice Studies, 22(4), 405-420. 


\section{$\underline{\text { Punish, Seduce or Persuade }}$}

111. Kini, R., Ramakrishna, H. \& Vijayraraman, B. (2004) Shaping of Moral Intensity regarding Software Piracy: A Comparison between Thailand and U.S. Students. Journal of Business Ethics, 49(1), 91-104.

112. Marcum, C., Higgins, G., Wolfe, S. \& Ricketts, M. (2011) Examining the Intersection of Selfcontrol, Peer Association and Neutralization in Explaining Digital Piracy. Western Criminology Review, 12(3), 60-74

113. Ramakrishna, H., Kini, R. \& Vijayraraman, B. (2001) Shaping of moral intensity regarding software piracy in university students: Immediate community effects. Journal of Computer Information Systems, 41(4), 47-51.

114. Wang, X. \& McClung, S. (2011) Toward a detailed understanding of illegal digital downloading intentions: An extended theory of planned behavior approach. New Media \& Society, 13(4), $663-$ 677.

115. Chiou, J., Huang, C. \& Lee, H. (2005) The Antecedents of Music Piracy Attitudes and Intentions. Journal of Business Ethics, 57(2), 161-174

116. Chiang, E. \& Assane, D. (2009) Estimating the Willingness to Pay for Digital Music. Contemporary Economic Policy, 27(4), 512-522.

117. Chiou, J., Cheng, H. \& Huang, C. (2011) The Effects of Artist Adoration and Perceived Risk of Getting Caught on the Attitude and Intention to Pirate Music in the United States and Taiwan. Ethics and Behavior, 21(3), 182-196.

118. Sinha, R. \& Mandel, N. (2008) Preventing Digital Music Piracy: the Carrot or the Stick. Journal of Marketing, 72(1), 1-15.

119. Robertson, K., McNeill, L., Green, J. Roberts, C. (2012) Illegal Downloading, Ethical Concern and Illegal Behavior. Journal of Business Ethics, 108(2), 215-227.

120. Gerlach, J., Kuo, F. \& Lin, C. (2009) Self sanction and regulative sanction against copyright infringement: a comparison between U.S. and China college students. Journal of the American Society for Information Science Technology, 60(8), 1687-1701.

121. Burrus, G., Bossler, A. \& Holt, T. (2013) Assessing the Mediation of a Fuller Social Learning Model on Low Self-Control's Influence on Software Piracy. Crime and Delinquency, 59(8), 1157-1184.

122. Higgins, G., Fell, B. \& Wilson A. (2006) Digital Piracy: Assessing the Contributions of an Integrated Self-Control Theory and Social Learning Theory Using Structural Equation Modeling. Criminal Justice Studies, 19(1), 3-22.

123. Higgins, G., Marcum, C., Freiburger, T. \& Ricketts, M. (2012) Examining the Role of Peer Influence and Self-Control on Downloading Behavior. Deviant Behavior, 33(5), 412-423.

124. Higgins, G., Wolfe, S. \& Ricketts, M. (2009) Digital piracy: A latent class analysis. Social Science Computer Review, 27(1), 24-40.

125. Holt, T. \& Copes, H. (2010) Transferring subcultural knowledge on-line: Practices and beliefs of persistent digital pirates. Deviant Behavior, 31(7), 625-654.

126. Holt, T., Bossler, A. \& May, D. (2011) Low Self-Control, Deviant Peer Associations, and Juvenile Cyberdeviance. American Journal of Criminal Justice, 37(3), 1-18.

127. Morris, R. \& Higgins, G. (2009) Neutralizing potential and self-reported digital piracy: A multitheoretical exploration among college undergraduates. Criminal Justice Review, 34(2), 173-195.

128. Morris, R. \& Higgins, G. (2010) Criminological theory in the digital age: The case of social learning theory and digital piracy. Journal of Criminal Justice, 38(4), 470-480.

129. Wang, J., Yang, Z. \& Bhattacharjee, S. (2012) Same Coin, Different Sides: Differential Impact of Social Learning on Two Facets of Music Piracy. Journal of Management Information Systems 28(3), 343-384

130. Aleassa, H., Pearson, J. \& McClurg, S. (2011) Investigating Software Piracy in Jordan: An Extension of the Theory of Reasoned Action. Journal of Business Ethics, 98(4), 663-676.

131. Chan, R. \& Lai, J. (2011) Does ethical ideology affect software piracy attitude and behaviour? An empirical investigation of computer users in China. European Journal of Information Systems, 20(6), 1-15. 


\section{Appendix I: Reference list for the realist synthesis}

132. Lysonski, S. \& Durvasula, S. (2008) Digital piracy of MP3s: consumer and ethical predispositions. Journal of Consumer Marketing, 25(3), 167-178.

133. Nandedkar, A. \& Midha, V. (2012) It won't happen to me: An assessment of optimism bias in music piracy. Computers in Human Behavior, 28(1), 41-48.

134. Siegfried, M. (2004) Student Attitudes on Software Piracy and Related Issues of Computer Ethics. Ethics and Information Technology, 6(4), 215-222.

135. Douglas, D., Cronan, T. \& Behel, J. (2007) Equity perceptions as a deterrent to software piracy behavior. Information and Management, 44(5), 503-512.

136. Ouellet, J. (2007) The Purchase Versus Illegal Download of Music by Consumers: The Influence of Consumer Response towards the Artist and Music. Canadian Journal of Administrative Sciences, 24(2), 107-119.

137. Tang, J. \& Farn, C. (2005) The Effect of Interpersonal Influence on Softlifting Intention and Behaviour. Journal of Business Ethics, 56(2), 149-161.

138. Glass, R. \& Wood, W. (1996) Situational Determinants of Software Piracy: An Equity Theory Perspective. Journal of Business Ethics, 15(11), 1189-1198.

139. Limayem, M., Khalifa, M. \& Chin W. (2004) Factors Motivating Software Piracy: A Longitudinal Study. IEEE Transactions on Engineering Management, 51(4), 414-425.

140. Steinmetz, K. \& Tunnel, K. (2013) Under the Pixelated Jolly Roger: A Study of On-Line Pirates. Deviant Behavior, 34(1), 53-67.

141. Nunes, J., Hsee, C. \& Weber, E. (2004) Why Are People So Prone to Steal Software? The Effect of Cost Structure on Consumer Purchase and Payment Intentions. Journal of Public Policy \& Marketing, 32(1), 43-53.

142. Gibbs, J. \& Giever, D. (1995) Self-Control and its Manifestations among University Students: An Empirical Test of Gottfredson and Hirschi's General Theory. Justice Quarterly, 12(2), 231256.

143. Higgins, G., Wolfe, S. \& Marcum, C. (2008) Digital Piracy: An Examination of Three Measurements of Self-Control. Deviant Behavior, 29(5), 440-460.

144. Donner, C., Marcum, C., Jennings, W., Higgins, G. \& Banfield, J. (2014) Low self-control and cybercrime: Exploring the utility of the general theory of crime beyond digital piracy. Computers in Human Behavior, 34, 165-172.

145. Higgins, G. (2007) Digital Piracy: An Examination of Low Self-Control and Motivation Using Short-Term Longitudinal Data. Cyberpsychology \& Behavior, 10(4), 523-529.

146. Higgins, G. (2007) Digital Piracy, Self-Control, and Rational Choice: An Examination of the Role of Value. International Journal of Cyber Criminology, 1(1), 33-55.

147. Higgins, G., Wolfe, S. \& Marcum, C. (2008) Music Piracy and Neutralization: A Preliminary Trajectory Analysis from Short-Term Longitudinal Data. International Journal of Cyber Criminology, 2(2), 324-336.

148. Hinduja, S. (2012) General Strain, Self-Control, and Music Piracy. International Journal of Cyber Criminology, 6(1), 339-357.

149. Moore, R. \& McMullan E. (2009) Neutralizations and Rationalizations of Digital Piracy: A Qualitative Analysis of University Students. International Journal of Cyber Criminology, 3(1), 441-451.

150. Hinduja, S. (2007) Neutralization theory and online software piracy: An empirical analysis. Ethics and Information Technology, 9(3), 197-204.

151. Ingram, J. \& Hinduja, S. (2008) Neutralizing music piracy: an empirical examination. Deviant Behavior, 29(4), 334-366.

152. Yu, S. (2013) Digital Piracy Justification: Asian Students Versus American Students. International Criminal Justice Review, 23(2), 185-196.

153. Sang, Y., Lee, J., Kim, Y., \& Woo, H. (2015). Understanding the intentions behind illegal downloading: A comparative study of American and Korean college students. Telematics and Informatics, 32(2), 333-343.

154. Arli, D., Tjiptono, F., \& Porto, R. (2015). The impact of moral equity, relativism and attitude on individuals' digital piracy behaviour in a developing country. Marketing Intelligence \& Planning, 33(3), 348-365. 


\section{$\underline{\text { Punish, Seduce or Persuade }}$}

155. Phau, I., Teah, M., \& Lwin, M. (2014). Pirating Pirates of the Caribbean: The curse of cyberspace. Journal of Marketing Management, 30(3-4), 312-333.

156. Alleyne, P., Soleyn, S., \& Harris, T. (2015). Predicting Accounting Students' Intentions to Engage in Software and Music Piracy. Journal of Academic Ethics, 13(4), 291-309.

157. Casidy, R., Phau, I., \& Lwin, M. (2016). The role of religious leaders on digital piracy attitude and intention. Journal of Retailing and Consumer Services, 32, 244-252.

158. Cox, J., \& Collins, A. (2014). Sailing in the same ship? Differences in factors motivating piracy of music and movie content. Journal of Behavioral and Experimental Economics, 50, 70-76.

159. Kim, J., \& Kim, J. (2015). Software Piracy among Korean Adolescents: Lessons from Panel Data. Deviant Behavior, 36(9), 705-724

160. Tjiptono, F., Arli, D., \& Viviea. (2016). Gender and digital privacy: examining determinants of attitude toward digital piracy among youths in an emerging market. International Journal of Consumer Studies, 40, 168-178.

161. Borja, K., \& Dieringer, S. (2016). Streaming or stealing? The complementary features between music streaming and music piracy. Journal of Retailing and Consumer Services, 32, 86-95.

162. Jackman, M., \& Lorde, T. (2014). Why buy when we can pirate? The role of intentions and willingness to pay in predicting piracy behavior. International Journal of Social Economics, 41(9), 801-819.

163. Miranda, D., \& Kim, J. (2015). Peer contagion, lenient legal-ethical position, and music piracy intentions in emerging adults: Mindfulness as a protective factor. Musicae Scientiae, 19(1), 3 22.

164. Yang, Z., \& Wang, J. (2015). Differential effects of social influence sources on self-reported music piracy. Decision Support Systems, 69(4), 70-81.

165. Phau, I., Lim, A., Liang, J., \& Lwin, M. (2014). Engaging in digital piracy of movies: a theory of planned behaviour approach. Internet Research, 24(2), 246-266.

166. Huang, Y., Lin, C., Su, H., \& Tung, M. (2015). I worship, so I download? Idol worship, music purchase and piracy by young consumers in Taiwan. Asia Pacific Journal of Marketing and Logistics, 27(1), 99-126.

167. Koklic, M., Kukar-Kinney, M., \& Vida, I. (2016). Three-Level Mechanism of Consumer Digital Piracy: Development and Cross-Cultural Validation. Journal of Business Ethics, 134(1), 15-27.

168. Culiberg, B., Kos Koklic, M., Vida, I., \& Badje, D. (2016). Examining the effects of utilities and involvement on intentions to engage in digital piracy. Computers in Human Behavior, 61, $146-154$. 


\section{Appendix II: The 24 scenarios}

The first empirical study relied heavily on the scenarios that were used to examine how the respondents reacted to the mechanisms used in anti-piracy interventions. It was not feasible to present each scenario in detail in Chapter 7. Instead, all 24 scenarios are presented in this second appendix. They are presented in pairs and in the same sequence that was used to present them to the respondents. It should be noted that these scenarios were not identified as being stick-, carrot- or sermon-based, in order to avoid influencing the respondents. Instead, they are presented as scenario A to X. To restate, these scenarios were presented in Dutch originally. Adjustments to the scenarios for the Belgian respondents are presented between brackets.

\begin{tabular}{|ll|}
\hline Scenario A & Scenario B \\
\hline $\begin{array}{l}1 \text { out of a } 100 \text { individuals who download music } \\
\text { from an illegal source receives a fine, which is } \\
\text { imposed by The BREIN Foundation }(B A F) \text {. }\end{array}$ & $\begin{array}{l}\text { The average price one has to pay to obtain a music } \\
\text { album legally is } € 4.99 .\end{array}$ \\
\hline $\begin{array}{l}\text { On average, this fine is } € 100.00 \text { per downloaded } \\
\text { music file. }\end{array}$ & $\begin{array}{l}\text { These albums come with a free digital copy and } \\
\text { other extras. }\end{array}$ \\
\hline 7 out of 10 Internet users believe that one should & $\begin{array}{l}\text { On average, } 3 \text { out of } 10 \text { music files that have been } \\
\text { never download music from an illegal source. }\end{array}$ \\
& virus. \\
\hline
\end{tabular}

$\begin{array}{ll}\text { Scenario C } & \text { Scenario D }\end{array}$

The average price one has to pay to obtain a Approximately $50 \%$ of Internet users think that music album legally is €9.99. one should never download music from an illegal source.

On average, 5 out of 10 music files that have been $\quad$ The Dutch (Belgian) economy loses $€ 150(€ 140)$ downloaded from an illegal source contain a million annually due to music downloads from an virus. illegal source.

The musicians themselves are affect the most by losses due to music downloads from an illegal source.

\section{Scenario E}

Approximately $70 \%$ of Internet users think that one should never download music from an illegal source.

The Dutch (Belgian) economy loses $€ 50$ (€35) million annually due to music downloads from an illegal source.

The publishers and labels are affect the most by 5 out of 10 Internet users believe that one should

losses due to music downloads from an illegal never download music from an illegal source. source.

\section{Scenario $\mathbf{F}$}

1 out of a 10 individuals who download music from an illegal source receives a fine, which is imposed by The BREIN Foundation $(B A F)$.

On average, this fine is $€ 25.00$ per downloaded music file. 


\section{$\underline{\text { Punish, Seduce or Persuade }}$}

\begin{tabular}{|ll|}
\hline Scenario G & Scenario $\mathbf{H}$ \\
\hline $\begin{array}{l}\text { 1 out of a } 10 \text { individuals who download music } \\
\text { from an illegal source receives a fine, which is } \\
\text { imposed by The BREIN Foundation }(B A F) .\end{array}$ & $\begin{array}{l}\text { The average price one has to pay to obtain a music } \\
\text { album legally is } € 14.99 .\end{array}$ \\
\hline $\begin{array}{l}\text { On average, this fine is } € 250.00 \text { per downloaded } \\
\text { music file. }\end{array}$ & $\begin{array}{l}\text { These albums come with a free digital copy and } \\
\text { other extras. }\end{array}$ \\
\hline $\begin{array}{l}3 \text { out of } 10 \text { Internet users believe that one should } \\
\text { never download music from an illegal source. }\end{array}$ & $\begin{array}{l}\text { On average, 1 out of 10 music files that have been } \\
\text { downloaded from an illegal source contain a } \\
\text { virus. }\end{array}$ \\
\hline
\end{tabular}

\begin{tabular}{|ll|}
\hline Scenario I & Scenario J \\
\hline $\begin{array}{l}\text { The average price one has to pay to obtain a music } \\
\text { album legally is } € 4.99 .\end{array}$ & $\begin{array}{l}\text { Approximately 50\% of Internet users think that } \\
\text { one should never download music from an illegal } \\
\text { source. }\end{array}$ \\
\hline $\begin{array}{l}\text { On average, } 3 \text { out of } 10 \text { music files that have been } \\
\text { downloaded from an illegal source contain a } \\
\text { virus. }\end{array}$ & $\begin{array}{l}\text { The Dutch (Belgian) economy loses } € 100(€ 85) \\
\text { million annually due to music downloads from an } \\
\text { illegal source. }\end{array}$ \\
\hline & $\begin{array}{l}\text { An increase in the downloading of music from an } \\
\text { illegal source is paired with a decrease in the } \\
\text { development of new music. }\end{array}$ \\
\hline
\end{tabular}

\begin{tabular}{ll} 
Scenario K & Scenario L \\
\hline Approxing
\end{tabular}

Approximately $30 \%$ of Internet users think that 1 out of a 25 individuals who download music one should never download music from an illegal source. from an illegal source receives a fine, which is imposed by The BREIN Foundation $(B A F)$.

The Dutch (Belgian) economy loses $€ 150(\epsilon 140) \quad$ On average, this fine is $€ 100.00$ per downloaded million annually due to music downloads from an music file. illegal source.

The musicians themselves are affect the most by 5 out of 10 Internet users believe that one should losses due to music downloads from an illegal never download music from an illegal source. source.

\begin{tabular}{|ll|}
\hline Scenario M & Scenario $\mathbf{N}$ \\
\hline $\begin{array}{l}1 \text { out of a } 100 \text { individuals who download music } \\
\text { from an illegal source receives a fine, which is } \\
\text { imposed by The BREIN Foundation }(B A F) .\end{array}$ & $\begin{array}{l}\text { The average price one has to pay to obtain a music } \\
\text { album legally is } € 14.99 .\end{array}$ \\
\hline $\begin{array}{l}\text { On average, this fine is } € 25.00 \text { per downloaded } \\
\text { music file. }\end{array}$ & $\begin{array}{l}\text { On average, 5 out of 10 music files that have been } \\
\text { downloaded from an illegal source contain a } \\
\text { virus. }\end{array}$ \\
\hline $\begin{array}{l}7 \text { out of } 10 \text { Internet users believe that one should } \\
\text { never download music from an illegal source. }\end{array}$ & \\
\hline
\end{tabular}

\begin{tabular}{|ll|}
\hline Scenario $\mathbf{O}$ & Scenario P \\
\hline $\begin{array}{l}\text { The average price one has to pay to obtain a } \\
\text { music album legally is } € 9.99 .\end{array}$ & $\begin{array}{l}\text { Approximately } 70 \% \text { of Internet users think that } \\
\text { one should never download music from an illegal } \\
\text { source. }\end{array}$ \\
\hline $\begin{array}{l}\text { These albums come with a free digital copy and } \\
\text { other extras. }\end{array}$ & $\begin{array}{l}\text { The Dutch (Belgian) economy loses } € 50(€ 35) \\
\text { million annually due to music downloads from an } \\
\text { illegal source. }\end{array}$ \\
\hline
\end{tabular}




\section{Appendix II: The 24 scenarios}

On average, 1 out of 10 music files that have been downloaded from an illegal source contain a virus.

\section{Scenario $\mathbf{Q}$}

Approximately $30 \%$ of Internet users think that one should never download music from an illegal source.

The Dutch (Belgian) economy loses $€ 100$ (€85) million annually due to music downloads from an illegal source.

An increase in the downloading of music from an 3 out of 10 Internet users believe that one should illegal source is paired with a decrease in the never download music from an illegal source. development of new music.

\begin{tabular}{ll} 
Scenario $\mathrm{S}$ & Scenario $\mathrm{T}$ \\
\hline
\end{tabular}

1 out of a 10 individuals who download music The average price one has to pay to obtain a music from an illegal source receives a fine, which is album legally is $€ 4.99$. imposed by The BREIN Foundation $(B A F)$.

On average, this fine is $€ 100.00$ per downloaded music file.

On average, 1 out of 10 music files that have been downloaded from an illegal source contain a virus.

5 out of 10 Internet users believe that one should never download music from an illegal source.

\begin{tabular}{ll}
\hline Scenario $\mathbf{U}$ & Scenario $\mathbf{V}$
\end{tabular}

The average price one has to pay to obtain a Approximately 50\% of Internet users think that music album legally is $€ 14.99$. one should never download music from an illegal source.

These albums come with a free digital copy and The Dutch (Belgian) economy loses $€ 150(€ 140)$ other extras. million annually due to music downloads from an illegal source.

On average, 5 out of 10 music files that have been The musicians themselves are affect the most by downloaded from an illegal source contain a losses due to music downloads from an illegal virus. source.

Scenario W $\quad$ Scenario $X$

Approximately $70 \%$ of Internet users think that 1 out of a 100 individuals who download music one should never download music from an illegal source. from an illegal source receives a fine, which is imposed by The BREIN Foundation $(B A F)$.

The Dutch (Belgian) economy loses $€ 50(€ 35) \quad$ On average, this fine is $€ 25.00$ per downloaded million annually due to music downloads from an music file. illegal source.

An increase in the downloading of music from an 3 out of 10 Internet users believe that one should illegal source is paired with a decrease in the never download music from an illegal source. development of new music. 



\section{Curriculum vitae}

Bastiaan Leeuw (1985) began his legal studies in 2004, at the Faculty of Law at Maastricht University. After obtaining a bachelor (LLB) in Dutch Law in 2007, the specialized in the field of criminal law, obtaining a master's degree (LLM) in 2008. After working as an academic researcher at the Leuven Institute of Criminology (LINC), he enrolled in the Master of Criminology programme at the University of Sydney, where he obtained a degree in 2010 (MCrim). In late 2010, he started the position of PhD-researcher at the Faculty of Law at Maastricht University. In addition to his research, he taught a variety of courses in the fields of criminal law and criminology. In 2015 he was appointed to the position of empirical methodologist at this faculty. Since 2016, Bastiaan has been involved in the creation and maintenance of the Empirical Legal Studies initiative (ELSi). Bastiaan has a wide range of research interests, which include cybercrime, cybersociety, Big Data, evaluations and policy studies, criminology and empirical legal research. 